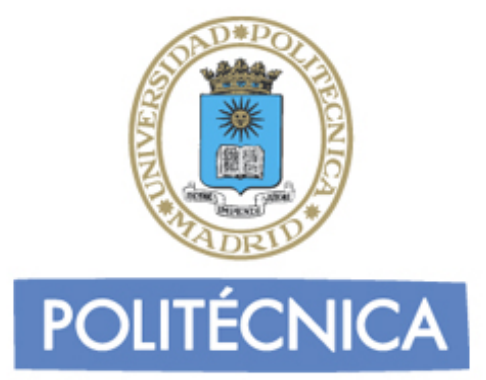

DEPARTAMENTO DE LENGUAJES Y SISTEMAS INFORMÁTICOS E INGENIERÍA DE SOFTWARE

ESCUELA TÉCNICA SUPERIOR DE INGENIEROS INFORMÁTICOS UNIVERSIDAD POLITÉCNICA DE MADRID

\title{
Estudio empírico de la influencia de la experiencia y del conocimiento del dominio del analista en la efectividad de la educción de requisitos
}

Tesis que presento para optar al título de Doctor

Alejandrina María Aranda López King

Dirigida por

Dr. Oscar Dieste y Dra. Natalia Juristo

MADRID, 2016 



\section{Agradecimientos}

En primer lugar agradezco a Dios y a la Virgen María, por todas las gracias y luces concedidas en estos años de estudio aquí en España.

Agradezco a mis padres y hermanos que a pesar de la distancia física que nos separa, han estado acompañándome muy de cerca durante todo este tiempo, animándome a confiar y a seguir adelante a pesar de las dificultades.

A las chicas del piso con las que he convivido durante este tiempo, por la gran amistad que hemos cultivado, por el ejemplo que me han dado y me seguirán dando de perseverancia, estudio, confianza, alegría, olvido de sí, entrega a los demás desinteresada y sin límites, la importancia de dar mucho valor a las pequeñas cosas que parecen insignificantes pero que en realidad tienen gran valor. iGracias por todo chicas!.

Y muy especialmente a las mayores, que han sido como mis madres "segundas", han estado acompañándome en todo momento, escuchándome, orientándome, corrigiéndome cuando hacía falta y más que nada por el buen ejemplo que transmiten, el bien que hacen y pueden hacer desde el lugar en que se encuentran. Y de manera especial a Conchi Pedregal, una gran investigadora y madre espiritual, quien con su ejemplo, oración, sencillez y alegría me ha ayudado a saber orientar la investigación como un servicio al bien común, animándome a aspirar a metas altas y a darle al día a día su verdadero sentido e importancia.

A mis tutores Oscar Dieste y Natalia Juristo por su profesionalidad, enseñanzas, orientaciones, paciencia que han tenido conmigo, por sus palabras de ánimo, correcciones y buenos consejos.

A los estudiantes de RE de la UPM, profesionales del REFSQ, John Castro y Rodrigo Fonseca quienes hicieron posible que esta investigación pudiera llevarse a cabo.

A Itaipu Binacional quien me ha dado la oportunidad de estar aquí, capacitarme y crecer como profesional.

A mis compañeros/as del doctorado por la ayuda que me han dado durante este tiempo y por los buenos momentos que hemos pasado.

A mis amigos/as y a todas las personas que de alguna forma con su entrega y oraciones diarias, me han estado ayudando a la distancia. 



\section{Resumen}

Contexto: La presente tesis doctoral se enmarca en la actividad de educción de los requisitos. La educción de requisitos es generalmente aceptada como una de las actividades más importantes dentro del proceso de Ingeniería de Requisitos, y tiene un impacto directo en la calidad del software. Es una actividad donde la comunicación entre los involucrados (analistas, clientes, usuarios) es primordial. La efectividad y eficacia del analista en la compresión de las necesidades de clientes y usuarios es un factor crítico para el éxito del desarrollo de software. La literatura se ha centrado principalmente en estudiar y comprender un conjunto específico de capacidades o habilidades personales que debe poseer el analista para realizar de forma efectiva la actividad de educción. Sin embargo, existen muy pocos trabajos que han estudiado dichas capacidades o habilidades empíricamente.

Objetivo: La presente investigación tiene por objetivo estudiar el efecto de la experiencia, el conocimiento acerca del dominio y la titulación académica que poseen los analistas en la efectividad del proceso de educción de los requisitos, durante los primeros contactos del analista con el cliente.

Método de Investigación: Hemos ejecutado 8 estudios empíricos entre cuasi-experimentos (4) y experimentos controlados (4). Un total de 110 sujetos experimentales han participado en los estudios, entre estudiantes de post-grado de la Escuela Técnica Superior de Ingenieros Informáticos de la Universidad Politécnica de Madrid y profesionales. La tarea experimental consistió en realizar sesiones de educción de requisitos sobre uno o más dominios de problemas (de carácter conocido y desconocido para los sujetos). Las sesiones de educción se realizaron empleando la entrevista abierta. Finalizada la entrevista, los sujetos reportaron por escrito toda la información adquirida.

Resultados: Para dominios desconocidos, la experiencia (entrevistas, requisitos, desarrollo y profesional) del analista no influye en su efectividad. En dominios conocidos, la experiencia en entrevistas $(r=0.34$, $p$-valor $=0.080)$ y la experiencia en requisitos $(r=0.22$, p-valor $=0.279)$, ejercen un efecto positivo. Esto es, los analistas con más años de experiencia en entrevistas y/o requisitos tienden a alcanzar mejores efectividades. Por el contrario, la experiencia en desarrollo $(r=-0.06$, $p$-valor $=0.765)$ y la experiencia profesional $(r=-0.35, p$-valor $=0.077)$, tienden a ejercer un efecto nulo y negativo, respectivamente.

En lo que respecta al conocimiento acerca del dominio del problema que poseen los analistas, ejerce un moderado efecto positivo $(r=0.31)$, estadísticamente significativo ( $p$-valor $=0.029)$ en la efectividad de la actividad de educción. Esto es, los analistas con conocimiento tienden a ser más efectivos en los dominios de problema conocidos.

En lo que respecta a la titulación académica, por falta de diversidad en las titulaciones académicas de los sujetos experimentales no es posible alcanzar una conclusión. Hemos podido explorar el efecto de la titulación académica en sólo dos cuasi-experimentos, sin embargo, nuestros resultados arrojan efectos contradictorios ( $r=0.694, p$-valor $=0.51$ y $r=-0.266, p$-valor $=0.383$ ).

Además de las variables estudiadas indicadas anteriormente, hemos confirmado la existencia de variables moderadoras que afectan a la actividad de educción, tales como el entrevistado o la formación. Nuestros datos experimentales confirman que el entrevistado es un factor clave en la actividad de educción. Estadísticamente ejerce una influencia significativa en la efectividad de los analistas ( $p$-valor $=0.000$ ). La diferencia entre entrevistar a uno u otro entrevistado, en unidades naturales, varía entre un $18 \%$ - $23 \%$ en efectividad. Por otro lado, la formación en requisitos aumenta 
considerablemente la efectividad de los analistas. Los sujetos que realizaron la educción de requisitos después de recibir una formación específica en requisitos tienden a ser entre un $12 \%$ y $20 \%$ más efectivos que aquellos que no la recibieron. El efecto es significativo ( $p$-valor $=0.000$ ).

Finalmente, hemos observado tres hechos que podrían influir en los resultados de esta investigación. En primer lugar, la efectividad de los analistas es diferencial dependiendo del tipo de elemento del dominio. En dominios conocidos, los analistas con experiencia tienden a adquirir más conceptos que los analistas noveles. En los dominios desconocidos, son los procesos los que se adquieren de forma prominente. En segundo lugar, los analistas llegan a una especie de "techo de cristal" que no les permite adquirir más información. Es decir, el analista sólo reconoce (parte de) los elementos del dominio del problema mencionado. Este hecho se observa tanto en el dominio de problema desconocido como en el conocido, y parece estar relacionado con el modo en que los analistas exploran el dominio del problema. En tercer lugar, aunque los años de experiencia no parecen predecir cuán efectivo será un analista, sí parecen asegurar que un analista con cierta experiencia, en general, tendrá una efectividad mínima que será superior a la efectividad mínima de los analistas con menos experiencia.

Conclusiones: Los resultados obtenidos muestran que en dominios desconocidos, la experiencia por sí misma no determina la efectividad de los analistas de requisitos. En dominios conocidos, la efectividad de los analistas se ve influenciada por su experiencia en entrevistas y requisitos, aunque sólo parcialmente. Otras variables influyen en la efectividad de los analistas, como podrían ser las habilidades débiles.

El conocimiento del dominio del problema por parte del analista ejerce un efecto positivo en la efectividad de los analistas, e interacciona positivamente con la experiencia incrementando aún más la efectividad de los analistas.

Si bien no fue posible obtener conclusiones sólidas respecto al efecto de la titulación académica, si parece claro que la formación específica en requisitos ejerce una importante influencia positiva en la efectividad de los analistas.

Finalmente, el analista no es el único factor relevante en la actividad de educción. Los clientes/usuarios (entrevistados) también juegan un rol importante en el proceso de generación de información. 


\section{Abstract}

Context: This PhD dissertation addresses requirements elicitation activity. Requirements elicitation is generally acknowledged as one of the most important activities of the requirements process, having a direct impact in the software quality. It is an activity where the communication among stakeholders (analysts, customers, users) is paramount. The analyst's ability to effectively understand customers/users' needs represents a critical factor for the success of software development. The literature has focused on studying and comprehending a specific set of personal skills that the analyst must have to perform requirements elicitation effectively. However, few studies have explored those skills from an empirical viewpoint.

Goal: This research aims to study the effects of experience, domain knowledge and academic qualifications on the analysts' effectiveness when performing requirements elicitation, during the first stages of analyst-customer interaction.

Research method: We have conducted eight empirical studies, quasi-experiments (four) and controlled experiments (four). 110 experimental subjects participated, including: graduate students with the Escuela Técnica Superior de Ingenieros Informáticos of the Universidad Politécnica de Madrid, as well as researchers and professionals. The experimental tasks consisted in elicitation sessions about one or several problem domains (ignorant and/or aware for the subjects). Elicitation sessions were conducted using unstructured interviews. After each interview, the subjects reported in written all collected information.

Results: In ignorant domains, the analyst's experience (interviews, requirements, development and professional) does not influence her effectiveness. In aware domains, interviewing experience $(r=0.34$, $p$-value $=0.080)$ and requirements experience $(r=0.22$, $p$-value $=0.279)$, make a positive effect, i.e.: the analysts with more years of interviewing/requirements experience tend to achieve higher effectiveness. On the other hand, development experience $(r=-0.06, p$-value $=0.765)$ and professional experience $(r=$ $-0.35, \mathrm{p}$-value $=0.077$ ) tend to make a null and negative effect, respectively.

On what regards the analyst's problem domain knowledge, it makes a modest positive effect $(r=0.31)$, statistically significant ( $p$-value $=0.029)$ on the effectiveness of the elicitation activity, i.e.: the analysts with tend to be more effective in problem domains they are aware of.

On what regards academic qualification, due to the lack of diversity in the subjects' academic degrees, we cannot come to a conclusion. We have been able to explore the effect of academic qualifications in two experiments; however, our results show opposed effects $(r=0.694, p$-value $=0.51 \mathrm{y}$ $r=-0.266$, p-value $=0.383$ ).

Besides the variables mentioned above, we have confirmed the existence of moderator variables influencing the elicitation activity, such as the interviewee and the training. Our data confirm that the interviewee is a key factor in the elicitation activity; it makes statistically significant effect on analysts' effectiveness ( $p$-value $=0.000)$. Interviewing one or another interviewee represents a difference in effectiveness of $18 \%-23 \%$, in natural units. On the other hand, requirements training increases to a large extent the analysts' effectiveness. Those subjects who performed requirements elicitation after specific training tend to be $12 \%$ - $20 \%$ more effective than those who did not receive training. The effect is statistically significant ( $p$-value $=0.000)$. 
Finally, we have observed three phenomena that could have an influence on the results of this research. First, the analysts' effectiveness differs depending on domain element types. In aware domains, experienced analysts tend to capture more concepts than novices. In ignorant domains, processes are identified more frequently. Second, analysts get to a "glass ceiling" that prevents them to acquire more information, i.e.: analysts only identify (part of) the elements of the problem domain. This fact can be observed in both the ignorant and aware domains. Third, experience years do not look like a good predictor of how effective an analyst will be; however, they seem to guarantee that an analyst with some experience years will have a higher minimum effectiveness than the minimum effectiveness of analysts with fewer experience years.

Conclusions: Our results point out that experience alone does not explain analysts' effectiveness in ignorant domains. In aware domains, analysts' effectiveness is influenced the experience in interviews and requirements, albeit partially. Other variables influence analysts' effectiveness, e.g.: soft skills.

The analysts' problem domain knowledge makes a positive effect in analysts' effectiveness; it positively interacts with the experience, increasing even further analysts' effectiveness.

Although we could not obtain solid conclusions on the effect of the academic qualifications, it is plain clear that specific requirements training makes a rather positive effect on analysts' effectiveness.

Finally, the analyst is not the only relevant factor in the elicitation activity. The customers/users (interviewees) play also an important role in the information generation process. 


\section{Índice Abreviado}

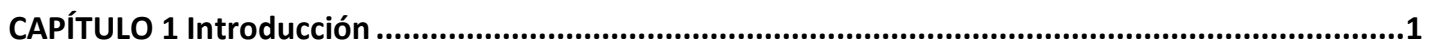

CAPÍTULO 2 Estado de la Cuestión ................................................................................................9

CAPÍTULO 3 Preguntas de Investigación....................................................................................35

CAPÍTULO 4 Metodología de Investigación .................................................................................37

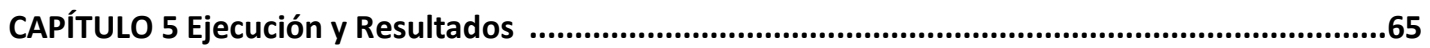

CAPÍTULO 6 Síntesis de Resultados ......................................................................................129

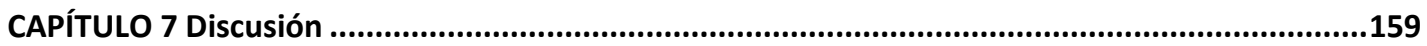

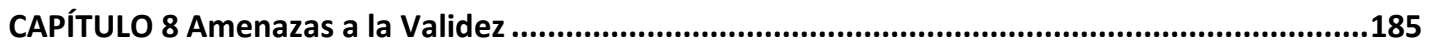

CAPÍTULO 9 Conclusiones y Futuras líneas de Investigación .............................................................199

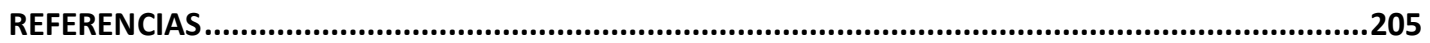

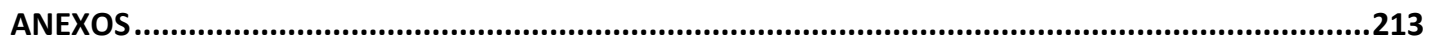





\section{Índice Extendido}

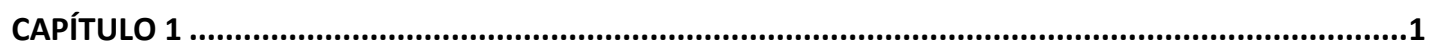

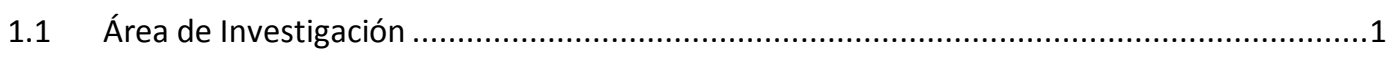

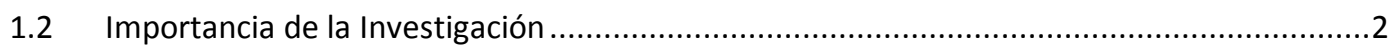

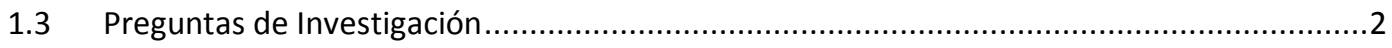

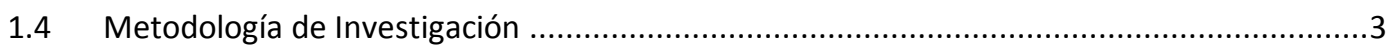

1.5 Ejecución y Resultados Principales .........................................................................

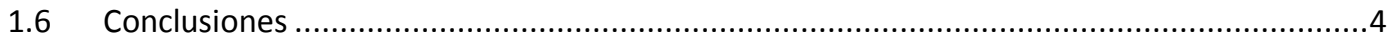

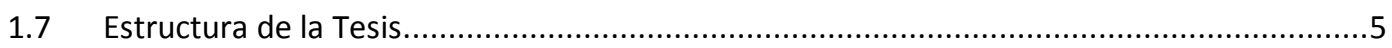

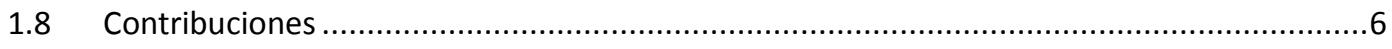

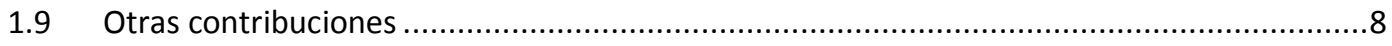

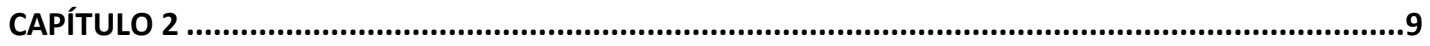

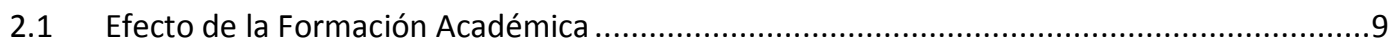

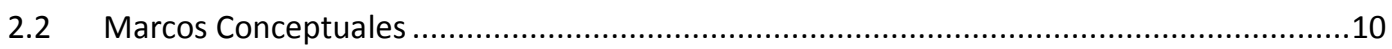

2.2.1 Marco de Chatzoglou .............................................................................. 11

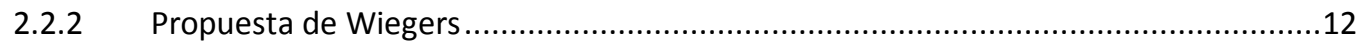

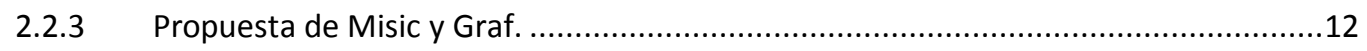

2.2.4 Propuesta de Chakraborty, Sarker y Valacich .......................................................13

2.2.5 Marco de Chakraborty, Sarker y Sarker ................................................................13

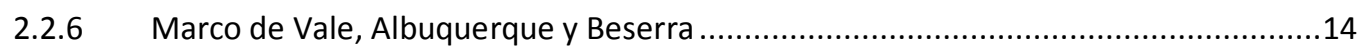

2.2.7 Marco de Anwar, Rozilawati y Kamsuriah .............................................................17

2.2.8 Marco de Mcleod y MacDonell ............................................................................

2.2.9 Propuesta de Herrmann ............................................................................ 18

2.3 Identificación de las Habilidades Personales más Relevantes ...........................................18

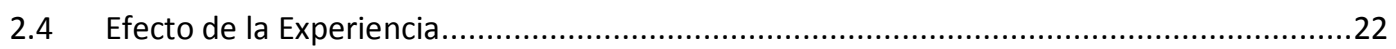

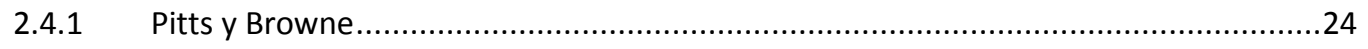

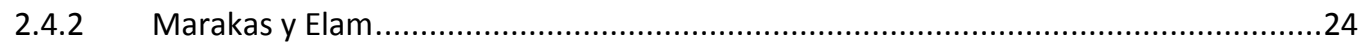

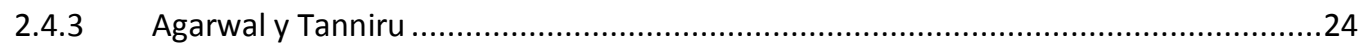

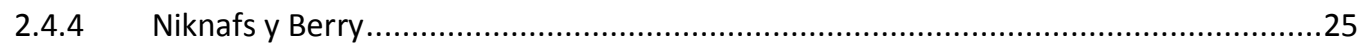

2.5 Efecto del Conocimiento sobre el dominio del problema.......................................27 
Estudio empírico de la influencia de la experiencia y del conocimiento del dominio del analista en la efectividad del proceso de educción de requisitos

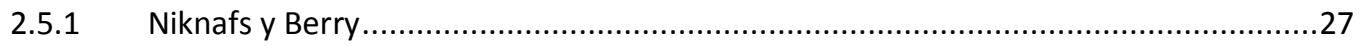

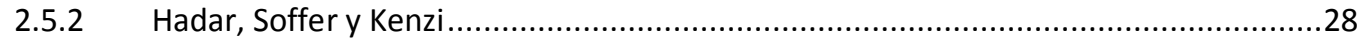

2.5.3 Kristensson, Gustafsson y Archer. ............................................................28

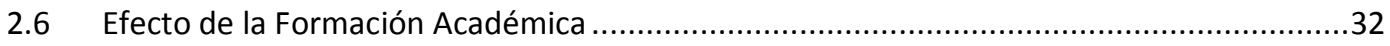

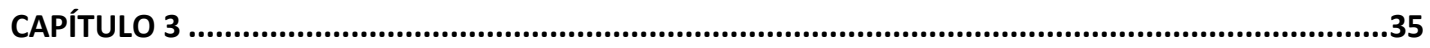

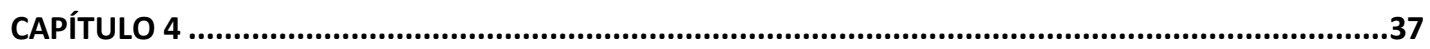

Estimación del tamaño muestral necesario ...............................................................38

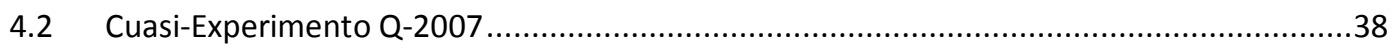

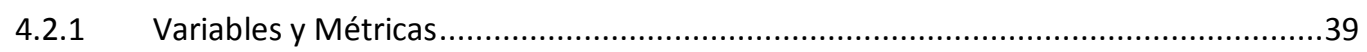

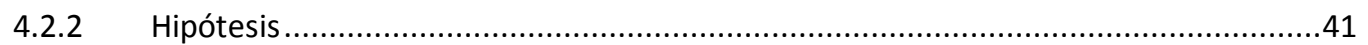

Selección de Sujetos ..................................................................................

4.2.4 Asignación de los Sujetos a Tratamientos..........................................................

Estimación del Tamaño Muestral ......................................................................43

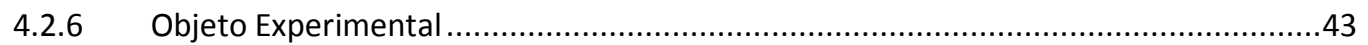

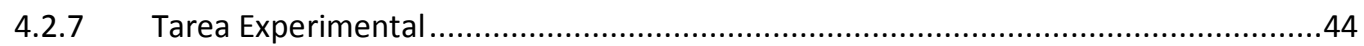

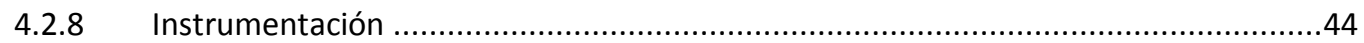

4.2.9 Protocolo y Procedimiento de Recolección de Datos .........................................45

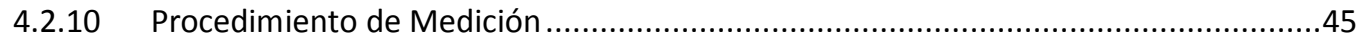

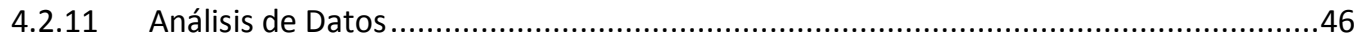

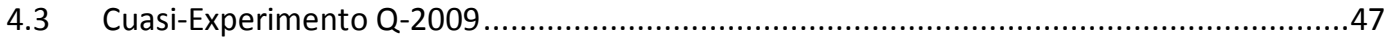

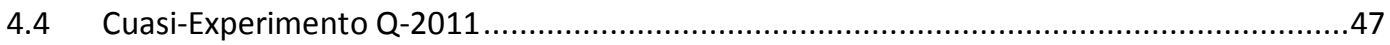

4.5 Cuasi-Experimento Q-2012 (REFSQ) ….......................................................... 48

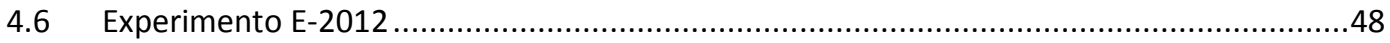

4.6.1 Variables, Factores y Métricas...................................................................49

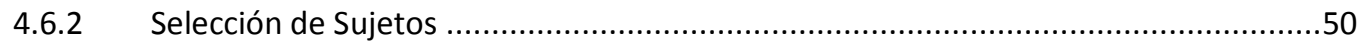

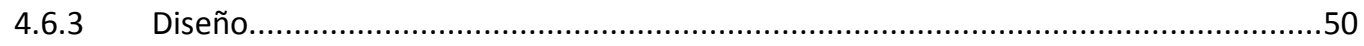

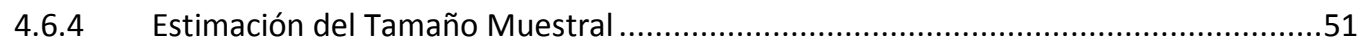

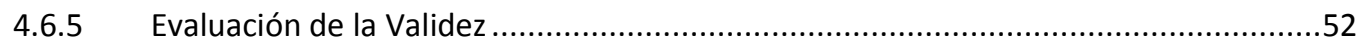

4.6.6 Asignación de Sujetos a Tratamientos ................................................................52

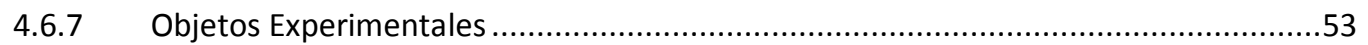

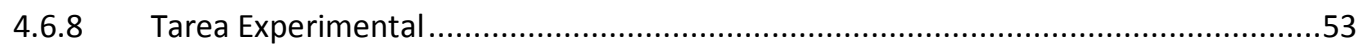

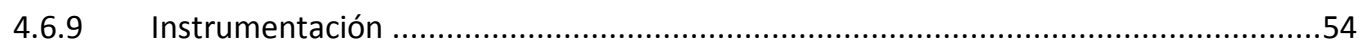

4.6.10 Protocolo y Procedimiento de Recolección de Datos ................................................54

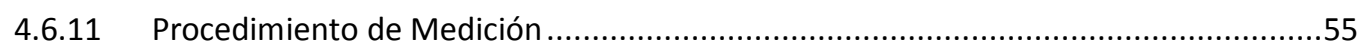

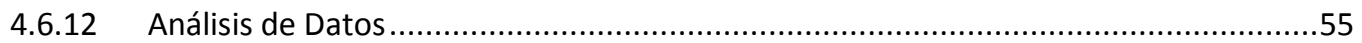




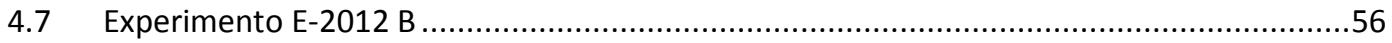

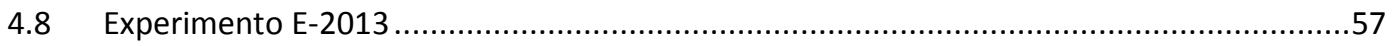

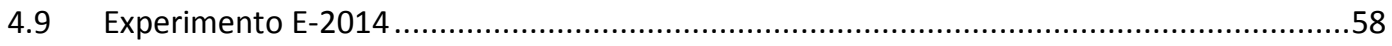

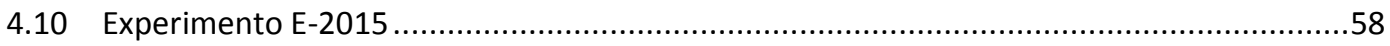

4.11 Resumen - Familia de Experimentos ...............................................................59

4.11.1 Diferencias contextuales entre estudios empíricos ...............................................60

4.11.2 Variables dependientes e independientes......................................................62

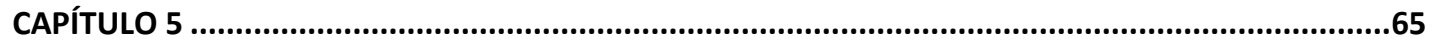

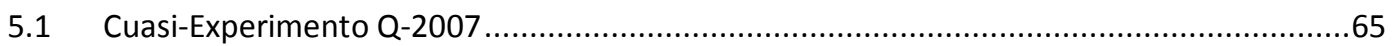

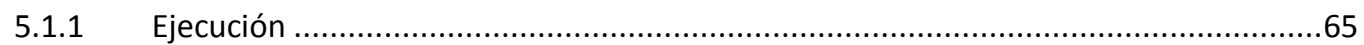

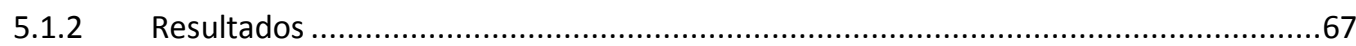

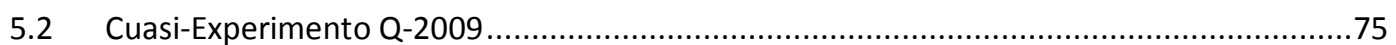

5.2.1 Cambios de la Replicación Q-2009 respecto al Experimento Base ..........................75

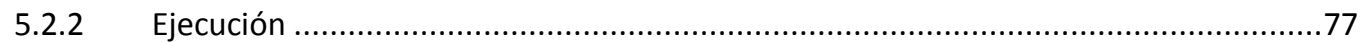

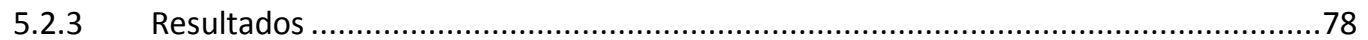

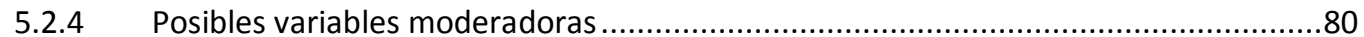

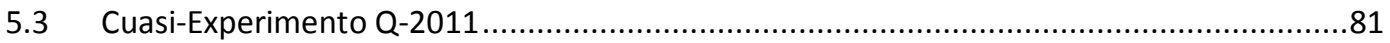

5.3.1 Cambios de la replicación Q-2011 respecto al Experimento Base ...........................81

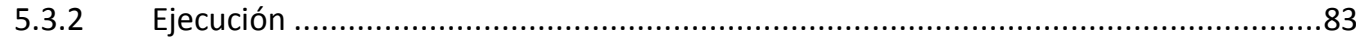

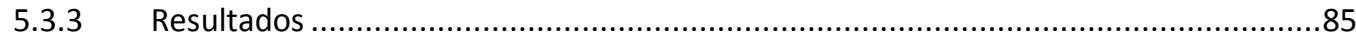

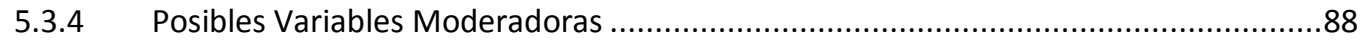

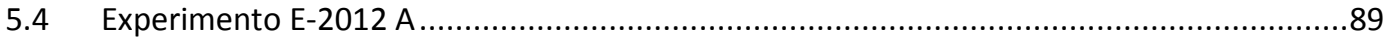

5.4.1 Cambios de E-2012 A respecto a la serie Histórica de Experimentos .......................89

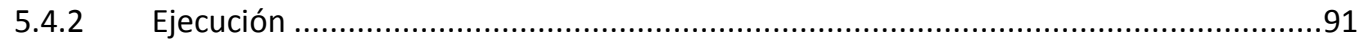

5.4.3 Resultados del Experimento Base E-2012 A................................................93

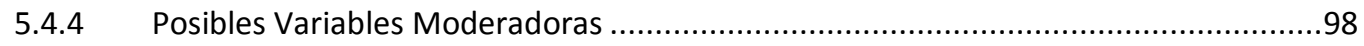

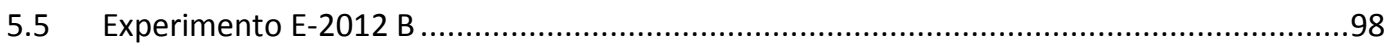

5.5.1 Cambios en la Replicación E-2012B respecto al Experimento E-2012A ....................98

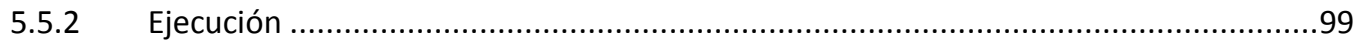

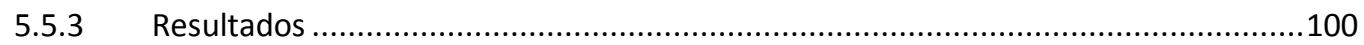

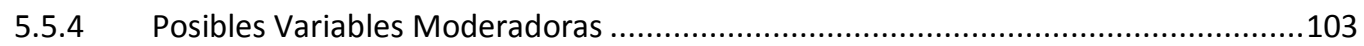

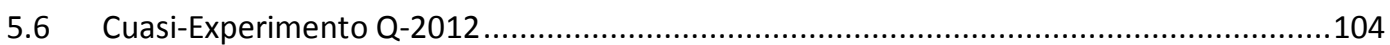

5.6.1 Cambios de la Replicación Externa Q-2012 respecto a Q-2011 ...............................104

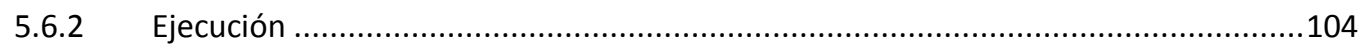

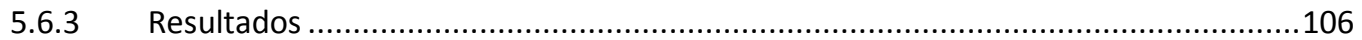


Estudio empírico de la influencia de la experiencia y del conocimiento del dominio del analista en la efectividad del proceso de educción de requisitos

5.6.4 Posibles variables Moderadoras ..............................................................109

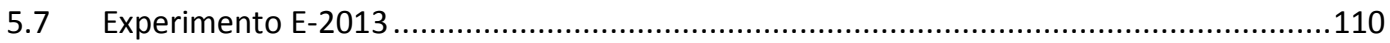

5.7.1 Cambios del experimento E-2013 respecto a E-2012 ......................................110

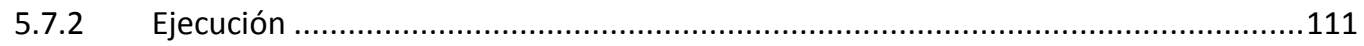

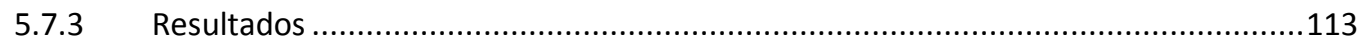

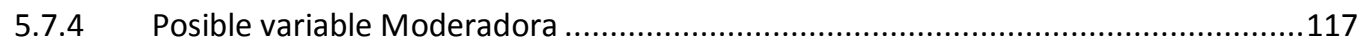

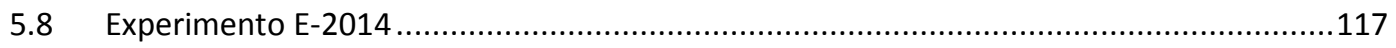

5.8.1 Cambios del Experimento E-2014 respecto a E-2013.......................................117

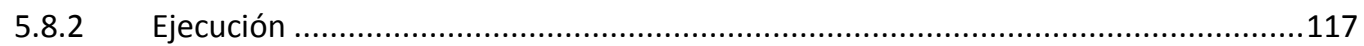

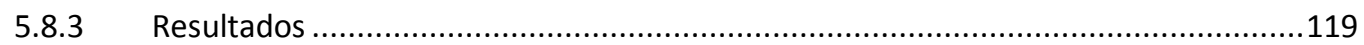

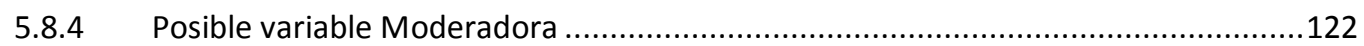

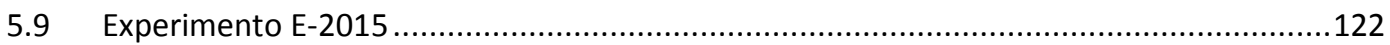

5.9.1 Cambios del Experimento E-2015 respecto a E-2013 ...........................................122

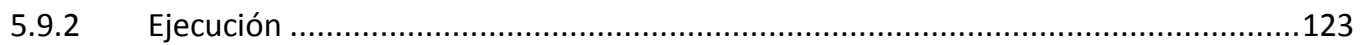

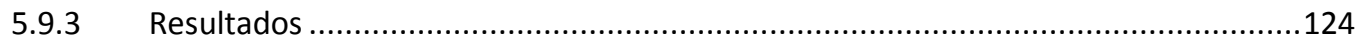

5.9.4 Posible variable Moderadora ................................................................................128

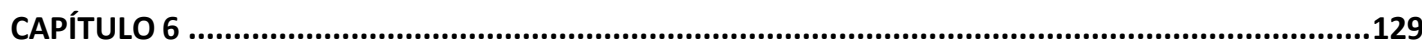

6.1 ¿Influye la experiencia del analista en la efectividad del proceso de educción de los requisitos? (RQ1) ............................................................................................... 129

6.1.1 Efecto de la experiencia operacionalizada como número de años........................130

6.1.2 Efecto de la experiencia operacionalizada como la Habilidad ..............................147

6.2 ¿Influye el conocimiento que el analista posee acerca del dominio en la efectividad del proceso de educción de requisitos? ..........................................................................150

6.2.1 Efecto del conocimiento operacionalizado como factor ....................................150

6.2.2 Efecto del conocimiento operacionalizado como la Familiaridad ...........................154

6.3 ¿Influye la titulación académica del analista en la efectividad del proceso de educción de

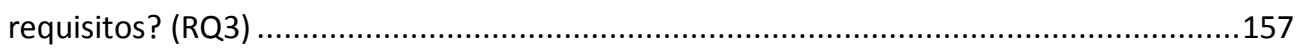

CAPÍTULO 7

7.1 ¿Influye el conocimiento del dominio en la efectividad del proceso de educción de los

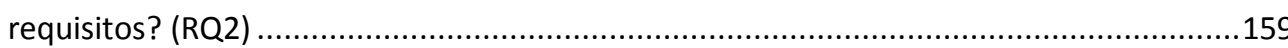

7.1.1 Comparación con los trabajos empíricos relacionados .....................................159

7.1.2 Evidencias de un efecto Experiencia $x$ Conocimiento .......................................160

7.2 ¿Influye la experiencia del analista en la efectividad del proceso de educción de los

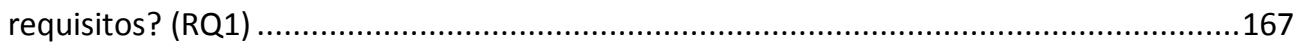

7.2.1 Comparación con los trabajos empíricos relacionados ......................................168

7.2.2 Evidencias del efecto de la experiencia sobre la efectividad mínima .....................170 
7.2.3 Otros factores que podrían explicar las diferencias en la efectividad 171

7.3 ¿Influye la formación académica en la efectividad del proceso de educción de los requisitos? (RQ3) 176

7.4 Variables Moderadoras .176

7.4.1 Efecto del Entrevistado ........................................................................ 176

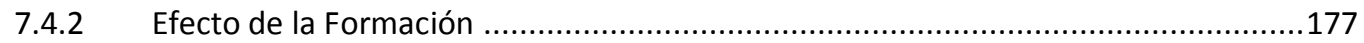

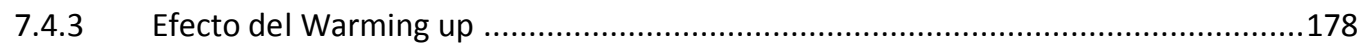

7.5 Medición utilizando variables subjetivas y objetivas..................................................179

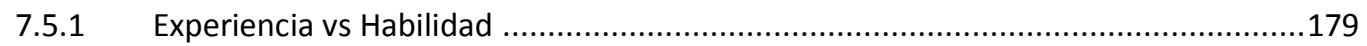

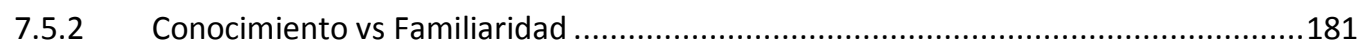

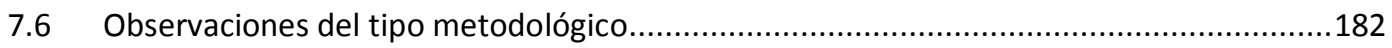

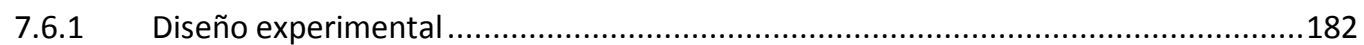

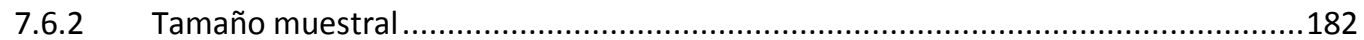

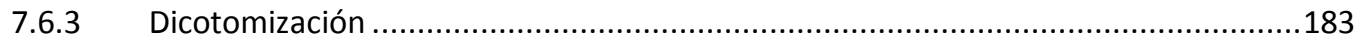

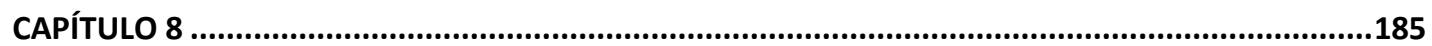

8.1 Amenazas a la validez de conclusión estadística ...................................................185

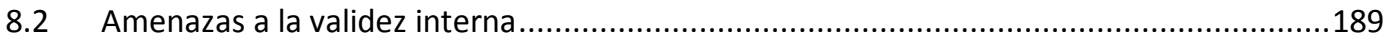

8.3 Amenazas a la validez de constructo ........................................................................ 192

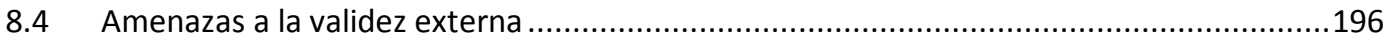

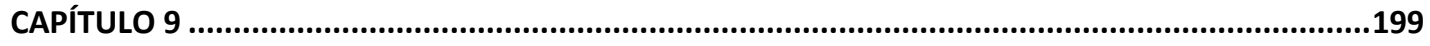

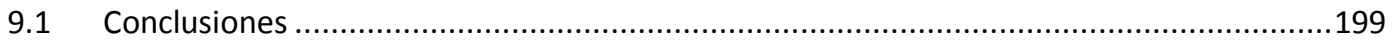

9.1.1 ¿Influye la experiencia del analista en la efectividad del proceso de educción de los requisitos? (RQ1)

9.1.2 ¿̇nfluye el Conocimiento del dominio en la efectividad del proceso de educción de los requisitos? (RQ2)

9.1.3 ¿influye la formación académica en la efectividad del proceso de educción de los

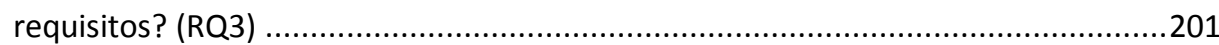

9.1.4 Existencia de variables moderadoras ....................................................................201

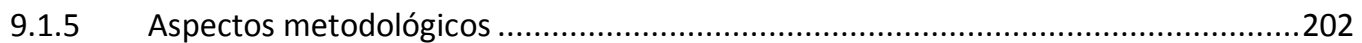

$9.2 \quad$ Futuras Líneas de Investigación .........................................................................202

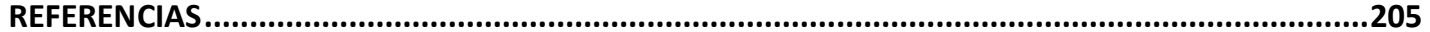

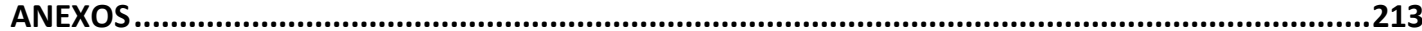

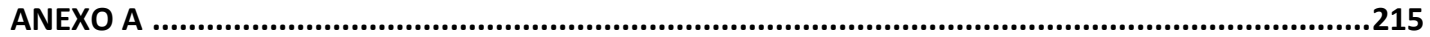

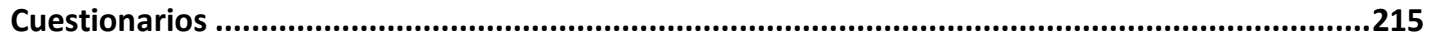

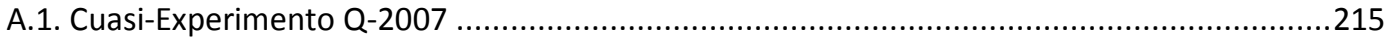

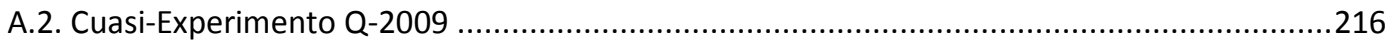


Estudio empírico de la influencia de la experiencia y del conocimiento del dominio del analista en la efectividad del proceso de educción de requisitos

A.3. Cuasi-Experimento Q-2011 217

A.4. Cuasi-Experimento Q-2012 219

A.5. Experimentos: E-2012, E-2013, E-2014 y E-2015 .220

ANEXO B. .224

Objetos Experimentales .224

B.1. Problema Conocido: Mensajería de Texto (PC1) .224

PC1 - Modelo de conceptos. .226

PC1 - Diagrama de Actividades. .226

B.2. Problema Desconocido: Reciclado de Pilas (PD1) 227

PD1 - Modelo de Conceptos .228

PD1 - Diagrama de Actividades. .229

B.3. Problema Conocido: Punto de Información Universitaria (PC2)........ .229

PC2 - Modelo de Conceptos .231

PC2 - Modelo de Actividades. .232

B.4. Problema Desconocido: Compra y venta de Acciones (PD2) .232

PD2 - Modelo de Actividades .234

PD2 - Modelo de Conceptos .235

ANEXO C .236

Tabla Resúmenes .236

C.1. Problema Desconocido: Reciclado de Pilas (PD1)

C.2. Problema Conocido: Mensajería de Texto (PC1) .246

C.3. Problema Desconocido: Compra y Venta de acciones (PD2) .250

C.4. Problema Conocido: Matrícula (PC2) .252

ANEXO D .254

Conjunto de Datos (DataSet). .254

ANEXO E. .255

Ajuste de Datos .255

E.1. Procedimiento de AJuste de los Datos - Problema PD1 .255

E.2. Procedimiento de AJuste de los Datos - Problema PC1. .257

ANEXO $F$ .259

Efecto de la Experiencia

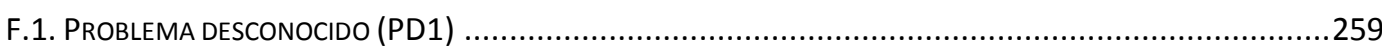

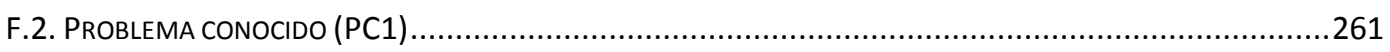

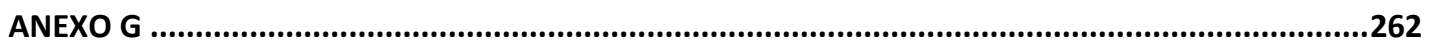

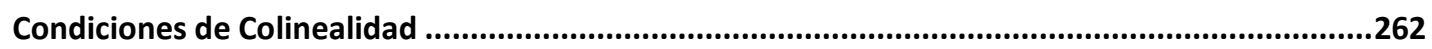




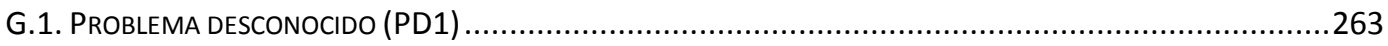

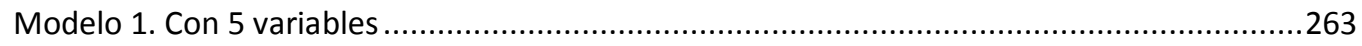

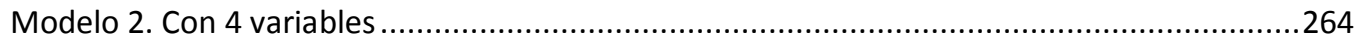

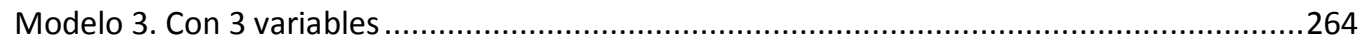

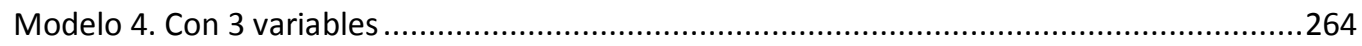

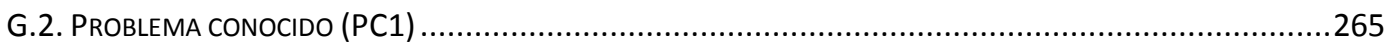

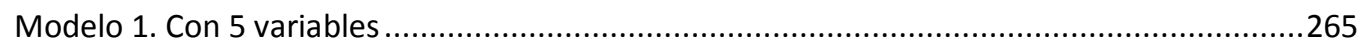

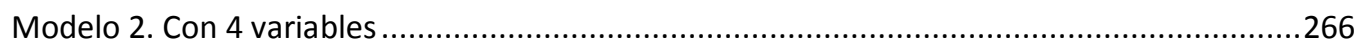

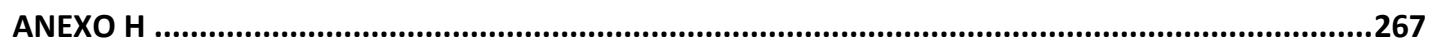

Meta-análisis por tipo de elementos ...................................................................................267

H.1. META-ANÁLISIS DE LA EXPERIENCIA EN REQUISITOS DIfERENCIADA POR TIPO DE ElEMENTO PC1 ...............267

H.2. META-ANÁLISIS DE LA EXPERIENCIA EN REQUISITOS DIFERENCIADA POR TIPO DE ELEMENTO PD1...............268

H.3. META-ANÁLISIS DE LA EXPERIENCIA EN ENTREVISTAS DIfERENCIADA POR TIPO DE ElEMENTO PC1..............269

H.4. META-ANÁLISIS DE LA EXPERIENCIA EN ENTREVISTAS DIfERENCIADA POR TIPO DE ElEMENTO PD1 .............270

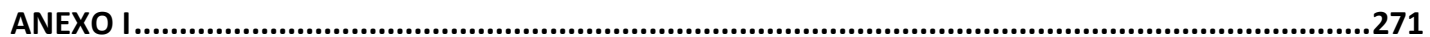

Comparación de los efectos de entrevistas individuales vs. grupales .........................................271 



\section{Índice de Figuras}

Figura 4.1 - Estimación del tamaño muestral para cuasi-experimentos

Figura 4.2 - Tareas o actividades del cuasi-experimento Q-2007 ............................................44

Figura 4.3 - Protocolo experimental (planeado) .........................................................................45

Figura 4.4 - Estimación del tamaño muestral para diseños within-subjects.................................51

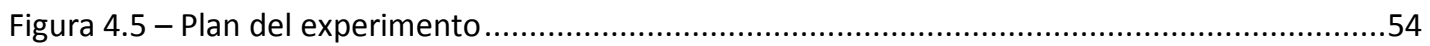

Figura 4.6 - Estimación del tamaño muestral para diseños between-subjects ...............................58

Figura 5.1 - Relación de la experiencia y la efectividad en la educción Q-2007 ...........................68

Figura 5.2 - Relación entre familiaridad del sujeto y la efectividad en la educción Q-2007 ..............69

Figura 5.3 - Efecto de la titulación académica en la efectividad de los sujetos Q-2207 ..................70

Figura 5.4 - Relación de la experiencia y la efectividad en la consolidación Q-2007 .......................71

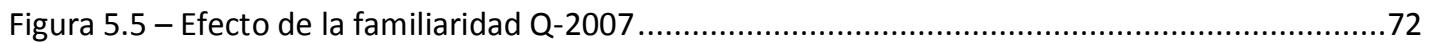

Figura 5.6 - Efecto de la titulación académica en la efectividad de la consolidación Q-2007 ............72

Figura 5.7 - Relación de la experiencia en sus distintas vertientes y la efectividad........................73

Figura 5.8 - Efecto de la familiaridad de los sujetos en la capacidad de retención Q-2007 ..............74

Figura 5.9 - Efecto de la titulación académica en la capacidad de retención Q-2007 .....................75

Figura 5.10 - Efectividad promedio en las fases del proceso de educción Q-2007........................76

Figura 5.11 - Relación de la experiencia en sus distintas vertientes y la efectividad Q-2009 ...........79

Figura 5.12 - Comparación de la efectividad media obtenida en Q-2007 y Q-2009 .......................80

Figura 5.13 - Relación de la experiencia y la efectividad Q-2011 .............................................86

Figura 5.14 - Relación de la habilidad en entrevistas y requisitos con la efectividad Q-2011 ...........87

Figura 5.15 - Relación entre familiaridad del sujeto y la efectividad en la consolidación Q-2011 .....88

Figura 5.16 - Comparación de efectividades entre Q-2007, Q-2009 y Q-2011.............................89

Figura 5.17 - Efectividad promedio diferenciada por problema y entrevistado E-2012A ................94

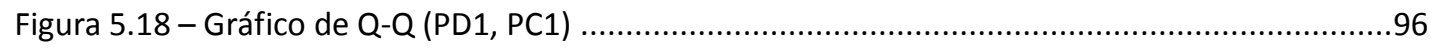

Figura 5.19 - Efectividad promedio diferenciada por problema y entrevistado E-2012B ..............101

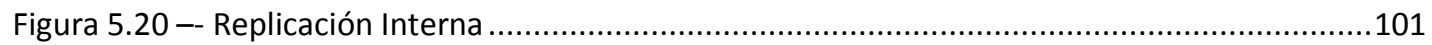

Figura 5.21 - Efectividad en la consolidación. Histórico de Experimentos - PD1 - Entrevistado OD.103

Figura 5.22 - Gráficos de Dispersión - Relación de la experiencia y la efectividad Q-2012 ............107

Figura 5.23 - Efecto de la familiaridad de los sujetos en la efectividad Q-2012 ...........................108 
Estudio empírico de la influencia de la experiencia y del conocimiento del dominio del analista en la efectividad del proceso de educción de requisitos

Figura 5.24 - Efecto de la titulación académica en la efectividad de la consolidación Q-2012 ........109

Figura 5.25 - Comparación de la efectividad media entre Q-2011 y Q-2012 .............................110

Figura 5.26 - Ejemplo de la nota empleada para notificar a los sujetos sobre el experimento .......118

Figura 6.1 - Fases que componen la estrategia de análisis ................................................131

Figura 6.2 - Efectividad promedio de los experimentos diferenciados por entrevistado ...............132

Figura 6.3 - Ejemplo ficticio sobre el efecto de una variable moderadora.................................134

Figura 6.4 - Tamaño muestral requerido en un modelo de regresión ......................................140

Figura 6.5 - Gráfico Q-Q - Normalidad de los datos.............................................................142

Figura 6.6 - Gráfico de dispersión formado con los residuos del modelo ....................................143

Figura 6.7 - Meta análisis Efecto de la Experiencia en Entrevistas PD1......................................144

Figura 6.8 - Meta análisis Efecto de la Experiencia en Requisitos PD1......................................145

Figura 6.9 - Meta análisis Efecto de la Experiencia en Desarrollo PD1...........................................146

Figura 6.10 - Meta análisis Efecto de la Experiencia Profesional PD1 .........................................146

Figura 6.11 - Gráfico de dispersión ................................................................................148

Figura 6.12 - Meta análisis Efecto de la Habilidad en Entrevistas PD1.......................................149

Figura 6.13 - Meta análisis Efecto de la Habilidad en Requisitos PD1.......................................149

Figura 6.14 - Meta-análisis Efecto del conocimiento diferenciado por diseño experimental ..........153

Figura 6.15 - Efectividad Promedio diferenciada por problema ............................................156

Figura 6.16 - Meta-análisis Efecto de la familiaridad en problemas desconocidos .......................156

Figura 6.17 - Meta-análisis Efecto de la familiaridad en problemas conocidos..........................157

Figura 7.1 - Homocedasticidad, gráfico de dispersión PC1 ...................................................162

Figura 7.2 - Meta-análisis de la Experiencia en Entrevistas .................................................163

Figura 7.3 - Meta-análisis de la Experiencia en Requisitos ...................................................163

Figura 7.4 - Meta-análisis de la Experiencia en Desarrollo ......................................................164

Figura 7.5 - Meta-análisis de la Experiencia Profesional ..........................................................164

Figura 7.6 - Homocedasticidad Gráfico de Dispersión .......................................................166

Figura 7.7 - Meta-análisis habilidad en requisitos ..........................................................166

Figura 7.8 - Meta-análisis habilidad en entrevistas .............................................................167

Figura 7.9 - Comparación efectividades mínimas en función de los años de experiencia ..............171

Figura 7.10 - Relación entre el tiempo de educción y las efectividades de los analistas ................171

Figura 7.11 - Efectividad media diferenciada por sesión de educción ........................................172

Figura 7.12 - Efecto "techo de cristal” diferenciado por dominio del problema ............................174

Figura 7.13 - Curvas de isoprobabilidad del diagrama de actividades (PD1, PC1) .........................175

Figura 7.14 - Curvas de isoprobabilidad del diagrama de conceptos (PD1, PC1) .......................175

Figura 7.15 - Efecto warming up diferenciado por dominio del problema ..................................178 
Figura 7.16 - Ejemplo efecto warming up positivo - PD1

Figura 7.17 - Ejemplo sobrevaloración de la experiencia en requisitos ..... .181

Figura 7.18 - Efectos de la experiencia en función del punto de corte escogido... .184

Figura 8.1 - Efectividad media de los sujetos a lo largo de la serie histórica (PD1) .188 



\section{Índice de Tablas}

Tabla 2.1 - Factores Humanos pertenecientes a la categoría miembros del equipo

Tabla 2.2 - Factores que influyen en el proceso de educción de requisitos .................................14

Tabla 2.3 - Habilidades personales identificadas para el perfil de analista de requisitos .................14

Tabla 2.4 - Relevancia de las Habilidades Personales............................................................16

Tabla 2.5 - Categoría de las Habilidades Personales Relevantes.................................................16

Tabla 2.6 - Factores que ejercen influencia en el proceso de desarrollo del software ....................18

Tabla 2.7 - Relevancia de los aspectos humanos en base a la revisión de literatura realizada ..........21

Tabla 2.8 - Estudios empíricos sobre el efecto de la experiencia en Ingeniería de Requisitos ..........26

Tabla 2.9 - Estudios empíricos sobre el Efecto del Conocimiento en Ingeniería de Requisitos ...........30

Tabla 2.10 - Estudios Empíricos sobre el Efecto de la Formación Académica .................................33

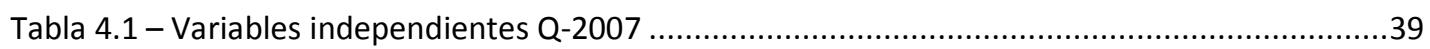

Tabla 4.2 - Variables Dependientes Q-2007 ..........................................................................40

Tabla 4.3 - Número total de elementos que definen el tamaño del problema ...............................44

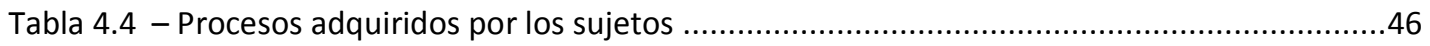

Tabla 4.5 - Convenciones de tamaños de efectos según Cohen ................................................47

Tabla 4.6 - Variables independientes E-2012 A ................................................................50

Tabla 4.7 - Diseño within-subjects con dos niveles incluyendo el bloqueo .................................50

Tabla 4.8 - Dominios del problema utilizados en el experimento E-2012 ..................................53

Tabla 4.9 - Dominios del problema utilizados en el experimento E-2012B .................................56

Tabla 4.10 - Número total de elementos que definen los problemas.......................................56

Tabla 4.11 - Familia de estudios empíricos acerca de educción de requisitos ................................59

Tabla 4.12 - Diferencias principales relacionadas con la ejecución de los experimentos .................61

Tabla 4.13 - Variables independientes, secuencia de aparición ...................................................62

Tabla 5.1 - Características principales de los sujetos experimentales Q-2007 .............................66

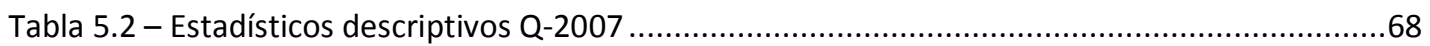

Tabla 5.3 - Relación de la experiencia y la efectividad en la educción Q-2007...............................69

Tabla 5.4 - Efectividad media en función de su familiaridad (Fam) Q-2007 .................................70

Tabla 5.5 - Relación de la titulación académica (TIT) y la efectividad en la educción Q-2007 ...........70

Tabla 5.6 - Relación de la experiencia y la efectividad en la consolidación Q-2007 ..........................71 
Estudio empírico de la influencia de la experiencia y del conocimiento del dominio del analista en la efectividad del proceso de educción de requisitos

Tabla 5.7 - Relación la Familiaridad (Fam) y la Efectividad en la Consolidación Q-2007 72

Tabla 5.8 - Relación de la titulación académica (TIT) y la efectividad en la consolidación Q-2007 ....73

Tabla 5.9 - Relación de la experiencia y la capacidad de retención Q-2007.................................74

Tabla 5.10 - Relación la familiaridad (Fam) y la capacidad de retención Q-2207 ..........................74

Tabla 5.11 - Relación de la titulación y la efectividad en la capacidad de retención de los analistas 75

Tabla 5.12 - Esfuerzo de transcripción de las entrevistas en Q-2007......................................76

Tabla 5.13 - Características principales de los sujetos experimentales Q-2009 ..........................77

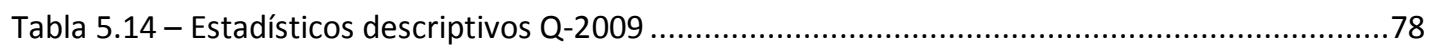

Tabla 5.15 - Relación de la experiencia y la efectividad en la consolidación Q-2009 .....................79

Tabla 5.16 - Cantidad de sujetos que identifican los tipos de mentales y máquinas.......................80

Tabla 5.17 - Características principales de los sujetos experimentales Q-2011 ..........................83

Tabla 5.18 - Valores perdidos del cuasi-experimento Q-2011 ..................................................85

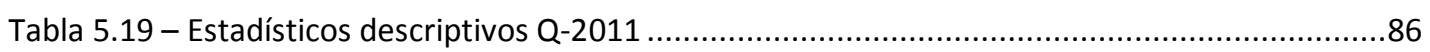

Tabla 5.20 - Relación de la experiencia y la efectividad en la consolidación Q-2011 ......................87

Tabla 5.21 - Relación de la habilidad (Hab) y la efectividad en la consolidación Q-2011 ..................87

Tabla 5.22 - Relación la familiaridad (Fam) y la efectividad en la consolidación ..............................88

Tabla 5.23 - Características principales de los sujetos experimentales E-2012 A..........................91

Tabla 5.24 - Valores perdidos del cuasi-experimento Q-2011 ..............................................93

Tabla 5.25 - Estadísticos descriptivos en función del dominio del problema y por entrevistados .....94

Tabla 5.26 - Relación de la experiencia y la efectividad en la consolidación E-2012 A ....................95

Tabla 5.27 - Relación de la habilidad (Hab) y la efectividad en la consolidación E-2012A................95

Tabla 5.28 - Relación la familiaridad (Fam) y la efectividad en la consolidación E-2012 A ...............96

Tabla 5.29 - Pruebas de normalidad MLG E-2012 A .........................................................97

Tabla 5.30 - Efecto del conocimiento (GLM) - E-2012 A .................................................97

Tabla 5.31 - Características principales de los sujetos experimentales E-2012B.........................99

Tabla 5.32 - Estadísticos descriptivos. Problemas: PC2 y PD2, diferenciado por entrevistado .......100

Tabla 5.33 - Pruebas de normalidad E-2012B ................................................................. 102

Tabla 5.34 - Efecto del conocimiento (GLM) - E-2012 B ................................................102

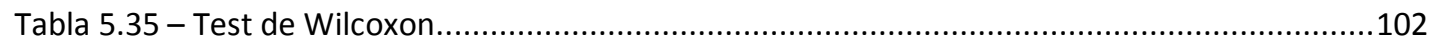

Tabla 5.36 - Características principales de los sujetos experimentales Q-2012 ..........................105

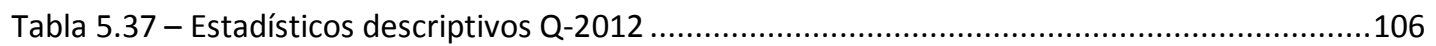

Tabla 5.38 - Relación de la experiencia y la efectividad en la consolidación Q-2012 .....................107

Tabla 5.39 - Relación de la experiencia y la efectividad en la consolidación..................................108

Tabla 5.40 - Relación la familiaridad y la efectividad en la consolidación ...................................109

Tabla 5.41 - Relación de la titulación académica (Form) y la efectividad en la consolidación ..........109 
Tabla 5.42 - Características principales de los sujetos experimentales E-2013 ..........................111

Tabla 5.43 - Valores perdidos del cuasi-experimento E-2013 ...........................................113

Tabla 5.44 - Estadísticos descriptivos E-2013 .....................................................................114

Tabla 5.45 - Estadísticos descriptivos E-2013 - segundas entrevistas ......................................114

Tabla 5.46 - Relación de la experiencia y la efectividad en la consolidación E-2013 .....................115

Tabla 5.47 - Relación de la habilidad y la efectividad en la consolidación E-2013........................115

Tabla 5.48 - Prueba de normalidad E-2013 ….........................................................116

Tabla 5.49 - Efecto del conocimiento (ANOVA)E-2013 ........................................................116

Tabla 5.50 - Relación la familiaridad (Fam) y la efectividad en la consolidación E-2013 ................116

Tabla 5.51 - Características principales de los sujetos experimentales E-2014 ..........................117

Tabla 5.52 - Valores perdidos del cuasi-experimento E-2014 .................................................119

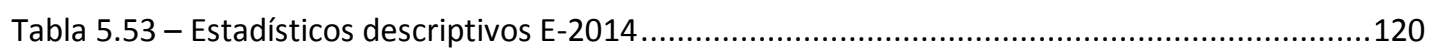

Tabla 5.54 - Relación de la experiencia y la efectividad en la consolidación E-2014 .....................120

Tabla 5.55 - Relación de la Habilidad y la Efectividad en la Consolidación E-2014 ........................121

Tabla 5.56 - Prueba de normalidad E-2014 .......................................................................121

Tabla 5.57 - Efecto del conocimiento (ANOVA) E-2014 ......................................................121

Tabla 5.58 - Efecto de la familiaridad E-2014 .....................................................................122

Tabla 5.59 - Características Principales de los sujetos Experimentales E-2015 ..........................123

Tabla 5.60 - Valores perdidos del cuasi-experimento E-2015...............................................124

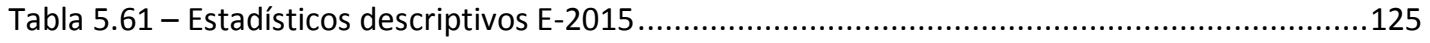

Tabla 5.62 - Relación de la experiencia y la efectividad en la consolidación E-2015 .....................126

Tabla 5.63 - Relación de la habilidad y la efectividad en la consolidación E-2015........................126

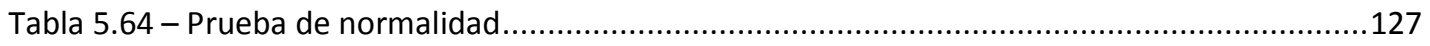

Tabla 5.65 - Efecto del conocimiento (ANOVA) ...............................................................127

Tabla 5.66 - Efecto de la familiaridad - Prueba t E-2015 ...............................................127

Tabla 6.1 - Efecto de la experiencia en requisitos en los distintos experimentos - Problema PD1 .130

Tabla 6.2 - Efecto de la formación con las demás variables moderadoras constantes....................134

Tabla 6.3 - Efecto de la formación con las demás variables moderadoras no constantes..............135

Tabla 6.4 - Procedimiento de ajuste ...........................................................................136

Tabla 6.5 - Correlación entre las distintas vertientes de la experiencia PD1 ...............................137

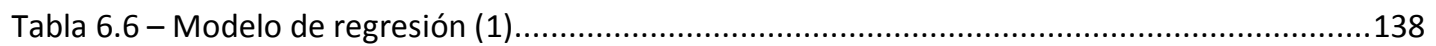

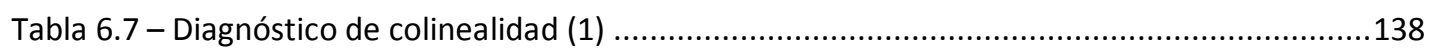

Tabla 6.8 - Determinación del modelo de regresión más adecuado.............................................140

Tabla 6.9 - Convenciones de tamaños de efectos según Cohen ...............................................141

Tabla 6.10 - Efecto de la Experiencia mediante el modelo de regresión (Análisis Conjunto) ..........142 
Tabla 6.11 - Pruebas de normalidad .143

Tabla 6.12 - Resumen relación entre la efectividad y la experiencia - PD1 147

Tabla 6.13 - Efecto de la habilidad en requisitos y entrevistas por estudio experimental PD1 147

Tabla 6.14 - Análisis conjunto. Modelo de regresión lineal - Habilidad PD1 .148

Tabla 6.15 - Resumen relación entre la efectividad y la habilidad - PD1. .149

Tabla 6.16 - Efecto del conocimiento en los experimentos individuales .151

Tabla 6.17 - Resultados Modelo Mixto (AR) - Estimaciones de los efectos fijos .151

Tabla 6.18 - Efecto del conocimiento en los experimentos individuales .152

Tabla 6.19 - Efecto del Conocimiento Conjunto ANOVA - Estudios Between Subjects .152

Tabla 6.20 - Resumen tamaño de efecto entre la efectividad y el conocimiento. .153

Tabla 6.21 - Diferencia entre medias - Efecto Familiaridad .154

Tabla 6.22 - Efecto de la familiaridad análisis conjunto .155

Tabla 6.23 - Resumen tamaño de efecto entre la efectividad y la familiaridad .157

Tabla 6.24 - Efecto de la Titulación académica .158

Tabla 7.1 - Efecto de la experiencia en requisitos en los distintos experimentos - Problema PC1..161

Tabla 7.2 - Efecto de la Experiencia mediante el modelo de regresión (Análisis Conjunto) PC1 .....162

Tabla 7.3 - Resumen relación entre la efectividad y la experiencia - PC1..... .164

Tabla 7.4 - Efecto de la habilidad diferenciado por estudio experimental PC1 .165

Tabla 7.5 - Análisis conjunto. Modelo de regresión lineal PC1 .165

Tabla 7.6 - Resumen relación entre la efectividad y la habilidad - PC1 167

Tabla 7.8 - Efecto Entrevistado diferenciado por experimento y por dominio del problema .177

Tabla 7.9 - Efecto warming up diferenciado por dominio del problema y entrevistado 179

Tabla 7.10 - Relación de la efectividad del analista con la experiencia y la habilidad .180

Tabla 7.11 - Efecto de la familiaridad diferenciado por dominio del problema .181

Tabla 7.12 - Efecto del conocimiento (meta-análisis). 181

Tabla 7.13 - Efecto de la Experiencia de requisitos en función de los puntos de corte...... .184 


\section{CAPÍTULO 1 INTRODUCCIÓN}

Este capítulo tiene por objetivo introducir al lector en el contexto de la investigación. En él se describen el área de investigación (Sección 1.1) y su importancia (Sección 1.2); se definen las preguntas de investigación (sección 1.3); se resume brevemente la metodología aplicada (Sección 1.4); los principales resultados (Sección 1.5) y conclusiones (Sección 1.6); y finalmente, se presenta la estructura de la tesis (Sección 1.7) y las contribuciones derivadas (Secciones 1.8 y 1.9).

\section{1 Área de Investigación}

La tesis doctoral se enmarca dentro de las líneas de investigación relacionadas a la Ingeniería de Requisitos y a la experimentación de ingeniería del software. Concretamente se centra en la fase de educción de los requisitos.

La educción de requisitos es la primera actividad del proceso de Ingeniería de Requisitos. Es el proceso de obtener, determinar, extraer e identificar las necesidades del cliente; así como, adquirir todo el conocimiento relevante del dominio del problema necesario para definir los requisitos del sistema (Saiediana \& Daleb, 2000; Sommerville, 2009)

Hoy en día, para realizar la educción de requisitos existe una amplia gama de técnicas de educción, tales como tormenta de ideas (Osborn, 1963), análisis de protocolos (Ericsson \& Simon, 1996), JAD (Wood \& Silver, 1989), entre otras. En la práctica, las técnicas de educción de requisitos más frecuentemente utilizadas (Hove \& Anda, 2005) y prácticamente inevitables en un desarrollo de software son las entrevistas (Cooke, 1999). Esto es debido a la capacidad de la técnica para adquirir información y conocimiento relevantes, así como a su facilidad de uso.

Existen diversos tipos de entrevistas: estructuradas y no estructuradas (Kotonya \& Sommerville, 1998), cognitivas (Moody, Blanton, \& Will, 1999), semánticas (Marakas \& Elam, 1998), entre otras. No obstante, parece indiscutible que la entrevista no estructurada (también denominada habitualmente "entrevista abierta") es la más frecuentemente utilizada (Wagner, Otto, \& Chung, 2002). La entrevista no estructurada se caracteriza por no poseer un plan (conjunto de preguntas, lista de aspectos que 
explorar) prefijado de antemano (Agarwal \& Tanniru, 1990; Hove \& Anda, 2005). La entrevista puede llevarse a cabo de forma individual como en grupo (Mishra \& Mohanty, 2011).

\subsection{Importancia de la Investigación}

La educción de requisitos es generalmente aceptada como una de las actividades más importantes dentro del proceso de Ingeniería de Requisitos (Zowghi \& Coulin, 2005), que tiene una influencia directa en la calidad del sistema software (Aurum \& Wohlin, 2005). Es una actividad de intensa comunicación entre los involucrados (por ejemplo, entre clientes y analistas). Las interacciones humanas juegan un papel crítico en este contexto (Anwar, Razali, \& Ahmad, 2011). Por un lado, el cliente debería ser capaz de interactuar y comunicar sus necesidades a los analistas. Por otro lado, los analistas deberían ser capaces de extraer y comprender toda la información del dominio necesaria del cliente. Por tanto, la educción de requisitos depende en gran medida de la calidad de la interacción entre los participantes (Zowghi \& Coulin, 2005).

Se cree que la efectividad de las actividades de Ingeniería de Requisitos depende parcialmente de las personas involucradas (Niknafs \& Berry, 2012). En la educción de requisitos, se ha observado que la efectividad de las entrevistas puede variar significativamente dependiendo de las habilidades del entrevistador (en este caso el analista de requisitos), probablemente porque dichas habilidades afectan la marcha de las preguntas a realizar (Hadar, Soffer, \& Kenzi, 2012), lo que provoca que la educción dependa en gran medida de las habilidades del entrevistador (Zowghi \& Coulin, 2005). Efectos parecidos han sido identificados aplicando tormentas de ideas (Niknafs\& Berry, 2012), así como en otras técnicas de educción (Kristensson, Gustafsson, \& Archer, 2004).

Existen diversas características personales que pueden influir en la efectividad de cualquier tarea relacionada con requisitos: la experiencia (Agarwal \& Tanniru, 1990; Marakas \& Elam, 1998; Niknafs \& Berry, 2012), formación académica (Albayrak \& Carver, 2014; Carrizo, Dieste, \& Juristo, 2014), capacidades cognitivas (Pitts \& Browne, 2004), el conocimiento del dominio (Christel \& Kang, 1992; Loucopoulos \& Karakostas, 1995; Niknafs \& Berry, 2012; Niknafs \& Berry, 2013; Young, 2002; Zowghi \& Coulin, 2005), entre otras.

En la comunidad de Ingeniería del Software está muy extendida la opinión de que tanto la experiencia (Schenk et al., 1998), el conocimiento del dominio (Christel \& Kang, 1992; Loucopoulos \& Karakostas, 1995; Young, 2002; Zowghi \& Coulin, 2005) y formación académica que poseen los analistas (Atkins, 2013; Niknafs, 2014) ayudan a los profesionales en el buen desempeño en sus actividades. Sin embargo, existe un reducido número de estudios empíricos que investigan experimentalmente dichas características, además se observa una gran incertidumbre y contradicción en los resultados.

\subsection{Preguntas de Investigación}

Debido a la incertidumbre existente, la presente tesis doctoral intentará responder empíricamente a las siguientes preguntas de investigación:

- RQ1: ¿Influye (ya sea positiva o negativamente) la experiencia del analista en la efectividad del proceso de educción de los requisitos?

- RQ2: ¿̇nfluye (ya sea positiva o negativamente) el conocimiento que el analista posee acerca del dominio en la efectividad del proceso de educción de requisitos?

- RQ3: ¿Influye (ya sea positiva o negativamente) la formación académica que el analista posee en la efectividad del proceso de educción de requisitos? 


\subsection{Metodología de Investigación}

Para responder a las preguntas de investigación hemos ejecutado 8 estudios experimentales: cuatro cuasi-experimentos y cuatro experimentos controlados, totalizando un conjunto de 110 sujetos, que se corresponde con 150 unidades experimentales.

La serie de estudios experimentales se realizó con estudiantes de post-grado de la Universidad Politécnica de Madrid, en el marco de la asignatura de Ingeniería de Requisitos y, con profesionales provenientes de distintos países e instituciones, en el marco de la feria empírica de la conferencia internacional en Ingeniería de Requisitos y Calidad de Software (REFSQ 2013).

Los estudios experimentales que componen la familia de experimentos, se diferencian entre ellos en leves aspectos derivados del contexto experimental (o setting). Por ejemplo, el modo en el que se llevaron a cabo las entrevistas; la cantidad de entrevistados que participaron en el estudio; número de sesiones; momentos de ejecución, entre otras. Dichas diferencias podrían considerarse como potenciales variables moderadoras que aumentan o disminuyen la efectividad de los analistas.

Tanto el experiencia como el conocimiento del analista sobre el dominio del problema se operacionalizaron utilizado dos constructos distintos, uno de carácter objetivo y otro subjetivo (escala de Likert) para cada variable. La experiencia se midió como la cantidad de años que el sujeto ha trabajado en esa tarea específica (por ejemplo, entrevistas o requisitos) así como la habilidad que posee el sujeto desde su punto de vista en la ejecución de dichas tareas. Por otro lado, el conocimiento se midió como la familiaridad que posee acerca del dominio del problema. El conocimiento también se operacionalizó como un factor con dos niveles: dominios conocidos para el analista, y dominios desconocidos.

Cuatro fueron los objetos experimentales empleados a lo largo de esta investigación: dos problemas conocidos y dos problemas desconocidos para los sujetos experimentales. Para cada problema, se confeccionó una lista patrón de los distintos elementos (conceptos, procesos, requisitos) que lo componían, las cuales fueron utilizadas para la medición de la efectividad de los analistas.

\subsection{Ejecución y Resultados Principales}

La tarea experimental consistió en realizar una sesión de educción (entrevista inicial) entre un analista y un cliente. Los sujetos experimentales ejercieron el rol de analistas de requisitos realizando la educción sobre uno o varios dominios de problema, en función del experimento en el que participaron. La sesión de educción se llevó a cabo utilizando la técnica de entrevista abierta con tiempo limitado. El rol de cliente (entrevistado, en nuestra terminología), fue ejercido por tres investigadores distintos a lo largo de la investigación. Finalizada la sesión de educción, los sujetos experimentales tuvieron que reportar por escrito, en formato libre, toda la información relevante generada y adquirida durante la entrevista así como rellenar un cuestionario post-experimental. Dicho cuestionario permitió recoger las características personales de los sujetos tales como la experiencia en requisitos, en entrevistas, en desarrollo, formación académica y familiaridad con el dominio, entre otras.

Nuestros resultados, ponen de manifiesto que el efecto de la experiencia del analista sobre su efectividad varía en función del tipo de dominio del problema (conocido, desconocido) en el que se produce la educción. Para el dominio del problema desconocido, la experiencia ejerce un efecto nulo. Para el dominio de problema conocido, se observan efectos positivos para la Experiencia en Entrevistas ( $r$ $=0.34$, p-valor $=0.080$ ) y la Experiencia en Requisitos $(r=0.22, p$-valor $=0.279)$. Estos resultados estan en concordancia con el conocimiento folk acerca de la experiencia en Ingeniería de Software, donde la experiencia es un aspecto que favorece la efectividad de los analistas (Schenk et al., 1998). No obstante, por el contrario, la Experiencia Profesional $(r=-0.35$, p-valor $=0.077)$ y la Experiencia en Desarrollo $(r=-$ 
$0.06, \mathrm{p}$-valor $=0.765)$ parecen afectar negativamente. Si bien este resultado es opuesto al sentido común, dichas tendencias no son significativas y por lo tanto no son conclusivas.

Respecto a la experiencia, también hemos podido destacar que ésta ejerce un efecto a nivel de tipo de elemento (que no de efectividad global), dependiendo del tipo de dominio. En dominios conocidos, los analistas con experiencia identifican más procesos, mientras que en dominios conocidos, los conceptos son identificados primordialmente.

En lo que respecta al conocimiento se ha constatado un efecto moderado $(r=0.31)$, aunque significativo ( $p$-valor $=0.029)$. Esto es, los analistas son ligeramente más efectivos en dominios conocidos que en dominios desconocidos. De nuevo, esto está en perfecta concordancia con el conocimiento folk en Ingeniería de Software.

Un factor clave en la educción de los requisitos, es el entrevistado (cliente o usuario) tal y como lo afirman Pacheco y Garcia (2012), Razali y Anwar (2011) y lo confirman empíricamente nuestros resultados. Por otro lado, la formación de los sujetos en requisitos ejerce una marcada influencia en la efectividad de los mismos

Finalmente, otro hallazgo importante, aunque paralelo a la línea principal de la investigación, tiene relación con la medición de las variables en un experimento, concretamente con el carácter objetivo y subjetivo de la métrica utilizada. Los resultados de este estudio ponen de manifiesto que ciertas métricas son susceptibles a sesgos negativos. Las variables cuyos valores se pueden establecer de manera objetiva (en nuestro caso, la experiencia y el conocimiento del dominio) generan resultados más precisos que los subjetivos (la habilidad y la familiaridad). No fue posible obtener conclusiones sólidas respecto a la titulación académica en la efectividad de los analistas. Nuestros resultados apuntan a efectos contradictorios.

\subsection{Conclusiones}

Los resultados obtenidos muestran claramente que en dominios desconocidos, la experiencia por sí misma no determina la efectividad de los analistas de requisitos. En dominios conocidos, la efectividad de los analistas se ve influenciada por su experiencia en entrevistas y requisitos, aunque sólo parcialmente. Otras muchas variables, desconocidas en este momento para nosotros, están influyendo. Es muy probable que estas variables estén relacionadas con las habilidades débiles, como por ejemplo, las habilidades comunicativas (las cuales podrían evitar fenómenos perniciosos como el observado "techo de cristal").

El conocimiento del dominio del problema ejerce un efecto positivo en la efectividad de los analistas, e interacciona positivamente con la experiencia incrementando aún más la efectividad de los analistas.

En lo que respecta a la titulación académica, por falta de diversidad en las titulaciones académicas de los sujetos experimentales, no fue posible llegar a conclusiones sólidas. Sin embargo, creemos que una titulación en informática ejerce una influencia positiva en la efectividad de los analistas, del mismo modo que la formación en requisitos, aumenta la efectividad de los mismos.

El analista no es el único factor relevante en la educción. Los clientes (entrevistados) también juegan un rol importante en la adquisición de la información, así como la formación en aspectos relacionados con los requisitos software. 


\subsection{Estructura de la Tesis}

La tesis doctoral se encuentra organizada en 9 capítulos, incluyendo el capítulo de introducción, los cuales se describen brevemente a continuación:

- En el Capítulo 2 se presenta una revisión del estado de la cuestión. En él, se analizan los trabajos relacionados con nuestra investigación.

- En el Capítulo 3 se describen las preguntas de investigación. Dichas preguntas tienen relación con el efecto de la experiencia, conocimiento y formación académica en la efectividad de los analistas en el proceso de educción.

- En el Capítulo 4 se presenta la metodología de investigación. Como se han ejecutado 8 estudios experimentales, entre experimentos y cuasi-experimentos, en este capítulo se detalla el diseño experimental tanto para el cuasi-experimento como para el experimento base, mencionando en las demás replicaciones sus principales diferencias contextuales o de diseño.

- En el Capítulo 5 se presentan la ejecución y los resultados obtenidos por cada estudio experimental, así como una descripción y justificación de las diferencias existentes entre los mismos.

- En el Capítulo 6 en función de las preguntas de investigación se presenta una síntesis de los resultados obtenidos, es decir, un análisis conjunto mediante meta-análisis de datos individuales y meta-análisis de datos agregados, empleando todos los datos obtenidos durante la investigación.

- En el Capítulo 7 se discute el efecto de la experiencia, el conocimiento y la titulación académica, así como aspectos relevantes derivados de las preguntas de investigación o aspectos metodológicos.

- En el Capítulo 8 se describen las limitaciones y amenazas a la validez de los resultados obtenidos en la investigación.

- $\quad$ En el Capítulo 9 se exponen las conclusiones y futuras líneas de investigación.

Finalmente se recogen las referencias bibliográficas citadas a lo largo de la presente investigación, seguidamente de los Anexos cuyos contenidos se indican a continuación:

- Anexo A - Cuestionarios Demográficos

- A.1. Cuestionario Q-2007

- A.2. Cuestionario Q-2009

- A.3. Cuestionario Q-2011

- A.4. Cuestionario Q-2012

- A.5. Cuestionarios E-2012, E-2013, E-2014, E-2015

- Anexo B - Objetos Experimentales

- $\quad$ B.1. Dominio del problema Desconocido (PD1)

- $\quad$ B.2. Dominio del problema Conocido (PC1)

- $\quad$ B.3. Dominio del problema Desconocido (PD2)

- $\quad$ B.4. Dominio del problema Conocido (PC2)

- Anexo C - Muestra las tablas resúmenes sobre las efectividades. Contiene el detalle de los elementos adquiridos, en función de los tipos de elementos que definen el dominio del problema (conceptos, requisitos y conceptos).

- Anexo D - Presenta el conjunto de datos adquiridos a lo largo de la serie histórica de experimentos.

- Anexo E - Detalla el procedimiento de ajuste aplicado al conjunto de datos experimentales.

- Anexo F - Muestra los efectos parciales de las distintas experiencias obtenidas de los estudios individuales, tanto del dominio de problema conocido y desconocido. 
- Anexo G - Presenta las condiciones de colinealidad correspondiente a los modelos finales de la experiencia, tanto para el dominio conocido como el desconocido.

- Anexo $\mathrm{H}$ - Expone los gráficos correspondientes a los meta-análisis de datos agregados asociados a la experiencia en requisitos y en entrevistas, diferenciados por tipo de dominio del problema (requisitos, conceptos y procesos).

- Anexo I - Presenta la comparación de los efectos de las entrevistas individuales vs las entrevistas en grupo sobre la efectividad de los analistas.

\subsection{Contribuciones}

Como resultado de la presente investigación se han presentado y publicado tres artículos en conferencias internacionales y uno en una revista de alto impacto. Adicionalmente, un artículo está a la espera de su respuesta y dos están en fase de elaboración que serán publicados en un futuro inmediato. A continuación se describen brevemente cada uno de los artículos con sus respectivas contribuciones.

\section{- Artículos Publicados}

(P1) Alejandrina Aranda, Oscar Dieste y Natalia Juristo. In search of requirements analyst characteristics that influence requirements elicitation effectiveness: A quasi-experiment. INTEAMSE (Managing the Influence of People and Team Factors in SE), Madrid, España, 2012.

El objetivo principal de este artículo fue explorar los efectos de determinadas características de los sujetos: formación académica, experiencia en requisitos, entrevistas y educción, familiaridad con el dominio del problema y el tiempo de educción, en la efectividad del analista durante el proceso de educción de los requisitos Los resultados fueron presentados en el INTEAMSE como parte de la conferencia PROFES'2012. Este artículo permitió al investigador recibir comentarios y sugerencias de otros investigadores en el área.

(P2) Alejandrina Aranda, Oscar Dieste, Natalia Juristo. A Quasi-Experiment for Studying the Effect of Experience on Elicitation Effectiveness. REFSQ (Requirements Engineering: Foundation for Software Quality), Essen, Alemania, 2013.

El objetivo principal de este cuasi-experimento fue evaluar el efecto de la experiencia de los analistas en el proceso de educción de los requisitos. El cuasi-experimento se realizó durante la feria empírica (Empirical Track) - Alive Empirical Study del REFSQ'13. La contribución principal de este experimento para la tesis consistió en aumentar la diversidad de experiencias y en consecuencia el tamaño muestral.

(P3) Alejandrina Aranda, Oscar Dieste, Natalia Juristo. Evidence of the presence of bias in subjective metrics: analysis within a family of experiments. EASE (Evaluation and Assessment in Software Engineering), Londres, Inglaterra, 2014.

El objetivo de este artículo fue comprobar que las métricas subjetivas usadas en ingeniería del software son propensas a sesgos. Este trabajo constituye una investigación paralela a la tesis doctoral.

(P4) Alejandrina Aranda, Oscar Dieste, Natalia Juristo. Effect of Domain Knowledge on Elicitation Effectiveness: An Internally Replicated Controlled Experiment. IEEE Transactions on Software Engineering (TSE), 2015.

El objetivo de este artículo fue evaluar experimentalmente el efecto del conocimiento del analista en la efectividad del proceso de educción de los requisitos. Contribuye al conocimiento científico experimental de RE respecto al impacto del conocimiento. 


\section{- $\quad$ Artículos Enviados}

(E1) Alejandrina Aranda, Oscar Dieste, Natalia Juristo. Effect of Experience on Elicitation Effectiveness: A Family of Empirical Studies. Enviado a IEEE Transactions on Software Engineering (TSE), 2016.

El objetivo de este artículo fue evaluar experimentalmente el efecto de la experiencia del analista en la efectividad del proceso de educción de los requisitos, durante sus primeras interacciones con el cliente. Contribuye al conocimiento científico experimental de RE respecto al impacto de la experiencia.

\section{- Artículos en Confección}

(C1) Alejandrina Aranda, Oscar Dieste, Natalia Juristo. The risk of dichotomizing continuous variables: Two examples in the domains of requirements and programming. Para enviar al ESEM 2016.

Este artículo es de carácter metodológico, correspondiente con una investigación paralela al tema central de la tesis. Si bien los problemas que trae consigo la dicotomización de variables continuas es bastante conocido y discutido en otras áreas de investigación como la psicología o la medicina, no lo es tanto en Ingeniería del Software. Creemos que es de vital importancia que la comunidad de Ingeniería de Software Empírica conozca los riesgos asociados a emplear dicotomizaciones, lo que permitirá decidir cuándo conviene aplicarlo y cuándo no, ya que los resultados o conclusiones finales varían mucho en función del punto de corte escogido para el análisis.

(C2) Alejandrina Aranda, Oscar Dieste, Natalia Juristo. Methodological considerations for performing requirements elicitations experiments: Design types, Samples sizes and Moderators variables. Para enviar a Research Method Track del REFSQ 2017.

Este artículo es de carácter metodológico, pero muy relacionado con el tema central de la tesis. El objetivo principal del artículo es advertir a experimentadores que harán experimentos en Ingeniería de Requisitos de la necesidad de contar con un diseño experimental y tamaño muestral adecuados para obtener resultados fiables e identificar con seguridad los efectos de las variables independientes y factores bajo estudio. También se pondrá de manifiesto que durante el análisis conjunto de una serie de experimentos, es necesario considerar los efectos de las variables moderadoras, ya que éstas influyen en los resultados de la investigación.

(C3) Alejandrina Aranda, Oscar Dieste, Natalia Juristo. Visibility of problem domain elements on requirements elicitation process: A Family of Empirical Studies. Para enviar a Empirical Software Engineering Journal (ESEM)

Este artículo tiene por objetivo conocer mejor el proceso de captura de información por parte del analista. Hemos realizado un estudio exploratorio con la finalidad de comprobar si la visibilidad (captura o identificación por parte del analista) de los elementos del dominio que pudiera depender del dominio estudiado, de la experiencia del analista o de la influencia del entrevistado (cliente). Los resultados ponen de manifiesto que, por un lado, indistintamente del dominio del problema los sujetos tienden a focalizarse en un subconjunto de elementos. Por otro lado, dentro de ese sub-conjunto de datos: a) en dominios desconocidos, los sujetos tienden a focalizarse más en los procesos; b) en dominios conocidos, más en los conceptos. Por otra parte, hemos podido constatar que durante las primeras sesiones de educción: en dominios desconocidos, es el entrevistado 
quien lidera la conversación, mientras que en dominios conocidos es el analista. Este hecho pone de manifiesto que la visibilidad o no de un elemento está estrechamente relacionado con la tipología del dominio y quien guía o lidera la conversación.

\subsection{Otras contribuciones}

(01) Oscar Dieste, Alejandrina Aranda, Fernando Uyaguari, Burak Turhan, Ayse Tosun, Davide Fucci, Markku Oivo, Natalia Juristo. Empirical Evaluation of the Effects of Experience on Code Quality and Programmer Productivity: An Exploratory Study. Enviado a Empirical Software Engineering Journal (ESEM), 2015.

El objetivo principal de este artículo fue determinar si los años de experiencia influyen en el desempeño del programador. Este artículo es una investigación paralela realizada dentro del proyecto FiDiPro ESEIL. Esta investigación complementa a la presente tesis ya que estudia el efecto de la experiencia en actividades distintas a la educción de requisitos. Como resultado principal de esta investigación obtuvimos que la experiencia en programación, no parece ejercer efecto alguno en la calidad y productividad del programador. No obstante, la experiencia general en programación adquirida en academia tiende a influir positivamente en el desempeño de los programadores. Estos resultados se parecen mucho a los que hemos obtenido acerca de la educción en dominios desconocidos. 


\section{CAPÍTULO 2}

\section{ESTADO DE LA CUESTIÓN}

Este capítulo tiene por objetivo presentar al lector una visión general sobre la influencia de los factores humanos en Educción de Requisitos. Con la finalidad de contextualizar la investigación, se describirán varios trabajos que tratan aspectos que ejercen influencia en los procesos de desarrollo y requisitos en general, y en la fase de educción de requisitos en particular.

\subsection{Efecto de la Formación Académica}

Determinar los factores que tienen influencia en el proceso de desarrollo del software ha sido objeto de una amplia y permanente investigación durante más de 30 años (McLeod \& MacDonell, 2011; Pirzadeh, 2010). La mayoría de los trabajos se han centrado en aspectos técnicos: metodologías, procesos, herramientas y técnicas que podrían mejorar el proceso de desarrollo del software. Ello aplica igualmente a la Ingeniería de Requisitos. Ahmed, Capretz, Bouktif y Campbell (2013) comentan que el analista requiere habilidades y conocimientos técnicos, es decir, fundamentos teóricos y prácticos necesarios para llevar a cabo su tarea.

No obstante, los aspectos técnicos no son los únicos que influyen en el resultado del proceso, sino que existen muchos otros, como por ejemplo las características de las personas que llevan a cabo las actividades de desarrollo (Anwar et al., 2011; Chakraborty, Sarker, \& and Valacich, 2007). El proceso de desarrollo del software es un proceso centrado en la persona (Curtis, Krasner, \& Iscoe, 1988) donde los factores humanos juegan un rol importante (Acuña, Gómez, Hannay, Juristo, \& Pfahl, 2015; Amrit, Daneva, \& Damian, 2014) y pueden tener un impacto en los resultados igual o mayor que las actividades técnicas (Matturro, 2013).

La Ingeniería de Requisitos, más que otras áreas de la Ingeniería del Software, requiere una intensa comunicación e interacción entre personas (Anwar et al., 2011) lo que conlleva que el analista no sólo deba poseer conocimientos técnicos específicos (por ejemplo, conocimientos acerca de educción), sino también habilidades/destrezas/capacidades (por ejemplo, habilidades interpersonales, analíticas, conocimiento del dominio, experiencia, entre otras) (Chakraborty et al., 2007; Vale, Albuquerque, \& 
Beserra, 2011). Los analistas están sujetos también a limitaciones cognitivas que pueden obstaculizar e impedir una educción de requisitos adecuada (Valenti, Panti, \& Cucchiarelli, 1998).

Curtis et al. (1988) en su investigación encontraron que la comunicación entre los analistas de requisitos y otras personas participantes (clientes y usuarios), así como, entre los analistas de requisitos y desarrolladores, es de crítica importancia. Para Ahmed et al. (2013), Ahmed, Capretz, y Campbell (2012) las habilidades de comunicación, analíticas y de resolución de problemas, así como el trabajo en equipo son requeridas por los analistas de sistemas para el buen desempeño de sus funciones. Los autores argumentan que los analistas de sistemas requieren una gran cantidad de interacción humana entre usuarios y clientes, por lo que la habilidad de comunicación es esencial. Adicionalmente, los analistas de sistemas deben ser capaces de empatizar con sus clientes para entender completamente sus necesidades, por lo que las habilidades interpersonales, analíticas y trabajo en equipo son muy deseables. Jabar, Yeong, y Sidi (2012) mencionan que la habilidad de adquirir requisitos eficazmente depende en parte de la experiencia, la familiaridad con el dominio y de las habilidades para resolución de problemas.

En la misma línea, Capretz y Ahmed (2010) argumentan que las personas extrovertidas y sensibles son preferibles para la fase de educción de requisitos. Acuña y Juristo (2004), Acuña, Gómez, y Juristo (2009) en su investigación apuntan que las capacidades necesarias para que el ingeniero de requisitos sea efectivo en su tarea deben poseer a) capacidades intrapersonales como: análisis, juicio y tolerancia al stress; b) orientación al entorno como capacidad de organización; c) capacidades interpersonales: servicio al cliente, empatía, sociabilidad, trabajo en equipo y cooperación.

Los trabajos anteriores ponen de manifiesto numerosos factores que pueden influir en la efectividad del analista durante el proceso de educción de requisitos. En las siguientes secciones se describirán marcos conceptuales que explícitamente han indicado qué características podrían perjudicar o favorecer la efectividad del analista. Como resultados obtendremos que las características más importantes para que el analista desempeñe eficientemente su función son: en primer lugar, las habilidades débiles o soft-skills, seguidas del conocimiento del dominio, el conocimiento técnico y la experiencia, entre otras.

\subsection{Marcos Conceptuales}

Al acercarnos a la literatura sobre factores humanos en Ingeniería de Requisitos aparecen en primer lugar una serie de trabajos de tipo principalmente teórico que presentan modelos conceptuales o marcos teóricos sobre factores (no necesariamente humanos sino también relacionados con el proceso, la tecnología, entre otros) que ejercen una influencia en la efectividad del proceso de desarrollo en general, y ciertas facetas de los requisitos en particular.

Nuestro propósito inicial para identificar los artículos relevantes que describen marcos conceptuales acerca de factores humanos en Ingeniería de Requisitos, fue realizar un Mapeo Sistemático de la Literatura siguiendo las recomendaciones de Kitchenham y Charters (2007). Para ello, intentamos aplicar una estrategia basada en el concepto de quasi-gold standard (Zhang \& Babar, 2010). El quasigold standard es una forma práctica de identificar la precisión y la sensibilidad de una búsqueda, con la finalidad de hacer más eficaz y eficiente el proceso de revisión. Para ello, es necesario identificar un sub-conjunto de artículos relevantes mediante búsquedas no sistemáticas que formen parte de este quasi-gold standard.

Realizamos diversas búsquedas no sistemáticas. Para ello utilizamos una diversidad de cadenas de búsquedas, como por ejemplo:

- (“Human Factors" OR "Human Issues") AND ("Requirement Engineering" OR "Requirement Elicitation" OR "Requirement Analysis") 
La base de datos escogida, por su facilidad para realizar búsquedas y su comodidad fue Google Scholar, ciertas búsquedas fueron realizadas en SCOPUS, IEEEXPLORE, Springer (Requirements Engineering y Empirical Software Engineering) sin que surgieran diferencias sustanciales. En general, todas las cadenas de búsquedas devolvieron una gran cantidad de artículos, pero dichos artículos no hacían referencia a la influencia de los factores humanos en Ingeniería de Requisitos. Este hecho, no nos resultó en absoluto sorprendente. En dos revisiones sistemáticas previas (Dieste \& Juristo, 2011; Condori-Fernandez et al., 2009), los supervisores de esta tesis ya experimentaron problemas similares, y más recientemente en el marco de un estudio sobre errores estadísticos en Ingeniería del Software, la situación fue incluso más complicada, llegando a sensibilidades inferiores a uno por mil. Cuando esto ocurre, lo que sucede es que el número de estudios relevantes es muy pequeño tanto en términos absolutos como en comparación a la literatura relacionada. Por este motivo, descartamos aplicar una SLR y utilizamos los artículos obtenidos mediante búsquedas oportunistas para confeccionar el estado de la cuestión.

Nótese, que por cada trabajo presentaremos un breve resumen de los modelos propuestos, sin embargo nos centraremos en aquellas categorías que afectan directamente a los aspectos/habilidades/ capacidades humanas de los analistas de requisitos, foco de nuestra investigación. Los trabajos presentados a continuación estarán ordenados cronológicamente por año de publicación.

\subsubsection{Marco de Chatzoglou}

Chatzoglou (1997) propuso ${ }^{1}$ un marco teórico compuesto por 12 factores que podrían afectar la fase de educción de requisitos de proyectos con características distintas. El método de investigación empleado es el cuestionario (survey) a través de e-mail (mail questionnaire survey method). El autor realizó tres encuestas distintas para identificar y justificar qué factores, cómo y en qué grado podrían influir en la planificación y gestión del proceso de desarrollo en general, y en el proceso de identificación y análisis de los requisitos en particular. Los datos fueron capturados de 107 proyectos de personas que trabajan para más de 70 organizaciones.

El marco propuesto está compuesto por tres categorías principales: los factores humanos asociados a los usuarios y miembros del equipo (analistas de sistemas y desarrolladores); factores técnicos y factores gestión del proyecto; además de las características del proyecto, tales como: organización, desarrolladores, tipo de proyecto, tipo de problema, aplicabilidad y usuario final (propia compañía o cliente externo). Nótese que la categorización y factores del modelo propuesto están basados en la literatura y a su vez se derivan estadísticamente del survey realizado.

En la presente investigación, la influencia de las características personales de los analistas son relevantes. Chatzoglou (1997) distingue cuatro factores que componen la categoría de factores humanos asociados a los miembros del equipo (analistas y desarrolladores), como se indica en la Tabla 2.1:

Tabla 2.1 - Factores Humanos pertenecientes a la categoría miembros del equipo

\begin{tabular}{|c|cl|}
\hline CATEgORía & & \multicolumn{1}{c|}{ FACTORES } \\
\hline Factores Humanos & - & Experiencia con elicitación de requisitos y desarrollo de sistemas; \\
/ Miembros del & - & Conocimiento sobre el dominio del problema; \\
equipo & - Ansiedad y stress por completar con éxito el proceso; \\
& - Compromiso y persistencia para el desarrollo de un sistema específico. \\
\hline
\end{tabular}

En lo que respecta al nivel de importancia de dichos factores, los autores han mostrado que la experiencia, el conocimiento, el compromiso y la persistencia de los miembros del equipo son muy

\footnotetext{
${ }^{1}$ Nótese que existe otro trabajo publicado por Chatzoglou y Macualay (1997) que contiene prácticamente la misma información, no descrito en esta sección.
} 
importantes para el proceso de educción de requisitos así como para llevar a cabo el desarrollo de un proyecto; mientras que la ansiedad y el stress parecen menos importantes o incluso completamente insignificantes.

\subsubsection{Propuesta de Wiegers}

Aunque Wiegers (2003) no propone un marco propiamente dicho, su trabajo contribuye a nuestra investigación con habilidades que, a criterio del autor, considera necesarias para aumentar la efectividad de los analistas. Según Wiegers, un analista efectivo debería poseer una serie de habilidades de comunicación e interpersonales, las cuales incluyen:

- la capacidad de saber escuchar

- la capacidad de hacer preguntas y entrevistar

- habilidades interpersonales

- habilidades de análisis

- habilidades de negociación y facilitación

- habilidades de observación

- habilidades de escritura

- capacidad de organización

- modelado

- creatividad

Además de las habilidades de comunicación e interpersonales, un analista efectivo debe poseer conocimiento técnico y conocimiento del dominio, junto con la correcta personalidad requerida para el trabajo. A este respecto, Wiegers recomienda que el analista posea conocimiento en el dominio y experiencia. Wiegers argumenta que el conocimiento sobre el dominio es un aspecto de la mayor relevancia para que un analista sea efectivo, ya que entre otras cosas, minimiza los problemas de comunicación con los usuarios, es capaz de detectar supuestos tácitos y requisitos implícitos, además de sugerir a los usuarios como mejorar el proceso de negocio. Por otro lado, la experiencia ayuda a un analista a descubrir los deseos no expresados por los clientes y usuarios.

\subsubsection{Propuesta de Misic y Graf.}

Misic y Graf (2004) realizaron una encuesta en la que participaron analistas de sistemas de aproximadamente 819 organizaciones. Uno de los objetivos principales de la investigación consistió en identificar las habilidades necesarias para que el analista de sistemas realizara sus actividades eficientemente. Cuatro fueron las categorías de habilidades estudiadas: habilidades interpersonales, técnicas, de análisis y comunicación.

Las habilidades interpersonales tienen relación con la capacidad que tiene el analista de interactuar con otras personas: usuarios finales, analistas, gerentes y proveedores externos. Las habilidades técnicas se definieron como la capacidad de emplear técnicas de desarrollo de sistemas, conocimientos de hardware y software y otras herramientas como ayuda al desarrollo de sistemas. Las habilidades de comunicación se definen como la capacidad de escribir y hablar claramente, resumir y documentar la información de una manera que otras personas puedan entender.

Como resultado, las habilidades más importantes son las habilidades de análisis con las que el analista examina críticamente las cosas y/o minuciosamente; mientras que las habilidades técnicas y de comunicación resultaron ser equivalentes en orden de importancia.

Las habilidades interpersonales resultaron ser las menos importantes.

A la luz de los resultados obtenidos, los autores argumentan que, a pesar de las cambiantes demandas en los analistas e importancia de las tareas relacionadas a su profesión, una persona con una 
fuerte capacidad de análisis será exitosa, dado que dicha habilidad constituye la base fundamental para que el analista pueda adaptarse a los cambios tecnológicos que dan lugar los avances de hoy en día.

\subsubsection{Propuesta de Chakraborty, Sarker y Valacich}

La habilidad o capacidad del analista ha sido vista como un factor crítico en el proceso de desarrollo de un sistema, especialmente para la fase de elicitación de los requisitos. Sin embargo, Chakraborty et al. (2007) argumentan que la capacidad del analista es condición necesaria pero no suficiente para ser efectivo. La efectividad del analista depende adicionalmente de un conjunto de factores contextuales como pueden ser: el proceso, entendido no como la metodología empleada durante la educción de requisitos, sino como la manera en que el analista interioriza y aplica la información relevante para comprender un requisito específico, así como las características del proyecto.

Los autores proponen un modelo teórico compuesto por tres dimensiones principales: la capacidad del analista, las características del proyecto y las características del proceso. La primera dimensión abarca un conjunto de capacidades que el analista necesita poseer, ya sean éstas habilidades relacionadas con el trabajo o características individuales de la persona. La segunda, tiene relación con las características que definen el proyecto. Finalmente, la tercera corresponde a las características del proceso.

En lo que respecta a las capacidades o habilidades que podrían influir en la efectividad del analista, éstas hacen referencia al:

- conocimiento acerca del negocio que facilita la comprensión del negocio;

- conocimiento técnico (técnicas, hardware o software);

- habilidades analíticas que permiten al analista examinar críticamente las cosas, así como

- las habilidades interpersonales que permite al analista interaccionar efectivamente con los involucrados en el proyecto, estas están compuestas por: habilidades de comunicación, habilidades políticas y habilidades de gestión.

\subsubsection{Marco de Chakraborty, Sarker y Sarker}

Chakraborty, Sarker y Sarker (2010) han identificado un conjunto de habilidades que tanto los analistas como los usuarios representativos deben poseer para terminar el proceso de educción de requisitos con éxito. La investigación consistió en un estudio empírico cualitativo en el que participaron miembros de dos organizaciones diferentes. Los datos empíricos se obtuvieron mediante entrevistas semiestructuradas y la aplicación sobre las observaciones de la metodología Teoría Asentada (Grounded Theory).

Los autores examinaron la Ingeniería de Requisitos desde la perspectiva del conocimiento compartido, confianza y el desarrollo de modelos mentales dentro de un contexto colaborativo (analistas de requisitos y usuarios representativos). Propusieron un modelo de proceso para la educción de requisitos en términos de estados y transiciones. El modelo se compone de cuatro estados diferentes: Scoping, Sense-making, Dissension y Termination con sus respectivas interacciones.

El primer estado Scoping corresponde al estado en el que se inicia la educción de requisitos. El usuario representativo transmite al analista su conocimiento acerca del dominio, las necesidades y objetivos del negocio. En el segundo estado Sense-making, tanto el analista como el usuario se esfuerzan por entender los límites del problema y las metas del proyecto a través de una serie de interacciones (o diálogos). El estado Dissension corresponde al tercer estado en el que los involucrados se centran en resolver las diferencias y desacuerdos que pueden surgir durante el estado anterior. Finalmente, en el estado Termination las dos partes llegan a un consenso respecto a los requisitos a través de la creación del documento de especificación de los requisitos. 
La Tabla 2.2 presenta los factores que podrían influir en la efectividad del proceso de educción, restringido a los factores propios del analista, que son los que conciernen a esta investigación. La mayoría de ellas hacen referencia al conocimiento en sus distintas vertientes: conocimiento del dominio de la aplicación, conocimiento en el proceso de desarrollo, conocimiento de la tecnología y conocimiento de la aplicación del sistema. Las restantes son: experiencia, habilidades de comunicación y capacidad de absorción.

Tabla 2.2 - Factores que influyen en el proceso de educción de requisitos

\begin{tabular}{|l|l|}
\hline \multicolumn{1}{|c|}{ FACTORES CLAVES DEL ANALISTA } & ESTADO EN EL QUE EL FACTOR SE CONSIDERA \\
\hline $\begin{array}{l}\text { Conocimiento del dominio de la } \\
\text { Aplicación }\end{array}$ & $\begin{array}{l}\text { Scoping } \\
\text { Sense Making } \\
\text { Dissension }\end{array}$ \\
\hline $\begin{array}{l}\text { Conocimiento del proceso de } \\
\text { desarrollo del sistema }\end{array}$ & $\begin{array}{l}\text { Sense Making } \\
\text { Dissension }\end{array}$ \\
\hline Conocimiento tecnológico & Sense Making \\
\hline Conocimiento en Ingeniería del & Dissension \\
Software & Sense Making \\
Experiencia & Dissension \\
\hline Capacidad de absorción & Scoping \\
\hline Habilidades de Comunicación y & Dense Making \\
Negociación & Sense Making \\
\hline
\end{tabular}

\subsubsection{Marco de Vale, Albuquerque y Beserra}

Vale et al. (2011) presentan un estudio cuantitativo y cualitativo sobre las habilidades personales necesarias para que los analistas de requisitos puedan realizar sus tareas de una manera más eficaz. En primer lugar, realizaron una revisión de la literatura sobre habilidades personales para profesionales que ejercen el papel de analistas de requisitos. Como resultado de la revisión obtuvieron un listado de 33 habilidades personales, las cuales se presentan en la Tabla 2.3.

Tabla 2.3 - Habilidades personales identificadas para el perfil de analista de requisitos

\begin{tabular}{|l|l|}
\hline \multicolumn{1}{|c|}{ HABILIDADES PERSONALES } & \multicolumn{1}{c|}{ DESCRIPCIón } \\
\hline Facilidad de relación & Habilidad para relacionarse con otras personas \\
\hline $\begin{array}{l}\text { Capacidad para motivar a otras } \\
\text { personas }\end{array}$ & $\begin{array}{l}\text { Habilidad para conseguir motivar a otras personas, consiguiendo de ellas } \\
\text { responsabilidad }\end{array}$ \\
\hline $\begin{array}{l}\text { Orientación a las necesidades del } \\
\text { cliente }\end{array}$ & Habilidad para identificar y atender las necesidades de sus clientes \\
\hline Orientación para resultados & Habilidad para alcanzar y/o superar metas y/u objetivos propuestos \\
\hline Capacidad de ejecución & $\begin{array}{l}\text { Habilidad para realizar correctamente las tareas que le sean atribuidas y en el } \\
\text { plazo definido }\end{array}$ \\
\hline Sentido de la organización & $\begin{array}{l}\text { Habilidad para ordenar, priorizar y controlar una ejecución de sus tareas de } \\
\text { acuerdo con lo planeado, así como los recursos bajo su responsabilidad }\end{array}$ \\
\hline Facilidad de adaptación al cambio & $\begin{array}{l}\text { Habilidad para adaptarse y trabajar eficazmente con diversas situaciones y } \\
\text { cambios }\end{array}$ \\
\hline Persistencia & $\begin{array}{l}\text { Habilidad de continuar trabajando y buscar alternativas aunque el proyecto } \\
\text { no vaya bien }\end{array}$ \\
\hline Minuciosidad & $\begin{array}{l}\text { Habilidad para observar los detalles referentes a las tareas bajo su } \\
\text { responsabilidad }\end{array}$ \\
\hline
\end{tabular}




\begin{tabular}{|c|c|}
\hline HABILIDADES PERSONALES & DESCRIPCIÓN \\
\hline Imparcialidad & Habilidad para no sacrificar la verdad en pro de consideraciones particulares \\
\hline Poder de persuasión & Habilidad para convencer a otras personas a seguir un determinado camino \\
\hline Capacidad para resolver conflictos & $\begin{array}{l}\text { Habilidad para conseguir resolver conflictos de interés en situaciones de } \\
\text { trabajo }\end{array}$ \\
\hline Capacidad de síntesis & Habilidad para combinar informaciones y componer un todo \\
\hline Capacidad de análisis & $\begin{array}{l}\text { Habilidad para entender y explicar cada parte de un todo, lo que permite } \\
\text { conocer mejor la naturaleza, funciones, causas, entre otros, del fenómeno } \\
\text { estudiado }\end{array}$ \\
\hline Capacidad de juzgar & Habilidad para juzgar alternativas y tomar decisiones adecuadas \\
\hline Credibilidad & Habilidad de demostrar entendimiento sobre las tareas y temas abordados \\
\hline Confiabilidad & Habilidad para que sus interlocutores puedan confiar en el analista \\
\hline Raciocinio lógico & $\begin{array}{l}\text { Habilidad para resolver un problema a partir de la comprensión y de las } \\
\text { relaciones lógicas existentes entre los elementos que lo componen }\end{array}$ \\
\hline Predicción & $\begin{array}{l}\text { Habilidad para realizar previsiones sobre la ocurrencia sobre determinados } \\
\text { fenómenos o comportamientos futuros }\end{array}$ \\
\hline Capacidad para innovar & Habilidad para identificar y crear nuevas ideas y oportunidades \\
\hline Pensamiento Crítico & $\begin{array}{l}\text { Habilidad para determinar cuidadosa y deliberadamente la aceptación, la } \\
\text { refutación o suspensión del ensayo a cerca de una información dada. }\end{array}$ \\
\hline Facilidad de comunicación oral & $\begin{array}{l}\text { Comunicarse oralmente de manera simple, concisa, no ambigua y de manera } \\
\text { que se le entienda fácilmente }\end{array}$ \\
\hline Facilidad de comunicación escrita & $\begin{array}{l}\text { Escribir de manera simple, concisa, no ambigua y que sea fácilmente } \\
\text { entendible }\end{array}$ \\
\hline Tolerancia a la presión & Capacidad de lidiar satisfactoriamente con situaciones de presión \\
\hline Presteza & Habilidad de quien es útil, de quien ayuda con buena voluntad y precisión \\
\hline Proactividad & Habilidad de anticiparse cuando es necesario \\
\hline Capacidad de concentración & Capacidad de orientar su atención o energías a un objetivo determinado \\
\hline Ética & $\begin{array}{l}\text { Habilidad de seguir un conjunto de reglas y preceptos de orden valorativo y } \\
\text { moral }\end{array}$ \\
\hline Capacidad de aprensión & Capacidad de asimilación o comprensión de lo que puede ser conocido \\
\hline Capacidad de escuchar & Capacidad para considerar lo que los interlocutores están informando \\
\hline Iniciativa & $\begin{array}{l}\text { Habilidad de proponer y/o realizar cualquier acción sin necesidad de que otro } \\
\text { venga a pedir o mandar }\end{array}$ \\
\hline Autonomía & Capacidad de gobernarse por sus propios medios \\
\hline Capacidad metódica & $\begin{array}{l}\text { Habilidad para utilizar un conjunto de etapas, ordenadamente dispuestas, } \\
\text { establecidas por métodos/técnicas, con el fin de solucionar un determinado } \\
\text { problema }\end{array}$ \\
\hline
\end{tabular}

En segundo lugar, con el objetivo de clasificar y priorizar las habilidades identificadas en la revisión de literatura, los autores realizaron un estudio empírico empleando un cuestionario (survey) administrado a 30 gerentes de proyectos. El cuestionario estuvo compuesto por la lista de habilidades personales identificadas en la literatura, junto su descripción y una escala de relevancia del 0 al 4 . La Tabla 2.4 presenta por cada categoría, 5 (cinco) habilidades ordenadas por mayor índice de respuestas. 
Tabla 2.4 - Relevancia de las Habilidades Personales

\begin{tabular}{|c|c|c|}
\hline \multicolumn{3}{|c|}{ Habilidades Personales } \\
\hline MÁxima Relevancia & Mucha Relevancia & Ninguna ReleVancia \\
\hline $\begin{array}{l}\text { 1. Orientación para las necesidades } \\
\text { de los clientes } \\
\text { 2. Facilidad de comunicación } \\
\text { escrita } \\
\text { 3. Facilidad de comunicación oral } \\
\text { 4. Facilidad de relacionamiento } \\
\text { 5. Capacidad de escuchar }\end{array}$ & $\begin{array}{ll}\text { 1. } & \text { Raciocinio lógico } \\
\text { 2. } & \text { Capacidad de innovar } \\
\text { 3. Pensamiento crítico } \\
\text { 4. Capacidad de ejecución } \\
\text { 5. Poder de persuasión }\end{array}$ & $\begin{array}{l}\text { 1. Poder de persuasión } \\
\text { 2. Presteza } \\
\text { 3. Rigurosidad metódica } \\
\text { 4. Raciocinio lógico } \\
\text { 5. Predicción }\end{array}$ \\
\hline
\end{tabular}

Finalmente, con la finalidad de ampliar el conocimiento respecto a las habilidades que pueden ser relevantes para que los analistas de requisitos puedan desempeñar de forma eficaz el papel que desempeñan, los autores realizaron una investigación cualitativa utilizando entrevistas semiestructuradas a gerentes de proyectos. El procedimiento de análisis se basó en la metodología Teoría Asentada (Grounded Theory). Como ejemplo, para la categoría Habilidades Personales Relevantes, los códigos asociados a las entrevistas se muestran en la Tabla 2.5.

Tabla 2.5 - Categoría de las Habilidades Personales Relevantes

\section{Categoría: Habilidades Personales Relevantes}

1. Inteligencia y habilidades cognitivas

2. Habilidades Interpersonales

3. Pensamiento creativo

4. Comunicación
a. Capacidad de escuchar
b. Comunicación oral
c. Comunicación escrita

5. Capacidad de Análisis

6. Capacidad metódica

7. Censo de la organización

8. Profesionales orientados a las necesidades del cliente

9. Tolerancia a la presión

Nótese que el resultado final de la investigación tiene un cierto grado de concordancia con lo que fue encontrado en la literatura.

Los resultados tanto de la encuesta como el estudio cualitativo ponen de manifiesto que:

- las habilidades interpersonales,

- habilidades de comunicación,

- habilidad de estar centrado en las necesidades del cliente,

entre otras, son relevantes para que el analista de requisitos sea efectivo en el rol que desempeña.

En una publicación previa (Vale, Albuquerque, \& Beserra, 2010) los mismos autores, siguiendo la misma metodología de investigación, obtuvieron resultados similares a las habilidades indicadas en la Tabla 2.4, con la diferencia de que la Ética también forma parte de las habilidades más relevantes. Más concretamente, según Vale et al. (2010) las habilidades más importantes necesarias para que el analista de requisitos obtenga buenos resultados son:

- saber orientar las necesidades de los clientes,

- habilidades de comunicación oral y escrita,

- facilidad de relacionamiento y

- ética. 
Los autores argumentan que dichas habilidades son importantes para cualquier profesional, pero sin embargo son críticas para profesionales que trabajan en el rol de analistas de requisitos, dado que ellos constantemente necesitan capturar y transmitir las ideas claramente al cliente, especialmente en la fase de educción de requisitos.

\subsubsection{Marco de Anwar, Rozilawati y Kamsuriah}

Anwar et al. (2011) discuten algunos factores que pueden afectar la comunicación entre los usuarios y analistas de requisitos durante el proceso de educción de requisitos. Para ello, tras una revisión de literatura y análisis de contenido, proponen un marco conceptual con la finalidad de proporcionar una visión general sobre cómo dichos factores se relacionan entre ellos en el esfuerzo por lograr una comunicación eficaz durante la educción.

El marco está compuesto por tres categorías esenciales: persona, proceso y producto. La primera categoría abarca aspectos de la persona que incluye los factores humanos. La segunda categoría, corresponde al proceso, compuesta por actividades realizadas antes (selección e identificación de los participantes) y durante (selección de las técnicas, adquisición y transmisión del conocimiento) la educción de los requisitos. El producto es la tercera categoría, el cual retrata la salida o resultado final del proceso.

Los factores humanos propuestos en la investigación son clasificados en cinco aspectos:

- confianza,

- formación,

- conocimiento,

- disposición al cambio y

- habilidades interpersonales tales como: comunicación oral y escrita, negociación y colaboración.

Según los autores la selección de los participantes con características intelectuales apropiadas (habilidades interpersonales, educación y conocimiento) junto con las actitudes correctas (confianza y disposición al cambio) puede facilitar el logro de una comunicación eficaz entre las personas involucradas (analistas de requisitos, clientes y usuarios). Este hecho conlleva a mejorar la educción de los requisitos.

\subsubsection{Marco de Mcleod y MacDonell}

McLeod y MacDonell (2011) estudian factores que influyen en el proceso de desarrollo de sistemas software. Los autores, tras una revisión de literatura, propusieron un marco de clasificación que representa una visión abstracta y sintética de los tipos de factores que ejercen influencia en el proceso de desarrollo de sistemas y su implantación.

El marco está compuesto por cuatro dimensiones principales: People and Action, Development Process, Project Content e Institutional Context. La primera dimensión People and Action incluye factores relacionados con los individuos y grupos que tienen interés en el sistema, sus acciones e interacciones. Development Process abarca varias actividades asociadas con el desarrollo del software y su implantación, partiendo desde la educción de los requisitos hasta la implantación del nuevo sistema. La dimensión Project Content comprende factores que son típicamente considerados como propiedades de un proyecto de desarrollo de sistemas: alcance y objetivos, recursos, hardware y software que se usarán en el desarrollo, etc. Finalmente Institutional Context incluye factores relacionados con la organización en el cual el sistema será implantado y el ambiente socio económico en el cual el sistema operará.

La dimensión People and Action es de interés para la presente investigación. Los autores identificaron distintas categorías de personas involucradas (stakeholders) para esta dimensión, tales 
como desarrolladores, usuarios, alta dirección, etc. La Tabla 2.6 muestra los factores para la categoría Developers, ya que no existe una categoría específica referida a los analistas de requisitos. Los autores argumentan que las habilidades y capacidades de los desarrolladores que pueden influir en su productividad y por tanto en sus resultados son: experticia y experiencia, capacidad de resolución de problemas, habilidades sociales y de comunicación, conocimiento del dominio, motivación, compromiso y la adherencia a normas, valores y creencias.

Tabla 2.6 - Factores que ejercen influencia en el proceso de desarrollo del software

\begin{tabular}{|c|c|c|}
\hline DIMENSIÓN & CATEGoRÍA & FACTOR \\
\hline $\begin{array}{l}\text { People and Action } \\
\text { (Persona y Acción) }\end{array}$ & Desarrolladores & $\begin{array}{l}\text { Experiencia y habilidad técnica } \\
\text { Resolución de problemas } \\
\text { Habilidades sociales y de comunicación } \\
\text { Conocimiento del problema / del dominio de la } \\
\text { aplicación } \\
\text { Motivación y compromiso } \\
\text { Normas, valores, creencias y suposiciones }\end{array}$ \\
\hline
\end{tabular}

\subsubsection{Propuesta de Herrmann}

La investigación realizada por Herrmann (2013) no propone un marco estructurado propiamente dicho como la mayoría de los estudios anteriores, pero sin embargo contribuye con factores concretos que podrían afectar en la efectividad de los analistas de requisitos.

Con la finalidad de averiguar qué habilidades son demandadas hoy en día en la práctica para ejercer el rol de ingenieros de requisitos, el autor hizo un análisis de 141 ofertas de empleo del 2009 y 67 del 2012. Como resultado, entre las habilidades demandas requeridas para el rol de ingeniero de requisitos están:

- conocimiento técnico,

- experiencia con métodos,

- experiencia con herramientas,

- experiencia específica en la tarea (ej: documentación, validación) a realizar,

- conocimientos sobre gestión de proyectos,

- habilidades débiles y

- conocimiento del dominio.

Sus hallazgos apuntan que las habilidades débiles, el conocimiento técnico y la experiencia previa con la tarea específica a realizar son las habilidades más demandadas. En lo que respecta a las habilidades débiles, las más importantes hacen referencia al idioma inglés, habilidades de comunicación y capacidad de trabajo en equipo.

\subsection{Identificación de las Habilidades Personales más Relevantes}

No existe un marco conceptual único en la literatura que categorice las habilidades personales requeridas por el analista de requisitos para realizar de forma efectiva la actividad de educción de requisitos. Basándonos en la literatura identificada, hemos agrupado las características mencionadas en los marcos y propuestas descritos en las sub-secciones anteriores, los cuales se muestran en la Tabla 2.7. Como se puede apreciar en la Tabla 2.7, hemos agrupado los aspectos personales en las siguientes categorías:

- Habilidades psicológicas y cognitivas. Las habilidades cognitivas se refieren a aquellas habilidades que operan directamente sobre la información adquirida por los sentidos, analizando, comprendiendo, procesando y guardando dicha información en la memoria para 
posteriormente poder recuperarla y utilizarla. Las habilidades psicológicas hacen referencia a las características intrínsecas de la persona (ej: introversión).

- Aspectos culturales. Engloban una amplia gama de estructuras organizacionales, prácticas y relaciones que hacen posible el desarrollo del sistema software. Esto incluye: normas institucionales, valores y creencias, la distribución de los recursos disponibles en la organización (tiempo, presupuesto y habilidades), reglas y procedimientos de la organización, costumbres y prácticas establecidas, estructuras formales e informales de la organización, mecanismos de control y coordinación, división del trabajo, etc.

- Habilidades débiles (soft skills). Habilidades o actitudes requeridas para tener una buena relación con los demás, por ejemplo: habilidades interpersonales, habilidades de comunicación, habilidades analíticas, entre otras.

- Habilidades técnicas. Se refieren a las capacidades y conocimiento técnicos necesarios para desempeñar una determinada tarea.

- Conocimiento del dominio.

- Experiencia.

- Formación.

En la columna derecha de la Tabla 2.7 hemos indicado el número de estudios que hace referencia a cada categoría de habilidades personales. Hemos denominado a este valor nivel de importancia, ya que parece razonable que cuantos más estudios hagan referencia a una categoría de habilidades personales, más relevantes serán los aspectos pertenecientes a dicha categoría para aumentar la efectividad de los analistas de requisitos.

De mayor a menor nivel de importancia, las categorías resultantes son: las habilidades débiles, el conocimiento del dominio, los aspectos técnicos y la experiencia. Dentro de la categoría de habilidades débiles, los aspectos con mayor nivel de importancia son las habilidades de comunicación e interpersonales. Este resultado es esperable, dado que la fase de Ingeniería de Requisitos es considerada una de las fases del proceso de desarrollo del software donde más interacción y comunicación existe (Al-Rawas \& Easterbrook, 1996; Anwar et al., 2011; Appan \& Browne, 2012; Coughlan, Lycett, \& Macredie, 2003) entre las personas involucradas (analistas, clientes, desarrolladores, etc.).

Nuestra investigación tendrá como objetivo estudiar experimentalmente la influencia de algunos aspectos de las categorías antes indicadas en la efectividad de los analistas. Por ello, debemos seleccionar cuáles son los más relevantes dados nuestros intereses y limitaciones de contexto experimental y recursos de investigación.

En lo que respecta a nuestros intereses, en nuestra opinión, no deberíamos estudiar las habilidades técnicas y las habilidades débiles. Las habilidades técnicas son un área de investigación donde existen numerosos estudios. Dichos estudios se centran en investigar la efectividad, productividad, eficiencia, etc. de una o más técnicas específicas, procesos, herramientas o metodologías, por lo que la contribución de nuestra investigación sería bastante limitada y previsiblemente de poco interés para la comunidad.

En lo que respecta a las habilidades débiles, son un área de gran interés para la comunidad y con mucha investigación realizada, al igual que las habilidades técnicas. Si bien sería un área relevante en la que pudiéramos trabajar y que pudiera tener un gran impacto en la efectividad de los analistas, nuestras las limitaciones metodológicas y de recursos impiden su investigación. Dichas limitaciones son:

- El ámbito donde se desarrollará la presente tesis doctoral es académico, en paralelo a una asignatura de Ingeniería de Requisitos como se comentará más adelante. Previsiblemente, las habilidades débiles de nuestros sujetos experimentales serán muy limitadas (ya que las 
Estudio empírico de la influencia de la experiencia y del conocimiento del dominio del analista en la efectividad del proceso de educción de requisitos

habilidades débiles no son innatas sino aprendidas, y nuestros sujetos son estudiantes con poca o ninguna experiencia profesional).

- Las habilidades débiles no son fácilmente observables. Son necesarias herramientas específicas (tests psicológicos, por ejemplo) y profesional especializado del que no se dispone.

- Existe una gran cantidad de habilidades débiles. No sería posible estudiar todas ellas. Ello implicaría realizar una pre-selección de aquellas más prometedoras. Sin embargo, no existe un marco conceptual sólido que guía dicha pre-selección y asegure mínimamente la identificación de habilidades débiles relevantes.

- Nuestra investigación no podrá estudiar la influencia de las habilidades débiles en la efectividad de los analistas. No obstante, es importante mencionar que los estudios existentes tampoco lo hacen. Dichos estudios se centran más en averiguar qué habilidades son las más adecuadas o demandadas para que una persona desempeñe mejor un rol en el proceso de desarrollo, que en estudiar el efecto de dichas habilidades la efectividad o desempeño de dicho rol. Este hecho pone de manifiesto una brecha o ausencia de investigaciones relacionadas con el efecto de la habilidades débiles en general, que nosotros no podemos afrontar aunque si señalar.

- Las habilidades psicológicas y cognitivas son un área de investigación inadecuada para nosotros por parecidas razones a las aducidas para las habilidades débiles; el factor que hace desaconsejable estudiar estas habilidades es nuestra falta de conocimientos específicos en psicología y sus herramientas asociadas, tales como los tests psicológicos.

Para ser completamente francos, existe una razón adicional por la que voluntariamente nos apartamos de investigaciones que impliquen actuaciones en el ámbito de lo psicológico. Es obvio que para estudiar el efecto de, por ejemplo, la introversión, es necesario administrar un test psicológico a los sujetos experimentales. Supongamos adicionalmente que nuestra investigación detectase un efecto negativo de la introversión en la efectividad de los analistas. Es indudable que para usar dicho resultado en la práctica (ej: para seleccionar analistas de requisitos) sería necesario administrar dichos tests. Esto es complicado tanto desde el punto de vista técnico (de nuevo, es necesario personal especializado) como ético y legal. El valor académico de dichas investigaciones es innegable, pero su aplicabilidad es harto discutible.

Los aspectos culturales deben ser igualmente descartados como área de investigación debido a que nuestros estudios empíricos se llevaran a cabo en un ámbito académico. Esto es completamente incompatible con, por ejemplo, estudiar el efecto de una estructura organizativa en la efectividad de los analistas. Al anclar los estudios empíricos que vamos a realizar en un ámbito social determinado (académico - universitario) ajeno al desarrollo software, queda descartado el estudio de otros ámbitos sociales. De la Tabla 2.7, restan por discutir el conocimiento del dominio, la experiencia y la formación.

El conocimiento del dominio y la experiencia son áreas de investigación prometedoras. Por una parte, existen pocos trabajos empíricos relacionados en Ingeniería de Requisitos (véanse secciones 2.4 y 2.5). Por otra parte, la medición de ambos aspectos parece menos controvertida que la medición de las habilidades débiles; por ejemplo, la experiencia puede medirse de forma bastante objetiva en número de años. Finalmente, y aunque los sujetos experimentales serán fundamentalmente estudiantes, esperamos que el rango de experiencias que posean sea lo suficientemente amplia como para poder determinar sus efectos. Lo mismo puede indicarse acerca del conocimiento del dominio: confiamos en que mediante una selección cuidadosa de los problemas experimentales (ver sección 4) podremos modular el grado de conocimiento del dominio de los sujetos experimentales.

La formación académica es un área de investigación muy poco estudiada en Ingeniería de Requisitos (como se verá en la sección 2.5). Estudiar los efectos de la formación académica en tareas de Ingeniería del Software es interesante y relevante debido a la gran variedad de formaciones que poseen 
los ingenieros software hoy en día, en la práctica. Lo que motiva la necesidad de entender el impacto que posee dicha formación en la actividad que desempeñan. Concretamente, en esta investigación en la educción de requisitos.

Por consiguiente, nuestra investigación se focalizará en las categorías de conocimiento del dominio, experiencia y formación, y su relación con la efectividad de los analistas de requisitos. El estado de la cuestión en lo referente a estas tres categorías se expone a continuación.

Tabla 2.7 - Relevancia de los aspectos humanos en base a la revisión de literatura realizada

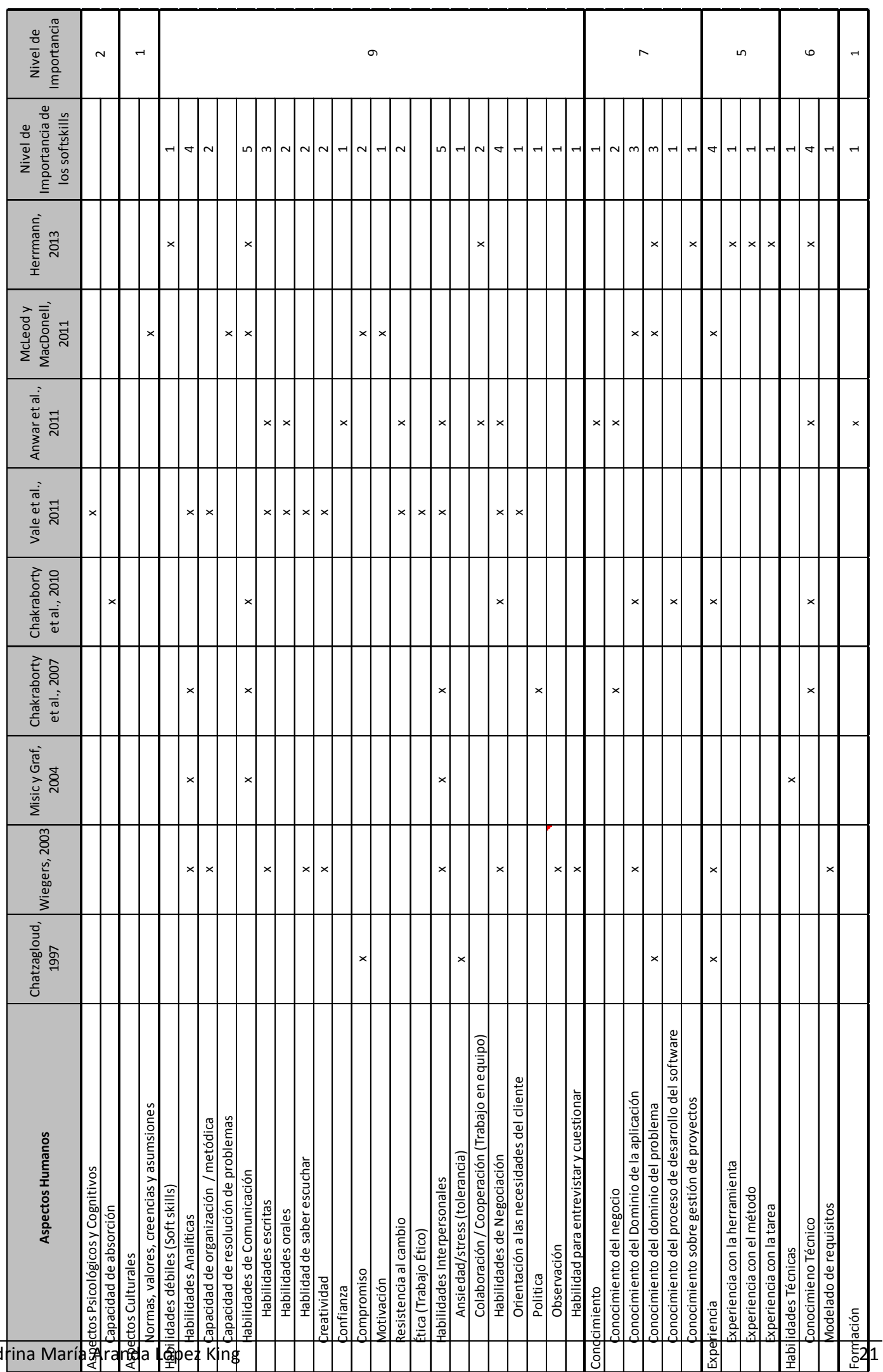




\subsection{Efecto de la Experiencia}

El estudio de la experiencia tiene una larga tradición. Su primer objetivo fue determinar qué factores determinaban el desempeño superior que mostraban los sujetos expertos. Los estudios de De Groot (1978) revelaron dos características principales que compartían los expertos: un conocimiento profundo de su área de competencia, y un largo tiempo de dedicación a la misma. Chase y Simon (1973) formalizaron la experiencia como un proceso por el cual, a lo largo del tiempo, los expertos adquirían conocimientos que almacenaban en patrones mentales complejos y que usaban para resolver rápida y efectivamente problemas en su área de competencia.

La experiencia no está relacionada con ningún talento innato, como puede ser la inteligencia, y resulta muy específica, esto es, la experiencia no se transfiere entre áreas (Colvin, 2008). El tiempo necesario para adquirir una cantidad sustancial de patrones es de unos 10 años, 010.000 horas de dedicación, aunque este número no es ni mucho menos fijo y depende del área y del tipo de instrucción recibida (Ericsson, 2006a).

Los trabajos seminales antes citados tienen como objeto el estudio del ajedrez, pero los resultados de las investigaciones son consistentes entre áreas muy diversas ej: Física (Chi, Feltovich, \& Glaser, 1981). En consecuencia, durante un cierto tiempo se asumió que la adquisición de conocimiento experto era un mero efecto del paso del tiempo (Ericsson , 2006a), esto es, los 10 años de dedicación antes indicados.

La experiencia también ha sido objeto de estudio en Ingeniería del Software desde casi sus inicios. En los años 80, las áreas de interés fueron la programación y el diseño de bajo nivel (Curtis, 1984). Con posterioridad, la experiencia ha sido estudiada virtualmente en todas las áreas de la Ingeniería del Software: diseño (Sonnentag, 1998), usabilidad (MacDorman, Whalen, Ho, \& Patel, 2011), pruebas (Chmiel \& Loui, 2004), etc. En general, la teoría de la experiencia de (Chase \& Simon, 1973) ha sido repetidamente contrastada en Ingeniería del Software. Por ejemplo, los expertos reconocen o recuerdan más sentencias en un lenguaje de programación que los expertos (McKeithen, Reitman, Rueter, \& Hirtle, 1981), o poseen un razonamiento más rico, o mejores estrategias de solución de problemas que los novatos (Jeffries, Turner, Polson, \& Atwood, 1981).

En lo que respecta a la educción de requisitos, la situación es un tanto más confusa. Por una parte, dos $^{2}$ estudios empíricos de gran calidad, como son (Schenk et al., 1998) y (Vitalari \& Dickson, 1983), confirman que los analistas expertos poseen conocimiento específico y realizan razonamientos más complejos que los analistas sin experiencia (las diferencias entre analistas con baja y alta experiencia son más sutiles). Sin embargo, por otra parte, otros cuatro estudios (Agarwal \& Tanniru, 1990; Marakas \& Elam, 1998; Niknafs \& Berry, 2012; Pitts \& Browne, 2004) de calidad comparable, que han sido incapaces de detectar una mayor efectividad de los sujetos expertos. En el caso de (Niknafs \& Berry, 2012), la experiencia tiene incluso un efecto negativo. Esta aparente contradicción puede resolverse fácilmente atendiendo a dos diferencias, sustanciales, entre dichos estudios:

a) (Schenk et al., 1998) y (Vitalari \& Dickson, 1983) utilizan medidas indirectas del desempeño experto, como son el grado de verbalización de estrategias. Por el contrario, todos los otros estudios (Agarwal \& Tanniru, 1990; Marakas \& Elam, 1998; Niknafs \& Berry, 2012; Pitts \& Browne, 2004) utilizan medidas directas, derivadas de los productos generados por los analistas, como pueden ser el numero de reglas, ideas o requisitos.

La operacionalización de las variables respuesta puede ser muy relevante. (Camerer \& Johnson, 1997) indican que la gente con experiencia razona de forma distinta a los novatos, ej: la gente

\footnotetext{
2 Es muy posible que Schenk, Vitalari y Davis (1998) hayan usado los datos obtenidos en (Vitalari \& Dickson, 1983). De ser cierto, nos encontraríamos ante un único estudio.
} 
con experiencia utiliza más conocimiento, por lo que los procesos de búsqueda en las correspondientes estructuras cognitivas son más limitados. Este tipo de procesos mentales son, precisamente, los que (Schenk et al., 1998) y (Vitalari \& Dickson, 1983) podrían estar identificando como razonamiento experto.

Sin embargo, este tipo de procesamiento mental no tiene que ser constitutivo de comportamiento experto. Se ha observado repetidamente que juicios o predicciones de sujetos con experiencia no son más certeros que los de los sujetos sin experiencia, o son incluso peores (Camerer \& Johnson, 1997; Chi et al., 1981; Ericsson, 2006a). Por lo tanto, los estudios de Schenk et al. (1998) y Vitalari y Dickson (1983) podrían estar identificando razonamiento experto, pero ese razonamiento no tendría por qué suponer un mejor desempeño, que es el resultado obtenido por (Agarwal \& Tanniru, 1990; Marakas \& Elam, 1998; Niknafs \& Berry, 2012; Pitts \& Browne, 2004).

b) Schenk et al. (1998) y Vitalari y Dickson (1983) dividen a los sujetos experimentales en grupos novatos y expertos no sólo en base a su tipo (estudiantes/profesionales) o a sus años de experiencia, sino también en base a indicadores de rendimiento. Por el contrario, ninguno de los otros estudios (Agarwal \& Tanniru, 1990; Marakas \& Elam, 1998; Niknafs \& Berry, 2012; Pitts \& Browne, 2004) evalúa específicamente el grado de rendimiento de los sujetos experimentales.

Para alcanzar un desempeño experto, es necesario pasar a través de un periodo de práctica intensa, con la intención deliberada de mejorar el rendimiento (Ericsson, 2006b). En este sentido, se debe distinguir entre experiencia y expertise. La mera realización de una actividad (esto es, la experiencia de los sujetos entendida como tiempo de dedicación, en el sentido de los 10 años indicados anteriormente) no conlleva mejoras dramáticas del desempeño profesional (esto es, expertise).

Los estudios de Agarwal y Tanniru (1990), Marakas y Elam (1998), Niknafs y Berry (2012), Pitts y Browne (2004) asumen que una persona llega a ser experto gracias a la mera existencia de una exposición a una actividad, como puede ser desempeñar un trabajo (esto es, ser profesional) o la dedicación a dicho trabajo durante un numero de años (esto es, la experiencia). Al categorizar de esta manera a los expertos, no resultaría extraño que dichos estudios no detecten un rendimiento superior de los expertos, ya que éstos podrían no serlo. Por el contrario, Schenk et al. (1998) y Vitalari y Dickson (1983) si utilizan indicadores de rendimiento a la hora de definir la expertise de sus sujetos experimentales.

La discusión anterior pone de manifiesto dos debilidades ${ }^{3}$ de los estudios clásicos cuando se intenta extrapolar sus resultados a la práctica actual de la Ingeniería de Requisitos. En primer lugar, la forma más habitual de establecer la expertise de un profesional en la práctica es mediante sus años de experiencia (Siegmund, Kästner, Liebig, Apel, \& Hanenberg, 2014). No es sencillo disponer o aplicar instrumentos de evaluación de rendimiento, como los utilizados por Schenk et al. (1998) y Vitalari y Dickson (1983). Por otra parte, la observación de comportamiento aparentemente experto puede ocurrir sin que exista rendimiento superior (Camerer \& Johnson, 1997). Por este motivo, en esta tesis adoptaremos la visión expert-performance (Ericsson \& Smith, 1991), cuyo punto de partida es la identificación de instancias de rendimiento superior, para a continuación establecer si la experiencia

${ }^{3}$ En realidad, no es nuestra intención poner en duda los resultados de Schenk et al. (1998) y Vitalari y Dickson, (1983). Los efectos beneficiosos de la experiencia están bien comprobados en la literatura científica, y los estudios de Schenk et al. (1998) y Vitalari y Dickson (1983) están incluidos claramente en dicha tradición (ej: evalúan el comportamiento de expertos reconocidos en su área de competencia respectiva). 
ejerce o no un efecto beneficioso o perjudicial. En consecuencia, nuestros antecedentes vienen conformados por los estudios que utiliza medidas directas para observar el comportamiento de los sujetos con diversos años de experiencia. Dichos estudios son (Agarwal \& Tanniru, 1990; Marakas \& Elam, 1998; Niknafs \& Berry, 2012; Pitts \& Browne, 2004), los cuales se describen a continuación. La Tabla 2.8 presenta un resumen de las características principales de los estudios.

\subsubsection{Pitts y Browne}

Pitts y Browne (2004) diseñaron un experimento en el ámbito de los Sistemas de Información en el que examinaron el uso de reglas de paradas cognitivas con la finalidad de medir la suficiencia o punto en el que los requisitos adquiridos son suficientes para continuar con el desarrollo del sistema. Para ello, los experimentadores han estudiado las siguientes relaciones: la relación entre la experiencia del analista y la efectividad o determinación de los requisitos; la influencia de la experiencia del analista sobre la aplicación de reglas de paradas cognitivas y finalmente, el uso de las reglas de parada durante la elicitación de requisitos.

En el experimento participaron 54 analistas profesionales, con al menos dos años de experiencia en desarrollo de sistemas. El número promedio de años de experiencia fue de 11 años, por lo tanto es razonable creer que los sujetos poseen la madurez suficiente para desarrollar estrategias de elicitación de requisitos. Era de interés que la experiencia fuese la mayor posible, ya que de este modo los efectos serían más perceptibles.

Los experimentadores analizaron la influencia de la experiencia (medida en número de años) en términos de la cantidad, amplitud y profundidad de los requisitos educidos. Como resultado, en lo que a nosotros respecta, reportaron que la experiencia del analista no influye en la determinación de los requisitos, esto es, la cantidad, la amplitud y la profundidad de los requisitos no dependen del número de años de experiencia que posee el analista.

\subsubsection{Marakas y Elam}

Marakas y Elam (1998) diseñaron y ejecutaron un experimento controlado en el ámbito de los Sistemas de Información, con el objetivo de evaluar la efectividad la técnica de entrevista semántica (un tipo de entrevista semi-estructurada) frente a la entrevista no estructurada.

En el experimento participaron 20 sujetos con baja y alta experiencia. La experiencia estaba medida por la cantidad de años que el sujeto ha trabajado en análisis de sistemas y desarrollo de software. Los sujetos con baja experiencia fueron estudiantes del último año de un programa de máster de Ingeniería del Software, mientras que los sujetos con alta experiencia fueron profesionales: analistas de sistemas y desarrolladores de software.

Los experimentadores pudieron identificar diferencias de efectividad entre ambos tipo de entrevistas (en concreto, los sujetos eran más efectivos utilizando la entrevista semántica). Sin embargo, independientemente del tipo de entrevista utilizada, los sujetos con experiencia sólo fueron marginalmente superiores (alrededor de un 3\%) a los sujetos novatos, resultando en todo caso las diferencias estadísticamente, no significativas.

\subsubsection{Agarwal y Tanniru}

Agarwal y Tanniru (1990) Ilevaron a cabo un experimento controlado en al ámbito de los Sistemas Expertos con el objetivo de comparar la efectividad de la entrevista estructurada y la entrevista no estructurada en términos del número de reglas extraídas, entre otras medidas.

En el experimento participaron 30 sujetos con distintos niveles de experiencia: novatos y expertos. Los sujetos novatos fueron estudiantes de postgrado con backgrounds y experiencia laborales similares, 
mientras que los expertos fueron por un lado profesionales con experiencia en ingeniería del conocimiento y experiencia laboral en al menos un sistema experto y por otro, analistas con al menos tres años de experiencia en análisis de sistemas.

Los investigadores reportaron como resultado, en lo que respecta a la experiencia, que los sujetos con experiencia (los cuales utilizaron entrevistas estructuradas) fueron ligeramente superiores (en un $9 \%$ aproximadamente) a los sujetos sin experiencia (quienes utilizaron entrevistas no estructuradas), sin embargo las diferencias estadísticas fueron no significativas. No obstante, la efectividad de los sujetos novatos y expertos (quienes utilizaron la entrevista no estructurada) resultó no significativa, mientras que los sujetos novatos (quienes aplicaron la técnica estructurada) obtuvieron mejores resultados que los demás. Los investigadores argumentan que es difícil obtener una conclusión unívoca frente a los hallazgos, sin embargo los datos sugieren respecto al background y la experiencia previa de los analistas que las entrevistas no estructuradas obtienen peores resultados que las entrevistas estructuradas.

\subsubsection{Niknafs y Berry}

(Niknafs \& Berry, 2012) realizaron un experimento controlado con el fin de estudiar empíricamente el impacto del conocimiento del dominio y el efecto de la experiencia en requisitos en la efectividad de la elicitación de requisitos medida en términos del número de ideas generadas por el grupo. A diferencia de las investigaciones anteriores, los sujetos experimentales utilizaron como técnica de elicitación la tormenta de ideas.

En el experimento participaron 19 grupos, cada uno con 3 sujetos de pregrado con distintos niveles de experiencia en desarrollo y en escritura de requisitos. La experiencia fue medida en número de años. Los resultados ponen de manifiesto un efecto negativo de la experiencia en la efectividad. Los experimentadores argumentan que si bien el sentido común dice que debería existir una relación positiva entre la experiencia y la efectividad en la elicitación de los requisitos, las tendencias observadas indican un efecto contrario. Esto es, los sujetos con experiencia entre 1 y 2 años fueron ligeramente menos efectivos que los sujetos sin experiencia, mientras que en grupos con más de 2 años de experiencia la efectividad cae de manera pronunciada.

Niknafs, 2014 entre otros estudios empíricos, contiene dos experimentos controlados (E1 y E2) con estudiantes de ciencias de la computación e ingeniería del software. E1 es el experimento publicado en (Niknafs \& Berry, 2012) y E2 es una replicación interna y exacta de E1. El objetivo de E2 es aumentar el tamaño muestral conseguido en E1. En total participaron 40 grupos, compuestos por 3 miembros cada uno, con distintos niveles de experiencias profesional y en requisitos hasta 4 años. E2 es analizado de forma conjunta con E1. Los resultados obtenidos muestran un efecto ningún positivo aunque no significativo de la experiencia profesional en la generación de ideas (relevantes, factibles, innovadoras y generales). Por el contrario, la experiencia en requisitos tiende a ejercer un efecto positivo, estadísticamente significativo en la generación de ideas relevantes. En lo demás casos, el efecto es no significativo. 
Tabla 2.8 - Estudios empíricos sobre el efecto de la experiencia en Ingeniería de Requisitos

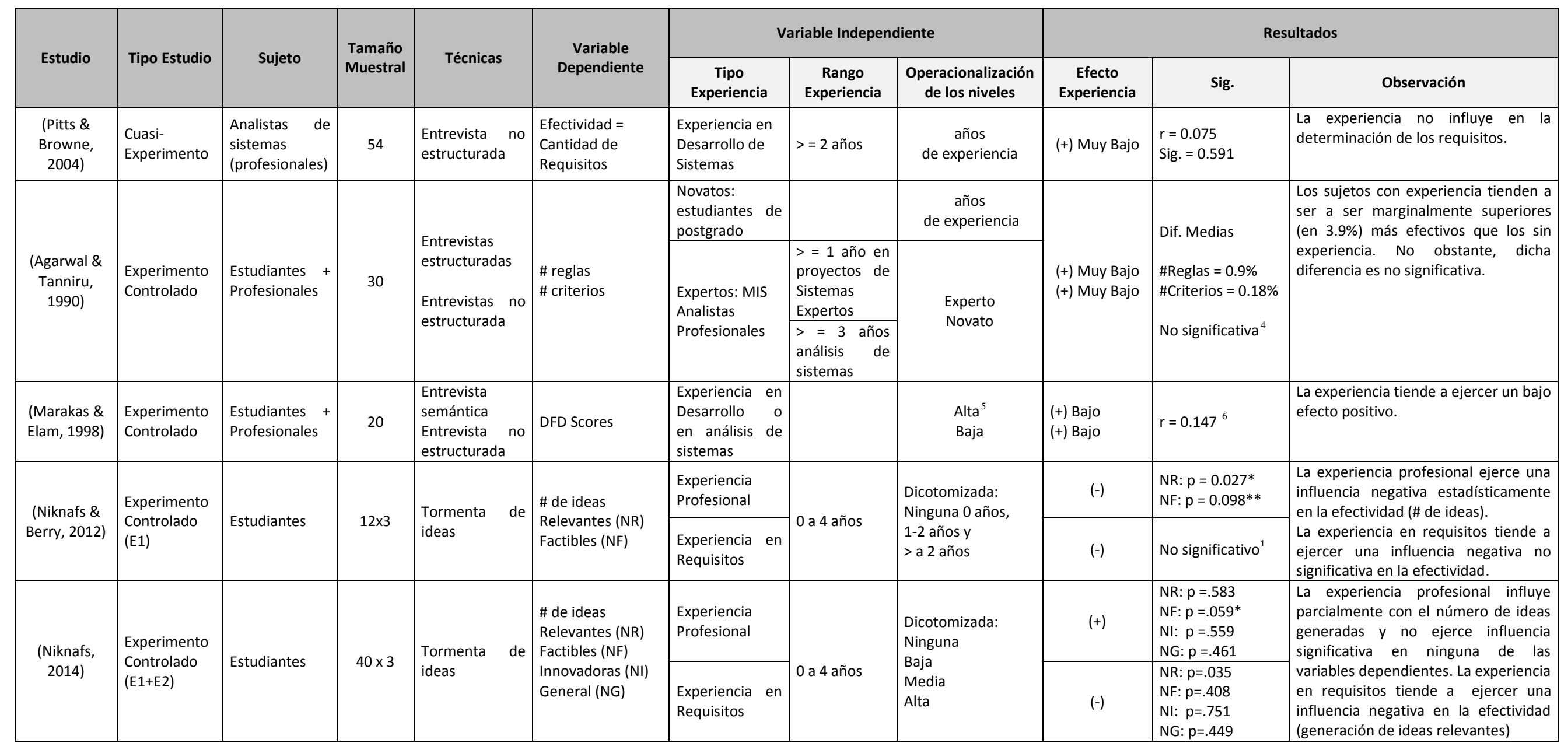

${ }^{4}$ Los autores no indican ni magnitud ni dirección.

${ }^{5}$ Experiencia medida en años. Los autores no indican el rango de experiencia correspondiente a cada categoría (Alta o Baja)

${ }^{6}$ Calculado mediante las medias y desviaciones estándares correspondientes a cada grupo 


\subsection{Efecto del Conocimiento sobre el dominio del problema}

Se suele asumir como cierto que el conocimiento del dominio del problema hace que los analistas de requisitos sean más efectivos (Christel \& Kang, 1992; Loucopoulos \& Karakostas, 1995; Young, 2002; Zowghi \& Coulin, 2005). Se cree que dicha mejora en efectividad viene motivada por varios aspectos, principalmente por la mejora de la comunicación analista - cliente/usuario.

Vitharana, Jain y Zahedi (2012) apuntan a que el conocimiento del dominio permite que los analistas no realicen preguntas elementales, las cuales, además de consumir tiempo durante la sesión de educción, dañan la credibilidad del analista a ojos del cliente/usuario. Hadar et al. (2012) se expresan en términos prácticamente idénticos; estos autores argumentan que el cocimiento del dominio permite a los analistas formular preguntas focalizadas que permitan capturar información específica del problema a resolver. Dicha información no puede obtenerse utilizando preguntas más generales. Adicionalmente, en ambos trabajos se indica que el conocimiento del dominio permite al analista identificar malentendidos, conflictos y resolverlos rápidamente.

Algunos autores han sugerido que el conocimiento del dominio podría ejercer efectos negativos. En una encuesta realizada por McAllister (2006), los clientes y usuarios indican que los analistas con conocimiento del dominio hacen suposiciones acerca de los requisitos en función de sus conocimientos y experiencias pasadas. El autor hipotetiza que este hecho puede deberse a que los analistas asumen que conocen las necesidades de los clientes/usarios, y en consecuencia especifican el sistema que ellos creen conveniente, y no el que los usuarios realmente solicitan. En la misma dirección, Niknafs y Berry (2013) indican que, si bien el conocimiento profundo del dominio facilita el entendimiento sobre los detalles del problema, al mismo tiempo puede promover en el analista realice suposiciones acerca de los requisitos. De esta misma opinión son Browne y Rogich (2001), Pitts y Browne (2004) van incluso más allá y mencionan que el conocimiento previo acerca del dominio puede causar que el analista ignore requisitos implícitos.

No obstante, casi todas las afirmaciones indicadas anteriormente parten de posiciones teóricas. En Ingeniería de Requisitos existen algunos estudios empíricos (Hadar et al., 2012; Niknafs \& Berry, 2012; Kristensson et al., 2004; Niknafs, 2014) que han estudiado del efecto del conocimiento, aunque los resultados obtenidos son en parte conflictivos y, en todo caso, no concluyentes. La Tabla 2.9 resume las principales características de dichos estudios, los cuales se describen a continuación.

\subsubsection{Niknafs y Berry}

Niknafs y Berry (2012) llevaron a cabo un experimento controlado en el ámbito de ciencias de la computación, con el fin de descubrir en la efectividad del equipo de elicitación de requisitos, el efecto de mezclar personas que conocen y desconocen el dominio del problema. La efectividad de la elicitación fue medida por la cantidad de ideas generadas, ya que la técnica de elicitación empleada fue tormenta de ideas.

En el experimento participaron 19 grupos compuestos por 3 sujetos cada uno, con diversas experiencias y conocimientos en el dominio. Todos los sujetos eran estudiantes de grado del cuarto año inscritos en la asignatura de Requisitos Software y Especificación. El conocimiento del dominio tiene dos niveles: dominio conocido (domain aware-DA) y dominio desconocido (domain ignorant-DI).

Los resultados respecto al impacto del conocimiento del dominio en la efectividad del equipo, ponen de manifiesto que al añadir un analista que desconoce el dominio al equipo de elicitación de requisitos, el número de ideas generadas incrementan (es decir, mejora la efectividad del equipo).

Niknafs y Berry (2013) realizaron también un caso de estudio con profesionales de la industria, con la finalidad de corroborar las conclusiones del experimento controlado (Niknafs \& Berry, 2012). En el 
estudio participaron 8 sujetos, 4 son empleados desarrolladores en una empresa cuyo nombre se ha omitido (en lo que sigue, empresa C), mientras que los otros cuatro provienen de la Universidad de Waterloo. De estos cuatro últimos, dos son estudiantes de doctorado en ciencias de la computación. La técnica de educción utilizada en la sesión fue tormenta de ideas en un único grupo. El conocimiento acerca del dominio fue medido utilizando un dominio del problema conocido para las personas que trabajan en la empresa $\mathrm{C}$ y desconocido para los de la universidad.

Los resultados observados son similares entre los sujetos con y sin conocimiento acerca del dominio. Sin embargo, los sujetos que no poseen conocimiento acerca del dominio son mejores en generar nuevas ideas, mientras que las ideas generadas por los que conocen el dominio se limitan a la familiaridad que ellos tienen sobre sus productos generados en su dominio particular. Los autores argumentan que los sujetos que desconocen el dominio ayudan a proporcionar nuevas ideas, que inicialmente no son consideradas por los sujetos que conocen el dominio, pero que sin embargo les son útiles y tratan de ampliarlas.

Niknafs (2014), entre otros estudios empíricos, contiene dos experimentos controlados (E1 y E2) con estudiantes de ciencias de la computación e ingeniería del software. E1 es el experimento publicado en (Niknafs \& Berry, 2012) y E2 es una replicación interna y exacta (mismo procedimiento, dominios de problemas, proceso de evaluación, etc.) de E1. El objetivo de E2 es aumentar el tamaño muestral conseguido en E1, así como mejorar el balance entre los mix de familiaridades (es decir, el número de sujetos DI y DA que pertenecen a cada equipo). E2 es analizado en (Niknafs, 2014) de forma conjunta con E1, que es la información que reportamos a continuación. Los resultados obtenidos no muestran ningún efecto significativo del mix de familiaridades para ninguna de las variables respuesta ensayadas (número de ideas relevantes, factibles, innovadoras y generales).

\subsubsection{Hadar, Soffer y Kenzi}

Hadar et al. (2012) realizaron un estudio empírico exploratorio, con el objetivo de evaluar el efecto del conocimiento sobre el dominio que posee el analista cuando realiza elicitación mediante entrevistas. El experimento se realizó con estudiantes de pregrado del último año en Ingeniería del Software. El estudio estuvo compuesto por dos sesiones con diferentes grupos de participantes. En la primera sesión participaron 27 sujetos y en la segunda 31. Dos problemas del dominio fueron escogidos para cada sesión. Los sujetos fueron asignados en los dominios conocidos y desconocidos en función de grado de conocimiento sobre los problemas experimentales mediante cuestionarios y entrevistas llevadas a cabo por los investigadores.

Los investigadores compararon la relación entre el conocimiento del dominio alto y bajo y el tipo de preguntas realizadas por los analistas. Los resultados muestran que los sujetos quienes no poseían conocimiento, generalmente realizaban preguntas generales, sin embargo los sujetos con conocimiento eran capaces de realizar preguntas más específicas. Esto podría permitir a los sujetos adquirir más detalles acerca del dominio del problema y obtener una comprensión más profunda sobre el mismo.

\subsubsection{Kristensson, Gustafsson y Archer.}

Kristensson et al. (2004) condujeron un cuasi-experimento con el fin de estudiar la creatividad (generación de ideas) sobre un problema que pertenece al dominio de tecnologías móviles.

En el cuasi-experimento participaron un total de 47 sujetos categorizados en tres tipos de usuarios: 1) los usuarios avanzados son estudiantes en ciencias de la computación (16), que poseen conocimiento avanzado en tecnologías móviles y en lenguaje de programación que facilita el desarrollo de servicios para móviles; 2 ) los usuarios ordinarios estudiantes de administración de negocios o ciencias sociales (19); y 3) desarrolladores profesionales en el servicio (12). 
Los resultados indican que los usuarios ordinarios generan significativamente más ideas originales y valiosas que los desarrolladores profesionales y usuarios avanzados. Por otro lado, los desarrolladores profesionales y usuarios avanzados generan ideas fácilmente realizables, y los usuarios ordinarios (usuarios que desconocen el dominio del problema a falta de un conocimiento detallado acerca del problema), crean ideas más valiosas.

Los autores argumentan que los usuarios avanzados generan menos ideas originales que los usuarios ordinarios, posiblemente al efecto restrictivo del mayor conocimiento previo del dominio del problema (sistema de teléfonos móviles).

Los autores argumentan que los usuarios avanzados generan menos ideas originales que los usuarios ordinarios, posiblemente al efecto restrictivo del mayor conocimiento previo del dominio del problema (sistema de teléfonos móviles).

Los resultados observados son similares entre los sujetos con y sin conocimiento acerca del dominio. Sin embargo, los sujetos que no poseen conocimiento acerca del dominio son mejores en generar nuevas ideas, mientras que las ideas generadas por los que conocen el dominio se limitan a la familiaridad que ellos tienen sobre sus productos generados en su dominio particular. Los autores argumentan que los sujetos que desconocen el dominio ayudan a proporcionar nuevas ideas, que inicialmente no son consideradas por los sujetos que conocen el dominio, pero que sin embargo les son útiles y tratan de ampliarlas. 
Tabla 2.9 - Estudios empíricos sobre el Efecto del Conocimiento en Ingeniería de Requisitos

\begin{tabular}{|c|c|c|c|c|c|c|c|c|c|c|}
\hline \multirow{2}{*}{ Estudio } & \multirow{2}{*}{ Tipo Estudio } & \multirow{2}{*}{ Sujeto } & \multirow{2}{*}{ Tamaño Muestral } & \multirow{2}{*}{ Técnicas } & \multirow{2}{*}{$\begin{array}{c}\text { Variable } \\
\text { Dependiente }\end{array}$} & \multicolumn{2}{|c|}{ Variable Independiente } & \multicolumn{3}{|c|}{ Resultados } \\
\hline & & & & & & Factor / Niveles & $\begin{array}{l}\text { Operacionalización } \\
\text { de los niveles }\end{array}$ & $\begin{array}{c}\text { Efecto del } \\
\text { Conocimiento }\end{array}$ & Sig. & Observación \\
\hline $\begin{array}{l}\text { (Niknafs \& } \\
\text { Berry, 2012) }\end{array}$ & $\begin{array}{l}\text { Experimento } \\
\text { Controlado } \\
\text { (E1) }\end{array}$ & $\begin{array}{l}\text { Estudiantes } \\
\text { de ciencias de } \\
\text { la } \\
\text { computación } \\
\text { (CS) }\end{array}$ & $\begin{array}{l}19 \text { grupos de } 3 \\
\text { personas }\end{array}$ & $\begin{array}{l}\text { Tormenta } \\
\text { de ideas }\end{array}$ & \begin{tabular}{|l} 
\# de ideas \\
Relevantes (NR) \\
Factibles (NF) \\
General (NG)
\end{tabular} & $\begin{array}{l}\text { Conocimiento del } \\
\text { dominio: } \\
\text { Desconocido (DI) } \\
\text { Conocido (DA) }\end{array}$ & $\begin{array}{l}\text { Los dominios fueron } \\
\text { seleccionados en } \\
\text { función del } \\
\text { conocimiento de los } \\
\text { sujetos mediante un } \\
\text { cuestionario } \\
\text { aplicando la escala } \\
\text { de Likert }\end{array}$ & $(-)^{7}$ & $\begin{array}{l}\text { NR: } p=0.032^{*} \\
\text { NF: } p=0.015^{*} \\
\text { NG: } p=0.915\end{array}$ & $\begin{array}{l}\text { El número de ideas relevantes } \\
\text { (NR) y factibles (NF) generado } \\
\text { por grupos con al menos un DI } \\
\text { es mayor que aquellos grupos } \\
\text { sin ningún DI. } \\
\text { Por tanto, al incluir un analista } \\
\text { que desconoce el dominio del } \\
\text { problema a un grupo de trabajo } \\
\text { que posee conocimiento, la } \\
\text { efectividad del equipo mejora. }\end{array}$ \\
\hline $\begin{array}{l}\text { (Niknafs \& } \\
\text { Berry, 2013) }\end{array}$ & $\begin{array}{ll}\text { Caso } & \text { de } \\
\text { estudio } & \text { en } \\
\text { Industria } & \end{array}$ & $\begin{array}{l}\text { Profesionales } \\
\text { en CS }\end{array}$ & $\begin{array}{c}8 \text { sujetos } \\
(4 \text { DI y } 4 \mathrm{DA})^{8}\end{array}$ & $\begin{array}{l}\text { Tormenta } \\
\text { de ideas }\end{array}$ & \# de ideas Nuevas & $\begin{array}{l}\text { Conocimiento del } \\
\text { dominio: } \\
\text { Desconocido (DI) } \\
\text { Conocido (DA) }\end{array}$ & $\begin{array}{l}\text { Los dominios fueron } \\
\text { seleccionados en } \\
\text { función del } \\
\text { conocimiento de los } \\
\text { sujetos mediante un } \\
\text { cuestionario } \\
\text { aplicando la escala } \\
\text { de Likert } \\
\end{array}$ & $(-)$ & & $\begin{array}{l}\text { El número de ideas generadas } \\
\text { son muy similares entre los } \\
\text { analistas DI y los analistas DA. } \\
\text { Sin embargo, los analistas DI } \\
\text { fueron mejores en generar } \\
\text { nuevas ideas }\end{array}$ \\
\hline $\begin{array}{l}\text { (Niknafs, } \\
\text { 2014) }\end{array}$ & $\begin{array}{l}\text { Experimento } \\
\text { Controlado } \\
\text { (E1 + E2) }\end{array}$ & $\begin{array}{l}\text { Estudiantes } \\
\text { en CS e } \\
\text { Ingeniería del } \\
\text { Software }+ \\
\text { participantes } \\
\text { con otros } \\
\text { backgrounds }\end{array}$ & $\begin{array}{c}40 \text { grupos de } 3 \\
\text { personas }\end{array}$ & $\begin{array}{l}\text { Tormenta } \\
\text { de ideas }\end{array}$ & & $\begin{array}{l}\text { Conocimiento del } \\
\text { dominio: } \\
\text { Desconocido (DI) } \\
\text { Conocido (DA) }\end{array}$ & $\begin{array}{l}\text { Los dominios fueron } \\
\text { seleccionados en } \\
\text { función del } \\
\text { conocimiento de los } \\
\text { sujetos mediante un } \\
\text { cuestionario } \\
\text { aplicando la escala } \\
\text { de Likert }\end{array}$ & $(-)$ & $\begin{array}{l}\text { NR: } p=.941 \\
\text { NF: } p=.181 \\
\text { NI: } p=.515 \\
\text { NG: } p=.521\end{array}$ & $\begin{array}{l}\text { La efectividad del grupo durante } \\
\text { la generación de ideas se ve } \\
\text { afectada por la diversidad de } \\
\text { familiaridades con el dominio. } \\
\text { En general, los grupos con al } \\
\text { menos un DI fueron más } \\
\text { efectivos que los grupos sin } \\
\text { ningún DI. } \\
\text { Para todas las variables } \\
\text { dependientes ensayadas, } \\
\text { estadísticamente los efectos son } \\
\text { no significativos. }\end{array}$ \\
\hline
\end{tabular}

\footnotetext{
${ }^{7}$ A medida que aumenta la cantidad de miembros que desconocen el dominio del problema (DI) aumenta la efectividad.
}

${ }^{8}$ DI: Domain Ignorant - ignorante en el dominio; DA: Domain Aware- con conocimiento del dominio 


\begin{tabular}{|c|c|c|c|c|c|c|c|c|c|c|}
\hline \multirow{2}{*}{ Estudio } & \multirow{2}{*}{ Tipo Estudio } & \multirow{2}{*}{ Sujeto } & \multirow{2}{*}{ Tamaño Muestral } & \multirow{2}{*}{ Técnicas } & \multirow{2}{*}{$\begin{array}{c}\text { Variable } \\
\text { Dependiente }\end{array}$} & \multicolumn{2}{|c|}{ Variable Independiente } & \multicolumn{3}{|c|}{ Resultados } \\
\hline & & & & & & Factor / Niveles & $\begin{array}{c}\text { Operacionalización } \\
\text { de los niveles }\end{array}$ & $\begin{array}{c}\text { Efecto del } \\
\text { Conocimiento }\end{array}$ & Sig. & Observación \\
\hline $\begin{array}{c}\text { (Hadar et al., } \\
\text { 2012) }\end{array}$ & $\begin{array}{l}\text { Estudio } \\
\text { empírico } \\
\text { exploratorio }\end{array}$ & $\begin{array}{l}\text { Estudiantes } \\
\text { de grado del } \\
\text { último año en } \\
\text { SE }\end{array}$ & $58(31+27)$ & Entrevistas & $\begin{array}{l}\text { \#de preguntas } \\
\text { Especificas (NE) } \\
\text { Generales (NG) }\end{array}$ & $\begin{array}{l}\text { Conocimiento del } \\
\text { dominio: } \\
\text { Posee (exists) } \\
\text { Carece (lacks) }\end{array}$ & $\begin{array}{l}\text { Se escogieron } 4 \\
\text { dominios, dos por } \\
\text { cada interacción } \\
\text { (entrevista). } \\
\text { La familiaridad } \\
\text { respecto al dominio } \\
\text { se obtuvo mediante } \\
\text { un cuestionario. }\end{array}$ & $(+)$ & $\begin{array}{l}N E( \\
p=0.029^{9}{ }^{9} \\
\left.p=0.010^{* 10}\right) \\
N G( \\
p=0.389^{6} ; \\
\left.p=0.125^{7}\right)\end{array}$ & $\begin{array}{l}\text { En ambos contextos (académico } \\
\text { y real): } \\
-\quad \text { Los sujetos con } \\
\text { conocimiento del dominio } \\
\text { durante la educción generan } \\
\text { preguntas más específicas, las } \\
\text { cuales permiten entender mejor } \\
\text { el dominio del problema y educir } \\
\text { más detalles. } \\
-\quad \text { Los sujetos sin } \\
\text { conocimiento en el dominio } \\
\text { tienden a formular preguntas } \\
\text { más generales durante la } \\
\text { educción, sin embargo este } \\
\text { hallazgo es estadísticamente no } \\
\text { significativo. }\end{array}$ \\
\hline $\begin{array}{l}\text { (Kristensson } \\
\text { et al., 2004) }\end{array}$ & $\begin{array}{l}\text { Cuasi- } \\
\text { Experimento }\end{array}$ & $\begin{array}{l}\text { Estudiantes y } \\
\text { Profesionales }\end{array}$ & $\begin{array}{l}47 \text { sujetos } \\
12 \text { desarrolladores } \\
16 \text { estudiantes CS } \\
19 \text { estudiantes en } \\
\text { administración de } \\
\text { negocios }\end{array}$ & $\begin{array}{l}\text { Reactive } \\
\text { data- } \\
\text { gathering } \\
\text { technique }\end{array}$ & \# de ideas & $\begin{array}{l}\text { Tipo de usuario: } \\
\text { Desarrollador_Prof } \\
\text { esional } \\
\text { Usuario Avanzado } \\
\text { Usuario ordinario }\end{array}$ & $\begin{array}{l}\text { Datos relacionados } \\
\text { con el conocimiento } \\
\text { previo en el dominio } \\
\text { e información } \\
\text { demográfica como } \\
\text { rasgos sobre su } \\
\text { personalidad fueron } \\
\text { recogidos mediante } \\
\text { un cuestionario } \\
\text { demográfico. }\end{array}$ & $(+)$ & $\begin{array}{l}p=0.198 \\
\text { Diferencia } \\
\text { entre grupos } \\
\text { no significativa }\end{array}$ & $\begin{array}{l}\text { Tres son los resultados } \\
\text { principales: } \\
\text { Los usuarios ordinarios } \\
\text { producen nuevas ideas más } \\
\text { originales, lo que indica un estilo } \\
\text { más divergente de pensamiento. } \\
\text { Usuarios ordinarios producen } \\
\text { ideas que se evaluaron como } \\
\text { significativamente más valiosas. } \\
\text { Desarrolladores profesionales y } \\
\text { usuario avanzados producen } \\
\text { ideas más realizables (factibles). }\end{array}$ \\
\hline
\end{tabular}

\footnotetext{
${ }^{9}$ En un contexto académico (sesiones de educción con un cliente simulado)

${ }^{10}$ En un contexto real (sesiones de educción con un cliente real)
} 


\subsection{Efecto de la Formación Académica}

El sentido común indica que la formación académica debería influir positivamente en la realización de actividades relacionadas. Por ejemplo, un curso de requisitos debería mejorar (al menos hasta cierto punto) el modo en que los asistentes al curso, educen, analizan o documentan requisitos. En esta línea, Urquhart (2001) menciona en su investigación que la formación académica es un factor que el analista y el usuario deben poseer durante la educción de los requisitos para que la interacción sea efectiva.

Sin embargo, como en muchas otras áreas de la Ingeniería del Software, el efecto de la formación académica apenas ha sido estudiado empíricamente y, cuando lo ha sido, el resultado no siempre ha estado en concordancia con lo que el sentido común indica. Curiosamente, todos los estudios que conocemos están encuadrados en la Ingeniería de Requisitos, aunque no específicamente en educción. La Tabla 2.10 presenta un resumen de las características principales de dichos estudios empíricos.

Por ejemplo, uno de los pocos trabajos existentes es el estudio empírico acerca del efecto de la formación académica en la efectividad de la actividad de inspección de requisitos realizado por Carver, Nagappan y Page (2008) (así como su replicación posterior reportada en (Albayrak \& Carver, 2014)). Los resultados de ambos estudios ponen de manifiesto un efecto negativo de la formación académica en la efectividad, esto es, los sujetos sin formación académica en informática resultaron más efectivos que los sujetos con formación.

Carver y Albayrak no son los únicos que reportan un impacto negativo de la formación académica. (Atkins, 2013) realizó una encuesta a gerentes de proyectos e ingenieros de requisitos, con el objetivo de determinar qué habilidades, cualificaciones y experiencias del los analistas están asociados con el éxito de un proyecto. Los resultados de la encuesta indican que, si bien la presencia de ingenieros de requisitos en el proyecto mejora la efectividad, la formación académica no impacta directamente en el éxito de un proyecto.

En lo que respecta específicamente a la educción de requisitos, solo hemos encontrado un estudio empírico que aborde el efecto de la formación académica. Niknafs (2014) realizó un experimento controlado con el fin de explorar si la formación académica de los miembros que conforman el grupo de educción de los requisitos influye en la efectividad de los mismos. La efectividad de los analistas fue medida mediante el número de ideas (generales, relevantes, factibles e innovadoras) que podrían generar los grupos de trabajo empleando tormenta de ideas como técnica de educción.

En el experimento participaron 40 grupos compuesto por 3 miembros cada uno. Los sujetos que participaron del experimento fueron estudiantes con diferentes titulaciones académicas, experiencias y conocimientos sobre el dominio.

Para el estudio, los estudiantes fueron categorizados en tres grupos distintos, aquellos con formación en: 1) ciencias de la computación (NCS); 2) ingeniería del software (NSE) y 3) estudiantes de grado (NGRAD).

Los resultados de la investigación ponen de manifiesto que la formación académica influye positiva y significativamente en la efectividad de los analistas, esto es, el grupo compuesto por sujetos con formación en académica en CS y SE son más efectivos en la generación de ideas generales, factibles e innovadores. Nótese no obstante que la efectividad de los grupos compuestos únicamente por estudiantes de grado, no se ve influida significativamente por la formación de los mismos.

Los autores a su vez, comprobaron que no existe una interacción de la formación académica con la experiencia y el conocimiento acerca del dominio. 
Tabla 2.10 - Estudios Empíricos sobre el Efecto de la Formación Académica

\begin{tabular}{|c|c|c|c|c|c|c|c|c|c|c|}
\hline \multirow{2}{*}{ Estudio } & \multirow{2}{*}{ Tipo Estudio } & \multirow{2}{*}{ Sujeto } & \multirow{2}{*}{ Tamaño Muestral } & \multirow{2}{*}{ Técnicas } & \multirow{2}{*}{$\begin{array}{c}\text { Variable } \\
\text { Dependiente }\end{array}$} & \multicolumn{2}{|c|}{ Variable Independiente } & \multicolumn{3}{|c|}{ Resultados } \\
\hline & & & & & & Factor / Niveles & $\begin{array}{l}\text { Operacionalización de } \\
\text { los niveles }\end{array}$ & $\begin{array}{c}\text { Efecto del } \\
\text { Conocimiento }\end{array}$ & Sig. & Observación \\
\hline $\begin{array}{l}\text { (Niknafs, } \\
\text { 2014) }\end{array}$ & $\begin{array}{l}\text { Experimento } \\
\text { Controlado } \\
\text { (E1 + E2) }\end{array}$ & \begin{tabular}{|l|} 
Estudiantes \\
en CS e \\
Ingeniería del \\
Software + \\
participantes \\
con otros \\
backgrounds \\
\end{tabular} & $\begin{array}{l}40 \text { grupos de } 3 \\
\text { personas }\end{array}$ & $\begin{array}{l}\text { Tormenta } \\
\text { de ideas }\end{array}$ & $\begin{array}{l}\text { \# de ideas } \\
\text { Relevantes (NR) } \\
\text { Factibles (NF) } \\
\text { Innovadoras (NI) } \\
\text { General (NG) }\end{array}$ & $\begin{array}{l}\text { NCS } \\
\text { NSE } \\
\text { NGRAD }\end{array}$ & -- & $(+)$ & $\begin{array}{l}N R: p=.048 \\
N F: p=.006 \\
N I: p=.013 \\
N G: p=.008\end{array}$ & $\begin{array}{l}\text { La formación académica ejerce } \\
\text { una influencia positiva y } \\
\text { estadísticamente significativa en } \\
\text { la efectividad de los analistas en } \\
\text { la generación de ideas. }\end{array}$ \\
\hline $\begin{array}{l}\text { (Carver et al., } \\
\text { 2008) }\end{array}$ & Experimento & \begin{tabular}{|l} 
Estudiantes \\
con diversas \\
titulaciones
\end{tabular} & $\begin{array}{l}73 \text { sujetos } \\
\text { (52 con títulos de } \\
\text { grado y } 21 \text { con } \\
\text { títulos de máster) }\end{array}$ & $\begin{array}{l}\text { Inspección } \\
\text { de } \\
\text { requisitos }\end{array}$ & \# de faltas & $\begin{array}{l}\text { Informáticos } \\
\text { No Informáticos }\end{array}$ & -- & $(-)$ & $p=0.022$ & $\begin{array}{l}\text { La formación ejerce un efecto } \\
\text { negativo significativo en la } \\
\text { efectividad de inspección de } \\
\text { requisitos. } \\
\text { Esto es, los sujetos con títulos } \\
\text { no informáticos encontraron } \\
\text { significativamente más defectos } \\
\text { durante la inspección de los } \\
\text { requisitos que los inspectores } \\
\text { con títulos informáticos. }\end{array}$ \\
\hline $\begin{array}{l}\text { (Albayrak \& } \\
\text { Carver, 2014) }\end{array}$ & Experimento & $\begin{array}{l}\text { Profesionales } \\
\text { diferentes } \\
\text { compañías }\end{array}$ & 69 & $\begin{array}{l}\text { Inspección } \\
\text { de } \\
\text { requisitos }\end{array}$ & \# de faltas & $\begin{array}{l}\text { Informáticos } \\
\text { No Informáticos }\end{array}$ & -- & $(-)$ & $p=0.014$ & $\begin{array}{l}\text { La formación ejerce un efecto } \\
\text { negativo significativo en la } \\
\text { efectividad de inspección de } \\
\text { requisitos }\end{array}$ \\
\hline (Atkins, 2013) & $\begin{array}{l}\text { Encuesta } \\
\text { (Survey) }\end{array}$ & $\begin{array}{l}\text { Gerentes } \\
\text { ingenieros } \\
\text { software }\end{array}$ & $\begin{array}{l}116 \text { personas } \\
\text { (60 gerentes de } \\
\text { proyectos y } 56 \\
\text { ingenieros de } \\
\text { requisitos) }\end{array}$ & Cuestionario & -- & -- & -- & $(x)$ & & $\begin{array}{l}\text { La formación no impacta en el } \\
\text { éxito de un proyecto. }\end{array}$ \\
\hline
\end{tabular}





\section{CAPÍTULO 3}

\section{PREGUNTAS DE INVESTIGACIÓN}

En la comunidad de Ingeniería del Software está muy extendida la opinión de que tanto la experiencia (Schenk et al., 1998; Vitalari, 1992; Walz, Elam, \& Curtis, 1993) como el conocimiento del dominio (Christel \& Kang, 1992; Loucopoulos \& Karakostas, 1995; Young, 2002; Zowghi \& Coulin, 2005) ayudan a los analistas en la realización de la tarea de educción. Lo mismo ocurre con la titulación académica de los analistas (Urquhart, 2001). Sin embargo, los estudios experimentales tienden a concluir que dichos factores no ejercen efecto positivo alguno e incluso, en algún caso, el efecto detectado es negativo (esto es: perjudican, en lugar de favorecer, la efectividad de los analistas).

En lo que respecta a los efectos de la experiencia, Pitts y Browne (2004) reportan que la experiencia del analista no influye en la cantidad, amplitud o profundidad de los requisitos. Marakas y Elam (1998) observan que los analistas con experiencia son sólo marginalmente superiores que los novatos. En la misma línea Agarwal y Tanniru (1990) argumentan que los sujetos con experiencia son ligeramente superiores a los sujetos sin experiencia. Estadísticamente hablando, la diferencia entre expertos y novatos ha resultado siempre no significativa. Por el contrario, Niknafs y Berry en su primer experimento (E1) publicado en (Niknafs \& Berry, 2012) concluyen que la experiencia (tanto en industria como en RE) ejerce una influencia negativa (estadísticamente significativa para el primer caso, y no significativa para el segundo). Esto es, los sujetos con experiencia tienen una efectividad un poco peor que los sujetos sin experiencia. No obstante, los autores en un segundo experimento (E2) analizado conjuntamente con E1, mostraron que la experiencia en industria afecta positivamente en la efectividad, mientras que por el contrario, la experiencia en RE influye negativamente (Niknafs, 2014). En ambos casos, el efecto es estadísticamente no significativo.

Es claro, por lo tanto, que existe una considerable incertidumbre respecto a los efectos de la experiencia. Por ello, los investigadores se plantean la siguiente pregunta de investigación:

- RQ1: ¿Influye (ya sea positiva o negativamente) la experiencia del analista en la efectividad del proceso de educción de los requisitos?

En lo que respecta al conocimiento, al igual que la experiencia, la situación dista de ser clara. Los experimentos de Niknafs y Berry (2012) (con estudiantes) y Niknafs y Berry (2013) (con profesionales de 
la industria) concluyeron que la inclusión de una persona que ignora el dominio del problema mejora la efectividad (por ejemplo, la generación de nuevas ideas innovadoras o relevantes) en los grupos de tormentas de ideas (brainstorming). Sin embargo, a medida que los autores acumularon más evidencia empírica, los resultados se tornaron no conclusivos (Niknafs, 2014). Esto es, aunque las tendencias se mantienen, no consiguieron obtener efectos estadísticamente significativos al incluir personas que ignoran el dominio del problema. Kristensson et al. (2004) concluyen que los usuarios con conocimiento del dominio (usuarios avanzados) son menos efectivos que aquellos que lo desconocen (usuarios ordinarios). Los hallazgos de Hadar et al. (2012) indican que el conocimiento del dominio ayuda al analista en la formulación de preguntas específicas en el momento de la educción de los requisitos. Concretamente, han demostrado estadísticamente que los sujetos con conocimiento en el dominio formulan más preguntas específicas que los sujetos sin conocimiento. Los sujetos sin conocimiento tienden formular preguntas más generales. Los autores sugieren que un mayor número de preguntas específicas podría estar relacionado con una mayor efectividad durante la educción.

Los estudios anteriormente indicados arrojan, con la única excepción de (Hadar et al., 2012), resultados que sugieren que el conocimiento previo tiene un efecto pernicioso (o quizás nulo), sobre la efectividad de los analistas. Esta conclusión es diametralmente opuesta a lo que el sentido común indica, esto es, que los sujetos con conocimiento en el dominio tienden a ser más efectivos. Esto lleva a los investigadores plantearse la siguiente pregunta de investigación:

- RQ2: ¿Influye (ya sea positiva o negativamente) el conocimiento que el analista posee acerca del dominio del problema en la efectividad del proceso de educción de requisitos?

Finalmente, en lo que respecta a la titulación académica, existe solo un estudio empírico que investiga su impacto en la efectividad de los analistas en la fase de educción de requisitos. El experimento de Niknafs (2014) muestra que la titulación académica influye positivamente en la generación de nuevas ideas durante la fase de educción de requisitos. Por el contrario, si bien no son experimentos de educción de requisitos, Albayrak y Carver (2014) y Carver et al. (2008) indican que los sujetos sin formación en ciencias de la computación o ingeniería del software son más efectivos en la inspección de requisitos. Atkins (2013) muestra que la titulación académica no es un requisito indispensable para alcanzar el éxito en un proyecto software. Aunque en este punto no tiene porqué existir contradicción, dado que las diferencias en los resultados se producen en áreas muy distintas de la Ingeniería de Requisitos, no deja de ser cierto que solo existe un estudio acerca del efecto de la titulación académica en la efectividad de los analistas. Nuevos estudios podrían refutar o confirmar los resultados del estudio previo. Por ello, los investigadores se plantearon la siguiente pregunta de investigación:

- RQ3: ¿Influye (ya sea positiva o negativamente) la titulación académica que el analista posee en la efectividad del proceso de educción de requisitos? 


\section{CAPÍTULO 4}

\section{METODOLOGÍA DE INVESTIGACIÓN}

En el presente capítulo se describen los diseños experimentales utilizados con el objeto de responder a las preguntas de investigación planteadas en el Capítulo 3. En total hemos realizado 8 estudios empíricos (entre cuasi-experimentos y experimentos controlados) que analizan la efectividad de los sujetos en la actividad de educción de requisitos. Dichos estudios pueden reducirse a dos diseños fundamentales, uno de carácter cuasi-experimental (implementado por primera vez en Q-2007) y otro de carácter experimental (implementado por primera vez en E-2012).

En primer lugar, se describirá el cuasi-experimento base Q-2007 siguiendo las guías para reportar experimentos propuestas por Jedlitschka y Pfahl (2005). Seguidamente se describirán los cuasiexperimentos derivados. Estos cuasi-experimentos son replicaciones literales-nativas-internas y externas con algunas diferencias metodológicas y/o contextuales. Según Gómez, Juristo y Vegas (2014) una replicación literal-nativa-interna es el estudio donde el mismo investigador del estudio base, en el mismo sitio, con el mismo protocolo, con las mismas operacionalizaciones y con el mismo tipo de poblaciones verifica el resultado observado; mientras que la replicación externa es cuando el estudio se realiza en otro sitio distinto al estudio base. Dichas diferencias se describirán siguiendo las guías para reportar replicaciones propuestas por Carver (2010).

Cabe mencionar que la descripción de las replicaciones será mediante diferencias referidas a la manera de llevar a cabo los cuasi-experimentos. No se mencionarán las razones que motivan las diferencias existentes entre las replicaciones, ya que ello implica un conocimiento de los resultados obtenidos. El lector interesado en conocer dichas razones deberá dirigirse al Capítulo 5 donde se indicarán los motivos que originan dichos cambios metodológicos, además de presentar las diferencias contextuales que fueron surgiendo a lo largo de la investigación.

Finalizada la descripción de los cuasi-experimentos, se describirán el experimento base E-2012 y los experimentos derivados, empleando el mismo procedimiento utilizado con el cuasi-experimento base. Estos experimentos son replicaciones internas-nativas-operacionales: internas (porque se realizan en el mismo sitio donde se efectuó el experimento base), nativas (se realiza por los mismos investigadores que participaron en el experimento base) y operacionales (porque varían las operacionalizaciones de causa y/o efecto con el fin de verificar hasta qué limites de las operacionalizaciones de los constructos 
de causa y efecto se mantienen en los resultados obtenidos (Gómez et al., 2014)). Las razones que motivan las diferencias entre experimentos se describen en el Capítulo 5.

\subsection{Estimación del tamaño muestral necesario}

Antes de ejecutar un experimento se recomienda estimar el tamaño muestral necesario para que los test estadísticos posean un poder estadístico suficiente y de esta manera se obtengan resultados más fiables, en particular se eviten errores de tipo II (Kitchenham et al., 2002). La estimación del tamaño muestral se realiza mediante el análisis del poder estadístico. Existen distintas formas de realizar dicho análisis. La más habitual es mediante herramientas especializadas como G*Power (Faul, Erdfelder, Lang, \& Buchner, 2007).

El tamaño muestral (o número de sujetos requeridos) varía en función del tipo de diseño experimental (cuasi-experimentos, experimentos controlados: within-subjects o between-subjects). Normalmente, para estimar el tamaño muestral, se aplica un procedimiento similar al que sigue (Dattalo, 2007):

1. Seleccionar el nivel de poder estadístico deseado. El estándar adecuado de poder estadístico para la mayoría de las investigaciones es $0.80(80 \%)$.

2. Seleccionar el nivel de significación $\alpha$. El nivel alfa normalmente aceptado es de 0.05 (5\%.)

3. Estimar el tamaño de efecto poblacional. En Ingeniería del Software se acostumbra utilizar tamaños de efectos medios (Tuya, Ramos Román \& Dolado Cosín, 2007), determinados de acuerdo a las definiciones de Cohen (1988) (por ejemplo, $d=0.5, r=0.3 ; f=0.25$, etc.)

4. Identificar la fórmula adecuada (test estadístico) según el tipo de diseño experimental.

5. Calcular el tamaño muestral necesario.

Como se verá a lo largo del capítulo, para la presente investigación, el tamaño muestral requerido en cuasi-experimentos (sección 4.2.5) o experimentos (sección 4.6.4) oscila entre 82 y 128 sujetos. En el contexto del programa de estudios donde el experimento será realizado, el número de alumnos típico por clase está entre 15 y 20, por lo que alcanzar el tamaño muestral estimado en un único experimento es muy difícil. Por este motivo sería necesario replicar el experimento múltiples veces hasta alcanzar un número de sujetos suficiente para obtener resultados razonablemente fiables.

\subsection{Cuasi-Experimento Q-2007}

A continuación se reportará el proceso experimental seguido en Q-2007, basado en las guías para reportar experimentos en Ingeniería del Software, propuestas por Jedlitschka y Pfahl (2005). Q-2007 es el cuasi-experimento base que inaugura la línea de investigación. Este cuasi-experimento está inspirado principalmente en tres fuentes:

1. Por un lado, el experimento de Agarwal y Tanniru (1990), que estudian la efectividad de los analistas durante la actividad de educción mediada por entrevistas.

2. Por otro lado, el cuasi-experimento de Pitts y Browne (2004), que estudia las "reglas de parada" de los analistas durante la educción mediada por entrevistas.

3. Finalmente, el experimento de Marakas y Elam (1998), que evalúa la efectividad de los analistas en función de la técnica de entrevista empleada: técnica de entrevista semántica (un tipo de entrevista semi-estructurada) frente a la entrevista no estructurada.

Dichos experimentos tenían como objetivo principal estudiar la efectividad de los analistas (operacionalizada de formas distintas) empleando la entrevista como técnica de educción, y coincidían en la imposibilidad de identificar efectos significativos de la experiencia de los analistas sobre la 
efectividad durante la actividad de educción. El diseño de Q-2007 se derivó del cuasi-experimento de Pitts y Browne (2004).

\subsubsection{Variables y Métricas}

En esta sección describiremos las variables independientes y dependientes estudiadas en el cuasiexperimento, así como también la forma en que fueron medidas.

\subsubsection{Variables Independientes}

Las variables independientes son todas aquellas variables que servirán para explicar el comportamiento de los analistas durante el proceso de adquisición y consolidación de los requisitos para el objeto experimental propuesto (dominio sobre el reciclado de pilas, como se verá a continuación). En nuestro caso, las variables independientes hacen referencia a las características del sujeto resumidas en la Tabla 4.1.

Los valores de dichas variables se obtuvieron, por cada sujeto, mediante un cuestionario postexperimental (disponible en el Anexo A.1) aplicado al final del cuasi-experimento con la única excepción del tiempo, el cual se ha determinado a partir de las grabaciones de las sesiones de educción.

Tabla 4.1 - Variables independientes Q-2007

\begin{tabular}{|c|c|c|}
\hline VARIABLE INDEPENDIENTE & DESCRIPCIÓN & MÉTRICA \\
\hline $\begin{array}{l}\text { Experiencia: en entrevistas, } \\
\text { en educción, en requisitos y } \\
\text { experiencia profesional. }\end{array}$ & $\begin{array}{l}\text { Experiencia del sujeto en: entrevistas, } \\
\text { requisitos, educción y profesional. }\end{array}$ & $\begin{array}{l}\text { Cantidad de años de experiencia en las } \\
\text { distintas vertientes. }\end{array}$ \\
\hline $\begin{array}{l}\text { Conocimiento del Problema } \\
\text { (operacionalizado como } \\
\text { familiaridad) }\end{array}$ & $\begin{array}{l}\text { Conocimiento que posee el sujeto } \\
\text { sobre el dominio del problema a tratar. }\end{array}$ & $\begin{array}{l}\text { Escala de Likert del } 1 \text { al } 3 \text { (de baja a alta } \\
\text { familiaridad) } \\
\text { 1. No familiar: Es la primera vez que } \\
\text { me enfrento al problema. } \\
\text { 2. Familiar: Me resulta familiar el } \\
\text { problema, pero nunca he trabajado } \\
\text { en este ámbito. } \\
\text { 3. Muy Familiar: Conozco bien el } \\
\text { problema pues he trabajado antes } \\
\text { en este ámbito. }\end{array}$ \\
\hline Titulación académica & $\begin{array}{l}\text { Titulación Académica: conocimiento } \\
\text { teórico del sujeto en el área de } \\
\text { desarrollo de software. }\end{array}$ & $\begin{array}{l}\text { Dicotomizada en: } \\
\text { 0. No Informático } \\
\text { 1. Informático }\end{array}$ \\
\hline Tiempo de educción & Duración de la sesión de educción & Medida en minutos:segundos \\
\hline
\end{tabular}

La principal variable independiente es la experiencia. Sin embargo, resulta inmediato percibir que el concepto de "experiencia" es ambiguo (experiencia en qué: ¿entrevistas, requisitos, etc.?) Considerar únicamente la experiencia profesional parece bastante inespecífico, debido a que los sujetos pudieron haber realizado muy diversas actividades a lo largo de su carrera. Por este motivo, decidimos considerar además de la experiencia profesional, la experiencia específica en requisitos, así como la experiencia en educción y en entrevistas. La experiencia la hemos medido en número de años que el sujeto experimental ha trabajado con requisitos, entrevistas, educción, etc.

Además de la experiencia (en sus distintas vertientes), decidimos introducir en Q-2007 tres variables no exploradas en los estudios de la literatura en los que se basó el cuasi-experimento base. Éstas son:

- La familiaridad: mide el grado de conocimiento que, desde un punto de vista subjetivo, poseen los sujetos acerca del dominio del problema. La familiaridad se ha medido mediante una escala de Likert del 1 al 3 (siendo 1. No familiar; 2 Familiar y 3. Muy familiar). 
- La titulación académica: si bien los sujetos poseían limitados niveles de experiencia, tenían sin embargo antecedentes académicos muy diversos (ej. Ingenieros de sistemas o ciencias de la computación, licenciado en economía, tecnólogo en procesamiento de datos, etc.). Esto dio la oportunidad de estudiar el efecto de la titulación en la efectividad de los analistas, categorizados como informáticos y no informáticos.

- El tiempo de educción: corresponde a un tiempo limitado (no más de 30 minutos) establecido para las sesiones de educción.

\subsubsection{Variables Dependientes}

Las variables dependientes seleccionadas deben dar respuesta a las preguntas de investigación planteadas en el Capítulo 3. Como tenemos interés de estudiar la efectividad del analista en el proceso de educción de los requisitos, nuestra variable dependiente hace referencia a la efectividad del proceso de educción.

En este cuasi-experimento hemos evaluado tres variables dependientes. Las variables dependientes seleccionadas se indican en la Tabla 4.2. Dichas variables hacen referencia a la efectividad del sujeto, medida teniendo en cuenta la cantidad de información mencionada, retenida e identificada (o, al menos, hecha explícita en los informes resultantes del proceso de consolidación) por el sujeto durante la educción. Estas variables se obtienen analizando las sesiones de educción que han sido grabadas durante el cuasi-experimento, así como los informes presentados por los sujetos como resultado del proceso de consolidación de los requisitos.

Tabla 4.2 - Variables Dependientes Q-2007

\begin{tabular}{|l|l|l|l|}
\hline \multicolumn{1}{|c|}{ Variable Dependiente } & \multicolumn{1}{|c|}{ Descripción } & \multicolumn{1}{c|}{ Ítem Evaluado } & MÉtRica \\
\hline $\begin{array}{l}\text { Efectividad de la sesión de } \\
\text { educción }\end{array}$ & $\begin{array}{l}\text { Cantidad de elementos del } \\
\text { dominio mencionados durante } \\
\text { la sesión de educción. }\end{array}$ & $\begin{array}{l}\text { Entrevistas (sesiones de } \\
\text { educción grabadas) }\end{array}$ & Efectividad \\
\hline $\begin{array}{l}\text { Efectividad del proceso de } \\
\text { consolidación de } \\
\text { información }\end{array}$ & $\begin{array}{l}\text { Cantidad de elementos del } \\
\text { dominio reportados. }\end{array}$ & $\begin{array}{l}\text { Informes (lista de requisitos e } \\
\text { información consolidada) }\end{array}$ & Efectividad \\
\hline Capacidad de Retención & $\begin{array}{l}\text { Cantidad de elementos del } \\
\text { dominio identificados de la } \\
\text { información mencionada en las } \\
\text { sesiones de educción. }\end{array}$ & $\begin{array}{l}\text { Sesiones de educción e } \\
\text { informes }\end{array}$ & Efectividad \\
\hline
\end{tabular}

Actualmente no existe una métrica ampliamente aceptada para medir la efectividad de la educción de requisitos. Sin embargo, es posible encontrar en la literatura y trabajos empíricos existentes diversas alternativas de medida: Agarwal y Tanniru (1990) miden la efectividad en términos del número total de reglas identificadas; Pitts y Browne (2004) según la cantidad de requisitos adquiridos; Burton, Shadbolt, Rugg, y Hedgecock (1988) teniendo en cuenta la cantidad de reglas y cláusulas elicitadas; Browne y Rogich (2001) diferenciándola por categorías: cantidad total de requisitos, procesos e información; Niknafs y Berry (2012) consideran la efectividad según el número de ideas generadas por el equipo de RE.

La efectividad, por tanto, se ha venido operacionalizando como la cantidad de ítems (ya sean conceptos, reglas, procesos, entre otros) obtenidos por el analista durante la educción. En nuestro caso, hemos procedido de modo similar a las investigaciones citadas y medimos la efectividad del proceso de educción de requisitos como el porcentaje total de elementos del dominio del problema identificados por los sujetos experimentales.

El dominio del problema está compuesto por distintos tipos de elementos. La literatura coincide en los elementos esenciales, aunque difiere en los detalles. Por ejemplo, según Yadav, Bravoco, Chatfield, y Rajkumar (1988) los problemas se suelen analizar en términos de objetivos de la organización, procesos 
de negocio y tareas que se deben realizar dentro de los procesos para lograr los objetivos. En la misma línea, Davis (1993) menciona que los requisitos, independientemente del lenguaje, de la notación o la técnica utilizada: 1) definen un objeto, una función o un estado, 2) limita o controla las acciones asociadas con un objeto, una función o un estado, o 3) define relaciones entre objetos, funciones y estados. Formulaciones más modernas como el "Frisco Report" (Falkenberg et al., 1996) incorporan elementos que en la literatura precedente estaban implícitos, tales como actores o reglas, además de conservar los ya mencionados conceptos, acciones o estados.

Basándonos en los trabajos anteriores, para medir la efectividad de la educción utilizamos dos tipos de elementos principales: conceptos y procesos. Los objetivos, aunque considerados inicialmente, fueron posteriormente descartados, ya que su número es muy pequeño en relación al número de procesos o conceptos y son siempre identificados por los sujetos, por lo que no proporcionan información relevante a efectos experimentales. Dado que hemos seleccionado dominios sencillos (con pocos actores y ninguna regla de negocio), aspectos más refinados como actores y reglas no parecen adecuados para medir la efectividad.

Los procesos y conceptos de un dominio pueden describirse a varios niveles de detalle (inputs, outputs, atributos, relaciones, etc.). Considerando que el cuasi-experimento consiste en una entrevista inicial, parece bastante difícil que el analista pueda aprehender detalles finos del dominio. Por este motivo, no tendremos en consideración los detalles antes citados (ej. relaciones) y nos restringiremos a los elementos de "grano grueso", que proporcionan una imagen incompleta, aunque probablemente más justa de la efectividad de los analistas en una primera sesión de educción de un problema sencillo.

Para facilitar la instrumentación, hemos excluido del estudio los requisitos no funcionales, centrándonos únicamente en los requisitos funcionales. Desde la perspectiva de sistemas de información, los requisitos consisten esencialmente en la automatización de procesos pre-existentes en el dominio. Los procesos y requisitos podrían verse como redundantes a efectos de medir la cantidad de información obtenida por los sujetos. No obstante, estas peculiaridades de los sistemas de información no se reproducen en otros tipos de sistemas, como por ejemplo los sistemas de control. En dichos contextos, la caracterización de Gunter, Gunter, Jackson y Zave (2000), que considera los requisitos (en oposición a las especificaciones) como declaraciones operativas en un dominio parece más adecuada. Bajo este punto de vista, los requisitos son parte del dominio del problema, separadamente de los procesos y conceptos, y debería como tal ser incluidos. Para el presente cuasi-experimento, la segunda opción es la más razonable ya que el dominio del problema utilizado en el cuasi-experimento pude calificarse como sistema de información y sus características se asemejan más a sistemas de control.

En resumen, los elementos del dominio del problema que serán considerados en la presente investigación son: conceptos, procesos y requisitos. La medida de efectividad se obtendrá de acuerdo a la fórmula siguiente:

$$
\text { Efectividad }=\frac{\begin{array}{c}
\text { \#conceptos } \\
\text { identificados }
\end{array}+\begin{array}{c}
\# \text { procesos } \\
\text { identificados }
\end{array}+\begin{array}{c}
\# \text { requisitos } \\
\text { identificados }
\end{array}}{\text { número total de elementos }}
$$

Hemos optado por no realizar una media ponderada ya que el hecho de que un determinado elemento aparezca en mayor proporción en un dominio no significa que éste sea intrínsecamente más relevante. Todos los elementos juegan un papel importante en la construcción del futuro sistema software.

\subsubsection{Hipótesis}

El objetivo principal del cuasi-experimento base consiste en analizar experimentalmente la influencia que de la experiencia (en sus distintas vertientes: requisitos, entrevistas, educción y profesional) y la familiaridad acerca del dominio del problema que poseen los analistas en la efectividad de la actividad 
de educción de requisitos. Para poder alcanzar el objetivo propuesto hemos planteado las siguientes hipótesis de investigación en base a su respectiva hipótesis nula $\left(\mathrm{H}_{0 . \mathrm{j}}\right)$ y alternativa $\left(\mathrm{H}_{\mathrm{j} . \mathrm{k}}\right)$.

RQ1: ¿Influye la experiencia del analista en la efectividad del proceso de educción de los requisitos?

- H1.a. No hay ninguna relación entre la experiencia (en requisitos /entrevistas/ educción Iprofesional) y la efectividad (educción / consolidación / retención) en el proceso de educción.

- H1. $a_{1}$ : Existe una relación entre la experiencia y la efectividad del analista.

RQ2: ¿Influye el conocimiento ${ }^{11}$ que el analista posee acerca del dominio en la efectividad del proceso de educción de requisitos?

- H2.ao: No hay relación entre la familiaridad que posee el sujeto y su efectividad (educción/ consolidación ( retención) en el proceso de educción.

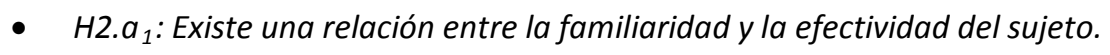

Como nuestro estudio es de carácter exploratorio y en la literatura se observan tendencias distintas sobre el efecto de la experiencia y del conocimiento, no podemos anticipar la dirección de los efectos potenciales de dichas variables. Por tanto, la hipótesis alternativa es 2-colas (2-tailed).

Por otro lado, el carácter profesional del máster donde se realizó el cuasi-experimento, propició que los estudiantes poseyeran distintos perfiles y titulaciones, lo cual podría ejercer algún tipo de influencia en sus efectividades. Sería esperable que los estudiantes con formación en informática sean más efectivos que los no informáticos. Por tanto, este hecho llevó a los investigadores a plantearse la siguiente pregunta de investigación:

RQ3. ¿Influye la titulación académica en la efectividad (educción/ consolidación/ retención) del proceso de educción?

- $H 3_{0}$ : No hay relación entre la titulación académica que posee el sujeto y su efectividad (educción / consolidación / retención) en el proceso de educción.

- $\quad H 3_{1}$ : Existe una relación entre la titulación académica y la efectividad del sujeto.

\subsubsection{Selección de Sujetos}

Hemos usado muestreo por conveniencia para seleccionar los sujetos experimentales. Los sujetos que participaron en el experimento fueron estudiantes del Máster en Ingeniería del Software de la Escuela Técnica Superior de Ingenieros Informáticos de la Universidad Politécnica de Madrid (anteriormente Facultad de Informática), matriculados en la asignatura de Ingeniería de Requisitos. La asignatura de Ingeniería de Requisitos fue seleccionada para reclutar a los sujetos, dado que Q-2007, así como sus replicaciones se puede ejecutar naturalmente como parte de la asignatura.

\subsubsection{Asignación de los Sujetos a Tratamientos}

El estudio empírico realizado en Q-2007 es un cuasi-experimento. Los cuasi-experimentos se realizan cuando los sujetos no pueden asignarse aleatoriamente a una condición experimental o, alternativamente, un tratamiento no puede ser asignado a un grupo. Este es nuestro caso, ya que las características de los sujetos experimentales no pueden aleatorizarse ni bloquearse al ser intrínsecas del sujeto experimental.

Por tanto, en el presente estudio no se produce una asignación a sujetos propiamente dicha, debido a que todos los sujetos realizan el mismo tratamiento. Es decir, todos los sujetos que participan del cuasi-experimento realizan la actividad de educción de requisitos sobre el mismo problema y con el mismo entrevistado (ver sección 4.2.7).

\footnotetext{
${ }^{11}$ Nótese que el conocimiento en este cuasi-experimento está operacionalizado como la familiaridad.
} 


\subsubsection{Estimación del Tamaño Muestral}

Para tener una idea sobre el tamaño muestral mínimo deseable para la ejecución del cuasi-experimento, hemos utilizado la herramienta G*Power 3.1 con los valores proporcionados por defecto, tal y como se indica en la Figura 4.1. Siguiendo los pasos recomendados en la sección 4.1, para la determinación del tamaño muestral hemos establecido el poder estadístico al 80\%, con un nivel de significación del 5\% en la detección de efectos medios (Cohen's $r=0.3$ ). El test estadístico seleccionado corresponde a "Correlation: Bivariate normal model".

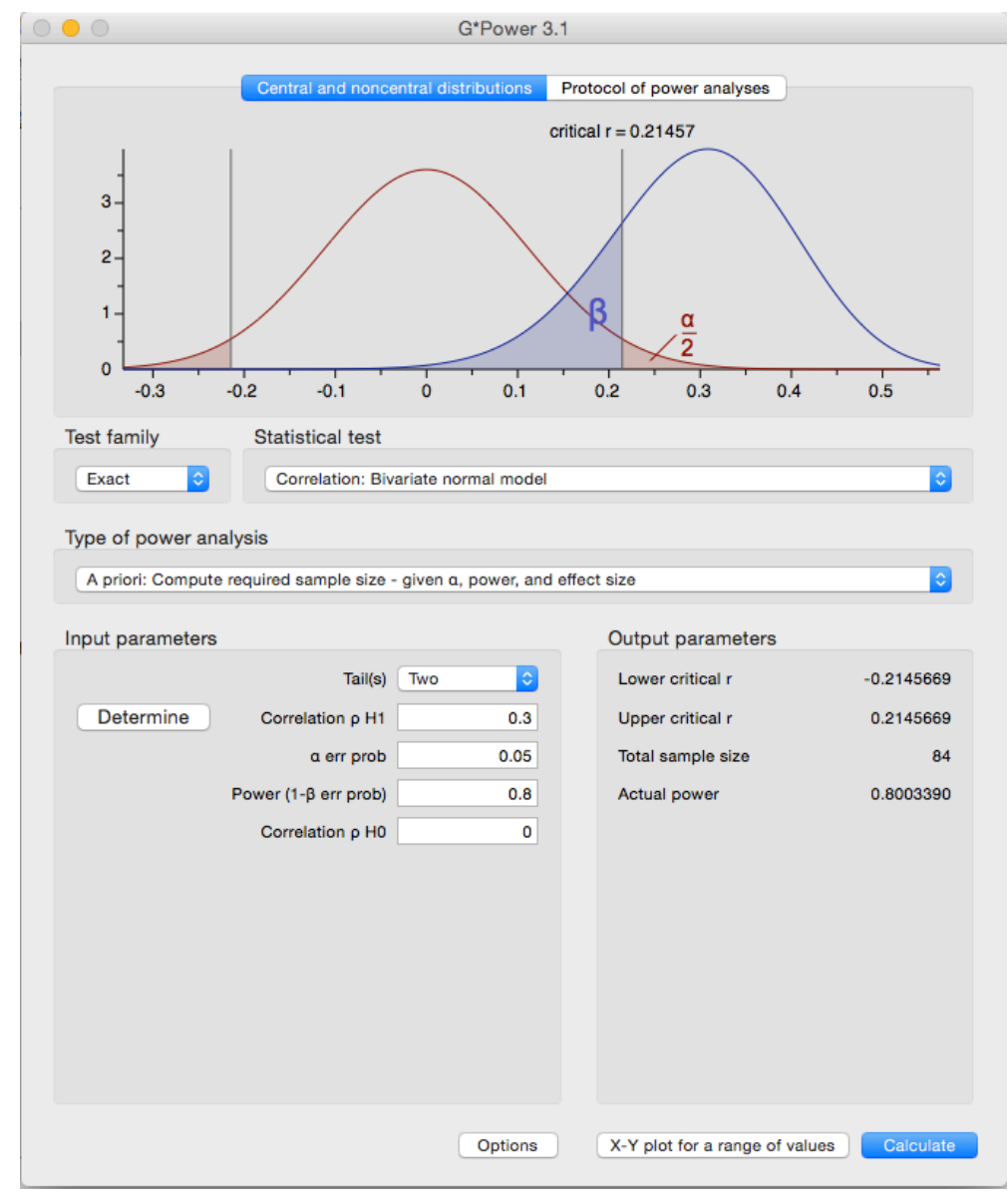

Figura 4.1 - Estimación del tamaño muestral para cuasi-experimentos

Tal y como se puede apreciar en la figura anterior, el tamaño mínimo estimado para la ejecución de un cuasi-experimento es de 84 sujetos. Sabemos de ante mano que en Q-2007 no alcanzaremos la cantidad esperada, por ello la necesidad replicaciones hasta obtener el tamaño estimado.

\subsubsection{Objeto Experimental}

El problema planteado consistió en un sistema de control de máquinas de reciclado de pilas (al que hemos asignado el código PD1). Lo inusual del problema seleccionado se debe a que una de las amenazas que deseamos evitar es el impacto del conocimiento previo sobre el dominio del problema en la efectividad del analista. Por ello, el problema debía ser poco habitual de modo que un buen número de sujetos tuvieran poca o ninguna experiencia en el mismo.

El dominio del problema tiene relación con una planta de reciclado de pilas, donde se utilizan una serie de máquinas y procesos muy específicos del dominio que son imposibles de inferir a menos que se posea experiencia específica en dicho dominio. El problema está basado en un sistema real pero con menor complejidad con la finalidad de que sea abordable por los estudiantes del máster en el tiempo limitado de las sesiones experimentales. El problema fue completamente descrito en función de los tres 
tipos de elementos que lo definen: requisitos del sistema, conceptos y procesos (disponible en el Anexo B.2). La Tabla 4.3 presenta el número total de elementos que definen y delimitan el tamaño del dominio del problema. Esta subdivisión del dominio del problema en elementos se ha utilizado como una lista patrón referente y ha permitido a los investigadores medir la efectividad de la educción (ya sea durante la sesión de educción o la consolidación posterior).

Tabla 4.3 - Número total de elementos que definen el tamaño del problema

\begin{tabular}{|c|c|c|c|c|}
\hline \multirow{2}{*}{ Problema } & \multicolumn{4}{|c|}{ Elementos Que definen el Problema (\#) } \\
\cline { 2 - 5 } & ReQuisitos & Conceptos & Procesos & Total \\
\hline PD1 $^{12}$ & 15 & 24 & 12 & 51 \\
\hline
\end{tabular}

\subsubsection{Tarea Experimental}

El experimento estuvo compuesto por tres tareas, como se muestra en la Figura 4.2. Estas fueron: la sesión de educción, reporte de la información obtenida y contestación del cuestionario postexperimental. En la sesión de educción, los sujetos desempeñaron el rol de analistas de requisitos (entrevistador) y el experimentador actuó como cliente o usuario (entrevistado). Los sujetos pudieron llevar a cabo la tarea experimental ya que son titulados en informática y poseen los conocimientos mínimos necesarios para realizar una educción de requisitos.

Durante la sesión de educción, cada sujeto tuvo que identificar la información relevante del dominio del problema. La sesión de educción se llevó a cabo mediante una entrevista abierta (esto es, una conversación sin restricciones, como es común en las primeras etapas del proceso de requisitos) en un tiempo limitado a 30 minutos. Finalizada la sesión de educción, durante un tiempo limitado a una semana (7 días), los sujetos experimentales reportaron por escrito toda la información que han adquirido durante la entrevista. El formato del informe fue libre. Los sujetos terminaron el experimento rellenando el cuestionario post-experimental, lo que toma menos de 5 minutos, una vez entregado el reporte final.
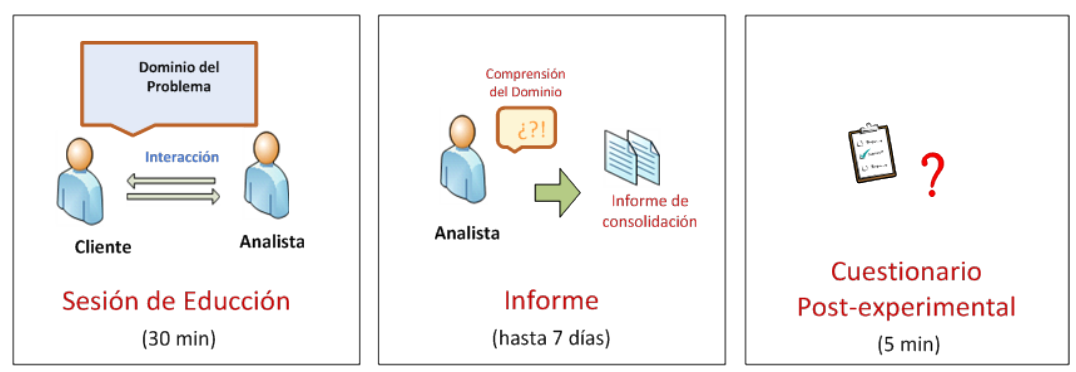

Figura 4.2 - Tareas o actividades del cuasi-experimento Q-2007

\subsubsection{Instrumentación}

La instrumentación está asociada a la documentación requerida para la formación del entrevistado para la ejecución del cuasi-experimento, así como el cuestionario proporcionado a los sujetos experimentales.

Como el proceso de educción de requisitos fue realizado en un entorno académico, se trató de un proceso simulado. En consecuencia, el sujeto que ejerció el rol de entrevistado no conocía realmente el dominio del problema. Para llegar a proporcionar información a los sujetos, fue necesario que el entrevistado estudie en profundidad el dominio de reciclado de pilas, de modo que pudiera responder de forma natural lo más completa y certeramente posible a las preguntas planteadas por los sujetos

${ }^{12}$ En la investigación hemos utilizado más de un dominio del problema con carácter conocido (C) y/o desconocido (D), con la finalidad de estudiar los efectos del conocimiento como se verá en la sección 4.6.7. El problema del reciclado de pilas (PD1) corresponde al primero. 
experimentales, sin que tuviera que retener ni proporcionar más información de la solicitada. Ello fue posible dado que el problema PD1 fue explícito y exhaustivamente descrito tal y como se describe en el Anexo B.2. En el caso de que el analista realizase al entrevistado preguntas no referidas al dominio del problema (por ejemplo, preguntas relacionadas con la gestión, proyecto, tiempos, etc.) las respuestas podrían ser cualesquiera sin requerir consistencia entre sujetos.

En lo que respecta al cuestionario, el mismo estuvo dividido en dos secciones principales, la primera referida a datos relacionados con la titulación académica y los años de experiencia en sus distintas vertientes, y la segunda, referida a datos relacionados con la familiaridad que posee el sujeto sobre el problema y la dificultad percibida en la comprensión del problema.

Nótese que las preguntas son relativamente sencillas (preguntas simples, escalas de Likert, etc.) aunque las variables estudiadas son de difícil medición. Tal y como se ha indicado en la sección 4.2.1, la titulación académica la hemos medido como informático y no informático; la experiencia en número de años y la familiaridad mediante una escala de Likert de tres valores que refleja el conocimiento subjetivo del analista en el dominio. Dichas variables, podrían medirse en otras unidades, por ejemplo, la experiencia en lugar de ser en años, podría ser en cantidad de proyectos; o mediante una escala de Likert del 0 al 5; o nivel de educación (estudiantes de grado, postgrado, etc.). Sin embargo hemos optado por la manera más sencilla y la más utilizada en la literatura de Ingeniería de Requisitos (por ejemplo, todos los artículos empíricos acerca de la experiencia y conocimiento del dominio que manejamos miden la experiencia en años).

Por otro lado, es conveniente mencionar que el cuestionario utilizado en este cuasi-experimento fue evolucionando en paralelo con la investigación, lo que implicó añadir, eliminar o refinar las preguntas. En el Anexo A, se encuentra disponible los cuestionarios utilizados en los distintos estudios experimentales.

\subsubsection{Protocolo y Procedimiento de Recolección de Datos}

El protocolo experimental se muestra en la Figura 4.3. La semana anterior a la ejecución del experimento, los estudiantes fueron notificados del: día, hora y lugar del experimento. El cuasiexperimento fue planteado como una práctica evaluable de la asignatura.

En concordancia con el diseño experimental mostrado en la Figura 4.3 los sujetos realizaron el proceso de educción de requisitos distribuidos en dos días distintos, para evitar efectos de cansancio por parte del experimentador. El primer día la educción de requisitos la realizó el grupo 1 (G1), mientras que el segundo día el grupo 2 (G2).

\begin{tabular}{|c|c|c|c|}
\hline DíA 1 & DíA 2 & \multirow{2}{*}{ ( 7 DíAs ) } & DíA 8 \\
\cline { 1 - 1 } G1 & G2 & G1, G2 \\
\hline Sesión de educción & Consolidación & $\begin{array}{c}\text { Entrega Informe + } \\
\text { Cuestionario Post- } \\
\text { experimental }\end{array}$ \\
\hline
\end{tabular}

Figura 4.3 - Protocolo experimental (planeado)

Finalizadas las sesiones de educción, los sujetos tuvieron una semana para reportar la información adquirida durante las entrevistas. Ese mismo día respondieron al cuestionario post-experimental. No se les solicitó a los estudiantes que especifiquen el tiempo transcurrido entre la educción y consolidación ya que el riesgo de que proporcionasen información segada es evidente.

\subsubsection{Procedimiento de Medición}

Como hemos comentado anteriormente, la efectividad del proceso de educción se midió sobre las transcripciones de las entrevistas y los informes presentados por los sujetos al finalizar el proceso de la 
consolidación. Para ello, se utilizó la lista patrón compuesta por los elementos que definen el dominio del problema tal y como se indica en el Anexo B.2. La lista patrón fue definida de antemano; no se ha añadido o eliminado ningún elemento de la misma durante la medición de los reportes de los sujetos.

Para analizar la efectividad de la sesión de educción, en primer lugar hemos transcrito las entrevistas, con el objetivo de facilitar el posterior análisis de la información mencionada durante la sesión de educción. En dichas transcripciones, hemos marcado la aparición de cualquier elemento de la lista patrón sin considerar repeticiones. Ello nos ha permitido generar tablas de resumen como la mostrada en la Tabla 4.4. Por cada sujeto experimental (Ei), hemos registrado el número total de elementos mencionados en la entrevista (eje horizontal) y, el porcentaje promedio por cada elemento mencionado en las entrevistas (eje vertical). Por ejemplo, en la Tabla 4.4 se observa que en la entrevista del sujeto E06 se ha mencionado el $75 \%$ de los procesos definidos para el problema. Nótese que esta estrategia nos permite analizar tanto la efectividad global alcanzada por el sujeto como la efectividad diferenciada por tipo de elementos (por ejemplo, el elemento A2 ha sido mencionado en el $86 \%$ de las entrevistas).

De manera similar al procedimiento seguido en la sesión de educción, para evaluar la efectividad del proceso de consolidación, hemos recolectado los datos a partir de los informes presentados por los sujetos, siguiendo los mismos criterios de referencia anteriores. Los resultados obtenidos, también han sido resumidos en tablas (igual que la Tabla 4.4).

Para evaluar la capacidad de retención del sujeto hemos calculado la diferencia entre los resultados obtenidos en la sesión de educción y consolidación (ElementosConsolidados/ElementosMencionados).

Los datos de las tablas resúmenes generadas, los hemos utilizado para calcular la efectividad de los analistas de acuerdo a la fórmula indicada en la sección 4.2.1.2.

Tabla 4.4 - Procesos adquiridos por los sujetos

\begin{tabular}{|c|c|c|c|c|c|c|c|c|c|c|c|c|c|c|}
\hline \multirow[b]{2}{*}{ Sujeto } & \multicolumn{14}{|c|}{ PROCESOS } \\
\hline & $\mathrm{A} 1$ & A2 & A3 & A4 & A5 & A6 & A7 & A8 & A9 & A10 & A11 & A12 & $\begin{array}{l}\text { Total } \\
\text { (12) }\end{array}$ & $\begin{array}{c}\text { \% Total } \\
\text { (12) }\end{array}$ \\
\hline E01 & & $x$ & & $x$ & & & & & & & & & 2 & $17 \%$ \\
\hline E02 & & $x$ & & $x$ & & $x$ & $x$ & $x$ & $x$ & & & & 6 & $50 \%$ \\
\hline E03 & & & & & & & & & & & & & 0 & $0 \%$ \\
\hline E04 & $x$ & $x$ & & & $x$ & $x$ & & & $x$ & & & & 5 & $42 \%$ \\
\hline E05 & & $x$ & & $x$ & & $x$ & $x$ & & $x$ & & & & 5 & $42 \%$ \\
\hline E06 & & $x$ & $\mathrm{x}$ & $x$ & $\mathrm{x}$ & $x$ & $\mathrm{x}$ & $x$ & $\mathrm{x}$ & $x$ & & & 9 & $75 \%$ \\
\hline E07 & & $x$ & $x$ & $x$ & $x$ & & & $x$ & $x$ & & & $x$ & 7 & $58 \%$ \\
\hline Promedio & $14 \%$ & $86 \%$ & $29 \%$ & $71 \%$ & $43 \%$ & $57 \%$ & $43 \%$ & $43 \%$ & $71 \%$ & $14 \%$ & $0 \%$ & $14 \%$ & 5 & $40 \%$ \\
\hline
\end{tabular}

\subsubsection{Análisis de Datos}

La estrategia de análisis utilizada para evaluar los efectos de las variables independientes sobre la efectividad será la correlación estadística. Utilizaremos el coeficiente de correlación de Pearson con un nivel de significación definido al $\alpha=0.05$, cuyos resultados serán apoyados mediante gráficos de dispersión y estadísticos descriptivos.

El análisis de correlación permite evaluar la relación de dependencia entre dos variables, es decir, evaluar si los valores de la variable dependiente, dependen o están influidos por los valores de la variable independiente. Los efectos los interpretaremos según las convenciones sobre tamaños de efectos propuestos por Cohen (1988) tal y como se indica en la Tabla 4.5. 
Por otro lado, para comparar las medias de los grupos, utilizaremos la prueba estadística T (t-test) apoyada mediante gráficos de cajas (box-plot). El análisis será realizado utilizando el paquete estadístico SPSS V 21.

Tabla 4.5 - Convenciones de tamaños de efectos según Cohen

\begin{tabular}{|c|c|c|c|c|}
\hline Efecto & Fuerte & Moderado & Bajo & Ninguno \\
\hline Correlación $(r)$ & $\pm(0.5-1)$ & $\pm(0.3-0.5)$ & $\pm(0.1-0.3)$ & $\pm(0-0.09)$ \\
\hline Cohen's d $^{13}$ & $\pm(0.8-1)$ & $\pm(0.5-0.8)$ & $\pm(0.2-0.5)$ & $<0.2$ \\
\hline
\end{tabular}

\subsection{Cuasi-Experimento Q-2009}

Q-2009 es una replicación interna del cuasi-experimento base (Q-2007). Sellevó a cabo en el mismo sitio y bajo las mismas condiciones experimentales, salvo algunas excepciones contextuales que se indicarán más adelante. El objetivo principal de Q-2009 fue comprobar los resultados obtenidos en Q-2007 y ampliar la validez de los resultados.

Metodológicamente hablando, Q-2009 se diferencia de Q-2007 principalmente en las variables dependientes tenidas en consideración. No se ha estudiado la efectividad de los analistas en las sesiones de educción (entrevistas) y en consecuencia tampoco la capacidad de retención de los mismos, debido fundamentalmente al alto costo que implica transcribir y analizar todas las entrevistas (mayores detalles consúltese la sección 5.2.1). Al final del capítulo (sección 4.10) se presenta una tabla resumen con las diferencias principales entre cuasi-experimentos.

\subsection{Cuasi-Experimento Q-2011}

Q-2011 es una replicación interna del cuasi-experimento Q-2009, que en comparación con los cuasiexperimentos anteriores, se diferencia fundamentalmente en el modo de realizar las entrevistas. Los sujetos en Q-2011 durante la sesión de educción emplearon la entrevista abierta en grupo (1:N) ${ }^{14}$ donde varios analistas entrevistan a un cliente. El cambio se debe fundamentalmente al costo y esfuerzo que implicaría realizar 16 entrevistas individuales y la influencia que podría ejercer el cansancio del experimentador en la efectividad de los sujetos. Para mayores detalles consúltese la sección 5.3.1.

Por otro lado, en Q-2011 la experiencia se operacionalizó desde dos puntos de vista: a) en función de los años de experiencia y b) como la habilidad ${ }^{15}$ que el propio sujeto cree tener en el manejo de requisitos y realización de entrevistas. Por lo que los investigadores se plantearon las siguientes hipótesis de investigación adicionales:

- H1. $b_{0}$ : No hay ninguna relación entre la habilidad (en requisitos /entrevistas) y la efectividad en el proceso de educción.

- H1. $b_{1}$ : Existe una relación entre la habilidad y la efectividad del analista.

\footnotetext{
${ }^{13}$ http://imaging.mrc-cbu.cam.ac.uk/statswiki/FAQ/effectSize

${ }^{14}$ Utilizaremos los términos entrevista abierta y entrevista abierta en grupo a lo largo de la tesis con el fin de indicar cómo los tratamientos se han administrado. No obstante, para los propósitos de esta tesis, ambas dinámicas son modos de reflejar el intercambio de información de una persona a otra (1:1) o de una a varias personas (1:N). En la relación 1:1 el analista depende de la interacción personal con el entrevistado para entender el dominio y ser capaz de conceptualizarlo. En la entrevista 1: $\mathrm{N}$ todos los analistas reciben la misma información. No pretendemos afirmar que la "entrevista abierta en grupo" represente una técnica de educción establecida (independientemente de qué dinámicas similares como los "Requirements Workshops" sean bastante usuales durante la educción de los requisitos).

${ }^{15}$ Nótese que la habilidad corresponde con otra operacionalización de la experiencia, distinta de la medida en años.
} 


\subsection{Cuasi-Experimento Q-2012 (REFSQ)}

Q-2012 es una réplica externa del experimento Q-2011. El objetivo principal de Q-2012 consistió en aumentar los puntos datos recogidos a lo largo de la serie histórica de experimentos aumentando la diversidad de experiencias.

Hasta este entonces, los resultados de los cuasi-experimentos ponían de manifiesto un efecto negativo o nulo de la experiencia, aspecto que llama la atención a los investigadores. No obstante, la población experimental utilizada en Q-2007 era demasiado reducida (7 sujetos) para afirmar con seguridad la existencia de un efecto negativo de la experiencia. Para recopilar más datos se realizaron las replicaciones Q-2009 (con 8 sujetos) y Q-2011 (con 16 sujetos). Lamentablemente, los estudiantes en Q-2009 y Q-2011 poseían poca experiencia en requisitos y por ello una comparación fiable entre novatos/expertos no parecía posible. Fue en este momento cuando los investigadores se plantearon la posibilidad de realizar un cuasi-experimento con sujetos profesionales con mayores años de experiencia.

El cuasi-experimento Q-2012 se ejecutó como parte del Alive Empirical Study del REFSQ 2013 (International Working Conference on Requirements Engineering). El Alive Empirical Study estuvo abierto a todos los participantes de la conferencia. Dadas las restricciones del contexto y el objetivo de nuestra investigación, el cuasi-experimento Q-2012 se limitó a 90 minutos (60 minutos para la sesión de educción y 30 minutos a la consolidación ${ }^{16}$ ). La sesión de educción consistió en una entrevista en grupo, lo que permitió a los investigadores emplear menos tiempo y esfuerzo en comparación con las entrevistas individuales, ampliando de esta manera el tamaño muestral muy fácilmente. Para mayores detalles sobre el cuasi-experimento consúltese la sección 5.6.

\subsection{Experimento E-2012}

Nuestro interés principal consiste en estudiar el efecto de la experiencia y del conocimiento que poseen los analistas acerca del dominio del problema, en su efectividad durante la actividad de requisitos. En los cuasi-experimentos indicados anteriormente, los efectos del conocimiento del dominio, resultaron ser pequeños, negativos en algunos casos y nulos en otros. Dichos hallazgos llaman poderosamente la atención, lo que lleva a los investigadores a replantearse el modo de estudiar el efecto del conocimiento.

Podemos entender el conocimiento y la experiencia como aspectos intrínsecos de la persona, ó como una relación entre la persona y un dominio. En el caso de la experiencia, dicha relación no está clara, y por lo tanto es difícil manipularla (esto es, se hace difícil decir de antemano cuando un sujeto posee o no experiencia). Sin embargo, en el caso del conocimiento, como conocemos a la población experimental (estudiantes de post-grado) podemos aventurar con bastante seguridad si conoce o no un determinado dominio del problema. Este hecho nos permite pasar de un diseño cuasi-experimental a uno experimental, ya que el conocimiento que inicialmente en los cuasi-experimentos se ha operacionalizado como familiaridad (una valoración subjetiva ${ }^{17}$ que cada sujeto realiza sobre su conocimiento acerca del dominio), en E-2012 lo hemos operacionalizado como un factor con dos niveles

${ }^{16}$ Los participantes tuvieron la libertad de realizar el proceso de consolidación, en paralelo a la educción. En la medida que iban tomando notas durante las entrevistas ya iban componiendo la información que formaría parte del reporte final.

${ }^{17}$ Como se describe en el capítulo 7 hemos demostrado que los resultados en los que se emplean métricas subjetivas resultan menos precisos que aquellos con métricas objetivas. Este es otro de los motivos, que llevó a los experimentadores aplicar un control sobre el conocimiento del dominio del problema. 
(problema conocido y desconocido) de manera similar a los trabajos experimentales de (Niknafs \& Berry, 2012; Niknafs \& Berry, 2013). ${ }^{18}$

El diseño experimental utilizado en E-2012 es un diseño de medidas repetidas (de aquí en adelante within-subjects). Los diseños within-subjects presentan varias ventajas con respecto a los diseños entre sujetos (between-subjects). A continuación destacamos las más relevantes:

1. En primer lugar, es posible reducir la varianza de error, debido a que en este tipo de diseño el sujeto es su propio control. Puesto que las comparaciones en el diseño de medidas repetidas se realizan within-subjects, la variabilidad provocada por las diferencias individuales se elimina del término de error.

2. En segundo lugar, debido a la reducción de la varianza total es posible conseguir un poder estadístico razonable utilizando una menor cantidad de sujetos de los que se requieren para llevar a cabo el estudio respecto a los diseños between-subjects.

E-2012 es bastante diferente a los cuasi-experimentos indicados anteriormente, en casi todos los aspectos: diseño experimental, aumento de tratamientos, aumento de entrevistados, modo de análisis de los datos experimentales, entre otros. En esta sección se describirá el protocolo experimental, siguiendo las guías de Carver (2010); Jedlitschka y Pfahl (2005). Estará planteado como un nuevo experimento base con su correspondiente replicación interna.

\subsubsection{Variables, Factores y Métricas}

En este experimento hemos utilizado una variable dependiente, un factor, otras cuatro variables independientes y una variable de bloque. La variable dependiente hace referencia la efectividad del proceso de educción, concretamente a la efectividad en la consolidación de la información adquirida en las sesiones de educción, medida del mismo modo que Q-2007, como se ha indicado en la sección 4.2.1.2.

El factor bajo estudio es el conocimiento que posee el analista acerca del dominio del problema, con dos niveles: conocido y desconocido, de forma similar a Niknafs y Berry (2012). La estrategia seguida por los investigadores en E-2012 fue definir problemas conocidos y desconocidos para los sujetos experimentales. Esto es posible, porque se conoce a la población experimental (estudiantes de postgrado), y por tanto se puede anticipar con precisión el conocimiento que podrían tener los estudiantes sobre los dominios del problema. Un dominio es desconocido cuando el sujeto no ha tenido contacto previamente con el mismo; en caso contrario, el dominio es conocido. Todas las suposiciones realizadas sobre el conocimiento del dominio que poseen los sujetos se han comprobado a posteriori mediante un cuestionario.

Las variables independientes consideradas en este estudio son las mismas que los cuasiexperimentos anteriores. Tienen relación con la titulación académica, la experiencia y habilidades en sus distintas vertientes: en entrevistas, en educción, en requisitos y profesional. La Tabla 4.6 presenta una breve descripción de cada una de ellas. Los valores correspondientes se han recogido mediante un cuestionario post-experimental (ver Anexo A.3). Dichas variables las estudiaremos a nivel cuasiexperimental ${ }^{19}$.

Las variables de bloque son aquellas variables que probablemente tengan un efecto en la variable dependiente, pero que no se tiene interés en estudiar su efecto (Juristo \& Moreno, 2001). En nuestro caso, hemos bloqueado el experimento por entrevistado. Los detalles que justifican porqué hemos bloqueado el experimento por entrevistado e idioma se describen en el capítulo 5, secciones 5.4.1.1 y 5.4.1.2, respectivamente.

18 Nótese que nuestro experimento fue ideado, diseñado e incluso ejecutado de forma previa a dichas investigaciones.

${ }^{19}$ Esto es, de una forma similar a lo reclutado en los cuasi-experimentos Q-2007 a Q-2012. 
Estudio empírico de la influencia de la experiencia y del conocimiento del dominio del analista en la efectividad del proceso de educción de requisitos

Tabla 4.6 - Variables independientes E-2012 A

\begin{tabular}{|l|l|l|}
\hline \multicolumn{1}{|c|}{ VARIABLE INDEPENDIENTE } & \multicolumn{1}{|c|}{ DeSCRIPCIÓN } & \multicolumn{1}{c|}{ MÉTRICA } \\
\hline $\begin{array}{l}\text { Experiencia en: } \\
\text { Entrevistas, Educción, } \\
\text { Requisitos y Profesional. }\end{array}$ & $\begin{array}{l}\text { Experiencia profesional del sujeto } \\
\text { medida en años. }\end{array}$ & $\begin{array}{l}\text { Medida en número de años } \\
\text { trabajando con entrevistas, } \\
\text { educción, requisitos y } \\
\text { profesional. }\end{array}$ \\
\hline $\begin{array}{l}\text { Habilidad en: } \\
\text { Entrevistas y Requisitos }\end{array}$ & $\begin{array}{l}\text { Experiencia (subjetiva) que el sujeto } \\
\text { cree que tiene en Entrevistas y } \\
\text { Requisitos }\end{array}$ & $\begin{array}{l}\text { Medida mediante la escala de } \\
\text { Likert del 1 al 5. }\end{array}$ \\
\hline Familiaridad & $\begin{array}{l}\text { Conocimiento (subjetivo) acerca del } \\
\text { dominio del problema }\end{array}$ & $\begin{array}{l}\text { Medida mediante la escala de } \\
\text { Likert del 1 al 3. }\end{array}$ \\
\hline
\end{tabular}

El objetivo principal de E-2012 consiste en analizar experimentalmente la influencia que tiene el conocimiento acerca del dominio del problema que poseen los analistas en la efectividad del proceso de educción de requisitos. Para poder alcanzar el objetivo propuesto hemos planteado la siguiente hipótesis de investigación en base a su respectiva hipótesis nula $\left(H_{0 . j}\right)$ y alternativa $\left(H_{j . k}\right)$.

- H1. $b_{0}$ : La efectividad de los sujetos es la misma en el problema conocido como en el problema desconocido.

- H1. $b_{1}$ : Los sujetos poseen distintas efectividades en los dominios conocido y desconocido.

Como nuestro estudio es de carácter exploratorio y en la literatura se observan tendencias distintas sobre el efecto del conocimiento, no podemos anticipar la dirección de los efectos potenciales del conocimiento sobre el dominio del problema. Por tanto la hipótesis alternativa es de 2 colas.

\subsubsection{Selección de Sujetos}

Los sujetos que participaron en el experimento fueron estudiantes del Máster en Ingeniería del Software de la Escuela Técnica Superior de Ingenieros Informáticos de la Universidad Politécnica de Madrid, matriculados en la asignatura de Ingeniería de Requisitos. Se utilizó un muestreo por conveniencia para la selección de los sujetos.

Utilizar estudiantes en lugar de profesionales posee la ventaja adicional que el conocimiento del dominio y la experiencia estarán bastante disociados, ya que los estudiantes poseen en general poca experiencia. Por este motivo, los efectos observados en el experimento podrán asignarse con mayor seguridad al factor conocimiento.

\subsubsection{Diseño}

El diseño es otra diferencia fundamental entre E-2012 y los cuasi-experimentos (Q-2007, Q-2009 y Q2011) ejecutados con anterioridad. E-2012 es un experimento controlado compuesto por un factor (el conocimiento que poseen los sujetos sobre el dominio del problema) con dos niveles o tratamientos (dominio conocido y dominio desconocido) bloqueado por entrevistado como se indica en la Tabla 4.7.

Tabla 4.7 - Diseño within-subjects con dos niveles incluyendo el bloqueo

\begin{tabular}{|c|c|c|c|}
\hline \multirow{2}{*}{ GRUPO } & $\begin{array}{l}\text { VARIABLE DE } \\
\text { BLOQUE }\end{array}$ & \multicolumn{2}{|c|}{ SECUENCIA EN EL TIEMPO } \\
\hline & Entrevistado & 10 Sesión & 2o Sesión \\
\hline G1 & OD (Inglés) & \multirow{2}{*}{$\begin{array}{l}\text { Dominio } \\
\text { Conocido }\end{array}$} & \multirow{2}{*}{$\begin{array}{c}\text { Dominio } \\
\text { Desconocido }\end{array}$} \\
\hline G2 & JW (Español) & & \\
\hline
\end{tabular}

El diseño mostrado en la Tabla 4.7 corresponde a un diseño pareado con dos objetos experimentales (Juristo \& Moreno, 2001), lo que Cook y Campbell (1979) denominan genéricamente un diseño pre-post. Este tipo de diseño exige que los dominios de problema se estudien en un orden determinado (en nuestro caso, primero el dominio conocido, después el dominio desconocido, por lo que se confunde dominio y orden de realización de las sesiones de educción (de aquí en adelante orden 
de realización). Un diseño cross-over (Kuehl, 2000) permitiría eliminar esta amenaza a la validez, aunque a costa de introducir el peligro de que la información acerca de los dominios se filtre entre sesiones. En un entorno académico, este riesgo es muy alto, lo que desaconseja el diseño cross-over. No obstante, un diseño muy parecido al cross-over puede obtenerse mediante una replicación interna de E-2012, que es la opción que hemos elegido. La sección 5.5 discute la replicación interna (código E-2012 B) que hemos realizado invirtiendo el orden de los tratamientos.

\subsubsection{Estimación del Tamaño Muestral}

Para hacernos una idea del tamaño muestral mínimo necesario para la ejecución de un experimento cuyo diseño es within-subjects, hemos utilizado la herramienta G*Power 3.1 con los parámetros indicados en la Figura 4.4. Siguiendo los pasos recomendados en la sección 4.2, para la determinación del tamaño muestral, hemos establecido el poder estadístico al $80 \%$, con un nivel de significación del 5\% en la detección de efectos medios (Cohen's $f>=0.25, d>=0.5$ ). Nótese que el número de grupo es igual a 2 (corresponde a los niveles del factor between, en nuestro caso el entrevistado (OD, JW) y, el número de medidas es igual a 2 (corresponde a los niveles del factor within, en nuestro caso el conocimiento: dominio conocido y desconocido). El test estadístico seleccionado corresponde a " $\mathrm{F}$ tests - ANOVA: Repeated measures, within-factors".

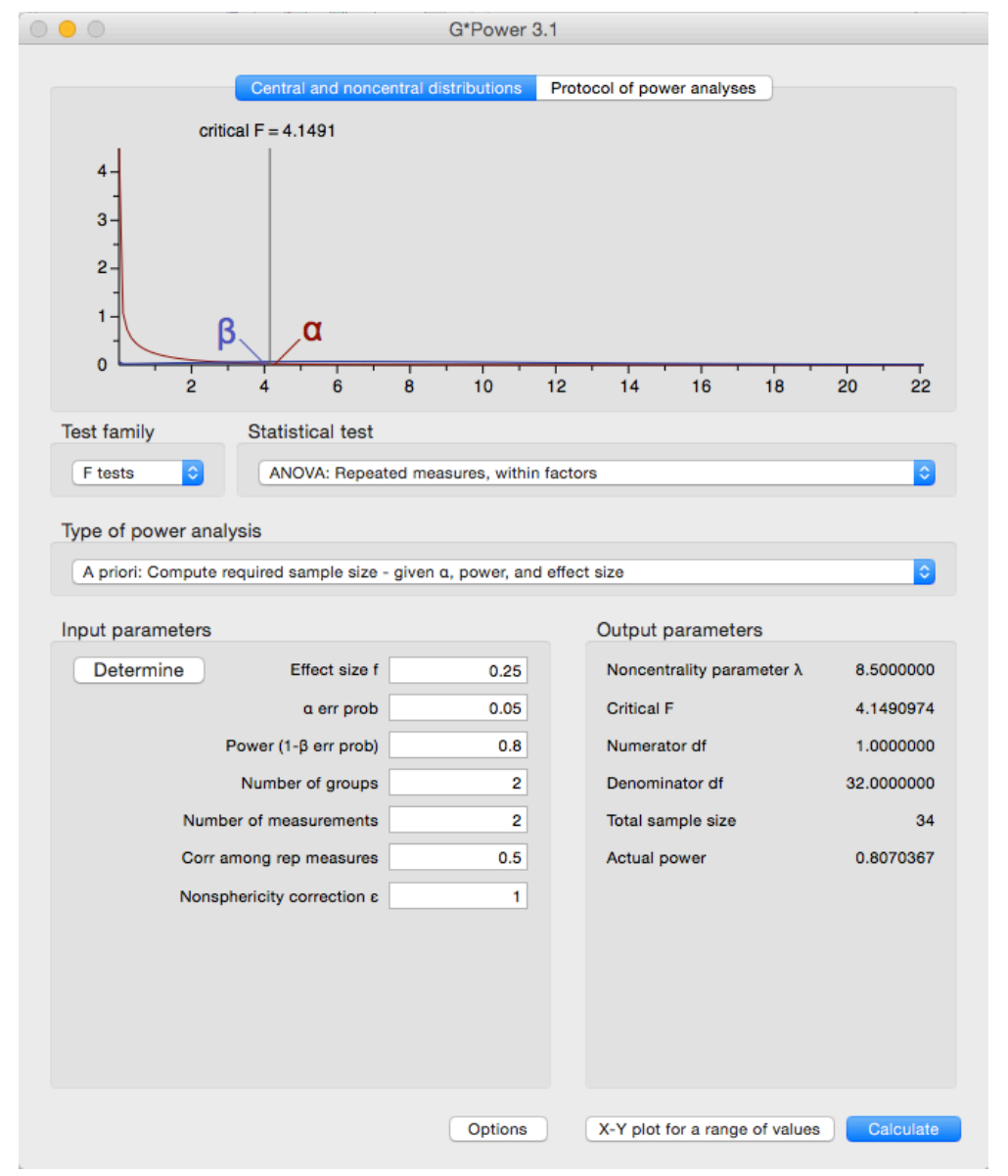

Figura 4.4 - Estimación del tamaño muestral para diseños within-subjects

Como se puede apreciar en la Figura 4.4, el tamaño mínimo estimado para la ejecución de un experimento de diseño de medidas repetidas, con un factor within-subjects requiere al menos unos 34 sujetos experimentales. Dado que es muy poco probable que consigamos 34 sujetos en el curso de Ingeniería de Requisitos, necesitaremos replicar E-2012 para alcanzar el tamaño muestral requerido. Esta es otra buena razón para ejecutar la replicación interna E-2012 B indicado anteriormente. 


\subsubsection{Evaluación de la Validez}

El diseño experimental de within-subjects corresponde a un experimento controlado expuesto a algunas amenazas de la validez: efectos de cansancio, efectos de aprendizaje y efectos de arrastre o carry-over. Creemos que hemos logrado mitigar estas amenazas en nuestro experimento con las siguientes estrategias:

- Efectos de cansancio: el hecho de que cada sujeto deba analizar los dos problemas provoca que sean necesarias dos sesiones para realizar el experimento. Si estas sesiones se realizan muy próximas en el tiempo, es posible que los sujetos experimenten un efecto de cansancio que disminuya su efectividad a medida que transcurren las sesiones experimentales. Sin embargo, las sesiones del experimento distan varios días, por lo que a la $2^{\circ}$ sesión que se produce en condiciones semejantes a la primera.

- Efectos de aprendizaje: el efecto aprendizaje tiene su origen en la realización de la misma tarea experimental por el mismo sujeto experimental en repetidas ocasiones. En este experimento, cada sujeto analizará dos dominios completamente distintos, por lo que la reutilización de información del problema conocido (PC1) al problema desconocido (PD1) es improbable. Por otra parte, la educción se realiza mediante entrevista abierta, por lo que una mejora sustancial de las habilidades del sujeto tras sólo 30 min de conversación (la educción es incluso más corta) parece poco probable a priori. No obstante, el efecto de aprendizaje puede ser identificado mediante la síntesis del experimento y la replicación interna, por lo que su influencia puede ser verificada.

- Efectos de carry over: el efecto residual que un tratamiento aplicado sobre un sujeto puede tener sobre otro tratamiento administrado posteriormente al mismo sujeto se conoce como carry-over (Brown, 1980). El carry over puede tener efectos positivos o negativos sobre el tratamiento aplicado en segundo lugar, mejorando o empeorando artificialmente su efecto real. El carry-over es un riesgo importante en experimentos médicos, ya que los residuos de medicamentos pueden permanecer en el cuerpo durante bastante tiempo e interactuar con los tratamientos posteriores (Senn, 2002). Sin embargo, en este experimento los sujetos experimentales utilizan siempre la misma técnica (entrevista abierta), por lo que no pueden existir efectos residuales sino, en todo caso, efectos de aprendizaje ya discutidos anteriormente.

Además de las amenazas a la validez introducidas por el tipo de experimento empleado (withinsubjects), existen otras amenazas a la validez de carácter más sutil inducidas por las decisiones de diseño:

- Exclusión de los requisitos no funcionales: no considerar los requisitos no funcionales en la investigación puede penalizar la efectividad de los sujetos que tienden a focalizarse en dichos aspectos. Para minimizar esta amenaza, los entrevistados desviaron intencionalmente la conversación cuando los sujetos preguntaban acerca de este tipo de requisitos. La forma de desviar la conversación fue responder de forma absolutamente certera, indicando adicionalmente que el aspecto no funcional correspondiente no era relevante.

- Aspectos referidos a la gestión: al igual que ocurre con los requisitos no funcionales, los sujetos que pusieron especial énfasis en los aspectos de gestión (por ejemplo, plazos, costes) podrían ver penalizada su efectividad. Para minimizar esta amenaza, se ha aplicado la misma estrategia que con los requisitos no funcionales.

\subsubsection{Asignación de Sujetos a Tratamientos}

Como se puede apreciar en la Tabla 4.7 presentada en la sección 4.6 .3 hemos dividido los sujetos experimentales en dos grupos $(\mathrm{G} 1, \mathrm{G} 2)$ según el idioma de los sujetos. Los estudiantes de lengua inglesa (ninguno de ellos es nativo en inglés, en todos los casos, se trata de estudiantes internacionales, sin 
conocimiento de español) han sido asignados a G1, mientras que los estudiantes de lengua española a G2. Con ello se evita que el idioma sea un factor influyente en la efectividad del proceso de educción tanto para los entrevistadores como para los entrevistados. Los estudiantes de lengua inglesa fueron asignados a OD, mientras que los estudiantes de lengua española a JW. Los entrevistados manejan adecuadamente los respectivos idiomas.

\subsubsection{Objetos Experimentales}

La Tabla 4.8 muestra los problemas utilizados en E-2012. Una descripción detallada de los mismos puede encontrarse en el Anexo B. A continuación damos una breve descripción de cada uno con sus principales características:

- Sistema de la Mensajería (PC1): consiste en un sistema de mensajería instantánea donde los usuarios de una operadora de telecomunicación específica podrán realizar operaciones básicas como: intercambio mensajes de texto plano, interconexión entre usuarios, consultas históricos de mensajes, entre otros.

- Sistema de control de reciclado de pilas (PD1): consiste en un sistema de control automático y en tiempo real del proceso de reciclado de pilas, desde la separación de las pilas hasta el destilado y obtención de los metales.

Tabla 4.8 - Dominios del problema utilizados en el experimento E-2012

\begin{tabular}{|c|l|c|c|}
\hline Problema & \multicolumn{1}{|c|}{ BreVe DescriPCIÓn } & Niveles & ExPerimento \\
\hline PC1 & $\begin{array}{l}\text { Consiste en un sistema de } \\
\text { intercambio de mensajes } \\
\text { de textos. }\end{array}$ & $\begin{array}{c}\text { Dominio } \\
\text { Conocido }\end{array}$ & \multirow{2}{*}{$\begin{array}{c}\text { Experimento } \\
\text { Base } \\
\text { E-2012 A }\end{array}$} \\
\hline PD1 & $\begin{array}{l}\text { Consiste en un sistema de } \\
\text { control de máquinas de } \\
\text { reciclado de pilas. }\end{array}$ & $\begin{array}{c}\text { Dominio } \\
\text { Desconocido }\end{array}$ & \\
\hline
\end{tabular}

Nótese que el problema conocido PC1 es la instanciación para este experimento del tratamiento Dominio Conocido (DC), dado que los dispositivos móviles y la mensajería instantánea son utilizados con frecuencia por los estudiantes y, en general, por un amplio sector de la población. Por el contrario, el problema desconocidos (PD1) fue especialmente seleccionado como instancia del tratamiento Dominio Desconocido (DD) con el fin de que sea un sistema poco común e inusual para los estudiantes.

\subsubsection{Tarea Experimental}

La tarea experimental es la misma que en los cuasi-experimentos anteriores. La sesión de educción se llevó a cabo mediante la entrevista abierta en un tiempo máximo de 30 minutos, con un margen de 5 a 10 minutos a más, para que el sujeto pudiera terminar su entrevista con normalidad. Finalizada la sesión de educción, por un tiempo aproximado 90 minutos, los sujetos experimentales reportaron por escrito toda la información que han adquirido durante la entrevista. La forma más habitual de reportar requisitos es mediante templates.

En anteriores cuasi-experimentos, los sujetos experimentales han usado el template IEEE 830 para reportar los resultados de la sesión de educción, así como formatos libres. La experiencia nos indica que los sujetos prefieren usar formatos libres cuando los estudios empíricos preceden a la formación, y el template cuando el estudio empírico sigue a la formación ${ }^{20}$. Por este motivo, hemos optado por permitir que los sujetos usen su formato de reporte preferido, en lugar de exigir un determinado template que podría producir algún tipo de sesgo. No obstante, un formato libre no significa que los sujetos hayan

${ }^{20}$ Por ejemplo, en el primer experimento (E-2012 A), sólo 10 de 28 sujetos usaron un template; en la replicación (E2012 B) el template fue usado por 16 de 25 sujetos. 
expresado la información del dominio de forma narrativa. Al contrario, la forma más habitual de reporte ha sido una lista de ítems, en muchos casos dividida en apartados (por ejemplo.: requisitos funcionales, requisitos no-funcionales, etc.).

El experimento culminó con el cuestionario post-experimental, que los sujetos rellenaron en aproximadamente 5 minutos.

\subsubsection{Instrumentación}

Al igual que los experimentos anteriores, corresponde con la formación y preparación de los experimentadores para el rol de entrevistado, así como a la implantación del cuestionario post experimental. Las actividades realizadas son similares a las expuestas para Q-2007.

\subsubsection{Protocolo y Procedimiento de Recolección de Datos}

El protocolo experimental se muestra en la Figura 4.5. La semana anterior a la ejecución del experimento, los estudiantes fueron notificados por e-mail acerca de: el día, la hora, el lugar y las instrucciones necesarias para realizar el experimento. El experimento se ha planteado como una práctica evaluable de la asignatura, para no dar lugar a amenazas a la validez relacionadas con la reactividad $^{21}$ a la situación experimental (Cook \& Campbell, 1979).

El sujeto experimental en función del día, hora, grupo y entrevistado asignado acudió al Despacho 1 - Despacho 2 para iniciar con las sesiones de educción (entrevistas) durante el tiempo establecido para ello. Finalizada la sesión de educción, el sujeto experimental se trasladó al aula de clase (Aula 1) bajo la vigilancia de un investigador, quien les entregó un formulario en el que el sujeto informó el inicio y fin del reporte, y estuvo dispuesto a aclarar cualquier duda sobre el ejercicio que pudieran tener los alumnos. Finalizado el proceso de reportar la información adquirida en la sesión de educción, el estudiante entregó al vigilante el reporte por escrito o en formato digital. Al terminar la segunda sesión del experimento (Día 4) los sujetos respondieron el cuestionario post-experimental.

\begin{tabular}{|c|c|c|c|c|c|c|}
\hline \multicolumn{3}{|c|}{ Día 1} & \multirow{3}{*}{$\begin{array}{l}\text { DíA } 2 \text { y } \\
\text { DíA } 3\end{array}$} & \multicolumn{3}{|c|}{ Día 4} \\
\hline Despacho 1 & Despacho 2 & Aula 1 & & Despacho 1 & Despacho 2 & Aula 1 \\
\hline $\begin{array}{c}\text { Entrevistado } \\
\text { OD / G1 }\end{array}$ & $\begin{array}{c}\text { Entrevistado } \\
\text { JW / G2 }\end{array}$ & Vigilante & & $\begin{array}{c}\text { Entrevistado } \\
\text { OD / G1 }\end{array}$ & $\begin{array}{c}\text { Entrevistado } \\
\text { JW / G2 }\end{array}$ & Vigilante \\
\hline \multicolumn{2}{|c|}{$\begin{array}{c}\text { Sesión de educción sobre el } \\
\text { Dominio Conocido }\end{array}$} & Reporte & Descanso & \multicolumn{2}{|c|}{$\begin{array}{c}\text { Sesión de educción sobre el } \\
\text { Dominio Desconocido }\end{array}$} & $\begin{array}{c}\text { Reporte + } \\
\text { Cuestionario Post- } \\
\text { experimental }\end{array}$ \\
\hline
\end{tabular}

Figura 4.5 - Plan del experimento

Según el diseño experimental mostrado en la Figura 4.5, los sujetos realizaron el proceso de educción de requisitos en dos días distintos, no contiguos, para evitar efectos de cansancio. En el primer día (Día 1), la educción de requisitos fue sobre el dominio conocido para el sujeto, mientras que el cuarto día (Día 4) trató sobre el dominio desconocido. Durante los días 2 y 3 , los sujetos no realizaron ninguna actividad relacionada con el experimento, para evitar efectos de cansancio o aburrimiento. Los sujetos experimentales realizaron la actividad de educción de requisitos completo (es decir, las sesiones de educción e, inmediatamente a continuación, el proceso de consolidación.

${ }^{21}$ Reactividad a la situación experimental significa que los sujetos son conscientes de que están realizando un experimento y cambian su comportamiento (por ejemplo, pueden demostrar su rechazo disminuyendo sus esfuerzos en la realización de la tarea experimental. Cuando los sujetos no saben que realizan un experimento, se comportan de forma más natural. 


\subsubsection{Procedimiento de Medición}

Para cada uno de los dominios, la efectividad del proceso de educción de requisitos, concretamente la efectividad en la consolidación, se midió como el número total de elementos definitorios del dominio identificados por los sujetos experimentales, sobre el total de elementos. Mayores detalles relacionados al procedimiento de medición se describen en la sección 4.2.10.

\subsubsection{Análisis de Datos}

El Modelo Lineal General de medidas repetidas (GLM) (también conocido como ANOVA de medidas repetidas) es el método estadístico más apropiado para analizar los datos de este experimento. Si no existiera la variable de bloque, se podrían utilizar diferentes test estadísticos dependiendo de la normalidad de los datos, tales como: paired-sample t-test (datos normales) o Wilcoxon matched-pairs test (datos no normales). Para usar GLM con garantía es necesario que se verifiquen tres condiciones: esfericidad, homocedasticidad y normalidad de residuos.

- Esfericidad. Las covarianzas entre cada par de tratamientos sean iguales. El test de Mauchly es habitualmente utilizado para comprobar la condición de esfericidad. En nuestro caso, sin embargo, hay sólo dos niveles de medidas repetidas que se oponen a la violación de esfericidad y por lo tanto, esta prueba es innecesaria (Meyers, Gamst, \& Guarino, 2012).

- Homocedasticidad. Las varianzas poblacionales de los diversos grupos de la variable dependiente deben ser homogéneas. Para comprobar la homogeneidad de varianzas se podría utilizar el test de Levene, sin embargo, en nuestro caso como el factor bajo estudio es intrasujetos y no inter-sujetos, este test es innecesario.

- Normalidad de residuos. Los procedimientos de aleatorización y bloqueo deben haber eliminado la influencia de toda fuente de variación en los tratamientos. Ello implica que la distribución de los residuos debe tener media cero y varianza arbitraria pero constante, siguiendo una distribución normal. La normalidad de los residuos puede comprobarse mediante un gráfico Q-Q y el test de Kolmogorov-Smirnov y Shapiro-wilks.

Nótese que el experimento E-2012 desde el punto metodológico puede considerarse como dos cuasi-experimentos:

- Uno de dichos cuasi-experimentos, que utiliza PD1 es similar a Q-2007 (con las diferencias del contexto mencionadas en la sección 4.10).

- El otro cuasi-experimento, que utiliza PC1, es también similar a Q-2007 con la diferencia de que el objeto experimental (dominio del problema) es conocido para los sujetos.

Dado que E-2012 es un experimento mayor que engloba a dos cuasi-experimentos, las variables independientes indicadas en la sección 4.6.1 serán analizadas cuasi-experimentalmente, mediante un modelo de regresión con dos variables: la variable independiente bajo estudio y la variable de bloque. Nótese que no hemos realizado el análisis cuasi-experimental mediante correlaciones de Pearson, dado que esta técnica no permite separar los efectos de la experiencia y del entrevistado. Lamentablemente, el modelo de regresión no proporciona un coeficiente de correlación, sino un valor B o beta. Para obtener coeficientes de correlación comparables a los obtenidos en los estudios Q-2007 a Q-2012, emplearemos una transformación basada en el valor de la t proporcionado por el modelo y los grados de libertad correspondientes. Esta transformación la haremos aplicando la fórmula recomendada por Becker ${ }^{22}: r_{Y \lambda}= \pm$ raíz $\left(t^{2} /\left(t^{2}+d f\right)\right)$

\footnotetext{
${ }^{22}$ http://www.uccs.edu/ Ibecker/
} 
Finalmente, para comprobar las tendencias observadas en los análisis, calcularemos estadísticos descriptivos, gráficos de box y de perfil. La significación estadística de los resultados la definiremos a un nivel $\alpha=0.05$. La herramienta estadística empleada para el análisis de los resultados será SPSS V. 21.

\subsection{Experimento E-2012 B}

El experimento E-2012 B es una replicación interna del experimento base (E-2012 A), realizada con el propósito de aumentar el tamaño muestral, así como identificar posibles efectos de la formación. La diferencia fundamental entre E-2012A y E-2012B reside en los objetos experimentales utilizados. Dichos problemas se muestran en la Tabla 4.9 y se describen brevemente a continuación. Mayores detalles sobre los mismos, pueden encontrarse en el Anexo B.

- Sistema de compra y venta de acciones (PD2): consiste en un sistema de compra y venta de acciones en bolsa para aplicaciones móviles. El usuario podrá comprar, vender y consultar su cartera de acciones, así como recibir notificaciones según las operaciones realizadas.

- Sistema de control de matrículas universitarias (PC2): consiste en un sistema de gestión de matrículas universitarias a través de un terminal autoservicio, permitiendo mediante un lector de tarjetas, reconocer el carnet universitario del alumno y de estar forma acceder al sistema. El alumno podrá realizar el proceso de matriculación, de abonar la matrícula, de consultar de expedientes académicos, etc.

Tabla 4.9 - Dominios del problema utilizados en el experimento E-2012B

\begin{tabular}{|c|c|c|c|}
\hline Problema & BREVE DESCRIPCIÓN & Niveles & EXPERIMENTO \\
\hline PD2 & $\begin{array}{l}\text { Sistema de compra y } \\
\text { venta de acciones. }\end{array}$ & $\begin{array}{c}\text { Dominio } \\
\text { Desconocido }\end{array}$ & \multirow{2}{*}{$\begin{array}{l}\text { Replicación } \\
\text { interna } \\
\text { E-2012 B }\end{array}$} \\
\hline PC2 & $\begin{array}{l}\text { Sistema de gestión de } \\
\text { matrículas de un punto de } \\
\text { información universitaria }\end{array}$ & $\begin{array}{l}\text { Dominio } \\
\text { Conocido }\end{array}$ & \\
\hline
\end{tabular}

Al igual que en E-2012 A, el problema conocido PC2 corresponde a una instanciación del tratamiento Dominio Conocido (DC); mientras que, por el contrario, el problema desconocidos (PD2) del tratamiento Dominio Desconocido (DD), por los motivos ya indicados anteriormente.

Un aspecto importante, que merece la pena destacar, es que a la hora de definir los distintos problemas de E-2012 B se ha intentado que los mismos sean lo más parecidos posibles a los de E-2012 $A$, en términos del número total de elementos. De esta manera se evita que el tamaño del problema sea otro aspecto que pudiera influir en los resultados, porque de lo contrario tendríamos una iteración indeseada en lo que respecta al Conocimiento x Tamaño. La Tabla 4.10 presenta el número total de elementos que definen y delimitan el tamaño de cada uno de los dominios del problema.

Nótese que replicación de E-2012 B, se diferencia respecto a E-2012 A, en el momento en el que se ejecutó la replicación. E-2012 B se realiza después de que los sujetos (estudiantes) hayan recibido formación en requisitos. El análisis conjunto de E-2012 (código: E-2012 A y E-2012 B) es precisamente lo que permite identificar el efecto de formación.

Tabla 4.10 - Número total de elementos que definen los problemas

\begin{tabular}{|c|c|c|c|c|c|}
\hline \multirow{2}{*}{ Experimentos } & \multirow{2}{*}{ Problema } & \multicolumn{4}{|c|}{ Elementos Que definen el Problema (\#) } \\
\cline { 3 - 6 } & & Requisitos & ConCePtos & Procesos & Total \\
\hline $\begin{array}{c}\text { Experimento } \\
\text { E-2012 A }\end{array}$ & PC1 & 28 & 10 & 16 & 54 \\
\cline { 2 - 6 } & PD1 & 15 & 24 & 12 & 51 \\
\hline $\begin{array}{c}\text { Replicación } \\
\text { E-2012 B }\end{array}$ & PD2 & 24 & 12 & 14 & 50 \\
\cline { 2 - 6 } & PC2 & 17 & 20 & 17 & 54 \\
\hline
\end{tabular}




\subsection{Experimento E-2013}

El cambio fundamental del experimento E-2013 frente al experimento E-2012 hace referencia al diseño experimental. Los efectos observados en el experimento anterior (E-2012) y a lo largo de la serie histórica, respecto a la influencia del conocimiento en la efectividad de los analistas siguen siendo o muy bajos o negativos. Este hecho llevó a los experimentadores a replantearse nuevamente el diseño. Dichos resultados aparentemente anómalos, podrían estar motivados por el tipo de diseño, dado que como se ha mencionado en la sección 4.6.3, el diseño de within-subjects tiene inconvenientes relacionados con las características intrínsecas del propio diseño.

Entre tales inconvenientes destacamos el siguiente que motivó a los investigadores al cambio: el efecto de aprendizaje. Uno de los problemas asociados a los diseños de medidas repetidas (withinsubjects) se deriva de la secuencia con la que se aplican los tratamientos (repetición de la tarea experimental sobre los cuatro dominios de problemas) y que podría dar lugar a un sesgo derivado del orden en el que se administran los tratamientos a los sujetos. Por ejemplo, el efecto aprendizaje (efecto positivo, que tiene su origen en la realización de la misma tarea experimental) podría hacer que los sujetos sean más efectivos de lo que realmente lo habrían sido en otro caso en el problema desconocido (aplicado en segundo lugar).

Por tanto, en E-2013 aplicaremos diseño entre sujetos (between-subjects) denominado también diseño de medidas independientes ya que cada sujeto sólo se somete a un tratamiento. Este tipo de diseño elimina las posibilidades de que los sujetos se cansen a lo largo de la aplicación de los tratamientos o que, por otro lado, logren mejores resultados por la práctica o aprendizaje, sesgando los resultados.

El diseño equivalente between-subjects, requiere 128 sujetos para alcanzar un poder similar. La Figura 4.6 presenta los valores utilizados para el cálculo del tamaño muestral. El test estadístico seleccionado corresponde a " $t$ tests - Means: Difference between two independent means (two groups)". Es imposible en un entorno académico para un único experimento contar con 128 sujetos. Se requiere seguir realizando replicaciones hasta alcanzar el valor estimado.

Al igual que E-2012, el experimento E-2013 se considera como un experimento y un cuasiexperimento. El análisis de los datos cuasi-experimentales lo haremos mediante un modelo de regresión con su respectiva transformación. Para el análisis experimental del conocimiento emplearemos un modelo lineal univariante (ANOVA) donde el factor conocimiento es considerado un factor fijo y el entrevistado como covariable.

Para utilizar el ANOVA de forma satisfactoria deben cumplirse tres condiciones, aunque se aceptan ligeras desviaciones de las condiciones ideales: 1) cada conjunto de datos debe ser independiente del resto; 2) las varianzas de cada conjunto de datos no deben diferir de forma significativa (homocedasticidad); 3) los resultados obtenidos para cada conjunto deben seguir una distribución normal (normalidad de residuos). 


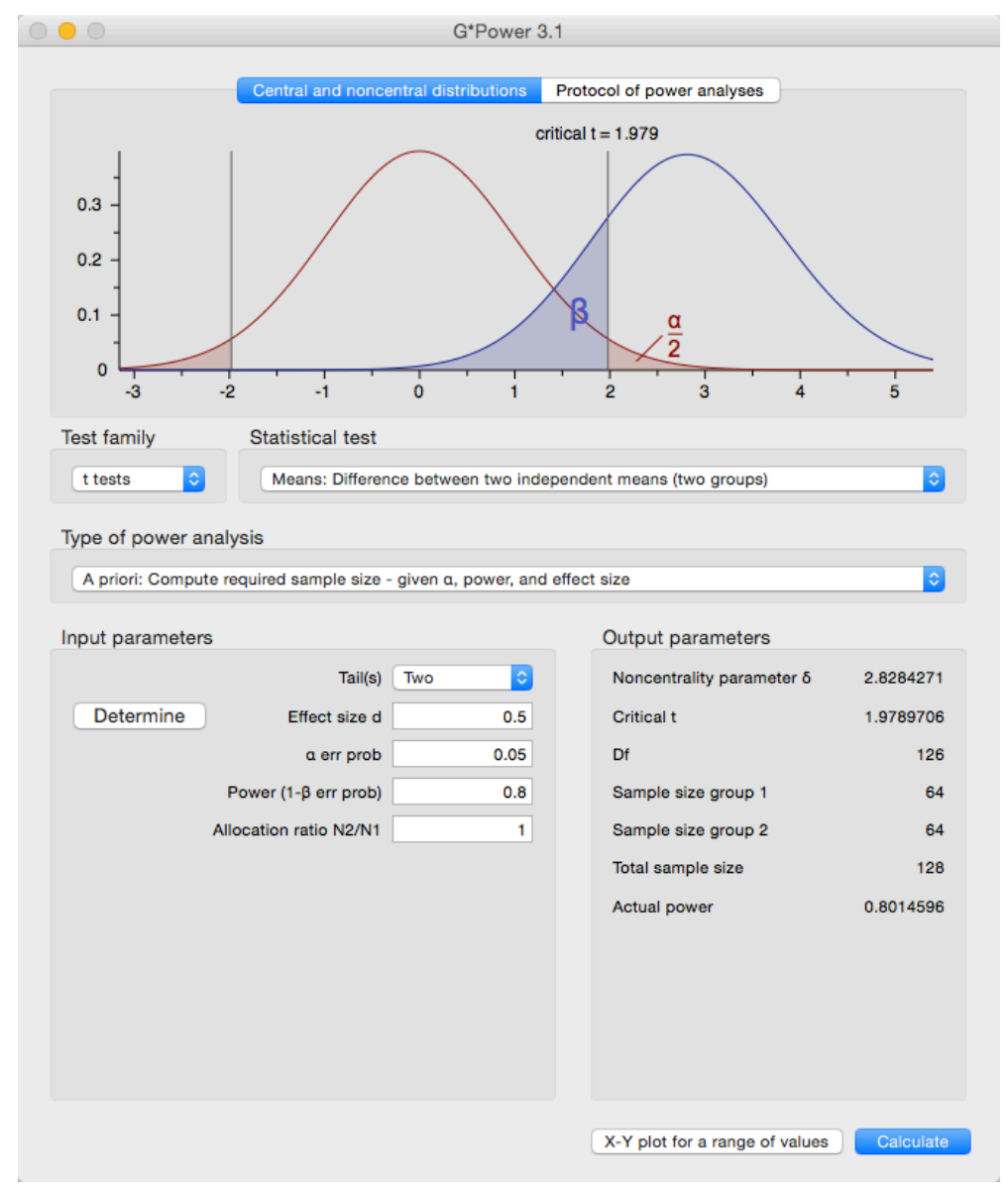

Figura 4.6 - Estimación del tamaño muestral para diseños between-subjects

\subsection{Experimento E-2014}

Con la finalidad de obtener más puntos de datos (tanto para el problema conocido PC1, como el problema desconocido PD1) los investigadores han replicado internamente el experimento E-2013. E2014 se diferencia de E-2013 fundamentalmente en el número de entrevistados, quedando reducido a uno sólo. Este cambio fue debido a la indisponibilidad de unos de los entrevistados, que ha participado en los experimentos anteriores, debido a causas de fuerza mayor.

Al igual que E-2012 y E-2013, E-2014 se considera como un experimento y un cuasi-experimento. Dado que se cuenta con un único entrevistado, para el análisis cuasi-experimental en lugar del modelo de regresión se ha empleado: el t-test para estudiar la familiaridad y el análisis de correlación de Pearson y Tau_b de Kendall para la experiencia y la habilidad respectivamente; mientras que el análisis experimental del conocimiento se ha realizado empleando la prueba t para muestras independientes en lugar del ANOVA.

\subsection{Experimento E-2015}

E-2015 corresponde a una réplica interna casi exacta de E-2013. Esto es, el experimento se ha realizado en la misma universidad con el mismo tipo de alumnos; con el mismo diseño experimental (betweensubjects), empleando los mismos objetos experimentales (PC1, PD1) y los mismos entrevistados (OD, JW). Con la única diferencia de que el warming up de una semana pasó a dos semanas. 


\subsection{Resumen - Familia de Experimentos}

A lo largo de la investigación hemos realizado ocho estudios empíricos (entre cuasi-experimentos y experimentos controlados) los cuales se resumen en la Tabla 4.11. La Tabla 4.11 presenta la serie de estudios realizados, con sus correspondientes: diseño, tipo de replicación, lugar de ejecución, sujetos y unidades experimentales.

Tal y como se puede apreciar en la Tabla 4.11 hemos totalizado en conjunto 110 sujetos experimentales, que se corresponden con 152 unidades experimentales. Es un número bastante elevado en comparación con los experimentos existentes en la literatura de Ingeniería de Requisitos. Q-2007 es el cuasi-experimento que dio inicio a la investigación, del cual parten 7 replicaciones que se diferencian fundamentalmente en el lugar de ejecución y en aspectos de contexto derivados por restricciones del contexto (setting), y limitaciones de tiempo y recursos, presentadas en la Tabla 4.12.

Tabla 4.11 - Familia de estudios empíricos acerca de educción de requisitos

\begin{tabular}{|c|c|c|c|c|c|c|c|c|}
\hline & \multicolumn{2}{|c|}{ EXPERIMENTO } & $\begin{array}{c}\text { TIPO } \\
\text { EXPERIMENTO }\end{array}$ & $\begin{array}{c}\text { TIPO } \\
\text { REPLIACIÓN }\end{array}$ & LUGAR & $\begin{array}{l}\text { Sujetos } \\
\text { (N) }\end{array}$ & ENTREVISTADO & $\begin{array}{l}\text { UNIDADES } \\
\text { EXPERIMENT } \\
\text { ALES }\end{array}$ \\
\hline 1 & \multicolumn{2}{|c|}{ Q-2007 } & $\begin{array}{l}\text { Cuasi- } \\
\text { Experimento } \\
\text { Base }\end{array}$ & $\begin{array}{l}\text { Experimento } \\
\text { Base }\end{array}$ & UPM & 7 & OD & 7 \\
\hline 2 & \multicolumn{2}{|c|}{ Q-2009 } & $\begin{array}{l}\text { Cuasi- } \\
\text { Experimento }\end{array}$ & $\begin{array}{l}\text { Replicación } \\
\text { Interna } \\
\text { Q-2007 }\end{array}$ & UPM & 8 & $A G$ & 8 \\
\hline 3 & \multicolumn{2}{|c|}{ Q-2011 } & $\begin{array}{l}\text { Cuasi- } \\
\text { Experimento }\end{array}$ & $\begin{array}{l}\text { Replicación } \\
\text { Interna } \\
\text { Q-2009 }\end{array}$ & UPM & 16 & OD & 16 \\
\hline 4 & \multicolumn{2}{|c|}{ Q-2012 } & $\begin{array}{l}\text { Cuasi- } \\
\text { Experimento }\end{array}$ & $\begin{array}{l}\text { Replicación } \\
\text { Externa } \\
\text { Q-2011 }\end{array}$ & RefsQ & 21 & OD & 21 \\
\hline \multirow[t]{2}{*}{5} & \multirow[t]{2}{*}{ E-2012 } & $\begin{array}{c}E-2012 \\
A\end{array}$ & $\begin{array}{l}\text { Experimeto } \\
\text { (within- } \\
\text { subjects) }\end{array}$ & $\begin{array}{l}\text { Experimento } \\
\text { Base }\end{array}$ & UPM & \multirow{2}{*}{14} & $\begin{array}{l}\text { OD } \\
\text { JW }\end{array}$ & 28 \\
\hline & & $\begin{array}{c}\mathrm{E}-2012 \\
\mathrm{~B}\end{array}$ & $\begin{array}{l}\text { Experimeto } \\
\text { (within- } \\
\text { subjects) }\end{array}$ & $\begin{array}{l}\text { Replicación } \\
\text { Interna } \\
\text { E-2012 A }\end{array}$ & UPM & & $\begin{array}{l}\text { OD } \\
\text { JW }\end{array}$ & 26 \\
\hline 6 & \multicolumn{2}{|c|}{ E-2013 } & $\begin{array}{l}\text { Experimento } \\
\text { (between- } \\
\text { subjects) }\end{array}$ & $\begin{array}{l}\text { Experimento } \\
\text { Base }\end{array}$ & UPM & 15 & $\begin{array}{l}\text { OD } \\
\text { JW }\end{array}$ & 15 \\
\hline 7 & \multicolumn{2}{|c|}{ E-2014 } & $\begin{array}{l}\text { Experimento } \\
\text { (between- } \\
\text { subjects) }\end{array}$ & $\begin{array}{l}\text { Replicación } \\
\text { Interna } \\
\text { E-2013 } \\
\end{array}$ & UPM & 16 & OD & 16 \\
\hline 8 & \multicolumn{2}{|c|}{ E-2015 } & $\begin{array}{l}\text { Experimento } \\
\text { (between- } \\
\text { subjects) }\end{array}$ & $\begin{array}{l}\text { Replicación } \\
\text { Interna } \\
\text { exacta } \\
\text { E-2013 }\end{array}$ & UPM & 13 & $\begin{array}{l}\text { OD } \\
\text { JW }\end{array}$ & 13 \\
\hline \multicolumn{3}{|c|}{ TOTAL } & $\begin{array}{l}8 \text { estudios } \\
\text { empíricos }\end{array}$ & $\begin{array}{l}8 \text { Estudios } \\
\text { Empíricos }\end{array}$ & $\begin{array}{l}\text { UPM } \\
\text { REFSQ }\end{array}$ & $\begin{array}{c}\text { NTotal }= \\
110\end{array}$ & $\begin{array}{c}3(O D, J W \\
A G)\end{array}$ & 150 \\
\hline
\end{tabular}

La mayoría de los estudios se ejecutaron en un entorno académico con estudiantes de post-grado de la UPM, con excepción de Q-2012, que es una replicación externa con sujetos con mayores rangos de experiencias (entre estudiantes de doctorado, post-doctorado, investigadores y profesionales de la industria), quienes proporcionaron mayor diversidad variabilidad de experiencia al conjunto de datos obtenidos en la serie histórica. En lo que respecta a los entrevistados han participado tres (3), de los cuales dos (JW, AG) no tenía conexión con la investigación. 


\subsubsection{Diferencias contextuales entre estudios empíricos}

La Tabla 4.12 presenta un resumen de las diferencias contextuales existentes entre los experimentos. Las celdas resaltadas en un tono azul claro representan dichas diferencias. Por ejemplo, Q-2009 se diferencia de Q-2007, en el idioma en el que se llevaron a cabo las entrevistas y en el entrevistado. Mayores detalles sobre el origen y el porqué de dichas diferencias véase el capítulo 5 . Cada una de las variables contextuales indicadas se resume brevemente a continuación:

- Tipo de Entrevista: se refiere al modo en que los analistas realizaron la educción de requisitos: mediante entrevista abierta individual (1:1) o entrevista en grupo (entrevista 1: N) donde varios analistas entrevistan a un cliente al mismo tiempo.

- Entrevistado: persona que ejerce el rol de cliente durante el proceso de educción de los requisitos. El cliente conocedor del dominio del problema es quien proporciona al analista la información necesaria para la obtención de los requisitos del futuro sistema software.

- Formación: la secuencia de estudios se ejecutó en dos momentos principales: Antes de que los sujetos recibieran formación específica ${ }^{23}$ y por tanto, los sujetos realizan la educción con base a su experiencia y conocimientos previos; Después de que los sujetos recibieran formación: los sujetos realizan la educción de requisitos al final del curso académico, como evaluación final del mismo, durante el cual recibieron formación específica en requisitos y tareas relacionadas con la educción de los mismos.

- Warming Up: hace referencia a una formación breve en actividades relacionadas con requisitos (definiciones, conceptos, técnicas de educción, etc.) con la finalidad de que los estudiantes pudieran conocer o recordar aspectos fundamentales de requisitos, ya que para muchos era la primera vez que realizaban entrevistas, o no tenían claro lo que se esperaba del ejercicio propuesto. Dichos aspectos podrían ejercer influencia en la efectividad de los sujetos. El Warming Up podría formar parte de la formación, pero con la finalidad de estudiar su efecto, lo hemos considerado como dos variables distintas. Nótese que aquellos experimentos sin warming up (Q-2012, E-2012) se ejecutaron: el primer día de clases para el caso de los estudiantes (E-2012) planteado como una actividad introductoria a la asignatura de requisitos; mientras que para los profesionales (Q-2012) no fue necesario un warming up, por la experiencia que poseen los sujetos en sus actividades diarias. Con la finalidad de explorar un posible efecto de warming up, en los últimos experimentos de la serie histórica (E-2013, E-2014 y E-2015), el warming up se amplió a 1, 6 y 2 semanas.

La diferencia con la variable formación indicada anteriormente reside en que esta última es esencialmente una variable binaria (con los valores antes y después). El warming up, por el contrario, hace referencia a la duración de la formación breve, en nuestro caso oscila de 0 a 6 semanas.

- Idioma: se refiere al idioma en el que se llevaron a cabo las entrevistas. El idioma está bloqueado con el entrevistado. Esto implica que cualquier aumento o disminución de la efectividad de los sujetos no podría ser adscrita al entrevistado o al idioma. Esta limitación del diseño se discute en la sección de amenazas a la validez.

- Dominio del Problema: corresponde a los problemas tratados durante las entrevistas. Nótese que a partir de E-2012 se estudiaron al menos dos dominios de problemas con la finalidad de explorar el efecto del conocimiento en la efectividad de los analistas.

${ }^{23}$ En algunos experimentos como E-2013 y E-2014 los sujetos recibieron un entrenamiento de 1 semana y 6 semanas, respectivamente. Dicho entrenamiento (o warming up) corresponde a un repaso general sobre educción de requisitos. 
Tabla 4.12 - Diferencias principales relacionadas con la ejecución de los experimentos

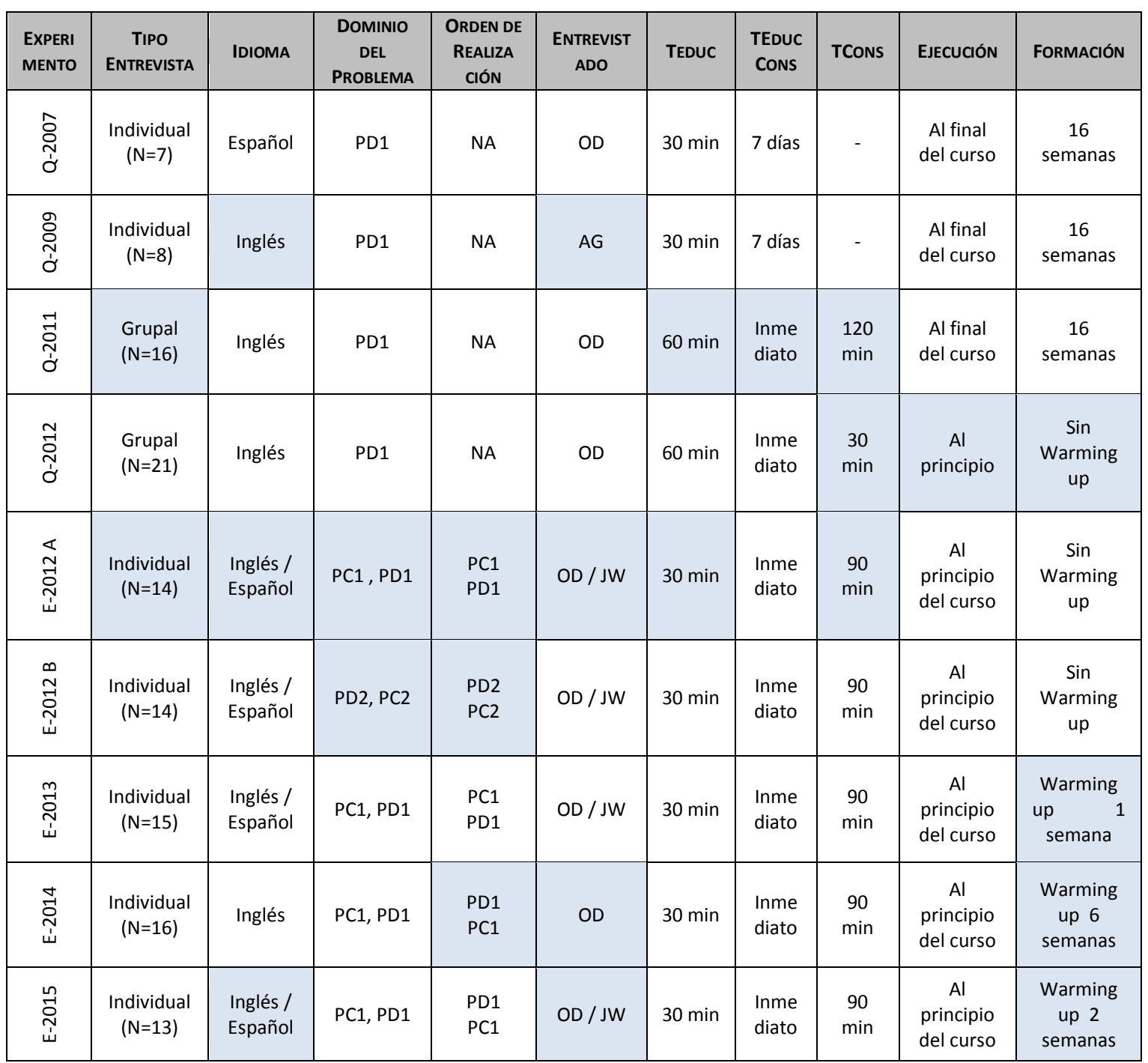

- Orden de realización: corresponde al orden en el que se realizaron las sesiones de educción sobre los dominios del problema utilizados en cada experimento. Por ejemplo: en E-2012 A, PC1 ha sido estudiado en primer lugar y PD1 en segundo.

- Tiempo de Educción (tEduc): hace referencia a la duración de las entrevistas. Las entrevistas individuales tuvieron una duración recomendada de 30 minutos, mientras que las entrevistas en grupo de 60 minutos. Creemos que los tiempos asignados son realistas (en función de la complejidad del dominio) y, en todo caso, son suficientes para adquirir una cantidad relevante de elementos del dominio del problema. Nótese que el tiempo de educción en Q-2011 y Q2012 está confundida por el tipo de entrevista en grupo, es decir, no es posible saber si el incremento o decremento de la efectividad de los sujetos se debe a la entrevista en grupo o al tiempo empleado, tal y como se describe en la sección de amenazas a la validez.

- Tiempo entre la educción y la consolidación (tEducCons): hace referencia al tiempo transcurrido entre la sesión de educción y la consolidación de la información. En Q-2007 y Q2009 este tiempo fue de una semana. A partir de Q-2011 la consolidación siguió inmediatamente a la sesión de educción. Creemos que esta segunda opción es preferible ya que: 1) evita que los sujetos olviden detalles del dominio del problema que podría disminuir su efectividad y 2) nos permite un mayor control de la situación experimental. La falta de control 
sobre el tiempo transcurrido entre la educción y la consolidación en Q-2007 y Q-2009 se considera una amenaza y como tal se describe en el capítulo de las amenazas de la validez.

- Tiempo de Consolidación (tCons): hace referencia al tiempo disponible para que el analista presente por escrito la información adquirida en las sesiones de educción. El proceso de consolidación tuvo una duración recomendada de 90 minutos, con excepción del Q-2012 que fue de unos 30 minutos aproximadamente. Estas diferencias en los tiempos de consolidación suponen una cierta pérdida de control sobre los estudios empíricos y como tal se discuten en la sección de amenazas a la validez.

\subsubsection{Variables dependientes e independientes}

Además de las diferencias indicadas en las tablas resúmenes anteriores, la Tabla 4.13 resume las variables consideradas en cada estudio (las variables: independientes, dependientes y de bloque). Las celdas en blanco representan ausencia de información (no contamos con dichos valores), los valores en cursiva y subrayados representan una nueva variable bajo estudio. Las razones que motivaron su aparición están descritas en el capítulo 5.

Tabla 4.13 - Variables independientes, secuencia de aparición

\begin{tabular}{|c|c|c|c|c|c|c|c|c|}
\hline \multirow{3}{*}{$\begin{array}{l}\text { EXPERIM } \\
\text { ENTO }\end{array}$} & \multicolumn{6}{|c|}{ VARIABLES INDEPENDIENTES } & \multirow{3}{*}{$\begin{array}{c}\text { VARIABLE } \\
\text { DEPENDIENTE }\end{array}$} & \multirow{3}{*}{$\begin{array}{l}\text { VARIABLE DE } \\
\text { BLOQUE }\end{array}$} \\
\hline & \multirow{2}{*}{$\begin{array}{l}\text { TITULACIÓN } \\
\text { ACADÉMICA }\end{array}$} & \multicolumn{2}{|c|}{ EXPERIENCIA } & \multicolumn{2}{|c|}{ CONOCIMIENTO } & \multirow{2}{*}{$\begin{array}{r}\text { DIFICULTAD } \\
\text { (LIKERT 1-3) }\end{array}$} & & \\
\hline & & $\begin{array}{l}\text { EXPERIENCIA } \\
\text { (AÑOS) }\end{array}$ & $\begin{array}{l}\text { HABILIDAD } \\
\text { (LIKERT } 1 \text {-5) }\end{array}$ & $\begin{array}{l}\text { FAMILIARIDAD } \\
\text { (LIKERT 1-3) }\end{array}$ & $\begin{array}{l}\text { CONOCIMIENTO } \\
\text { (c/ } 2 \text { NIVELES) }\end{array}$ & & & \\
\hline $\begin{array}{l}\hat{O} \\
\text { ơ } \\
\text { ơ }\end{array}$ & $\begin{array}{l}\text { Titulación } \\
\text { académica }\end{array}$ & $\begin{array}{l}\text { Exp. Requisitos } \\
\text { Exp. Educción } \\
\text { Exp. Entrevistas } \\
\text { Exp. Profesional }\end{array}$ & & Familiaridad & & & $\begin{array}{l}\text { Efectividad en } \\
\text { la Educción } \\
\text { Efectividad en } \\
\text { la Consolidación } \\
\text { Capacidad de } \\
\text { Retención }\end{array}$ & No Aplica \\
\hline $\begin{array}{l}\text { Oे } \\
\text { ᄋ } \\
\text { ơ }\end{array}$ & $\begin{array}{l}\text { Titulación } \\
\text { académica }\end{array}$ & $\begin{array}{l}\text { Exp. Requisitos } \\
\text { Exp. Educción } \\
\text { Exp. Entrevistas } \\
\text { Exp. Profesional } \\
\text { Exp. Desarrollo* }\end{array}$ & & Familiaridad** & & & $\begin{array}{l}\text { Efectividad en } \\
\text { la Consolidación }\end{array}$ & No Aplica \\
\hline 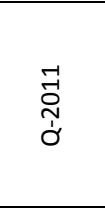 & $\begin{array}{l}\text { Titulación } \\
\text { académica }\end{array}$ & $\begin{array}{l}\text { Exp. Requisitos } \\
\text { Exp. Entrevistas } \\
\text { Exp. Profesional* } \\
\text { Exp. Desarrollo* }\end{array}$ & $\underline{\underline{\text { Hab. Requisitos }}} \underline{\underline{\text { Hab. Entrevistas }}}$ & Familiaridad & & & $\begin{array}{l}\text { Efectividad en } \\
\text { la Consolidación }\end{array}$ & No Aplica \\
\hline 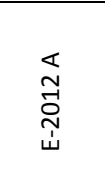 & $\begin{array}{l}\text { Titulación } \\
\text { académica }\end{array}$ & $\begin{array}{l}\text { Exp. Requisitos } \\
\text { Exp. Educción } \\
\text { Exp. Entrevistas } \\
\text { Exp. Profesional* } \\
\text { Exp. Desarrollo* }\end{array}$ & $\begin{array}{l}\text { Hab. Requisitos } \\
\text { Hab. Entrevistas }\end{array}$ & Familiaridad & Conocimiento & $\underline{\text { Dificultad }}$ & $\begin{array}{l}\text { Efectividad en } \\
\text { la Consolidación }\end{array}$ & $\begin{array}{l}\text { Entrevistado } \\
\text { / Idioma }\end{array}$ \\
\hline 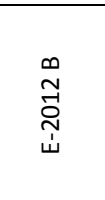 & $\begin{array}{l}\text { Titulación } \\
\text { académica }\end{array}$ & $\begin{array}{l}\text { Exp. Requisitos } \\
\text { Exp. Educción } \\
\text { Exp. Entrevistas } \\
\text { Exp. Profesional* } \\
\text { Exp. Desarrollo* }\end{array}$ & $\begin{array}{l}\text { Hab. Requisitos } \\
\text { Hab. Entrevistas }\end{array}$ & Familiaridad & Conocimiento & $\underline{\text { Dificultad }}$ & $\begin{array}{l}\text { Efectividad en } \\
\text { la Consolidación }\end{array}$ & $\begin{array}{l}\text { Entrevistado } \\
\text { / Idioma }\end{array}$ \\
\hline
\end{tabular}




\begin{tabular}{|c|c|c|c|c|c|c|c|c|}
\hline \multirow{3}{*}{$\begin{array}{l}\text { EXPERIM } \\
\text { ENTO }\end{array}$} & \multicolumn{6}{|c|}{ VARIABLES INDEPENDIENTES } & \multirow{3}{*}{$\begin{array}{c}\text { VARIABLE } \\
\text { DEPENDIENTE }\end{array}$} & \multirow{3}{*}{$\begin{array}{c}\text { VARIABLE DE } \\
\text { BLOQUE }\end{array}$} \\
\hline & \multirow{2}{*}{$\begin{array}{l}\text { TITULACIÓN } \\
\text { ACADÉMICA }\end{array}$} & \multicolumn{2}{|c|}{ EXPERIENCIA } & \multicolumn{2}{|c|}{ CONOCIMIENTO } & \multirow{2}{*}{$\begin{array}{l}\text { DIFICULTAD } \\
\text { (LIKERT 1-3) }\end{array}$} & & \\
\hline & & $\begin{array}{l}\text { EXPERIENCIA } \\
\text { (AÑOS) }\end{array}$ & $\begin{array}{l}\text { HABILIDAD } \\
\text { (LIKERT 1 -5) }\end{array}$ & $\begin{array}{l}\text { FAMILIARIDAD } \\
\text { (LIKERT 1-3) }\end{array}$ & $\begin{array}{l}\text { CONOCIMIENTO } \\
\text { (c/ } 2 \text { NiVELES) }\end{array}$ & & & \\
\hline 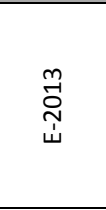 & $\begin{array}{l}\text { Titulación } \\
\text { académica }\end{array}$ & $\begin{array}{l}\text { Exp. Requisitos } \\
\text { Exp. Educción } \\
\text { Exp. Entrevistas } \\
\text { Exp. Profesional* } \\
\text { Exp. Desarrollo }\end{array}$ & $\begin{array}{l}\text { Hab. Requisitos } \\
\text { Hab. Entrevistas } \\
\text { Hab. Desarrollo }\end{array}$ & Familiaridad & Conocimiento & Dificultad & $\begin{array}{l}\text { Efectividad en } \\
\text { la Consolidación } \\
\text { (1ㅇs sesión) } \\
\text { Efectividad en } \\
\text { la Consolidación } \\
\text { (2o sesión) }\end{array}$ & $\begin{array}{l}\text { Entrevistado } \\
\text { / Idioma }\end{array}$ \\
\hline$\underset{\text { 突 }}{\text { 山े }}$ & $\begin{array}{l}\text { Titulación } \\
\text { académica }\end{array}$ & $\begin{array}{l}\text { Exp. Requisitos } \\
\text { Exp. Educción } \\
\text { Exp. Entrevistas } \\
\text { Exp. Profesional } \\
\text { Exp. Desarrollo }\end{array}$ & $\begin{array}{l}\text { Hab. Requisitos } \\
\text { Hab. Entrevistas } \\
\text { Hab. Desarrollo }\end{array}$ & Familiaridad & Conocimiento & Dificultad & $\begin{array}{l}\text { Efectividad en } \\
\text { la Consolidación }\end{array}$ & No Aplica \\
\hline 脶 & $\begin{array}{l}\text { Titulación } \\
\text { académica }\end{array}$ & $\begin{array}{l}\text { Exp. Requisitos } \\
\text { Exp. Educción } \\
\text { Exp. Entrevistas } \\
\text { Exp. Profesional } \\
\text { Exp. Desarrollo }\end{array}$ & $\begin{array}{l}\text { Hab. Requisitos } \\
\text { Hab. Entrevistas } \\
\text { Hab. Desarrollo }\end{array}$ & Familiaridad & Conocimiento & Dificultad & $\begin{array}{l}\text { Efectividad en } \\
\text { la Consolidación }\end{array}$ & $\begin{array}{l}\text { Entrevistado } \\
\text { / Idioma }\end{array}$ \\
\hline
\end{tabular}

* Obtenidas del CV; surgió en el experimento indicado

** Como el cuestionario demográfico fue rellenado muy posteriormente a la ejecución de los experimentos, tanto la familiaridad como la dificultad podrían obtener valores sesgados. Por ello, no se solicitó dicha información a los sujetos experimentales. 



\section{CAPÍTULO 5}

\section{EJECUCIÓN Y RESULTADOS}

El presente capítulo tiene como propósito presentar al lector los principales resultados de la investigación. Cada sub-sección corresponde a un cuasi-experimento o experimento. Para cada uno de ellos, se presentará: a) la ejecución del experimento (incluyendo características de la muestra preparación del experimento, cómo fue llevado a cabo y posibles desviaciones con la planificación inicial); b) los resultados en función de las hipótesis de investigación. En cada caso, se indicará y justificará las diferencias que exigieron alguna adaptación metodológica.

Cabe mencionar que el tamaño muestral de cada uno de los experimentos individuales es muy pequeño, por consiguiente las técnicas estadísticas que se aplican sobre este conjunto de datos, debido al reducido tamaño muestral darán unos resultados que en nuestra opinión no son fiables. Por lo tanto, los resultados deben tomarse con cierta cautela.

Por motivos de claridad se realizará el análisis según corresponda al tipo de diseño y se presentarán los resultados parciales obtenidos. En el capítulo 6 se presentará la síntesis de los resultados, donde los efectos se analizarán a nivel global empleando la muestra total recogida a lo largo de la serie de experimentos. De esta manera conseguiremos obtener resultados realmente fiables.

\subsection{Cuasi-Experimento Q-2007}

\subsubsection{Ejecución}

\subsubsection{Muestra}

En Q-2007 participaron 12 estudiantes del Máster en Ingeniería del Software de la Escuela Técnica Superior de Ingenieros Informáticos (anteriormente Facultad de Informática) de la Universidad Politécnica de Madrid (España). Todos son profesionales titulados superiores en informática y áreas afines, procedentes de varios países latinoamericanos (Argentina, Brasil, Colombia, Ecuador, Perú) y España. 
La Tabla 5.1 resume los datos demográficos principales de la muestra. Como se ha indicado en la sección 4.2, Q-2007 es el único cuasi-experimento de la serie histórica en el que se ha analizado la efectividad de los sujetos tanto en las sesiones de educción como en el proceso de consolidación, además como se indicará en la sección 5.1.2.1 no todos los sujetos respondieron al cuestionario ni todos los sujetos presentaron los informes correspondientes, por lo que la muestra quedó reducida a 10 sujetos para las sesiones de educción y 7 sujetos para la consolidación. Por estos motivos, en la Tabla 5.1 se presenta en función de cada una de las características, el número total de sujetos para la educción (\#Sujetos 10 Educción (Educ)) y la consolidación (\#Sujetos 7 (Cons)).

Tabla 5.1 - Características principales de los sujetos experimentales Q-2007

\begin{tabular}{|c|c|c|c|}
\hline \multicolumn{4}{|c|}{ CUASI-EXPERIMENTO Q-2007 (12) } \\
\hline CARACTERÍSTICAS & Nivel & $\begin{array}{l}\text { \#SUJETOS } \\
10 \text { (Educ) }\end{array}$ & $\begin{array}{l}\text { \#SUJETOS } \\
7 \text { (CONS) }\end{array}$ \\
\hline \multirow{2}{*}{$\begin{array}{l}\text { Titulación } \\
\text { académica }\end{array}$} & No Informático & 6 & 3 \\
\hline & Informático & 4 & 4 \\
\hline \multirow{4}{*}{$\begin{array}{l}\text { Experiencia en } \\
\text { Entrevistas }\end{array}$} & 0 año & 3 & 1 \\
\hline & $1-2$ años & 1 & 1 \\
\hline & 3-4 años & 4 & 3 \\
\hline & $>=5$ años & 2 & 2 \\
\hline \multirow{4}{*}{$\begin{array}{l}\text { Experiencia en } \\
\text { Educción }\end{array}$} & 0 año & 3 & 1 \\
\hline & 1-2 años & 5 & 4 \\
\hline & 3-4 años & 1 & 1 \\
\hline & $>=5$ años & 1 & 1 \\
\hline \multirow{4}{*}{$\begin{array}{l}\text { Experiencia en } \\
\text { Requisitos }\end{array}$} & 0 año & 3 & 1 \\
\hline & $1-2$ años & 5 & 4 \\
\hline & 3-4 años & 1 & 1 \\
\hline & $>=5$ años & 1 & 1 \\
\hline \multirow{4}{*}{$\begin{array}{l}\text { Experiencia } \\
\text { Profesional }\end{array}$} & 0 año & 0 & 0 \\
\hline & 1-2 años & 0 & 0 \\
\hline & 3-4 años & 1 & 1 \\
\hline & $>=5$ años & 9 & 6 \\
\hline \multirow{3}{*}{$\begin{array}{l}\text { Familiaridad con } \\
\text { el problema }\end{array}$} & No Familiar & 5 & 4 \\
\hline & Familiar & 4 & 2 \\
\hline & Muy Familiar & 1 & 1 \\
\hline
\end{tabular}

Como principales características de la muestra, destacan que los sujetos experimentales poseen experiencia profesional y en entrevistas mayores a 2 años, sin embargo cuentan mayoritariamente con experiencias en requisitos y educción hasta 2 años. Podríamos caracterizar a la muestra como sujetos profesionales con baja experiencia en requisitos y educción. En lo que respecta a la familiaridad con el problema, el $50 \%$ de los sujetos tienen familiaridad con el dominio del problema con excepción de un estudiante que reportó tener mucha familiaridad.

\subsubsection{Preparación}

El entrevistado, con la finalidad de simular lo más perfectamente posible el papel de cliente, estudió y preparó con antelación el dominio del problema. Para evitar el cansancio por parte del entrevistado, el experimento se ejecutó en días distintos de la misma semana.

\subsubsection{Realización}

Se realizaron 12 entrevistas distribuidas en dos días. Todas las entrevistas fueron llevadas a cabo individualmente, grabadas y entregadas a cada sujeto experimental. Cada entrevista tuvo una duración máxima de 25 minutos; donde los 5 primeros minutos de la sesión consistieron en explicar a los sujetos los objetivos de la sesión y el problema a tratar y, durante los 20 minutos restantes, se realizó la entrevista propiamente dicha. En promedio, las sesiones de educción consumieron 13 minutos, siendo 
la duración mínima 8 minutos y la duración máxima 17 minutos. En las sesiones de educción el alumno ejerció el rol de analista de requisitos y el experimentador el rol de entrevistado o cliente.

Al finalizar el cuasi-experimento, los sujetos respondieron a un cuestionario post-experimental (disponible en el anexo A.1) con el que se obtuvieron los valores de las variables independientes. Como resultado final del cuasi-experimento, los sujetos presentaron un informe de consolidación de la información educida. Este informe fue presentado una semana después de la realización de las entrevistas. No se solicitó a los estudiantes que especificaran el tiempo transcurrido entre la educción y consolidación ya que el riesgo de que proporcionasen información segada era demasiado alto.

\subsubsection{Desviaciones}

El experimento se llevó a cabo acorde con la planificación inicial, salvo para algunos sujetos que por motivos externos no respetaron la planificación y se tuvieron que reprogramar algunas sesiones de educción.

\subsubsection{Resultados}

\subsubsection{Reducción del Conjunto de Datos}

De los 12 sujetos que participaron del cuasi-experimento, dos sujetos no respondieron el cuestionario post-experimental y, tres sujetos no entregaron el informe de consolidación. Por lo tanto, hay que tener en cuenta que la población experimental quedó reducida a 10 sujetos para el análisis de la sesión de educción y a 7 sujetos para el análisis del proceso de consolidación. En consecuencia, como la capacidad de retención depende de la efectividad tanto de la educción como de la consolidación, el tamaño muestral para este caso queda reducido a 7 sujetos.

\subsubsection{Procedimiento de Análisis}

Los métodos estadísticos aplicados para el análisis de los datos fueron: la correlación de Pearson, la prueba t y estadísticos descriptivos, apoyados con gráficos de dispersión y box-plot según corresponda.

Para facilitar el análisis y la comprensión de los resultados, en lo que respecta al efecto de la familiaridad que poseen los sujetos sobre el dominio del problema, hemos reagrupado los datos experimentales. En el cuasi-experimento, la familiaridad se midió mediante una escala ordinal (probablemente equivalente a una escala de Likert) con los valores: Muy Familiar, Familiar y No Familiar. Solo un sujeto respondió que el problema le era Muy familiar (como se puede ver en la Tabla 5.1). Por este motivo y a efectos de análisis estadístico, hemos agrupado los sujetos familiarizados y muy familiarizados en el dominio del problema en uno sólo, quedando la familiaridad del problema con dos valores (niveles): No Familiar y Familiar ${ }^{24}$.

\subsubsection{Estadísticos Descriptivos}

La Tabla 5.2 presenta el número total de sujetos (N), la efectividad media, máxima y mínima alcanzada por los sujetos en las sesiones de educción y en la consolidación, así como la mediana, la varianza y la desviación típica. En media durante las entrevistas se mencionan el $62 \%$ de los elementos que definen el dominio del problema, sin embargo los sujetos tienden a consolidar el $39 \%$. Nótese, que ningún sujeto alcanza a educir o consolidar el $100 \%$ de los elementos, como máximo educen el $75 \%$ y reportan el $61 \%$ de los elementos definitorios del dominio del problema. Es importante destacar que los sujetos tienden a olvidar en media el $24 \%$ de los elementos que fueron mencionados en las sesiones de educción.

\footnotetext{
${ }^{24}$ El análisis original que se reporta en el artículo del INTEAMSE'12 (A. Aranda, Dieste, \& Juristo, 2012) utiliza una dicotomización de las escalas continuas para generar los box-plots y los tests estadísticos. Esta aproximación nos ha parecido posteriormente incorrecta, por eso no lo estamos reportando en esta tesis. Los motivos que nos llevaron a tomar esta decisión se describen en el capítulo 7, sección 7.7.3
} 
Tabla 5.2 - Estadísticos descriptivos Q-2007

\begin{tabular}{|l|r|r|r|}
\cline { 2 - 4 } \multicolumn{1}{c|}{} & $\begin{array}{c}\text { EfECTIVIDAD EN LA } \\
\text { Educción (\%) }\end{array}$ & $\begin{array}{c}\text { EfECTIVIDAD EN LA } \\
\text { ConsolidACIÓN (\%) }\end{array}$ & Olvido (\%) \\
\hline N & 10 & 7 & 7 \\
Media & 61.96 & 39.22 & 23.53 \\
Máximo & 75 & 61 & 63 \\
Mínimo & 43 & 10 & 0 \\
Mediana & 62.75 & 37.25 & 21.57 \\
Varianza & 97.569 & 319.108 & 474.177 \\
Desv. típ. & 9.878 & 17.864 & 21.776 \\
\hline
\end{tabular}

\subsubsection{Prueba de Hipótesis}

\subsection{Resultados sobre las sesiones de educción}

\section{H1a. Efecto de la Experiencia}

La experiencia se midió mediante el número de años que el sujeto ha trabajado con requisitos, entrevistas y educción, así como su experiencia profesional en actividades relacionados con requisitos. Para estudiar su efecto hemos generado gráficos de dispersión y calculado las correlaciones correspondientes, tal y como se muestran en la Figura 5.1 y Tabla 5.3 respectivamente.

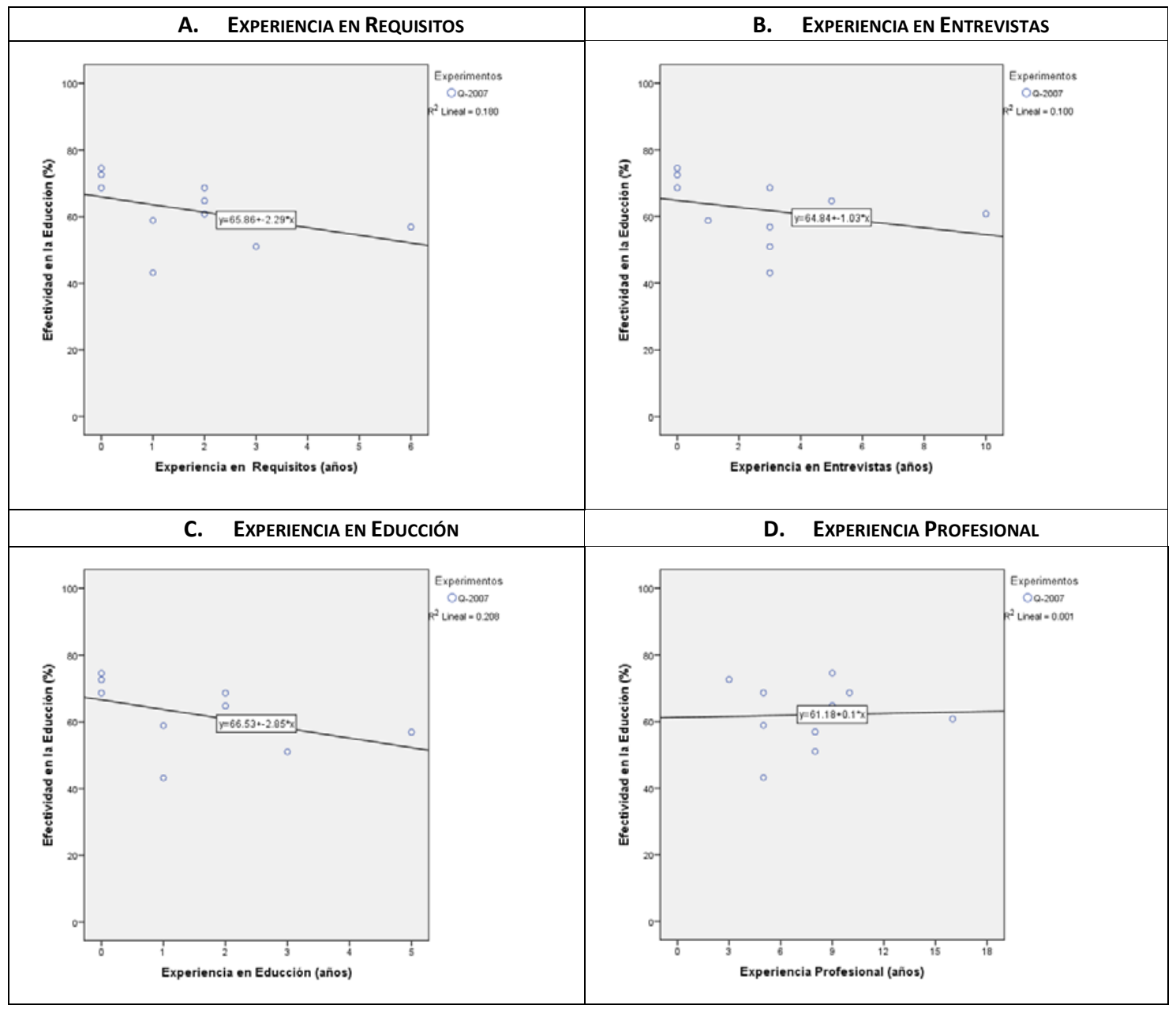

Figura 5.1 - Relación de la experiencia y la efectividad en la educción Q-2007 
La Figura 5.1 presenta por cada una de las vertientes de la experiencia un gráfico de dispersión, el cual presenta gráficamente la relación que existe entre la experiencia y la efectividad del analista. En el eje $x$ se muestra los años de experiencia en (requisitos, entrevistas, educción y profesional), mientras que en el eje y se muestra la efectividad promedio (\%) alcanzada por el sujeto. Como se puede apreciar en la Figura 5.1con excepción de la experiencia profesional, en todos los casos la experiencia ejerce un efecto negativo, esto es, los sujetos novatos tienden a ser más efectivos que los expertos (sujetos con más años de experiencia).

La Tabla 5.3 presenta por cada vertiente de la experiencia analizada, el coeficiente de correlación $(r)$, el valor de significación ( $\mathrm{p}$-valor), la cantidad total de sujetos analizados ( $\mathrm{N}=10$ ) y el efecto observado (positivo (+), negativo (-) o nulo (x)). Los resultados indican un efecto negativo de la experiencia, esto es, los sujetos con menos años de experiencia tienden a ser más efectivos en las sesiones de educción que los sujetos con más experiencia. No obstante, los coeficientes de correlación tienden a ser moderados y no significativos ya que los valores del $p$-valor son mayores al valor establecido. Nótese la experiencia profesional tiende a ejercer un efecto nulo en la efectividad. Por tanto, por lo general la experiencia del sujeto perece ejercer un efecto negativo en la efectividad de la sesión de educción.

Tabla 5.3 - Relación de la experiencia y la efectividad en la educción Q-2007

\begin{tabular}{|c|c|c|c|c|}
\hline \multirow{2}{*}{$\begin{array}{c}\text { VARIABLE } \\
\text { INDEPENDIENTE }\end{array}$} & \multicolumn{3}{|c|}{ CORRELACIÓN } & \multirow{2}{*}{ EFECTO } \\
\cline { 2 - 4 } & $r$ & $\mathrm{p}$-valor & $\mathrm{N}$ & \\
\hline ExpEntr & -.317 & .372 & 10 & $(-)$ \\
\hline ExpEduc & -.456 & .186 & 10 & $(-)$ \\
\hline ExpReq & -.425 & .221 & 10 & $(-)$ \\
\hline ExpProf & .037 & .919 & 10 & $(\mathrm{x})$ \\
\hline
\end{tabular}

\section{H2a. Efecto del la Familiaridad}

La Figura 5.2 representa a un gráfico de box donde en el eje de las abscisas (eje horizontal) se muestra la familiaridad de los sujetos y en el eje de ordenadas (eje vertical) la efectividad promedio de los sujetos en las sesiones de educción. En el gráfico se puede apreciar que los sujetos en las sesiones de educción en promedio tienden a alcanzar efectividades muy similares independientemente de su familiaridad con el dominio del problema.

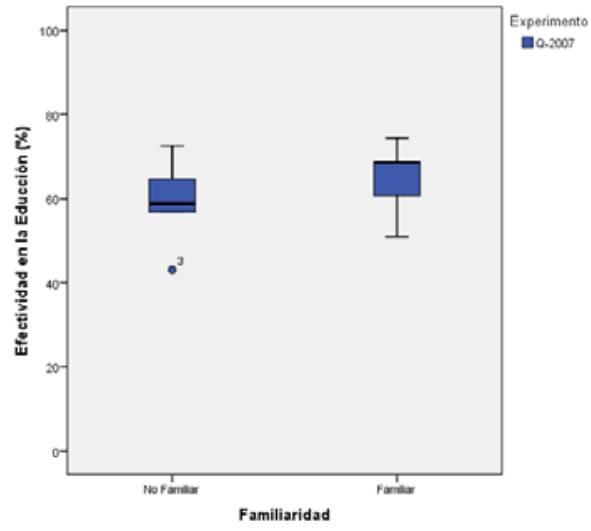

Figura 5.2 - Relación entre familiaridad del sujeto y la efectividad en la educción Q-2007

Como se puede observar en la Tabla 5.4 la familiaridad tiende a ejercer un efecto positivo moderado ( $d=0.613$ ) en la efectividad. Estadísticamente no se han alcanzado resultados significativos. El valor de significación obtenido ( $p$-valor $=0.411>0.05$ ) es mayor al nivel especificado. Por tanto, la diferencia de efectividades entre ambos grupos (No Familiar, Familiar) no es significativa. Concluimos 
que la familiaridad que poseen los sujetos sobre el problema tiende a ejercer un efecto positivo en la efectividad de la sesión de educción.

Tabla 5.4 - Efectividad media en función de su familiaridad (Fam) Q-2007

\begin{tabular}{|c|c|c|c|c|c|c|c|c|}
\hline \multicolumn{3}{|c|}{ TAMAÑo PoBlaCión } & \multirow{2}{*}{\multicolumn{2}{|c|}{$\begin{array}{c}\text { EFECTIVIDAD } \\
\text { MEDIA (\%) } \\
\text { Fam }\end{array}$}} & \multirow{3}{*}{$\mathbf{t}$} & \multirow{3}{*}{$\begin{array}{c}\text { EFFECT SIZE }^{25} \\
\text { COHEN (D) }\end{array}$} & \multirow{3}{*}{$\begin{array}{c}\text { SIG. } \\
\text { T-TEST }\end{array}$} & \multirow{3}{*}{$\begin{array}{c}\text { EFECTO } \\
\text { FAM }\end{array}$} \\
\hline \multirow{2}{*}{$\mathrm{N}$} & \multicolumn{2}{|c|}{ Fam } & & & & & & \\
\hline & $\operatorname{Sin}$ & Con & $\operatorname{Sin}$ & Con & & & & \\
\hline 10 & 5 & 5 & 59 & 65 & .867 & 0.613 & No (.411) & $(+)$ \\
\hline
\end{tabular}

\section{H3. Efecto de la Titulación Académica}

Como se muestra en la Figura 5.3, la cantidad de información obtenida en promedio por informáticos y no informáticos es similar. En las sesiones de educción de los informáticos se menciona un $59 \%$ de los elementos que definen el dominio del problema mientras que en las de los no informáticos un $63 \%$.

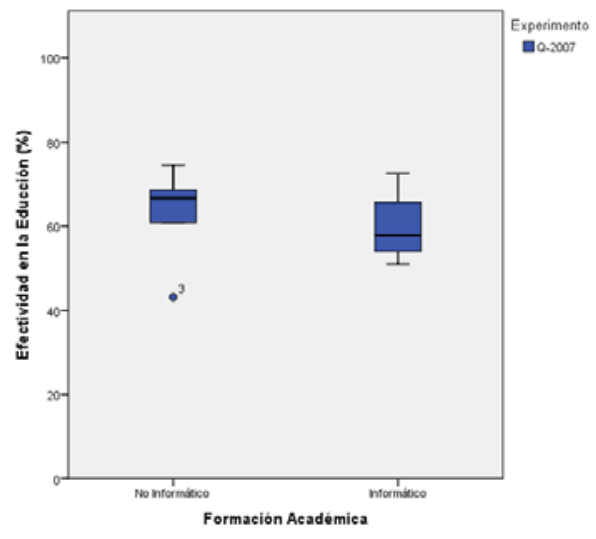

Figura 5.3 - Efecto de la titulación académica en la efectividad de los sujetos Q-2207

Los test estadísticos presentados en la Tabla 5.5 corroboran el bajo efecto ( $d=-0.383$ ) y negativo de la titulación académica en la efectividad de la educción, así como la falta de diferencias significativas entre ambos grupos (No Informáticos vs Informáticos).

Tabla 5.5 - Relación de la titulación académica (TIT) y la efectividad en la educción Q-2007

\begin{tabular}{|c|c|c|c|c|c|c|c|c|}
\hline \multicolumn{3}{|c|}{ TAMAÑo PoBlaCión } & \multirow{2}{*}{\multicolumn{2}{|c|}{$\begin{array}{c}\text { EFECTIVIDAD } \\
\text { MEDIA (\%) }\end{array}$}} & \multirow{3}{*}{$\mathbf{t}$} & \multirow{3}{*}{$\begin{array}{l}\text { EFFECT SIZE } \\
\text { COHEN (D) }\end{array}$} & \multirow{3}{*}{$\begin{array}{l}\text { SIG. } \\
\text { T-TEST }\end{array}$} & \multirow{3}{*}{$\begin{array}{c}\text { EFECTO } \\
\text { TIT }\end{array}$} \\
\hline \multirow{2}{*}{$\mathrm{N}$} & \multicolumn{2}{|c|}{ TIT } & & & & & & \\
\hline & nolnf & $\operatorname{lnf}$ & nolnf & $\operatorname{Inf}$ & & & & \\
\hline 10 & 6 & 4 & 63 & 59 & -0.541 & -0.383 & No (.603) & $(-)$ \\
\hline
\end{tabular}

\subsection{Resultados sobre la Consolidación}

\section{H1a. Efecto de la Experiencia}

En la Figura 5.4 se observan gráficos de dispersión que indican la relación existente entre la experiencia (en requisitos, entrevistas, educción y profesional) y la efectividad en la consolidación. Los gráficos de dispersión presentan en el eje de abscisas los años de experiencia y en el eje de ordenadas el porcentaje (\%) de elementos consolidados por los sujetos. Como se puede apreciar en la Figura 5.4, en todos los casos la experiencia ejerce un efecto negativo, esto es, los sujetos novatos tienden a ser más efectivos que los expertos (sujetos con más años de experiencia).

\footnotetext{
${ }^{25}$ Calculado con el "Effect Size Calculator" http://www.uccs.edu/ |becker/, $\mathrm{df}=\mathrm{N}-2$
} 


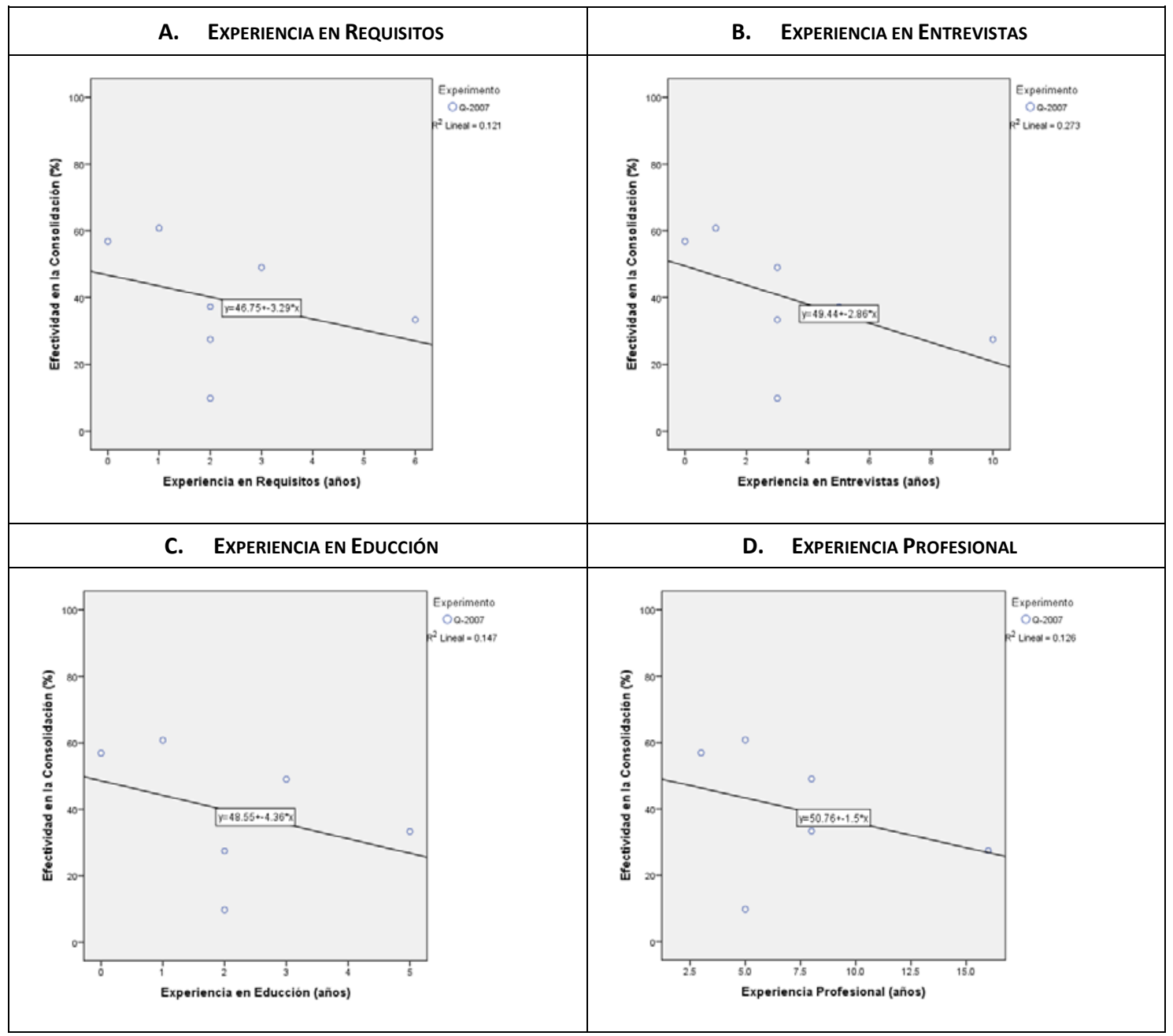

Figura 5.4 - Relación de la experiencia y la efectividad en la consolidación Q-2007

No obstante, las correlaciones presentadas en la figura anterior son estadísticamente no significativas, dado que los valores de significación obtenido son mayores al establecido (0.05) en todos los casos, tal y como se muestra en la Tabla 5.6. Se podría decir que la experiencia del sujeto perece ejercer un efecto negativo en la efectividad de la consolidación.

Tabla 5.6 - Relación de la experiencia y la efectividad en la consolidación Q-2007

\begin{tabular}{|c|c|c|c|c|}
\hline \multirow{2}{*}{$\begin{array}{c}\text { VARIABLE } \\
\text { INDEPENDIENTE }\end{array}$} & \multicolumn{3}{|c|}{ CORRELACIÓN } & \multirow{2}{*}{ EFECTO } \\
\cline { 2 - 5 } & $r$ & $p$-valor & $\mathrm{N}$ & \\
\hline ExpReq & -.348 & .444 & 7 & $(-)$ \\
\hline ExpEntr & -.522 & .229 & 7 & $(-)$ \\
\hline ExpEduc & -.384 & .396 & 7 & $(-)$ \\
\hline ExpProf & -.355 & -.435 & 7 & $(-)$ \\
\hline
\end{tabular}

\section{H2a. Efecto del la Familiaridad}

Como se puede apreciar en la Figura 5.5 existe una tendencia de que los sujetos no familiarizados con el dominio del problema sean capaces de consolidar un mayor número de elementos del dominio que aquellos sujetos familiarizados con el problema. En promedio los sujetos no familiarizados con el problema consolidan $47 \%$ de los elementos mencionados en sus sesiones de educción, mientras que los familiarizados un $29 \%$ de los elementos. 


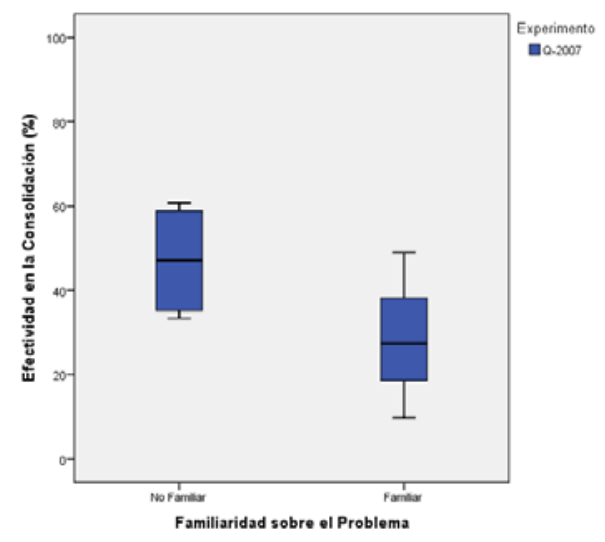

Figura 5.5 - Efecto de la familiaridad Q-2007

Se observa una tendencia negativa de la familiaridad en la efectividad, es decir, los sujetos sin familiaridad en el dominio del problema en media tienden a obtener una efectividad mayor ( $d=-1.3089$, que corresponde con un efecto alto) que los sujetos familiarizados. No obstante, la diferencia entre ambos grupos (Familiar y No familiar) es no significativa ( $p$-valor $=.203>0.05$ ), tal y como se puede apreciar en la Tabla 5.7.

Tabla 5.7 - Relación la Familiaridad (Fam) y la Efectividad en la Consolidación Q-2007

\begin{tabular}{|c|c|c|c|c|c|c|c|c|}
\hline \multicolumn{3}{|c|}{ TAMAÑo PoblaCión } & \multirow{2}{*}{\multicolumn{2}{|c|}{$\begin{array}{c}\text { EfECTIVIDAD } \\
\text { MEDIA (\%) } \\
\text { Fam } \\
\end{array}$}} & \multirow{3}{*}{$\mathbf{t}$} & \multirow{3}{*}{$\begin{array}{l}\text { EFFECT SIZE } \\
\text { COHEN (D) }\end{array}$} & \multirow{3}{*}{$\begin{array}{c}\text { SIG. } \\
\text { T-TEST }\end{array}$} & \multirow{3}{*}{$\begin{array}{c}\text { EFECTO } \\
\text { FAM }\end{array}$} \\
\hline \multirow{2}{*}{$\mathrm{N}$} & \multicolumn{2}{|c|}{ Fam } & & & & & & \\
\hline & $\operatorname{Sin}$ & Con & $\operatorname{Sin}$ & Con & & & & \\
\hline 7 & 4 & 3 & 47 & 29 & -1.463 & -1.3089 & No (.203) & $(-)$ \\
\hline
\end{tabular}

\section{H3. Efecto de la Titulación Académica}

Se ha podido comprobar que existe una marcada influencia entre la titulación académica del sujeto y la cantidad de elementos consolidados. Como se puede apreciar en la Figura 5.6, a pesar del pequeño número de sujetos estudiados, el efecto de la titulación académica es evidente: los informáticos en promedio adquieren mayor número de elementos del dominio del problema (50\%) que los no informáticos (25\%). Es notable que este efecto no sólo se aprecie visualmente, sino que también se verifica estadísticamente.

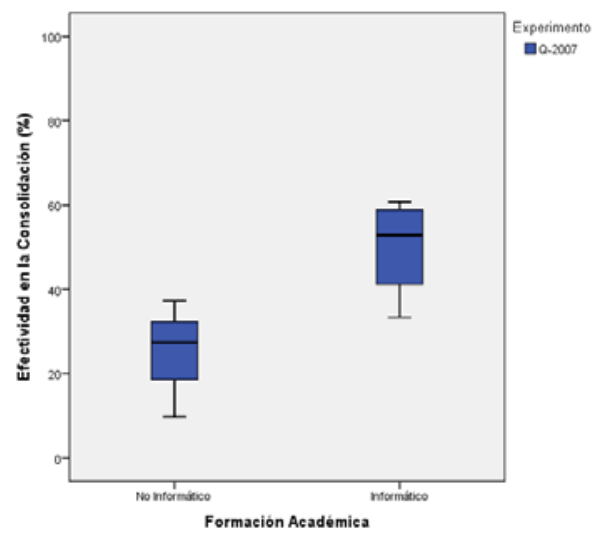

Figura 5.6 - Efecto de la titulación académica en la efectividad de la consolidación Q-2007

En concreto, como se muestra en la Tabla 5.8, el valor de significación obtenido ( $p$-valor $=0.051 \approx$ $0.05)$, es equivalente al nivel de significación establecido; podríamos asumir que este resultado indica que estadísticamente la diferencia entre promedios es significativa. Por lo tanto, se puede concluir, que 
existe una relación entre la titulación académica y el porcentaje de información adquirida durante el proceso de consolidación.

Tabla 5.8 - Relación de la titulación académica (TIT) y la efectividad en la consolidación Q-2007

\begin{tabular}{|c|c|c|c|c|c|c|c|c|}
\hline \multicolumn{3}{|c|}{ TAMAÑo POBLACIÓN } & \multirow{2}{*}{\multicolumn{2}{|c|}{$\begin{array}{c}\text { EFECTIVIDAD } \\
\text { MEDIA (\%) }\end{array}$}} & \multirow{3}{*}{$\mathbf{t}$} & \multirow{3}{*}{$\begin{array}{l}\text { EFFECT Size } \\
\text { COHEN (D) }\end{array}$} & \multirow{3}{*}{$\begin{array}{l}\text { SIG. } \\
\text { T-TEST }\end{array}$} & \multirow{3}{*}{$\begin{array}{c}\text { EFECTO } \\
\text { TIT }\end{array}$} \\
\hline \multirow{2}{*}{$\mathrm{N}$} & \multicolumn{2}{|c|}{ TIT } & & & & & & \\
\hline & nolnf & $\operatorname{lnf}$ & nolnf & $\operatorname{Inf}$ & & & & \\
\hline 7 & 3 & 4 & 25 & 50 & 2.558 & 2.2883 & Si $(.051)^{*}$ & $(+)$ \\
\hline
\end{tabular}

(*) Significativo al nivel 0.10

\subsection{Resultados sobre la Capacidad de Retención de los Analistas}

\section{H1a. Efecto de la Experiencia}

En la Figura 5.7 se observan los gráficos de dispersión que indican la relación entre la experiencia (en requisitos, entrevistas, educción y profesional) y la capacidad de retención de los analistas. Los gráficos de dispersión presentan en el eje de abscisas los años de experiencia y en el eje de ordenadas el porcentaje de elementos consolidados por los sujetos. Como se puede apreciar en la Figura 5.7, en todos los casos la experiencia ejerce un efecto negativo, en algunos casos más pronunciados (como la experiencia en entrevistas) que otros (como el de la experiencia en requisitos y educción).

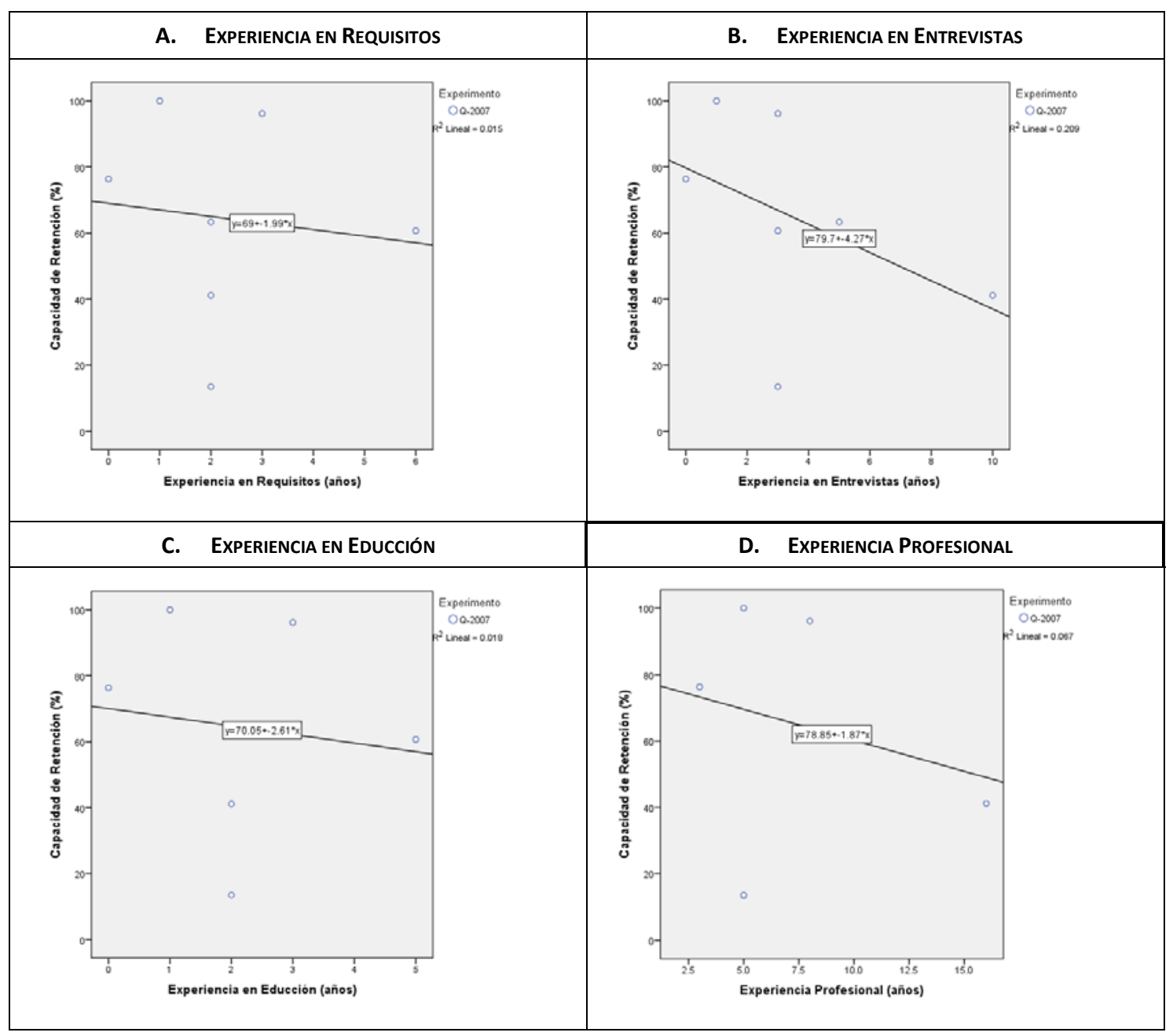

Figura 5.7 - Relación de la experiencia en sus distintas vertientes y la efectividad 
Estadísticamente, la experiencia tiene un efecto no significativo ( $p$-valor $>0.05$ ) sobre la capacidad de los analistas en recordar información tal y como se muestran en la Tabla 5.9. Los resultados parecen indicar que cuanto mayor son los años de experiencia del analista menor es la capacidad de retener información.

Tabla 5.9 - Relación de la experiencia y la capacidad de retención Q-2007

\begin{tabular}{|c|c|c|c|c|}
\hline \multirow{2}{*}{$\begin{array}{c}\text { VARIABLE } \\
\text { INDEPENDIENTE }\end{array}$} & \multicolumn{3}{|c|}{ CORRELACIÓN } & \multirow{2}{*}{ EFECTO } \\
\cline { 2 - 5 } & $r$ & $\mathrm{p}$-valor & $\mathrm{N}$ & \\
\hline ExpReq & -.123 & .792 & 7 & $(-)$ \\
\hline ExpEntr & -.457 & .303 & 7 & $(-)$ \\
\hline ExpEduc & -.135 & .773 & 7 & $(-)$ \\
\hline ExpProf & -.159 & .574 & 7 & $(-)$ \\
\hline
\end{tabular}

\section{H2a. Efecto del la Familiaridad}

La Figura 5.8 compara el porcentaje de información recordada por los sujetos en función de su familiaridad con el dominio del problema. Como se puede apreciar en la Figura 5.8, en promedio los sujetos no familiarizados con el dominio del problema tienden a olvidar menos información.

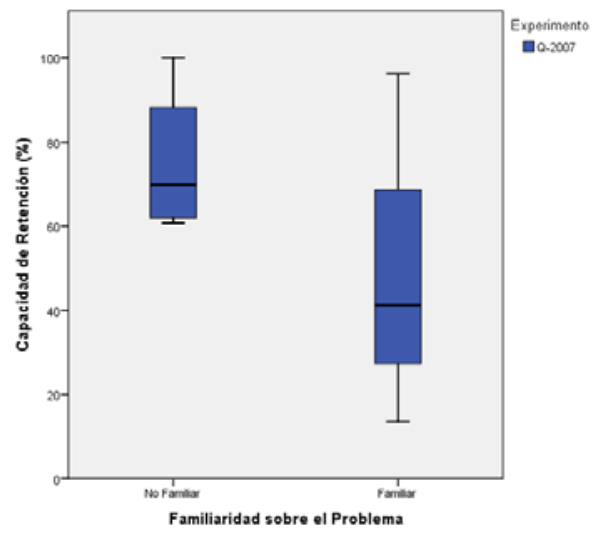

Figura 5.8 - Efecto de la familiaridad de los sujetos en la capacidad de retención Q-2007

Estadísticamente, los resultados presentan un efecto negativo moderado $(d=-.968$ ) entre la familiaridad y la capacidad de retención, siendo la diferencia de ambos grupos (Familiar, No Familiar) no significativa ( $p$-valor $=0.329>0.05$ ). Por tanto, se podría decir que la familiaridad tiende a ejercer un efecto negativo en la capacidad de retención, esto es, los sujetos sin familiaridad con el dominio tiende a recordar más información que los familiarizados.

Tabla 5.10 - Relación la familiaridad (Fam) y la capacidad de retención Q-2207

\begin{tabular}{|c|c|c|c|c|c|c|c|c|}
\hline \multicolumn{3}{|c|}{ TAMAÑo POBLACIÓN } & \multirow{2}{*}{\multicolumn{2}{|c|}{$\begin{array}{c}\text { EFECTIVIDAD } \\
\text { MEDIA (\%) } \\
\text { Fam }\end{array}$}} & \multirow{3}{*}{$\mathbf{t}$} & \multirow{3}{*}{$\begin{array}{l}\text { EFFECT SIZE } \\
\text { COHEN (D) }\end{array}$} & \multirow{3}{*}{$\begin{array}{l}\text { SIG. } \\
\text { T-TEST }\end{array}$} & \multirow{3}{*}{$\begin{array}{c}\text { EFECTO } \\
\text { FAM }\end{array}$} \\
\hline \multirow{2}{*}{$\mathrm{N}$} & \multicolumn{2}{|c|}{ Fam } & & & & & & \\
\hline & $\operatorname{Sin}$ & Con & $\operatorname{Sin}$ & Con & & & & \\
\hline 7 & 4 & 3 & 75 & 50 & -1.082 & -0.9678 & No(.329) & $(-)$ \\
\hline
\end{tabular}

\section{H3. Efecto de la Titulación Académica}

En el gráfico de box presentado en la Figura 5.9 se observa claramente un efecto positivo de la titulación en la capacidad de retención de información por parte de los analistas. Esto es, los informáticos tienden a recordar un $83 \%$ de información, mientras que los no informáticos un $39 \%$. 


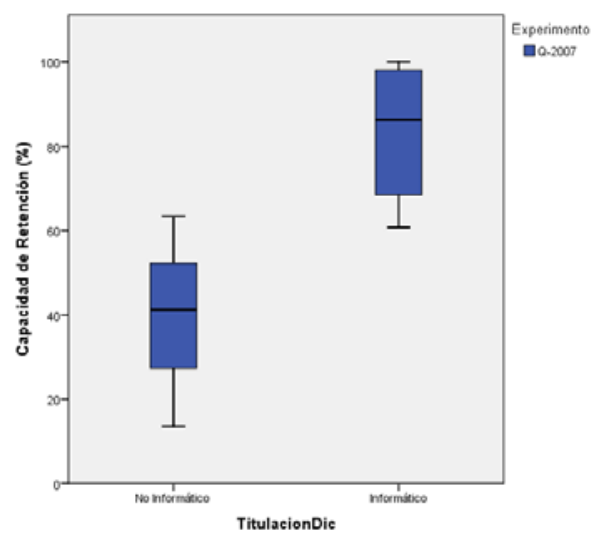

Figura 5.9 - Efecto de la titulación académica en la capacidad de retención Q-2007

Los datos presentados en Tabla 5.11 corroboran estadísticamente los efectos observados en la Figura 5.9. Esto es, la diferencia entre informáticos y no informáticos es estadísticamente significativa ( $p$-valor $=0.042<0.05$ ). La titulación parece ejercer un efecto positivo en la capacidad de retención de los analistas.

Tabla 5.11 - Relación de la titulación (TIT) y la efectividad en la capacidad de retención de los analistas

\begin{tabular}{|c|c|c|c|c|c|c|c|c|}
\hline \multicolumn{3}{|c|}{ TAMAÑo POBLACIÓN } & \multirow{2}{*}{\multicolumn{2}{|c|}{$\begin{array}{c}\begin{array}{c}\text { EFECTIVIDAD } \\
\text { MEDIA (\%) }\end{array} \\
\text { TIT }\end{array}$}} & \multirow{3}{*}{$\mathbf{t}$} & \multirow{3}{*}{$\begin{array}{l}\text { EFfect SIze } \\
\text { Cohen (D) }\end{array}$} & \multirow{3}{*}{$\begin{array}{c}\text { SIG. } \\
\text { T-TEST }\end{array}$} & \multirow{3}{*}{$\begin{array}{c}\text { EFECTO } \\
\text { TIT }\end{array}$} \\
\hline \multirow{2}{*}{$\mathrm{N}$} & \multicolumn{2}{|c|}{ TIT } & & & & & & \\
\hline & nolnf & $\operatorname{lnf}$ & $\overline{\text { nolnf }}$ & $\operatorname{lnf}$ & & & & \\
\hline 7 & 3 & 4 & 39 & 83 & 2.714 & 2.4270 & $\mathrm{Si}(0.042)^{*}$ & $(+)$ \\
\hline
\end{tabular}

(*) Significativo al nivel 0.05; TIT nolnf = no informáticos; Inf = informáticos

\subsection{Cuasi-Experimento Q-2009}

\subsubsection{Cambios de la Replicación Q-2009 respecto al Experimento Base}

La replicación Q-2009 tuvo los siguientes cambios respecto al experimento base:

- No se estudió la Efectividad en las Sesiones de Educción: principalmente por a) el alto costo en la transcripción y análisis de las entrevistas; b) la similitud de la efectividad entre sujetos influida por el entrevistado;

- No se estudió la capacidad de retención de los sujetos o el grado de olvido de los sujetos durante el proceso de consolidación de la información.

\subsubsection{Alto costo en la transcripción y análisis de las entrevistas}

Como ya se ha mencionado en la sección 4.2.10, para medir la efectividad de los analistas en las sesiones de educción, en primer lugar se transcribieron las entrevistas, seguidamente se identificaron los elementos definitorios del dominio de problema (definidos en una lista patrón) y finalmente se calculó la efectividad de la educción medida por la cantidad de elementos del dominio mencionados sobre el total de elementos.

Durante el proceso de transcripción de las entrevistas del experimento Q-2007 surgieron algunas dificultades como pueden ser:

- Calidad de las grabaciones.

- Diversidad de nacionalidades y por consiguiente distintas formas y estilos de expresión.

- Velocidad en la expresión.

- Tono de voz. 
Dichas dificultades implicaron repetir múltiples veces la audición de determinadas frases para poder comprenderlas, antes de transcribirlas. Es por ello que el proceso de transcripción de las entrevistas de Q-2007 se realizó manualmente, sin ayuda de ningún software que lo automatice. Ello asegura que el contenido transcrito sea lo más fidedigno posible, implica un gran tiempo y esfuerzo. Comparando la duración de educción frente al tiempo de transcripción de las entrevistas (indicados en la Tabla 5.12) se ve que el esfuerzo de transcripción promedio es aproximadamente 9 veces el tiempo de educción. Por lo tanto, que el proceso de transcribir una entrevista es una tarea ardua, que requiere invertir mucho tiempo y esfuerzo

Tabla 5.12 - Esfuerzo de transcripción de las entrevistas en Q-2007

\begin{tabular}{|c|c|c|c|c|c|c|c|c|c|c|c|c|c|}
\hline ENTREVISTA & E01 & E02 & E03 & E04 & E05 & E06 & E07 & E08 & E09 & E10 & E11 & E12 & $\begin{array}{c}\text { PROME } \\
\text {-DIO }\end{array}$ \\
\hline $\begin{array}{c}\text { Tiempo } \\
\text { Educción } \\
\text { (min) }\end{array}$ & $17: 15$ & $19: 59$ & $16: 01$ & $14: 39$ & $17: 44$ & $23: 04$ & $24: 09$ & $12: 09$ & $10: 40$ & $18: 34$ & $08: 29$ & $12: 40$ & $15: 34$ \\
\hline $\begin{array}{c}\text { Tiempo } \\
\text { Transcripción } \\
\text { (horas) }\end{array}$ & $03: 15$ & $02: 44$ & $01: 45$ & $02: 42$ & $02: 30$ & $04: 10$ & $04: 30$ & $01: 10$ & $01: 48$ & $02: 24$ & $00: 45$ & $02: 00$ & $02: 28$ \\
\hline
\end{tabular}

\subsubsection{Similitud de la efectividad en la educción entre sujetos}

La efectividad media alcanzada por los sujetos experimentales de Q-2007 en las distintas fases del proceso de educción de los requisitos (entrevistas + consolidación de la información) se muestra en el gráfico de box de la Figura 5.10. Se observa una mayor dispersión de la efectividad de los sujetos durante el proceso de consolidación, mientras que las efectividades de las sesiones de educción son más homogéneas.

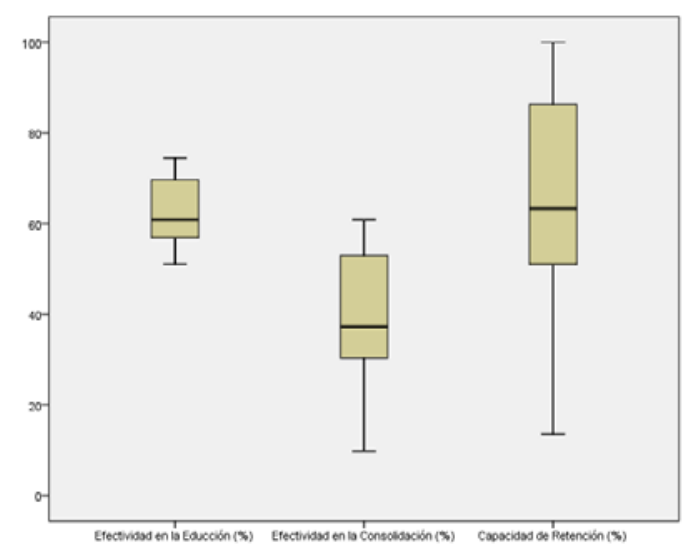

Figura 5.10 - Efectividad promedio en las fases del proceso de educción Q-2007

En la efectividad de la consolidación, la diferencia entre el máximo (61\%) y el mínimo (10\%) es de 51 puntos, lo que implica una variabilidad muy alta, mientras que por el contrario, en la efectividad de la educción existe una diferencia de 24 puntos, siendo el valor máximo (75\%) y el mínimo (51\%), lo que implica que todas las entrevistas son muy parecidas en lo que respecta a la cantidad de información proporcionada. Nótese que la efectividad en las sesiones de educción (es decir, la cantidad de información mencionada durante las entrevistas) no depende exclusivamente del analista que realiza la entrevista, sino que también del entrevistado. Ya que el entrevistado, naturalmente es quien conoce el dominio del problema, no oculta información, dice siempre la verdad y proporciona toda la información necesaria en función de las preguntas que surgen a lo largo de las entrevistas. Este hecho indica que no se está estudiando la efectividad del analista en la educción propiamente dicha.

Los hallazgos indicados llevan a los investigadores a replantearse el análisis de la efectividad de la educción. Al tratarse de entrevistas simuladas, donde las efectividades de los sujetos son muy parecidas 
y el entrevistado parece ejercer una gran influencia en la cantidad de información suministrada, no merece emplear tanto esfuerzo en estudiar la efectividad en las sesiones de educción. Por lo tanto, de aquí en adelante no se analizará la efectividad de la educción, ni la capacidad de retención (ya que éste está directamente relacionado con la efectividad de la educción, es decir, depende de la cantidad de los elementos mencionados y también de los elementos consolidados).

\subsubsection{Ejecución}

\subsubsection{Muestra}

En Q-2009 participaron 8 estudiantes del Máster en Ingeniería del Software de la Escuela Técnica Superior de Ingenieros Informáticos de la Universidad Politécnica de Madrid (España). Todos son profesionales titulados superiores en informática. La Tabla 5.13 resume los datos demográficos principales de la muestra.

Tabla 5.13 - Características principales de los sujetos experimentales Q-2009

\begin{tabular}{|c|c|c|}
\hline \multicolumn{3}{|c|}{ CUASI-EXPERIMENTO Q-2009 (7/8) } \\
\hline CARACterísticas & Nivel & \#SUJETOS \\
\hline \multirow{2}{*}{ Titulación } & No Informático & 0 \\
\hline & Informático & 8 \\
\hline \multirow{4}{*}{$\begin{array}{l}\text { Experiencia en } \\
\text { Entrevistas }\end{array}$} & 0 año & 5 \\
\hline & 1-2 años & 1 \\
\hline & 3-4 años & 1 \\
\hline & $>=5$ años & 0 \\
\hline \multirow{4}{*}{$\begin{array}{l}\text { Experiencia en } \\
\text { Educción }\end{array}$} & 0 año & 3 \\
\hline & 1-2 años & 2 \\
\hline & 3-4 años & 1 \\
\hline & $>=5$ años & 1 \\
\hline \multirow{4}{*}{$\begin{array}{l}\text { Experiencia en } \\
\text { Requisitos }\end{array}$} & 0 año & 1 \\
\hline & 1-2 años & 3 \\
\hline & 3-4 años & 1 \\
\hline & $>=5$ años & 1 \\
\hline \multirow{4}{*}{$\begin{array}{l}\text { Experiencia } \\
\text { Profesional }\end{array}$} & 0 año & 0 \\
\hline & 1-2 años & 2 \\
\hline & 3-4 años & 4 \\
\hline & $>=5$ años & 1 \\
\hline \multirow{3}{*}{$\begin{array}{c}\text { Familiaridad con } \\
\text { el Problema }\end{array}$} & No Familiar & 0 \\
\hline & Familiar & 0 \\
\hline & Muy Familiar & 0 \\
\hline
\end{tabular}

Como principales características de la muestra, destacan que los sujetos experimentales poseen experiencias en entrevistas y educción muy bajas, mayoritariamente entre 0 y 2 años, sin embargo cuentan con más años de experiencias en requisitos y profesional. Nótese que la familiaridad de los sujetos acerca del dominio del problema no se indica en la Tabla 5.13, esto se debe a que los datos demográficos de los sujetos no fueron recogidos en el mismo año del experimento, lo que podría hacer que la información proporcionada pudiera estar sesgada: es difícil que los sujetos recordaran con exactitud el ejercicio llevado a cabo durante el máster. Por tanto, los análisis correspondientes al efecto de la familiaridad acerca del dominio del problema en la educción de los requisitos no se realizarán.

\subsubsection{Preparación}

El entrevistado AG externo a la investigación, al igual que el entrevistado OD en Q-2007, se tuvo que estudiar y aprender el dominio del problema en detalle, con la finalidad de actuar con naturalidad y proporcionar la información lo más certera posible. 


\subsubsection{Realización}

La ejecución del experimento estuvo acorde con lo planificado. Se realizaron 8 entrevistas como práctica final de la asignatura de requisitos del máster igual que Q-2007, lo que aseguró que la motivación de los sujetos sea semejante en ambos experimentos.

Las sesiones de educción se realizaron individualmente y en inglés. El inglés fue un requisito obligatorio del máster a partir de ese año. Si bien el inglés no es la lengua nativa tanto del entrevistado como el de los alumnos, ambos contaban con el nivel exigido para poder dictar y cursar la asignatura, respectivamente. Al igual que Q-2007, los sujetos tuvieron 7 días para consolidar la información mencionada en las sesiones de educción. Tras presentar el informe con la información consolidada, los alumnos rellenaron manualmente el cuestionario post-experimental.

\subsubsection{Desviaciones}

No se observó ningún tipo de desviación respecto a la planificación inicial.

\subsubsection{Resultados}

\subsubsection{Reducción del Conjunto de Datos}

Si bien todos los sujetos experimentales completaron el experimento entero, uno no respondió al cuestionario post-experimental. Dicho sujeto fue eliminado del análisis.

\subsubsection{Procedimiento de Análisis}

Al tratarse de un cuasi-experimento los métodos de análisis aplicados fueron la correlación de Pearson y estadísticos descriptivos.

\subsubsection{Estadísticos Descriptivos}

La Tabla 5.14 presenta el número total de sujetos, la efectividad media, máxima y mínima alcanzada por los sujetos en la consolidación, así como la mediana, la varianza y la desviación típica. En media los sujetos tienden a consolidar el $62 \%$ de los elementos que definen el dominio del problema, siendo el máximo $80 \%$ y el mínimo un $29 \%$.

Tabla 5.14 - Estadísticos descriptivos Q-2009

Efectividad en la Consolidación (\%)

\begin{tabular}{|c|r|r|r|r|r|r|}
\hline N & Media & Mínimo & Máximo & Mediana & Varianza & Desv. típ. \\
\hline 8 & 66.39 & 29 & 80 & 61.76 & 341.627 & 18.483 \\
\hline
\end{tabular}

\subsubsection{Prueba de Hipótesis}

\section{H1a. Efecto de la Experiencia}

En la Figura 5.11 se observan gráficos de dispersión que indican la relación existente entre la experiencia (en requisitos, entrevistas, educción y profesional) y la efectividad en la consolidación. Los gráficos de dispersión presentan en el eje de abscisas los años de experiencia y en el eje de ordenadas el porcentaje (\%) de elementos consolidados por los sujetos. Como se puede apreciar en la Figura 5.11, en todos los casos la experiencia ejerce un efecto positivo, esto es, los sujetos con más años de experiencia tienden a ser más efectivos que los novatos. 


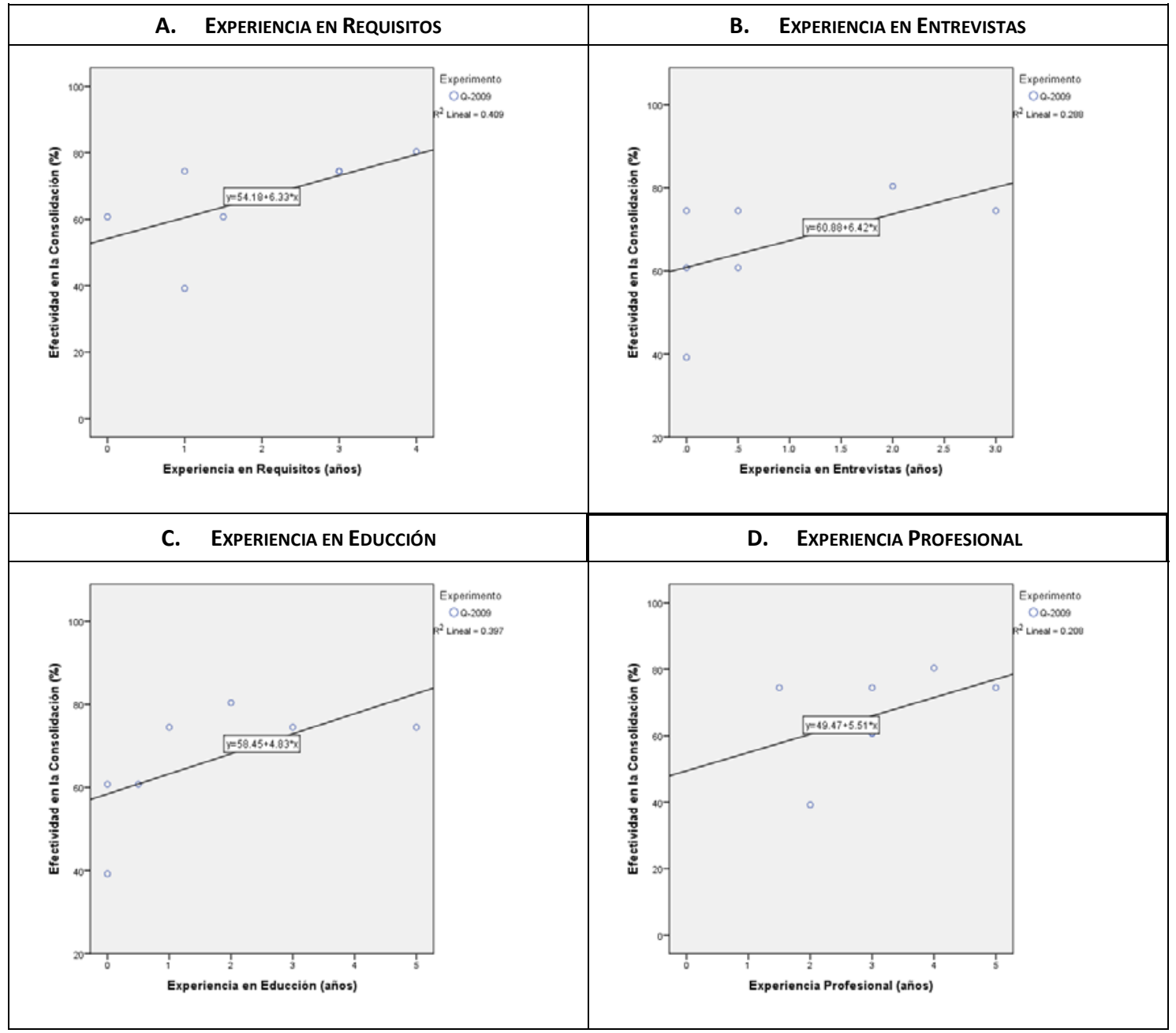

Figura 5.11 - Relación de la experiencia en sus distintas vertientes y la efectividad Q-2009

No obstante, las correlaciones presentadas en la figura anterior son estadísticamente no significativas, dado que los valores de significación obtenido son mayores al establecido (0.05) en todos los casos, tal y como se muestra en la Tabla 5.15. Se podría decir que la experiencia del sujeto perece ejercer un efecto positivo en la efectividad de la consolidación.

Tabla 5.15 - Relación de la experiencia y la efectividad en la consolidación Q-2009

\begin{tabular}{|c|c|c|c|c|}
\hline \multirow{2}{*}{$\begin{array}{c}\text { VARIABLE } \\
\text { INDEPENDIENTE }\end{array}$} & \multicolumn{3}{|c|}{ CORRELACIÓN } & \multirow{2}{*}{ EFECTO } \\
\cline { 2 - 4 } & $r$ & $\mathrm{p}$-valor & $\mathrm{N} / 8$ & \\
\hline ExpReq & .640 & .122 & 7 & $(+)$ \\
\hline ExpEntr & .537 & .214 & 7 & $(+)$ \\
\hline ExpEduc & .630 & .129 & 7 & $(+)$ \\
\hline ExpProf & .457 & .303 & 7 & $(+)$ \\
\hline
\end{tabular}

\section{H2a. Efecto del la Familiaridad}

Como se ha indicado en la sección 5.2.2.1, los datos demográficos correspondientes a la familiaridad acerca del dominio del problema no fueron recogidos. Con el fin de evitar que los efectos obtenidos resultaran sesgados, los análisis correspondientes no se llevaron a cabo.

\section{H3. Efecto de la Titulación Académica}

No fue posible estudiar el efecto de la Titulación académica en la efectividad de los sujetos, por falta de 
diversidad de titulación. Todos los sujetos que participaron en el experimento poseen formación superior en informática.

\subsubsection{Posibles variables moderadoras}

Los resultados de Q-2009 han llamado la atención a los investigadores debido al considerable incremento de la efectividad media de los sujetos. La efectividad promedio en Q-2009 en comparación con Q-2007 aumentó un 27\%; concretamente en Q-2007 los sujetos consolidaron un 39\% de los elementos mientras que en Q-2009 un 66\%, tal y como se puede apreciar en la Figura 5.12.

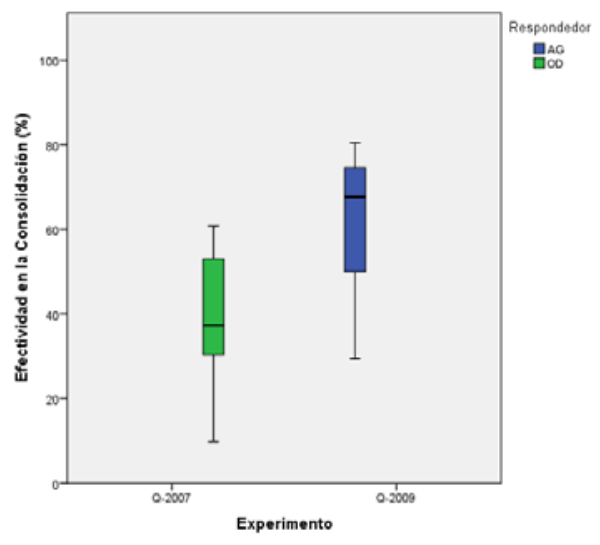

Figura 5.12 - Comparación de la efectividad media obtenida en Q-2007 y Q-2009

Muy probablemente, además de las variables estudiadas, existen otras que están influyendo en la efectividad de los sujetos. Como el proceso de educción es esencialmente un proceso donde existe una interacción humana: múltiples características cognitivas, de comunicación o personales podrían estar ejerciendo una influencia en los sujetos. Sin embargo, por una parte estudiar dichos aspectos está fuera del alcance de esta investigación. Por otra parte, no parece lógico que dichas características operen en los sujetos de un cuasi-experimento (Q-2009) y no en el otro (Q-2007). Por ello, creemos que otro tipo de variables podrían estar operando.

Q-2009 fue un experimento que se ejecutó antes el inicio de la tesis doctoral. Conversando con el entrevistado y estudiando los conceptos conceptualizados por los sujetos, los investigadores percibieron que los sujetos en 2009 durante la consolidación habían utilizado documentos adicionales. Es decir, con la finalidad de imitar más la realidad de la educción, los sujetos experimentales durante las sesiones de educción recibieron información adicional sobre el dominio del problema. Nótese que el dominio trata sobre un sistema de control de reciclado de pilas. Entre los elementos principales están las máquinas que permiten llevar a cabo el proceso de reciclado de pilas y como resultado del todo el proceso la obtención de una serie de tipos de metales. Por tanto, analizando dicha documentación los investigadores se dieron cuenta que contiene los parámetros funcionales de las máquinas así como los tipos de metales que se obtienen como resultado del proceso. Un 25\% (6 de 24) de los conceptos corresponden a los tipos de metales y un 21\% ( 5 de 24 ) a los tipos de máquinas. Es decir, un $46 \%$ (11 de 24) de los elementos que forman parte del dominio del problema. Los sujetos en 2009 dichos elementos los podrían identificar con mayor facilidad que los del 2007. Por ejemplo, en la Tabla 5.16 se presenta por cada metal y tipo de máquina (ambos tipos forman parte de los conceptos que definen el dominio del problema) la cantidad de sujetos que lo identifican.

Tabla 5.16 - Cantidad de sujetos que identifican los tipos de mentales y máquinas (conceptos del dominio)

\begin{tabular}{|c|c|c|c|c|c|c|c|c|c|c|c|}
\hline \multirow{2}{*}{ EXPERIMENTO } & \multicolumn{6}{|c|}{ TIPO METALES } & \multicolumn{5}{|c|}{ TIPO MÁQUINAS } \\
\hline & $\mathrm{C} 2$ & $\mathrm{C} 3$ & $\mathrm{C} 4$ & C5 & C6 & $\mathrm{C7}$ & $\mathrm{C} 20$ & $\mathrm{C} 21$ & $\mathrm{C} 22$ & $\mathrm{C} 23$ & $\mathrm{C} 24$ \\
\hline $\mathrm{Q}-2009(\mathrm{~N}=8)$ & 4 & 4 & 3 & 4 & 4 & 4 & 8 & 8 & 7 & 1 & 8 \\
\hline
\end{tabular}


Tanto los metales como los tipos de máquinas se identifican más en Q-2009. El 50\% de los sujetos tienden a identificar los tipos de mentales y casi el $100 \%$ identifican los tipos de máquinas. Mayores detalles sobre los elementos que definen el dominio del problema en el ANEXO B. Nótese que la documentación adicional podría ser un factor que ejerza influencia positiva a favor de los sujetos del 2009.

Otro aspecto que podría estar ejerciendo influencia en los resultados es el entrevistado, ya que él es quien proporciona más información relacionada con el dominio, aunque en este punto de la investigación aún no es posible determinar a qué se debe dicha variación de efectividad entre los experimentos. Aunque hasta el experimento E-2012 no hemos sido consientes de la importancia que tiene el entrevistado. Como se podrá observar en el Capítulo 7, sección 7.4.1 el entrevistado ejerce una marcada y significativa influencia en la efectividad de los analistas. Teniendo en cuenta que uno de los cambios en Q-2009 es el entrevistado, muy probablemente el incremento de efectividad en Q-2009 se deba a la influencia del entrevistado.

\subsection{Cuasi-Experimento Q-2011}

\subsubsection{Cambios de la replicación Q-2011 respecto al Experimento Base}

El experimento Q-2011 tuvo los siguientes cambios respecto al experimento base:

- $\quad$ Las entrevistas fueron en grupo (1:N), un entrevistado y $\mathrm{N}$ sujetos en el rol de analistas.

- Se consideraron nuevas variables relacionadas con: a) las habilidades de los sujetos en requisitos y entrevistas, fundamentalmente por la falta de diversidad de experiencia en los sujetos experimentales; b) tiempo de consolidación, tiempo que tardan los sujetos en dejar por escrito la información mencionada en las entrevistas.

- Aumento del tiempo de educción.

- El tiempo entre las sesiones de educción y el inicio de la consolidación se redujo de 7 días a 0 día, con la finalidad de aplicar un mayor control al experimento.

\subsubsection{Cambio en el modo de realizar la entrevista}

Q-2011 se diferencia de los experimentos anteriores (Q-2007, Q-2009) principalmente en el modo en que es realizada la entrevista durante la sesión de educción. La técnica de educción aplicada en los experimentos anteriores es la entrevista abierta individual (entrevista 1:1). Sin embargo, en Q-2011 es una entrevista abierta en grupo (entrevista 1: N) donde varios analistas entrevistan a un cliente al mismo tiempo. Tres son los motivos fundamentales que motivaron a los experimentadores realizar una entrevista en grupo:

- Costo del experimento: realizar un experimento en educción con entrevistas individuales es muy costoso. Para poder asegurar la comparación de las efectividades de un grupo de sujetos, es necesario que todos ellos entrevistasen a la misma persona. En caso contrario, cualquier efecto observado podría deberse tanto al sujeto en el rol de analista, como a la persona en el rol de cliente. Sin embargo, la repetición de entrevistas motiva a que surja el efecto cansancio en las personas entrevistadas dado que tienen que repetir varias veces la misma información a distintos analistas. Para mitigar este efecto de cansancio se podría: disminuir las sesiones de educción, lo que a su vez dificulta la identificación de efectos significativos de las variables estudiadas debido al reducido tamaño muestral o alternativamente, plantearse la opción de realizar una única sesión (un entrevistado frente a varios entrevistadores).

- Influencia del entrevistado en la efectividad de los sujetos: durante las entrevistas individuales se corre el riesgo de que el entrevistado influya en la efectividad de los analistas. Es decir, que 
el entrevistado proporcione más o menos información dependiendo de quién sea el sujeto que lo entreviste. Este hecho se podría evitar mediante entrevistas 1:N.

- Proceso de comprensión: una entrevista 1: $\mathrm{N}$ es diferente que la típica entrevista 1:1, ésta proporciona datos valiosos acerca de la habilidad de comprensión del analista (en oposición a la captura de información), que presumiblemente es uno de los factores claves que podría afectar a la efectividad. El hecho de que una persona pregunte durante la sesión de educción, hace que todos se beneficien de la pregunta y de las respuestas proporcionadas. Cabría esperar que la interacción analista-cliente sea más rica, aumentando consecuentemente la efectividad de los sujetos.

\subsubsection{Inclusión de nuevas variables independientes (habilidad en requisitos y en entrevistas)}

En Q-2009 y Q-2011 los estudiantes apenas poseían experiencia en requisitos y/o entrevistas, tal y como se puede apreciar en las secciones 5.2.2.1 y sección 5.3.2.1 respectivamente. Este hecho se puede deber muy probablemente al programa de postgrado de la UPM, ya que en 2007 estaba orientado a profesionales, mientras que a partir del 2008 estuvo abierto a estudiantes, quienes provenían mayoritariamente de cursos de grado. Esto trae como consecuencia que una comparación directa entre novatos/expertos en general no es posible.

La falta de diversidad en la experiencia dio lugar a contemplar otra variable o constructo que podría proporcionar información sobre una posible experiencia, subjetiva, en requisitos y actividades del área. Nótese, por tanto, que este hecho dio lugar a estudiar nuevas variables, como pueden ser las habilidades que los sujetos dicen o creen tener en requisitos y en entrevistas, respectivamente.

\subsubsection{Exclusión de la variable independiente Experiencia en Educción}

El efecto de la experiencia del analista en la efectividad se estudió bajo tres categorías: experiencia en requisitos, educción y entrevistas. En Q-2011 únicamente la experiencia en requisitos y entrevistas, dado que por olvido no se contempló la experiencia en educción.

\subsubsection{Variación del tiempo entre la educción y la consolidación}

Los procesos de educción y consolidación de los requisitos, aunque son consecutivos, no tienen por qué desarrollarse próximos en el tiempo. Es posible postergar el proceso de consolidación hasta horas más tarde o incluso días. Aunque esto es contrario a las recomendaciones generalmente aceptadas acerca de cómo realizar entrevistas, debido al riesgo de que el analista olvide información relevante, es un hecho de que dichos retrasos ocurren.

Nótese, que en Q-2007 y Q-2009 el tiempo que existe entre la sesión de educción y el proceso de consolidación de la información introduce una amenaza a la validez de los resultados, dado que no es posible saber si durante esos 7 días los sujetos han intercambiado información, trabajando juntos o se hayan copiado entre ellos. Con la finalidad de aplicar un control más riguroso, los investigadores plantearon que el proceso de consolidación de la información educida sea inmediato, es decir, que nada más terminar la sesión de educción el sujeto empezara con el reporte. De esta manera se evita que hayan aspectos, como los indicados, que estén afectando la efectividad del sujeto en la consolidación.

\subsubsection{Variación en el tiempo de educción}

La educción de requisitos de por sí es una actividad compleja, más aún al tratarse de una educción en grupo, dado que son varias personas las que interactúan con el cliente durante el levantamiento de sus primeras necesidades. Lo que provoca que el ritmo de educción sea más lento implicando que sea necesario aumentar el tiempo de educción. Este hecho motivó a los investigadores duplicar el tiempo de educción a 60 minutos. 
Merece la pena destacar, que el tiempo de educción es una variable cuyo valor se mantiene constante durante el experimento dadas las condiciones experimentales recientemente mencionadas. Por tanto, no es posible estudiar su efecto directamente. Se espera que cuanto mayor sea el tiempo empleado en la educción mayor sea la efectividad del sujeto, pero ello dependerá de cada sujeto particular y el efecto del tiempo no podrá separarse de otros efectos propios del sujeto, como la experiencia.

\subsubsection{Inclusión del tiempo de consolidación como variable contextual}

El tiempo de consolidación no se consideró en los experimentos anteriores (Q-2007 y Q-2009) por el hecho de que los informes solicitados a los sujetos al finalizar el experimento fueron presentados una semana después de la realización de las entrevistas, y por tanto existía el riesgo de que los sujetos proporcionasen información sesgada.

No obstante, en Q-2011 como fue la primera vez que los sujetos realizaron la consolidación de información de forma inmediata, fue posible medir el tiempo de la consolidación. Como el experimento fue una práctica evaluada de la asignatura de $\mathrm{RE}$, el tiempo de consolidación se limitó a la duración del examen, aproximadamente unos 180 minutos (3hs). Los sujetos podían entregar el informe de consolidación en el momento que lo deseasen, dentro del tiempo estipulado.

\subsubsection{Ejecución}

\subsubsection{Muestra}

En Q-2011 participaron 16 estudiantes del Máster en Ingeniería del Software de la Escuela Técnica Superior de Ingenieros Informáticos de la Universidad Politécnica de Madrid (España). Todos menos uno son profesionales informáticos, procedentes de varios países latinoamericanos y de Europa. La Tabla 5.17 resume los datos demográficos principales de la muestra.

Tabla 5.17 - Características principales de los sujetos experimentales Q-2011

\begin{tabular}{|c|c|c|}
\hline \multicolumn{3}{|c|}{ CUASI-EXPERIMENTO Q-2011 (16) } \\
\hline CARACTERÍ́STICAS & Nivel & \#SUJETOS \\
\hline \multirow{2}{*}{ Titulación } & No Informático & 1 \\
\hline & Informático & 15 \\
\hline \multirow{4}{*}{$\begin{array}{c}\text { Experiencia en } \\
\text { Entrevistas }\end{array}$} & 0 año & 11 \\
\hline & 1-2 años & 3 \\
\hline & 3-4 años & 1 \\
\hline & $>=5$ años & 1 \\
\hline \multirow{4}{*}{$\begin{array}{c}\text { Experiencia en } \\
\text { Requisitos }\end{array}$} & 0 año & 11 \\
\hline & 1-2 años & 3 \\
\hline & 3-4 años & 1 \\
\hline & $>=5$ años & 1 \\
\hline \multirow{4}{*}{$\begin{array}{l}\text { Experiencia } \\
\text { Profesional }\end{array}$} & 0 año & 2 \\
\hline & 1-2 años & 3 \\
\hline & 3-4 años & 0 \\
\hline & $>=5$ años & 3 \\
\hline \multirow{3}{*}{$\begin{array}{c}\text { Familiaridad con } \\
\text { el problema }\end{array}$} & No Familiar & 8 \\
\hline & Familiar & 7 \\
\hline & Muy Familiar & 1 \\
\hline \multirow{5}{*}{$\begin{array}{c}\text { Habilidad en } \\
\text { Requisitos } \\
\text { (Likert 1-5) }\end{array}$} & 1 menos habilidad & 1 \\
\hline & 2 & 2 \\
\hline & 3 & 6 \\
\hline & 4 & 7 \\
\hline & 5 mayor habilidad & 0 \\
\hline \multirow{2}{*}{$\begin{array}{c}\text { Habilidad en } \\
\text { Entrevistas }\end{array}$} & 1 menor habilidad & 2 \\
\hline & 2 & 4 \\
\hline
\end{tabular}


Estudio empírico de la influencia de la experiencia y del conocimiento del dominio del analista en la efectividad del proceso de educción de requisitos

\begin{tabular}{|c|l|c|}
\hline \multicolumn{3}{|c|}{ CUASI-EXPerimento Q-2011 (16) } \\
\hline CARActerísticAs & \multicolumn{1}{|c|}{ NIVEL } & \#SUJetos \\
\hline \multirow{2}{*}{ (Likert 1-5) } & 3 & 8 \\
\cline { 2 - 3 } & 4 & 2 \\
\cline { 2 - 3 } & 5 mayor habilidad & 0 \\
\hline
\end{tabular}

La población experimental prácticamente no cuenta con experiencia en entrevistas y requisitos. Los estudiantes reportaron mayoritariamente (14/16) experiencias menores o iguales a dos años. Sólo dos estudiantes reportaron experiencias en el rango de 3 a 5 años. Por tanto, los sujetos que participaron del cuasi-experimento Q-2011 pueden ser caracterizados como sujetos con baja experiencia. Este hecho se puede deber a que los estudiantes provienen en su mayoría de cursos de grado (recientemente acabados). No obstante, los sujetos creen poseer más habilidades que los reflejados por los años de experiencia. Los sujetos informan que poseen más habilidades en requisitos (niveles 3-4) que en entrevistas (niveles 2-3). En lo que respecta a la familiaridad el 50\% desconoce el dominio del problema.

El interés de los sujetos en ejecutar en forma debida la tarea experimental estaba asegurado dado que el cuasi-experimento correspondía a una evaluación final de la asignatura. Mediante esta prueba, los estudiantes debían demostrar su capacidad de educir información acerca de un problema a través de la técnica de entrevista abierta. Debían además demostrar su capacidad de analizar la información obtenida durante la sesión de educción y especificar por escrito los requisitos para el sistema a desarrollar.

\subsubsection{Preparación}

Al ser Q-2011 el examen final de la asignatura no fue necesario notificar individualmente a los alumnos de forma diferenciada el lugar y el día de presentación ya que todos lo harían en el mismo día.

En lo que respecta a la formación del entrevistado, no fue necesario un entrenamiento previo ya que el sujeto que actuó de entrevistado (profesor de la asignatura) fue el mismo del experimento base, y por lo tanto ya conocía el dominio del problema.

\subsubsection{Realización}

El experimento se ejecutó según lo previsto. La sesión de educción fue una entrevista en grupo con una duración máxima de 60 minutos, en la que existía un entrevistado y varios analistas. La sesión de educción fue en inglés, al igual que en Q-2009, por ser un requisito obligatorio del máster.

Es importante mencionar, por un lado, que las sesiones de educción a partir del experimento Q2011 en adelante fueron grabadas con el objetivo de recoger datos que puedan ser analizados posteriormente. No obstante, los sujetos no tuvieron acceso a dichas entrevistas como un medio de ayuda para la consolidación o elaboración de los requisitos, como ocurrió en Q-2007. Por otro lado, con el fin de explorar si la diferencia de efectividades tan pronunciada observada en Q-2009 respecto a Q2007 estuviera afectada por el uso de documentación (ver sección 5.2.4), los sujetos no tuvieron acceso a la documentación adicional durante las sesiones de educción.

Inmediatamente, finalizada la sesión de educción, los sujetos iniciaron el proceso de consolidación. En promedio, los sujetos demoraron 2 hs 15 minutos en reportar, siendo la duración máxima 3 hs y la mínima $1 \mathrm{~h} 7$ minutos. Era de esperar que el sujeto emplee el mayor tiempo posible al tratarse de un examen final.

En lo que respecta al cuestionario, éste fue implementado dentro de la plataforma de la asignatura que los estudiantes tienen acceso (Moodle). Por tanto, los datos demográficos se obtuvieron automáticamente utilizando un formulario on-line disponible en la plataforma. Los sujetos respondieron al cuestionario una semana después de la ejecución del experimento. 


\subsubsection{Desviaciones}

Todo ha ido conforme al plan previsto.

\subsubsection{Resultados}

\subsubsection{Reducción del conjunto de datos}

No fue necesario reducir el conjunto de datos experimentales, ya que todos los sujetos participaron en el experimento y en los datos no se observaron valores atípicos. Nótese no obstante, que como se ha indicado en el capítulo 4, tanto la experiencia profesional como la experiencia en desarrollo de los sujetos se obtuvieron de documentaciones adicionales (como por ejemplo, el Curriculm Vitae).

La Tabla 5.18 presenta por cada una de las variables independientes, el tamaño muestral (NTotal), la cantidad disponible de sujetos (NVálido) y la cantidad de casos perdidos (NPerdidos). Como se puede apreciar en la Tabla 5.18, en este cuasi-experimento hay 16 casos perdidos para para la experiencia en educción por los motivos indicados en la sección 5.3.1.3 y 6 casos tanto para la experiencia profesional como la experiencia en desarrollo, ya que no se disponía información adicional de todos los sujetos experimentales.

Nótese que esos sujetos serán eliminados automáticamente de los análisis que incorporen dichas variables, tanto en los análisis de los estudios individuales como a nivel de síntesis global.

Tabla 5.18 - Valores perdidos del cuasi-experimento Q-2011

\begin{tabular}{|l|c|c|c|}
\hline \multicolumn{1}{|c|}{ VARIABLE INDEPENDIENTE } & N TOTAL & N VÁLIDO & NPERDIDOS \\
\hline Experiencia en Entrevistas (años) & 16 & 16 & 0 \\
\hline Experiencia en Educción (años) & 16 & 0 & 16 \\
\hline Experiencia en Requisitos (años) & 16 & 16 & 0 \\
\hline Experiencia en Desarrollo (años) & 16 & 10 & 6 \\
\hline Experiencia Profesional (años) & 16 & 10 & 6 \\
\hline Familiaridad & 16 & 16 & 0 \\
\hline Formación Académica & 16 & 16 & 0 \\
\hline Habilidad en Entrevistas & 16 & 16 & 0 \\
\hline Habilidad en Requisitos & 16 & 16 & 0 \\
\hline
\end{tabular}

\subsubsection{Procedimiento de análisis}

Al igual que en Q-2007, para facilitar el análisis y comprensión del efecto de la familiaridad sobre la efectividad de los sujetos, se reagruparon ciertos valores. La familiaridad fue medida mediante una escala ordinal con tres valores: Muy Familiar, Familiar y No Familiar. Los resultados reportados en la sección 5.3.2.1 indican que solo un sujeto respondió que el problema le resultaba muy familiar. Por este motivo y a efectos de análisis estadísticos, hemos agrupado los sujetos familiarizados y muy familiarizados con el problema en uno sólo, quedando la familiaridad del problema con dos niveles: No Familiar, Familiar. Este hecho permite analizar la familiaridad utilizando la prueba estadística: t-test.

\subsubsection{Estadísticos descriptivos}

La Tabla 5.19 presenta el número total de sujetos que han participado del experimento, la efectividad media, máxima y mínima alcanzada por los sujetos, así como la mediana, la varianza y la desviación típica. En media los sujetos consolidan el $48 \%$ de los elementos que definen el dominio del problema, siendo la efectividad máxima un $69 \%$ y la mínima un $10 \%$. Nótese, que al igual que los experimentos anteriores ningún sujeto alcanzó a consolidar el 100\% de los elementos. 
Estudio empírico de la influencia de la experiencia y del conocimiento del dominio del analista en la efectividad del proceso de educción de requisitos

Tabla 5.19 - Estadísticos descriptivos Q-2011

Efectividad en la Consolidación (\%)

\begin{tabular}{|c|c|c|c|c|c|c|}
\hline $\mathbf{N}$ & MeDIA & MÁxıMo & Mínimo & MEDIANA & VARIANZA & DESV. TíP. \\
\hline 16 & 48.41 & 69 & 10 & 47.06 & 216.183 & 14.703 \\
\hline
\end{tabular}

\subsubsection{Prueba de Hipótesis}

Como se ha indicado en el capítulo 4, sección 4.4 la experiencia se estudiará desde dos puntos de vistas: años de experiencia y habilidad que el sujeto cree tener, correspondientes a las hipótesis H1a y H1b respectivamente.

\section{H1a. Efecto de la Experiencia}

Para estudiar el efecto de la experiencia hemos generado gráficos de dispersión y calculado las correlaciones correspondientes, tal y como se muestran en la Figura 5.13 y Tabla 5.20 respectivamente. Los gráficos presentados en la Figura 5.13 muestran que la experiencia apenas tiene efecto, las rectas de correlación son prácticamente horizontales.

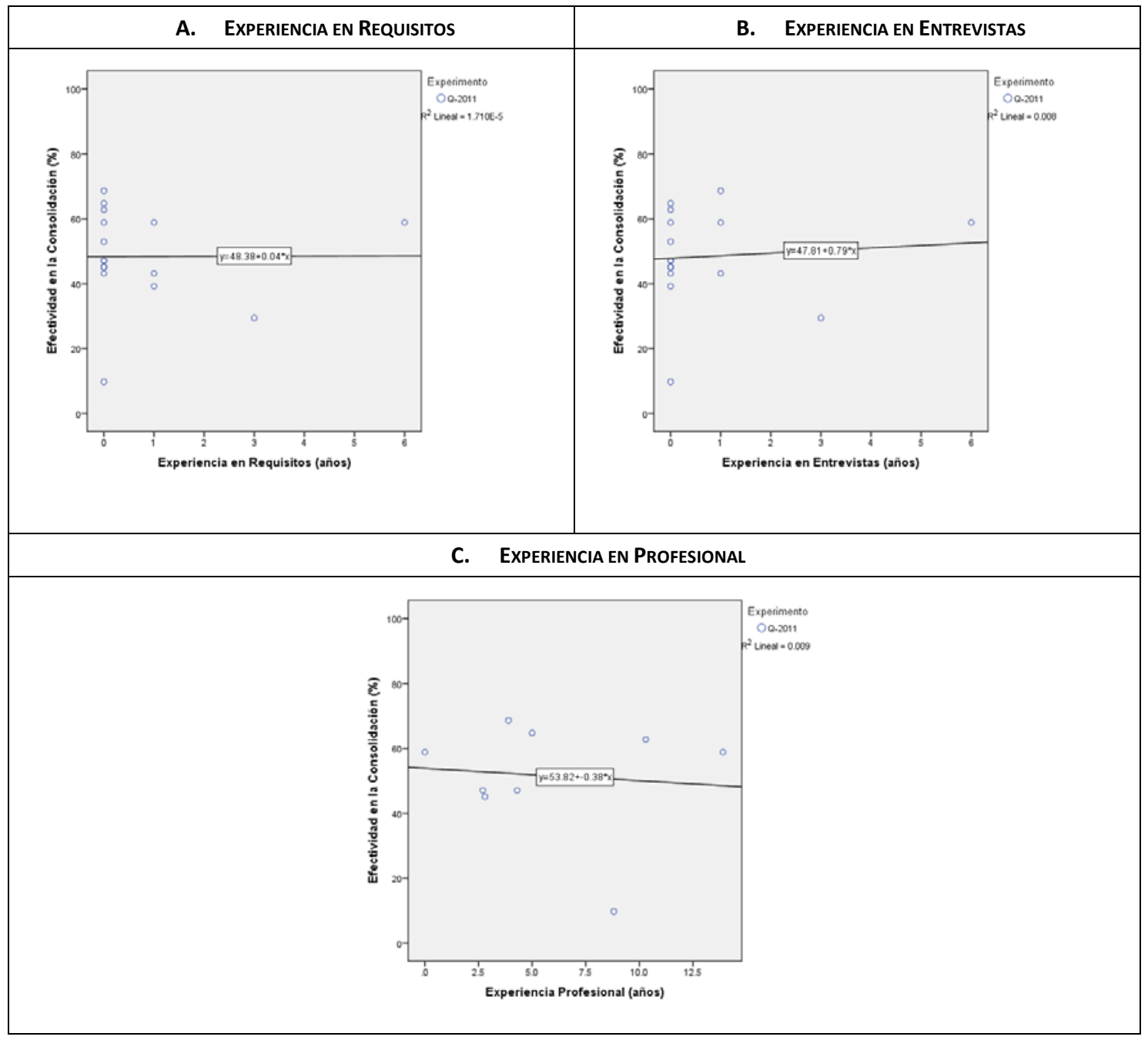

Figura 5.13 - Relación de la experiencia y la efectividad Q-2011

La Tabla 5.20 presenta por cada categoría de la experiencia analizada, el coeficiente de correlación $(r)$, el valor de significación ( $p$-valor) y la cantidad total de sujetos analizados $(\mathrm{N}=16)$. Ninguno de los coeficientes de correlación es significativo, ya que los valores $p$-valores son mayores al valor establecido (0.05). Nótese que en todos los casos, el efecto de la experiencia es nulo ( $r<=0.009$, según Cohen). 
Tabla 5.20 - Relación de la experiencia y la efectividad en la consolidación Q-2011

\begin{tabular}{|c|c|c|c|c|}
\hline \multirow{2}{*}{$\begin{array}{c}\text { VARIABLE } \\
\text { INDEPENDIENTE }\end{array}$} & \multicolumn{3}{|c|}{ CORRELACIÓN } & \multirow{2}{*}{ EFECTO } \\
\cline { 2 - 4 } & $r$ & $\mathrm{p}$-valor & $\mathrm{N}$ & \\
\hline ExpReq & .004 & .988 & 16 & $(\mathrm{X})$ \\
\hline ExpEntr & .087 & .749 & 16 & $(\mathrm{X})$ \\
\hline ExpProf & -.095 & .794 & 10 & $(\mathrm{X})$ \\
\hline
\end{tabular}

\section{H1b. Efecto de la Habilidad}

La habilidad hace referencia a la opinión subjetiva que tiene el sujeto en requisitos y en entrevistas. La habilidad se ha medido mediante una escala de Likert del 1 al 5 (menor a mayor habilidad). En los gráficos de box de la Figura 5.14 se observa una leve tendencia negativa en los datos. Tanto al considerar la habilidad en entrevistas como en requisitos, el descenso en efectividad entre los niveles 13 es evidente. La efectividad aumenta levemente en los niveles 3 y 4, pero por debajo de los niveles 1 y/o 2 respectivamente. Una recta trazada entre la mediana del nivel 1 dejaría por debajo las medianas de los demás niveles, y además la pendiente sería negativa, tal y como los coeficientes de correlación indican.

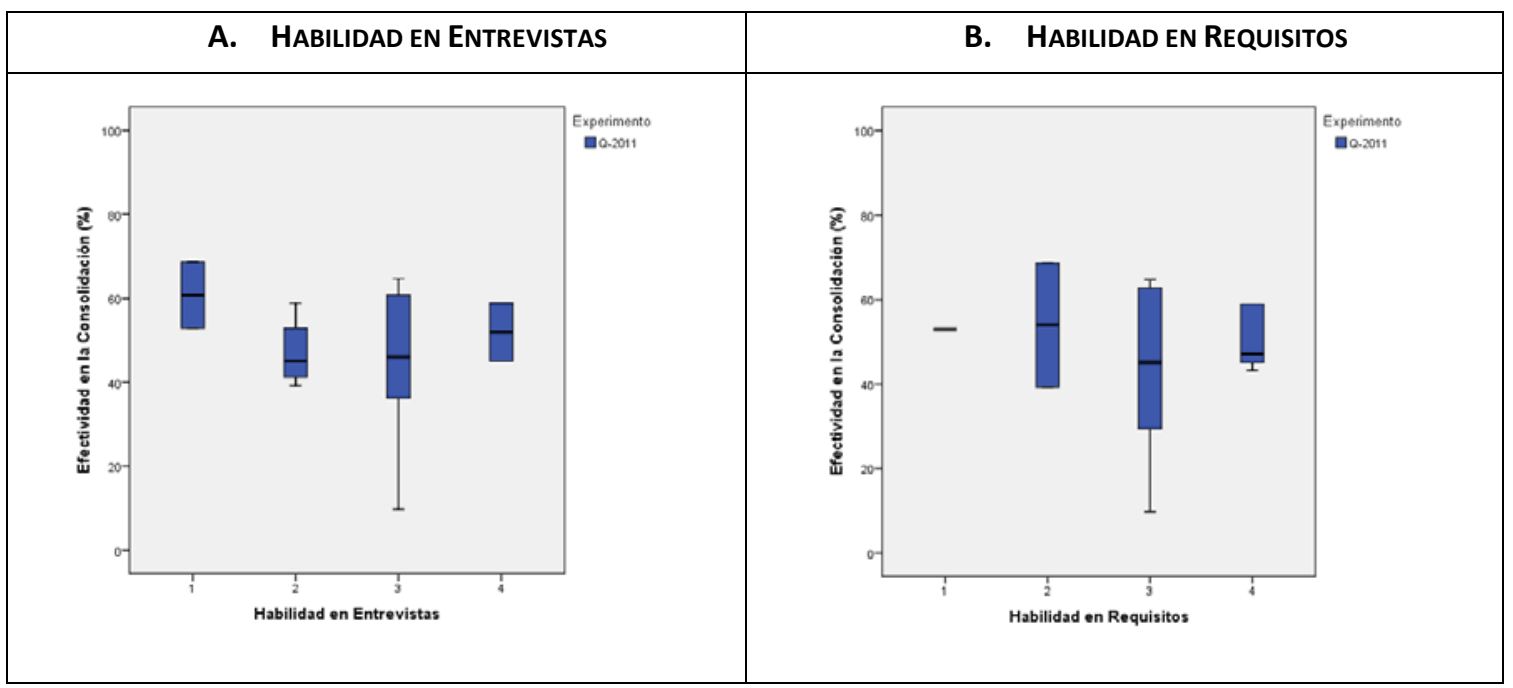

Figura 5.14 - Relación de la habilidad en entrevistas y requisitos con la efectividad Q-2011

Para comprobar las tendencias hemos calculado las correlaciones entre la habilidad y la efectividad. Como se puede apreciar en la Tabla 5.21 las correlaciones obtenidas tanto para la habilidad en requisitos como en entrevistas han sido negativas. Esto es, cuanto mayor es la valoración que el analista realiza acerca de su propia pericia, menos información relevante acerca del dominio del problema perece que es capaz de adquirir, aunque nuevamente los resultados no son significativos.

Tabla 5.21 - Relación de la habilidad (Hab) y la efectividad en la consolidación Q-2011

\begin{tabular}{|c|c|c|c|c|}
\hline \multirow{2}{*}{$\begin{array}{c}\text { VARIABLE } \\
\text { INDEPENDIENTE }\end{array}$} & \multicolumn{3}{|c|}{ CORRELACIÓN } & \multirow{2}{*}{ EFECTO } \\
\cline { 2 - 4 } & $r$ & $\mathrm{p}$-valor & $\mathrm{N}$ & \\
\hline HabReq & -.010 & $\mathrm{No}(.961)$ & 16 & $(\mathrm{X})$ \\
\hline HabEntr & -.120 & $\mathrm{No}(.659)$ & 16 & $(-)$ \\
\hline
\end{tabular}

\section{H2. Efecto del la Familiaridad}

Como se puede apreciar en la Figura 5.15 la efectividad media de los sujetos son muy similares. Los sujetos que están familiarizados con el dominio consolidan un $51 \%$ de los elementos, mientras que los que no están familiarizados un $46 \%$. La diferencia entre ambos grupos es de un $4 \%$. Sin embargo en el 
gráfico de box se puede percibir una tendencia de que los sujetos familiarizados sean más efectivos. Por otro lado, se observa una mayor variabilidad o dispersión en el grupo de los no familiarizados con el dominio siendo el mínimo un $10 \%$ y el máximo $69 \%$. El grupo de los familiarizados tienden a obtener efectividades más uniformes.

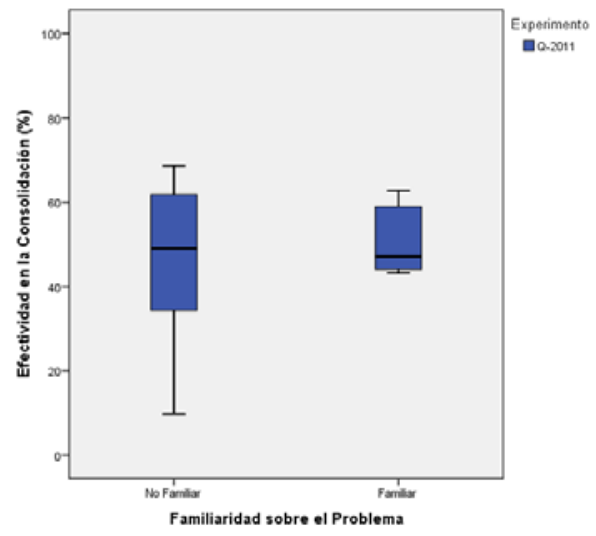

Figura 5.15 - Relación entre familiaridad del sujeto y la efectividad en la consolidación Q-2011

Los resultados estadísticos presentados en la Tabla 5.22 indican un bajo efecto positivo ( $d=0.332$ ) de la familiaridad, aunque la diferencia entre grupos es no significativa ( $p$-valor $=.545>0.05$ ). Esto es, los sujetos con familiaridad lo hacen mejor.

Tabla 5.22 - Relación la familiaridad (Fam) y la efectividad en la consolidación

\begin{tabular}{|c|c|c|c|c|c|c|c|c|}
\hline \multicolumn{3}{|c|}{ TAMAÑo POBLACIÓN } & \multirow{2}{*}{\multicolumn{2}{|c|}{$\begin{array}{c}\text { EFECTIVIDAD } \\
\text { MEDIA (\%) } \\
\text { Fam }\end{array}$}} & \multirow{3}{*}{$t$} & \multirow{3}{*}{$\begin{array}{l}\text { EFFECT Size } \\
\text { COHEN (D) }\end{array}$} & \multirow{3}{*}{$\begin{array}{l}\text { SIG. } \\
\text { T-TEST }\end{array}$} & \multirow{3}{*}{$\begin{array}{c}\text { EFECTO } \\
\text { FAM }\end{array}$} \\
\hline \multirow{2}{*}{$\mathrm{N}$} & \multicolumn{2}{|c|}{ Fam } & & & & & & \\
\hline & Sin & Con & Sin & Con & & & & \\
\hline 16 & 8 & 8 & 46 & 51 & 0.620 & 0.332 & .545 & $(+)$ \\
\hline
\end{tabular}

\section{H3. Efecto de la Titulación académica}

Como se observó en la sección 5.3.2.1 los sujetos que participaron en el experimento son todos profesionales titulados superiores en informática, menos uno. Este hecho hace que, al igual que en Q2009, no exista diversidad de titulación y por tanto no se pueda estudiar el efecto de la titulación académica sobre la efectividad de sujetos en el proceso de consolidación de los requisitos.

\subsubsection{Posibles Variables Moderadoras}

El gráfico de box de la Figura 5.16, compara la efectividad en la consolidación de los sujetos que participaron en los experimentos Q-2007, Q-2009 y Q-2011 respectivamente. Como se puede apreciar, los sujetos en Q-2011 tienden a ser menos efectivos que los sujetos en Q-2009 y más efectivos que Q2007. El decremento (o disminución) de efectividades se puede deber, como se ha comentado en la sección 5.2.9, muy probablemente al entrevistado y/o al uso de documentación adicional, mientras que el incremento (o aumento) de efectividades se pude atribuir: al modo en que se realizó la entrevista (entrevista en grupo), al aumento del tiempo de educción o a ambos conjuntamente.

A esta altura de la investigación no contamos con la cantidad suficiente de datos y diversidad para comprobar estadísticamente los efectos de las posibles variables moderadoras: entrevistado, tipo de entrevista y documentación adicional, sin embargo hipotetizamos que las diferencias se podrín deber a las razones mencionadas. 


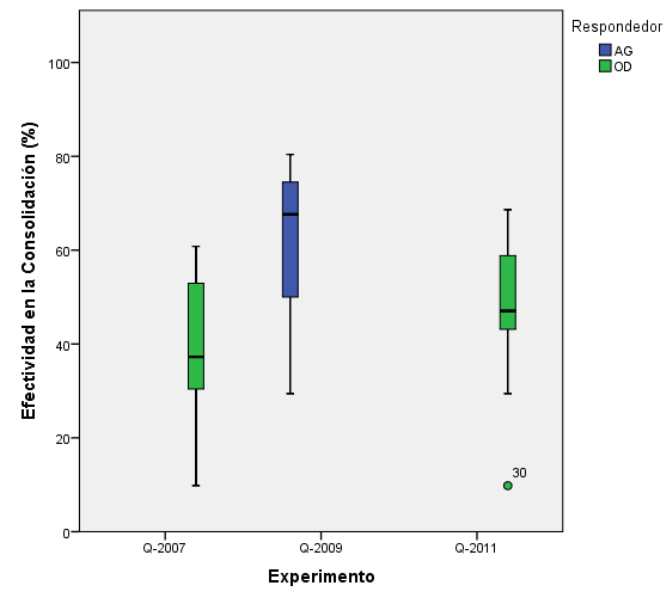

Figura 5.16 - Comparación de efectividades entre Q-2007, Q-2009 y Q-2011

\subsection{Experimento E-2012 A}

\subsubsection{Cambios de E-2012 A respecto a la serie Histórica de Experimentos}

\subsubsection{Cambio en el diseño experimental}

El motivo principal que llevó a los investigadores a modificar el diseño del cuasi-experimento a un diseño experimental de medidas repetidas, fue fundamentalmente los problemas de poder estadístico, tal y como se ha descrito en el capítulo de metodología sección 4.6. El nuevo diseño permitió estudiar experimentalmente los efectos del conocimiento con la ventaja de no necesitar un número elevado de sujetos tal y como se indicó en la sección 4.6.4.

\subsubsection{Bloqueo del experimento por entrevistado}

Para ejecutar un experimento con características similares a una educción de requisitos mediante entrevista abierta, es necesario contar con un entrevistado por entrevista. Es más que esperable que las características del entrevistado influyan en la efectividad del analista (por ejemplo, se obtiene más información de un entrevistado que habla más que de uno que hable menos). La situación ideal sería que las entrevistas fueran realizadas por el mismo entrevistado (siendo éste un parámetro del experimento). No obstante esto es difícil, ya que la carga de trabajo que el entrevistado debería asumir (alrededor 30 entrevistas, acerca de dos dominios de problemas distintos) podrían sesgar los resultados del experimento debido a efectos de fatiga u otras amenazas. Además los resultados del experimento podrían acusar una reducida validez externa (siendo este únicamente utilizado en el experimento).

Por motivos de conveniencia (recursos, cantidad de horas y de clases disponibles, número de alumnos) el número de entrevistados se ha establecido en dos. Por tanto los sujetos quedan bloqueados por entrevistado. Aunque tres entrevistados hubieran sido preferibles, dos parecen suficientes para paliar los efectos de cansancio y aprendizaje:

- Efecto de cansancio: la experiencia ganada en los estudios previos realizados en 2007, 2009 y 2011 apunta a que un entrevistado puede realizar unas 5 entrevistas por sesión sin experimentar cansancio. Realizar entre 5-7 entrevistas, con unas 4 horas de duración máxima es soportable. A partir de este punto las entrevistas comienzan a ser demandantes para el entrevistado. El diseño experimental planteado a continuación y el número de sujetos disponible permite que los entrevistados no superen las 7 entrevistas por sesión.

- Efecto de aprendizaje: la repetición de la misma entrevista una y otra vez podría provocar que la información suministrada a los entrevistados no fuera uniforme (e.j.: los primeros entrevistadores podrían obtener más/menos información que los últimos). Nuestra experiencia en estudios 
similares apunta a que la información suministrada a los entrevistados varia más entre-días que dentro-del-día. En el mismo día, los entrevistados tienden a automatizar las respuestas (es decir, repetir la misma respuesta para idénticas preguntas). Probablemente, esto se deba a que la concentración que el entrevistado debe mantener durante las sesiones de educción provoca que recuerde las respuestas dadas momentos antes y tienda a repetirlas. El diseño experimental planteado sólo precisa un día para cada sesión de entrevistas, lo que creemos que elimina (/mitiga) los efectos de aprendizaje en el entrevistado. La utilización de dos entrevistados permite resolver un problema práctico importante.

\subsubsection{Bloqueo del experimento por idioma}

La educción de requisitos es una fase donde la comunicación es primordial, y por lo tanto es esperable que los sujetos que utilicen su lengua materna sean más efectivos que los sujetos que utilizan una segunda lengua. Con el fin de evitar que el idioma sea un factor influyente en la efectividad tanto para los sujetos experimentales como para los entrevistados, hemos establecido que los sujetos nativos en lengua española deberían usar el español durante la entrevista, mientras que los demás sujetos (procedentes de diversas nacionalidades, tales como Alemania, Rumanía, Serbia, Suecia, Dinamarca y USA) deberían usar el inglés. Nótese que, excepto en un caso, el inglés es segunda lengua para todos los estudiantes. El primer grupo entrevistará a JW, mientras que el segundo grupo a OD.

Los entrevistados OD y JW son nativos en español. El entrevistado OD posee un conocimiento adecuado del inglés. Es conveniente indicar que el inglés es el idioma operativo en el programa de estudios (del máster) cursado por los sujetos experimentales. El entrevistado OD es docente de este máster.

La confusión Entrevistado-Idioma no es una amenaza a la validez en este caso. Al bloquear los sujetos por entrevistado, se evita que ambas variables (Entrevistado e Idioma) sufran interacciones (es decir, que un sujeto nativo español no pueda comunicarse suficientemente bien en Inglés) que aumenten la varianza del factor Conocimiento del Dominio y dificulte la identificación de efectos significativos. Naturalmente, los problemas de comunicación en un segundo idioma pueden disminuir la efectividad de los sujetos. Sin embargo, el diseño within-subjects asegura que cada sujeto realice la educción para los dominios conocido y desconocido en el mismo idioma, cancelado de esta forma los efectos negativos de las comunicación en Inglés.

\subsubsection{Momento en que E-2012 A se ha ejecutado}

Los experimentos que forman parte de la serie histórica (Q-2007 a Q-2011) fueron llevados a cabo a finales del curso de Ingeniería de Requisitos. Los sujetos durante los cursos académicos respectivos recibieron formación en tareas relacionadas con educción de requisitos, y al final del curso el experimento servía como práctica evaluable de la asignatura. Este hecho aseguraba la motivación que pudieran tener los sujetos a la hora de realizar el experimento. Por otro lado, la efectividad de los sujetos podría estar orientada en función de la formación que los sujetos hayan recibido durante el curso, es decir, los sujetos pueden ser más o menos efectivos, no porque realmente lo sean, sino por la formación recibida.

Por el contrario, el experimento base (E-2012 A) fue ejecutado al comienzo del curso académico 2012/2013, antes de que los estudiantes que actuaron como sujetos recibieran formación alguna en Ingeniería de Requisitos. Esto evita cualquier influencia que el curso pudiera ejercer sobre los sujetos. En contrapartida, dada la relativamente poca experiencia reportada por los sujetos en actividades relacionadas con los requisitos, ello sin duda podía ejercer un efecto nivelador en la efectividad de los sujetos, esto es, podía provocar que los sujetos no destacasen en ningún dominio en particular. 


\subsubsection{Cambio en el modo de realizar la entrevista}

Cuando los investigadores en Q-2011 se dieron cuenta de que el tipo de entrevista podría ser una potencial variable moderadora, buscaron la manera de balancear los puntos de datos obtenidos en la serie histórica, de forma a que el conjunto de datos sea más o menos equitativo. Nótese que en este punto de la investigación, considerando el mismo entrevistado (OD) y el mismo problema (PD1), se contaba con más datos en la entrevista en grupo (16 sujetos) frente a la individual (7 sujetos), era necesario aumentar los puntos de datos correspondientes a entrevistas individuales.

\subsubsection{Reducción del tiempo de educción}

La reducción del tiempo de educción a 30 minutos viene tras el cambio en el modo de realizar la entrevista. Nótese que en los experimentos anteriores con entrevista individual ninguno de los sujetos empleó el tiempo máximo de educción establecido ${ }^{26}$, esto sugiere que el tiempo de educción sea menor o igual. Por otro lado, se ha podido observar que en las entrevistas en grupo el tiempo puede estar confundido con el modo de realizar la entrevista, es decir, no se sabe si el incremento de efectividades se deba al aumento del tiempo de educción o al hecho de que la entrevista sea en grupo (esto es, que los sujetos se beneficien de las preguntas o respuestas hechas o dadas a los demás y en consecuencia aumenten sus efectividades). Los investigadores a demás de las razones expuestas, no disponían de tiempo y recursos suficientes para emplear más tiempo.

\subsubsection{Ejecución}

\subsubsection{Muestra}

En E-2012 participaron 14 estudiantes del Máster en Ingeniería del Software de la Escuela Técnica Superior de Ingenieros Informáticos de la Universidad Politécnica de Madrid (España). Todos son profesionales informáticos, aunque con distintas especialidades. La Tabla 5.23 resume los datos demográficos principales de la muestra. Nótese que no todos los sujetos respondieron al cuestionario.

Tabla 5.23 - Características principales de los sujetos experimentales E-2012 A

\begin{tabular}{|c|c|c|}
\hline \multicolumn{3}{|c|}{ CUASI-EXPERIMENTO E-2012 (14) } \\
\hline CARACTERÍSTICAS & Nivel & \#SUJETOS \\
\hline Titulación & $\begin{array}{l}\text { Ingenieros Informáticos o en } \\
\text { Ciencias de la Computación } \\
\text { (C.S) }\end{array}$ & 14 \\
\hline \multirow{4}{*}{$\begin{array}{c}\text { Experiencia en } \\
\text { Entrevistas }\end{array}$} & 0 año & 8 \\
\hline & 1-2 años & 3 \\
\hline & 3-4 años & 2 \\
\hline & $>=5$ años & 0 \\
\hline \multirow{4}{*}{$\begin{array}{l}\text { Experiencia en } \\
\text { Educción }\end{array}$} & 0 año & 7 \\
\hline & 1-2 años & 5 \\
\hline & 3-4 años & 1 \\
\hline & $>=5$ años & 0 \\
\hline \multirow{4}{*}{$\begin{array}{c}\text { Experiencia en } \\
\text { Requisitos }\end{array}$} & 0 año & 6 \\
\hline & 1-2 años & 5 \\
\hline & 3-4 años & 1 \\
\hline & $>=5$ años & 1 \\
\hline \multirow{4}{*}{$\begin{array}{l}\text { Experiencia } \\
\text { Profesional }\end{array}$} & 0 año & 2 \\
\hline & 1-2 años & 3 \\
\hline & 3-4 años & 0 \\
\hline & $>=5$ años & 3 \\
\hline Experiencia en & 0 año & 2 \\
\hline
\end{tabular}

\footnotetext{
${ }^{26}$ Para mayores detalles, en el Anexo D se encuentra disponible el conjunto de datos (dataset) de los experimentos.
} 
Estudio empírico de la influencia de la experiencia y del conocimiento del dominio del analista en la efectividad del proceso de educción de requisitos

\begin{tabular}{|c|c|c|}
\hline \multicolumn{3}{|c|}{ CUASI-EXPERIMENTO E-2012 (14) } \\
\hline CARACTERÍ́sticas & Nivel & \#SUJETOS \\
\hline \multirow[t]{3}{*}{ Desarrollo } & 1-2 años & 3 \\
\hline & 3-4 años & 3 \\
\hline & $>=5$ años & 0 \\
\hline \multirow{2}{*}{$\begin{array}{c}\text { Familiaridad con } \\
\text { el problema }\end{array}$} & Familiar - PC1 & 11 \\
\hline & Familiar - PD1 & 1 \\
\hline \multirow{5}{*}{$\begin{array}{c}\text { Habilidad en } \\
\text { Requisitos } \\
\text { (Likert 1-5) }\end{array}$} & 1 menos habilidad & 0 \\
\hline & 2 & 2 \\
\hline & 3 & 9 \\
\hline & 4 & 1 \\
\hline & 5 mayor habilidad & 1 \\
\hline \multirow{5}{*}{$\begin{array}{c}\text { Habilidad en } \\
\text { Entrevistas } \\
\text { (Likert 1-5) }\end{array}$} & 1 menor habilidad & 0 \\
\hline & 2 & 4 \\
\hline & 3 & 6 \\
\hline & 4 & 3 \\
\hline & 5 mayor habilidad & 0 \\
\hline
\end{tabular}

La población experimental no cuenta con mucha experiencia en tareas relacionadas con educción de requisitos. Los estudiantes reportan mayoritariamente experiencias menores a dos años. Sólo dos estudiantes reportan experiencias en el rango de 3 a 5 años. En lo que respecta a la familiaridad 11 sujetos de 14 están familiarizados con el problema PC1 y 1 con el PD1.

Existe una buena concordancia entre nuestro diseño y la familiaridad predicha por los sujetos. Para evitar influencias del experimentador en los resultados, hemos optado por seguir una política ITT Intention to Treat (Gupta, 2011) por lo que el análisis se realizará al diseño original no teniendo en cuenta la opinión de los participantes sobre su familiaridad con el problema.

\subsubsection{Preparación}

Para el experimento E-2012 A, los sujetos fueron notificados por correo electrónico: el día, la hora y lugar donde realizarían las sesiones de educción. Los entrevistados, con la finalidad de ejercer correctamente el papel de clientes, se han estudiado y preparado con antelación los problemas.

\subsubsection{Realización}

El experimento se realizó acorde a lo planificado. La primera sesión (problema conocido) tuvo lugar el 11 de septiembre del 2012. Las sesiones de educción tuvieron una duración aproximada de 30 minutos, sin embargo ninguno de los sujetos, en el experimento, sobrepasó el tiempo establecido para la educción. En promedio, las sesiones de educción consumieron 25 minutos, siendo la duración mínima 15 y la duración máxima 30, mientras que la segunda sesión (problema desconocido) tuvo lugar el 14 de octubre del 2012. En promedio las sesiones de educción duraron 28 minutos, siendo la duración mínima 26 y la máxima 30. En contrapartida, los sujetos consumieron todo el tiempo de reporte con pocas excepciones.

Finalizada la sesión de educción, los sujetos pasaron a la clase donde se encontraba el investigador con el rol de vigilante e iniciaron el reporte de toda la información relevante adquirida durante las entrevistas. El vigilante tuvo la función de aclarar cualquier duda respecto al ejercicio, así como también registrar los tiempos de consolidación. Los sujetos durante el reporte tuvieron libertad en el formato para documentar la información educida. El reporte generado por los estudiantes fue entregado al vigilante.

\subsubsection{Desviaciones}

Tanto el experimento base como la replicación se llevaron a cabo acorde con la planificación inicial. Por tanto no existieron desviaciones durante la ejecución del experimento. 


\subsubsection{Resultados del Experimento Base E-2012 A}

\subsubsection{Reducción del conjunto de datos}

No fue necesario reducir el conjunto de datos experimentales ya que no hubo dropouts (todos los sujetos completaron el experimento entero), y no existen valores atípicos o outliers que, eventualmente, pudieran excluirse.

Nótese, no obstante, que para este experimento hay tres casos perdidos tal y como se puede apreciar en la Tabla 5.24. De los cuales uno de los sujetos no respondió al cuestionario y dos de ellos no no proporcionaron información adicional sobres sus experiencias: profesional y de desarrollo.

Tabla 5.24 - Valores perdidos del cuasi-experimento Q-2011

\begin{tabular}{|l|r|r|r|}
\hline \multicolumn{1}{|c|}{ VARIABLE INDEPENDIENTE } & \multicolumn{1}{c|}{ N TOtAL } & \multicolumn{1}{c|}{ N VÁLIDO } & \multicolumn{1}{c|}{ NPERDIDOS } \\
\hline Experiencia en Entrevistas (años) & 14 & 13 & 1 \\
\hline Experiencia en Educción (años) & 14 & 13 & 1 \\
\hline Experiencia en Requisitos (años) & 14 & 13 & 1 \\
\hline Experiencia en Desarrollo (años) & 14 & 11 & 3 \\
\hline Experiencia Profesional (años) & 14 & 12 & 2 \\
\hline Familiaridad & 14 & 13 & 1 \\
\hline Formación Académica & 14 & 13 & 1 \\
\hline Habilidad en Entrevistas & 14 & 13 & 1 \\
\hline Habilidad en Requisitos & 14 & 13 & 1 \\
\hline
\end{tabular}

\subsubsection{Procedimiento de análisis}

Para estudiar los efectos de la experiencia, la habilidad y la familiaridad hemos aplicado el modelo de regresión en lugar del modelo de correlación o el t-test, ya que creemos que el entrevistado tiene un efecto en los resultados. Este hecho, nos permite estimar de manera más precisa los valores de dichas variables independientes, ya que de lo contrario la variabilidad motivada por el entrevistado se sumaría a la variabilidad de la propia población, lo que impediría diferenciar el efecto del entrevistado de los demás. Nótese que tanto la experiencia como para la familiaridad los resultados lo hemos presentado en términos del coeficiente de correlación $\left(r^{27}\right)$, el cual representa el grado de asociación que existe entre la efectividad y las distintas variables independientes.

Para estudiar el efecto del conocimiento hemos aplicado el MLG (Modelo Lineal General).

\subsubsection{Estadísticos descriptivos}

Como se puede apreciar en la Tabla 5.25, los sujetos que entrevistaron a JW, tanto para el dominio conocido como para el dominio desconocido, en media tienden a consolidar más elementos que definen el dominio del problema comparados con los sujetos que entrevistaron a OD. Sin embargo, al comparar las efectividades alcanzadas según el tipo de dominio, los sujetos que entrevistaron a OD tienden a adquirir más información en el problema conocido (28\%) frente al desconocido (25\%). Por el contrario, los sujetos que entrevistaron a JW en media adquieren menos información en el problema conocido (48\%) frente al desconocido (51\%).

27 Para obtener el valor del coeficiente de regresión, hemos empleado el calculador de tamaños de efectos: http://www.uccs.edu/ /becker/, en el que se informa el valor de la t (obtenido del modelo de regresión) y los grados de libertad que se corresponde con $\mathrm{N}-2$. 
Dichas diferencias confirman la previsible influencia del entrevistado en la efectividad del analista, así como el acierto de bloquear por entrevistado. No obstante los valores absolutos de efectividad, las diferencias de efectividades observadas entre los dos dominios (conocido, desconocido) por cada entrevistado son mínimas, alrededor de un $3 \%$.

Tabla 5.25 - Estadísticos descriptivos en función del dominio del problema, diferenciados por entrevistados

\begin{tabular}{|c|c|c|c|c|}
\hline \multicolumn{5}{|c|}{ Efectividad (\%) } \\
\hline & \multicolumn{4}{|c|}{ Conocimiento sobre el Dominio del Problema } \\
\hline & \multicolumn{2}{|c|}{ CONOCIDO (PC1) } & \multicolumn{2}{|c|}{ DESCONOCIDO (PD1) } \\
\hline & OD & JW & OD & JW \\
\hline $\mathrm{N}$ & 7 & 7 & 7 & 7 \\
\hline Media & 28.04 & 47.88 & 24.93 & 50.98 \\
\hline Máximo & 43 & 69 & 39 & 73 \\
\hline Mínimo & 13 & 20 & 14 & 24 \\
\hline Mediana & 24.07 & 53.70 & 23.53 & 52.94 \\
\hline Varianza & 105.657 & 417.728 & 72.683 & 246.059 \\
\hline Desv. típ. & 10.279 & 20.438 & 8.525 & 15.686 \\
\hline
\end{tabular}

En los gráficos de box mostrados en la Figura 5.17 se observa una mayor dispersión en los sujetos que entrevistaron a JW, mientras que con OD las efectividades alcanzadas por los sujetos son más homogéneas. Nótese que existe mayor variabilidad en JW tanto en el problema desconocido como en el conocido, siendo más elevada en el problema conocido. Nuevamente, dicha diferencia de dispersiones refleja los efectos del entrevistado sobre la efectividad de los analistas, los cuales pueden ser aislados gracias a su inclusión como variable de bloque.

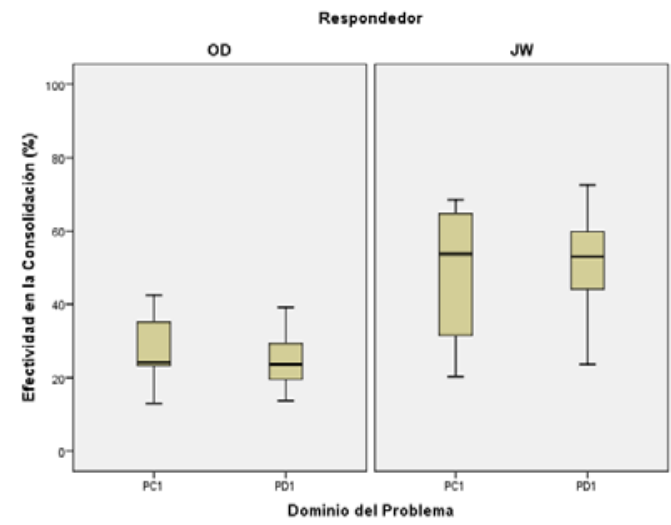

Figura 5.17 - Efectividad promedio diferenciada por problema y entrevistado E-2012A

\subsubsection{Prueba de hipótesis}

Dado que el experimento E-2012, además de permitir el estudio experimental del efecto del conocimiento en la efectividad, está compuesto por dos cuasi-experimentos: uno para el problema conocido (PC1) y otro para el problema desconocido (PD1). Los efectos de las variables independientes (experiencia, familiaridad y habilidad) los analizaremos en ambos cuasi-experimentos, por lo tanto las preguntas de investigación serán enfocadas y respondidas para un dominio conocido y uno desconocido.

\section{H1.a. Efecto de la Experiencia}

La Tabla 5.26 presenta por cada dominio del problema, la relación entre las distintas experiencias y la efectividad. Concretamente: 
- La experiencia en educción tiende a ejercer un efecto positivo en la efectividad de los sujetos, tanto en el problema PD1 $(r=.516)$ y el problema PC1 $(r=.322)$. Esto es los sujetos con más experiencia en educción tienden a ser más efectivos.

- La experiencia en entrevistas y la experiencia profesional ejercen un efecto negativo. Esto es, los sujetos con más años de experiencia profesional o en entrevistas tienden a ser menos efectivos.

- La experiencia en requisitos y la experiencia en desarrollo tienden a ejercer efectos contarios. Se observar un efecto positivo en el dominio desconocido y un efecto negativo en el dominio conocido.

Nótese que el efecto de las distintas experiencias tiende a ser moderado/bajo y en ningún caso son estadísticamente significativas.

Tabla 5.26 - Relación de la experiencia y la efectividad en la consolidación E-2012 A

\begin{tabular}{|c|c|c|c|c|c|}
\hline \multirow{2}{*}{$\begin{array}{l}\text { DOMINIO } \\
\text { PROBLEMA }\end{array}$} & \multirow{2}{*}{$\begin{array}{c}\text { VARIABLE } \\
\text { INDEPENDIENTE }\end{array}$} & \multicolumn{3}{|c|}{ CORRELACIÓN } & \multirow[t]{2}{*}{ ЕFесто } \\
\hline & & $r$ & $\mathrm{p}$-valor & $\mathrm{N}$ & \\
\hline \multirow{5}{*}{ PD1 } & ExpReq & .734 & No(.050) & 13 & $(+)$ \\
\hline & ExpEntr & -.188 & $\mathrm{No}(.540)$ & 13 & $(-)$ \\
\hline & ExpEduc & .516 & $\mathrm{No}(.063)$ & 13 & $(+)$ \\
\hline & ExpDes & .111 & No(.710) & 11 & $(+)$ \\
\hline & ExpProf & -.295 & $\mathrm{No}(.312)$ & 12 & $(-)$ \\
\hline \multirow{5}{*}{ PC1 } & ExpReq & .234 & $\mathrm{No}(.443)$ & 13 & $(-)$ \\
\hline & ExpEntr & -.188 & $\mathrm{No}(.540)$ & 13 & $(-)$ \\
\hline & ExpEduc & .322 & $\mathrm{No}(.286)$ & 13 & $(+)$ \\
\hline & ExpDes & -.103 & No(.765) & 11 & $(-)$ \\
\hline & ExpProf & -.286 & No(.370) & 12 & $(-)$ \\
\hline
\end{tabular}

\section{H1.b. Efecto de la Habilidad}

La Tabla 5.27 presenta por cada dominio del problema, la relación de la habilidad en requisitos y la habilidad en entrevistas con la efectividad. Los resultados ponen de manifiesto:

- Un bajo efecto positivo de la habilidad en requisitos tanto en PD1 $(r=.312)$ como en PC1 $(r=.187)$. Esto es, cuanto mayor es la percepción del sujeto sobre su propia pericia en entrevistas, mayor es la información adquirida.

- Efectos contrarios de la habilidad en entrevistas en función del dominio del problema. Se observa un efecto positivo en PD1 y un efecto negativos en PC1. Esto es, cuanto mayor es la experiencia que el sujeto cree tener en entrevistas, mayor es su efectividad en un dominio desconocido y menor en uno conocido.

Tabla 5.27 - Relación de la habilidad (Hab) y la efectividad en la consolidación E-2012A

\begin{tabular}{|c|c|c|c|c|c|}
\hline \multirow{2}{*}{$\begin{array}{l}\text { DOMINIO DEL } \\
\text { PROBLEMA }\end{array}$} & \multirow{2}{*}{$\begin{array}{c}\text { VARIABLE } \\
\text { INDEPENDIENTE }\end{array}$} & \multicolumn{3}{|c|}{ CORRELACIÓN } & \multirow{2}{*}{$\begin{array}{c}\text { EFECTO } \\
\text { HAB }\end{array}$} \\
\hline & & $r$ & $p$-valor & $N$ & \\
\hline \multirow{2}{*}{ PD1 } & HabReq & .312 & $\mathrm{No}(.302)$ & 13 & $(+)$ \\
\hline & HabEntr & .150 & No(.625) & 13 & $(+)$ \\
\hline \multirow{2}{*}{ PC1 } & HabReq & .187 & No(.543) & 13 & $(+)$ \\
\hline & HabEntr & -.111 & $\mathrm{No}(.719)$ & 13 & $(-)$ \\
\hline
\end{tabular}




\section{H2.a. Efecto de la Familiaridad}

Dado que no existe diversidad suficiente de familiaridad (ver sección 5.4.2), no es razonable estudiar su efecto. De un total de 13 sujetos 12 desconocen el dominio PD1. Este hecho era de esperarse, dado que el dominio del problema PD1 (Reciclado de pilas) fue planteado como desconocido, con la finalidad de separar el efecto de la experiencia del conocimiento. Por el contrario, 11 de 13 sujetos conocen el dominio PC1, al igual que PD1 no existe diversidad suficiente para estudiar su efecto. Sin embargo, para ambos casos, presentaremos el resultado obtenido para cada caso, aunque sabemos de antemano los resultados (en este caso, por la desproporción de los grupos) no serían fiables del todo.

Los resultados estadísticos presentados en la Tabla 5.22 indican un bajo efecto positivo de la familiaridad tanto en el problema PD1 ( $d=.110)$ como en el problema PC1 ( $d=.187)$, aunque la diferencia entre grupos es no significativa ( $p$-valor $>0.05$ ). Esto es, los sujetos con familiaridad lo hacen mejor. Nótese que dichos resultados hay que tomarse con la debida cautela.

Tabla 5.28 - Relación la familiaridad (Fam) y la efectividad en la consolidación E-2012 A

\begin{tabular}{|c|c|c|c|c|c|c|c|}
\hline \multirow{3}{*}{$\begin{array}{c}\text { DOMINIO } \\
\text { DEL } \\
\text { PROBLEMA }\end{array}$} & \multicolumn{3}{|c|}{ TAMAÑO POBLACIÓN } & \multirow{3}{*}{$\mathbf{t}$} & \multirow{3}{*}{$\begin{array}{l}\text { EFFECT SIZE } \\
\text { COHEN (D) }\end{array}$} & \multirow{3}{*}{$\begin{array}{c}\text { SIG. } \\
\text { T-TEST }\end{array}$} & \multirow{3}{*}{$\begin{array}{c}\text { EFECTO } \\
\text { FAM }\end{array}$} \\
\hline & \multirow{2}{*}{$\mathrm{N}$} & \multicolumn{2}{|c|}{ Fam } & & & & \\
\hline & & $\operatorname{Sin}$ & Con & & & & \\
\hline PD1 & 13 & 12 & 1 & 182 & .110 & $\mathrm{No}(.860)$ & $(+)$ \\
\hline PC1 & 13 & 2 & 11 & 311 & 187 & No(.763) & $(+)$ \\
\hline
\end{tabular}

\section{H2.b. Efecto del Conocimiento}

Antes de proceder con la prueba de la hipótesis planteada en la sección 4.7.2, comprobaremos si los datos experimentales cumplen o no la condición de homocedasticidad y normalidad de residuos exigidos por el GLM, tal y como se ha indicado en la sección 4.7.12

- Esfericidad. Como el diseño es within-subject sería necesario estudiar la condición de esfericidad, no obstante, como nuestro factor tiende dos niveles, la condición de esfericidad siempre se cumple (Meyers et al., 2012).

- Homocedasticidad. Para comprobar la homogeneidad de varianzas se podría utilizar el test de Levene, sin embargo, en nuestro caso como el factor bajo estudio es intra-sujetos y no inter-sujetos, este test es innecesario.

- Normalidad de los datos. Para comprobar la normalidad de los datos hemos generado el gráfico Q-Q mostrado en la Figura 5.18.

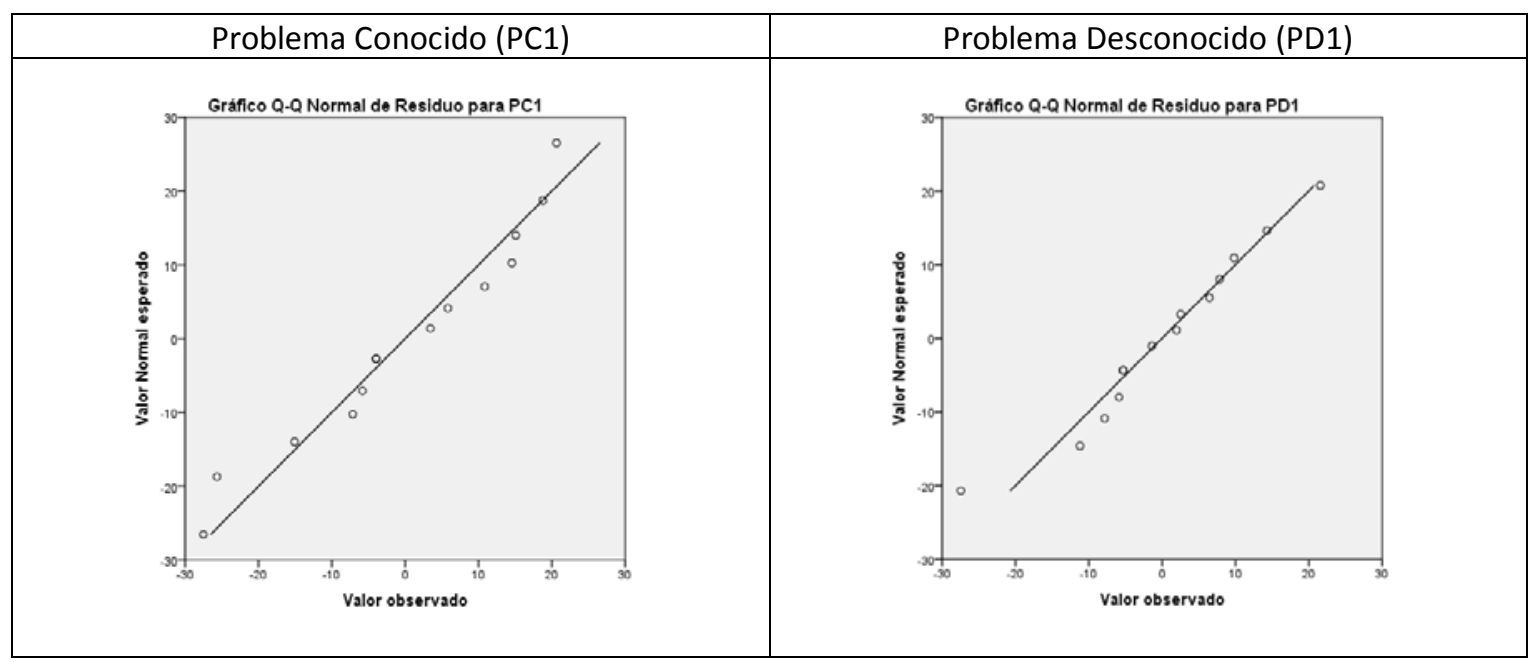

Figura 5.18 - Gráfico de Q-Q (PD1, PC1) 
El gráfico Q-Q presenta simultáneamente para cada elemento el valor esperado y el valor observado bajo el supuesto de normalidad. Cuanto más se asemeje la distribución de los puntos a una línea recta (bisectriz de los ejes de coordenadas), éstos estarán aproximadamente normalizados, es decir, se asemejarán a una distribución normal. En Figura 5.18 se observa por cada problema, que la distribución de los puntos se asemeja a una línea recta por lo que se pude decir que los valores obtenidos están aproximadamente normalizados.

La prueba de normalidad de Kolmogorov-Smirnov y Shapiro-Wilk (para muestras menores a 50 casos), presentada en la Tabla 5.29 confirma la normalidad del modelo para el problema PC1 normal (KS: $p$-value=0.132 y SW: $p$-value=0.129) y PD1 (KS: $p$-value=0.200 y SW: $p$-value=0.423).

Tabla 5.29 - Pruebas de normalidad MLG E-2012 A

\begin{tabular}{|l|r|r|r|r|r|r|r|r|}
\hline & \multicolumn{2}{|c|}{ Estadísticos } & \multicolumn{3}{c|}{ Kolmogorov-Smirnov $^{\text {a }}$} & \multicolumn{3}{c|}{ Shapiro-Wilk } \\
\cline { 2 - 9 } & Asimetría & Curtosis & Estadístico & \multicolumn{1}{c|}{ gl } & \multicolumn{1}{c|}{ Sig. } & Estadístico & \multicolumn{1}{c|}{ gl } & \multicolumn{1}{c|}{ Sig. } \\
\hline Residuo para PC1 & .517 & -.1 .117 & .200 & 14 & .132 & .904 & 14 & .129 \\
Residuo para PD1 & .483 & -.894 & .147 & 14 & $.200^{*}$ & .940 & 14 & .423 \\
\hline
\end{tabular}

*. Este es un límite inferior de la significación verdadera.

a. Corrección de la significación de Lilliefors

Los resultados del GLM de medidas repetidas se muestran en la Tabla 5.30. En primer lugar, se puede observar que la interacción Conocimiento $x$ Entrevistado es no significativa. Ello implica que es posible estudiar los efectos del conocimiento de forma conjunta entre entrevistados. Los resultados indican que no existe un efecto significativo del Conocimiento ( $p$-valor $=0.633>0.05$ ) sobre la efectividad del proceso de educción. La Hipótesis Nula $\left(\mathrm{H}_{1.0}\right)$ no puede ser rechazada, esto es los sujetos tienden a obtener efectividades similares tanto en el problema conocido como en el problema desconocido. Dado que el experimento tiene poder suficiente para detectar efectos medios, esto implica que el efecto del conocimiento, si existe, debe ser muy bajo, hecho confirmado por el estimador de tamaño de efecto $\mathrm{Eta}^{2}=0.02 . \mathrm{Eta}^{2}$ representa el \% de varianza explicada por el factor; cuanto mayor sea ésta, más influyente es el factor. No es posible traducir el valor $\mathrm{Eta}^{2}$ a unidades naturales, por lo que para su interpretación se utilizan las guías sugeridas por (Cohen, 1988). La ventaja de utilizar estas guías es que permiten comparar estimadores de naturaleza heterogénea. En nuestro caso, $\mathrm{Eta}^{2}=0.02<0.2$, lo cual corresponde de acuerdo a Cohen con un efecto muy pequeño. Este efecto muy pequeño puede considerarse equivalente a un efecto muy pequeño del estimador effect size $d$, esto es, prácticamente no existe efecto alguno.

Tabla 5.30 - Efecto del conocimiento (GLM) - E-2012 A

\begin{tabular}{|c|c|c|c|c|c|c|}
\hline ORIGEN & $\begin{array}{c}\text { SUMA DE } \\
\text { CUADRADOS TIPO } \\
\text { III }\end{array}$ & GL & $\begin{array}{c}\text { MEDIA } \\
\text { CUADRÁTICA }\end{array}$ & F & SIG. & ETA $^{2}$ \\
\hline Conocimiento & 33.904 & 1 & 33.904 & .240 & .633 & .020 \\
\hline Entrevistado & 3685.583 & 1 & 3685.583 & 13.181 & .003 & .523 \\
\hline $\begin{array}{c}\text { Conocimiento } \\
\text { Entrevistado }\end{array}$ & 67.469 & 1 & 67.469 & .477 & .503 & .038 \\
\hline
\end{tabular}

Aunque no era el objetivo de este experimento, el bloqueo por Entrevistado, nos permite descubrir que el Entrevistado tiene una influencia positiva y estadísticamente significativa ( $p$-valor $=0.003<$ 0.05) en la efectividad del proceso de educción. Esto pone de manifiesto que en la educción de requisitos, un componente crítico es la persona que proporciona la información, es decir el cliente o usuario. El grado de influencia del Entrevistado en la efectividad alcanzada por los sujetos es Eta2 = $0.523>0.5$, esto es, un efecto muy alto (Cohen, 1988). 


\section{H3. Efecto de la Titulación Académica}

No es posible estudiar su efecto, ya que todos los sujetos son titulados en informática, tal y como se indica en la Tabla 5.42 de la sección 5.4.2.1.

\subsubsection{Posibles Variables Moderadoras}

Dado que el experimento E-2012 A y el Experimento E-2012 B (descrito en la siguiente sección) pueden considerarse un único experimento, las posibles variables moderadoras se discutirán en la sección correspondiente del experimento E-2012B. Para mayores detalles consúltese la sección 5.5.4.

\subsection{Experimento E-2012 B}

\subsubsection{Cambios en la Replicación E-2012B respecto al Experimento E-2012A}

E-2012 B corresponde a la replicación interna de E-2012 A. Ambos experimentos son bastante similares en todos los aspectos: la hipótesis, el factor, la variable dependiente, la tarea experimental, entre otros, salvo algunas excepciones:

- Hemos modificado los dominios de problema utilizados en el experimento, pero uno sigue siendo dominio conocido (DC) y el otro dominio desconocido (DD).

- Hemos modificado el orden de realización de los problemas. Es decir, en la primera sesión del experimento se usa un problema desconocido y, en la segunda un problema conocido.

- La replicación se ha llevado a cabo después de que los sujetos hayan recibido formación en Ingeniería de Requisitos y específicamente en educción.

\subsubsection{Cambio de los objetos experimentales}

La diferencia principal entre el experimento base (E-2012 A) y la replicación interna radica en los objetos experimentales. En un experimento de medidas repetidas, todos los sujetos realizan la tarea experimental sobre todos los problemas. Dado que los problemas ya son conocidos por los sujetos por haber sido usados en el experimento, éstos no se pueden volver a utilizar. Por tanto nuevos problemas deben ser definidos.

En la replicación interna hemos decidido utilizar como problema conocido un sistema de gestión de matrículas de un punto de información universitaria, mientras que el problema desconocido trata sobre un sistema de compra y venta de carteras de acciones, tal y como indica la sección 4.6.7. Los problemas PD2 y PC2 corresponden a la instanciación de los tratamientos Dominio desconocido y Dominio conocido, respectivamente.

\subsubsection{Cambio en el orden de realización de los problemas}

Recordando, en E-2012 A, los sujetos realizaron la educción sobre el problema conocido en primer lugar, y el problema desconocido en segundo lugar. Este orden fue utilizado para que los estudiantes, al enfrentarse a un problema conocido, pudieran ganar confianza en su capacidad para realizar entrevistas. No obstante, al no haber llevado a cabo ningún tipo de actividad warning-up para evitar efectos de reactividad ${ }^{28}$ de la situación experimental, ello podría haber provocado un efecto negativo de la efectividad de los sujetos en el primer problema (PC1).

Cambiar el orden de los problemas durante la replicación interna (primero el problema PD2, perteneciente a un dominio desconocido, seguido por PC2, perteneciente al dominio conocido)

28 Reactividad a la situación experimental significa que los sujetos son conscientes de que están realizando un experimento y cambian su comportamiento (por ejemplo, pueden hacer más esfuerzos, para aumentar).Cuando los sujetos no saben que realizan un experimento, se comportan de forma más natural. 
permitirá, mediante un análisis conjunto del experimento y la replicación (ver sección 6.1.1.4), eliminar el efecto de orden. Nótese que dicho efecto no desaparecerá de la replicación, por lo que deberá tenerse en cuenta durante la interpretación de la misma.

\subsubsection{Momento en que la replicación se ha ejecutado}

Como se ha mencionado, el E-2012A fue ejecutado los primeros días del curso de Requisitos, antes de que los estudiantes recibieran formación alguna en Ingeniería de Requisitos. Por el contrario, E-2012 B se llevó a cabo a finales, por lo que los sujetos recibieron durante el curso formación, training en tareas relacionadas con educción de requisitos (como prácticas), documentación, así como también formación en análisis, verificación y validación. En total, los alumnos recibieron más de 40 horas de clase. A esto hay que añadir el trabajo propio y estudio, hasta completar 6 créditos ECTS ${ }^{29}$. Este cambio, permite a los investigadores explorar los efectos de la formación en la efectividad de los sujetos al disponer de información de línea base previa (E-2012 A).

\subsubsection{Ejecución}

\subsubsection{Muestra}

La Tabla 5.31 información relacionada con la familiaridad que poseen los sujetos respecto a los dominios del problema. Nótese, que las demás características demográficas de los sujetos son las mismas que las indicadas en la sección 5.4.2.1, ya que en E-2012 B participaron los mismos sujetos del experimento E2012 A.

Tabla 5.31 - Características principales de los sujetos experimentales E-2012B

\begin{tabular}{|c|c|c|}
\hline \multicolumn{3}{|c|}{ CUASI-EXPERIMENTO E-2012 (13/14) } \\
\hline CARACTERÍSTICAS & NIVEL & \#SUJETOS \\
\hline $\begin{array}{c}\text { Familiaridad con } \\
\text { el problema }\end{array}$ & Familiar (PD2) & 10 \\
\cline { 2 - 3 } & Familiar (PC2) & 12 \\
\hline
\end{tabular}

En la replicación del experimento E-2012B participaron 13 de los 14 estudiantes que participaron en el experimento, donde 10 sujetos dicen tener familiaridad con el problema PD2, y 12 sujetos con el problema PC2. Nótese que, varios sujetos aparentemente poseen familiaridad en el problema PD2, durante el análisis consideraremos que el problema PD2 es desconocido para los sujetos.

\subsubsection{Preparación}

Al igual que E-2012 A, los sujetos fueron notificados por correo electrónico: el día, la hora y lugar donde realizarían las sesiones de educción. Los entrevistados, con la finalidad de ejercer correctamente el papel de clientes, se han estudiado y preparado con antelación los problemas.

\subsubsection{Realización}

El experimento se realizó acorde a lo planificado. La primera sesión (problema desconocido) tuvo lugar el 17 de enero del 2013. Las sesiones de educción tuvieron una duración máxima de 30 minutos, sin embargo ninguno de los sujetos, en el experimento, sobrepasó el tiempo establecido para la educción. En promedio, las sesiones de educción consumieron 31 minutos, siendo la duración mínima 23 y la duración máxima 42, mientras que la segunda sesión (problema conocido) tuvo lugar el 18 de enero del 2013. En promedio las sesiones de educción duraron 24 minutos, siendo la duración mínima 15 y la máxima 33. En contrapartida, los sujetos consumieron todo el tiempo de reporte con pocas excepciones.

\footnotetext{
${ }^{29}$ http://ec.europa.eu/education/tools/ects_en.htm
} 


\subsubsection{Desviaciones}

Tanto el experimento base como la replicación se llevaron a cabo acorde con la planificación inicial. Por tanto no existieron desviaciones durante la ejecución de los experimentos.

\subsubsection{Resultados}

\subsubsection{Reducción del conjunto de datos}

Hemos tenido una incidencia en lo que respecta al número de sujetos experimentales: un sujeto, no ha realizado la tarea experimental del problema desconocido (PD2). Hemos eliminado dicho sujeto del análisis.

\subsubsection{Estadísticos descriptivos}

Los resultados observados en la Tabla 5.32 van en la dirección esperada. Los sujetos que entrevistaron a $\mathrm{JW}$, tanto para el problema conocido como para el problema desconocido, en media tienden a adquirir más información comparada con los sujetos que entrevistaron a OD. Los sujetos que entrevistaron a JW adquieren más información en el problema conocido (85\%) frente al problema desconocido (62\%). En la misma dirección pero en menor proporción, los sujetos que entrevistaron a OD adquieren más información en el problema conocido (46\%) frente al problema desconocido (40\%). Dichas diferencias confirman una vez más la influencia del entrevistado en la efectividad de los analistas.

Tabla 5.32 - Estadísticos descriptivos para la efectividad en los problemas: PC2 y PD2, diferenciado por entrevistado

\begin{tabular}{|c|c|c|c|c|}
\hline & \multicolumn{4}{|c|}{ Conocimiento sobre el Dominio del Problema } \\
\hline & \multicolumn{2}{|c|}{ DESCONOCIDO (PD2) } & \multicolumn{2}{|c|}{ CONOCIDO (PC2) } \\
\hline & OD & JW & OD & JW \\
\hline $\mathrm{N}$ & 5 & 7 & 6 & 7 \\
\hline Media & 40.00 & 62.29 & 46.30 & 85.19 \\
\hline Máximo & 58 & 78 & 67 & 93 \\
\hline Mínimo & 26 & 46 & 30 & 76 \\
\hline Mediana & 40.00 & 60.00 & 42.59 & 88.89 \\
\hline Varianza & 182.000 & 157.905 & 224.966 & 52.583 \\
\hline Desv. típ. & 13.491 & 12.566 & 14.999 & 7.251 \\
\hline
\end{tabular}

La efectividad media alcanzada por los sujetos experimentales en cada uno de los dominios de problema se muestra en el gráfico de perfil de la Figura 5.19. El gráfico de perfil representa en el eje de abscisas los dominios de problemas utilizados en la replicación y en el eje de ordenada la efectividad media de los sujetos. Nótese que las efectividades están diferenciadas por entrevistado.

El gráfico de perfil refleja un posible efecto positivo del Conocimiento para el problema conocido. Los sujetos que entrevistaron a OD son un $6 \%$ más efectivo en el PC2 mientras que con JW las diferencias son incluso más pronunciadas, alcanzando una diferencia de un $23 \%$. No puede descartarse que esta diferencia de efectividades observada entre entrevistados pueda deberse a una posible interacción del entrevistado con el conocimiento. En todo caso, dicha interacción tiene carácter ordinal, esto es, los efectos de un nivel de un factor no son iguales para todos los niveles de otros factores, pero siempre van en la misma dirección (Hair, Hair, Black, Babin, \& Anderson, 2013). Por lo tanto, el modelo de análisis sigue siendo válido. 


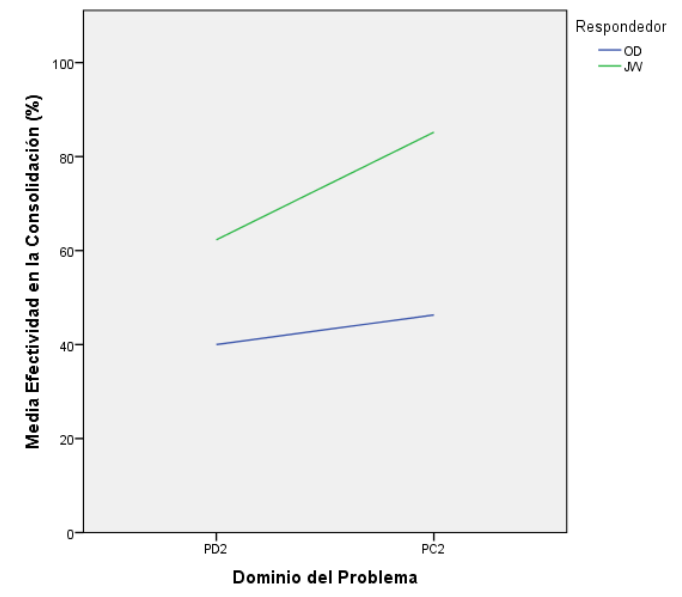

Figura 5.19 - Efectividad promedio diferenciada por problema y entrevistado E-2012B

En los gráficos de box mostrados en la Figura 5.20 se observa una mayor dispersión en los sujetos que entrevistaron a OD frente a los sujetos que entrevistaron a JW. Al diferenciar por dominio de problema, se observa una mayor variabilidad en el problema conocido con OD. Nuevamente, dicha diferencia de dispersiones refleja los efectos del Entrevistado sobre la efectividad de los analistas y una posible interacción con el conocimiento.

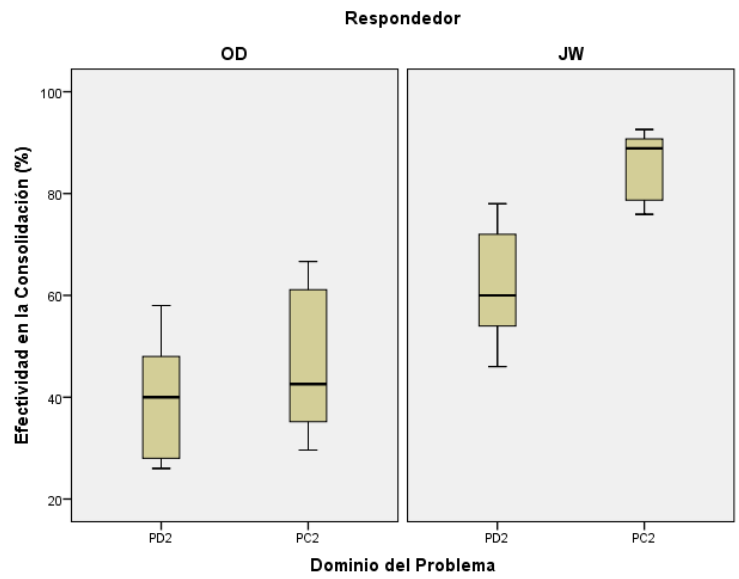

Figura 5.20 - Replicación Interna

\subsubsection{Prueba de hipótesis}

Es importante mencionar que los dominios del problema PC2 y PD2 surgieron con la finalidad de aumentar el tamaño muestral mínimo requerido para diseños de medidas repetidas (ver sección 4.7.5) pero fundamentalmente para estudiar los efectos del conocimiento del dominio del problema. Por este motivo, nos centraremos únicamente en responder a la pregunta de investigación RQ2 (hipótesis H2b) relacionada con el conocimiento y no seguiremos la estructura seguida hasta el momento.

\section{H2.b. Efecto del Conocimiento}

Al igual que el experimento base, antes de proceder con la prueba de hipótesis, comprobaremos si los datos experimentales cumplen o no la condición de homocedasticidad y normalidad de residuos, tal y como se ha indicado en la sección 4.6.12. La homogeneidad de varianzas, al igual que E-2012 A, como el factor bajo estudio es intra-sujetos y no inter-sujetos, este test es innecesario. Para comprobar la normalidad de los residuos del modelo hemos usado las pruebas de Kolmogorov-Smirnov (KS) y ShapiroWilk (SW). Los resultados presentados en la Tabla 5.33 muestran que los datos para PD2 provienen de una distribución normal (KS: $p$-value $=0.200$ y SW: $p$-value $=0.692$ ). Sin embargo, los datos de $P C 2$ tienen 
una pequeña desviación: son normales para KS ( $p$-value $=0.183$ ) pero no normales para SW ( $p$ value $=0.046$ ). Esta desviación es, sin embargo, ligeros (los valores de asimetría y curtosis están dentro de los rangos habituales de \pm 1 ). No obstante, creemos que el resultado generado por el MLG es fiable.

Tabla 5.33 - Pruebas de normalidad E-2012B

\begin{tabular}{|l|r|r|r|r|r|r|r|r|}
\hline & \multicolumn{2}{|c|}{ Estadísticos } & \multicolumn{3}{c|}{ Kolmogorov-Smirnov $^{\text {a }}$} & \multicolumn{3}{c|}{ Shapiro-Wilk } \\
\cline { 2 - 9 } & Asimetría & Curtosis & Estadístico & \multicolumn{1}{c|}{ gl } & \multicolumn{1}{c|}{ Sig. } & Estadístico & \multicolumn{1}{c|}{ gl } & Sig. \\
\hline Residuo para PD2 & -.090 & -.581 & .117 & 12 & .200 & .954 & 12 & .692 \\
Residuo para PC2 & -.746 & -.977 & .203 & 12 & .183 & .858 & 12 & .046 \\
\hline
\end{tabular}

*. Este es un límite inferior de la significación verdadera.

a. Corrección de la significación de Lilliefors

Los resultados del GLM de medidas se muestran en la Tabla 5.34. Los resultados indican que no existe un efecto significativo del Conocimiento ( $p$-valor $=0.301>0.05$ ) sobre la efectividad del proceso de educción. La Hipótesis Nula $\left(\mathrm{H}_{1.0}\right)$ no puede ser rechazada, esto es los sujetos tienden a obtener efectividades similares tanto en el problema conocido como en el problema desconocido. Este resultado es perfectamente coherente con el efecto del conocimiento sobre la efectividad medio-bajo (Eta2 = 0.106).

Tabla 5.34 - Efecto del conocimiento (GLM) - E-2012 B

\begin{tabular}{|c|c|c|c|c|c|c|}
\hline ORIGEN & $\begin{array}{c}\text { SUMA DE } \\
\text { CUADRADOS } \\
\text { TIPO III }\end{array}$ & GL & $\begin{array}{c}\text { MEDIA } \\
\text { CUADRÁTICA }\end{array}$ & F & SIG. & ETA $^{2}$ \\
\hline Conocimiento & 87.791 & 1 & 87.791 & 1.191 & .301 & .106 \\
\hline Entrevistado & 5523.851 & 1 & 5523.851 & 23.265 & .001 & .699 \\
\hline $\begin{array}{c}\text { conocimiento } \\
\text { entrevistado }\end{array}$ & 420.148 & 1 & 420.148 & 5.698 & .038 & .363 \\
\hline
\end{tabular}

Existe un efecto significativo del Entrevistado ( $p$-valor $=0.001<0.05$ ) y su interacción con el conocimiento (Entrevistado $\times$ Conocimiento) es significativa ( $p$-valor $=0.038>0.05$ ). Se confirma así la influencia del Entrevistado sobre la efectividad del proceso de educción, y por otro lado, la posible interacción Conocimiento x Entrevistado sugiere que la efectividad de la educción depende tanto o más del entrevistado que del analista.

Para comprobarlo, analizaremos el efecto del conocimiento diferenciado por entrevistado. Este enfoque hace que el tamaño muestral sea muy pequeño, por lo que resulta virtualmente imposible determinar si la muestra es normal o no. Por ello, aplicaremos el test no paramétrico de Wilcoxon para muestras pareadas.

Los resultados del test se reportan en la Tabla 5.35. Se puede apreciar que existe un efecto significativo del conocimiento tanto para el OD $(z=-1.438, p$-valor $=.138)$ como para JW $(z=-2.197, p$ valor $=0.028$ ).

Ateniendo únicamente a los test, la conclusión que se deriva es que el efecto del conocimiento es positivo, pero está fuertemente moderado por el entrevistado. Tanto para OD como para JW el efecto del conocimiento es marcado y significativo. En otras palabras, la presente replicación afirma la existencia de un efecto del conocimiento independientemente del entrevistado que ha participado en el proceso de educción.

Tabla 5.35 - Test de Wilcoxon

\begin{tabular}{|c|c|c|c|}
\hline ENTREVISTADO & SIG. & $\mathbf{Z}$ & $\begin{array}{c}\mathbf{H}_{\mathbf{0}} \\
\text { (PC2 }=\text { PD2) }\end{array}$ \\
\hline OD & .138 & -1.483 & Retener \\
\hline JW & .028 & -2.197 & Rechazar \\
\hline
\end{tabular}




\subsubsection{Posibles Variables Moderadoras}

El experimento base (E-2012A) y la replicación interna (E-2012B), pueden considerarse en conjunto, como un único experimento, lo que permite determinar los efectos de las potenciales variables moderadoras descritas a continuación. Nótese, que las moderadoras se analizan junto con el conocimiento en el capítulo 6 síntesis de resultados, para mayores detalles consúltese la sección 6.6.1.

Las variables moderadoras serían el Entrevistado, la Formación que recibieron los sujetos (al principio o al final del curso académico) y el Orden de Realización que refleja el orden en que los sujetos afrontaron los problemas. En el experimento base E-2012A, el orden fue conocido-desconocido mientras que en la replicación E-2012 B, el orden fue el inverso, es decir, problemas desconocidoconocido. Dado que los dos posibles órdenes han sido ensayados, el Orden de Realización puede interpretarse como un factor con dos niveles Antes y Después.

En lo que respecta a las moderadoras, los resultados de la Tabla 6.17 (disponible en el capítulo 6) ponen de manifiesto que:

- El Entrevistado ejerce un marcado efecto estadísticamente significativo en la efectividad de educción de los sujetos. En unidades naturales, un Entrevistado (JW) proporciona un $27.4 \%$ más de información que el otro (OD).

- La Formación ejerce un pronunciado efecto estadísticamente significativo en la efectividad de los sujetos. Los sujetos fueron un $20.9 \%$ más efectivos en promedio Después de la formación.

- El Orden de Realización de las sesiones de educción también posee un efecto, tal y como habíamos supuesto. En términos porcentuales, los sujetos fueron un $\mathbf{7 . 8 \%}$ más efectivos en el problema presentado en segundo lugar. El resultado es no significativo $(p=0.061)$, aunque muy próximo al nivel de significación $\alpha$.

Nótese, no obstante, que al comparar la efectividad de los sujetos con el histórico de experimentos, la efectividad de los mismos ha bajado aproximadamente un $20 \%$, tal y como se muestra en la Figura 5.21 .

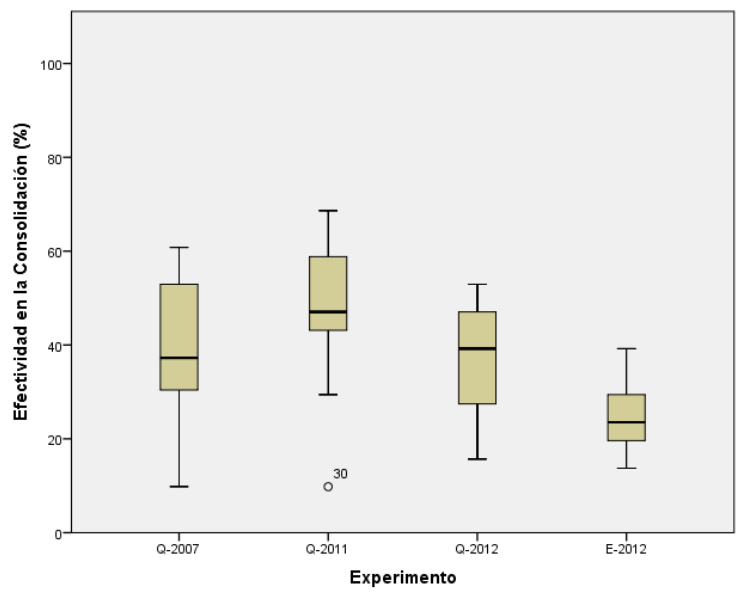

Figura 5.21 - Efectividad en la consolidación. Histórico de Experimentos - PD1 - Entrevistado OD

Varios pueden ser los motivos que justifiquen dichos resultados, entre ellos la formación que reciben los sujetos. Es importante indicar que los experimentos anteriores se realizaron al final del curso tras recibir la formación del curso de requisitos. No obstante, desde el punto de vista de los sujetos otros aspectos podrían estar afectando. En E-2012 hemos realizado unas entrevistas postexperimentales donde los sujetos manifestaron varias razones, por citar algunas: a) al tratarse de un experimento realizado el primer día de clases no tenían muy claro que se esperaba del ejercicio (ansiedad, para muchos era la primera vez que realizaban entrevistas); b) sugirieron realizar un warming up sobre requisitos con la finalidad de recordar aspectos relevantes sobre los mismos, ya que realizaban 
la educción de requisitos basándose en sus experiencias previas. Este hecho motivó a que el experimento E-2013 en lugar de ejecutarse el primer día de clases, tuviera lugar después de 2 semanas de clases. Por tanto, además de la formación que recibieron los sujetos, como bien se ha demostrado que afecta a la efectividad de los sujetos, una potencial variable moderadora podría ser el warming up.

\subsection{Cuasi-Experimento Q-2012}

\subsubsection{Cambios de la Replicación Externa Q-2012 respecto a Q-2011}

El experimento Q-2012 tuvo los siguientes cambios respecto al experimento Q-2011:

- Se consideraron nuevas variables independientes relacionadas con: a) la experiencia en desarrollo y b) las habilidades de los sujetos en desarrollo.

- Se redujo el tiempo de consolidación necesario para reportar la información educida fundamentalmente por restricciones de configuración del experimento.

\subsubsection{Inclusión de la Experiencia en Desarrollo como variable independiente}

Tras el análisis post-hoc realizado en E-2012, los investigadores al hablar con los estudiantes y comparar sus efectividades, observaron que el tipo de experiencia, concretamente la experiencia previa en desarrollos de sistemas, influía positiva o negativamente en la efectividad de los mismos. Para estudiar su efecto y comprobar tendencias, los investigadores vieron necesario la inclusión de esta variable en la investigación.

\subsubsection{Disminución del tiempo de consolidación}

La disminución del tiempo de consolidación en Q-2012 viene motivada por una restricción del setting (configuración del experimento) fundamentalmente porque en el Alive Empirical Study ${ }^{30}$ del REFSQ (donde se llevó a cabo el experimento) se contaba con 90 minutos para realizar la tarea experimental (educción + consolidación de los requisitos). Al ser Q-2012 una réplica externa del experimento Q-2011, el tiempo de educción debía ser limitado a 60 minutos, quedando los 30 minutos restantes para la consolidación.

\subsubsection{Ejecución}

\subsubsection{Muestra}

En Q-2012 participaron 21 profesionales con distintos rangos de experiencia: los sujetos contaban con más años experiencia en desarrollo y en requisitos, antes que en entrevistas o actividades relacionadas con la educción. El rango de experiencia estuvo entre 0 y 20 años, con excepción en requisitos y profesional que estuvieron entre 0 y 30 años. No obstante, los sujetos informaron ser más hábiles en requisitos (niveles 4-5), y en menor proporción en entrevistas y desarrollo (niveles 3-4), tal y como se puede comprobar en la Tabla 5.36.

En lo que respecta a la familiaridad que poseen los sujetos respecto al dominio del problema, 18 de 21 sujetos no están familiarizados con el dominio, este hecho confirma el carácter desconocido del problema.

${ }^{30}$ Alive Empirical Study: “Estudio empírico en Vivo" es un experimento controlado, que requiere no más de 90 minutos y que involucra a todos los participantes del REFSQ que quieran participar. 
Tabla 5.36 - Características principales de los sujetos experimentales Q-2012

\begin{tabular}{|c|c|c|}
\hline \multicolumn{3}{|c|}{ CUASI-EXPERIMENTO Q-2012 (21) } \\
\hline CARACterísticas & Nivel & \#SUJETOS \\
\hline \multirow{2}{*}{ Titulación } & No Informático & 3 \\
\hline & Informático & 18 \\
\hline \multirow{4}{*}{$\begin{array}{l}\text { Experiencia en } \\
\text { Entrevistas }\end{array}$} & 0 año & 3 \\
\hline & 1-2 años & 6 \\
\hline & 3-4 años & 3 \\
\hline & $>=5$ años & 9 \\
\hline \multirow{4}{*}{$\begin{array}{l}\text { Experiencia en } \\
\text { Requisitos }\end{array}$} & 0 año & 1 \\
\hline & 1-2 años & 2 \\
\hline & 3-4 años & 4 \\
\hline & $>=5$ años & 14 \\
\hline \multirow{4}{*}{$\begin{array}{l}\text { Experiencia en } \\
\text { Educción }\end{array}$} & 0 año & 1 \\
\hline & 1-2 años & 2 \\
\hline & 3-4 años & 4 \\
\hline & $>=5$ años & 14 \\
\hline \multirow{4}{*}{$\begin{array}{l}\text { Experiencia } \\
\text { Profesional }\end{array}$} & 0 año & 0 \\
\hline & 1-2 años & 1 \\
\hline & 3-4 años & 2 \\
\hline & $>=5$ años & 18 \\
\hline \multirow{4}{*}{$\begin{array}{l}\text { Experiencia en } \\
\text { Desarrollo }\end{array}$} & 0 año & 2 \\
\hline & 1-2 años & 0 \\
\hline & 3-4 años & 3 \\
\hline & $>=5$ años & 16 \\
\hline \multirow{3}{*}{$\begin{array}{l}\text { Familiaridad con } \\
\text { el problema }\end{array}$} & No Familiar & 18 \\
\hline & Familiar & 3 \\
\hline & Muy Familiar & 0 \\
\hline \multirow{5}{*}{$\begin{array}{c}\text { Habilidad en } \\
\text { Requisitos } \\
\text { (Likert 1-5) }\end{array}$} & 1 menos habilidad & 1 \\
\hline & 2 & 3 \\
\hline & 3 & 3 \\
\hline & 4 & 11 \\
\hline & 5 mayor habilidad & 3 \\
\hline \multirow{5}{*}{$\begin{array}{c}\text { Habilidad en } \\
\text { Entrevistas } \\
\text { (Likert 1-5) }\end{array}$} & 1 menor habilidad & 2 \\
\hline & 2 & 5 \\
\hline & 3 & 8 \\
\hline & 4 & 6 \\
\hline & 5 mayor habilidad & 0 \\
\hline
\end{tabular}

\subsubsection{Preparación}

Al ser Q-2012 parte del "Alive Experimental Study" de la conferencia REFSQ'13 no fue necesario ningún training para los participantes. La tarea experimental se llevó a cabo con la experiencia y conocimientos previos que los mismos poseían en ese momento. Tampoco fue necesaria una preparación o estudio en profundidad del dominio por parte del entrevistado, ya que es la misma persona quien ejerce el rol de cliente a lo largo de la serie histórica.

\subsubsection{Realización}

La realización del experimento fue de acuerdo al plan previsto. Se realizó una única entrevista (entrevista en grupo) en la que participaron alrededor de 30 sujetos experimentales. El experimento se llevó a cabo dentro de la 19o conferencia internacional en Ingeniería de Requisitos (REFSQ'13) ${ }^{31}$ durante los días 10 y 11 de abril del 2013 en Essen, Alemania (Aranda, Dieste, \& Juristo, 2013).

31 Working Conference on Requirements Engineering: Foundation for Software Quality: http://refsq.org/2013/empirical-track/ 
La entrevista tuvo una duración máxima de 60 minutos. De forma inmediata los participantes iniciaron con la consolidación de los requisitos. Los participantes emplearon en promedio unos 15 minutos para generar el reporte, aunque la duración máxima establecida para la consolidación fue de 30 minutos. Ninguno de los participantes manifestó que el tiempo de consolidación fue insuficiente.

Antes de iniciar el experimento fue proporcionado a los participantes un cuestionario en el cual reportaron sus experiencias y habilidades relacionadas con actividades de requisitos, así como su familiaridad con el dominio experimental.

\subsubsection{Desviaciones}

No se observó ningún tipo de desviación respecto a la planificación inicial.

\subsubsection{Resultados}

\subsubsection{Reducción del conjunto de datos}

Participaron en el experimento 30 sujetos, de los cuales 9 presentaron el cuestionario demográfico pero no los reportes de consolidación. Dichos sujetos fueron eliminados desde un principio del estudio, quedando un total de 21 sujetos.

\subsubsection{Procedimiento de análisis}

Varios fueron los test estadísticos empleados para analizar los datos experimentales. Tanto la experiencia como la habilidad de los sujetos se han estudiado empleando correlaciones de Pearson y correlaciones de Tau-b de Kendall respectivamente, mientras que para analizar los efectos de la familiaridad y titulación académica, la prueba t (t-test) fue utilizada. La familiaridad quedó dicotomizada en Familiar y No Familiar, dado que ningún sujeto era muy familiar al dominio del problema (como se ha indicado en la sección 5.6.2.1). En la misma línea, la titulación académica de los sujetos fue categorizada en informáticos (sujetos titulados en informática) y no informáticos (sujetos con otra titulación distinta a ciencias de la computación).

Los resultados fueron apoyados con los estadísticos descriptivos, gráficos de dispersión y de boxplot según corresponda.

\subsubsection{Estadísticos descriptivos}

La Tabla 5.37 presenta el número total de sujetos que han participado del experimento, la efectividad media, máxima y mínima alcanzada por los sujetos, así como la mediana, la varianza y la desviación típica. En media los sujetos consolidan el $37 \%$ de los elementos que definen el dominio del problema, siendo la efectividad máxima un $53 \%$ y la mínima un $16 \%$. Nótese que al igual que los experimentos anteriores, ningún sujeto alcanza a consolidar el $100 \%$ de los elementos. Sin embargo los sujetos tienden a obtener efectividades más uniformes, con una variabilidad menor.

Tabla 5.37 - Estadísticos descriptivos Q-2012

Efectividad en la Consolidación (\%)

\begin{tabular}{|r|r|r|r|r|r|r|}
\hline $\mathrm{N}$ & \multicolumn{1}{|c|}{ MEDIA } & \multicolumn{1}{c|}{ MÁxIMO } & \multicolumn{1}{c|}{ MíNIMO } & \multicolumn{1}{c|}{ MEDIANA } & \multicolumn{1}{c|}{ VARIANZA } & \multicolumn{1}{c|}{ DESV. TíP. } \\
\hline 21 & 37.07 & 53 & 16 & 39.22 & 127.222 & 11.279 \\
\hline
\end{tabular}

\subsubsection{Prueba de Hipótesis}

\section{H1.a. Efecto de la Experiencia}

Al igual que los cuasi-experimentos anteriores, para estudiar el efecto de la experiencia hemos generado gráficos de dispersión y calculado las correlaciones correspondientes, tal y como se muestran en la Figura 5.22 y Tabla 5.38 respectivamente. Los gráficos presentados en la Figura 5.22 muestran para 
todos los casos un efecto positivo de la experiencia, esto es, a mayores años de experiencia mayor es la efectividad de los sujetos.

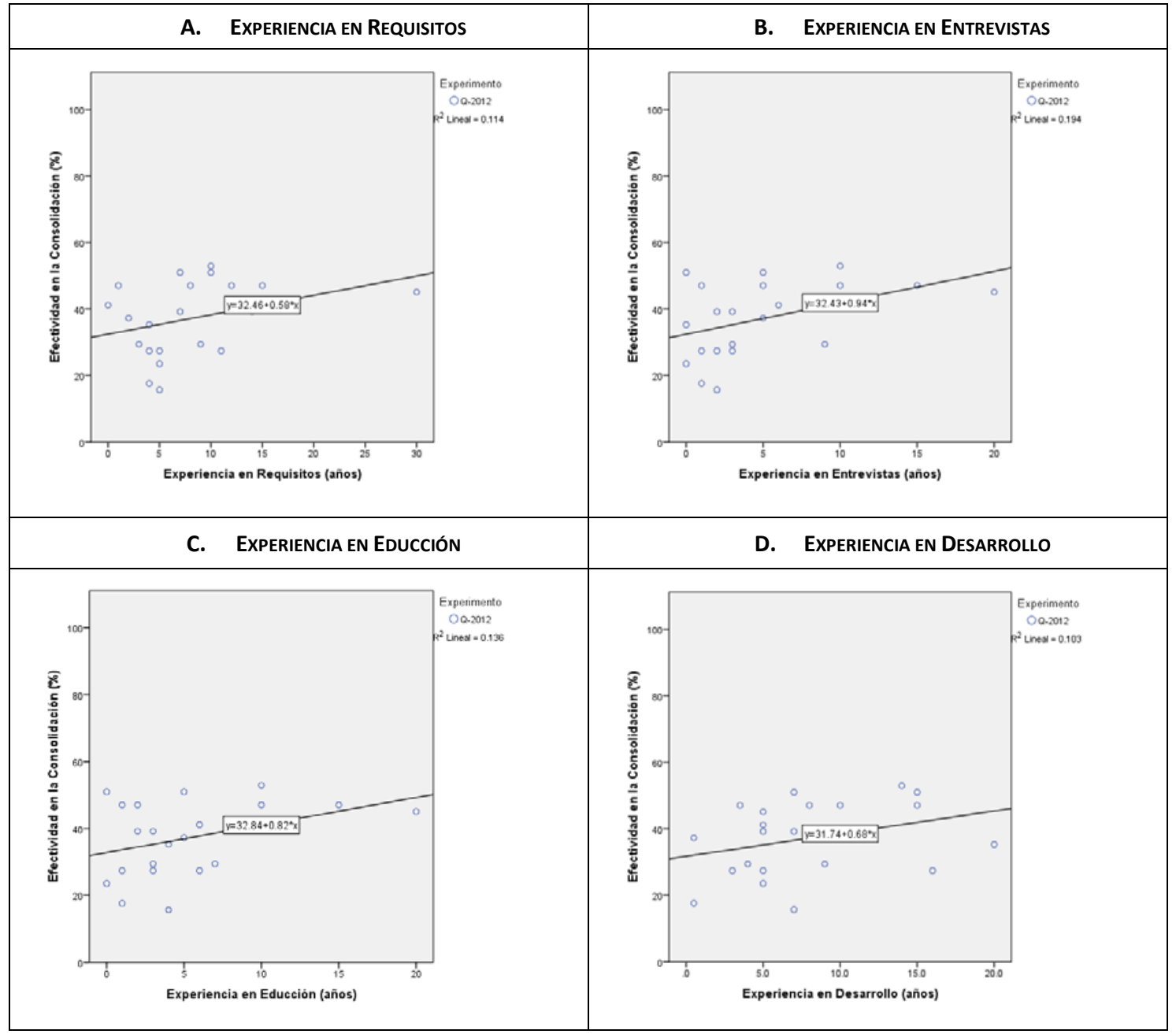

Figura 5.22 - Gráficos de Dispersión - Relación de la experiencia y la efectividad Q-2012

Los datos presentados en la Tabla 5.38 confirman el efecto positivo moderado de la experiencia en la efectividad de los sujetos en sus distintas vertientes: requisitos ( $r=0.338)$, entrevistas $(r=0.441)$, educción ( $r=0.369)$, desarrollo $(r=0.322)$ y profesional $(r=0.485)$. Nótese que el efecto es estadísticamente significativo para la experiencia en entrevistas ( $p$-valor=0.046 $<0.05$ ) y la experiencia profesional ( $r=0.026)$, estando los demás casos muy próximos a la significación.

Tabla 5.38 - Relación de la experiencia y la efectividad en la consolidación Q-2012

\begin{tabular}{|l|c|r|c|c|}
\hline \multirow{2}{*}{$\begin{array}{c}\text { VARIABLE } \\
\text { INDEPENDIENTE }\end{array}$} & \multicolumn{3}{c|}{ CORRELACIÓN } & \multirow{2}{*}{ EFECTO } \\
\cline { 2 - 4 } & $r$ & $\mathrm{p}$-valor & $\mathrm{N}$ & \\
\hline ExpReq & .338 & $\mathrm{No}(.134)$ & 21 & $(+)$ \\
\hline ExpEntr & $.441^{*}$ & $\mathrm{Si}(.046)$ & 21 & $(+)$ \\
\hline ExpEduc & .369 & $\mathrm{No}(.100)$ & 21 & $(+)$ \\
\hline ExpDes & .322 & $\mathrm{No}(.155)$ & 21 & $(+)$ \\
\hline ExpProf & $.485^{*}$ & $\mathrm{Si}(.026)$ & 21 & $(+)$ \\
\hline
\end{tabular}

$\left.{ }^{*}\right)$ La correlación es significante al nivel 0.05 (bilateral). 


\section{H1.b. Efecto de la Habilidad}

En lo que respecta a la relación entre la experiencia que los sujetos creen tener (habilidad) y la efectividad, los resultados son más diversos. Tal y como se puede apreciar en la Tabla 5.39, el efecto es nulo para la habilidad en requisitos ( $r=-.018$ ) y positivo para la habilidad en entrevistas $(r=.1233)$, aunque estadísticamente no significativos en ambos casos.

Tabla 5.39 - Relación de la experiencia y la efectividad en la consolidación

\begin{tabular}{|c|c|c|c|c|}
\hline \multirow{2}{*}{$\begin{array}{c}\text { VARIABLE } \\
\text { INDEPENDIENTE }\end{array}$} & \multicolumn{3}{|c|}{ Correlación } & \multirow{2}{*}{ EFeCto } \\
\cline { 2 - 4 } & $r$ & p-valor & $\mathrm{N}$ & \\
\hline HabReq & .018 & No $(.921)$ & 21 & $(\mathrm{X})$ \\
\hline HabEntr & .154 & No $(.387)$ & 21 & $(+)$ \\
\hline
\end{tabular}

Dichos resultados contradictorios o tendencias más bajas con el efecto de la experiencia no nos deben sorprender. Como se verá en la sección 7.6, la diferencia de tendencias se puede deber a la manera en que se miden los efectos de las variables, ya sea de forma objetiva (como por ejemplo años de experiencia) o subjetiva (opinión de los sujetos expresados en una escala de Likert).

\section{H2.a. Efecto del la Familiaridad}

No existe diversidad de sujetos, por lo que el efecto de la familiaridad no está claro. Los sujetos con familiaridad en media consolidan el $38 \%$ de los elementos mientras que los familiares un 35\%. La Figura 5.23 representa un gráfico de box que compara la efectividad de los sujetos con y sin familiaridad en el dominio. La percepción visual presenta un ligero efecto negativo de la familiaridad, esto es, los sujetos no familiarizados con el dominio tienden a ser ligeramente (un 3\%) más efectivos que los sujetos familiarizados. Por otro lado, en el gráfico de box muestra que los sujetos que desconocen el dominio tienden a mostrar más dispersión, siendo el mínimo 16\% y el máximo 53\%. Por el contrario, los sujetos familiarizados tienden a obtener efectividades más homogéneas, siendo el mínimo 18\% y el máximo $45 \%$.

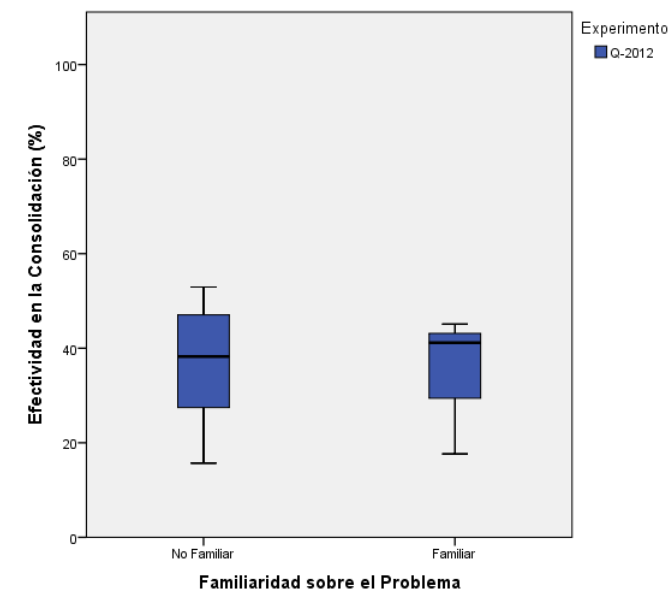

Figura 5.23 - Efecto de la familiaridad de los sujetos en la efectividad Q-2012

Estadísticamente, los datos corroboran un efecto negativo casi nulo de la familiaridad en la efectividad de los sujetos, aunque están lejos de la significación ( $p$-valor=0.698 > 0.05). Nótese que dicho resultado hay que tomarlo con cautela ya que podría estar amenazado por la desproporción (3 frente a 18) de sujetos en cada grupo (con y sin familiaridad). 
Tabla 5.40 - Relación la familiaridad y la efectividad en la consolidación

\begin{tabular}{|c|c|c|c|c|c|c|c|c|}
\hline \multicolumn{3}{|c|}{ TAMAÑo POBLACIÓN } & \multirow{2}{*}{\multicolumn{2}{|c|}{$\begin{array}{c}\begin{array}{c}\text { EfECTIVIDAD } \\
\text { MEDIA (\%) }\end{array} \\
\text { Fam }\end{array}$}} & \multirow{3}{*}{$\mathbf{t}$} & \multirow{3}{*}{$\begin{array}{l}\text { EFFECT SIZE } \\
\text { COHEN (D) }\end{array}$} & \multirow{3}{*}{$\begin{array}{l}\text { SIG. } \\
\text { T-TEST }\end{array}$} & \multirow{3}{*}{$\begin{array}{c}\text { EFECTO } \\
\text { FAM }\end{array}$} \\
\hline \multirow{2}{*}{$\mathrm{N}$} & \multicolumn{2}{|c|}{ Fam } & & & & & & \\
\hline & $\operatorname{Sin}$ & Con & $\operatorname{Sin}$ & Con & & & & \\
\hline 21 & 18 & 3 & 38 & 35 & -0.394 & -0.181 & .698 & $(-)$ \\
\hline
\end{tabular}

\section{H.3 Efecto del la Titulación Académica}

Como se puede apreciar en la Figura 5.6, aunque sólo sean tres los sujetos no informáticos, el efecto de la titulación tiende a ser negativa, esto es: los no informáticos en promedio adquieren mayor número de elementos del dominio del problema (43\%) que los informáticos (36\%).

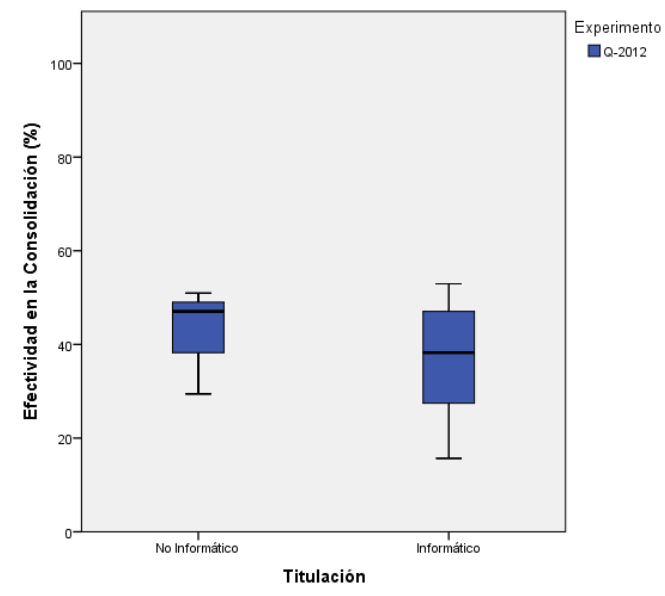

Figura 5.24 - Efecto de la titulación académica en la efectividad de la consolidación Q-2012

Estadísticamente la diferencia de medias entre ambos grupos es no significativa ( $p$-valor $=.383>$ 0.05), tal y como se muestra en la Tabla 5.41. La titulación académica tiende a ejercer un bajo efecto negativo ( $d=-.4101)$ en la efectividad.

Tabla 5.41 - Relación de la titulación académica (Form) y la efectividad en la consolidación

\begin{tabular}{|c|c|c|c|c|c|c|c|c|}
\hline \multicolumn{3}{|c|}{ TAMAÑo Población } & \multirow{2}{*}{\multicolumn{2}{|c|}{$\begin{array}{c}\text { EfECTIVIDAD } \\
\text { MEDIA (\%) } \\
\text { TIT } \\
\end{array}$}} & \multirow{3}{*}{$\mathbf{T}$} & \multirow{3}{*}{$\begin{array}{l}\text { EFFECt Size } \\
\text { COHEN (D) }\end{array}$} & \multirow{3}{*}{$\begin{array}{c}\text { SIG. } \\
\text { T-TEST }\end{array}$} & \multirow{3}{*}{$\begin{array}{c}\text { EFECTC } \\
\text { TIT }\end{array}$} \\
\hline \multirow{2}{*}{$\mathrm{N}$} & \multicolumn{2}{|c|}{ TIT } & & & & & & \\
\hline & nolnf & $\operatorname{lnf}$ & nolnf & $\operatorname{lnf}$ & & & & \\
\hline 21 & 3 & 18 & 43 & 36 & -.8937 & -.410 & No (.383) & $(-)$ \\
\hline
\end{tabular}

TIT nolnf = no informáticos; Inf = informáticos

\subsubsection{Posibles variables Moderadoras}

Tras comparar la efectividad promedio alcanzada por los sujetos en Q-2011 y en Q-2012 respectivamente (ver Figura 5.25), ha llamado la atención la diferencia de efectividades existentes entre ambos grupos. Los sujetos en Q-2011 (esto es, estudiantes) consolidaron en promedio un $11 \%$ de información a más que los sujetos en Q-2012 (esto es, investigadores y profesionales). Era esperable que las efectividades se mantuvieran o en todo caso aumentaran en Q-2012, dado que los sujetos cuentan con más años de experiencia. 


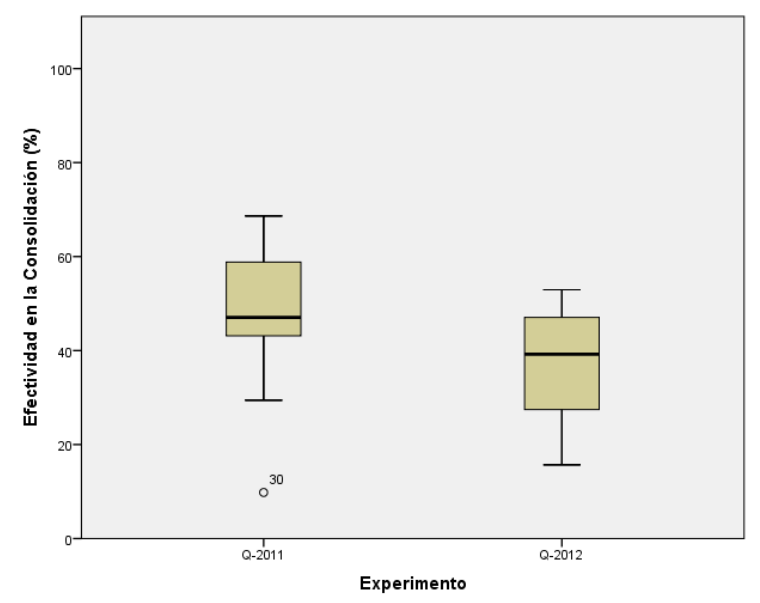

Figura 5.25 - Comparación de la efectividad media entre Q-2011 y Q-2012

La población experimental se diferencia en ambos cuasi-experimentos, fundamentalmente por los años de experiencia que poseen los sujetos y por el ámbito en el que se desenvuelven (académico e industrial). Cabe resaltar que Q-2011 se ha realizado con estudiantes del máster en el marco de la asignatura de RE, lo que implica una formación en varios aspectos relacionados con los requisitos: entre ellos el proceso de educción y especificación de los mismos. No obstante, por el contrario, en Q-2012 formado por profesionales (entre ellos investigadores, docentes y estudiantes de doctorado) como parte del Alive Empirical Study del REFSQ 2013, no fue necesaria una formación previa dada las condiciones experimentales: límite de tiempo disponible para el Alive Empirical Study, la cantidad de participantes y la experiencia de los mismos. Se asume que los sujetos por ser profesionales de la industria y de ambientes académicos cuenten con la experiencia suficiente para llevar a cabo el experimento.

Una explicación razonable al resultado observado (mayor efectividad alcanzada por los estudiantes en lugar de ser los profesionales) es que el cuasi-experimento Q-2011 se ejecutó al final del curso de RE como evaluación de la asignatura. La formación podía haber sesgado el comportamiento de los sujetos de modo que los estudiantes lo hacen mejor, no porque saben hacerlo mejor, sino porque saben lo que tienen que hacer para completar el experimento (que en su contexto es un examen) con éxito.

\subsection{Experimento E-2013}

\subsubsection{Cambios del experimento E-2013 respecto a E-2012}

E-2013 se diferencia de E-2012 fundamentalmente en el diseño experimental y en el número de interacciones (sesiones de educción) realizadas para la obtención de información necesaria para la especificación de los requisitos del nuevo sistema.

\subsubsection{Cambio en el Diseño Experimental}

El experimento E-2013 es una réplica interna de E-2012A, el cual se deferencia en el diseño experimental. E-2012 corresponde a un diseño de medidas repetidas (within-subjects), mientras que E2013 corresponde a un diseño factorial (between-subjects). Si bien el diseño de within posee ciertas ventajas frente al between, no está exento de ciertos inconvenientes relacionados con las características intrínsecas del propio diseño que amenazan la validez de los resultados (mayores detalles en la sección 4.7.4). Por tanto, ante el riesgo de que el diseño within-subjects pudiera influir en los resultados, los investigadores decidieron replicar E-2012 A utilizando un diseño estándar. 


\subsubsection{Incremento del número de iteraciones en la sesión de educción}

En el experimento E-2012, durante las entrevistas post-experimentales, los sujetos manifestaron la necesidad de una segunda o más sesiones de educción con el fin de mejorar y refinar la información adquirida en sus primeros contactos con el cliente.

Con el objeto de comprobar si el aumento de las interacciones incrementa la efectividad de la educción de los analistas, hemos adaptado el experimento a que el sujeto tenga dos sesiones por dominio del problema, cada una con un tiempo máximo de $30 \mathrm{~min}$.

\subsubsection{Ejecución}

\subsubsection{Muestra}

En E-2013 participaron 15 estudiantes del Máster en Ingeniería del Software de la Escuela Técnica Superior de Ingenieros Informáticos de la Universidad Politécnica de Madrid. Todos fueron profesionales informáticos. La Tabla 5.42 resume los datos demográficos principales de la población.

Tabla 5.42 - Características principales de los sujetos experimentales E-2013

\begin{tabular}{|c|c|c|}
\hline \multicolumn{3}{|c|}{ CUASI-EXPERIMENTO E-2012 (15) } \\
\hline CARACTERÍSTICAS & Nivel & \#SUJETOS \\
\hline \multirow{2}{*}{ Titulación } & Informático & $13 / 15$ \\
\hline & No informático & 0 \\
\hline \multirow{4}{*}{$\begin{array}{c}\text { Experiencia en } \\
\text { Entrevistas }\end{array}$} & 0 año & 10 \\
\hline & 1-2 años & 3 \\
\hline & 3-4 años & 0 \\
\hline & $>=5$ años & 0 \\
\hline \multirow{4}{*}{$\begin{array}{l}\text { Experiencia en } \\
\text { Educción }\end{array}$} & 0 año & 10 \\
\hline & 1-2 años & 3 \\
\hline & 3-4 años & 0 \\
\hline & $>=5$ años & 0 \\
\hline \multirow{4}{*}{$\begin{array}{l}\text { Experiencia en } \\
\text { Requisitos }\end{array}$} & 0 año & 7 \\
\hline & 1-2 años & 5 \\
\hline & 3-4 años & 1 \\
\hline & $>=5$ años & 0 \\
\hline \multirow{4}{*}{$\begin{array}{l}\text { Experiencia } \\
\text { Profesional }\end{array}$} & 0 año & 1 \\
\hline & 1-2 años & 7 \\
\hline & 3-4 años & 2 \\
\hline & $>=5$ años & 3 \\
\hline \multirow{4}{*}{$\begin{array}{c}\text { Experiencia en } \\
\text { Desarrollo }\end{array}$} & 0 año & 1 \\
\hline & $1-2$ años & 6 \\
\hline & 3-4 años & 3 \\
\hline & $>=5$ años & 3 \\
\hline \multirow{2}{*}{$\begin{array}{c}\text { Familiaridad con } \\
\text { el problema }\end{array}$} & Familiar - PC1 (7) & $4 / 6$ \\
\hline & Familiar - PD1 (8) & $0 / 7$ \\
\hline \multirow{5}{*}{$\begin{array}{l}\text { Habilidad en } \\
\text { Requisitos } \\
\text { (Likert 1-5) }\end{array}$} & 1 menos habilidad & 2 \\
\hline & 2 & 3 \\
\hline & 3 & 3 \\
\hline & 4 & 4 \\
\hline & 5 mayor habilidad & 1 \\
\hline \multirow{5}{*}{$\begin{array}{c}\text { Habilidad en } \\
\text { Entrevistas } \\
\text { (Likert 1-5) }\end{array}$} & 1 menor habilidad & 3 \\
\hline & 2 & 2 \\
\hline & 3 & 3 \\
\hline & 4 & 5 \\
\hline & 5 mayor habilidad & 0 \\
\hline
\end{tabular}


Los sujetos que participaron en E-2013 podrían ser caracterizados como sujetos desarrolladores sin o muy baja experiencia en actividades relacionadas con requisitos, dado que los estudiantes reportaron más años de experiencia en desarrollo y menos en entrevistas y requisitos (entre 0 y 2 años).

Como el diseño aplicado en el experimento es between-subjects, la población experimental fue dividida al azar en dos grupos ( 7 sujetos realizaron la educción sobre el problema PC1 y 8 sobre el problema PD1). En lo que respecta a la familiaridad 3 sujetos están familiarizados con el problema PC1 y ninguno con el problema PD1, nuevamente estos resultados muestran el carácter desconocido del problema PD1.

\subsubsection{Preparación}

Al igual que el experimento E-2012 los sujetos fueron notificados por correo electrónico: el día, la hora y lugar donde realizarían las sesiones de educción. Si bien, los entrevistados ya poseen cierta habilidad en el ejercicio de su rol como cliente, igualmente ambos se reunieron y prepararon los problemas.

\subsubsection{Realización}

En el experimento E-2013, a diferencia de los demás, los sujetos realizaron dos sesiones de educción por problema. La primera sesión se realizó con la finalidad de adquirir la mayor información posible para comprender el dominio y especificar los requisitos del sistema, mientras que la segunda con el fin de refinar y complementar la información adquirida.

La primera sesión de educción fue llevada a cabo en dos días no consecutivos; el primer día (27 de septiembre del 2013) se realizó la educción sobre el dominio del problema conocido (PC1), mientras que el segundo día (01 de octubre del 2013) sobre el dominio desconocido (PD1). La segunda sesión se llevó a cabo a finales del mes de octubre, siguiendo la misma dinámica que la primera: las entrevistas sobre los problemas PC1 y PD1 se realizaron el jueves 24 y el viernes 25 de octubre del 2013, respectivamente.

Como se ha indicado anteriormente, antes de la ejecución del experimento, los sujetos tuvieron un warming up de una semana con la finalidad de repasar conceptos básicos de requisitos. Las sesiones de educción se llevaron a cabo mediante entrevistas abiertas, durante un tiempo limitado a 30 minutos, mientras que el proceso de consolidación durante 90 minutos, aunque los sujetos tuvieron la libertad de emplear más o menos tiempo de lo establecido.

Además de los dos sujetos que desempeñaron el rol de entrevistados, otros dos desempeñaron el rol de vigilante. Durante el proceso de consolidación estuvieron presentes para aclarar cualquier duda respecto al ejercicio y por otro lado para controlar y evitar que los sujetos se copien.

Finalizada la primera parte del experimento, los sujetos siguieron con normalidad el desarrollo de las clases, donde recibieron formación sobre distintos aspectos relacionados con requisitos: como por ejemplo cómo especificar requisitos, elaboración del documento de visión, prácticas sobre técnicas de educción, entre otros. Tras este proceso de aprendizaje los sujetos realizaron las segundas sesiones de educción (entrevistas).

\subsubsection{Desviaciones}

El experimento se llevó a cabo acorde con la planificación inicial, salvo para dos sujetos que por motivos personales no pudieron presentarse en el día asignado, por lo que se tuvieron que reprogramar algunas sesiones de educción. 


\subsubsection{Resultados}

\subsubsection{Reducción del conjunto de datos}

No fue necesario reducir el conjunto de datos experimentales ya que todos los sujetos realizaron el proceso de educción completo. Nótese no obstante, que para este experimento hay dos casos perdidos, los cuales no respondieron al cuestionario demográfico. Dichos sujetos serán eliminados automáticamente de los análisis que incorporen dichas variables, tanto en los análisis de los estudios individuales como a nivel de síntesis global.

Tabla 5.43 - Valores perdidos del cuasi-experimento E-2013

\begin{tabular}{|l|c|c|c|}
\hline \multicolumn{1}{|c|}{ VARIABLE INDEPENDIENTE } & N TOTAL & N VÁLIDO & N PERDIDOS \\
\hline Experiencia en Entrevistas (años) & 15 & 13 & 2 \\
\hline Experiencia en Educción (años) & 15 & 13 & 2 \\
\hline Experiencia en Requisitos (años) & 15 & 13 & 2 \\
\hline Experiencia en Desarrollo (años) & 15 & 13 & 2 \\
\hline Experiencia Profesional (años) & 15 & 13 & 2 \\
\hline Familiaridad & 15 & 13 & 2 \\
\hline Formación Académica & 15 & 15 & 2 \\
\hline Habilidad en Entrevistas & 15 & 13 & 2 \\
\hline Habilidad en Requisitos & 15 & 13 & 2 \\
\hline
\end{tabular}

\subsubsection{Procedimiento de análisis}

Los métodos de análisis son similares a los cuasi-experimentos y experimentos anteriores, con la excepción de que el conocimiento se analizó empleando análisis de varianza con un factor (ANOVA) y la experiencia mediante el método de regresión lineal. En ambos casos, lo que se buscó fue separar los efectos del conocimiento y la experiencia de los efectos del entrevistado. Nótese que en las variables donde hemos aplicado el modelo de regresión lineal para estudiar su efecto (Efectividad $=B_{0}+B_{1}$ experiencia | habilidad | familiaridad $+B_{2}$ entrevistado $+\varepsilon$ ), partiendo del estadístico $t$ obtenido del modelo hemos calculado el grado de relación entre la variable independiente (experiencia, habilidad, familiaridad) y la efectividad. Para ello hemos aplicado el generador de effec size disponible en la web ${ }^{32}$.

\subsubsection{Estadísticos descriptivos}

La Tabla 5.44 presenta el número total de sujetos que han participado del experimento diferenciado por entrevistado, la efectividad media, máxima y mínima alcanzada por los sujetos, así como la mediana, la varianza y la desviación típica. Como se puede apreciar en la Tabla 5.44, los sujetos que entrevistaron a JW, tanto para el dominio conocido como para el dominio desconocido, en media tienden a consolidar más elementos que definen el dominio del problema comparados con los sujetos que entrevistaron a OD. Sin embargo, al comparar las efectividades alcanzadas según el tipo de dominio, los sujetos que entrevistaron a OD tienden adquirir más información en el problema desconocido (29\%) frente al conocido (17\%). Por el contrario, los sujetos que entrevistaron a JW en media adquieren menos información en el problema desconocido (44\%) frente al conocido (46\%), aunque las diferencias son ínfimas. Dichas diferencias confirman la previsible influencia del entrevistado en la efectividad del analista, así como el acierto de bloquear por entrevistado.

${ }^{32}$ http://www.uccs.edu/ |becker/ 
Tabla 5.44 - Estadísticos descriptivos E-2013

Efectividad (\%)

\begin{tabular}{|l|r|r|r|r|}
\hline \multirow{2}{*}{} & \multicolumn{3}{|c|}{ Conocimiento SObRe El Dominio del ProblemA } \\
\cline { 2 - 5 } & \multicolumn{2}{|c|}{ Conocido (PC1) } & \multicolumn{2}{|c|}{ Desconocido (PD1) } \\
\cline { 2 - 5 } & \multicolumn{1}{|c|}{ OD } & \multicolumn{1}{c|}{ JW } & \multicolumn{1}{c|}{ OD } & \multicolumn{1}{c|}{ JW } \\
\hline N & 3 & 4 & 5 & 3 \\
Media & 16.67 & 46.30 & 28.63 & 44.44 \\
Máximo & 22 & 74 & 39 & 69 \\
Mínimo & 9 & 17 & 18 & 20 \\
Mediana & 18.52 & 47.22 & 31.37 & 45.10 \\
Varianza & 44.582 & 564.701 & 78.047 & 601.051 \\
Desv. típ. & 6.677 & 23.763 & 8.834 & 24.516 \\
\hline
\end{tabular}

Los estadísticos descriptivos correspondientes a las segundas sesiones de educción de cada dominio del problema se presentan en la Tabla 5.45. En los resultados obtenidos no parece que los estudiantes identifiquen más elementos de los adquiridos en la primera entrevista, es decir, los sujetos tienden a no mejorar significativamente sus efectividades en las segundas entrevistas.

Tabla 5.45 - Estadísticos descriptivos E-2013 - segundas entrevistas

\begin{tabular}{|c|c|c|c|c|}
\hline & \multicolumn{4}{|c|}{ Conocimiento sobre el Dominio del Problema } \\
\hline & \multicolumn{2}{|c|}{ CONOCIDO (PC1) } & \multicolumn{2}{|c|}{ DESCONOCIDO (PD1) } \\
\hline & OD & JW & OD & JW \\
\hline $\mathrm{N}$ & 3 & 4 & 5 & 3 \\
\hline Media & 22.22 & 48.61 & 29.41 & 44.44 \\
\hline Máximo & 28 & 76 & 43 & 69 \\
\hline Mínimo & 19 & 19 & 18 & 20 \\
\hline Mediana & 20.37 & 50.00 & 31.37 & 45.10 \\
\hline Varianza & 24.005 & 588.420 & 101.884 & 601.051 \\
\hline Desv. típ. & 4.900 & 24.257 & 10.094 & 24.516 \\
\hline
\end{tabular}

Nótese que las diferencias entre medias son mínimas. Como se puede apreciar en la Tabla 5.45 los sujetos que entrevistaron a OD en promedio mejoran un $5 \%$ en el problema conocido, y un $0.75 \%$ en el problema desconocido. Por el contrario los sujetos que entrevistaron a JW en media mejoraron un $4 \%$ en el problema conocido y un $0 \%$ en el desconocido. Este hecho se puede deber a que los sujetos durante la segunda entrevista se focalizaron más en aspectos de visión: objetivos del negocio, presupuestos, tiempos, características no funcionales, recursos humanos, entre otros ${ }^{33}$.

\subsubsection{Prueba de Hipótesis}

\section{H1.a. Efecto de la Experiencia}

La relación entre las distintas experiencias y la efectividad se muestran en la Tabla 5.46. La Tabla 5.46 presenta por cada dominio de problema y por cada experiencia analizada, el coeficiente de correlación ( $r$ ) que indica el grado de relación entre la experiencia y la efectividad, la significación estadística (Sig.), la cantidad de sujeto que ha informado dicha experiencia $(N)$ y el efecto total de la experiencia.

${ }_{33}$ Una de las preguntas del cuestionario que los sujetos tuvieron que rellenar, hacía referencia a aspectos del dominio del problema focalizados por los sujetos durante la segunda entrevista. 
Para el dominio PD1, tanto la experiencia en requisitos como la experiencia en entrevistas tienden a ejercer un efecto negativo ( $r=.-843$ y $r=-.356$ respectivamente). Esto es, los sujetos con más años de experiencia en requisitos y/o en entrevistas tienden a ser menos efectivos. No obstante, la experiencia en educción como la experiencia profesional tiende a no influir en la efectividad de los sujetos ( $r=0$ y $r=0.25$, respectivamente). Por el contrario, la experiencia en desarrollo ejerce un efecto positivo $(r=.300)$. Todos los efectos son estadísticamente no significativos ( $p$-valor $>0.05$ ) con excepción de la experiencia en requisitos.

En lo que respecta al PC1, los efectos son contrarios al PD1. Como se muestra en la Tabla 5.46 tanto la experiencia en requisitos como la experiencia en desarrollo parecen no influir en la efectividad de los sujeto ( $r=.083$ y $r=.067$ respectivamente). No obstante, la experiencia en entrevistas como la experiencia en educción tienden a ejercer un efecto positivo ( $r=.558$ y $r=.712$, respectivamente), mientras que por el contario la experiencia profesional tiende a ejercer un efecto negativo ( $r=-.876)$.

Tabla 5.46 - Relación de la experiencia y la efectividad en la consolidación E-2013

\begin{tabular}{|c|c|c|c|c|c|}
\hline \multirow{2}{*}{$\begin{array}{l}\text { DOMINIO } \\
\text { PROBLEMA } \\
\end{array}$} & \multirow{2}{*}{$\begin{array}{c}\text { VARIABLE } \\
\text { INDEPENDIENTE } \\
\end{array}$} & \multicolumn{3}{|c|}{ CORRELACIÓN } & \multirow{2}{*}{ ЕFECTO } \\
\hline & & $r$ & p-valor & $\mathrm{N}$ & \\
\hline \multirow{5}{*}{ PD1 } & ExpReq* & -.843 & Si $(.025)$ & 7 & $(-)$ \\
\hline & ExpEntr & -.356 & No (.443) & 7 & $(-)$ \\
\hline & ExpEduc & .000 & No (1) & 7 & $(X)$ \\
\hline & ExpDes & .300 & No $(.521)$ & 7 & $(+)$ \\
\hline & ExpProf & .025 & No (.957) & 7 & (X) \\
\hline \multirow{5}{*}{ PC1 } & ExpReq & .083 & No (.879) & 6 & $(X)$ \\
\hline & ExpEntr & .558 & No (.271) & 6 & $(+)$ \\
\hline & ExpEduc & .712 & No (.135) & 6 & $(+)$ \\
\hline & ExpDes & .067 & No (.901) & 6 & $(X)$ \\
\hline & ExpProf* & -.876 & Si(.036) & 6 & $(-)$ \\
\hline
\end{tabular}

* La correlación es significativa al nivel 0.05 (bilateral).

\section{H1.b. Efecto de la Habilidad}

La Tabla 5.47 muestra las correlaciones obtenidas tanto para la habilidad en requisitos como en entrevistas, en un dominio desconocido (PD1) y en uno conocido (PC1) para los sujetos. La habilidad en requisitos tiende a ejercer un efecto positivo $(r=.205)$ para PD1 y negativo $(r=-.208)$ para PC1, mientras que por el contrario, tanto para PD1 como para PC1, la habilidad en entrevistas tiende a ejercer un efecto negativo ( $r=-.364$ y $r=-.437$ respectivamente). Esto es, cuanto mayor es la valoración que el analista realiza acerca de su propia pericia, el sujeto con habilidad en entrevista tiende a adquirir menos información relevante acerca del dominio del problema, mientras que por el contrario, el sujeto con habilidad en requisitos tienden a ser más efectivos que aquellos con menor habilidad en dominios desconocidos, mientras que un efecto nulo en dominios conocidos.

Tabla 5.47 - Relación de la habilidad y la efectividad en la consolidación E-2013

\begin{tabular}{|c|c|c|c|c|c|}
\hline \multirow{2}{*}{$\begin{array}{l}\text { DOMINIO DEL } \\
\text { PROBLEMA }\end{array}$} & \multirow{2}{*}{$\begin{array}{c}\text { VARIABLE } \\
\text { INDEPENDIENTE }\end{array}$} & \multicolumn{3}{|c|}{ CORRELACIÓN } & \multirow{2}{*}{$\begin{array}{c}\text { EFECTO } \\
\text { HAB }\end{array}$} \\
\hline & & $r$ & $\mathrm{p}$-valor & $\mathrm{N}$ & \\
\hline \multirow{2}{*}{ PD1 } & HabReq & .205 & No (.664) & 7 & $(+)$ \\
\hline & HabEntr & -.364 & No (.431) & 7 & $(-)$ \\
\hline \multirow{2}{*}{ PC1 } & HabReq & -.208 & No (.699) & 6 & $(-)$ \\
\hline & HabEntr & -.437 & No (.403) & 6 & $(-)$ \\
\hline
\end{tabular}


Estudio empírico de la influencia de la experiencia y del conocimiento del dominio del analista en la efectividad del proceso de educción de requisitos

\section{H2.a. Efecto del Conocimiento}

Antes de proceder con la prueba de hipótesis, comprobaremos si los datos experimentales cumplen o no la condición de independencia, homocedasticidad y normalidad de residuos exigidos por el ANOVA, tal y como se ha indicado en la sección 4.7

- Independencia. Se asume que cada conjunto de datos es independiente del otro.

- Homocedasticidad. Para contrastar la homogeneidad de varianzas hemos utilizado el test de Levene. El resultado del test $(F=.003$, $p$-valor=.955) es no significativo por lo que la varianza es homogénea entre grupos.

- Normalidad de los datos. La normalidad de los datos del modelo, la hemos comprobado aplicando el test estadístico de Shapiro-Wilk, dado que la muestra es menor a 50. El resultado del test presentado en la Tabla 5.48, indica que los datos presentan un distribución normal ( $p$ valor $=0.902>0.05$ )

Tabla 5.48 - Prueba de normalidad E-2013

\begin{tabular}{|l|r|r|r|r|r|r|}
\hline & \multicolumn{3}{|c|}{ Kolmogorov-Smirnov $^{\text {a }}$} & \multicolumn{3}{c|}{ Shapiro-Wilk } \\
\cline { 2 - 7 } & Estadístico & \multicolumn{1}{c|}{ gl } & \multicolumn{1}{c|}{ Sig. } & Estadístico & gl & Sig. \\
\hline $\begin{array}{l}\text { Residuo para } \\
\text { ElemConsSinObjPor }\end{array}$ & .119 & 15 & $.200^{*}$ & .973 & 15 & .902 \\
\hline
\end{tabular}

*. Este es un límite inferior de la significación verdadera.

a. Corrección de la significación de Lilliefors

Los resultados del ANOVA se muestran Tabla 5.49. En ella se puede apreciar que no existe un efecto significativo del Conocimiento ( $p$-valor $=.598>0.05$ ) sobre la efectividad. El efecto del conocimiento tiende a ser negativo, es decir, los sujetos son más efectivos en el dominio desconocido en un $5 \%$ (Conocimiento $=0, B=5.364$ ) frente a los sujetos que realizaron educción en el PC1. Nótese que el efecto del conocimiento tiende a ser muy bajo, hecho confirmado por el estimador de tamaño de efecto Eta ${ }^{2}=$ $0.029<0.2$, esto es, un efecto pequeño según las guías de Cohen.

Tabla 5.49 - Efecto del conocimiento (ANOVA)E-2013

Variable dependiente: Efectividad en la Consolidación (\%)

\begin{tabular}{|c|c|c|c|c|c|c|c|}
\hline \multirow[b]{2}{*}{ PARÁMETRO } & \multirow[b]{2}{*}{ B } & \multirow{2}{*}{$\begin{array}{c}\text { ERROR } \\
\text { TíP. }\end{array}$} & \multirow[b]{2}{*}{ T } & \multirow[b]{2}{*}{ SIG. } & \multicolumn{2}{|c|}{ INTERVALO DE CONFIANZA 95\% } & \multirow{2}{*}{$\begin{array}{c}\text { ETA AL } \\
\text { CUADRADO } \\
\text { PARCIAL }\end{array}$} \\
\hline & & & & & LÍMITE INFERIOR & LÍMITE SUPERIOR & \\
\hline Intersección & 20.79 & 8.22 & 2.529 & .026 & 2.88 & 38.70 & .348 \\
\hline Entrevistado & 22.41 & 8.97 & 2.498 & .028 & 2.86 & 41.97 & .342 \\
\hline [Conocimiento=0] & 5.36 & 8.97 & .598 & .561 & -14.19 & 24.92 & .029 \\
\hline [Conocimiento=1] & $0^{a}$ & & & & & & \\
\hline
\end{tabular}

a. Al parámetro se le ha asignado el valor cero porque es redundante.

Nivel del Conocimiento: 0-PD1, 1-PC1 Entrevistado: 0-OD, 1-JW

\section{H2.b. Efecto de la Familiaridad}

La Tabla 5.50 presenta por cada dominio del problema, la efectividad media alcanzada por cada grupo (sujetos sin y con familiaridad en el dominio), así como el tamaño de las muestras respectivas, el estadístico t con el nivel de significación (Sig. t-test), el tamaño de efecto y efecto final de la familiaridad en la efectividad.

Como se puede apreciar en la Tabla $\mathbf{5 . 5 0}$ no es posible estudiar el efecto de la familiaridad en el dominio del problema PD1, dado que el $100 \%$ de los sujetos que participaron del experimento, informaron que desconocen el dominio del problema experimental. Por el contrario, en el PC1 so observa un bajo efecto ( $d=1.384$ ) positivo, aunque la diferencia entre grupos es no significativa ( $p$-valor $=.239>0.05$ ). Esto es, los sujetos familiarizados con el dominio tienden a ser más efectivos

Tabla 5.50 - Relación la familiaridad (Fam) y la efectividad en la consolidación E-2013 


\begin{tabular}{|c|c|c|c|c|c|c|c|}
\hline \multirow{3}{*}{$\begin{array}{c}\text { DOMINIO } \\
\text { DEL } \\
\text { PROBLEMA }\end{array}$} & \multicolumn{3}{|c|}{ TAMAÑO POBLACIÓN } & \multirow{3}{*}{$\mathbf{t}$} & \multirow{3}{*}{$\begin{array}{l}\text { EFFECT SIZE } \\
\text { COHEN (D) }\end{array}$} & \multirow{3}{*}{$\begin{array}{l}\text { SIG. } \\
\text { T-TEST }\end{array}$} & \multirow{3}{*}{$\begin{array}{c}\text { EFECTO } \\
\text { FAM }\end{array}$} \\
\hline & \multirow{2}{*}{$\mathrm{N}$} & \multicolumn{2}{|c|}{ Fam } & & & & \\
\hline & & Sin & Con & & & & \\
\hline PD1 & 7 & 7 & 0 & No & Es & Posible & \\
\hline PC1 & 6 & 2 & 4 & 1.384 & 1.384 & $\mathrm{No}(.239)$ & $(+)$ \\
\hline
\end{tabular}

\section{H3. Efecto de la Titulación Académica}

No es posible estudiar su efecto, ya que todos los sujetos son titulados informáticos, tal y como se indica en la Tabla 5.42 de la sección 5.7.2.1.

\subsubsection{Posible variable Moderadora}

En E-2013 no fue posible identificar una posible variable moderadora que pueda influir en la efectividad de los sujetos experimentales.

\subsection{Experimento E-2014}

\subsubsection{Cambios del Experimento E-2014 respecto a E-2013}

E-2014 es una réplica interna de E-2013, se diferencia de E-2013 en dos aspectos importantes: a) Formación previa o warming up proporcionada a los estudiantes y b) el número de sujetos que actuaron como entrevistado (cliente).

\subsubsection{Incremento del warming up}

Dado que la warming up es una potencial variable moderadora, los investigadores han incrementado el tiempo de formación antes de la ejecución de la primera parte del experimento. En esta investigación el warming up se extendió a 6 semanas, donde los sujetos recibieron formación general en requisitos. Se espera que la efectividad promedio de los sujetos incremente si el warming up ejerce un efecto positivo.

\subsubsection{Entrevistado}

Por fuerzas mayores, el número de sujetos que actuaban como entrevistados se redujo a uno. Se mantuvo el entrevistado que ha participado en la mayoría de los estudios experimentales anteriores.

\subsubsection{Ejecución}

\subsubsection{Muestra}

En E-2014 participaron 16 estudiantes del Máster en Ingeniería del Software de la Escuela Técnica Superior de Ingenieros Informáticos de la Universidad Politécnica de Madrid. Todos son profesionales informáticos. Tabla 5.51 resume los datos demográficos principales de la población. Nótese que no contamos con los datos demográficos de uno de los sujetos.

Tabla 5.51 - Características principales de los sujetos experimentales E-2014

\begin{tabular}{|c|l|c|}
\hline \multicolumn{2}{|c|}{ CUASI-EXPerimento E-2014 (16) } \\
\hline CARActerísticas & \multicolumn{1}{|c|}{ Nivel } & \#SUJETos \\
\hline \multirow{2}{*}{ Titulación } & No informático & 0 \\
\cline { 2 - 3 } & Informático & $15 / 16$ \\
\hline \multirow{3}{*}{$\begin{array}{c}\text { Experiencia en } \\
\text { Entrevistas }\end{array}$} & 0 año & 12 \\
\cline { 2 - 3 } & $1-2$ años & 0 \\
\cline { 2 - 3 } & $3-4$ años & 1 \\
\cline { 2 - 3 } & $>=5$ años & 12 \\
\hline \multirow{2}{*}{$\begin{array}{c}\text { Experiencia en } \\
\text { Educción }\end{array}$} & 0 año & 1 \\
\cline { 2 - 3 } & $1-2$ años & \\
\hline
\end{tabular}


Estudio empírico de la influencia de la experiencia y del conocimiento del dominio del analista en la efectividad del proceso de educción de requisitos

\begin{tabular}{|c|c|c|}
\hline \multicolumn{3}{|c|}{ CUASI-EXPERIMENTO E-2014 (16) } \\
\hline CARACTERÍSTICAS & Nivel & \#SUJETOS \\
\hline & 3-4 años & 2 \\
\hline & $>=5$ años & 0 \\
\hline \multirow{4}{*}{$\begin{array}{l}\text { Experiencia en } \\
\text { Requisitos }\end{array}$} & 0 año & 9 \\
\hline & 1-2 años & 3 \\
\hline & 3-4 años & 2 \\
\hline & $>=5$ años & 1 \\
\hline \multirow{4}{*}{$\begin{array}{l}\text { Experiencia } \\
\text { Profesional }\end{array}$} & 0 año & 6 \\
\hline & 1-2 años & 3 \\
\hline & 3-4 años & 1 \\
\hline & $>=5$ años & 5 \\
\hline \multirow{4}{*}{$\begin{array}{l}\text { Experiencia en } \\
\text { Desarrollo }\end{array}$} & 0 año & 0 \\
\hline & 1-2 años & 5 \\
\hline & 3-4 años & 4 \\
\hline & $>=5$ años & 6 \\
\hline \multirow{2}{*}{$\begin{array}{c}\text { Familiaridad con } \\
\text { el problema }\end{array}$} & Familiar - PC1 & 4 \\
\hline & Familiar-PD1 & 0 \\
\hline \multirow{5}{*}{$\begin{array}{c}\text { Habilidad en } \\
\text { Requisitos } \\
\text { (Likert 1-5) }\end{array}$} & 1 menos habilidad & 0 \\
\hline & 2 & 4 \\
\hline & 3 & 3 \\
\hline & 4 & 4 \\
\hline & 5 mayor habilidad & 0 \\
\hline \multirow{5}{*}{$\begin{array}{c}\text { Habilidad en } \\
\text { Entrevistas } \\
\text { (Likert 1-5) }\end{array}$} & 1 menor habilidad & 1 \\
\hline & 2 & 3 \\
\hline & 3 & 4 \\
\hline & 4 & 5 \\
\hline & 5 mayor habilidad & 0 \\
\hline
\end{tabular}

Como se puede apreciar en la Tabla 5.51, los sujetos podrían caracterizarse como sujetos con experiencia en desarrollo y requisitos, sin ninguna experiencia en entrevistas y educción. En lo que respecta al dominio del problema, los sujetos que realizaron la educción sobre el problema PD1 ninguno poseen familiaridad del dominio, mientras que el $67 \%$ de los sujetos que realizaron la educción sobre el PC1 están familiarizados del dominio.

\subsubsection{Preparación}

Los sujetos en lugar de ser notificados por correo electrónico con las orientaciones de la práctica así como el lugar, el día y la hora de la sesión de educción, dichas orientaciones las recibieron en una nota cuya asignación al sujeto fue totalmente al azar. Un ejemplo de dicha nota se presenta en la Figura 5.26.

\section{Practical session: elicitation with interviews}

Your day/time: Fri 24 at 19.30

You are going to play the role of a requirements analyst. Your task will be elicitation of the requirements of a software system. Details will be given later. Please proceed to office 6203 (Oscar Dieste) for a 25'interview and later to the classroom specified in the email (you will receive it soon) for reporting (no time limit, but 90'max are recommended.

Figura 5.26 - Ejemplo de la nota empleada para notificar a los sujetos sobre el experimento 


\subsubsection{Realización}

Tras unas seis semanas de clase, las cuales sirvieron de warming up, se inició la ejecución de los experimentos. En el experimento E-2014, la primera sesión de educción fue llevada a cabo en dos días no consecutivos; el primer día (24 de octubre del 2014) se realizó la educción sobre el dominio del problema desconocido conocido (PD1), mientras que el segundo día (31 de octubre del 2014) sobre el dominio conocido (PC1).

El sujeto que actuó como entrevistado fue el mismo que participó a lo largo de la secuencia de experimentos. El rol de vigilante fue desempeñado por dos personas, una para el problema PC1 y otro para el problema PD1, quienes durante el proceso de consolidación estuvieron presentes para aclarar cualquier duda que tuvieran los alumnos respecto al ejercicio y por otro lado para controlar y evitar que los sujetos se copien.

\subsubsection{Desviaciones}

La ejecución de los experimentos se llevó conforme a la planificación inicial. Por tanto, no existieron desviaciones durante la ejecución de los mismos.

\subsubsection{Resultados}

\subsubsection{Reducción del conjunto de datos}

Dado que todos los sujetos realizaron el proceso de educción y consolidación no fue necesario reducir el conjunto de datos experimentales. Cinco de los 16 sujetos no respondieron el cuestionario demográfico, por tanto no contamos con las informaciones específicas asociadas a la habilidad y a la familiaridad de los problemas. Sin embargo, en lo que respecta a la experiencia, para cuatro de los cinco sujetos hemos adquirido los años de experiencia de los currículos vitae. Este hecho permitió aumentar el tamaño muestral de las experiencias.

Tabla 5.52 - Valores perdidos del cuasi-experimento E-2014

\begin{tabular}{|l|c|c|c|}
\hline \multicolumn{1}{|c|}{ VARIABLE INDEPENDIENTE } & N TOTAL & N VÁLIDO & NPERDIDOS \\
\hline Experiencia en Entrevistas (años) & 16 & 15 & 1 \\
\hline Experiencia en Educción (años) & 16 & 15 & 1 \\
\hline Experiencia en Requisitos (años) & 16 & 15 & 1 \\
\hline Experiencia en Desarrollo (años) & 16 & 15 & 1 \\
\hline Experiencia Profesional (años) & 16 & 15 & 1 \\
\hline Familiaridad & 16 & 11 & 5 \\
\hline Formación Académica & 16 & 15 & 1 \\
\hline Habilidad en Entrevistas & 16 & 11 & 5 \\
\hline Habilidad en Requisitos & 16 & 11 & 5 \\
\hline
\end{tabular}

\subsubsection{Procedimiento de análisis}

Al igual que los experimentos anteriores, el análisis de datos fue realizado desde el punto de vista cuasiexperimental y experimental. En el estudio cuasi-experimental se analizan los efectos de la experiencia, la habilidad, la familiaridad y la titulación académica, mientras que en la experimental el efecto del conocimiento. Para ello, hemos empleado los siguientes test estadísticos: correlaciones para la experiencia y la habilidad; t-test para la familiaridad y titulación académica; para el conocimiento el modelo lineal general univariante (ANOVA) siendo el conocimiento el factor fijo principal. No se cuenta con factores aleatorios y/o covariables. No fue necesario aplicar el modelo de regresión, dado que en este experimento no se cuenta con una variable de bloque, existe único entrevistado. 


\subsubsection{Estadísticos descriptivos}

La Tabla 5.53 presenta el número total de sujetos que han participado en el experimento diferenciado por dominio del problema, la efectividad media, máxima y mínima alcanzada por los sujetos, así como la mediana, la varianza y la desviación típica. Como se puede apreciar en la Tabla 5.53, los sujetos en promedio tienden a ser ligeramente más efectivos en el problema desconocido (PD1) siendo la efectividad media un $35 \%$, el máximo un $55 \%$ y el mínimo un $12 \%$. No obstante, en el dominio conocido (PC1) los sujetos alcanzaron una media del 33\%, siendo el máximo un 56\% y el mínimo un 15\%. Si bien los máximos y mínimos tienden a ser más elevados en el PC1, las varianzas son muy similares.

Tabla 5.53 - Estadísticos descriptivos E-2014

\begin{tabular}{|l|c|c|}
\hline \multirow{2}{*}{$\begin{array}{c}\text { Efectividad } \\
(\%)\end{array}$} & \multicolumn{2}{|c|}{ DominIo DEL PrIBLEMA } \\
\cline { 2 - 3 } & PC1 & PD1 \\
\hline $\mathrm{N}$ & 7 & 9 \\
Media & 33.07 & 35.08 \\
Máximo & 56 & 55 \\
Mínimo & 15 & 12 \\
Mediana & 29.63 & 35.29 \\
Varianza & 221.112 & 219.574 \\
Desv. típ. & 14.870 & 14.818 \\
\hline
\end{tabular}

\subsubsection{Prueba de hipótesis}

\section{H1.a. Efecto de la Experiencia}

Las correlaciones entre las distintas experiencias y la efectividad se muestran en la Tabla 5.54. Como se puede apreciar, las distintas experiencias en el PD1 tienden a ejercer un efecto negativo estadísticamente no significativos ( $p$-valor $>0.05$ ), en todos los casos con excepción de la experiencia en desarrollo que tiende a influir positivamente. Esto es, los sujetos con menos experiencia tienden a alcanzar efectividades mayores; mientras que por el contrario, para el problema PC1 el efecto de la experiencia es positiva. Nótese que en ningún caso los efectos son bajos y no significativos ( $p$-valor > 0.05).

Tabla 5.54 - Relación de la experiencia y la efectividad en la consolidación E-2014

\begin{tabular}{|c|c|c|c|c|c|}
\hline \multirow{2}{*}{$\begin{array}{l}\text { DOMINIO } \\
\text { Problema }\end{array}$} & \multirow{2}{*}{$\begin{array}{c}\text { VARIABLE } \\
\text { INDEPENDIENTE }\end{array}$} & \multicolumn{3}{|c|}{ CORRELACIÓN } & \multirow[t]{2}{*}{ ЕFECTO } \\
\hline & & $r$ & p-valor & $\mathrm{N}$ & \\
\hline \multirow{5}{*}{ PD1 } & ExpReq & -.243 & .562 & 8 & $(-)$ \\
\hline & ExpEntr & -.126 & .767 & 8 & $(-)$ \\
\hline & ExpEduc & -.065 & .878 & 8 & $(X)$ \\
\hline & ExpDes & .128 & .762 & 8 & $(+)$ \\
\hline & ExpProf & -.440 & .275 & 8 & $(-)$ \\
\hline \multirow{5}{*}{ PC1 } & ExpReq & -.049 & .916 & 7 & $(X)$ \\
\hline & ExpEntr & .750 & .052 & 7 & $(+)$ \\
\hline & ExpEduc & .740 & .057 & 7 & $(+)$ \\
\hline & ExpDes & .209 & .653 & 7 & $(+)$ \\
\hline & ExpProf & .134 & .775 & 7 & $(+)$ \\
\hline
\end{tabular}




\section{H1.b. Efecto de la Habilidad}

Como se muestra en la Tabla 5.55 las correlaciones obtenidas tanto para la habilidad en requisitos como en entrevistas han sido negativas ( $r=-.118$ y $r=-.667$, respectivamente), para el problema PD1. Esto es, cuanto mayor es la valoración que el analista realiza acerca de su propia pericia, menos información relevante acerca del dominio del problema perece que es capaz de adquirir. Por el contrario, para el problema PC1, los efectos tienden a ser positivos ( $r=.654$ y $r=.365$ ). En ambos casos los resultados son no siginficativos.

Tabla 5.55 - Relación de la Habilidad y la Efectividad en la Consolidación E-2014

\begin{tabular}{|c|c|c|c|c|c|}
\hline \multirow{2}{*}{$\begin{array}{c}\text { DOMINIO deL } \\
\text { Problema }\end{array}$} & \multirow{2}{*}{$\begin{array}{c}\text { VARIABLE } \\
\text { INDEPENDIENTE }\end{array}$} & \multicolumn{3}{|c|}{ CORRELACIÓN } & \multirow{2}{*}{$\begin{array}{c}\text { EFECTO } \\
\text { НАB }\end{array}$} \\
\hline & & $r$ & $p$-valor & $\mathrm{N}$ & \\
\hline \multirow{2}{*}{ PD1 } & HabReq & -.667 & No (.147) & 5 & $(-)$ \\
\hline & HabEntr & -.118 & No (.788) & 5 & $(-)$ \\
\hline \multirow{2}{*}{ PC1 } & HabReq & .365 & No (.355) & 6 & $(+)$ \\
\hline & HabEntr & .645 & No $(.079)$ & 6 & $(+)$ \\
\hline
\end{tabular}

\section{H2.a. Efecto del Conocimiento}

Antes de proceder con la prueba de hipótesis, comprobaremos si los datos experimentales cumplen o no la condición de independencia, homocedasticidad y normalidad de residuos exigidos por el ANOVA, tal y como se ha indicado en la sección 4.8 .

- Independencia. Se asume que cada conjunto de datos es independiente del otro.

- Homocedasticidad. Para contrastar la homogeneidad de varianzas hemos utilizado el test de Levene. El resultado del test $(F=0.012$, $p$-valor $=0.915)$ es no significativo por lo que la varianza es homogénea entre grupos.

- Normalidad de los datos. La normalidad de los datos del modelo, la hemos comprobado aplicando el test estadístico de Shapiro-Wilk, dado que la muestra es menor a 50. El resultado del test presentado en la Tabla 5.56, indica que los datos presentan un distribución normal ya el test es no significativo ( $p$-valor $=.525>0.05$ ).

Tabla 5.56 - Prueba de normalidad E-2014

\begin{tabular}{|l|r|r|r|r|r|r|}
\hline & \multicolumn{3}{|c|}{ Kolmogorov-Smirnov $^{\mathrm{a}}$} & \multicolumn{3}{c|}{ Shapiro-Wilk } \\
\cline { 2 - 7 } & Estadístico & gl & Sig. & Estadístico & gl & \multicolumn{1}{c|}{ Sig. } \\
\hline Residuo para Efectividad (\%) & .141 & 16 & $.200^{*}$ & .952 & 16 & .525 \\
\hline
\end{tabular}

*. Este es un límite inferior de la significación verdadera.; Corrección de la significación de Lilliefors

Los resultados del ANOVA se muestran Tabla 5.57. Los resultados indican que no existe un efecto significativo del Conocimiento ( $p$-valor $=0.792>0.05$ ) sobre la efectividad. Sin embargo, se observa que los sujetos tienden a ser más efectivos en el problema desconocido en un $2 \%$ (Conocimiento $=0$; $\mathrm{B}=2.007)$. El efecto del conocimiento, tiende a ser muy bajo $\left(\mathrm{Eta}^{2}=0.005<0.2\right.$ según las guías de Cohen), nulo a efectos prácticos.

Tabla 5.57 - Efecto del conocimiento (ANOVA) E-2014

\begin{tabular}{|c|c|c|c|c|c|c|c|c|}
\hline \multirow[b]{2}{*}{ Parámetro } & \multirow[b]{2}{*}{ B } & \multirow[b]{2}{*}{ Error típ. } & \multirow[b]{2}{*}{$\mathrm{t}$} & \multirow[b]{2}{*}{ Sig. } & \multicolumn{2}{|c|}{$\begin{array}{c}\text { Intervalo de } \\
\text { confianza 95\% }\end{array}$} & \multirow{2}{*}{$\begin{array}{c}\text { Eta al } \\
\text { cuadrado } \\
\text { parcial }\end{array}$} & \multirow[b]{2}{*}{$\begin{array}{l}\text { Potencia } \\
\text { observada }^{b}\end{array}$} \\
\hline & & & & & $\begin{array}{l}\text { Límite } \\
\text { inferior }\end{array}$ & $\begin{array}{l}\text { Límite } \\
\text { superior }\end{array}$ & & \\
\hline Intersección & 33.069 & 5.609 & 5.896 & .000 & 21.038 & 45.099 & .713 & 1.000 \\
\hline [Conocimiento=0] & 2.007 & 7.479 & .268 & .792 & -14.033 & 18.048 & .005 & .057 \\
\hline [Conocimiento=1] & $0^{\mathrm{a}}$ & & & & & & & \\
\hline
\end{tabular}




\section{H2.b. Efecto de la Familiaridad}

No es posible estudiar su efecto, dado que el $100 \%$ de los sujetos que participaron del experimento, informaron que desconocen el dominio desconocido.

La Tabla 5.58 presenta por cada dominio del problema, al igual que los resultados de los experimentos anteriores, la efectividad media alcanzada por cada grupo (sujetos sin y con familiaridad en el dominio), así como el tamaño de las muestras respectivas, el estadístico $t$ con el nivel de significación (Sig. t-test), el tamaño de efecto y efecto final de la familiaridad en la efectividad.

Como se puede apreciar en la Tabla 5.58 no es posible estudiar el efecto de la familiaridad en el dominio del problema PD1, dado que el $100 \%$ de los sujetos que participaron del experimento, informaron que desconocen el dominio del problema experimental. Por el contrario, en el PC1 so observa un bajo efecto ( $d=1.384$ ) positivo, aunque la diferencia entre grupos es no significativa ( $p$-valor $=.239>0.05$ ). Esto es, los sujetos familiarizados con el dominio tienden a ser más efectivos

Tabla 5.58 - Efecto de la familiaridad E-2014

\begin{tabular}{|c|c|c|c|c|c|c|c|}
\hline \multirow{3}{*}{$\begin{array}{c}\text { DOMINIO } \\
\text { DEL } \\
\text { PROBLEMA }\end{array}$} & \multicolumn{3}{|c|}{ TAMAÑO POBLACIÓN } & \multirow{3}{*}{$\mathbf{t}$} & \multirow{3}{*}{$\begin{array}{l}\text { EFFECT Size } \\
\text { COHEN (D) }\end{array}$} & \multirow{3}{*}{$\begin{array}{l}\text { SIG. } \\
\text { T-TEST }\end{array}$} & \multirow{3}{*}{$\begin{array}{c}\text { EFECTO } \\
\text { FAM }\end{array}$} \\
\hline & \multirow{2}{*}{$\mathrm{N}$} & \multicolumn{2}{|c|}{ Fam } & & & & \\
\hline & & $\operatorname{Sin}$ & Con & & & & \\
\hline PD1 & 7 & 7 & 0 & No & Es & Posible & \\
\hline PC1 & 6 & 2 & 4 & -.458 & -.458 & No(.671) & $(-)$ \\
\hline
\end{tabular}

\section{H3. Efecto de la Titulación Académica}

No es posible estudiar su efecto, ya que todos los sujetos son titulados informáticos, tal y como se indica en la Tabla 5.51 de la sección 5.8.2.1.

\subsubsection{Posible variable Moderadora}

En este experimento, ninguna variable fue identificada como posible moderadora.

\subsection{Experimento E-2015}

\subsubsection{Cambios del Experimento E-2015 respecto a E-2013}

\subsubsection{Incremento del warming up}

E-2015 es una réplica casi idéntica que E-2013 con la salvedad de que E-2015 tiene dos semanas de warming up en lugar de una. Con la finalidad de explorar un posible efecto de warming up, los investigadores han ido aumentando poco a poco el período de tiempo establecido. El experimento original E-2013 inició con una semana, seguidamente E-2014 con 6 semanas y finalmente E-2015 con 2 semanas. Nótese que el tiempo de los warming up fue establecido en función a la planificación del curso académico. Con la finalidad de que el experimento E-2015 se aproxime más a E-2013, el tiempo de 6 semanas establecido para E-2014, fue reducido a 2 semanas por los investigadores (ya que dicho era bastante para dicha actividad, correspondía más o menos a $1 / 3$ del curso académico). Lo que podría llevar a un posible efecto en la efectividad de los analistas. 


\subsubsection{Ejecución}

\subsubsection{Muestra}

En E-2015 participaron 13 estudiantes del Máster en Ingeniería del Software de la Escuela Técnica Superior de Ingenieros Informáticos de la Universidad Politécnica de Madrid. Todos son profesionales informáticos. La Tabla 5.59 resume los datos demográficos principales de la población.

Tabla 5.59 - Características Principales de los sujetos Experimentales E-2015

\begin{tabular}{|c|c|c|}
\hline \multicolumn{3}{|c|}{ CUASI-EXPERIMENTO E-2015 (13) } \\
\hline CARACTERÍSTICAS & Nivel & \#SUJETOS \\
\hline \multirow{2}{*}{ Titulación } & No informático & 0 \\
\hline & Informático & 11 \\
\hline \multirow{4}{*}{$\begin{array}{c}\text { Experiencia en } \\
\text { Entrevistas }\end{array}$} & 0 año & 9 \\
\hline & 1-2 años & 1 \\
\hline & 3-4 años & 1 \\
\hline & $>=5$ años & 0 \\
\hline \multirow{4}{*}{$\begin{array}{l}\text { Experiencia en } \\
\text { Educción }\end{array}$} & 0 año & 9 \\
\hline & 1-2 años & 0 \\
\hline & 3-4 años & 2 \\
\hline & $>=5$ años & 0 \\
\hline \multirow{4}{*}{$\begin{array}{l}\text { Experiencia en } \\
\text { Requisitos }\end{array}$} & 0 año & 8 \\
\hline & 1-2 años & 2 \\
\hline & 3-4 años & 1 \\
\hline & $>=5$ años & 0 \\
\hline \multirow{4}{*}{$\begin{array}{c}\text { Experiencia en } \\
\text { Desarrollo }\end{array}$} & 0 año & 0 \\
\hline & 1-2 años & 5 \\
\hline & 3-4 años & 4 \\
\hline & $>=5$ años & 2 \\
\hline \multirow{2}{*}{$\begin{array}{c}\text { Familiaridad con } \\
\text { el problema }\end{array}$} & Familiar - PC1 & $3 / 6$ \\
\hline & Familiar - PD1 & $1 / 5$ \\
\hline \multirow{5}{*}{$\begin{array}{c}\text { Habilidad en } \\
\text { Requisitos } \\
\text { (Likert 1-5) }\end{array}$} & 1 menos habilidad & 3 \\
\hline & 2 & 0 \\
\hline & 3 & 5 \\
\hline & 4 & 3 \\
\hline & 5 mayor habilidad & 0 \\
\hline \multirow{5}{*}{$\begin{array}{c}\text { Habilidad en } \\
\text { Entrevistas } \\
\text { (Likert 1-5) }\end{array}$} & 1 menor habilidad & 3 \\
\hline & 2 & 3 \\
\hline & 3 & 3 \\
\hline & 4 & 2 \\
\hline & 5 mayor habilidad & 0 \\
\hline
\end{tabular}

Como se puede apreciar los sujetos declaran poseer más experiencia en desarrollo (entre 1 y 5 años) y casi ninguna o muy bajas experiencias en entrevistas, educción y requisitos. Por otro lado, en lo que respecta a las habilidades, llama la atención de que los sujetos declaran poseer habilidades en requisitos y entrevistas. Hemos observado previamente que existen biases cuando los datos demográficos se miden en escalas de Likert (A. Aranda, Dieste, \& Juristo, 2014) ya que los sujetos tienden a sobre valorar su experiencia verdadera.

En lo que respecta al conocimiento del dominio del problema, el $50 \%$ de los sujetos que realizaron la educción sobre el problema conocido desconoce el dominio, mientras que el $90 \%$ de los sujetos que realizaron la educción sobre el problema desconocido, no está familiarizado con el mismo.

\subsubsection{Preparación}

Los sujetos fueron notificados por correo electrónico con las orientaciones de la práctica así como el lugar, el día y la hora de la sesión de educción. El experimento fue propuesto como un ejercicio de clase, 
con la finalidad de que los sujetos se sientan motivados, de forma a evitar que los alumnos cambien su manera de actuar porque están siendo evaluados.

\subsubsection{Realización}

Tras unas dos semanas de clase, las cuales sirvieron de warming up, se inició la ejecución de los experimentos. En el experimento E-2015, las sesiones de educción fueron llevadas a cabo en dos días consecutivos: el primer día (28 de septiembre del 2015) se realizó la educción sobre el dominio del problema desconocido (PD1), mientras que en el segundo día (29 de septiembre del 2015) sobre el dominio conocido (PC1).

Los sujetos que actuaron como entrevistado fueron los mismos que participaron a lo largo de la secuencia de experimentos (OD para las sesiones en inglés y JW para las sesiones en Español). El rol de vigilante fue desempeñado por una única persona, tanto en el problema PC1 y otro en el problema PD1, quien durante el proceso de consolidación estuvo presente para aclarar cualquier duda que tuvieran los alumnos respecto al ejercicio y por otro lado para controlar y evitar que los sujetos se copien. No obstante, los alumnos tuvieron la posibilidad de llevar el ejercicio para terminarlo en la casa. Este hecho podría suponer una amenaza a la validez, ya que podrían emplear más del tiempo sugerido (90 minutos) para la consolidación, obtener tiempos sesgados o que se copien entre ellos. Esta amenaza creemos que no opera, ya que al analizar las especificaciones presentadas eran muy distintas entre ellas.

\subsubsection{Desviaciones}

La ejecución del experimento se llevó a cabo según la planificación inicial. No obstante, para el problema PD1 dos alumnos no se presentaron a la hora del experimento. Dichos alumnos fueron evaluados en días distintos al experimento, sin embargo no los hemos incluido en el análisis, ya que los datos podrían estar sesgados. Este hecho dio lugar a una reducción del sample size inicial, quedando 13 sujetos en lugar de 15.

\subsubsection{Resultados}

\subsubsection{Reducción del conjunto de datos}

Dado que todos los sujetos realizaron el proceso de educción y consolidación no fue necesario reducir el conjunto de datos experimentales. Si bien existe un valor atípico lo hemos mantenido dado que su efectividad no influye en el resultado final. Nótese no obstante, que para este experimento hay dos casos perdidos, los cuales no respondieron al cuestionario demográfico. Dichos sujetos serán eliminados automáticamente de los análisis que incorporen dichas variables, tanto en los análisis de los estudios individuales como a nivel de síntesis global.

Tabla 5.60 - Valores perdidos del cuasi-experimento E-2015

\begin{tabular}{|l|c|c|c|}
\hline \multicolumn{1}{|c|}{ VARIABLE INDEPENDIENTE } & N TOTAL & N VÁLIDO & NPERDIDOS \\
\hline Experiencia en Entrevistas (años) & 13 & 11 & 2 \\
\hline Experiencia en Educción (años) & 13 & 11 & 2 \\
\hline Experiencia en Requisitos (años) & 13 & 11 & 2 \\
\hline Experiencia en Desarrollo (años) & 13 & 11 & 2 \\
\hline Experiencia Profesional (años) & 13 & 11 & 2 \\
\hline Familiaridad & 13 & 11 & 2 \\
\hline Formación Académica & 15 & 11 & 2 \\
\hline Habilidad en Entrevistas & 13 & 11 & 2 \\
\hline Habilidad en Requisitos & 13 & 11 & 2 \\
\hline
\end{tabular}




\subsubsection{Procedimiento de análisis}

El procedimiento de análisis es el mismo que E-2013. Para estudiar los efectos de la experiencia, habilidad y familiaridad hemos aplicado el modelo de regresión, mientras que para el conocimiento el modelo univariante de un factor (ANOVA).

\subsubsection{Estadísticos descriptivos}

La Tabla 5.53 presenta el número total de sujetos que han participado en el experimento diferenciado por dominio del problema y entrevistado, la efectividad media, máxima y mínima alcanzada por los sujetos, así como la mediana, la varianza y la desviación típica. Como se puede apreciar en la Tabla 5.61 los sujetos que entrevistaron a JW, tanto para el problema PC1 como el problema PD1, en promedio tienden a ser más efectivos comparados con los sujetos que entrevistaron a OD. Los sujetos que entrevistaron a JW adquieren más información en el problema conocido (49\%) frente al problema desconocido (45\%). Mientras que por el contrario y en menor proporción, los sujetos que entrevistaron a OD adquieren más información en el problema desconocido (44\%) frente al problema conocido (27\%). Dichas diferencias confirman una vez más la influencia del entrevistado en la efectividad de los analistas.

Tabla 5.61 - Estadísticos descriptivos E-2015

Efectividad (\%)

\begin{tabular}{|c|c|c|c|c|}
\hline & \multicolumn{4}{|c|}{ Conocimiento SOBRE el DOMINIO DEL PROBLema } \\
\hline & \multicolumn{2}{|c|}{ CONOCIDO (PC1) } & \multicolumn{2}{|c|}{ DESCONOCIDO (PD1) } \\
\hline & OD & JW & OD & JW \\
\hline $\mathrm{N}$ & 5 & 3 & 3 & 2 \\
\hline Media & 26.67 & 48.77 & 43.79 & 45.10 \\
\hline Máximo & 69 & 54 & 53 & 45 \\
\hline Mínimo & 15 & 43 & 31 & 45 \\
\hline Mediana & 16.67 & 50.00 & 47.06 & 45.10 \\
\hline Varianza & 549.726 & 32.007 & 124.311 & .000 \\
\hline Desv. típ. & 23.446 & 5.658 & 11.149 & .000 \\
\hline
\end{tabular}

\subsubsection{Prueba de hipótesis}

\section{H1.a. Efecto de la Experiencia}

Como se puede apreciar en la Tabla 5.62, en el dominio PD1 como en el PC1 las distintas experiencias tienden a ejercer un efecto nulo o negativo, estadísticamente no significativo ( $p$-valor $>0.05$ ). Concretamente:

- Los sujetos con más años de experiencia en desarrollo y/o experiencia profesional tienden a ser menos efectivos ( $r=-.522$ y $r=-.355$ respectivamente).

- La experiencia en entrevistas parece ejercer un efecto negativo ( $r=-.245)$ en el dominio conocido, mientras que en el desconocido un efecto nulo.

- Dado que todos los sujetos del PC1 no poseen experiencia en educción, no es posible calcular su efecto, sin embargo en PD1 tiende a ejercer un efecto negativo $(r=-.554)$.

- La experiencia en requisitos no influye en la efectividad tanto en el PD1 como en el PC1 ( $r=.000$ y $r=.007$ respectivamente).

Nótese que la correlación negativa o nula lo más probable se deba al reducido número de sujetos experimentales empleados ( $\mathrm{N}=5$ y $\mathrm{N}=6$ para PD1 y PC1 respectivamente). 
Estudio empírico de la influencia de la experiencia y del conocimiento del dominio del analista en la efectividad del proceso de educción de requisitos

Tabla 5.62 - Relación de la experiencia y la efectividad en la consolidación E-2015

\begin{tabular}{|c|c|c|c|c|c|}
\hline \multirow{2}{*}{$\begin{array}{l}\text { DOMINIO } \\
\text { Problema }\end{array}$} & \multirow{2}{*}{$\begin{array}{c}\text { VARIABLE } \\
\text { INDEPENDIENTE }\end{array}$} & \multicolumn{3}{|c|}{ CORRELACIÓN } & \multirow{2}{*}{ EFECTO } \\
\hline & & $r$ & $\mathrm{p}$-valor & $\mathrm{N}$ & \\
\hline \multirow{5}{*}{ PD1 } & ExpReq & 0 & 1 & 5 & $(x)$ \\
\hline & ExpEntr & 0 & 1 & 5 & $(x)$ \\
\hline & ExpEduc & -.554 & No (.369) & 5 & $(-)$ \\
\hline & ExpDes & -.592 & $\mathrm{No}(.331)$ & 5 & $(-)$ \\
\hline & ExpProf & -.656 & $\mathrm{No}(.271)$ & 5 & $(-)$ \\
\hline \multirow{5}{*}{ PC1 } & ExpReq & .007 & No(.989) & 6 & $(x)$ \\
\hline & ExpEntr & -.249 & No(.643) & 6 & $(-)$ \\
\hline & ExpEduc & \multicolumn{4}{|c|}{ No es posible, valor constante } \\
\hline & ExpDes & -.522 & No(.308) & 6 & $(-)$ \\
\hline & ExpProf & -.355 & $\mathrm{No}(.503)$ & 6 & $(-)$ \\
\hline
\end{tabular}

\section{H1.b. Efecto de la Habilidad}

Como se muestra en la Tabla 5.63, tanto en el PD1 como en el PC1, la habilidad tiende a ejercer efectos contarios, concretamente:

- La habilidad en entrevistas tiende a influir positivamente en la efectividad del PD1 ( $r=.218$ ) y PC1 ( $r=.657)$, esto es, cuanto mayor es la valoración que el analista realiza acerca de su propia pericia en entrevistas, más información relevante acerca del dominio del problema tiende a adquirir.

- La habilidad en requisitos a ejercer un efecto positivo en el PC1 ( $r=.158)$ mientras que por el contrario, un efecto negativo en el PD1 ( $r=-201)$. Esto es, cuanto mayor es la valoración que el analista realiza acerca de su propia pericia en requisitos, más información tiende a adquirir en el problema conocido, y menos en el desconocido.

Nótese que en todos los casos, el efecto es estadísticamente no significativo ( $p$-valor > 0.05, como ya se ha mencionado, se pude deber al reducido tamaño muestral disponible para cada problema.

Tabla 5.63 - Relación de la habilidad y la efectividad en la consolidación E-2015

\begin{tabular}{|c|c|c|c|c|c|}
\hline \multirow{2}{*}{$\begin{array}{l}\text { DOMINIO DEL } \\
\text { PROBLEMA }\end{array}$} & \multirow{2}{*}{$\begin{array}{c}\text { VARIABLE } \\
\text { INDEPENDIENTE }\end{array}$} & \multicolumn{3}{|c|}{ CORRELACIÓN } & \multirow{2}{*}{$\begin{array}{c}\text { EFECTO } \\
\text { НАB }\end{array}$} \\
\hline & & $r$ & $p$-valor & $N$ & \\
\hline \multirow{2}{*}{ PD1 } & HabReq & -.201 & .756 & 5 & $(-)$ \\
\hline & HabEntr & .218 & .736 & 5 & $(+)$ \\
\hline \multirow{2}{*}{ PC1 } & HabReq & .158 & .770 & 6 & $(+)$ \\
\hline & HabEntr & .657 & .179 & 6 & $(+)$ \\
\hline
\end{tabular}

\section{H2.a. Efecto del Conocimiento}

Antes de proceder con la prueba de hipótesis, comprobaremos si los datos experimentales cumplen o no la condición de independencia, homocedasticidad y normalidad de residuos exigidos por el ANOVA, tal y como se ha indicado en la sección 4.7.

- Independencia. Se asume que cada conjunto de datos es independiente del otro. 
- Homocedasticidad. Para contrastar la homogeneidad de varianzas hemos utilizado el test de Levene. El resultado del test $(F=.850, p$-valor=.376) es no significativo por lo que la varianza es homogénea entre grupos.

- Normalidad de los datos. La normalidad de los datos del modelo, la hemos comprobado aplicando el test estadístico de Shapiro-Wilk, dado que la muestra es menor a 50 . El resultado del test presentado en la Tabla 5.64, indica que los datos presentan un distribución no normal ya que el test es significativo ( $p$-valor $=.035)$.

Tabla 5.64 - Prueba de normalidad

\begin{tabular}{|l|r|r|r|r|r|r|}
\hline & \multicolumn{4}{|c|}{ Kolmogorov-Smirnov $^{\text {a }}$} & \multicolumn{3}{c|}{ Shapiro-Wilk } \\
\cline { 2 - 7 } & Estadístico & \multicolumn{1}{|c|}{$\mathrm{gl}$} & \multicolumn{1}{c|}{ Sig. } & Estadístico & \multicolumn{1}{c|}{ gl } & \multicolumn{1}{c|}{ Sig. } \\
\hline Residuo para Efectividad (\%) & .222 & 13 & .078 & .857 & 13 & .035 \\
\hline
\end{tabular}

*. Este es un límite inferior de la significación verdadera.; Corrección de la significación de Lilliefors

Los resultados del ANOVA se muestran Tabla 5.65. Los resultados indican un efecto negativo no significativo del Conocimiento ( $p$-valor $=.370>0.05$ ) sobre la efectividad. Se observa que los sujetos tienden a ser más efectivos en el problema desconocido en un $9 \%$ (Conocimiento $=0 ; \mathrm{B}=9.010$ ). $\mathrm{El}$ efecto del conocimiento, tiende a ser muy bajo, hecho confirmado por el estimador de tamaño de efecto $\mathrm{Eta}^{2}=0.005<0.2$, esto es, un efecto pequeño según las guías de Cohen.

Tabla 5.65 - Efecto del conocimiento (ANOVA)

\section{Estimaciones de los parámetros}

Variable dependiente: Efectividad (\%)

\begin{tabular}{|c|c|c|c|c|c|c|c|c|c|}
\hline \multirow[b]{2}{*}{ Parámetro } & \multirow[b]{2}{*}{ B } & \multirow[b]{2}{*}{$\begin{array}{l}\text { Error } \\
\text { típ. }\end{array}$} & \multirow[b]{2}{*}{$\mathrm{t}$} & \multirow[b]{2}{*}{ Sig. } & \multicolumn{2}{|c|}{$\begin{array}{c}\text { Intervalo de } \\
\text { confianza } 95 \%\end{array}$} & \multirow{2}{*}{$\begin{array}{c}\text { Eta al } \\
\text { cuadrado } \\
\text { parcial }\end{array}$} & \multirow{2}{*}{$\begin{array}{l}\text { Parámetro } \\
\text { de no } \\
\text { centralidad } \\
\text { Parámetro }\end{array}$} & \multirow{2}{*}{$\begin{array}{c}\text { Potencia } \\
\text { observad } \\
a^{b}\end{array}$} \\
\hline & & & & & $\begin{array}{l}\text { Límite } \\
\text { inferior }\end{array}$ & $\begin{array}{c}\text { Límite } \\
\text { superior }\end{array}$ & & & \\
\hline Intersección & 29.709 & 6.948 & 4.276 & .002 & 14.227 & 45.191 & .646 & 4.276 & .970 \\
\hline [Conocimiento=0] & 9.010 & 9.590 & .940 & .370 & -12.357 & 30.378 & .081 & .940 & .136 \\
\hline [Conocimiento $=1]$ & $0^{a}$ & & & & & & & & \\
\hline Entrevistado & 13.985 & 9.590 & 1.458 & .175 & -7.382 & 35.352 & .175 & 1.458 & .262 \\
\hline
\end{tabular}

a. Al parámetro se le ha asignado el valor cero porque es redundante.

b. Calculado con alfa $=.05$

$\mathrm{R}^{2}=.235$

\section{H2.b. Efecto de la Familiaridad}

La Tabla 5.66 presenta por cada dominio del problema, la efectividad media alcanzada por cada grupo (sujetos sin y con familiaridad en el dominio), así como el tamaño de las muestras respectivas, el estadístico $t$ con el nivel de significación (Sig. t-test), el tamaño de efecto y efecto final de la familiaridad en la efectividad. Nótese que los efectos asociados a la familiaridad varían en función del tipo de dominio del problema.

Tabla 5.66 - Efecto de la familiaridad - Prueba t E-2015

\begin{tabular}{|c|c|c|c|c|c|c|c|}
\hline \multirow[t]{3}{*}{ DOMINIO PROBLEMA } & \multicolumn{3}{|c|}{ TAMAÑO POBLACIÓN } & \multirow{3}{*}{$\mathbf{t}$} & \multirow{3}{*}{$\begin{array}{l}\text { EFFECT SIZE } \\
\text { COHEN }(D)^{34}\end{array}$} & \multirow{3}{*}{$\begin{array}{l}\text { SIG. } \\
\text { T-TEST }\end{array}$} & \multirow{3}{*}{$\begin{array}{c}\text { EFECTO } \\
\text { FAM }\end{array}$} \\
\hline & \multirow{2}{*}{$\mathrm{N}$} & \multicolumn{2}{|c|}{ Fam } & & & & \\
\hline & & Sin & Con & & & & \\
\hline PD1 & 5 & 4 & 1 & .371 & .429 & .746 & $(+)$ \\
\hline PC1 & 6 & 3 & 3 & -.577 & -.577 & .618 & $(-)$ \\
\hline
\end{tabular}

En lo que respecta al dominio desconocido (PD1), no es posible estudiar el efecto de la familiaridad en la efectividad del sujeto, dado que el $80 \%$ (4/5) de los sujetos que participaron del experimento, informaron que desconocen el dominio. El sujeto que conoce el dominio del problema en media tiende

${ }^{34}$ Calculado utilizando http://www.uccs.edu/ /becker/ 
a ser más efectivo. Si bien es posible obtener los estadísticos descriptivos los resultados no son conclusivos: 1) por el reducido tamaño muestral $(\mathrm{N}=5)$ y 2 ) por el desbalanceo entre grupos ( 1 frente a 4 conoce el dominio de problema).

En lo que respecta al dominio conocido (PC1), el 50\% de los sujetos conoce el dominio. En media los sujetos familiarizados con el dominio adquieren un $23 \%$ de los elementos del dominio, mientras que los sujetos no familiarizados con el mismo un 33\%. Nótese que se observa un efecto negativo, esto es los sujetos no familiarizados tienden a ser más efectivos. No obstante, la diferencia entre medias es de un de $10 \%$ y no significativa.

\section{H3. Efecto de la Titulación Académica}

No es posible estudiar su efecto, ya que todos los sujetos son titulados informáticos, tal y como se indica en la Tabla 5.59 de la sección 5.9.2.1.

\subsubsection{Posible variable Moderadora}

En E-2015 no fue posible identificar una posible variable moderadora que pueda influir en la efectividad de los sujetos experimentales. 


\section{CAPÍTULO 6}

\section{SÍNTESIS DE RESULTADOS}

El presente capítulo tiene como propósito sintetizar los resultados obtenidos a lo largo de la investigación en función de las tres preguntas de investigación (RQ), referidas al efecto de la experiencia (Sección 6.1), del conocimiento (Sección 6.2) y de la titulación académica (Sección 6.3).

Realizamos la síntesis porque, tal como se indicó en el capítulo 4 de metodología y a lo largo del capítulo 5 de resultados, ninguno de los estudios empíricos por separado alcanzan el tamaño de la muestra mínimo necesario para llegar a obtener resultados estadísticamente significativos. Mediante el análisis conjunto, se aumenta el tamaño muestral y en consecuencia el poder estadístico, el grado de generalización de los resultados y una mayor capacidad predictiva que al hacerlo de forma independiente e individual para cada uno de los estudios.

\section{1 ¿Influye la experiencia del analista en la efectividad del proceso de educción de los requisitos? (RQ1)}

Para dar respuesta a la presente pregunta de investigación utilizaremos el dominio del problema PD1, fundamentalmente porque: a) se trata de un dominio desconocido para la mayoría de los sujetos experimentales, lo que evita que el conocimiento previo sobre el mismo interactúe con la experiencia e influya de modo no controlado en la efectividad del analista; b) es el problema que se ha replicado de manera ininterrumpida a lo largo de la serie histórica, permitiendo alcanzar el tamaño muestral mínimo requerido y c) las replicaciones fueron realizadas en distintos contextos, lo que nos ha permitido obtener una mayor diversidad de experiencias.

El efecto de la experiencia lo hemos estudiado desde dos puntos de vista. Por un lado, como hemos comentado en los capítulos anteriores, la experiencia fue operacionalizada como el número de años que posee el sujeto en distintas vertientes (entrevistas, educción, requisitos, desarrollo y profesional) y por el otro, la experiencia fue operacionalizada mediante una escala de Likert que refleja la percepción o experiencia subjetiva que el sujeto cree tener. En consecuencia, esta pregunta de investigación será 
Estudio empírico de la influencia de la experiencia y del conocimiento del dominio del analista en la efectividad del proceso de educción de requisitos

respondida desde ambos puntos de vistas, reconciliando las diferencias en resultados que puedan ocurrir.

\subsubsection{Efecto de la experiencia operacionalizada como número de años}

La Tabla 6.1 a modo de ejemplo, presenta un resumen de los efectos obtenidos respecto a la experiencia en requisitos a lo largo de la serie histórica. En el Anexo F.1, presentamos la misma información para los demás tipos de experiencia estudiados. El detalle de cada uno de los resultados se describe en el capítulo 5 .

Tabla 6.1 - Efecto de la experiencia en requisitos en los distintos experimentos - Problema PD1

\begin{tabular}{|c|c|r|r|c|}
\hline \multirow{2}{*}{ Experimento } & \multirow{2}{*}{$\mathbf{N}$} & \multicolumn{3}{|c|}{ Correlación - PD1 } \\
\cline { 3 - 5 } & & \multicolumn{3}{|c|}{ Efectividad * [ExpReq] } \\
\cline { 3 - 5 } & & \multicolumn{1}{|c|}{ Sig. } & Efecto \\
\hline Q-2007 & 7 & -.348 & .444 & $(-)$ \\
\hline Q-2009 & $7 / 8$ & .640 & .122 & $(+)$ \\
\hline Q-2011 & 16 & .004 & .988 & $(x)$ \\
\hline Q-2012 & 21 & .338 & .134 & $(+)$ \\
\hline E-2012* & $13 / 14$ & .734 & .050 & $(+)$ \\
\hline E-2013* & $7 / 8$ & -.843 & .025 & $(-)$ \\
\hline E-2014 & $8 / 9$ & -.243 & .562 & $(-)$ \\
\hline E-2015 & $5 / 5$ & -.000 & 1.000 & $(x)$ \\
\hline
\end{tabular}

* La correlación es significativa al nivel .05

La Tabla 6.1 muestra, para cada uno de los cuasi-experimentos ejecutados a lo largo de la investigación, la relación existente entre la experiencia en requisitos y la efectividad de los sujetos. Con la excepción de Q-2007, E-2013 y E-2014 la correlación es positiva, esto es, cuantos más años de experiencia posee el analista mayor tiende a ser su efectividad en la educción de requisitos. En el caso de Q-2007, E-2013 y E-2014, la correlación es negativa ( $r=-.348, r=-.843$ y $r=-.243$ respectivamente); es decir, los analistas novatos (con menos años de experiencia) tienden a ser mejores que los analistas expertos (con más años de experiencia) en la captura de información relevante acerca del dominio del problema. A la vista de los resultados obtenidos en $Q-2009$, Q-2012 y E-2012 ( $r=.640, r=.338$ y $r=.734$ respectivamente), lo más probable es que la correlación negativa se deba al reducido número de sujetos experimentales empleados ( $N=7,7$ y 8 respectivamente). En realidad, ninguno de los estudios por sí mismo posee un número elevado de sujetos experimentales ( $N$ va entre 7 y 21 sujetos), lo que provoca que la precisión de los coeficientes de correlación obtenidos no sea muy elevada. Los niveles de significación corroboran este hecho, ya que ningún estudio alcanza la significación estadística, con excepción de E-2012 y E-2013.

Un mecanismo para superar las limitaciones de los estudios individuales es sintetizar los resultados de los 8 estudios empíricos mostrados en la Tabla 6.1, lo que dará lugar a resultados más fiables y generalizables, dado que aumenta la variabilidad de experiencias y el tamaño muestral. Ello es posible, ya que como se ha comentado en los capítulos anteriores, los experimentos son replicaciones muy parecidas y a la vez complementarias entre ellas. Por un lado, los sujetos de todos los experimentos, con excepción de Q-2012, fueron estudiantes de máster con relativamente poca o ninguna experiencia. En Q-2012 los sujetos fueron en su mayoría personas que se mueven en ambientes académicos superiores: estudiantes de doctorado, profesores e investigadores con un número considerable de años de experiencia. En consecuencia Q-2012 complementa la falta de diversidad de experiencias de los restantes cuasi-experimentos. Todo ello permite alcanzar un total de 88 sujetos experimentales.

Un posible problema derivado de sintetizar todos los estudios conjuntamente es que las diferencias contextuales y metodológicas podrían provocar la aparición de efectos espurios, o impedir la 
identificación de efectos fidedignos. Para ello, estableceremos una estrategia de síntesis, tal y como se indica inmediatamente a continuación. El hecho de sintetizar juntos los estudios realizados mediante entrevista individual y entrevista en grupo puede causar cierta aprensión. Sin embargo, en nuestra opinión ello es posible, por los motivos indicados en el Anexo I.

\subsubsection{Estrategia de síntesis}

La técnica de análisis utilizada para evaluar los efectos de la experiencia sobre la efectividad en los cuasiexperimentos individuales fue el método de correlación estadística de Pearson. Sin embargo, para la síntesis de resultados, este método no es el más adecuado dado que no puede estudiar varias variables independientes al mismo tiempo. Es preferible utilizar métodos de análisis más versátiles. Por ejemplo, en aquellos estudios donde el entrevistado era considerado como una variable de bloque, fue posible utilizar modelos de regresión. En la presente síntesis intentaremos aplicar una estrategia parecida.

La estrategia de síntesis seguida para analizar conjuntamente la secuencia de cuasi-experimentos se divide en dos partes:

1) Meta-análisis de datos individuales. Esta estrategia se resume en la Figura 6.1. Como se puede apreciar, la estrategia de síntesis está compuesta por seis fases principales: 1) Ajuste de los datos experimentales; 2) Exploración de los datos experimentales; 3) Influencia del tamaño muestral; 4) Selección del modelo más adecuado; 4) Análisis conjunto y obtención de resultados $y$, finalmente 6) Comprobación de las condiciones de aplicación posteriores a la determinación del modelo. A continuación describiremos en detalle las actividades que componen cada una de las fases.

2) Meta-análisis de datos agregados. En este caso agregaremos los coeficientes de correlación obtenidos para cada uno de los cuasi-experimentos realizados (véase Tabla 6.1 o con mayor generalidad en el capítulo 5 de resultados).

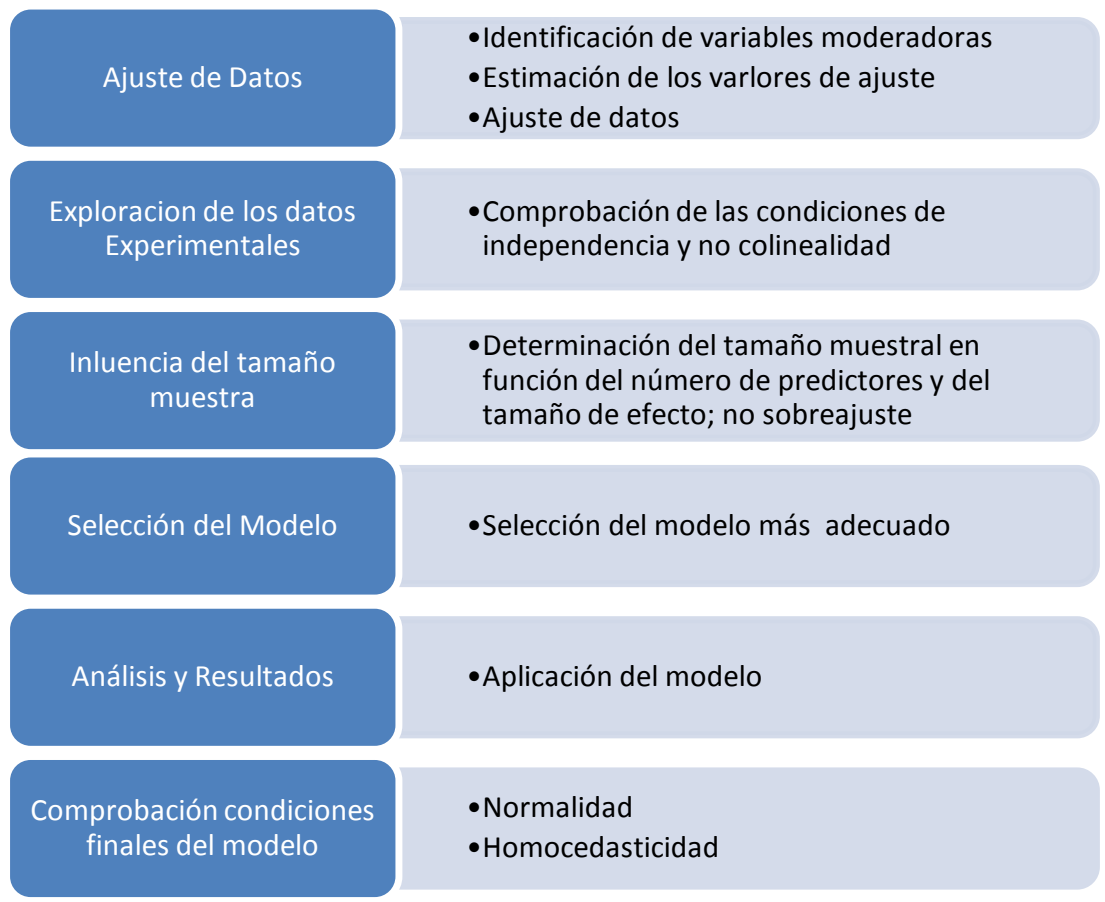

Figura 6.1 - Fases que componen la estrategia de análisis 


\subsubsection{Meta-análisis de datos Individuales}

\subsection{Ajuste de los datos experimentales}

La primera fase hace referencia al ajuste de los datos experimentales, ya que los mismos si bien son complementarios en lo que respecta a la diversidad de experiencia de los sujetos, se diferencian en ciertos aspectos derivados del contexto (como se ha indicado en la sección 4.10). Por ejemplo, en Q2011 los sujetos experimentales realizaron la educción de requisitos mediante la entrevista en grupo, mientras que en Q-2007 mediante la entrevista individual. Muy probablemente el tipo de entrevista ejerza una influencia en la efectividad de los sujetos, por lo que para poder comparar los distintos estudios sería necesario realizar un ajuste en los datos.

El ajuste de datos experimentales está compuesto por tres tareas principales: a) Identificación de las posibles variables moderadoras; b) Estimación de los valores de ajuste; y c) Ajuste de los datos propiamente dicho.

\section{a. Identificación de las posibles variables moderadoras}

Según (Baron \& Kenny, 1986) las variables moderadoras son variables que afectan la dirección y/o la intensidad de la relación entre una variable independiente y una variable dependiente (reduciéndola, incrementándola, anulándola o invirtiéndola). En nuestro caso las variables moderadoras afectan al efecto de la experiencia aumentando o disminuyendo la efectividad de los sujetos.

Creemos que algunas de las variables que definen el contexto de los experimentos (ver sección 4.10): el tipo de entrevista, el entrevistado, la formación y el warming up, están ejerciendo dicho efecto moderador en la efectividad. Por ejemplo, en los experimentos E-2012, E-2013 y E-2015, representados en la Figura 6.2, se observa claramente una posible influencia del entrevistado en la efectividad: los sujetos que entrevistaron a JW tienden en promedio a ser más efectivos que los sujetos que entrevistaron a OD. Nótese que en E-2012 los sujetos que realizan la entrevista con JW en promedio consolidan $51 \%$ de los elementos del dominio, mientras que los sujetos que entrevistan a OD un $25 \%$. Existe aproximadamente un $26 \%$ de diferencia entre entrevistados. Lo mismo ocurre en E-2013 y E2015.

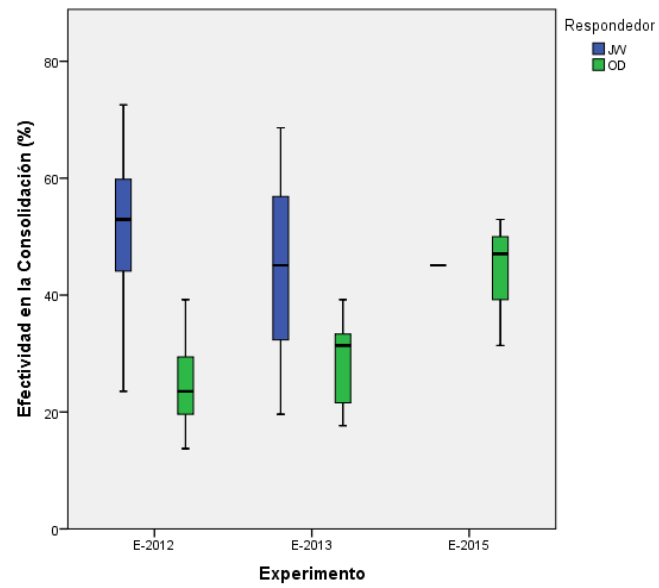

Figura 6.2 - Efectividad promedio de los experimentos diferenciados por entrevistado

Nótese que varias variables que definen el contexto experimental (indicadas en el capítulo 4, sección 4.10) no se considerarán como variables moderadoras, concretamente las variables asociadas con el idioma, el dominio del problema y los tiempos (el tiempo de educción y consolidación de los requisitos). Este hecho se debe fundamentalmente a: 
- El idioma no se ha considerado, porque como se ha explicado en los capítulos anteriores, está bloqueado con el entrevistado. No es posible separar dichos efectos.

- El dominio del problema, es considerado como objeto experimental y no como una variable independiente.

- El tiempo de educción y consolidación son desde el punto de vista experimental consideradas como variables contextuales. Nótese que el tiempo de educción como el de consolidación son tiempos recomendados, por lo que se observa una variabilidad de dichos tiempos por sujeto. Es decir, algunos sujetos tardan más y otros menos del tiempo establecido. Nótese por tanto, que la duración de los tiempos es determinada por cada uno de los sujetos ya que forma parte de la propia dinámica de las entrevistas. Es decir, así como los sujetos escogen las preguntas y estrategias a seguir durante las entrevistas, los sujetos también escogen los tiempos de educción y consolidación necesarios. Por consiguiente, dichos tiempos podrían considerarse como variables mediadoras y no moderadoras. Nótese por tanto, que el tiempo no debería ser objeto de análisis experimental.

\section{b. Estimación de los valores de ajuste}

Para que los resultados de los distintos experimentos sean comparables entre sí, es necesario ajustar los datos de modo que los efectos de las variables moderadoras sean eliminados. Es decir, es necesario calcular el efecto de cada una de las variables moderadoras (que denominaremos \% de ajuste) que serán eliminados de las efectividades totales alcanzadas por cada uno de los sujetos experimentales.

Un ejemplo nos ayudará a entender el porqué del procedimiento anterior: imaginémonos que disponemos de los datos de un total de 40 sujetos. 20 sujetos participaron en el experimento $\mathrm{A}$ y los otros 20 en el experimento $B$. La única diferencia del experimento $B$ con respecto al $A$ es que en éste opera una variable moderadora que hace que se incremente en 10 puntos la efectividad de todos los sujetos (como se pude apreciar en la Figura 6.3 a., los puntos azules están 10 unidades por debajo de los puntos verdes). Los coeficientes de correlación de A y B por separado son iguales $(r=0.962)$.

Si agregásemos los datos de A y B tal y como están, se obtendría la gráfica mostrada en la Figura 6.3.c. El coeficiente de correlación es $r=0.854$, que no es el correcto ya que en ambos casos el coeficiente de correlación correcto es $r=0.962$. La razón del cálculo erróneo, reside precisamente en la variable moderadora que hace que los sujetos de B sean más efectivos. El efecto de esta variable se mezcla con el efecto de la variable independiente propiamente dicho, causando el error en la estimación del coeficiente de correlación.

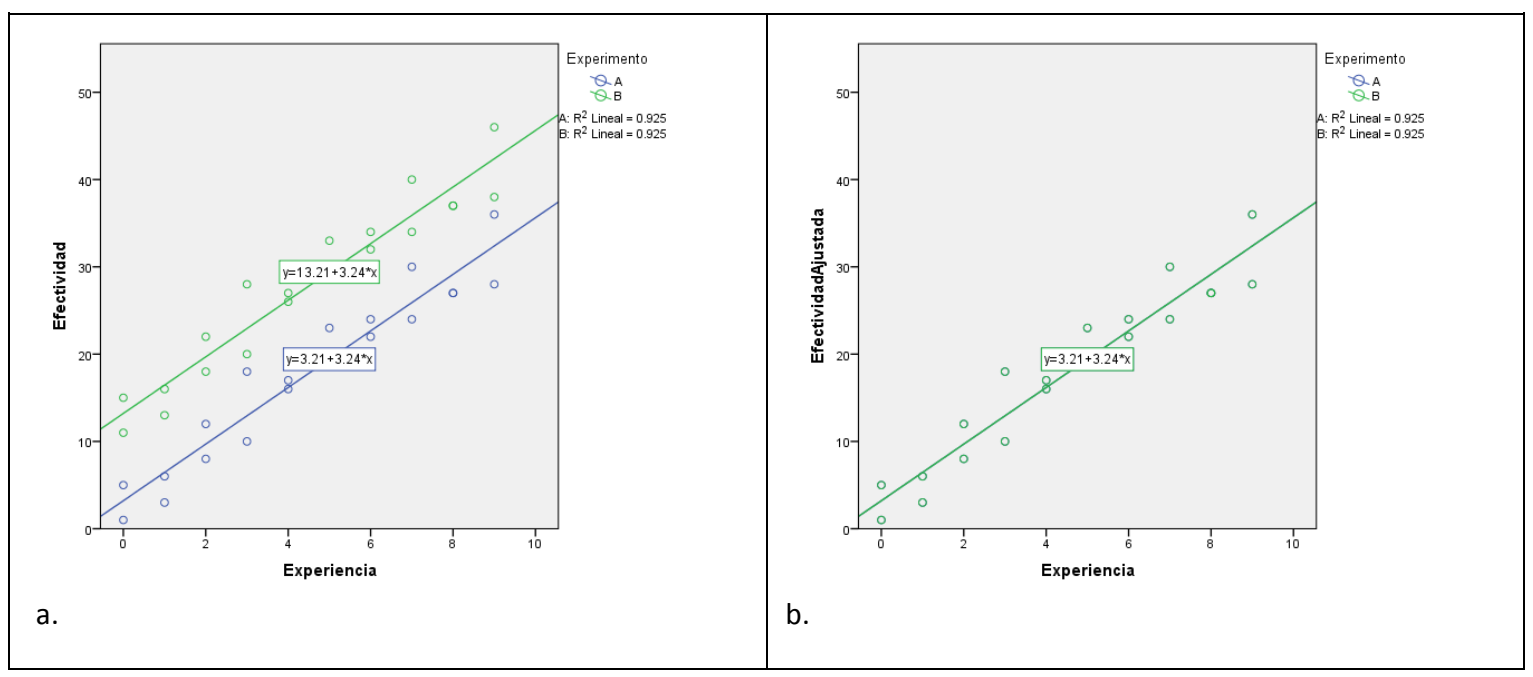




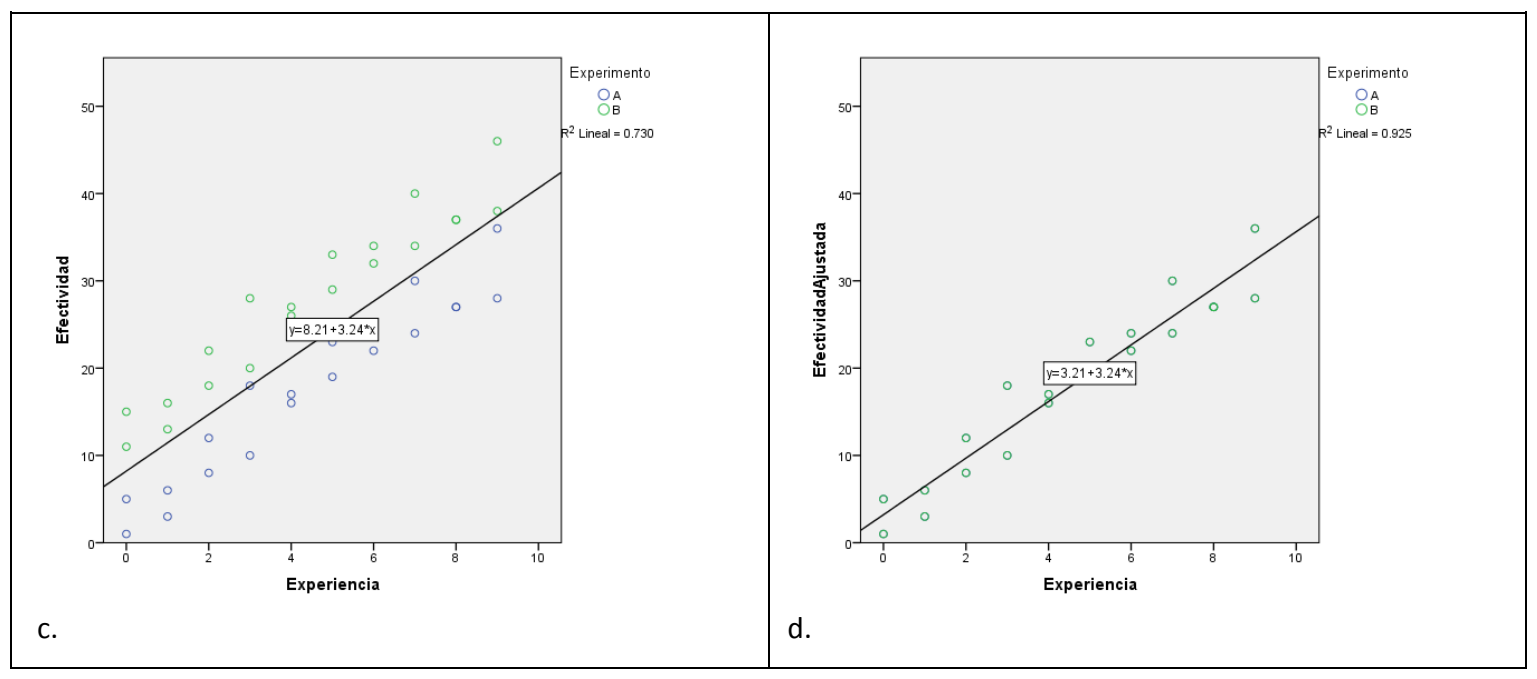

Figura 6.3 - Ejemplo ficticio sobre el efecto de una variable moderadora

Para eliminar este error, es suficiente con sustraer el efecto de la variable moderadora de cada uno de los sujetos del experimento B. Al proceder de esta forma los puntos de datos correspondientes a los experimentos $A$ y $B$ se superponen exactamente (ver Figura 6.3.b) y el análisis conjunto (ver Figura 6.3.d) arroja el resultado correcto.

El procedimiento seguido para obtener el \% de ajuste es el mismo para todas las potenciales variables moderadoras que podrían influir en la efectividad, por lo que a continuación presentaremos como ejemplo el detalle de un caso concreto. El cálculo de las estimaciones de las demás variables moderadoras se puede consultar el Anexo E.

- Efecto de Formación: corresponde con el hecho de si los sujetos han recibido formación específica antes de cursar la asignatura de requisitos o después. Para calcular este efecto, hemos utilizado la diferencia ponderada entre la efectividad promedio total alcanzada por los sujetos en los experimentos que se ejecutaron antes de impartir docencia en RE y la efectividad promedio total alcanzada en los experimentos que se realizaron al final del curso, manteniendo el resto de las variables moderadoras constantes.

Por ejemplo, en la Tabla 6.2 si observamos las variables moderadoras que influyen en los experimentos Q-2007 y E-2012, podemos comprobar que coinciden en todos los casos excepto la formación. Por lo tanto, el efecto de la formación podría calcularse como:

$$
\text { EfectoFormación }=\mid \text { Efectividad Q-2007 }- \text { Efectividad E-2012 }|=| 39-25|=| 14 \mid=14
$$

Nótese que dado que no deja de ser una estimación, calculamos el efecto de la formación como un valor entero.

Tabla 6.2 - Efecto de la formación cuando las demás variables moderadoras permanecen constantes

Efectividad en la Consolidación (\%)

\begin{tabular}{|c|c|c|c|c|c|c|}
\hline EXPERIMENTO & $\begin{array}{c}\text { TIPO } \\
\text { ENTREVISTA }\end{array}$ & FORMACIÓN & $\begin{array}{l}\text { WARMINGUP } \\
\text { (FORMACIÓN) }\end{array}$ & ENTREVISTADO & $\mathbf{N}$ & Media \\
\hline Q-2007 & Individual & Final & Ninguno & OD & 7 & 39.22 \\
\hline \multirow[t]{2}{*}{ E-2012 } & \multirow[t]{2}{*}{ Individual } & \multirow[t]{2}{*}{ Principio } & \multirow[t]{2}{*}{ Ninguno } & OD & 7 & 24.93 \\
\hline & & & & JW & 7 & 50.98 \\
\hline
\end{tabular}

No sería posible calcular el efecto de la formación utilizando los experimentos Q-2012 y E2012, ya que como se puede apreciar en la Tabla 6.3, la variable Formación es la misma en ambos experimentos y las demás variables moderadoras (como TipoEntrevista y Entrevistado) no son constantes. 
Tabla 6.3 - Efecto de la formación cuando las demás variables moderadoras no permanecen constantes

Efectividad en la Consolidación (\%)

\begin{tabular}{|c|c|c|c|c|c|c|}
\hline EXPERIMENTO & $\begin{array}{c}\text { TIPO } \\
\text { ENTREVISTA } \\
\end{array}$ & FORMACIÓN & $\begin{array}{l}\text { WARMINGUP } \\
\text { (FORMACIÓN) }\end{array}$ & ENTREVISTADO & $\mathbf{N}$ & MEDIA \\
\hline Q-2012 & Grupal & Principio & Ninguno & OD & 21 & 37.07 \\
\hline \multirow[t]{2}{*}{$\mathrm{E}-2012$} & \multirow[t]{2}{*}{ Individual } & \multirow[t]{2}{*}{ Principio } & \multirow[t]{2}{*}{ Ninguno } & OD & 7 & 24.93 \\
\hline & & & & JW & 7 & 50.98 \\
\hline
\end{tabular}

Procediendo de esta manera obtenemos para el caso del efecto de la formación dos posibles valores de ajustes:

$$
\begin{aligned}
& \text { EfectoFormación }_{1}=\mid \text { Efectividad Q-2007 }- \text { Efectividad E-2012 }|=| 39-25|=| 14 \mid=14 \\
& \text { EfectoFormación }_{2}=\mid \text { Efectividad Q-2012 - EfectividadQ-2011 }|=| 7-48|=|-11 \mid=11
\end{aligned}
$$

Cada uno de estos valores de ajustes se ha obtenido mediante estudios que poseen distintos tamaños muestrales. Los estudios de mayor tamaño se consideran más precisos que aquellos de menor tamaño. Por ello, para calcular un único efecto de formación, usaremos la media ponderada (en función del tamaño muestral) de los efectos individuales obtenidos. De esta manera obtenemos:

$$
\text { EfectoFormación } \mathrm{n}_{\text {MediaPonderada }}=(14 * 14+11 * 37) / 51=11.82=12
$$

Esto es: En promedio, los sujetos tienden a ser $12 \%$ más efectivos después de que hayan recibido formación en actividades de requisitos.

- Efecto Tipo Entrevista: corresponde con el aumento de la efectividad de los sujetos causado por las entrevistas en grupo frente a las individuales. El porcentaje de ajuste es de un $11 \%$.

- $\quad$ Efecto de WarmingUp: dado las diferencias contextuales entre experimentos, se observan tres tipos de warming up: de una, dos y seis semanas respectivamente.

- El efecto warming Up para una semana (Wup1): corresponde a la diferencia entre la efectividad promedio total entre el experimento sin warmingup (E-2012) y con warming up de una semana (E-2013). El Efecto Warming para una semana (EfectoWup1) es de $-1 \%$.

- El efecto warming Up para dos semanas (Wup2): corresponde a la diferencia entre la efectividad promedio total entre el experimento sin warmingup (E-2012) y con warming up de dos semanas (E-2015). El porcentaje de ajuste para el Efecto Warming de dos semanas (EfectoWUp2) es de un 7\%.

- El efecto warming Up para seis semanas (Wup6): corresponde a la diferencia entre la efectividad promedio total entre el experimento sin warmingup (E-2012) y con warming up de seis (6) semanas (E-2014). El porcentaje de ajuste para el Efecto Warming de seis semanas (EfectoWUp6) es de un $10 \%$.

- Efecto de Entrevistado: en la secuencia de experimentos participaron tres entrevistados (OD, AG y JW). Para calcular el efecto del entrevistado se considerará a OD como caso base. Por lo que contaremos con dos ajustes: Efecto EntrevistadoODAG y Efecto EntrevistadoODJW. El efecto del entrevistado corresponde con la información adicional que proporciona un entrevistado frente a otro. El porcentaje de ajuste para el EfectoEntrevistadoODAG es de un $23 \%$ y para el EfectoEntrevistadoODJW es de un $18 \%$.

\section{c. Ajuste de los datos}

Como hemos mencionado, el ajuste de los datos consiste en eliminar los efectos adicionales que las variables moderadoras ejercen en la efectividad de los sujetos. Para ello hemos sustraído de la efectividad de cada sujeto el porcentaje (o porcentajes) de ajuste correspondiente. El procedimiento de ajuste de los datos se resume en la Tabla 6.4. 
Estudio empírico de la influencia de la experiencia y del conocimiento del dominio del analista en la efectividad del proceso de educción de requisitos

Tabla 6.4 - Procedimiento de ajuste

Ajuste de los datos experimentos correspondientes a cada uno de los experimentos de la serie histórica
Q-2007 Ajustado $=$ Efectividad Q-2007 - Efecto Formación
Q-2009 Ajustado = Efectividad Q-2009 - Efecto Formación - Efecto EntrevistadoODAG
Q-2011 Ajustado = Efectividad Q-2011 - Efecto Formación - Efecto TipoEntrevista
Q-2012 Ajustado = Efectividad Q-2012 - Efecto TipoEntrevista
E-2012 Ajustado OD = Efectividad E-2012_OD
E-2012 Ajustado JW= Efectividad E-2012_JW - Efecto EntrevistadoODJW
E-2013 Ajustado OD= Efectividad E-2013 OD - Efecto WarmingUp1
E-2013 Ajustado JW= Efectividad E-2013 JW - Efecto EntrevistadoODJW - Efecto WarmingUp1
E-2014 Ajustado OD = Efectividad E-2013 - EfectoWarmingUp6
E-2015 Ajustado OD= Efectividad E-2015 OD - Efecto WarmingUp2
E-2015 Ajustado JW= Efectividad E-2015 JW - Efecto EntrevistadoODJW - Efecto WarmingUp2

Es importante mencionar que todos los valores fueron ajustados al momento antes, entrevista individual y al nivel de OD quien es el entrevistado que ha participado en un mayor número de experimentos de la serie histórica, aunque cualquier otra combinación de valores de moderadoras sería igualmente válida.

\subsection{Exploración de los datos experimentales}

La segunda fase, hace referencia a la exploración de los datos experimentales, donde se comprueban las condiciones necesarias previas para la aplicación de un modelo de regresión lineal (MRL), concretamente la independencia y la no colinealidad entre variables independientes. Nótese que para la síntesis del efecto de la experiencia utilizaremos como método de análisis el modelo de regresión, ya que las variables bajo estudio son continuas.

\section{a. Comprobación de la independencia de los datos}

Los datos han sido obtenidos para cada sujeto de forma independiente de los demás, por lo tanto no debería existir independencia entre los mismos.

\section{b. Comprobación condiciones de no-colinealidad}

La colinealidad en un modelo de regresión ocurre cuando una o más variables independientes están corraladas linealmente con otras variables del modelo. La existencia de colinealidad (o multicolinealidad) en el MRL podría acarrear determinados problemas al realizar inferencias, como por ejemplo, alteraciones en los valores de los coeficientes estimados. Los coeficientes son muy sensibles ante pequeños cambios en los datos. Las tendencias de los coeficientes podrían ser opuestas (positivas/negativas) o muy elevados.

La no-colinealidad de las variables independientes se puede comprobar de formas distintas, las más usuales son: la matriz de correlaciones bivariadas; el índice de varianza (FIV), la tolerancia (T) e índice de colinealidad (IC), entre otros.

Para comprobar la no-colinealidad de las variables independientes, en primer lugar hemos utilizado el test de correlación bivariadas de Pearson con la finalidad de identificar qué variables están más fuertemente relacionadas entre ellas. La Tabla 6.5 presenta por cada variable independiente el índice de correlación ( $\mathrm{r}$ ), el grado de significación (Sig.) y la cantidad de casos considerados (N). Nótese que el $\mathrm{N}$ no es un valor constante, dado que algunos sujetos abandonaron el experimento, otros no respondieron los cuestionarios demográficos o en algunos experimentos algunas experiencias no fueron 
estudiadas, como pueden ser la experiencia en educción en Q-2011 y la experiencia en desarrollo en Q2007.

Tabla 6.5 - Correlación entre las distintas vertientes de la experiencia PD1

\begin{tabular}{|c|c|c|c|c|c|c|}
\hline & & $\begin{array}{c}\text { EXPERIENCIA } \\
\text { ENTREVISTAS } \\
\text { (AÑOS) } \\
\end{array}$ & $\begin{array}{c}\text { EXPERIENCIA EN } \\
\text { EDUCCIÓN } \\
\text { (AÑOS) }\end{array}$ & $\begin{array}{c}\text { EXPERIENCIA } \\
\text { REQUISITOS } \\
\text { (AÑOS) } \\
\end{array}$ & $\begin{array}{c}\text { EXPERIENCIA } \\
\text { DESARROLLO } \\
\text { (AÑOS) } \\
\end{array}$ & $\begin{array}{c}\text { EXPERIENCIA } \\
\text { PROFESIONAL } \\
\text { (AÑOS) } \\
\end{array}$ \\
\hline \multirow{3}{*}{$\begin{array}{c}\text { EXPERIENCIA EN } \\
\text { ENTREVISTAS (AÑOS) }\end{array}$} & $\mathrm{R}$ & 1 & $.908^{* *}$ & $.780^{* *}$ & $.380^{* *}$ & $.751^{* *}$ \\
\hline & Sig. (bilateral) & & .000 & .000 & .001 & .000 \\
\hline & $\mathrm{N}$ & 84 & 68 & 84 & 69 & 76 \\
\hline \multirow{3}{*}{$\begin{array}{l}\text { EXPERIENCIA EN } \\
\text { EDUCCIÓN (AÑOS) }\end{array}$} & $\mathrm{R}$ & & 1 & $.830^{* *}$ & $.484^{* *}$ & $.760^{* *}$ \\
\hline & Sig. (bilateral) & & & .000 & .000 & .000 \\
\hline & $\mathrm{N}$ & & 68 & 68 & 59 & 66 \\
\hline \multirow{3}{*}{$\begin{array}{c}\text { EXPERIENCIA EN } \\
\text { REQUISITOS (AÑOS) }\end{array}$} & $\mathrm{R}$ & & & 1 & $.502^{* *}$ & $.811^{* *}$ \\
\hline & Sig. (bilateral) & & & & .000 & .000 \\
\hline & $\mathrm{N}$ & & & 84 & 69 & 76 \\
\hline \multirow{3}{*}{$\begin{array}{c}\text { EXPERIENCIA EN } \\
\text { DESARROLLO (AÑOS) }\end{array}$} & $\mathrm{R}$ & & & & 1 & $.639^{* 1}$ \\
\hline & Sig. (bilateral) & & & & & .000 \\
\hline & $\mathrm{N}$ & & & & 69 & 69 \\
\hline \multirow{3}{*}{$\begin{array}{c}\text { EXPERIENCIA } \\
\text { PROFESIONAL (AÑOS) }\end{array}$} & $\mathrm{R}$ & & & & & 1 \\
\hline & Sig. (bilateral) & & & & & \\
\hline & $\mathrm{N}$ & & & & & 77 \\
\hline
\end{tabular}

La correlación es significativa al nivel 0,01 (bilateral). ** La correlación es significante al nivel 0,05 (bilateral). *

Como se puede apreciar en la Tabla 6.5 las distintas experiencias están fuertemente correlacionadas (sombreados en color verde) y son estadísticamente significativas, con excepción de la experiencia en desarrollo cuyas correlaciones son moderadas. Nótese que la experiencia en entrevistas, la experiencia en educción y la experiencia en requisitos son potencialmente colineales, ya que las correlaciones entre las mismas son muy altas, casi perfectas ( $r=.908 ; r=.830$ significativas al nivel .01), así como la experiencia en requisitos y la experiencia profesional ( $r=.811$ significativa al nivel .01 ). Aunque la experiencia en desarrollo tiene un cierto grado de correlación con las demás, no parece que los coeficientes de correlación bivariadas sean tan grandes como para sospechar que haya un riesgo de colinealidad. Por tanto, según la matriz de colinealidad las variables potencialmente colineales tienen relación con: la experiencia en educción, requisitos, entrevistas y la profesional.

Como hemos indicado otra de las maneras de determinar si existe colinealidad entre las variables independientes es mediante el Factor de inflación de la varianza (FIV) en conjunto con el índice de condición (IC).

- El Factor de inflación de la varianza (FIV): mide el impacto de colinealidad entre las variables del modelo de regresión. Valores altos de FIV son evidencias de que la variable puede explicarse en gran medida por las variables restantes, es decir, existe colinealidad de variables en el modelo. Los valores del FIV se obtienen mediante la siguiente fórmula: FIV: $1 /\left(1-R_{j}{ }_{j}\right)$ siendo $R^{2}$ el coeficiente de determinación obtenido al efectuar la regresión de una variable independiente sobre el resto de las variables del modelo.

- Un parámetro relacionado con el FIV es la Tolerancia (T), que se define como el recíproco del FIV: $\mathrm{T}=1 / \mathrm{FIV}=1-\mathrm{R}_{\mathrm{j}}^{2}$. Una recomendación utilizada frecuentemente por investigadores (O'brien, 2007) es considerar un FIV grande, esto es, FIV $>10$, el cual se obtiene cuando $\mathrm{R}^{2}>0.9$ y $\mathrm{T}<0.1$. Una segunda opción, más rigurosa, consiste en rebajar los límites a FIV $>5$ con $\mathrm{R}^{2}>$ 0.8 y $T<0.2$ (Heiberger \& Holland, 2013) como evidencia de colinealidad.

- El índice de condición (IC): Belsley (1991) sugiere tres grados de colinealidad: leve (IC < 10), moderada $(10<I C<30)$ y severa $(I C \geq 30)$. Cuando un modelo posee un índice de condición severo, alguna o varias de sus variables comparten colinealidad sustancial de su varianza con las 
restantes variables. Habitualmente se considera que cuando una variable manifiesta una proporción de la varianza alta (superior a 0.5), indica que ésta está implicada en la colinealidad.

La serie histórica de estudios tiene 5 variables independientes que se podrían incluir en el modelo de regresión. La Tabla 6.6 y Tabla 6.7 exponen los resultados de la colinealidad. Nótese que los estadísticos de colinealidad presentados en la Tabla 6.6 indican que las variables experiencia en Educción y la experiencia en Entrevistas tienen problemas de colinealidad, ya que dichas variables tienen un FIV superior a 10 (con T menor a 0.1), incluso si consideramos la opción más rigurosa, la experiencia en requisitos, también tiene problemas de colinealidad (FIV superior 5 con T menor a 0.2). Por el contrario, los estadísticos de colinealidad de las demás variables están dentro de los valores esperados, lo que indica ausencia de colinealidad entre las mismas.

Tabla 6.6 - Modelo de regresión (1)

\begin{tabular}{|c|c|c|c|c|c|c|c|c|}
\hline & & \multicolumn{2}{|c|}{$\begin{array}{l}\text { Coeficientes no } \\
\text { estandarizados }\end{array}$} & \multirow{2}{*}{$\begin{array}{c}\begin{array}{c}\text { Coeficientes } \\
\text { tipificados }\end{array} \\
\text { Beta }\end{array}$} & \multirow[b]{2}{*}{ T } & \multirow[b]{2}{*}{ Sig. } & \multicolumn{2}{|c|}{$\begin{array}{l}\text { Estadísticos de } \\
\text { colinealidad }\end{array}$} \\
\hline \multicolumn{2}{|c|}{ Modelo } & B & Error típ. & & & & Tolerancia & FIV \\
\hline \multirow[t]{6}{*}{1} & Constante & 28.202 & 2.576 & & 10.949 & .000 & & \\
\hline & $\begin{array}{l}\text { Experiencia en } \\
\text { Entrevistas (años) }\end{array}$ & -.789 & 1.514 & -.242 & -.521 & .604 & .084 & 11.903 \\
\hline & $\begin{array}{l}\text { Experiencia en } \\
\text { Educción (años) }\end{array}$ & 1.511 & 1.618 & .454 & .934 & .355 & .077 & 13.033 \\
\hline & $\begin{array}{l}\text { Experiencia en } \\
\text { Requisitos (años) }\end{array}$ & .233 & .791 & .096 & .294 & .770 & .170 & 5.870 \\
\hline & $\begin{array}{l}\text { Experiencia en } \\
\text { Desarrollo (años) }\end{array}$ & .216 & .584 & .074 & .370 & .713 & .452 & 2.214 \\
\hline & $\begin{array}{l}\text { Experiencia Profesional } \\
\text { (años) }\end{array}$ & -.604 & .733 & -.286 & -.823 & .414 & .150 & 6.662 \\
\hline
\end{tabular}

La Tabla 6.7 muestra los resultados del diagnóstico de colinealidad del modelo indicado en la Tabla 6.6. Nótese que la dimensión 6 posee un índice de condición moderado (IC $=12.7>10$ ) lo que sugiere que determinadas variables del modelo están relacionadas ejerciendo un moderado impacto en el modelo. Al comparar las proporciones de varianza de cada una de las variables del modelo, se observa que las variables experiencia en educción y la experiencia en entrevistas tienen una proporción de varianza elevada con valores 0.91 y 0.89 respectivamente. Este hecho confirma que tanto la experiencia en entrevistas como la experiencia en educción, están fuertemente relacionadas.

Tabla 6.7 - Diagnóstico de colinealidad (1)

\begin{tabular}{|c|c|c|c|c|c|c|c|c|c|}
\hline \multirow[b]{2}{*}{$\begin{array}{l}\frac{0}{0} \\
\frac{0}{0} \\
\frac{0}{2}\end{array}$} & \multirow[b]{2}{*}{$\begin{array}{l}: \frac{c}{n} \\
\frac{1}{d} \\
\frac{\varepsilon}{0}\end{array}$} & \multirow[b]{2}{*}{ Autovalores } & \multirow[b]{2}{*}{$\begin{array}{l}\text { Índice de } \\
\text { condición }\end{array}$} & \multicolumn{5}{|c|}{ Proporciones de la varianza } & \multirow[b]{2}{*}{$\begin{array}{c}\text { Experiencia } \\
\text { Profesional } \\
\text { (años) }\end{array}$} \\
\hline & & & & (Constante) & $\begin{array}{l}\text { Experiencia } \\
\text { en } \\
\text { Entrevistas } \\
\text { (años) }\end{array}$ & $\begin{array}{c}\text { Experiencia } \\
\text { en } \\
\text { Educción } \\
\text { (años) }\end{array}$ & $\begin{array}{l}\text { Experiencia } \\
\text { en } \\
\text { Requisitos } \\
\text { (años) }\end{array}$ & $\begin{array}{c}\text { Experiencia } \\
\text { en } \\
\text { Desarrollo } \\
\text { (años) }\end{array}$ & \\
\hline \multirow[t]{6}{*}{1} & 1 & 4.762 & 1.000 & .01 & .00 & .00 & .00 & .01 & .00 \\
\hline & 2 & .733 & 2.550 & .25 & .02 & .01 & .01 & .05 & .00 \\
\hline & 3 & .260 & 4.278 & .67 & .02 & .01 & .01 & .27 & .02 \\
\hline & 4 & .162 & 5.423 & .04 & .04 & .05 & .31 & .26 & .05 \\
\hline & 5 & .053 & 9.448 & .02 & .03 & .03 & .63 & .19 & .85 \\
\hline & 6 & .030 & 12.705 & .00 & .89 & .91 & .04 & .22 & .07 \\
\hline
\end{tabular}

a. Variable dependiente: Efectividad Ajustada (\%)

Una de las soluciones para resolver el problema de colinealidad es eliminar la/s variable/s que está/n más afectadas por la colinealidad. En nuestro caso, según los resultados anteriores, tendríamos que decidir entre eliminar la experiencia en educción (con varianza $=0.91$ ) o la experiencia en entrevistas (con varianza $=0.89$ ). Hemos optado por eliminar la experiencia en educción del modelo, en primer lugar porque es la que mayor correlación tiene con las demás variables (experiencia en entrevistas: $r=.908$, experiencia en requisitos: $r=.830$; ver Tabla 6.5). En segundo lugar, disponemos de más puntos de datos para la experiencia en entrevistas $(\mathrm{N}=84)$ que la experiencia en educción $(\mathrm{N}=68)$, 
esto se debe a que en Q-2011 no se ha considerado la experiencia en educción). En tercer lugar, dudamos que los sujetos tengan una conciencia clara del concepto de experiencia en educción; probablemente, la experiencia en educción es de esperar que sea similar a la experiencia en entrevistas o requisitos. Finalmente, lo cierto es que, la experiencia en educción (según el coeficiente de correlación r) y la proporción de varianza, está muy relacionada con las demás variables y no permitirá explicar la efectividad de los analistas mejor que la experiencia en entrevistas o requisitos.

Hemos aplicado el mismo procedimiento de determinación de la colinealidad para el modelo con 4 variables (experiencias en entrevistas, requisitos, desarrollo y profesional), el cual ha resultado no estar afectado por colinalidad. Los detalles están disponibles en el Anexo G.

\subsection{Influencia del tamaño muestral}

Para poder aplicar con rigor un modelo de regresión, es deseable disponer de un tamaño muestral mínimo. En caso contrario, la estimación del efecto de las variables independientes será muy pobre, siendo posible que se produzca el fenómeno de sobreajuste (u overfitting). El fenómeno de sobreajuste ocurre cuando el modelo se ajusta muy bien a los datos debido al alto número de variables independientes en relación al número de casos, aunque este ajuste es espurio.

Existen diferentes formas de determinar el tamaño muestral mínimo necesario para un modelo de regresión. Las más frecuentemente utilizadas se basan en: 1) el número de predictores del modelos ó 2) el tamaño de efecto y poder estadístico esperado.

Nótese que aunque tenemos 5 variables independientes, una de ellas (la experiencia en educción) ha sido eliminada por motivos de colinealidad. Por este motivo los cálculos mostrados a continuación se realizarán empleando 4 variables independientes o predictoras.

\section{- Determinación del tamaño muestral en función del número de predictores}

(Green, 1991) sugiere dos reglas heurísticas para determinar un tamaño mínimo aceptable de la muestra. La primera hace referencia al ajuste global del modelo, y la segunda a cada una de las variables independientes del modelo.

1. Ajuste global del modelo de regresión. Una regla de pulgar utilizada frecuentemente para determinarlo es que para $\mathrm{k}$ variables predictoras, es necesario un tamaño muestral de $\mathrm{n}=50+8^{*} \mathrm{k}$.

2. Ajuste para cada variable independiente del modelo. Se sugiere un tamaño mínimo de $\mathrm{n}=104+\mathrm{k}$.

En nuestro caso, para el modelo (1) presentado en la Tabla 6.6 con 4 variables independientes $(\mathrm{K}=4)$ necesitaríamos aproximadamente $50+8 * 4=82$ sujetos para ajustar el modelo globalmente, mientras que para detectar un efecto significativo en cada uno de los predictores necesitaríamos $104+4=108$ sujetos experimentales.

\section{- Determinación del tamaño muestral en función del tamaño de efecto}

Además del número de predictores, es posible determinar el tamaño muestral en función del tamaño de efecto y el nivel de poder estadístico requerido. Existen distintas formas de realizar dicho análisis. La más habitual es mediante herramientas especializadas como G*Power (Faul et al., 2007) (como lo hemos indicado en los capítulos anteriores). En nuestro caso, para 5 variables predictoras, con un tamaño de efecto medio ( $\mathrm{f} 2=0.15$ ) y un poder del $80 \%$ (el habitualmente requerido para considerar fiables los resultados de un estudio empírico) necesitaríamos 85 sujetos para ajustar el modelo de regresión global. 
Por otro lado, Miles y Shevlin (2001) proponen algunos gráficos muy útiles que ilustran los tamaños de las muestras necesarios para alcanzar un poder del $80 \%$, para diferentes tamaños de efecto $y$ números de predictores. La Figura 6.4 muestra un gráfico resumen que presenta el tamaño muestral requerido para un modelo de regresión en función del número de predictores del modelo y el tamaño de efecto esperado (grande, medio y bajo). En nuestro caso, para el modelo (1) según los datos de la gráfica, para un tamaño de efecto medio y 4 variables predictoras, necesitaríamos aproximadamente unos 90 sujetos experimentales, mientras que para un efecto grande unos 40 casos.

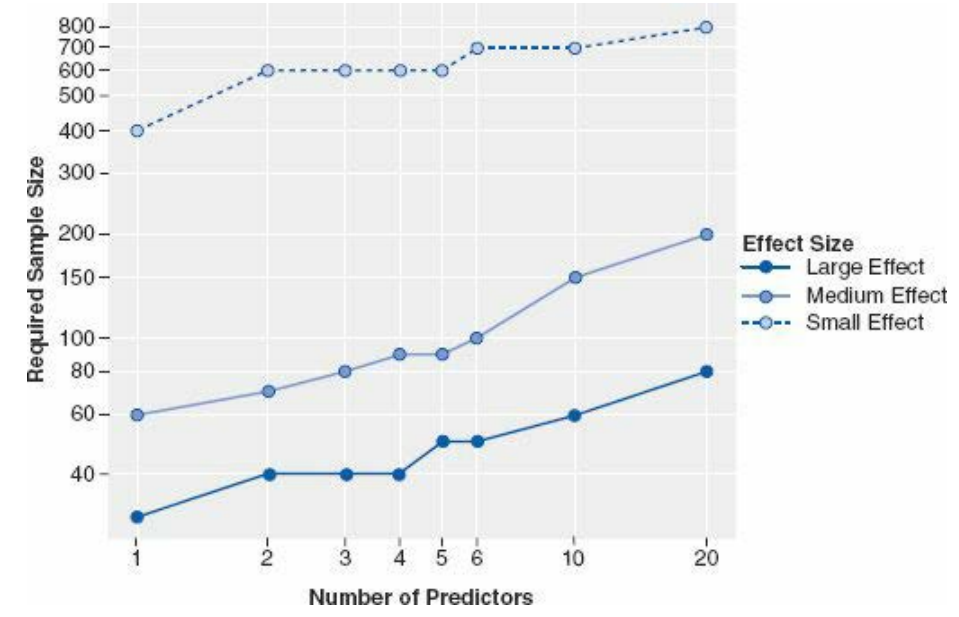

Figura 6.4 - Tamaño muestral requerido en la regresión en función del número de variables predictoras y el tamaño de efecto esperado. Gráfico extraído de Miles y Shevlin (2001).

\section{- Comprobación de la no existencia de sobreajuste}

A modo de ejemplo, la Tabla 6.8 presenta las variables independientes o predictoras, el coeficiente de determinación $\mathrm{R}^{2}$, el número de datos que disponemos $(\mathrm{N})$ y el tamaño muestral requerido para cuatro posibles modelos de regresión que podrían explicar el efecto de las experiencias en la efectividad de los sujetos. Los modelos de 1 a 4 difieren únicamente en la variable que permite aumentar el número de datos disponibles. Por ejemplo, al eliminar la variable experiencia en educción pasamos de 59 a 69. Nótese que en lugar de incrementar 16 puntos de datos incrementa 10 ya que en Q-2011 (cuasiexperimento que se incrementa al modelo, al eliminar la experiencia en educción), no se cuenta con los datos de 6 sujetos para las demás experiencias, concretamente la experiencia en desarrollo y la experiencia profesional.

Tabla 6.8 - Determinación del modelo de regresión más adecuado

\begin{tabular}{|c|c|c|c|c|}
\hline \multirow{2}{*}{ Experiencia en: } & \multicolumn{3}{|c|}{ Síntesis de Resultados } & \multirow[b]{2}{*}{ Modelo (4) } \\
\hline & Modelo (1) & Modelo (2) & Modelo (3) & \\
\hline Entrevistas & -.789 & .532 & .383 & .114 \\
\hline Educción & 1.511 & & & \\
\hline Requisitos & .233 & .271 & -.069 & .497 \\
\hline Desarrollo & .216 & .231 & .007 & \\
\hline Profesional & -.604 & -.540 & & -.461 \\
\hline
\end{tabular}

\begin{tabular}{|c|c|c|c|c|}
\hline $\mathrm{R}^{2}$ & .037 & .020 & .008 & .013 \\
\hline $\mathrm{N}$ & 59 & 69 & 69 & 76 \\
\hline N Esperado $50+8 * \mathrm{k}$ & 90 & 82 & 74 & 74 \\
\hline
\end{tabular}

*Modelo significativo 
Si comparamos el coeficiente de determinación $\left(R^{2}\right)$ obtenido en los distintos modelos ( 1 al 4$)$, se observa en general un efecto muy bajo. Las variables del modelo (1) explican un $3.7 \%$ la variabilidad de la efectividad de los analistas, mientras que el modelo ( 2 al 4) un $2 \%$, un $0.8 \%$ y un $1.3 \%$ respectivamente. Por lo tanto podemos concluir que no se observa el fenómeno de sobreajuste en ninguno de los modelos $1-4$.

\subsection{Selección del modelo}

Tal y como se puede apreciar en la Tabla 6.8, el modelo (2) es perfectamente válido para estudiar los efectos de la experiencia en la efectividad de los sujetos por los siguientes motivos:

1. Cumple con las condiciones de no colinealidad (FIV $<10$ e IC $<30$ ) requeridas para poder aplicar el modelo de regresión (mayores detalles indicados en el Anexo G.1).

2. Si bien el tamaño muestral $(\mathrm{N}=69)$ es inferior en comparación con el esperado $(\mathrm{N}=82$, para 4 variables), está muy próximo e incluso supera el $\mathrm{N}$ deseable para detectar efectos grandes ( $\mathrm{N}=40$, ver Figura 6.4).

3. No se observa sobreajuste.

Los modelos (3) y (4) poseen propiedades similares al modelo (2) esto es, no existen variables colineales y no se observa el fenómeno de sobreajuste. En ambos caso incluso el tamaño muestral requerido ( $\mathrm{N}=74$ ) se aproxima mucho al tamaño muestral disponible ( $\mathrm{N}=69$ y $\mathrm{N}=76$ respectivamente). En contrapartida, tanto los modelos (3) como el (4) poseen menos variables independientes o predictoras que el modelo (2). Por todo ello, dado que identificar la relación entre variables independientes y dependientes es nuestro principal objetivo, creemos que el modelo (2) es el modelo más adecuado para la síntesis.

\subsection{Análisis y Resultados}

El modelo de regresión que hemos utilizado para determinar el efecto de la experiencia de los sujetos en la efectividad del proceso de educción es el modelo (2) de la Tabla 6.8. Los resultados del modelo de regresión se muestran en la Tabla 6.10. Como se puede apreciar, la experiencia en entrevistas ( $\left.B_{1}=.532\right)$, la experiencia en requisitos $\left(B_{2}=.271\right)$, la experiencia en desarrollo $\left(B_{3}=.231\right)$ tienden a ejercer un efecto positivo en la efectividad. Por el contrario, la experiencia profesional $\left(B_{3}=.231\right)$ ejerce un efecto negativo.

Las unidades de las B's son las mismas que la de la variable respuesta efectividad, esto es, porcentajes. A diferencia de los tamaños de efecto, no disponemos de referencias para poder nombrar si una determinada B corresponde a un efecto grande, medio o bajo. Por este motivo fijaremos en este punto un criterio de interpretación de las B's de la forma siguiente:

Tabla 6.9 - Convenciones de tamaños de efectos según Cohen

\begin{tabular}{|c|c|c|c|c|}
\hline Efecto & Fuerte & MOderado & Bajo & Ninguno \\
\hline Correlación (B) & $\pm(>3)$ & $\pm(2-3)$ & $\pm(1-2)$ & $\pm(0-1)$ \\
\hline
\end{tabular}

Las B's obtenidas representan incrementos (o decrementos) de efectividad menores a $1 \%$ por año de experiencia. De acuerdo a la interpretación anterior, en todos los casos, los efectos son muy bajos, que a efectos prácticos corresponden a un efecto nulo.

Tras analizar el coeficiente de determinación $\left(R^{2}\right)$, el grado de ajuste del modelo es muy bajo $\left(R^{2}=\right.$ $.020=2 \%$ ) y no significativo ( $p$-valor $=0.860$ ). Este hecho pone de manifiesto, que las experiencias por sí mismas no explican la variabilidad de efectividades en los analistas. Esto es, existen otras variables que ejercen influencia y no aparecen en el modelo de análisis. 
Estudio empírico de la influencia de la experiencia y del conocimiento del dominio del analista en la efectividad del proceso de educción de requisitos

Tabla 6.10 - Efecto de la Experiencia mediante el modelo de regresión (Análisis Conjunto)

\begin{tabular}{|c|c|c|c|c|c|c|c|c|}
\hline & \multirow[t]{2}{*}{ MOdelo } & \multicolumn{2}{|c|}{$\begin{array}{l}\text { COEFICIENTES NO } \\
\text { ESTANDARIZADOS }\end{array}$} & \multirow{2}{*}{$\begin{array}{c}\text { COEFICIENTES } \\
\text { TIPIFICADOS } \\
\text { Beta } \\
\end{array}$} & \multirow[t]{2}{*}{$T$} & \multirow[t]{2}{*}{ SIG. } & \multicolumn{2}{|c|}{$\begin{array}{c}\text { ESTADÍSTICOS DE } \\
\text { COLINEALIDAD }\end{array}$} \\
\hline & & B & Error típ. & & & & Tolerancia & FIV \\
\hline \multirow[t]{5}{*}{1} & (Constante) & 28.73 & 2.54 & & 11.297 & .000 & & \\
\hline & $\begin{array}{l}\text { Experiencia en } \\
\text { Entrevistas (años) }\end{array}$ & .532 & .785 & .149 & .678 & .500 & .318 & 3.145 \\
\hline & $\begin{array}{l}\text { Experiencia en } \\
\text { Requisitos (años) }\end{array}$ & .271 & .717 & .102 & .378 & .707 & .209 & 4.787 \\
\hline & $\begin{array}{l}\text { Experiencia en } \\
\text { Desarrollo (años) }\end{array}$ & .231 & .524 & .072 & .441 & .661 & .574 & 1.742 \\
\hline & $\begin{array}{l}\text { Experiencia } \\
\text { Profesional (años) }\end{array}$ & -.540 & .606 & -.235 & -.891 & .376 & .221 & 4.535 \\
\hline
\end{tabular}

\subsection{Comprobación condiciones finales del modelo de regresión}

El modelo de regresión utilizado para calcular los efectos de la experiencia debe reunir las condiciones de normalidad y homogeneidad. Ello asegura la aplicabilidad del modelo, así como la fiabilidad y precisión de los resultados obtenidos.

\section{a. Comprobación de las condiciones de normalidad de residuos}

Para comprobar la normalidad de los datos, hemos utilizado el gráfico de Q-Q y prueba de KolmogorovSmirnov con la modificación de Lillierfors. Los resultados se muestran en la Figura 6.5 y

Tabla 6.11 respectivamente.

El gráfico de Q-Q mostrado en la Figura 6.5 presenta simultáneamente para cada punto de datos, el valor observado del residuo frente al valor estandarizado del mismo. Si los residuos poseen una distribución normal, los puntos se asemejarán a una línea recta (bisectriz de los ejes de coordenadas). En Figura 6.5 se observa que la distribución de los puntos que se asemeja a una línea recta por lo que se puede afirmar que los residuos son aproximadamente normales.

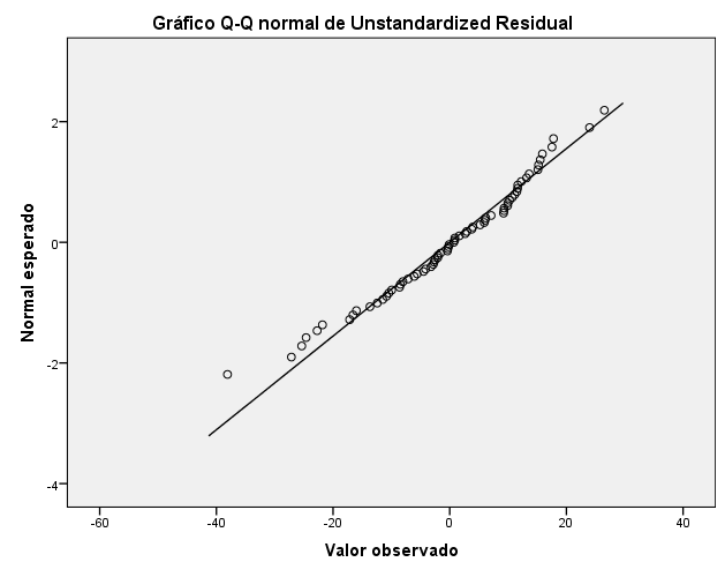

Figura 6.5 - Gráfico Q-Q - Normalidad de los datos

Los resultados presentados en la figura anterior, han sido confirmados mediante la prueba de Kolmogorov-Smirnov con la modificación de Lillierfors. Como se puede apreciar en la Tabla 6.11 el pvalor $=.2$ es mayor a .05 , por lo que asumimos que existe una distribución normal. El test de Shapiro Wilk (más adecuado para pequeñas muestras) arroja un resultado similar. Por otro lado, se confirma la normalidad de los datos mediante los estadísticos de asimetría y curtosis, ya que están dentro de los rangos habituales de \pm 1 . 
Tabla 6.11 - Pruebas de normalidad

\begin{tabular}{|l|r|r|r|r|r|r|r|r|}
\hline & \multicolumn{2}{|c|}{ Estadísticos } & \multicolumn{3}{c|}{ Kolmogorov-Smirnov $^{\mathrm{a}}$} & \multicolumn{3}{c|}{ Shapiro-Wilk } \\
\cline { 2 - 8 } & Asimetría & \multicolumn{1}{c|}{ Curtosis } & Estadístico & \multicolumn{1}{c|}{$\mathrm{gl}$} & \multicolumn{1}{c|}{ Sig. } & Estadístico & \multicolumn{1}{c|}{$\mathrm{gl}$} & Sig. \\
\hline $\begin{array}{l}\text { Unstandardized } \\
\text { Residual }\end{array}$ & -.538 & .233 & .082 & 69 & $.200^{*}$ & .977 & 69 & .243 \\
\hline
\end{tabular}

*. Este es un límite inferior de la significación verdadera.

a. Corrección de la significación de Lilliefors

\section{b. Comprobación de las condiciones de homocedasticidad}

Para comprobar la condición de homocedasticidad hemos elaborado un gráfico de dispersión con los valores pronosticados y esperados de los residuos. Como se puede apreciar en la Figura 6.6, los residuos se distribuyen aproximadamente en una banda, sin que se aprecien figuras similares a un embudo. Esto significa que la varianza es bastante uniforme a lo largo del rango de valores pronosticados tipificados. Ello implica que se cumplen la condición de homocedasticidad o igualdad de varianzas.

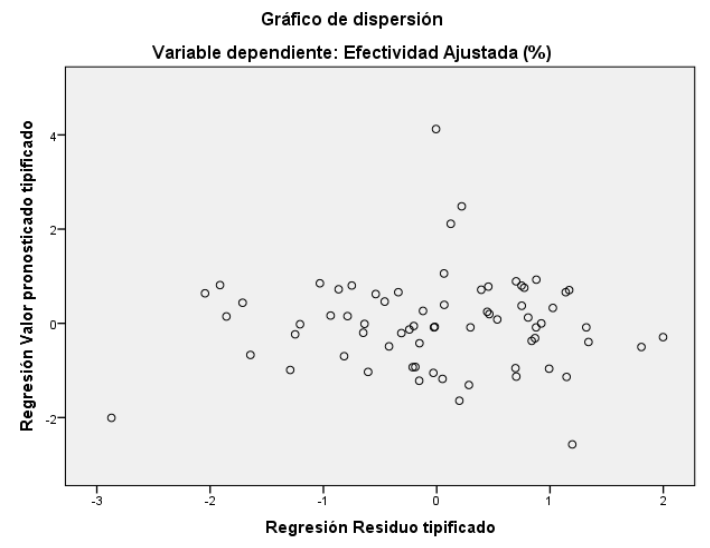

Figura 6.6 - Gráfico de dispersión formado con los residuos del modelo

\subsubsection{Meta-análisis de datos agregados}

El meta-análisis de datos agregados nos permite analizar el efecto de la experiencia no a partir de los datos individuales de los sujetos sino a partir de las tendencias observadas en los estudios empíricos individuales. Por tanto, como complemento y con la finalidad de comprobar los efectos observados en la Tabla 6.10, aplicaremos el meta-análisis también como estrategia de síntesis.

Nótese no obstante que a diferencia de los modelos de regresión, el meta-análisis no es capaz de separar los efectos de las variables como ocurre con el modelo de regresión. Por ello, los resultados que se obtengan no coincidirán con los modelos de regresión, sino que únicamente esperamos que muestren tendencias parecidas. En contra partida, el meta-análisis nos permitirá utilizar todos los datos disponibles sin que sea necesario descartar sujetos porque dispongamos de los valores de ciertas variables independientes pero no de otras, esto es, a diferencia de los 69 sujetos utilizados en el análisis de regresión, algunos meta-análisis emplearán hasta 84 sujetos. Ello mejorará la estimación de los efectos de las experiencias.

Antes de proceder a la presentación de los distintos resultados, comentaremos brevemente cómo interpretar y leer un meta-análisis. Gráficamente, el meta-análisis se representa mediante un gráfico de efectos (o forest plot). Para la presente investigación en el lado izquierdo de la figura, reportaremos los estudios individuales en orden cronológico junto con el tamaño muestral de los mismos. Inmediatamente debajo aparecen los resultados del meta-análisis a partir de los modelos de efectos fijos y aleatorios, con sus respectivos valores de significación y el análisis de heterogeneidad entre los estudios. Cabe mencionar, que los modelos de efectos fijos consideran que no existe heterogeneidad entre los estudios, por lo que se asume que la variabilidad observada entre los estudios individuales se 
debe únicamente al error que se produce al realizar el muestreo aleatorio de cada estudio. Por el contrario, los modelos de efectos aleatorios consideran la heterogeneidad o variabilidad entre estudios individuales.

En el lado derecho del gráfico de efectos se reporta el tamaño de efecto (en nuestro caso el coeficiente de correlación), el intervalo de confianza, y los pesos ponderados tanto fijos como aleatorios. En la representación gráfica del meta análisis, por cada experimento:

- Las líneas horizontales representan el intervalo de confianza. En este caso, hemos considerado un intervalo de confianza del $95 \%$ para cada experimento.

- Si el intervalo de confianza cruza el valor 0 los resultados son no significativos.

- El tamaño de efecto es representado por un cuadrado cuyas dimensiones son proporcionales al peso del experimento en el meta-análisis. Las estimaciones de los estudios con un mayor tamaño muestral son más precisas, lo que significa que poseen un mayor peso en la estimación del efecto global.

- El diamante de la última fila representa el resultado del meta-análisis. La línea central del diamante representa el efecto global, mientras que las puntas laterales del diamante representan el intervalo de confianza asociado.

A continuación por cada variable independiente presentaremos el meta-análisis.

\section{a. Efecto de la Experiencia en Entrevistas}

La Figura 6.7 presenta el meta-análisis de correlaciones para la Experiencia en Entrevista, basada en 8 estudios y 84 sujetos totales. Se puede apreciar que la experiencia en entrevistas tiende a ejercer un efecto nulo $(r=0.09$ ) estadísticamente no significativo ( $p$-valor $=0.4607$ ). El intervalo de confianza oscila entre [-0.16 y 0.33]. Nótese que al no resultar significativo el efecto global, el intervalo de confianza cruza el valor cero.

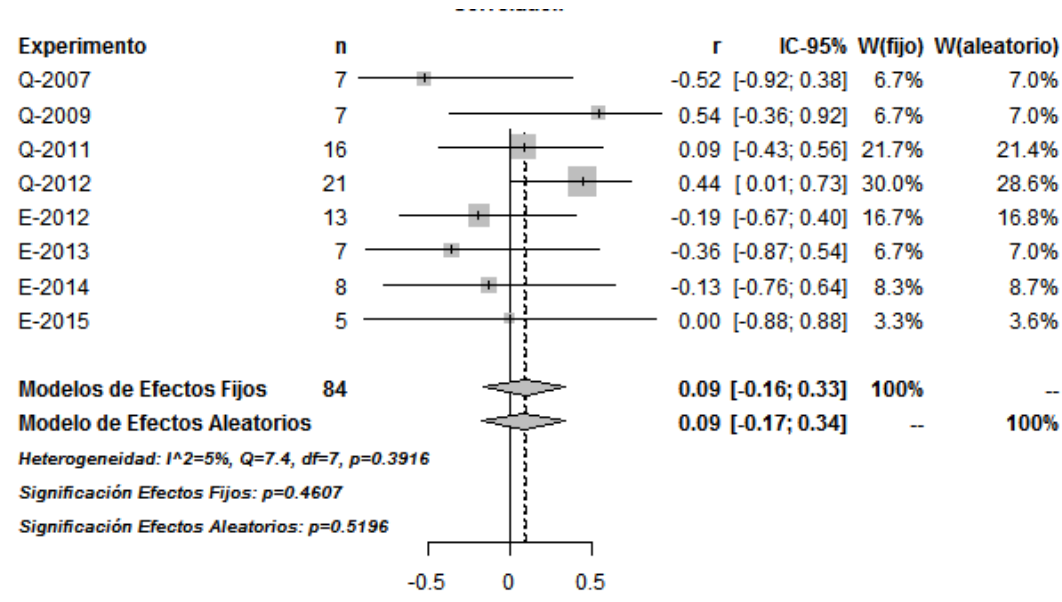

Figura 6.7 - Meta análisis Efecto de la Experiencia en Entrevistas PD1

\section{b. Efecto de la Experiencia en Requisitos}

Como se puede apreciar en la Figura 6.8 existe heterogeneidad entre los estudios individuales $\left(1^{2}=\right.$ $61.4 \%, \mathrm{Q}=18.1, \mathrm{df}=7, \mathrm{p}$-valor $=0.011<0.05$ ). Ello implica que probablemente existen diferencias sistemáticas entre los estudios. La heterogeneidad muy probablemente viene dada por E-2012, E-2013 y Q-2009, donde el coeficiente de correlación es moderadamente positivo para Q-2009 y E-2012, y fuertemente negativo para E-2013. La experiencia en requisitos es estadísticamente significativa para E2012 y E-2013. No obstante, el motivo de las diferencias no es evidente. Dichas diferencias podrían deberse al tamaño muestral de los experimentos, al diseño experimental de los mismos, a la formación recibida a lo largo del curso o un warming up previo a la ejecución del experimento, entre otras. Sin 
embargo, no están claras las diferencias entre los estudiados. Por ejemplo, Q-2009 se diferencia de E2012 y E-2013 en el momento en que se realizaron las sesiones de educción. Q-2009 se ejecutó al final del curso académico mientras que E-2012 y E-2013 al principio. Se espera que la efectividad media de los sujetos sea mayor después de recibir formación específica, sin embargo Q-2009 y E-2012 resultaron positivos. E-2012 de E-2013 se diferencian fundamentalmente en el tipo de diseño y warming up. E-2012 no posee warming up y E-2013 posee una semana. Se espera que el efecto warming up mejore las efectividades, sin embargo los resultados obtenidos presentan efectos contrarios a los esperados. El efecto de la experiencia en los experimentos between-subjects (E-2013, E-2014 y E-2015) resultaron negativos, mientras que en el within-subject (E-2012) positivo y en los cuasi-experimentos se observan efectos diversos, por tanto no parece que el tipo o diseño del experimento sea lo que esté influyendo .

Dado que no existe ninguna razón que explique la heterogeneidad entre estudios, tomaremos como efecto global el indicado por el modelo de efectos aleatorios. La Figura 6.8 presenta el meta-análisis de correlaciones para la Experiencia en Requisitos, basada en 8 estudios y 84 sujetos totales. Se puede apreciar que la experiencia en requisitos tiende a ejercer un efecto nulo ( $r=0.09$ ) estadísticamente no significativo ( $p$-valor $=0.689$ ). El intervalo de confianza oscila entre [-0.34 y 0.49$]$.

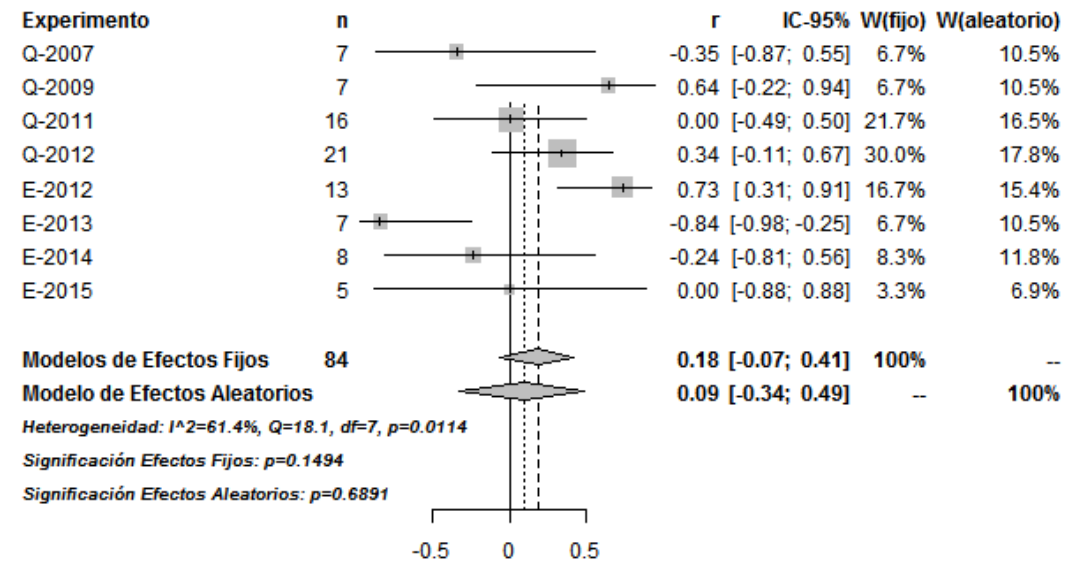

Figura 6.8 - Meta análisis Efecto de la Experiencia en Requisitos PD1

\section{c. Efecto de la Experiencia en Educción}

Dado que la experiencia en educción está fuertemente corralada con la experiencia en requisitos y la experiencia en entrevistas (tal y como se muestra en la Tabla 6.5), no hemos realizado el meta-análisis de correlación para la experiencia en educción. Por un lado, porque los efectos observados podrían deberse a la relación para con la experiencia en requisitos o entrevistas y no exclusivamente a la experiencia en educción y por otro lado, para mantener una coherencia con las variables estudiadas mediante el modelo de regresión de la Tabla 6.10.

\section{d. Efecto de la Experiencia en Desarrollo}

La Figura 6.9 presenta el meta-análisis de correlaciones para la Experiencia en Desarrollo, basada en 7 estudios y 69 sujetos totales. Se puede apreciar que la experiencia en desarrollo, tiende a ejercer un efecto nulo ( $r=0.06$ ) estadísticamente no significativo ( $p$-valor $=0.6949)$. El intervalo de confianza oscila entre [-0.22 y 0.33]. Nótese que al no resultar significativo el efecto global, el intervalo de confianza cruza el valor cero. 


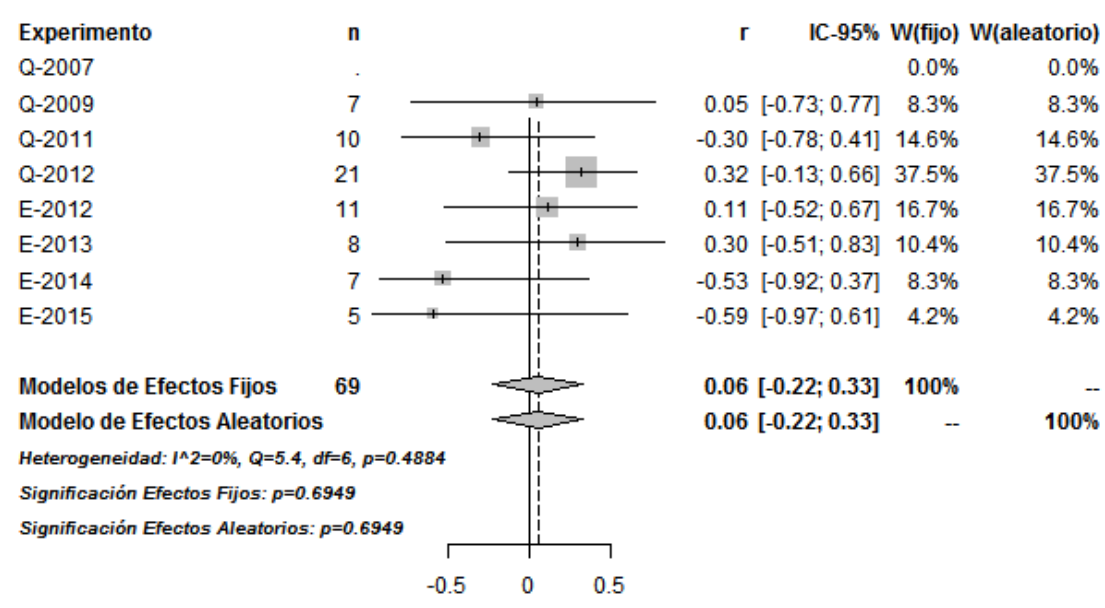

Figura 6.9 - Meta análisis Efecto de la Experiencia en Desarrollo PD1

\section{e. Efecto de la Experiencia Profesional}

La Figura 6.10 presenta el meta-análisis de correlaciones para la Experiencia Profesional, basada en 8 estudios y 77 sujetos totales. Aunque la heterogeneidad ha resultado no significativa, ésta es sustancial $\left(I^{2}=36.7 \%, Q=11.1, d f=7, p\right.$-valor=0.136). Por ello, se podría utilizar el efecto global arrojado tanto por el modelo de efectos fijos como por el modelo de efectos aleatorios. Nosotros utilizaremos este último. Se puede apreciar que la Experiencia Profesional tiende a ejercer un efecto nulo $(r=-0.05)$ estadísticamente no significativo ( $p$-valor $=0.768$ ). El intervalo de confianza oscila entre $[-0.39$ y 0.30$]$.

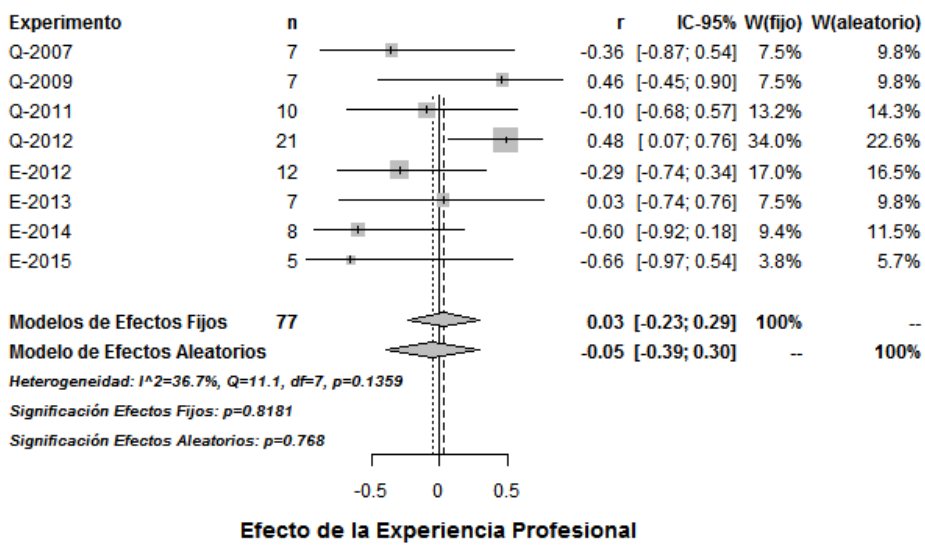

Figura 6.10 - Meta análisis Efecto de la Experiencia Profesional PD1

\subsubsection{Comparación del meta-análisis de datos individuales con el meta-análisis de datos agregados}

La Tabla 6.12 compara los coeficientes de correlación obtenidos en el meta-análisis con los coeficientes de correlación derivados del modelo de regresión. Estos coeficientes se han calculado ${ }^{35}$ a partir de la $\mathrm{t}$ y los grados de libertad correspondientes $(\mathrm{N}-4)$. Tanto el modelo de regresión como el meta-análisis son esencialmente coincidentes. En todos los casos, indistintamente del método de síntesis aplicado, el coeficiente de correlación ( $r$ ) es menor (en valor absoluto) a 0.11 (efecto prácticamente nulo según Cohen) y estadísticamente no significativo ( $p$-valor $>0.05$ ). Ello implica que la experiencia en sus distintas vertientes: entrevistas, requisitos, desarrollo y profesional, por sí mismas no determinan la efectividad de los sujetos.

35 Para obtener el valor del coeficiente de regresión, hemos empleado el calculador de tamaños de efectos: http://www.uccs.edu/ /becker/. 
Tabla 6.12 - Resumen relación entre la efectividad y la experiencia - PD1

\begin{tabular}{|l|c|c|c|c|}
\hline \multirow{2}{*}{ EXPERIENCIAS } & \multicolumn{2}{|c|}{ MODELO DE REGRESIÓN } & \multicolumn{2}{c|}{ META-ANÁLISIS } \\
\cline { 2 - 5 } & $\mathbf{r}$ & \multicolumn{1}{c|}{ Sig. } & $\mathbf{r}$ & \multicolumn{1}{c|}{ Sig. } \\
\hline $\begin{array}{l}\text { Experiencia en } \\
\text { Entrevistas }\end{array}$ & .08 & .500 & .09 & .461 \\
\hline $\begin{array}{l}\text { Experiencia en } \\
\text { Requisitos }\end{array}$ & .05 & .707 & .09 & .689 \\
\hline $\begin{array}{l}\text { Experiencia en } \\
\text { Desarrollo }\end{array}$ & .06 & .661 & .06 & .695 \\
\hline $\begin{array}{l}\text { Experiencia } \\
\text { Profesional }\end{array}$ & -.11 & .376 & -.05 & .761 \\
\hline
\end{tabular}

\subsubsection{Efecto de la experiencia operacionalizada como la Habilidad}

Tabla 6.13 presenta un resumen de los efectos de la habilidad en requisitos y en entrevistas obtenidos a lo largo de la serie histórica de experimentos.

En general, los resultados poseen un carácter mixto. La Habilidad en Entrevistas resulta positiva en la mitad de estudios y negativa en la otra mitad. La Habilidad en Requisitos resulta nula en dos casos, positiva en dos casos y negativa en otros dos casos. No se observa un efecto claro.

Tabla 6.13 - Efecto de la habilidad en requisitos y entrevistas diferenciado por estudio experimental PD1

\begin{tabular}{|c|c|c|c|c|c|}
\hline \multirow{2}{*}{$\begin{array}{c}\text { VARIABLE } \\
\text { INDEPENDIENTE }\end{array}$} & \multirow{2}{*}{ EXPERIMENTO } & \multicolumn{3}{|c|}{ CORRELACIÓN } & \multirow[t]{2}{*}{ ЕFECTO } \\
\hline & & $r$ & p-valor & $\mathrm{N}$ & \\
\hline \multirow{6}{*}{ HabReq } & Q-2011 & -.010 & .961 & 16 & (X) \\
\hline & Q-2012 & .018 & .921 & 21 & $(X)$ \\
\hline & E-2012 & .311 & .302 & 13 & $(+)$ \\
\hline & E-2013 & .205 & .664 & 7 & $(+)$ \\
\hline & E-2014 & -.667 & .147 & 5 & $(-)$ \\
\hline & E-2015 & -.201 & .756 & 5 & $(-)$ \\
\hline \multirow{6}{*}{ HabEntr } & Q-2011 & -.102 & .622 & 16 & $(-)$ \\
\hline & Q-2012 & .154 & .387 & 21 & $(+)$ \\
\hline & E-2012 & .150 & .625 & 13 & $(+)$ \\
\hline & E-2013 & -.364 & .431 & 7 & $(-)$ \\
\hline & E-2014 & -.118 & .788 & 5 & $(-)$ \\
\hline & E-2015 & .218 & .736 & 5 & $(+)$ \\
\hline
\end{tabular}

Para obtener resultados más precisos, hemos procedido al igual que la sección anterior. Hemos sintetizado los datos disponibles respecto a la habilidad en requisitos y entrevistas mediante un metaanálisis de datos individuales que describiremos a continuación.

\subsubsection{Meta-análisis de datos individuales}

En lo que respecta al análisis estadístico, al igual que la experiencia, hemos aplicado el modelo de regresión lineal, donde la variable dependiente hace referencia a la efectividad ajustada y las variables independientes a las habilidades en entrevistas y requisitos. El modelo (ver Tabla 6.14) cumple con los supuestos requeridos, tal y como se describe brevemente a continuación:

- No Colinealidad. Los estadísticos de colinealidad están dentro de los rangos establecidos (FIV $<10$ y $\mathrm{T}>0.1$ )

- Normalidad. Los residuos del modelo poseen una distribución normal ( $p$-valor $=0.084>$ 0.05 para Kolmogorov-Smirnov y p-valor $=.247$ para Shapiro-Wilk). Se confirma la 
normalidad de los datos mediante los estadísticos de asimetría (-.501) y curtosis (.558), ya que están dentro de los rangos habituales \pm 1 .

- Tamaño muestral. El modelo cuenta con dos variables independientes, por lo que para alcanzar un efecto del $80 \%$ se necesita contar con al menos $50+8 * 2=66$ casos. En nuestro caso, contamos con 67 casos, uno por encima de lo requerido.

- Homocedasticidad. Los datos cumplen con la condición de homocedasticidad o igualdad de varianzas, ya que la varianza observada es bastante uniforme a lo largo del rango de valores pronosticados tipificados, como se puede apreciar en la Figura 6.11.

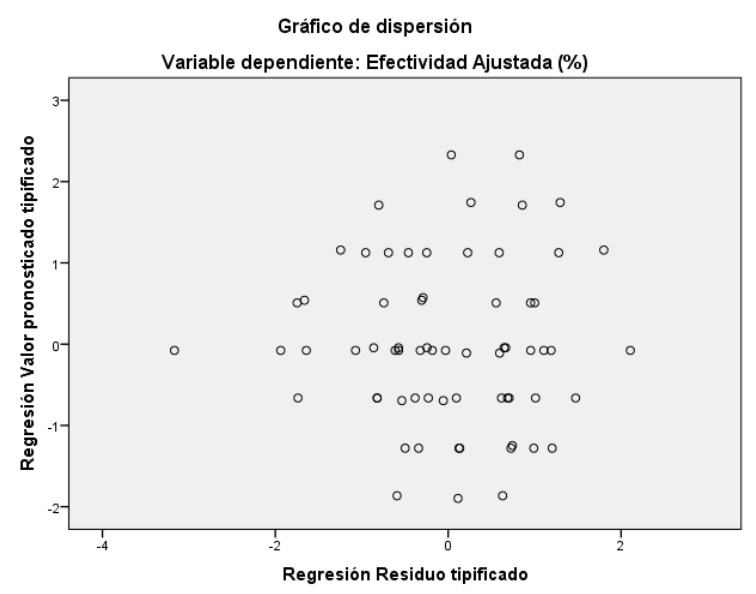

Figura 6.11 - Gráfico de dispersión

El modelo de regresión presentado en la Tabla 6.14 pone de manifiesto un efecto negativo en la efectividad de los analistas tanto para la habilidad en entrevistas $\left(B_{1}=-.510\right)$ como para la habilidad en requisitos $\left(B_{2}=.-484\right)$. No obstante, dichas tendencias son nulas y estadísticamente no significativas ( $p$ valor $>0.05)$. El grado de ajuste del modelo $\left(R^{2}=0.004\right)$ es nulo a efectos prácticos, lo que significa que la percepción subjetiva del sujeto sobre su experiencia en requisitos y en entrevistas, no explica la efectividad de los mismos.

Tabla 6.14 - Análisis conjunto. Modelo de regresión lineal - Habilidad PD1

\begin{tabular}{|c|c|c|c|c|c|c|c|c|}
\hline \multirow{2}{*}{\multicolumn{2}{|c|}{ MODELO }} & \multicolumn{2}{|c|}{$\begin{array}{l}\text { COEFICIENTES NO } \\
\text { ESTANDARIZADOS }\end{array}$} & \multirow{2}{*}{$\begin{array}{c}\text { COEFICIENTES } \\
\text { TIPIFICADOS } \\
\text { Beta } \\
\end{array}$} & \multirow[b]{2}{*}{$\mathrm{t}$} & \multirow[b]{2}{*}{ SIG. } & \multicolumn{2}{|c|}{$\begin{array}{c}\text { ESTADÍSTICOS DE } \\
\text { COLINEALIDAD }\end{array}$} \\
\hline & & B & Error típ. & & & & Tolerancia & FIV \\
\hline \multirow[t]{3}{*}{1} & (Constante) & 30.474 & 5.799 & & 5.255 & .000 & & \\
\hline & $\begin{array}{l}\text { Habilidad en } \\
\text { Entrevistas }\end{array}$ & -.510 & 1.900 & -.038 & -.269 & .789 & .793 & 1.262 \\
\hline & $\begin{array}{l}\text { Habilidad en } \\
\text { Requisitos }\end{array}$ & -.484 & 1.746 & -.039 & -.277 & .783 & .793 & 1.262 \\
\hline
\end{tabular}

\subsubsection{Meta-análisis de datos agregados}

Al igual que la experiencia, hemos comprobado los efectos de la habilidad de los sujetos sobre la efectividad mediante meta-análisis de datos agregados. La Figura 6.12 y Figura 6.13 la muestran los meta-análisis correspondiente a la habilidad en entrevistas y la habilidad en requisitos respectivamente.

La Figura 6.12 presenta el meta-análisis de correlaciones para la Habilidad en Entrevistas, basada en 6 estudios y 67 sujetos totales. Se puede apreciar que la habilidad en entrevistas tiende a ejercer un efecto nulo $(r=0.03)$ estadísticamente no significativo ( $p$-valor $=0.813$ ). El intervalo de confianza oscila entre $[-0.24$ y 0.30$]$. Nótese que al no resultar significativo el efecto global, el intervalo de confianza cruza el valor cero. 


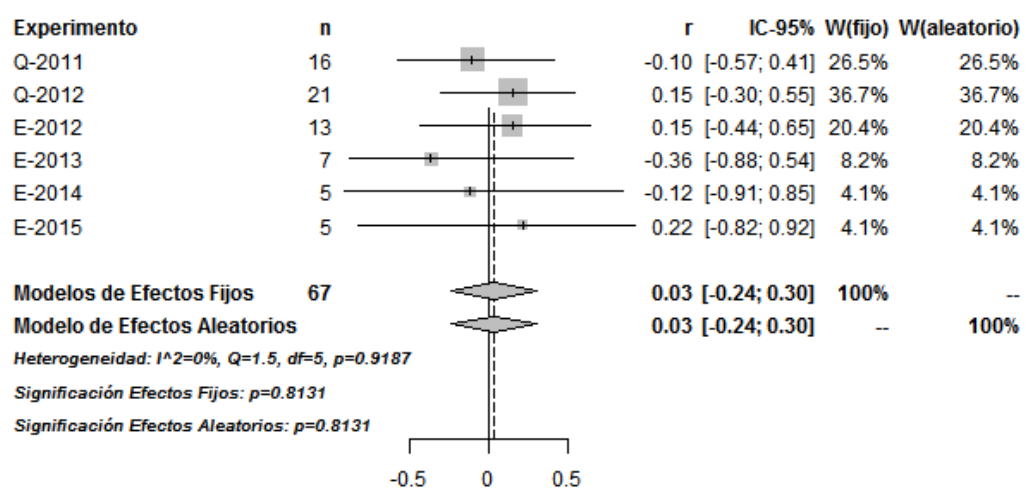

Figura 6.12 - Meta análisis Efecto de la Habilidad en Entrevistas PD1

La Figura 6.13 presenta el meta-análisis de correlaciones para la Habilidad en Requisitos, basada en 6 estudios y 67 sujetos totales. Se puede apreciar que la habilidad en requisitos tiende a ejercer un efecto nulo $(r=0.05)$ estadísticamente no significativo ( $p$-valor $=0.751$ ). El intervalo de confianza oscila entre [-0.23 y 0.31]. Nótese que al no resultar significativo el efecto global, el intervalo de confianza cruza el valor cero.

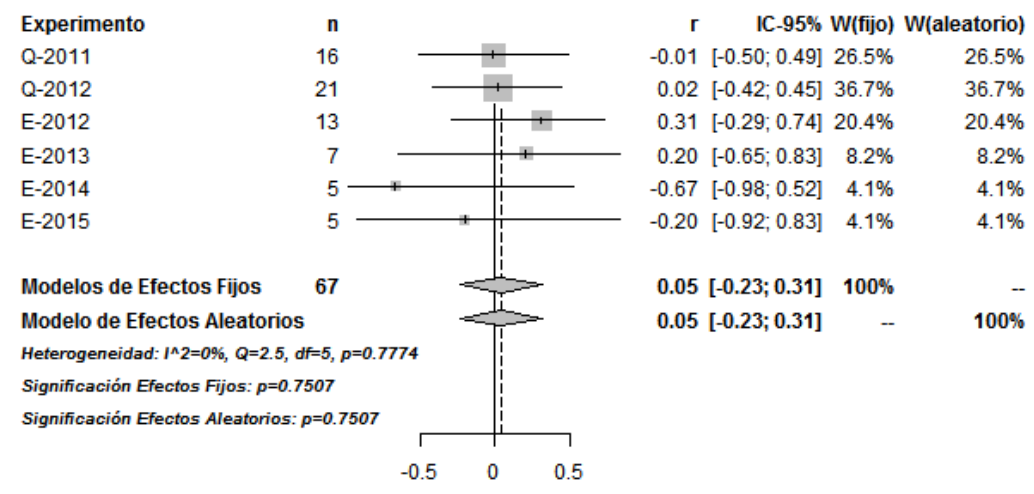

Figura 6.13 - Meta análisis Efecto de la Habilidad en Requisitos PD1

\subsubsection{Comparación del meta-análisis de datos individuales con el meta-análisis de datos agregados}

La Tabla 6.15 compara los coeficientes de correlación obtenidos en el meta-análisis con los coeficientes de correlación derivados del modelo de regresión. Estos coeficientes se han calculado ${ }^{36}$ a partir de la $\mathrm{t} y$ los grados de libertad correspondientes (N-2). Tanto el modelo de regresión como el meta-análisis son esencialmente coincidentes.

Tabla 6.15 - Resumen relación entre la efectividad y la habilidad - PD1

\begin{tabular}{|l|c|c|c|c|}
\hline \multirow{2}{*}{ HABILIDAD } & \multicolumn{2}{|c|}{ MODELO DE REGRESIÓN } & \multicolumn{2}{c|}{ META-ANÁLISIS } \\
\cline { 2 - 5 } & $\mathbf{r}$ & \multicolumn{1}{c|}{ Sig. } & $\mathbf{r}$ & Sig. \\
\hline $\begin{array}{l}\text { Habilidad en } \\
\text { Entrevistas }\end{array}$ & -.033 & .789 & .03 & .813 \\
\hline $\begin{array}{l}\text { Habilidad en } \\
\text { Requisitos }\end{array}$ & -.034 & .783 & .05 & .751 \\
\hline
\end{tabular}

En todos los casos, indistintamente del método de síntesis aplicado, el coeficiente de correlación ( $r$ ) es menor (en valor absoluto) a 0.09 (efecto nulo según Cohen) y estadísticamente no significativo ( $p$ valor > 0.05). Ello implica que la habilidad en entrevistas y la habilidad en requisitos por sí mismas no determinan la efectividad de los sujetos.

36 Para obtener el valor del coeficiente de regresión, hemos empleado el calculador de tamaños de efectos: http://www.uccs.edu/ /becker/. 


\section{2 ¿Influye el conocimiento que el analista posee acerca del dominio en la efectividad del proceso de educción de requisitos?}

Al inicio de la investigación, tanto el conocimiento como la experiencia, al tratarse de características personales, fueron estudiadas mediante cuasi-experimentos, donde la experiencia se midió como años y el conocimiento se estudió en términos de la familiaridad con el dominio (véase la sección 4.3.1). Esta aproximación fue utilizada en los estudios: Q-2007, Q-2009, Q-2011 y Q-2012.

En E-2012 nos percatamos de que el conocimiento, aunque sea una característica propia de la persona, no implica necesariamente que deba estudiarse únicamente de manera cuasi-experimental. El grado de conocimiento o desconocimiento que tiene una persona puede manipularse modificando el dominio. Esto es, escogiendo un dominio desconocido por la población experimental como objeto experimental, automáticamente aseguramos (al menos hasta cierto punto) de que los sujetos participantes no poseen conocimiento acerca del mismo. Lo mismo puede afirmarse de un dominio conocido. Esta aproximación fue utilizada en los experimentos: E-2012 A, E-2012 B, E-2013, E-2014 y E2015.

Cabe indicar que en los experimentos antes citados también se recogieron datos acerca de la familiaridad con el dominio. En consecuencia, puede considerarse que los experimentos: E-2012 A, E2012 B, E-2013, E-2014 y E-2015 contienen cada uno dos cuasi-experimentos, uno de los cuales (el referido al dominio PD1) es una replicación de los cuasi-experimentos Q-2007 y siguientes.

Por tanto, para dar respuesta a la presente pregunta de investigación, hemos estudiado el efecto del conocimiento desde dos puntos de vista. Por un lado, hemos utilizado los datos de la serie histórica referidos a los cuasi-experimentos, donde el conocimiento fue operacionalizado como la familiaridad acerca del dominio del problema que posee el sujeto. Por otro, mediante los experimentos controlados (E-2012 A, E-2012 B, E-2013, E-2014 y E-2015) donde el conocimiento fue operacionalizado como un factor, con dos niveles (desconocido, conocido).

\subsubsection{Efecto del conocimiento operacionalizado como factor}

El efecto del conocimiento lo analizaremos en primer lugar mediante el meta-análisis de los datos individuales. En este caso, los experimentos no se pueden meta-analizar conjuntamente dado que E2012A y E-2012B son experimentos within-subjects y, E-2013, E-2014 y E-2015 son experimentos between-subjects. Por tanto, realizaremos dos análisis conjuntos distintos: a) Meta-análisis sobre los datos de los experimentos E-2012A y E-2012B mediante el modelo mixto; b) Meta-análisis los datos sobre los datos de los experimentos E-2013, E-2014 y E-2015 mediante el análisis de varianza (ANOVA). Nótese que para la síntesis del efecto del conocimiento utilizaremos como método de análisis la ANOVA o el modelo mixto, ya que dicha variable es categórica.

En segundo lugar analizaremos, todos los experimentos conjuntamente, mediante el meta-análisis de los datos agregados.

\subsubsection{Meta-análisis de los datos individuales}

\section{a. Meta-análisis de los experimentos within-subjects}

La Tabla 6.16 presenta un resumen de los efectos del conocimiento observados en los experimentos E2012 A y E-2012 B (mayores detalles en el capítulo 5, secciones 5.4.4.1 y 5.4.4.2 respectivamente). Los resultados indican que tanto en E-2012 A y E-2012 B el conocimiento ejerce un efecto positivo bajo, aunque no significativo. 
Tabla 6.16 - Efecto del conocimiento en los experimentos individuales

\begin{tabular}{|c|c|c|c|c|}
\hline EXPERIMENTO & $\mathbf{N}$ & SIG. & ETA2 & EFECTO \\
\hline E-2012 A & 14 & No (.633) & .020 & $(+)$ \\
\hline E-2012 B & 12 & No (.301) & .106 & $(+)$ \\
\hline
\end{tabular}

Los experimentos E-2012 A y la replicación interna E-2012 B pueden considerarse, en conjunto, como un único experimento con dos factores (Conocimiento y Orden de Realización de los problemas) y dos variables de bloque (Entrevistado y Formación). Mayores detalles respecto a los factores consúltese el Capítulo 4, sección 4.10. En consecuencia, ambos experimentos pueden sintetizarse fácilmente sin realizar ajuste de datos alguno.

Para analizar el efecto del conocimiento mediante la síntesis de E-2012 A y E-2012 B, en lugar de utilizar el Modelo Lineal General (GLM) de medidas repetidas (empleado en los estudios individuales), utilizamos un modelo mixto, que permite tener en consideración al mismo tiempo efectos fijos (los efectos separados de los factores y variables de bloque) así como los factores aleatorios (los incrementos o decrementos de efectividad en los sujetos en función del Orden de Realización y la Formación). Más concretamente, el modelo de efectos fijos planteado es:

Efectividad = Conocimiento + Formación + Orden de Realización + Entrevistado $+\varepsilon_{1}$

El modelo de efectos aleatorios planteado es:

Efectividad (Sujeto) $=$ Formación + Orden de Realización $+\varepsilon_{2}$

Hemos utilizado una matriz de covarianzas $A R(1)$, ya que la naturaleza del experimento sugiere que las medidas cercanas para cada sujeto estarán más fuertemente correladas que las medidas lejanas. Los resultados del modelo mixto no varían sustancialmente si utilizamos una matriz de covarianzas no estructurada (que es la estructura más genérica posible). Una ventaja adicional de AR(1) es que favorece la convergencia del procedimiento REML (Restricted Maximum Likelihood) usado en el modelo mixto.

Si bien mediante el modelo mixto permite obtener los efectos de determinadas variables moderadoras como: el Entrevistado y la Formación, nos centraremos únicamente en el efecto del conocimiento. Para dichas variables, remitimos al lector a la sección 7.4. Como se puede apreciar en la Tabla 6.17 el conocimiento tiende a ejercer un efecto positivo y significativo ( $p$-valor $=.045<.05$ ) pero bastante pequeño, tal y como ocurría tanto en el experimento E-2012 A como en la replicación E-2012 B. Los sujetos han sido sólo un $7.8 \%$ más efectivos en los problemas conocidos que en los desconocidos.

Tabla 6.17 - Resultados Modelo Mixto (AR) - Estimaciones de los efectos fijos

\begin{tabular}{|c|c|c|c|c|c|c|c|}
\hline \multirow[b]{2}{*}{ PARÁMETRO } & \multirow[b]{2}{*}{ ESTIMACIÓN } & \multirow[b]{2}{*}{$\begin{array}{l}\text { ERROR } \\
\text { Tí́IICO }\end{array}$} & \multirow[b]{2}{*}{ GL } & \multirow[b]{2}{*}{$\mathrm{T}$} & \multirow[b]{2}{*}{ SIG. } & \multicolumn{2}{|c|}{ INTERVALO DE CONFIANZA 95\% } \\
\hline & & & & & & $\begin{array}{l}\text { Límite } \\
\text { inferior }\end{array}$ & $\begin{array}{l}\text { Límite } \\
\text { superior }\end{array}$ \\
\hline Intersección & 52.95 & 4.49 & 34.262 & 11.804 & .000 & 43.84 & 62.06 \\
\hline$[$ Entrevistado=JW] & $\begin{array}{r}27.40 \\
0^{b}\end{array}$ & $\begin{array}{r}4.66 \\
0\end{array}$ & 17.121 & 5.876 & .000 & 17.57 & 37.24 \\
\hline $\begin{array}{l}\text { [Formación=Antes] } \\
\text { [Formación=Después] }\end{array}$ & $\begin{array}{r}-20.88 \\
0^{b}\end{array}$ & $\begin{array}{r}2.92 \\
0\end{array}$ & 29.424 & -7.155 & .000 & -26.85 & -14.92 \\
\hline $\begin{array}{l}{[\text { Conocimiento }=\mathrm{PD} 1]} \\
{[\text { Conocimiento }=\mathrm{PC} 1]}\end{array}$ & $\begin{array}{r}-7.81 \\
0^{b}\end{array}$ & $\begin{array}{r}3.79 \\
0\end{array}$ & 46.952 & -2.061 & .045 & -15.44 & -.19 \\
\hline $\begin{array}{l}\text { [Orden=Antes] } \\
\text { [Orden=Después] }\end{array}$ & $\begin{array}{r}-7.80 \\
0^{\mathrm{b}}\end{array}$ & $\begin{array}{r}3.23 \\
0\end{array}$ & 36.381 & -2.413 & .021 & -14.36 & -1.25 \\
\hline
\end{tabular}

Variable dependiente: Efectividad en la Consolidación (\%).

b. Se ha establecido este parámetro en cero porque es redundante.

\section{b. Meta-análisis de los experimentos between-subjects}

La Tabla 6.18 presenta un resumen de los efectos del conocimiento observados en los experimentos individuales (mayores detalles en el capítulo 5, secciones 5.7-5.9 respectivamente). Los resultados 
indican que el efecto del conocimiento en los experimentos (E-2013, E-2014 y E-2015) tiende a ser negativo aunque estadísticamente no significativos.

Tabla 6.18 - Efecto del conocimiento en los experimentos individuales

\begin{tabular}{|c|c|c|c|c|}
\hline EXPERIMENTO & $\mathbf{N}$ & SIG. & ETA $^{2}$ & EFECTO \\
\hline E-2013 & 15 & No $(561)$ & .029 & $(-)$ \\
\hline E-2014 & 16 & No $(.792)$ & .005 & $(-)$ \\
\hline E-2015 & 13 & No $(.370)$ & .081 & $(-)$ \\
\hline E-2013 a E-2015 & 44 & No $(.354)$ & .021 & $(-)$ \\
\hline
\end{tabular}

Dado que los experimentos (E-2013, E-2014 y E-2015) son replicaciones internas exactas, es posible analizar los estudios individuales conjuntamente. Al igual que los estudios individuales, el método de análisis utilizado es el Análisis de Varianza (ANOVA). La variable dependiente corresponde a la Efectividad en la consolidación, el factor principal al conocimiento y el entrevistado como co-variable. Los resultados del ANOVA se muestran en la Tabla 6.19. Como se puede apreciar el conocimiento tiende a ejercer un efecto negativo en la efectividad de los sujetos, esto es los sujetos en el problema desconocido tienden a ser un $(B=4.461 \%)$ más efectivos que los sujetos en el dominio conocido. No obstante, el efecto es bajo $(E t a 2=0.021)$ estadísticamente no significativo $(p$-valor $=.354>0.05)$.

Tabla 6.19 - Efecto del Conocimiento Conjunto ANOVA - Estudios Between Subjects (E-2013 a E-2015)

Variable dependiente: Efectividad en la Consolidación (\%)

\begin{tabular}{|c|c|c|c|c|c|c|c|c|c|}
\hline \multirow[b]{2}{*}{ Parámetro } & \multirow[b]{2}{*}{ B } & \multirow[b]{2}{*}{$\begin{array}{l}\text { Error } \\
\text { típ. }\end{array}$} & \multirow[b]{2}{*}{$\mathrm{t}$} & \multirow[b]{2}{*}{ Sig. } & \multicolumn{2}{|c|}{$\begin{array}{c}\text { Intervalo de confianza } \\
95 \% \\
\end{array}$} & \multirow{2}{*}{$\begin{array}{c}\text { Eta al } \\
\text { cuadrado } \\
\text { parcial }\end{array}$} & \multirow{2}{*}{$\begin{array}{c}\text { Parámetro } \\
\text { de no } \\
\text { centralidad } \\
\text { Parámetro }\end{array}$} & \multirow[b]{2}{*}{$\begin{array}{l}\text { Potencia } \\
\text { observada }^{\text {b }}\end{array}$} \\
\hline & & & & & $\begin{array}{l}\text { Límite } \\
\text { inferior }\end{array}$ & $\begin{array}{c}\text { Límite } \\
\text { superior }\end{array}$ & & & \\
\hline Intersección & 29.04 & 3.76 & 7.733 & .000 & 21.45 & 36.62 & .593 & 7.73 & 1.000 \\
\hline Entrevistado & 15.36 & 5.34 & 2.874 & .006 & 4.56 & 26.14 & .168 & 2.87 & .801 \\
\hline [Conocimiento $=0]$ & 4.46 & 4.76 & .937 & .354 & -5.15 & 14.07 & .021 & .94 & .150 \\
\hline [Conocimiento $=1]$ & & & & & & & & & \\
\hline
\end{tabular}

a. Al parámetro se le ha asignado el valor cero porque es redundante; $b$. Calculado con alfa $=.05$

El modelo presentado en la Tabla 6.19 cumple con los supuestos requeridos para la aplicación del ANOVA, tal y como se describe brevemente a continuación:

- Independencia. Se asume que cada conjunto de datos es independiente del otro.

- Homocedasticidad. Para contrastar la homogeneidad de varianzas hemos utilizado el test de Levene. El resultado del test $(\mathrm{F}=0.804$, $\mathrm{p}$-valor $=0.375)$ es no significativo por lo que la varianza es homogénea entre grupos.

- Normalidad de los datos. Los residuos del modelo poseen una distribución normal ( $p$-valor = 0.200 para Kolmogorov-Smirnov y $p$-valor $=.641$ para Shapiro-Wilk). Se confirma la normalidad de los datos mediante los estadísticos de asimetría (.408) y curtosis (-.090), ya que están dentro de los rangos habituales \pm 1 .

\subsubsection{Meta-análisis de los datos agregados}

Mediante el meta-análisis de datos agregados es posible estudiar conjuntamente el efecto del conocimiento en la efectividad de los sujetos utilizando los datos obtenidos en todos los experimentos. Como se puede apreciar en la Figura 6.14, el conocimiento tiende a ejercer un efecto positivo pero bajo $\left(d=0.31\right.$, según la $d^{\prime}$ de Cohen), estadísticamente significativo ( $p$-valor $\left.=0.029\right)$. El intervalo de confianza oscila entre [0.03 y 0.59]. Nótese que como resulta significativo el efecto global, el intervalo de confianza no cruza el valor cero.

Dado que el meta-análisis de datos individuales no fue posible realizarlo de forma conjunta, sino que fue necesario sintetizar los experimentos within y between por separado, en la misma Figura 6.14 se presentan igualmente dichos meta-análisis parciales. Los resultados son los siguientes: 
- Para los experimentos within-subjects (E-2012 A y E-2012B), el conocimiento tiende a ejercer un efecto positivo $(d=.48)$, estadísticamente significativo ( $p$-valor $=.002)$. El intervalo de confianza oscila entre [0.17 y 0.80$]$.

- Para los experimentos between-subjects (E-2013, E-2014 y E-2015), el conocimiento tiende a ejercer un efecto negativo $(d=-.33)$, estadísticamente no significativo ( $p$-valor $=.282)$.. El intervalo de confianza oscila entre [-.93 y .27].

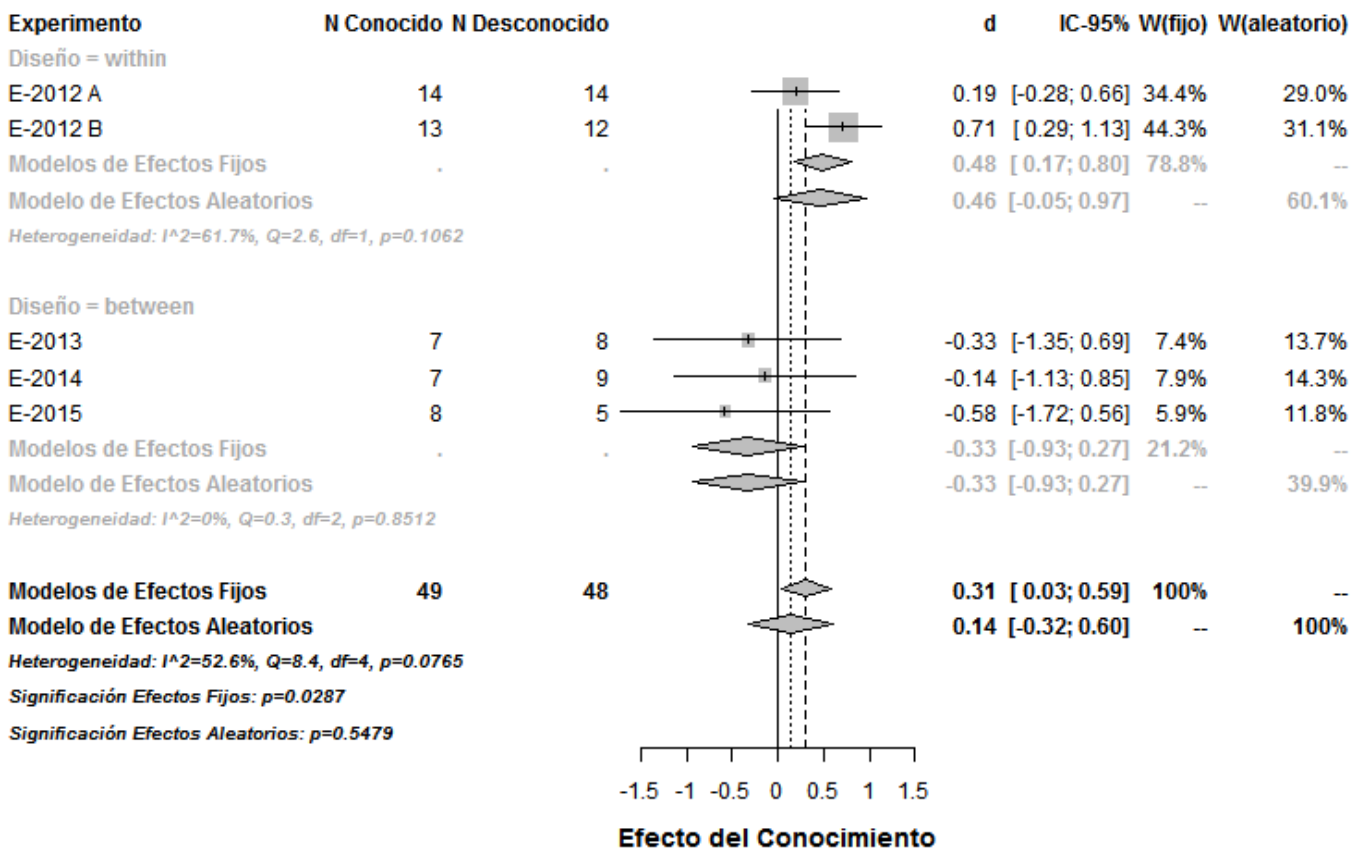

Figura 6.14 - Meta-análisis Efecto del conocimiento diferenciado por diseño experimental

\subsubsection{Comparación del meta-análisis de datos individuales con el meta-análisis de datos agregados}

La Tabla 6.23 compara los tamaños de efectos (d) obtenidos en el meta-análisis de los datos individuales (mediante el modelo mixto y el ANOVA) como en el meta-análisis de los datos agregados, tanto para los experimentos within como los experimentos between. Para los experimentos within, el valor de la d se ha obtenido del modelo mixto, mientras que para los experimentos between se ha calculado ${ }^{37}$ a partir de la $t$ y los grados de libertad correspondientes ( $N-2$ ).

Indistintamente del método de síntesis aplicado los efectos son coincidentes. Para los experimentos within el tamaño de efecto es positivo y moderado ( $d>=.40$ y <.75)) estadísticamente significativos; mientras que por el contrario, para los experimentos between el tamaño de efecto es negativo pero pequeño ( $\mathrm{d}>=.15 \mathrm{y}<.40$ ), estadísticamente no significativos. El tamaño de efecto global del conocimiento, obtenido mediante el meta-análisis de los datos agregados, es positivo, pequeño y estadísticamente significativo. Ello implica, que el conocimiento determina la efectividad de los analistas muy levemente.

Tabla 6.20 - Resumen tamaño de efecto entre la efectividad y el conocimiento

\begin{tabular}{||l|l|c|c|c|c|c|c|}
\hline \multicolumn{2}{|c|}{ Conocimiento } & \multicolumn{3}{c|}{ Modelo Mixto/AnOVA } & \multicolumn{3}{c|}{ MetA-ANÁlisis } \\
\cline { 3 - 7 } & d & Sig. & \multicolumn{2}{c|}{ d } & \multicolumn{2}{c|}{ Sig. } \\
\hline \multirow{2}{*}{ Efecto } & within & .60 & .044 & .48 & \multirow{2}{*}{.31} & .002 & \multirow{2}{*}{029} \\
\cline { 2 - 6 } & between & -.29 & .354 & -.33 & & .282 & \\
\hline
\end{tabular}

37 Para obtener el valor del coeficiente de regresión, hemos empleado el calculador de tamaños de efectos: http://www.uccs.edu/ /becker/. 


\subsubsection{Efecto del conocimiento operacionalizado como la Familiaridad}

La Tabla 6.21 presenta un resumen de los resultados obtenidos acerca del efecto de la familiaridad en cada uno de los cuasi-experimentos de la serie histórica diferenciada por problema (mayores detalles en el capítulo 5). Como se puede apreciar en la Tabla 6.21, el efecto de la familiaridad en el dominio desconocido PD1 tiende a ser negativa en casi todos los estudios (esto es, sujetos familiarizados con el dominio tienden a ser menos efectivos, y viceversa), con excepción de Q-2011 y E-2015 donde la tendencia es positiva (los sujetos con familiaridad en el dominio del problema obtienen efectividades mejores). En el caso de E-2015 el resultado podría estar amenazado por el desbalanceo de grupos (4 frente a 1). En E-2013 y E-2014 no es posible calcular el efecto de la familiaridad, dado que todos los sujetos dicen desconocer el dominio del problema.

El efecto de la familiaridad en el dominio desconocido PD2 tiende a ser negativa y estadísticamente no significativo ( $p$-valor $=.429>0.05$ ). Este resultado debería tomarse con cautela, fundamentalmente por la desproporción existente en los tamaños de la población (10 frente a 2).

En lo que respecta al dominio conocido PC1, los resultados en E-2012 y E-2013 van en la dirección esperada, esto es, los sujetos con familiaridad en el dominio tienden a obtener mejores efectividades. En los experimentos E-2014 y E-2015 la familiaridad tiene el efecto contrario. En todos los casos los resultados son no significativos.

El efecto de la familiaridad en el dominio conocido PC2 es negativo y estadísticamente no significativo ( $p$-valor $=.618>0.05$ ). Esto es, los sujetos familiarizados con el dominio tienden a obtener efectividades mayores, y viceversa.

Tabla 6.21 - Diferencia entre medias (Sujetos familiares y no familiares con el dominio del problema)

\begin{tabular}{|c|c|c|c|c|c|c|c|c|}
\hline \multirow{3}{*}{ DOMINIO } & \multirow{3}{*}{$\begin{array}{c}\text { EXPERIME } \\
\text { NTO }\end{array}$} & \multicolumn{3}{|c|}{$\begin{array}{l}\text { TAMAÑo } \\
\text { PoBLACIÓN }\end{array}$} & \multirow{3}{*}{ T } & \multirow{3}{*}{$\begin{array}{c}\text { EfFeCt } \\
\text { SIZE }^{38} \\
\text { CoHen (D) }\end{array}$} & \multirow{3}{*}{$\begin{array}{l}\text { SIG. } \\
\text { T-TEST }\end{array}$} & \multirow{3}{*}{$\begin{array}{c}\text { EFECTO } \\
\text { FAM }\end{array}$} \\
\hline & & \multirow{2}{*}{$\mathrm{N}$} & \multicolumn{2}{|c|}{ Fam } & & & & \\
\hline & & & Sin & Con & & & & \\
\hline \multirow[t]{7}{*}{ PD1 } & Q-2007 & 7 & 4 & 3 & -1.463 & -1.309 & No (.203) & $(-)$ \\
\hline & Q-2011 & 16 & 8 & 8 & .620 & .332 & No (.545) & $(+)$ \\
\hline & Q-2012 & 21 & 18 & 3 & -.394 & -.211 & No (.698) & $(-)$ \\
\hline & $E-2012 \mathrm{~A}$ & 13 & 12 & 1 & .182 & .110 & No (.860) & $(-)$ \\
\hline & E-2013 & 7 & 7 & 0 & No & Es & Posible & \\
\hline & E-2014 & 5 & 5 & 0 & No & Es & Posible & \\
\hline & E-2015 & 5 & 4 & 1 & .371 & .429 & No (.746) & $(+)$ \\
\hline PD2 & E-2012 B & 12 & 2 & 10 & -.856 & -.542 & No (.414) & $(-)$ \\
\hline \multirow[t]{4}{*}{ PC1 } & E-2012 & 13 & 2 & 11 & .311 & .187 & No (.763) & $(+)$ \\
\hline & E-2013 & 6 & 2 & 4 & 2.235 & 2.235 & No (.111) & $(+)$ \\
\hline & E-2014 & 6 & 2 & 4 & -.458 & -.458 & No (.671) & $(-)$ \\
\hline & E-2015 & 6 & 3 & 3 & -.507 & -.507 & No (.618) & $(-)$ \\
\hline PC2 & E-2012B & 13 & 1 & 12 & -.682 & -.411 & No (.511) & $(-)$ \\
\hline
\end{tabular}

Los efectos oscilantes de la familiaridad pueden deberse al reducido tamaño muestral de los cuasiexperimentos. Al igual que en RQ1, con la finalidad de aumentar el tamaño muestral y la precisión en los resultados, hemos sintetizado los estudios individuales. Ello es posible, ya que como hemos comentado anteriormente, los experimentos son muy parecidos entre sí. Al igual que en el caso anterior, utilizaremos tanto el meta-análisis de datos individuales como de datos agregados.

Una diferencia importante con la síntesis realizada anteriormente, es que la familiaridad no es un factor. Por este motivo, no parece razonable utilizar modelos mixtos o ANOVAS para su análisis. En los modelos within-subjects, la familiaridad no estará balanceada dentro de los sujetos, lo que impide el análisis. En los modelos between-subjects el análisis es posible, pero precisamente estos experimentos

${ }^{38}$ Calculado con el "Effect Size Calculator" http://www.uccs.edu/ lbecker/, df= N-2 y t tomado del modelo de regresión 
son los que menor tamaño muestral poseen (E-2013, E-2014 y E-2015). Por todo ello, hemos optado por analizar por separado cada tipo de dominio (conocido, desconocido). Para ello un t-test es suficiente. Los datos fueron ajustados conforme el procedimiento descrito en la sección 6.1.1.

Nótese que para los problemas PC2 y PD2 disponemos de muy pocos datos, ya que dichos dominios del problema sólo se han ensayado en el experimento E-2012 B. Por este motivo, no incluiremos PC2 y PD2 en el meta-análisis de datos individuales (ya que ellos podrían sesgar los resultados), aunque sí en el meta-análisis agregados.

\subsubsection{Meta-análisis de los datos individuales}

La Tabla 6.22 presenta para cada dominio de problema utilizado en la investigación, el tamaño de la población total, la cantidad de sujetos familiarizados o no con el problema, el porcentaje de efectividad media alcanzada en ambos grupos, el valor de la t, el tamaño de efecto, la significación estadística y el efecto final obtenido.

Tabla 6.22 - Efecto de la familiaridad análisis conjunto

\begin{tabular}{|c|c|c|c|c|c|c|c|c|c|c|c|}
\hline \multirow{3}{*}{ Dominio } & \multirow{3}{*}{$\begin{array}{c}\text { EXPERIMEN } \\
\text { TO }\end{array}$} & \multicolumn{3}{|c|}{ TAMAÑo Población } & \multicolumn{3}{|c|}{$\begin{array}{l}\text { EFECTIVIDAD } \\
\text { MEDIA (\%) }\end{array}$} & \multirow{3}{*}{$\mathbf{T}$} & \multirow{3}{*}{$\begin{array}{c}\text { EFFECt SIZE }^{39} \\
\text { COHEN (D) }\end{array}$} & \multirow{3}{*}{$\begin{array}{l}\text { SIG. } \\
\text { T-TEST }\end{array}$} & \multirow{3}{*}{$\begin{array}{c}\text { EFECTO } \\
\text { FAM }\end{array}$} \\
\hline & & \multirow{2}{*}{$\mathrm{N}$} & \multicolumn{2}{|c|}{ Fam } & \multirow{2}{*}{$\mathrm{N}$} & \multicolumn{2}{|c|}{ Fam } & & & & \\
\hline & & & $\operatorname{Sin}$ & Con & & $\operatorname{Sin}$ & Con & & & & \\
\hline PD1 & $\begin{array}{l}\text { Conjunto } \\
\text { Ajustado }\end{array}$ & 74 & 58 & 16 & 74 & 28 & 26 & -.640 & -.151 & $\mathrm{No}(.524)$ & $(-)$ \\
\hline PC1 & $\begin{array}{l}\text { Conjunto } \\
\text { Ajustado }\end{array}$ & 31 & 9 & 22 & 31 & 25 & 27 & .157 & .058 & $\mathrm{No}(.876)$ & $(+)$ \\
\hline
\end{tabular}

Como se muestra en la Tabla 6.22, los sujetos familiarizados con el dominio desconocido (16 de 74) alcanzaron una efectividad media del $26 \%$, mientras que casi en igual proporción, los sujetos que desconocen el dominio (58 de 74) alcanzaron una efectividad media del $28 \%$. La diferencia entre medias es no significativa ( $p$-valor $=.524>0.05$ ). La familiaridad tiende a ejercer un efecto negativo, esto es, los sujetos familiarizados con el dominio tienden a obtener efectividades más bajas que aquellos no familiarizados. No obstante, el efecto de la familiaridad en la efectividad es baja (-.151).

En lo que respecta al problema conocido, en la Tabla 6.22 se puede apreciar que los sujetos familiarizados con el dominio conocido (22 de 31) alcanzaron una efectividad media del $27 \%$, mientras que casi en igual proporción, los sujetos que desconocen el dominio (9 de 31) alcanzaron una efectividad media del $26 \%$. Nótese no obstante que la diferencia entre medias es no significativa ( $p$ valor $=.876>0.05)$. Se observa una tendencia positiva $(t=.157)$, esto es, los sujetos familiarizados con el dominio tienden a obtener efectividades más altas. No obstante, el efecto de la familiaridad en la efectividad es insignificante (.058), nulo a efectos prácticos.

Dado que el tipo de análisis es t-test, es posible representar los datos de forma sencilla. La Figura 6.15, confirma los resultados de la Tabla 6.22. La Figura 6.15 presenta la efectividad media alcanzada por los sujetos experimentales en cada uno de los dominios de problema. El gráfico de perfil representa en el eje de abscisas los dominios de problemas PC1 y PD1 (conocido y desconocido respectivamente) y en el eje de ordenada la efectividad media de los sujetos. Nótese que las efectividades están diferenciadas por la familiaridad que poseen los sujetos. El gráfico de perfil confirma que la familiaridad tiende a ejercer un efecto positivo en el dominio conocido (PC1) y un efecto negativo en el dominio desconocido (PD1). Nótese no obstante, que la familiaridad en general apenas tiene efecto; ya que independientemente del $\pm 2 \%$ de diferencia inter-problemas, las líneas son prácticamente horizontales.

${ }^{39}$ Calculado con el "Effect Size Calculator" http://www.uccs.edu/ |becker/, df= N-2 


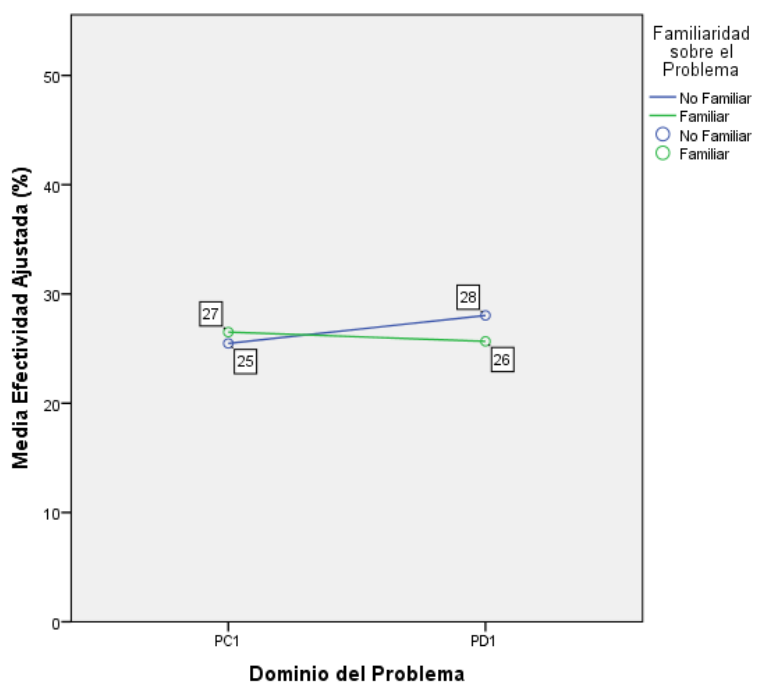

Figura 6.15 - Efectividad Promedio diferenciada por problema

En resumen, el efecto de la familiaridad parece estar en función del tipo de dominio del problema. Sin embargo, los efectos observados están muy lejos de la significación. Finalmente, los resultados obtenidos se deben tomar con cierta cautela, ya que los mismos se podrían ver sesgados por la falta de balanceo entre grupo ( 58 sujetos frente a 16 en el desconocido, y 9 frente a 22 en el conocido).

\subsubsection{Meta-análisis de los datos agregados}

Con la finalidad de confirmar los resultados obtenidos en la sección anterior, a continuación presentamos los meta-análisis de datos agregados correspondientes. La Figura 6.16 presenta el metaanálisis para el dominio desconocido PD1. La familiaridad tiende a ejercer un efecto negativo pero bajo $(r=-.014)$, estadísticamente no significativo ( $p$-valor $=0.648>0.05)$. El intervalo de confianza oscila entre $[-0.72$ y 0.45$]$.

\begin{tabular}{|c|c|}
\hline Experimento & N Familiar \\
\hline$Q-2007$ & 3 \\
\hline Q-2011 & 8 \\
\hline Q-2012 & 3 \\
\hline $\mathrm{E}-2012 \mathrm{~A}$ & 1 \\
\hline $\mathrm{E}-2012 \mathrm{~B}$ & 10 \\
\hline E-2013 & 0 \\
\hline E-2014 & 0 \\
\hline E-2015 & 1 \\
\hline \multicolumn{2}{|c|}{ Modelo de Efectos Aleatorios } \\
\hline \multicolumn{2}{|c|}{ Heterogeneidad: $I^{\wedge} 2=0 \%, Q=3.4, d f=5, p=0.6378$} \\
\hline \multicolumn{2}{|c|}{ Significación Efectos Fijos: $p=0.6483$} \\
\hline \multicolumn{2}{|c|}{ Significación Efectos Aleatorios: $p=0.6483$} \\
\hline
\end{tabular}

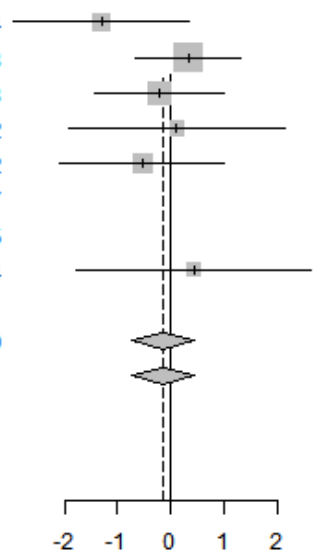

$\begin{array}{rrr}\text { d } & \text { IC-95\% W(fijo) } & \text { W(aleatorio) } \\ -1.31[-2.96 ; 0.34] & 12.6 \% & 12.6 \% \\ 0.33[-0.65 ; 1.32] & 35.0 \% & 35.0 \% \\ -0.21[-1.43 ; 1.01] & 22.8 \% & 22.8 \% \\ 0.11[-1.93 ; 2.15] & 8.2 \% & 8.2 \% \\ -0.54[-2.08 ; 0.99] & 14.5 \% & 14.5 \% \\ & 0.0 \% & 0.0 \% \\ & 0.0 \% & 0.0 \% \\ 0.43[-1.78 ; 2.64] & 7.0 \% & 7.0 \% \\ & & \\ -0.14[-0.72 ; 0.45] & \mathbf{1 0 0 \%} & -\end{array}$

Efecto de la Familiaridad Problema Desconocido

Figura 6.16 - Meta-análisis Efecto de la familiaridad en problemas desconocidos

La Figura 6.17 presenta el meta-análisis para el dominio conocido. Como se pude apreciar en la Figura 6.17 no se observa variabilidad entre los estudios individuales, aunque el p-valor es bajo (heterogeneidad: $p$-valor $=0.277$ ). La causa podría deberse al problema E-2013, cuyo tamaño de efecto (d) es bastante elevado. Aún incluyendo este estudio, la familiaridad tiende a ejercer un efecto nulo 
$(r=0.08)$, estadísticamente no significativo $(p$-valor $=0.834>0.05)$. El intervalo de confianza oscila entre $[-0.70$ y 0.87$]$.

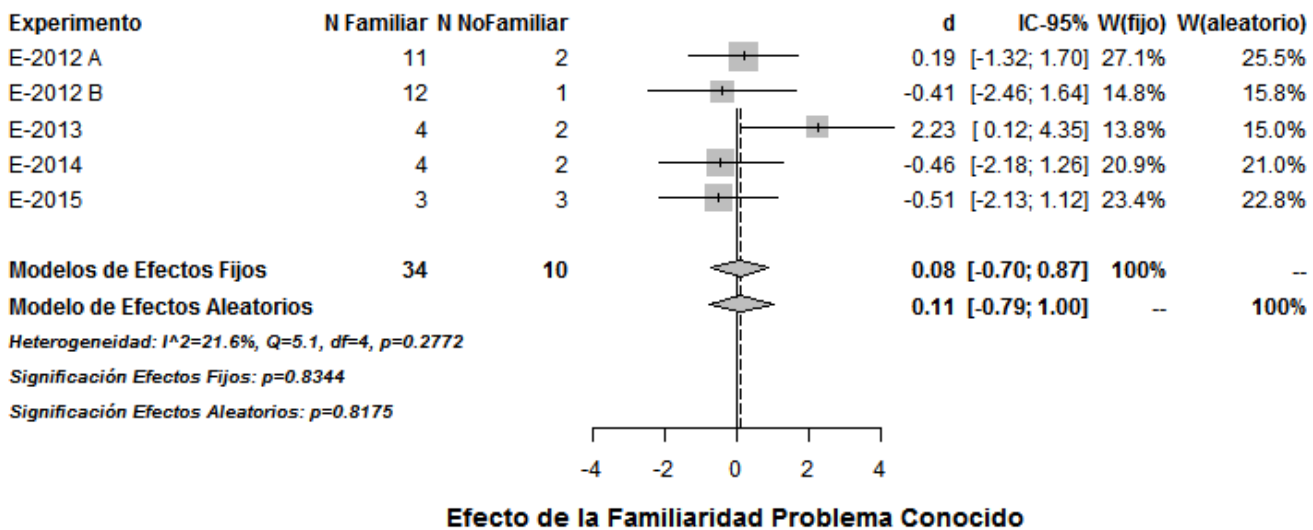

Figura 6.17 - Meta-análisis Efecto de la familiaridad en problemas conocidos

\subsubsection{Comparación del meta-análisis de datos individuales con el meta-análisis de datos agregados}

La Tabla 6.23 compara los tamaños de efectos (d) obtenidos en el meta-análisis con los tamaños de efectos derivados del t-test, para el dominio desconocido (PD) y el dominio conocido (PC), respectivamente. Estos coeficientes se han calculado ${ }^{40}$ a partir de la $t$ y los grados de libertad correspondientes $(\mathrm{N}-2)$. Tanto el meta-análisis como el t-test las tendencias obtenidas son esencialmente coincidentes.

Indistintamente del método de síntesis aplicado, para el dominio PD el tamaño de efecto obtenido es negativo y bajo; mientras que para el PC el tamaño de efecto es menor (en valor absoluto) a 0.15 (efecto nulo según Cohen). Ello implica que la familiaridad no determina la efectividad, ya que tiende a influir muy poco o nada en la efectividad de los analistas.

Tabla 6.23 - Resumen tamaño de efecto entre la efectividad y la familiaridad

\begin{tabular}{|c|c|c|c|c|}
\hline \multirow{2}{*}{ FAMILIARIDAD } & \multicolumn{2}{|c|}{ T-TEST } & \multicolumn{2}{c|}{ META-ANÁLISIS } \\
\cline { 2 - 5 } & d & Sig. & d & Sig. \\
\hline Familiaridad PD & -.151 & No(.524) & -0.14 & No (.648) \\
\hline Familiaridad PC & .058 & No(.876) & 0.08 & No (.834) \\
\hline
\end{tabular}

\section{3 ¿influye la titulación académica del analista en la efectividad del proceso de educción de requisitos? (RQ3)}

No tiene interés práctico realizar la síntesis de resultados respecto al efecto de la titulación académica en la efectividad del proceso de educción de los requisitos, fundamentalmente por falta de diversidad en la titulación: la inmensa mayoría de los sujetos poseen un grado en informática. Como hemos indicado en varias ocasiones a lo largo del texto la falta de desbalanceo podría sesgar los resultados obtenidos.

Si hemos podido explorar su efecto en estudios individuales, concretamente en los cuasiexperimentos: Q-2007 y Q-2012. La Tabla 6.24 presenta los resultados obtenidos tanto en Q-2007 como

40 Para obtener el valor del coeficiente de regresión, hemos empleado el calculador de tamaños de efectos: http://www.uccs.edu/ /becker/. 
en Q-2012. Nótese que en el cuasi-experimento Q-2007 la titulación académica se analizó tanto para la efectividad de las sesiones de educción como para la consolidación.

Tabla 6.24 - Efecto de la Titulación académica tanto en la efectividad de la educción (Educ) como en la efectividad de la Consolidación (Cons)

\begin{tabular}{|c|c|c|c|c|c|c|c|c|c|c|c|c|}
\hline \multirow{3}{*}{\multicolumn{2}{|c|}{$\begin{array}{l}\text { EXPERIMENTO } \\
\text { (P2) }\end{array}$}} & \multicolumn{3}{|c|}{ TAMAÑo POBLACIÓN } & \multicolumn{3}{|c|}{$\begin{array}{l}\text { EFECTIVIDAD } \\
\text { MEDIA (\%) }\end{array}$} & \multirow{3}{*}{$\mathbf{t}$} & \multirow{3}{*}{$r^{41}$} & \multirow{3}{*}{$\begin{array}{l}\text { EfFECT } \\
\text { SIZE }^{42} \\
\text { COHEN }\end{array}$} & \multirow{3}{*}{$\begin{array}{l}\text { SIG. } \\
\text { T-TEST }\end{array}$} & \multirow{3}{*}{ ЕFеCтO } \\
\hline & & \multirow{2}{*}{$\mathrm{N}$} & \multicolumn{2}{|c|}{ TIT } & \multirow{2}{*}{$\mathrm{N}$} & \multicolumn{2}{|c|}{ TIT } & & & & & \\
\hline & & & Nolnf & $\operatorname{lnf}$ & & No Inf & Inf & & & & & \\
\hline \multirow{2}{*}{ Q-2007 } & Educ & 10 & 6 & 4 & 10 & 63 & 60 & -.541 & -.009 & -.383 & No (.603) & $(-)$ \\
\hline & Cons & 7 & 4 & 3 & 7 & 25 & 50 & 2.558 & .694 & 2.2883 & Si $(.051)^{*}$ & $(+)$ \\
\hline Q-2012 & Cons & 21 & 3 & 18 & 21 & 42 & 36 & -.8937 & -.266 & -.4101 & No (.383) & $(-)$ \\
\hline
\end{tabular}

Los resultados de Q-2007 indican que la formación tiende a influir negativamente en la efectividad de la educción, mientras que, por el contrario, tiende a ejercer una marcada influencia positiva (estadísticamente significativa) en la efectividad de la consolidación.

En Q-2012 el efecto es inverso, esto es, los sujetos no informáticos tienden a ser más efectivos que los informáticos. No obstante, nuevamente nos encontramos con un marcado desbalanceo ( 3 frente a 18) en la distribución de titulación académica entre sujetos. Respecto a esta pregunta, no parece que podamos llegar a ninguna conclusión sólida.

\footnotetext{
${ }^{41}$ Calculado con el "Effect Size Calculator" http://www.uccs.edu/ /becker/ emplando las medias y desv. típicas
}

${ }^{42}$ Calculado con el "Effect Size Calculator" http://www.uccs.edu/ /becker/, df= N-2 por cada grupo 


\section{CAPÍTULO 7 DISCUSIÓN}

El presente capítulo tiene como propósito discutir por cada pregunta de investigación los resultados obtenidos. En este capítulo, nos desviaremos del orden en que hemos planteado las preguntas de investigación para introducir los temas de una forma más gradual y natural. En primer lugar, se discutirá el efecto del conocimiento (RQ2) en la efectividad de educción (Sección 7.1). A continuación discutiremos RQ1, esto es, el efecto de la experiencia (Sección 7.2). Finalmente se dará respuesta a la RQ3 asociada al efecto de la formación académica (Sección 7.3). Además de las preguntas de investigación, en el presente capítulo se discutirán aspectos paralelos a la investigación como pueden ser: la existencia de variables moderadoras (Sección 7.4), la fiabilidad de la medición utilizando variables objetivas y subjetivas (Sección 7.5) y aspectos de tipo metodológico (Sección 7.6).

\section{1 ¿̇Influye el Conocimiento del dominio en la efectividad del proceso de educción? (RQ2)}

Tras el análisis conjunto del efecto del conocimiento acerca del dominio del problema en la efectividad de los analistas durante el proceso de educción de requisitos, nuestros resultados experimentales ponen de manifiesto un efecto positivo. En el caso del meta-análisis de los datos individuales el efecto tiende a ser moderado $(d=0.60)$ estadísticamente significativo ( $p$-valor $=0.044)$, mientras que en el caso del meta-análisis de los datos agregados el efecto tiende a ser pequeño $(d=0.31)$ estadísticamente significativo ( $p$-valor= 0.029). Este resultado es consistente con la opinión más extendida en SE acerca del efecto del Conocimiento, esto es, los sujetos con conocimiento sobre el dominio del problema son más efectivos que aquellos que no lo poseen.

\subsubsection{Comparación con los trabajos empíricos relacionados}

Nuestros experimentos han arrojado resultados contrarios a los obtenidos por (Niknafs \& Berry, 2012; Niknafs \& Berry, 2013). En ambos trabajos, dichos autores concluyeron que la inclusión de un sujeto que desconoce el dominio mejoraba el desempeño (por ejemplo, generar más ideas innovadoras) de grupos empleando tormenta de ideas. Sin embargo, a medida que los autores acumularon más evidencia empírica, los resultados se tornaron inconclusivos. En Niknafs(2014), con un análisis de 40 grupos (más 
Estudio empírico de la influencia de la experiencia y del conocimiento del dominio del analista en la efectividad del proceso de educción de requisitos

del doble de los empleados en (Niknafs \& Berry, 2012)) no se consiguió obtener efectos estadísticamente significativos tras la inclusión de sujetos que desconocen el dominio como miembros del grupo. No obstante, los datos crudos apuntan a la existencia de diferencias entre la gente que conoce o desconoce el dominio, no siempre en favor de los primeros; por ejemplo: los grupos 31 (consistentes en 3 sujetos ajenos al dominio) son los que generan un mayor número de ideas factibles (Niknafs, 2014, p. 48, Tabla 4).

Existen muchas posibles explicaciones para las inconsistencias. En lo que respecta a lo inconclusivo de los resultados de Niknafs (2014) frente a los efectos significativos del presente estudio, en nuestra opinión se debe a que los experimentos combinados E1 + E2 en Niknafs (2014) no poseen el tamaño muestral necesario para detectar efectos pequeños. Nótese que el diseño utilizado por dichos autores es between-subjects, el cual requiere más de 100 unidades experimentales para detectar efectos medios. Independientemente del carácter significativo o no de los resultados, quedaría pendiente explicar por qué en ciertos casos los grupos formados únicamente por sujetos que desconocen el dominio son más efectivos que los otros grupos, lo que puede interpretarse como un efecto negativo del conocimiento del dominio. Una posible causa de la diferencia en los resultados es la técnica de educación utilizada (entrevistas vs tormenta de ideas). La tormenta de ideas es esencialmente un proceso creativo; los sujetos que desconocen el dominio, al no encontrarse mediatizados por experiencias previas, pueden proponer ideas más libremente. En nuestro caso, la entrevista requiere la comunicación entre un entrevistado y un entrevistador, por lo que el conocimiento previo podría ayudar a hacer esta comunicación más efectiva. En nuestra opinión, Nikasfs y Berry podrían estar reportando un fenómeno de einstellung ${ }^{43}$ (Anderson, 2000) en el ámbito de la educción de requisitos, y no una diferencia de efectividades trazables al conocimiento del dominio.

No obstante, estas conclusiones sólo pueden tomarse como preliminares. No deja de ser curioso, por ejemplo, que los grupos más efectivos en Niknafs (2014) son 0l (todos los miembros que conocen el dominio) y 31 (todos los miembros que desconocen el dominio). Los equipos 11 y 21 generan casi siempre menos ideas. Es posible que múltiples aspectos (conocimiento del dominio, tarea, facilidad de comunicación, etc.) interaccionen de forma compleja durante la tarea de educción, lo que provoca la inestabilidad observada en el efecto del conocimiento del dominio. A su vez, dicha inestabilidad explica que no exista una postura clara (cada profesional habla desde el punto del vista, limitado, de su experiencia) acerca del efecto del conocimiento del dominio; por ejemplo: (Mehrotra, 2011), después de realizar un survey en el que participaron 40 profesionales con diversos grados de experiencia, concluye que tanto el conocimiento del dominio como la ignorancia del dominio son positivas para la educación de requisitos.

El estudio de Kristensson et al. (2004) utilizando un tamaño muestral mayor (47 sujetos, mezcla de profesionales y estudiantes) es interpretable en los mismos términos de einstellung y llega a similares conclusiones que Nikasfs y Berry.

Los resultados de nuestros experimentos se alinean con los obtenidos por Hadar et al. (2012). En este estudio, los sujetos con conocimiento del dominio realizan más preguntas específicas que los sujetos sin conocimiento, lo que se asocia a una mayor efectividad durante el proceso de educción. El tamaño de efecto observado es bajo (Hedges' $g=0.36$ ), lo cual coindice con nuestros resultados. Para observar tal efecto, Hadar et al. (2012) han empleado 56 sujetos experimentales. Este número es casi el mismo que la cantidad de unidades experimentales que hemos empleado en la presente investigación.

\subsubsection{Evidencias de un efecto Experiencia $x$ Conocimiento}

La pregunta de investigación RQ1 perseguía estudiar el efecto de la experiencia del analista independientemente de su conocimiento acerca del dominio del problema. Para ello, hemos utilizado

${ }^{43}$ El efecto Einstellung es el efecto negativo de la experiencia previa en la resolución de nuevos problemas. 
un dominio del problema desconocido para los sujetos experimentales. Al utilizar un dominio de problema desconocido, los sujetos no pueden usar conocimiento previo alguno durante la educción de requisitos (o, como mínimo, durante la primera entrevista). De este modo, cualquier efecto observado sobre la efectividad de los analistas debe provenir de la Experiencia, independientemente del Conocimiento del dominio.

A partir de E-2012, hemos recogido datos acerca de la efectividad de los analistas en dominios conocidos, por motivos ya indicados en la sección 5.4. Esto nos permite estudiar además de los efectos del Conocimiento del dominio (RQ2) también la interacción Experiencia $x$ Conocimiento. En dominios del problema conocidos, los sujetos experimentales pueden usar sus conocimientos para guiar la educción y comprender las respuestas de los clientes y usuarios. Por lo tanto, los potenciales efectos de la experiencia se combinan, positiva o negativamente, con el conocimiento del dominio, esto es, se produce una interacción Experiencia $x$ Conocimiento. Procederemos igual que la sección 6.1, estudiando el efecto de la experiencia medida en años (sección 7.1.2.1) y mediante una escala Likert (sección 7.1.2.2)

\subsubsection{Efecto de la experiencia operacionalizada como número de años}

La Tabla 7.1 presenta un resumen de los efectos obtenidos respecto a la experiencia en requisitos a lo largo de la serie histórica. En el Anexo F.2, presentamos la misma información para los demás tipos de experiencia estudiados.

Tabla 7.1 - Efecto de la experiencia en requisitos en los distintos experimentos - Problema PC1

\begin{tabular}{|c|c|r|r|c|}
\hline \multirow{2}{*}{ EXPERIMENTO } & \multirow{2}{*}{$\mathbf{N}$} & \multicolumn{3}{|c|}{ Correlación } \\
\cline { 3 - 5 } & & \multicolumn{3}{|c|}{ Efectividad * [ExpReq] } \\
\cline { 3 - 5 } & & .234 & Sig. & Efecto \\
\hline E-2012 & 13 & .083 & No $(.879)$ & $(-)$ \\
\hline E-2013 & 6 & $(X)$ \\
\hline E-2014 & 7 & -.049 & No(.916) & $(X)$ \\
\hline E-2015 & 6 & .007 & No(.989) & $(X)$ \\
\hline
\end{tabular}

En general, la experiencia en requisitos tiende a ejercer un efecto muy pequeño, aunque a efectos prácticos es nulo $(r<0.09)$ y no significativo.

Para obtener resultados más precisos, hemos sintetizado los datos disponibles mediante: a) el meta-análisis de datos individuales y b) el meta-análisis de datos agregados, descritos a continuación.

\subsection{Meta-análisis de los datos Individuales}

Para estudiar los efectos de la experiencia en la efectividad de los sujetos, hemos seguido la misma estrategia de análisis aplicada al dominio desconocido (PD1) (Ver sección 6.1.1.1). En primer lugar, con la finalidad de que los datos sean comparables, los hemos ajustado por entrevistado y warming up (detalles del proceso disponible en el Anexo E.2). Nótese que el entrevistado y warming up son variables que podrían ejercer un efecto moderador en los resultados, mientras que las demás (el tipo de entrevista y el momento) se mantienen constantes.

Al igual que el dominio del problema desconocido, el modelo de regresión aplicado está en función de cuatro variables: experiencia en entrevistas, experiencia en requisitos, la experiencia en desarrollo y la experiencia profesional:

Efectividad $=\beta_{0}+\beta_{1}$ ExpEntr $+\beta_{2}$ ExpReq $+\beta_{3}$ ExpDes $+\beta_{4}$ ExpProf $+\varepsilon$

Los resultados del modelo de regresión se muestran en la Tabla 7.2. Como se puede apreciar, la experiencia en entrevistas $\left(\beta_{1}=4.429\right)$ y la experiencia en requisitos $\left(\beta_{2}=2.868\right)$ tienden a ejercer un efecto positivo en la efectividad. Por el contrario, la experiencia en desarrollo $\left(\beta_{3}=-.619\right)$ y la experiencia 
profesional $\left(\beta_{4}=-2.556\right)$ un efecto negativo, aunque nulo a efectos práctico para la experiencia en desarrollo. Nótese, no obstante, que en todos los casos, los efectos tienden a ser muy bajos y no significativos, aunque la experiencia en entrevistas y la experiencia profesional están muy próximas a la significación. Tras analizar el coeficiente de determinación $\left(R^{2}\right)$, el grado de ajuste del modelo es bastante bajo $\left(R^{2}=.214=2.14 \%\right)$. Este hecho pone de manifiesto, al igual que el problema desconocido, que las experiencias por sí mismas no explican la variabilidad de efectividades en los analistas; existen otras variables que ejercen influencia.

Tabla 7.2 - Efecto de la Experiencia mediante el modelo de regresión (Análisis Conjunto) PC1

\begin{tabular}{|c|c|c|c|c|c|c|c|c|}
\hline \multirow{2}{*}{\multicolumn{2}{|c|}{ Modelo }} & \multicolumn{2}{|c|}{$\begin{array}{l}\text { COEFICIENTES NO } \\
\text { ESTANDARIZADOS }\end{array}$} & \multirow{2}{*}{$\begin{array}{c}\text { COEFICIENTES } \\
\text { TIPIFICADOS } \\
\text { Beta }\end{array}$} & \multirow[b]{2}{*}{$\mathrm{T}$} & \multirow[b]{2}{*}{ SIG. } & \multicolumn{2}{|c|}{$\begin{array}{l}\text { ESTADÍSTICOS DE } \\
\text { COLINEALIDAD }\end{array}$} \\
\hline & & B & Error típ. & & & & Tolerancia & FIV \\
\hline \multirow[t]{5}{*}{1} & (Constante) & 29.247 & 5.823 & & 5.023 & .000 & & \\
\hline & $\begin{array}{l}\text { Experiencia en } \\
\text { Entrevistas (años) }\end{array}$ & 4.429 & 2.424 & .376 & 1.827 & .080 & .773 & 1.294 \\
\hline & $\begin{array}{l}\text { Experiencia en } \\
\text { Requisitos (años) }\end{array}$ & 2.868 & 2.542 & .244 & 1.128 & .270 & .698 & 1.432 \\
\hline & $\begin{array}{l}\text { Experiencia en } \\
\text { Desarrollo (años) }\end{array}$ & -.619 & 2.050 & -.071 & -.302 & .765 & .597 & 1.674 \\
\hline & $\begin{array}{l}\text { Experiencia } \\
\text { Profesional (años) }\end{array}$ & -2.556 & 1.383 & -.421 & -1.848 & .077 & .631 & 1.585 \\
\hline
\end{tabular}

a. Variable dependiente: Efectividad Ajustada (\%)

Es importante mencionar que el modelo presentado en la Tabla 7.2 cumple con los supuestos requeridos, tal y como se describe a continuación:

- No Colinealidad. Los estadísticos de colinealidad están dentro de los rangos establecidos (FIV $<10$ y $\mathrm{T}>0.1$ ).

- Normalidad. Los residuos del modelo poseen una distribución normal ( $p$-valor $=2.00>0.05$ para Kolmogorov-Smirnov y p-valor $=.453>0.05$ para Shapiro-Wilk). Se confirma la normalidad de los datos mediante los estadísticos de asimetría (.623) y curtosis .580), ya que están dentro de los rangos habituales \pm 1 .

- Tamaño muestral. El modelo cuenta con cuatro variables independientes, por lo que para alcanzar un efecto del $80 \%$ se espera contar con al menos $50+8 * 4=82$ casos. En nuestro caso $(n=29)$, los resultados se deben tomar con cautela, ya que no contamos con tamaño muestral mínimo requerido.

- Homocedasticidad. Los datos podrían no cumplir con la condición de homocedasticidad o igualdad de varianzas, ya que la distribución de los residuos podría no ser uniforme a lo largo del rango de valores pronosticados tipificados, tal y como se puede apreciar en la Figura 7.1. Lamentablemente, contamos con pocos datos para realizar afirmaciones más concluyentes a este respecto

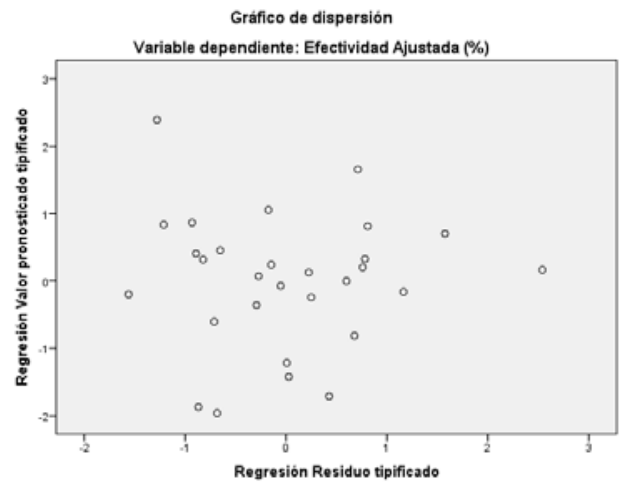

Figura 7.1 - Homocedasticidad, gráfico de dispersión PC1 


\subsection{Meta-análisis de los datos agregados}

\section{a. Efecto de la Experiencia en Entrevistas}

La Figura 7.2 presenta el meta-análisis de correlaciones para la Experiencia en Entrevistas, basada en 4 estudios y 32 sujetos totales. Se puede apreciar que la experiencia en entrevistas tiende a ejercer un efecto positivo bajo ( $r=0.16)$ estadísticamente no significativo ( $p$-valor $=0.482$ ). El intervalo de confianza oscila entre [-0.27 y 0.53]. Nótese que al no resultar significativo el efecto global, el intervalo de confianza cruza el valor cero.

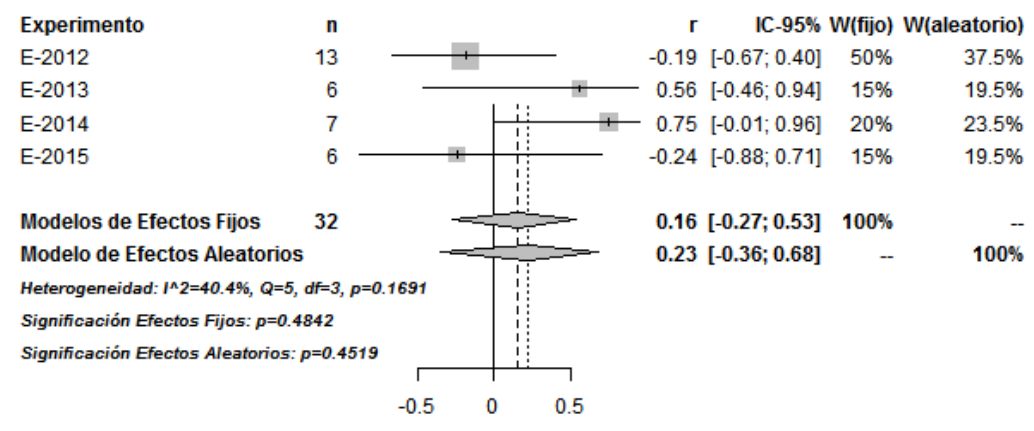

Figura 7.2 - Meta-análisis de la Experiencia en Entrevistas

\section{b. Efecto de la Experiencia en Requisitos}

La Figura 7.3 presenta el meta-análisis de correlaciones para la Experiencia en Requisitos, basada en 4 estudios y 32 sujetos totales. Se puede apreciar que la habilidad en requisitos tiende a ejercer un efecto positivo bajo ( $r=0.12$ ) estadísticamente no significativo ( $p$-valor $=0.583$ ). El intervalo de confianza oscila entre $[-0.31$ y 0.51$]$.

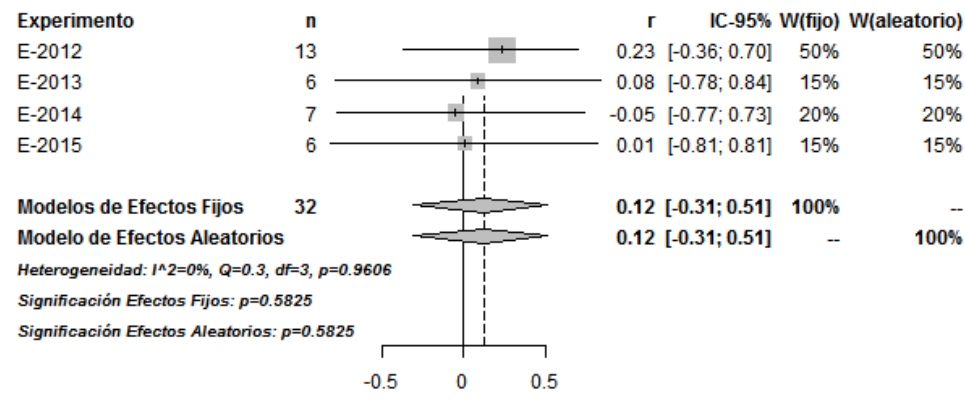

Figura 7.3 - Meta-análisis de la Experiencia en Requisitos

\section{c. Efectos de la Experiencia en Desarrollo}

La Figura 7.4 presenta el meta-análisis de correlaciones para la Experiencia en Desarrollo, basada en 4 estudios y 30 sujetos totales. Se puede apreciar que la experiencia en desarrollo, tiende a ejercer un efecto nulo $(r=-0.08$ ) estadísticamente no significativo ( $p$-valor $=0.721$ ). El intervalo de confianza oscila entre $[-0.50$ y 0.36$]$. 


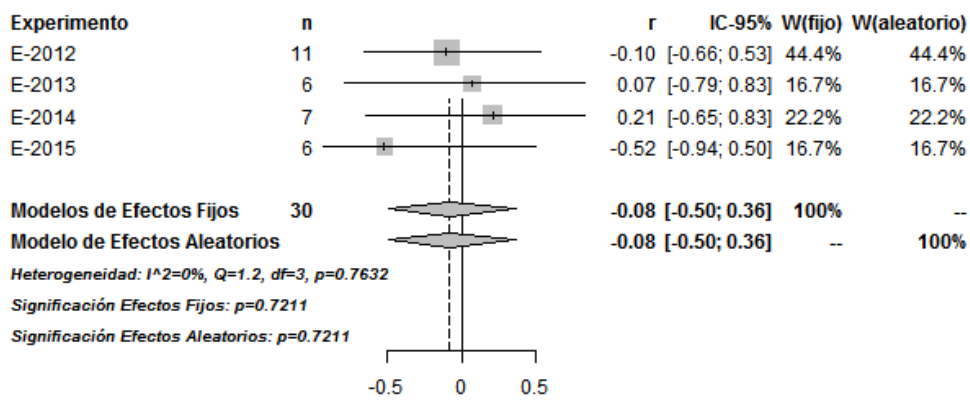

Figura 7.4 - Meta-análisis de la Experiencia en Desarrollo

\section{d. Efecto de la Experiencia profesional}

La Figura 7.5 presenta el meta-análisis de correlaciones para la Experiencia Profesional, basada en 4 estudios y 31 sujetos totales. Se puede apreciar que la Experiencia Profesional tiende a ejercer un efecto moderado negativo ( $r=-0.37$ ), estadísticamente no significativo ( $p$-valor $=0.094$ ) aunque muy próxima a la significación. El intervalo de confianza oscila entre [-0.68 y 0.07].

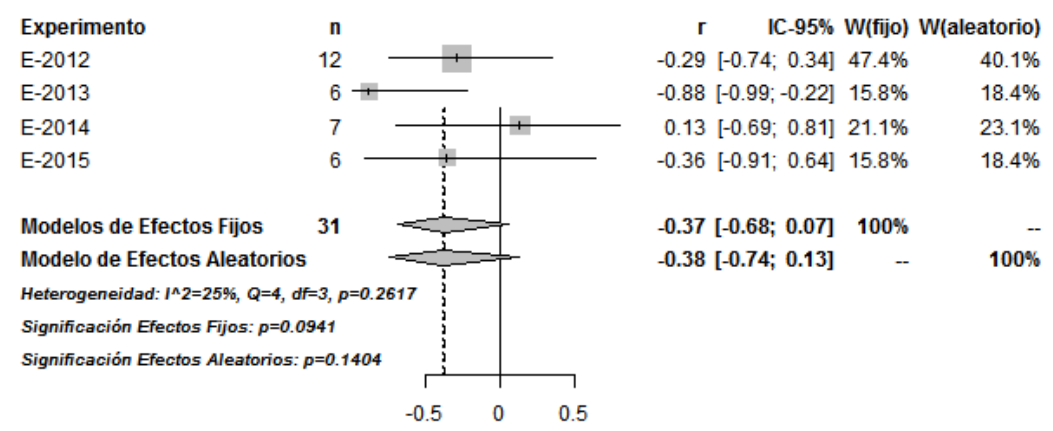

Figura 7.5 - Meta-análisis de la Experiencia Profesional

\subsection{Comparación del meta-análisis de datos individuales con el meta-análisis de datos agregados}

Resumiendo, como se puede apreciar en la Tabla 7.3, tanto el modelo de regresión como el metaanálisis ponen de manifiesto que la experiencia en requisitos y entrevistas tienden a ejercer un bajo efecto positivo en la efectividad de los sujetos en los problemas conocidos, mientras que por el contrario la experiencia profesional un efecto negativo y la experiencia en desarrollo un efecto nulo.

Tabla 7.3 - Resumen relación entre la efectividad y la experiencia - PC1

\begin{tabular}{|l|c|c|c|c|}
\hline \multirow{2}{*}{ EXPERIENCIAS } & \multicolumn{2}{|c|}{ MODELO DE REGRESIÓN } & \multicolumn{2}{c|}{ META-ANÁLISIS } \\
\cline { 2 - 5 } & $\mathbf{r}$ & \multicolumn{1}{c|}{ Sig } & $\mathbf{r}$ & \multicolumn{1}{c|}{ Sig. } \\
\hline $\begin{array}{l}\text { Experiencia en } \\
\text { Entrevistas }\end{array}$ & 0.34 & 0.080 & 0.16 & 0.484 \\
\hline $\begin{array}{l}\text { Experiencia en } \\
\text { Requisitos }\end{array}$ & 0.22 & 0.270 & 0.12 & 0.583 \\
\hline $\begin{array}{l}\text { Experiencia en } \\
\text { Desarrollo }\end{array}$ & -0.06 & 0.765 & -0.08 & 0.721 \\
\hline $\begin{array}{l}\text { Experiencia } \\
\text { Profesional }\end{array}$ & -0.35 & 0.077 & -0.37 & 0.094 \\
\hline
\end{tabular}

Esto es, parece confirmarse que existe un efecto Experiencia $x$ Conocimiento. En dominios de problemas desconocidos, la experiencia no ejerce efecto alguno (ver sección 6.1). Por el contrario, en dominios conocidos, la experiencia en entrevistas y requisitos poseen efectos positivos. Este hecho, deberá ser tenido en cuenta en la discusión de RQ1 (ver sección 7.2). Ya por último, indicar que la 
experiencia profesional también parece interaccionar con el conocimiento, aunque en este caso de forma negativa: a mayor experiencia profesional, menor efectividad del analista en dominios conocidos.

\subsubsection{Efecto de la experiencia operacionalizada como la Habilidad}

La Tabla 7.4 presenta un resumen de los efectos de la habilidad en requisitos y en entrevistas obtenidos en los distintos experimentos donde fue posible analizarlas. Como se puede apreciar en la Tabla 7.4, la Habilidad en Requisitos tiende a ejercer un efecto positivo en la efectividad ( $r=.187, r=.365, .158$ en E2012, E.214 y E-2015 respectivamente), con excepción de E-2013 donde el efecto es negativo ( $r=-.208)$. Por el contrario, la Habilidad en Entrevistas tiende a ejercer un efecto negativo ( $r=.-111$ y $r=-.437$ en $E$ 2012 y E-2013 respectivamente), mientras que en E-2014 y E-2015 un efecto positivo ( $r=.645$ y $r=.657$ en E-2014 y E-2015 respectivamente). En ambos casos los efectos son estadísticamente no significativos. Nótese que dichos efectos tienden a ser bajos ${ }^{44}$ en la habilidad en requisitos y moderado-altos ${ }^{45}$ en la habilidad en entrevistas.

Tabla 7.4 - Efecto de la habilidad en requisitos y entrevistas diferenciado por estudio experimental PC1

\begin{tabular}{|c|c|c|c|c|c|}
\hline \multirow{2}{*}{$\begin{array}{c}\text { VARIABLE } \\
\text { INDEPENDIENTE }\end{array}$} & \multirow{2}{*}{ EXPERIMENTO } & \multicolumn{3}{|c|}{ CORRELACIÓN } & \multirow{2}{*}{$\begin{array}{c}\text { EFECTO } \\
\text { HAB }\end{array}$} \\
\hline & & $r$ & $p$-valor & $\mathrm{N}$ & \\
\hline \multirow{4}{*}{ HabReq } & E-2012 & .187 & .543 & $13 / 14$ & $(+)$ \\
\hline & E-2013 & -.208 & 699 & $6 / 7$ & $(-)$ \\
\hline & E-2014 & .365 & .355 & $6 / 6$ & $(+)$ \\
\hline & E-2015 & .158 & .770 & $6 / 8$ & $(+)$ \\
\hline \multirow{4}{*}{ HabEntr } & E-2012 & -.111 & .719 & $13 / 14$ & $(-)$ \\
\hline & E-2013 &.- .437 & .403 & $6 / 7$ & $(-)$ \\
\hline & E-2014 & .645 & .079 & $6 / 6$ & $(+)$ \\
\hline & E-2015 & .657 & .179 & $6 / 8$ & $(+)$ \\
\hline
\end{tabular}

Los resultados obtenidos en cada uno de los experimentos por separado, deben tomarse con cierta cautela, dado que poseen un tamaño muestral muy reducido. Por ello, hemos sintetizado los resultados de los estudios individuales, empleando los dos métodos estadísticos: a) meta-análisis de datos individuales mediante el modelo de regresión y b) meta-análisis de datos agregados.

\subsection{Meta-análisis de los datos individuales}

Los resultados del modelo se presentan en la Tabla 7.5. Tanto la Habilidad en Entrevistas $\left(\beta_{1}=1.521\right)$ como la Habilidad en Requisitos $\left(\beta_{2}=1.140\right)$ tienden a ejercer un efecto positivo en la efectividad. No obstante, dichas tendencias son bajas y estadísticamente no significativas ( $p$-valor $>0.05$ ). El grado de ajuste del modelo es muy reducido $\left(R^{2}=0.022\right)$, nulo a efectos prácticos, lo que significa que la percepción subjetiva del sujeto sobre su experiencia en requisitos y en entrevistas en dominios conocidos, no explica su efectividad en los mismos.

Tabla 7.5 - Análisis conjunto. Modelo de regresión lineal PC1

\begin{tabular}{|c|c|c|c|c|c|c|c|c|}
\hline & & \multicolumn{2}{|c|}{$\begin{array}{l}\text { Coeficientes no } \\
\text { estandarizados }\end{array}$} & \multirow{2}{*}{\begin{tabular}{|c|}
$\begin{array}{c}\text { Coeficientes } \\
\text { tipificados }\end{array}$ \\
Beta \\
\end{tabular}} & \multirow[b]{2}{*}{$\mathrm{t}$} & \multirow[b]{2}{*}{ Sig. } & \multicolumn{2}{|c|}{$\begin{array}{c}\text { Estadísticos de } \\
\text { colinealidad }\end{array}$} \\
\hline \multicolumn{2}{|c|}{ Modelo } & B & Error típ. & & & & Tolerancia & FIV \\
\hline \multirow[t]{3}{*}{1} & (Constante) & 18.278 & 10.531 & & 1.736 & .094 & & \\
\hline & Habilidad en Entrevistas & 1.521 & 3.813 & .093 & .399 & .693 & .646 & 1.549 \\
\hline & Habilidad en Requisitos & 1.140 & 3.714 & .071 & .307 & .761 & .646 & 1.549 \\
\hline
\end{tabular}

a. Variable dependiente: Efectividad Ajustada (\%) $\mathrm{R}^{2}=.022 ; \mathrm{N}=31 ; \mathrm{N}-$ Esperado $=66$

\footnotetext{
${ }^{44}$ Según Cohen un efecto es bajo si el valor de r está dentro del rango \pm (0.1- 03)

${ }^{45}$ Efectos medios \pm (0.3- 0.5); efectos altos $\pm(0.5-1)$ según Cohen.
} 
En lo que respecta a los supuestos necesarios para aplicar el modelo de regresión se tiene que:

- No Colinealidad. Los estadísticos de colinealidad están dentro de los rangos establecidos (FIV $<10$ y $\mathrm{T}>0.1$ ).

- Normalidad. Los residuos del modelo poseen una distribución normal ( $p$-valor $=2.000>$ 0.05 para Kolmogorov-Smirnov y p-valor $=.748$ para Shapiro-Wilk). Se confirma la normalidad de los datos mediante los estadísticos de asimetría (.412) y curtosis (.523), ya que están dentro de los rangos habituales \pm 1 .

- Tamaño muestral. El modelo cuenta con dos variables independientes, por lo que para alcanzar un efecto del $80 \%$ se espera contar con al menos $50+8 * 2=66$ casos. En nuestro caso, contamos con 31 menos de los esperados, por lo que los resultados deben tomarse con cierta cautela.

- Homocedasticidad. Los datos cumplen con la condición de homocedasticidad o igualdad de varianzas, ya que la varianza observada parece bastante uniforme a lo largo del rango de valores pronosticados tipificados, como se puede apreciar en la Figura 7.6.

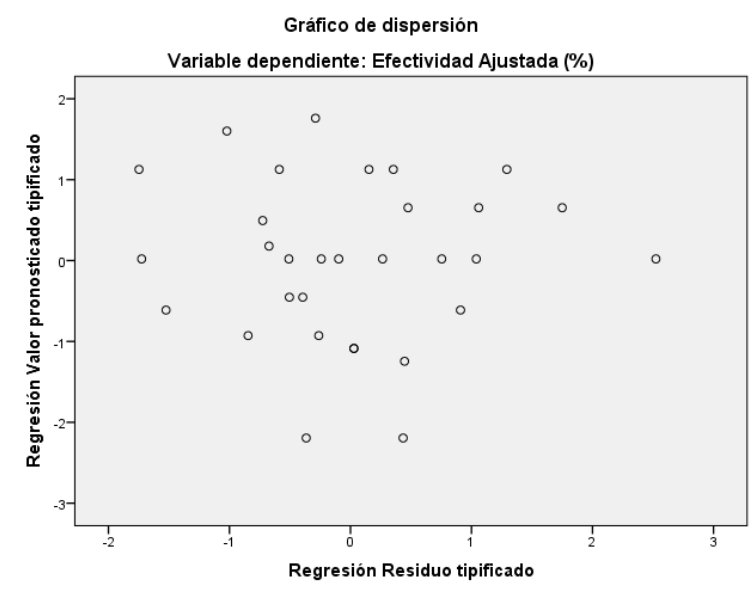

Figura 7.6 - Homocedasticidad Gráfico de Dispersión

\subsection{Meta-análisis de los datos agregados}

La Figura 7.7 y la Figura 7.8 muestran los meta-análisis de correlación correspondiente a la habilidad en entrevistas y la habilidad en requisitos respectivamente, basados en 4 estudios y 31 sujetos totales.

Como se pude apreciar en la Figura 7.7, la habilidad que poseen los sujetos en entrevistas tiende a ejercer un efecto bajo positivo ( $r=0.15)$, estadísticamente no significativo ( $p$-valor $=0.508>0.05$ ) en la efectividad. El intervalo de confianza oscila entre [-0.29 y 0.54$]$.

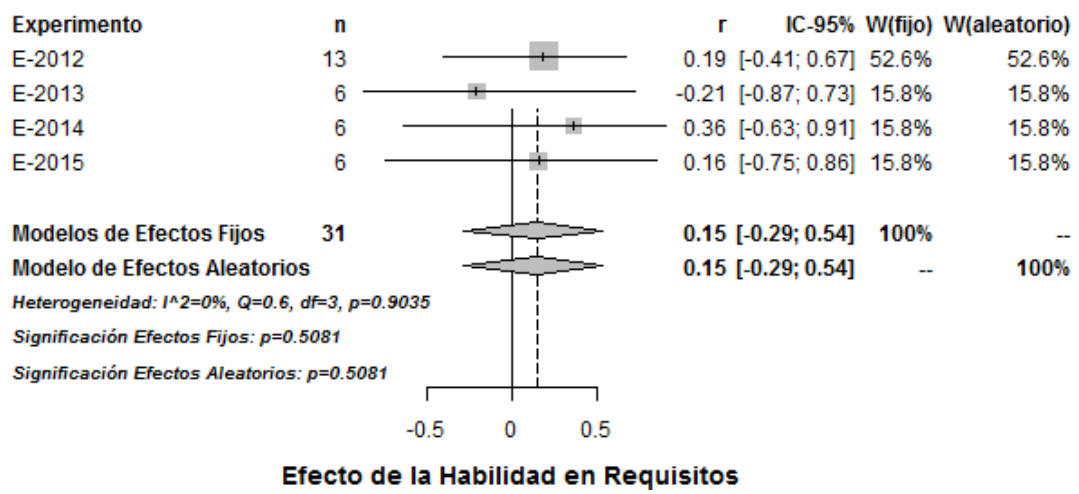

Figura 7.7 - Meta-análisis Habilidad en Requisitos 
En lo que respecta a la habilidad en requisitos, en la Figura 7.8 no se observa heterogeneidad entre los estudios individuales ( $p$-valor $=0.244>0.05$ ). La habilidad que poseen los sujetos en requisitos tiende a ejercer un efecto bajo positivo $(r=0.11)$, estadísticamente no significativo ( $p$-valor $=06231>$ 0.05 ) en la efectividad. El intervalo de confianza oscila entre [-0.32 y 0.51$]$.

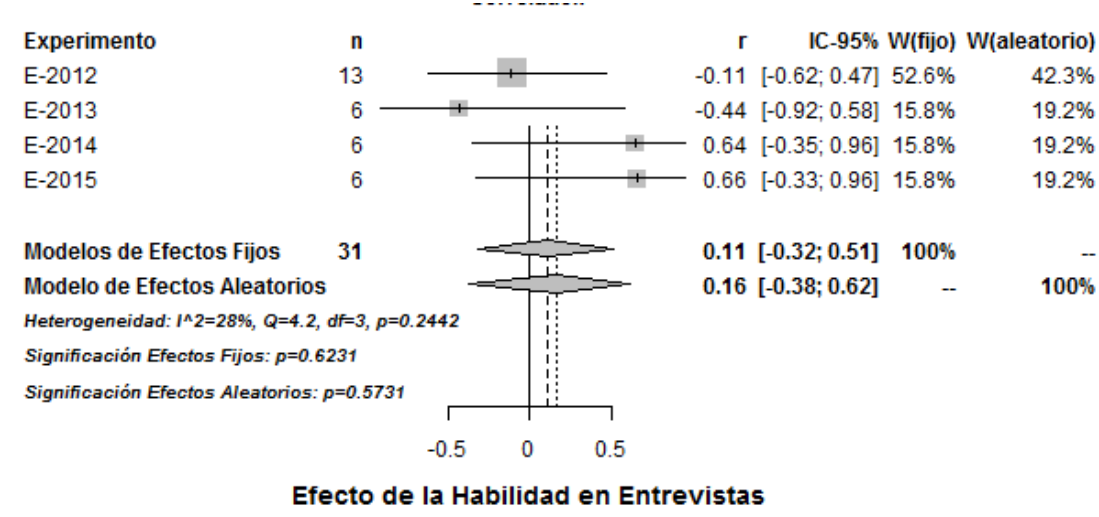

Figura 7.8 - Meta-análisis Habilidad en Entrevistas

\subsection{Comparación del meta-análisis de datos individuales con el meta-análisis de datos agregados}

La Tabla 7.6 compara los coeficientes de correlación obtenidos en el meta-análisis con los coeficientes de correlación derivados del modelo de regresión. Estos coeficientes se han calculado ${ }^{46}$ a partir de la t y los grados de libertad correspondientes (N-2).

En todos los casos, para el modelo de regresión, el coeficiente de correlación ( $r$ ) es menor (en valor absoluto) a 0.09 (efecto nulo según Cohen) y estadísticamente no significativo ( $p$-valor >0.05). Lo mismo ocurre a efectos prácticos con el meta-análisis de datos agregados. Ello implica que la percepción subjetiva que poseen los analistas sobre su experiencia en requisitos y entrevistas no determina su efectividad.

Tabla 7.6 - Resumen relación entre la efectividad y la habilidad - PC1

\begin{tabular}{|l|r|r|r|r|}
\hline \multirow{2}{*}{ Habilidad } & \multicolumn{2}{|c|}{ Modelo de Regresión } & \multicolumn{2}{c|}{ Meta-análisis } \\
\cline { 2 - 5 } & \multicolumn{1}{|c|}{$\mathbf{r}$} & \multicolumn{1}{c|}{ Sig. } & \multicolumn{1}{c|}{ r } & \multicolumn{1}{c|}{ Sig. } \\
\hline $\begin{array}{l}\text { Habilidad en } \\
\text { Entrevistas }\end{array}$ & .06 & .693 & .11 & .623 \\
\hline $\begin{array}{l}\text { Habilidad en } \\
\text { Requisitos }\end{array}$ & .07 & .761 & .15 & .508 \\
\hline
\end{tabular}

\section{2 ¿̇nfluye la experiencia del analista en la efectividad del proceso de educción de los requisitos? (RQ1)}

Como hemos podido comprobar en la sección 6.1, los resultados obtenidos tanto en el meta-análisis de datos individuales como en el meta-análisis de datos agregados son bastantes consistentes entre ellos. Más concretamente, los resultados ponen de manifiesto que, para dominios desconocidos, las distintas experiencias (en entrevistas, requisitos, desarrollo y profesional) tienden a ejercer un efecto nulo en la efectividad de los analistas.

Así mismo, en la sección 7.1, quedó establecido de forma también bastante consistente que, para problemas conocidos, el efecto varía en función del tipo de experiencia. Esto es, la experiencia en

46 Para obtener el valor del coeficiente de regresión, hemos empleado el calculador de tamaños de efectos: http://www.uccs.edu/ /becker/. 
Estudio empírico de la influencia de la experiencia y del conocimiento del dominio del analista en la efectividad del proceso de educción de requisitos

entrevistas y la experiencia en requisitos ejercen un efecto positivo, aunque no significativo y, la experiencia profesional un efecto negativo próximo a la significación.

Nótese que la experiencia en desarrollo, posee un efecto nulo y no significativo en ambos dominios de problema.

En lo que sigue, compararemos nuestros resultados con los estudios indicados en el estado de la cuestión. La comparación aprovechará que nuestro trabajo considera distintos tipos de experiencias, así como dominios de problemas conocidos y desconocidos (Sección 7.2.1). También discutiremos aspectos asociados con el proceso de educción de los requisitos y el comportamiento de los involucrados (analistas y entrevistados). En la sección 7.2.2 discutiremos la relación de la experiencia y las efectividades mínimas obtenidas. En la sección 7.2.3 algunos factores que podrían explicar las diferencias de efectividades.

\subsubsection{Comparación con los trabajos empíricos relacionados}

Nuestros hallazgos coinciden casi perfectamente con los estudios de Pitts y Browne (2004), Marakas y Elam (1998) y Agarwal y Tanniru (1990), que al igual que en nuestro caso emplean las entrevistas como técnica de educción de requisitos en sus investigaciones. En los tres casos, los autores concluyen que no existen diferencias significativas entre novatos y expertos, pero los expertos han resultado mejores (aunque muy levemente) que los novatos. Nótese que en nuestra investigación hemos categorizado a los dominios del problema utilizados durante el proceso de educción, como dominios conocidos y desconocidos. Los dominios empleados en los distintos experimentos de la literatura indicada corresponden a dominios conocidos. Por este motivo para la comparación y discusión de nuestros resultados con dichos trabajos, utilizaremos nuestros resultados respecto al dominio conocido.

El estudio de Pitts y Browne (2004) es un experimento que obtiene la relación entre la experiencia en desarrollo y la cantidad de requisitos identificados por los analistas es de $r=0.075$. Este valor corresponde a un efecto muy pequeño según Cohen (1988). En nuestro caso, dicha correlación es r=0.06 , un valor también muy pequeño, nulo a efectos prácticos. Tanto para los autores como en nuestra investigación las correlaciones son no significativas ( $p$-value $=0.591$ y 0.661 , respectivamente). Nótese que el hecho de que las correlaciones tengan signos distintos no tiene una gran importancia. Ambos valores están muy próximos a cero y en estas circunstancias, que la correlación tenga un valor positivo o negativo, es puramente efecto de la casualidad.

El estudio de Marakas y Elam (1998) es experimental y por lo tanto reporta el efecto de la experiencia como una diferencia entre grupos (Baja vs Alta Experiencia). En porcentaje, los sujetos con experiencia son un $3.09 \%$ más efectivos que los sujetos sin experiencia. El resultado es estadísticamente no significativo ( $p$-valor=0.749). Nótese que para comparar este efecto con el obtenido en nuestro estudio, deberemos dividir 3.09\% entre los años de experiencia que poseen los sujetos del grupo de Experiencia Alta. Este dato no está disponible en (Marakas \& Elam, 1998); sólo se indica que "high experience subjects were [...] employed at several major corporations". Suponiendo una media de unos $5-10$ años de experiencia, el efecto por año estaría entre $3.09 \% / 5=.618 \%$ y $3.09 \% / 10=.309 \%$.

Un problema adicional con el estudio de Marakas y Elam, es que no indica claramente si la experiencia se refiere a desarrollo o requisitos. En nuestro caso, el efecto de la experiencia en desarrollo es $-.619 \%$ ( $p$-valor=0.765), mientras que el efecto de la experiencia en requisitos es de $2.9 \%$ ( $p$ valor $=0.270$ ). El efecto de la experiencia que hemos calculado para Marakas y Elam se encuentra entre nuestros valores, más cercano al efecto de la experiencia en desarrollo que al efecto de la experiencia en requisitos. En nuestra opinión esto es precisamente lo esperable, ya que creemos que resulta más sencillo disponer de sujetos con experiencia en desarrollo que con experiencia en requisitos para realizar un experimento. 
El estudio de Agarwal y Tanniru (1990) es también experimental. Los sujetos del experimento fueron estudiantes y profesionales con al menos 3 años de experiencia en análisis de sistemas. En este caso, la diferencia entre sujetos novatos y expertos es de 0.9 , medida en número de reglas (métrica un tanto distinta a la empleada en nuestro estudio, pero que no deja de representar una cantidad de elementos relevantes del dominio del problema educidos, que es justamente lo que nosotros también hacemos). Este resultado es nuevamente no significativo (los autores no indican ni magnitud ni dirección).

Sin embargo, al no definir los autores un gold standard para las reglas que contiene el problema experimental, es imposible transformar el efecto de la experiencia a un valor comparable con nuestro estudio (\% de elementos educidos respecto al total). Lo máximo que podemos hacer es calcular el \% de mejora de los expertos sobre los novatos y razonar cualitativamente. Este valor equivale a (0.9/5.2)*100 $=17.3 \%$, lo cual puede leerse como que el experto es un $17.3 \%$ más efectivo que los novatos. Ahora bien, para comparar con nuestros datos debemos normalizar los valores por año, al igual que hemos hecho en Marakas y Elam (1998). Como mínimo, los sujetos tienen 3 años de experiencia. Por ello, el \% de mejora máximo por año es de $17.3 \% / 3=5.77 \%$.

Este valor se trata de un efecto es prácticamente el doble al obtenido por nosotros para la experiencia en requisitos (una mejora del $2.9 \%$ por año). No obstante, nótese que el \% depende de la escala de medida. En Agarwal y Tanniru (1990) el número medio de reglas educidas es relativamente bajo, en torno a 6 , mientras que en nuestro caso, el número medio de elementos educidos es de 14 . Por lo tanto, es esperable una relación entre $\%$ de mejora de $14 / 6=2.3$. Bajo este razonamiento (que nosotros mismos creemos poco fiable, pero eso es a lo máximo que podemos aspirar), el \% de mejora de Agarwal y Tanniru debería ser de 5.77/2.3 = 2.5\%, mucho más cerca a lo obtenido por nosotros.

En lo que respecta al estudio de Niknafs y Berry, se producen ciertas contradicciones, aunque como veremos a continuación son más aparentes que reales. Nótese que la metodología del estudio de Niknafs es muy distinta a la nuestra, por lo que haremos ciertas simplificaciones y comentaremos únicamente aspectos destacados del mismo.

En Niknafs y Berry (2012) los autores observaron un efecto negativo de la experiencia profesional en la generación de ideas (relevantes y factibles), estadísticamente significativo al $\alpha=0.10$ y un efecto no significativo de la experiencia en requisitos (los autores no indican ni magnitud ni dirección). En Niknafs, (2014) detectaron un efecto parcialmente positivo para la experiencia profesional, aunque estadísticamente no significativo en las variables dependientes estudiadas (generación de ideas en general, relevantes e innovadoras), y casi significativo para ideas factibles. En el caso de la experiencia en requisitos, se observa un efecto negativo, estadísticamente significativo para una de las variables dependientes estudiadas (generación de ideas relevantes). En el resto de las variables el efecto de la experiencia en requisitos oscila entre positivo y negativo y siempre no significativo.

Nuestros resultados no pueden compararse directamente con los de Niknafs y Berry porque los sujetos que participaron en el experimento en algunos casos conocen y otros no el dominio del problema. Además el rango de experiencias tanto en requisitos como la profesional está bastante limitado (0 a 4 años). En nuestro caso existe una mayor diversidad de experiencias (0 a 30 años). Finalmente, los resultados que hemos presentado en la sección 6 separan netamente el efecto de la experiencia para dominios conocidos y desconocidos. Se trata por lo tanto de metodologías muy distintas.

Para aproximarnos a lo realizado por Niknafs y Berry, hemos re-analizado conjuntamente nuestros datos pertenecientes a los dominios conocidos y desconocidos, empleando el mismo método de análisis utilizado por los autores (correlaciones estadísticas) y limitado el rango de experiencias de las experiencias de 0 a 4 años. Al comparar nuestros resultados con los suyos, no se observan coincidencias. En los estudios de Niknafs la experiencia en requisitos influye negativamente y la experiencia profesional 
Estudio empírico de la influencia de la experiencia y del conocimiento del dominio del analista en la efectividad del proceso de educción de requisitos

positivamente. En nuestro caso, dichas experiencias no ejercen influencia ( $r=.002$ y $r=.065$, respectivamente) y están muy lejos de la significación ( $p$-valor $=.989$ y $p$-valor $=.588$ ).

Las diferencias podrían deberse virtualmente a cualquier cosa. Un aspecto destacable es la técnica de educción utilizada. En el caso de Niknafs y Berry se usó la técnica de Tormenta de Ideas, mientras que en nuestra investigación se usó la técnica abierta. Es buen sabido que cada técnica de educción posee requisitos y genera resultados distintos (Carrizo, Dieste, \& Juristo, 2014). La técnica de educción podría, por lo tanto explicar las diferencias observadas.

Otra posibilidad es la co-existencia de otros fenómenos internos al analista, además de la experiencia. A este respecto, en la sección 7.1.2 apuntamos que las diferencias con Ninafs y Berry podrían deberse también a un fenómeno de Einstellung. Esto último, en nuestra opinión, es la conclusión más plausible.

\subsubsection{Evidencias del efecto de la experiencia sobre la efectividad mínima de los analistas}

En la presente investigación hemos podido comprobar que, para dominios del problema desconocidos, la experiencia del analista (ya sea en entrevistas o requisitos) no influyen en su efectividad. Por tanto, no es posible predecir si sujetos con más años de experiencia tendrán mejores o peores desempeños que aquellos sujetos con menos años, ya que los sujetos con los mismos años de experiencia obtienen efectividades muy diversas. Para dominios del problema conocidos, ambos tipos de experiencias ejercen efectos positivos.

Un modelo de regresión múltiple no puede representarse en toda su complejidad en un diagrama de dispersión. No obstante, las tendencias, cuando son claras, son igualmente visibles, aunque la magnitud de la pendiente de la recta de regresión lineal no coincida con el modelo de regresión múltiple. A este respecto, véase la Figura 7.9, donde representamos la efectividad de los analistas frente a la experiencia en requisitos. Para el dominio del problema desconocido ( Figura 7.9a), la pendiente es más pequeña que para el dominio del problema conocido ( Figura 7.9b), tal y como el meta-análisis indica.

Independientemente de la regresión lineal utilizada, puede observase tanto en la Figura 7.9a como en la Figura 7.9b que en la parte inferior derecha de los gráficos (marcada como "zona sin puntos") existe una zona donde no aparece ningún punto de datos. La línea roja delimita esta zona (los otros límites son el eje de abscisas y el lateral derecho del gráfico. Nótese que esta línea está trazada a mano sin seguir ningún criterio matemático.

En ambos gráficos se puede apreciar como la efectividad mínima de los analistas tiende a ir aumentando conforme aumentan los años de experiencia. La línea roja sugiere que los analistas con más años de experiencia consiguen efectividades mínimas más elevadas que los analistas con menores experiencias. Este hecho pone de manifiesto que, si bien los años de experiencia no parecen predecir cuánto de bueno será un analista, sí parecen asegurar que un analista con cierta experiencia, en general, tendrá una efectividad mínima que será superior a la efectividad mínima de los analistas con menos experiencia.

La línea roja que hemos marcado tiene una forma similar a las "curvas de aprendizaje" que la literatura acerca de la experiencia representa con frecuencia (ej: (Ericsson, 2006)). Las curvas de aprendizaje son idealizaciones que denotan cuanto mejora el rendimiento de una persona a medida que su experiencia aumenta. En nuestro caso, esta mejora de rendimiento no está relacionada con la efectividad concreta de cada sujeto (la efectividad varia ampliamente dependiendo de los años de experiencia), sino con un mínimo de efectividad que en prácticamente en todos los casos (sólo hay una excepción en PC1) los analistas alcanzan. 


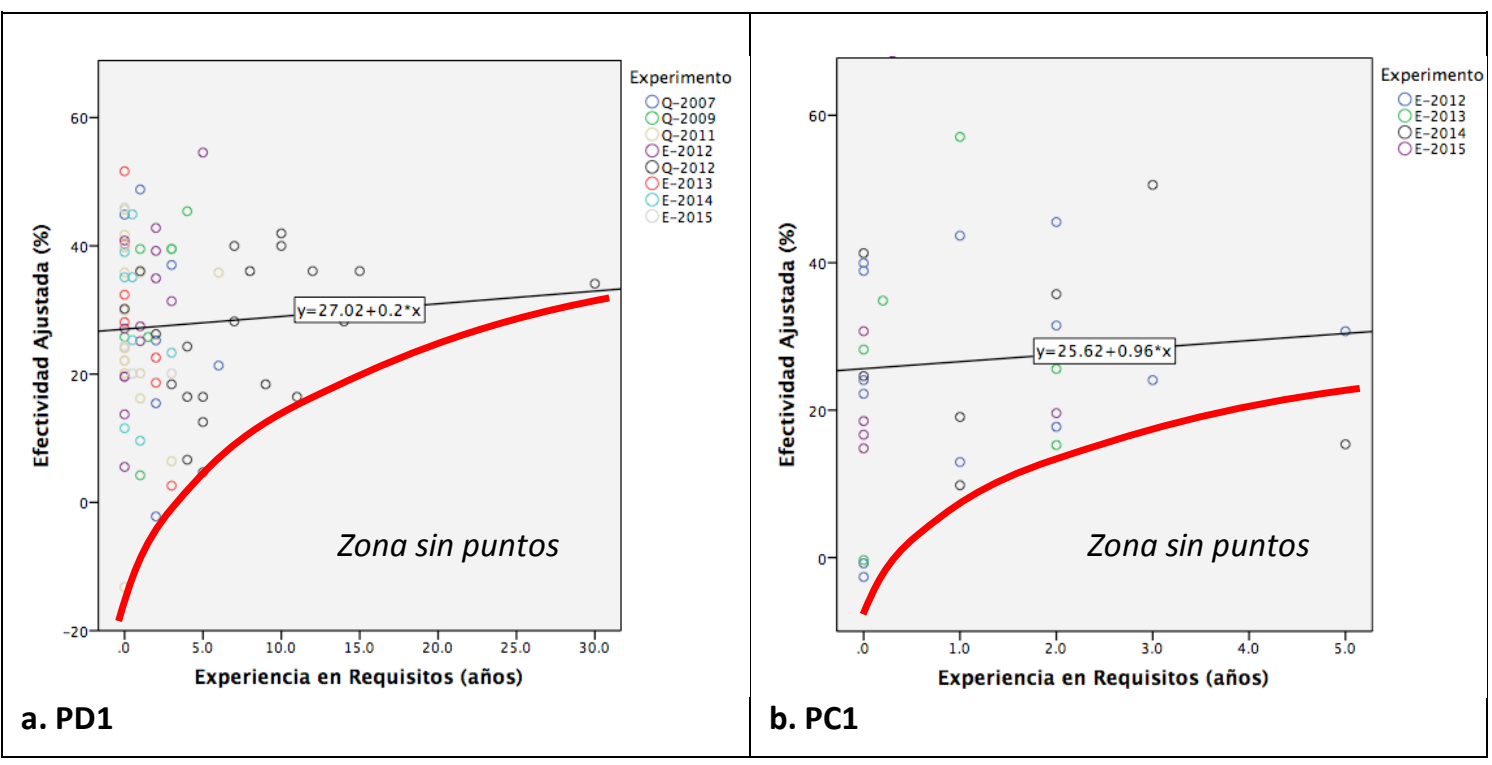

Figura 7.9 - Comparación efectividades mínimas en función de los años de experiencia

\subsubsection{Otros factores que podrían explicar las diferencias en la efectividad de los analistas}

Aunque existen investigaciones que indican que la experiencia juega un factor diferencial entre expertos y novatos, está claro que la experiencia por sí misma no es un factor suficiente que explique dichas diferencias. Existen otros factores que están influyendo tal y como los bajísimos coeficientes $\mathrm{R}^{2}$ indican. Uno podría preguntarse ¿cuáles podrían ser los motivos que hacen que los expertos sean tan o menos efectivos que los novatos y vice-versa?. Si bien podría haber muchos factores que estén influyendo, nuestra investigación permite estudiar alguno de ellos. Entre dichos factores están:

\section{a. Influencia del tiempo de educción}

Un aspecto que podría ejercer influencia en las efectividades es el tiempo de educción, es decir, el tiempo que emplearon los sujetos para realizar la educción de requisitos. Si bien se ha sugerido un promedio de 30 minutos para las entrevistas, hubo sujetos que emplearon más o menos del tiempo establecido. Nuestros resultados, como se puede apreciar en los gráficos de dispersión mostrados en la Figura 7.10, ponen de manifiesto que el tiempo de educción no influye en la efectividad de los analistas, tanto para el dominio desconocido como para el conocido. Si bien se observa una muy leve tendencia positiva, de un $0.4 \%$ y $0.5 \%$ por minuto, ésta no es significativa.

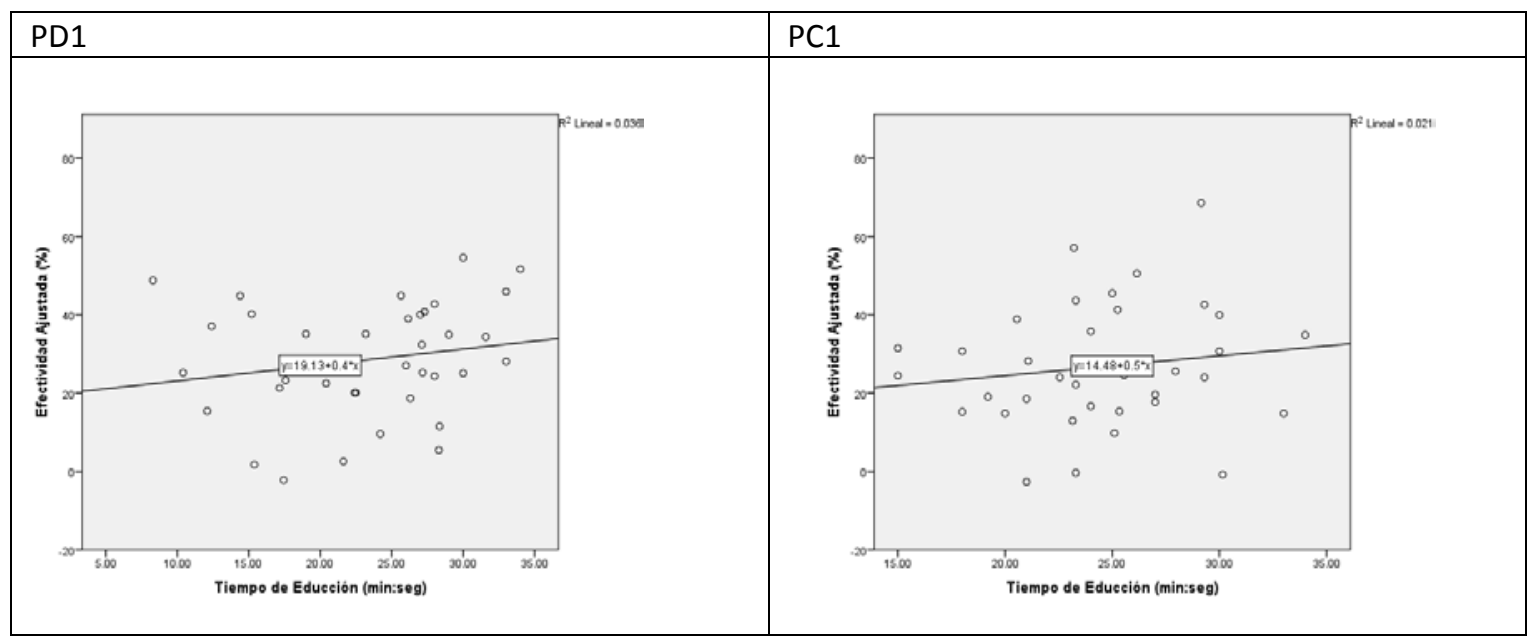

Figura 7.10 - Relación entre el tiempo de educción y las efectividades de los analistas 


\section{b. Influencia del número de sesiones de educción}

Creemos que, la incapacidad de detectar efectos significativos de la experiencia podría estar asociada al número de entrevistas que el analista realiza. Nótese que en la presente investigación, las entrevistas están limitadas a una única sesión. Esta característica (única sesión) es compartida por los experimentos relacionado (Agarwal \& Tanniru, 1990; Marakas \& Elam, 1998; Pitts \& Browne, 2004). Con la finalidad de comprobar esta suposición hemos realizado por un lado, un experimento (E-2013) donde los sujetos tuvieron una segunda entrevista y por otro, un experimento (E-2014) planteado como práctica de la asignatura, donde los alumnos (en grupos de 2 a 3 personas) a partir de la entrevista inicial (llevada a cabo individualmente), pudieran refinar el documento de requisitos hasta llegar al prototipo del sistema, lo que dio lugar a más entrevistas.

Como se puede apreciar en los gráficos de líneas de la Figura 7.11, los sujetos en E-2013 tras realizar una segunda entrevista, en el problema desconocido alcanzaron promedios similares, mientras que en el problema conocido, las efectividades promedios varían entre un $3 \%$ y $5 \%$, diferencias prácticamente inexistentes.

Nuestros resultados ponen de manifiesto que los sujetos en sus segundas entrevistas no mejoraron su efectividad.

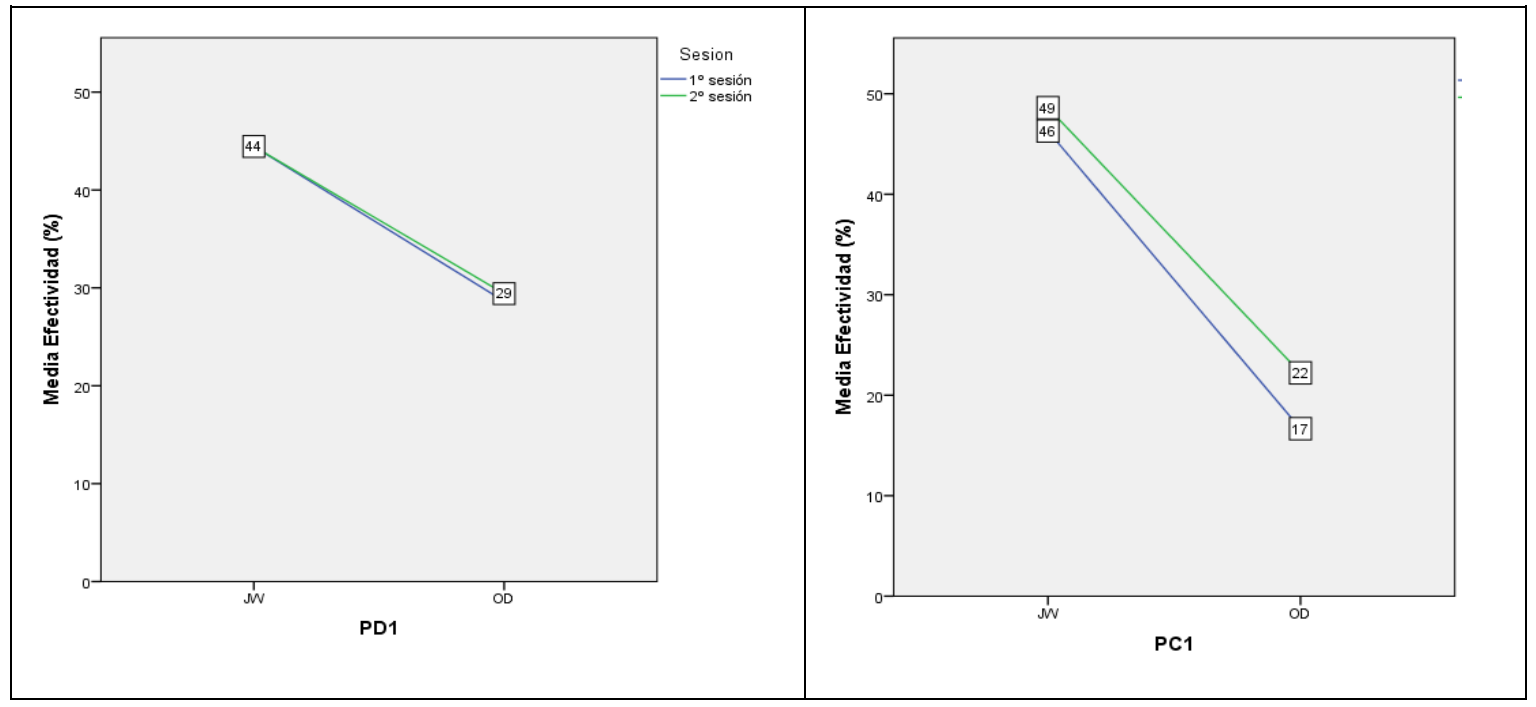

Figura 7.11 - Efectividad media diferenciada por sesión de educción

En E-2014, durante la práctica propuesta a lo largo de la asignatura, hemos observado una mejor comprensión de los dominios del problema en las especificaciones presentadas por los estudiantes. Sin embargo, los estudiantes no llegaron a una comprensión muchísimo más profunda del dominio y, desde luego, no se acercaron ni de lejos a identificar todos los elementos relevantes. Bien es cierto que las efectividades mejoraron progresivamente mediante el trabajo en equipo con varias sesiones de educción. También es cierto que el progreso fue exasperadamente lento.

Las mejoras sustanciales ocurrieron en el momento en que los sujetos abandonan la entrevista y comenzaron a utilizar otras técnicas de educción, como pueden ser los prototipos. Por lo tanto, el techo de cristal podría estar también motivado (al menos en parte) por limitaciones comunicativas relacionadas con la utilización de las entrevistas como técnica de educción.

\section{c. Captura diferencial de distintos tipos de elementos}

Un aspecto que podría afectar o influir en la efectividad de los analistas podría venir derivado por el modo en que las personas afrontan o estudian las características del propio dominio del problema. Por 
ejemplo, los tipos de elementos identificados por los expertos podrían ser distintos (ej: aquellos que tuvieran mayor relevancia) que los obtenidos por los novatos.

Para determinar si los analistas capturasen un tipo de elemento u otro en función de su experiencia, hemos estudiado la relación de la experiencia con la efectividad del analista para cada uno de los elementos que definen el dominio del problema (requisitos, conceptos y procesos), mediante un metaanálisis de datos agregados. Dichos meta-análisis se muestran en el Anexo H.2. Para el dominio desconocido PD1, la experiencia en requisitos tiende a ejercer:

- un efecto positivo pero bajo ( $r=0.23)$ en la identificación de los procesos estadísticamente no significativo ( $p$-valor $>0.05$ ) pero muy próximo a la significación ( $p$-valor $=0.07$ ). El intervalo de confianza oscila entre [-0.02 y 0.45].

- un efecto positivo pero bajo $(r=0.15)$ en la identificación de los conceptos, estadísticamente no significativo ( $p$-valor $=0.234)$. El intervalo de confianza que oscila entre [-0.10 y 0.39$]$.

- un efecto nulo ( $r=0.06)$ en la identificación de los requisitos dado que se observa una heterogeneidad en los datos. El efecto es estadísticamente no significativo ( $p$-valor $=0.246$ ) y el intervalo de confianza oscila entre [-0.39 y 0.49$]$.

Mientras que, para el dominio conocido PC1, la experiencia en requisitos tiende a ejercer:

- un efecto nulo ( $r=.09$ ) en la identificación de los procesos, estadísticamente no significativo $(p$-valor $=.872>0.05)$. El intervalo de confianza oscila entre $[-0.34$ y 0.48$]$.

- un efecto positivo pero medio $(r=0.31)$ en la identificación de los conceptos, estadísticamente no significativo ( $p$-valor $=0.149$ ). El intervalo de confianza que oscila entre [-0.12 y 0.64$]$

- un efecto nulo $(r=0.04)$ en la identificación de los requisitos, estadísticamente no significativo ( $p$-valor $=0.872$ ). El intervalo de confianza oscila entre [-0.38 y 0.44$]$.

Los resultados en lo que respecta a la experiencia en entrevistas son esencialmente equivalentes. Estos resultados sugieren tres conclusiones:

1. Los analistas se comportan de forma distinta dependiendo del tipo (conocido/desconocido) del dominio del problema.

2. La experiencia ejerce un efecto diferencial dependiendo del tipo de elementos (procesos, conceptos, requisitos).

3. La experiencia (en este caso, en requisitos) aumenta la efectividad de los analistas en la identificación de los procesos (en dominios desconocidos) y procesos (en dominios conocidos). Respecto a este último, nótese que disponemos de muchos menos estudios para PC1 que para PD1, por lo que las estimaciones de los p-valores son mucho menos precisas.

En el punto 3) es perfectamente compatible con la respuesta dada a RQ1 en esta tesis. Efectivamente, los procesos no son lo único importante en PD1, los conceptos y requisitos juegan un papel relevante. Por este motivo, la efectividad del analista se calcula en conjunto, tal y como se ha justificado en la sección 4.2.1.2. Ello provoca que el efecto positivo de la experiencia en la identificación de los procesos se diluya y no pueda ser identificado en el meta-análisis.

En el caso de PC1, el efecto positivo de la experiencia en la identificación de conceptos si es visible en conjunto (nótese que el coeficiente de correlación asociado, r=0.31, es moderado).

Que los requisitos aparezcan siempre en último lugar, independientemente del tipo de dominio estudiado, no debería parecer sorprendente. El sentido común indica que en las primeras etapas de la educción no deberían estar dominadas por la discusión acerca de la solución a implementar (esto es, los requisitos), sino por una investigación de las características del problema (procesos, conceptos). 
Nuestros resultados son también coherentes con lo observado (Walz, Elam, \& Curtis, 1993), los cuales indican que en las primeras fases de un proyecto, los analistas adquieren fundamentalmente conocimiento acerca del problema a resolver, y no es hasta fases más tardías que prestan atención a los requisitos $\mathrm{y}$ aspectos referidos al diseño del sistema.

\section{d. Modo en que los analistas analizan el dominio del problema}

Llama poderosamente la atención que los sujetos tanto expertos como novatos, en general, tienden a consolidar como máximo alrededor del 50\% de los elementos del dominio (línea azul de la Figura 7.12). Ninguno llega al $100 \%$. No se observa que los sujetos consoliden más conforme aumenten sus años de experiencia, sino que de hecho su efectividad tiende a aproximarse a un promedio del $27 \%-28 \%$, el cual es un valor asombrosamente similar tanto en el dominio conocido como en el desconocido, tal y como se puede apreciar en la Figura 7.12.

Es difícil discernir con exactitud cuál puede ser el motivo de tal "techo de cristal" que impide que los sujetos adquieran más información. La explicación más plausible, en nuestra opinión, es que el "techo de cristal" viene inducido por las características del propio dominio del problema, más concretamente, al modo en que las personas afrontan o estudian esas características.

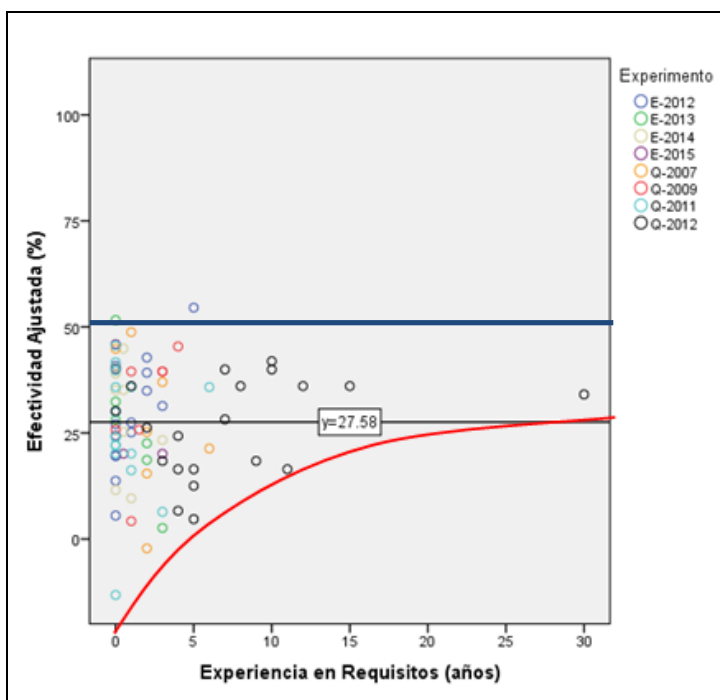

a. PD1

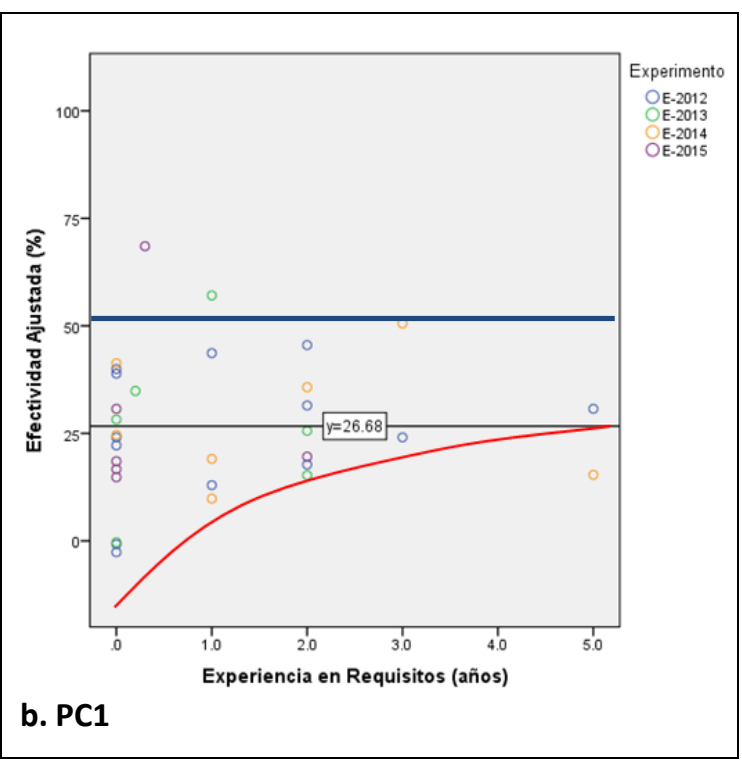

Figura 7.12 - Efecto "techo de cristal" diferenciado por dominio del problema

Los tipos de elementos que conforman el dominio del problema, tienen la probabilidad de ser más o menos visibles (es decir, son más o menos frecuentemente identificados) por los analistas. La visibilidad de los elementos puede calcularse como el número de veces que un elemento concreto es identificado en el conjunto de entrevistas realizadas. Ese valor de visibilidad es incluso tratable a nivel estadístico, aunque ello no será abordado aquí.

En los siguientes gráficos (Figura 7.13 y Figura 7.14), mostramos la visibilidad de cada elemento situado en su posición correspondiente en los modelos de conceptos y procesos. Para facilitar la lectura de dichos gráficos, los elementos se han rodeado por curvas de isoprobabilidad. Los colores cálidos representan a los elementos más visibles y los colores fríos los menos visibles.

Un aspecto que llama la atención en todos los gráficos es que los analistas se focalizan en ciertos aspectos (elementos más visibles) e ignoran otros (elementos menos visibles). Esto ocurre no solo en el diagrama de actividades (procesos), sino que también en el diagrama de conceptos, tal y como se puede apreciar en la Figura 7.14.a (dominio desconocido) y en la Figura 7.14.b (dominio conocido). 


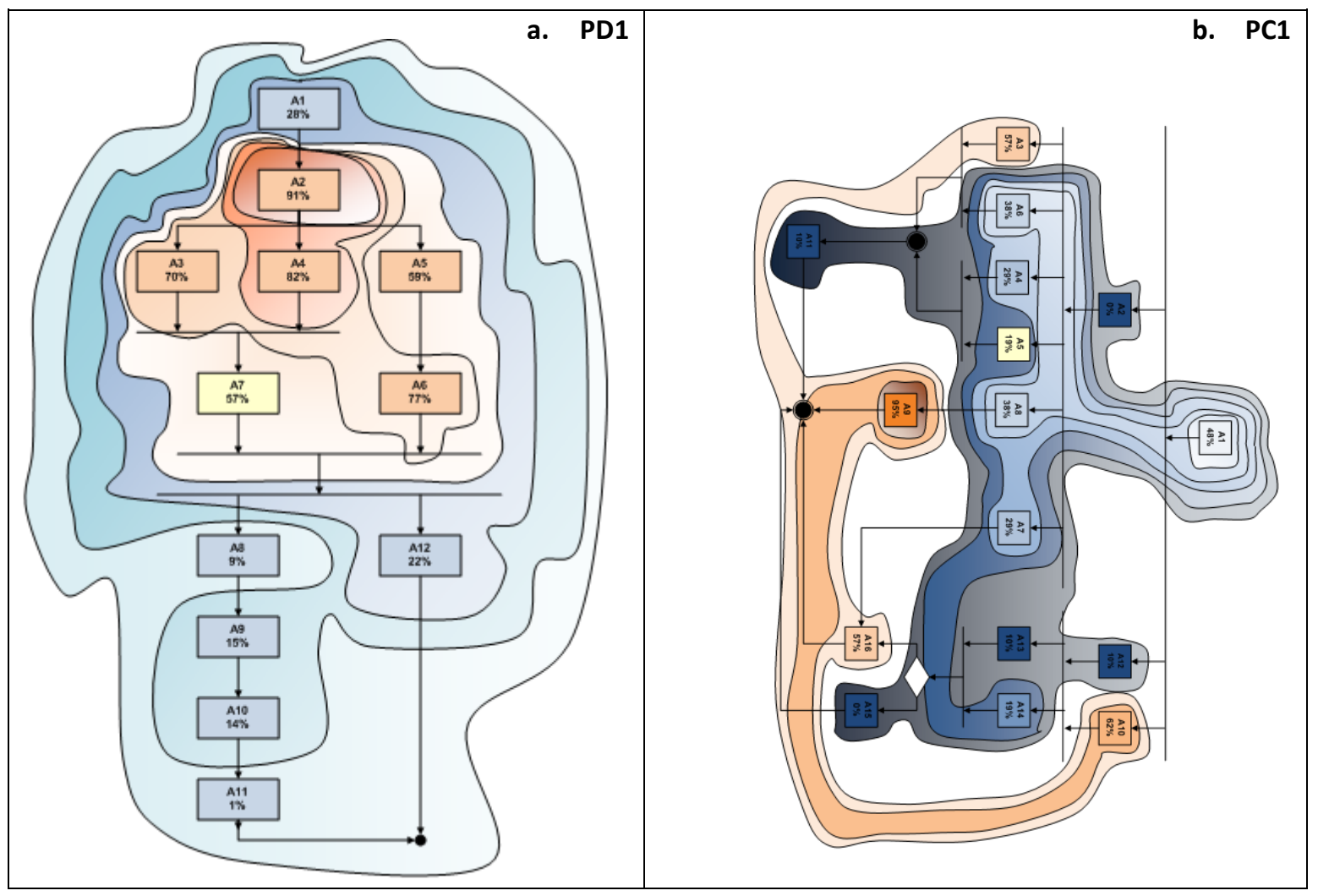

Figura 7.13 - Curvas de isoprobabilidad del diagrama de actividades (PD1, PC1)

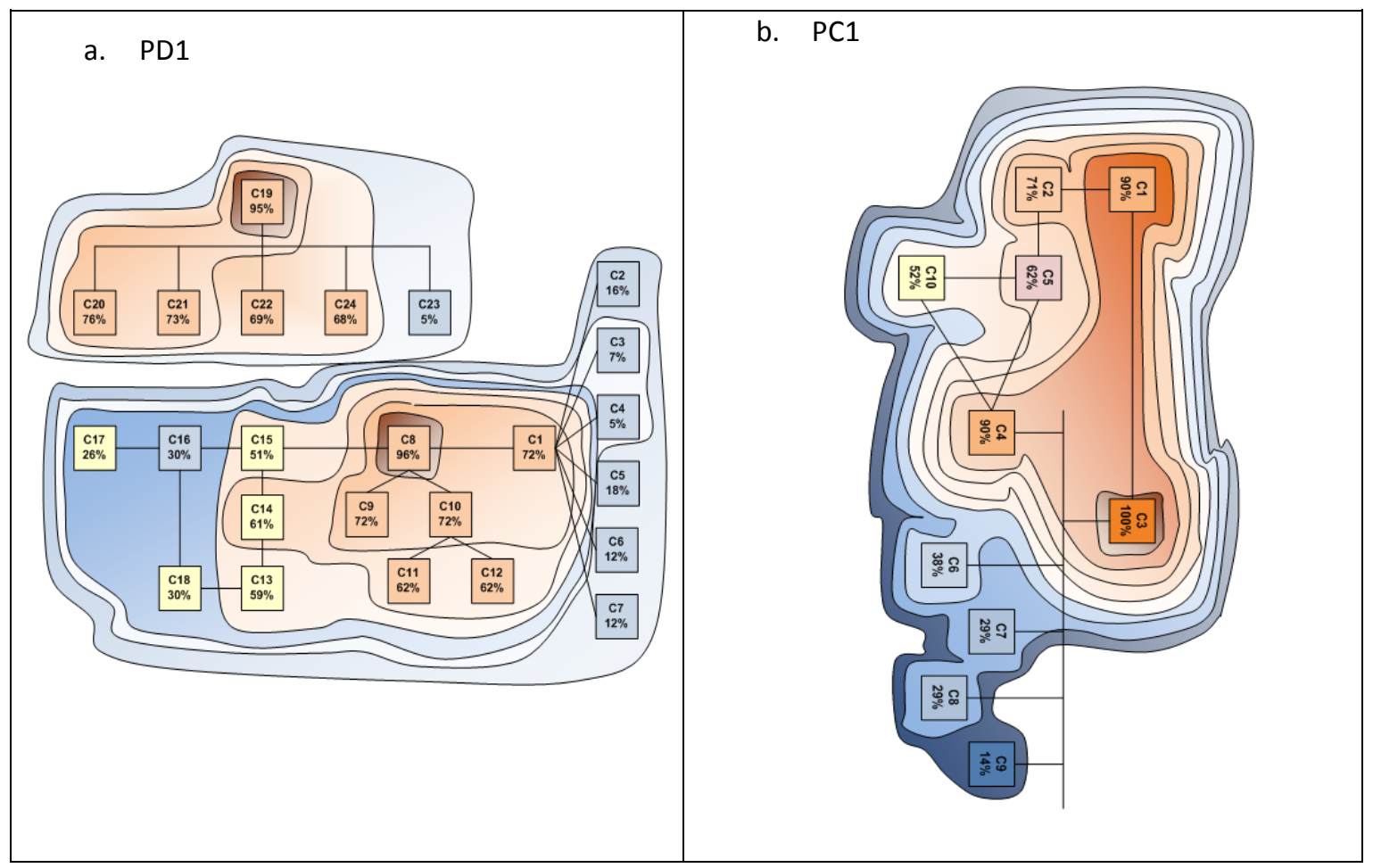

Figura 7.14 - Curvas de isoprobabilidad del diagrama de conceptos (PD1, PC1)

En los diagramas de actividades, la ubicación de los elementos visibles difiere en los dominios conocidos y desconocidos. Creemos que ello se debe a quien ejerce el liderazgo de la sesión de educción (entrevistado o analista). 
El hecho de que los analistas se focalicen en sólo una fracción de los elementos del dominio, ignorando los restantes, explica de modo convincente el fenómeno del techo de cristal, antes indicado. Por qué los analistas se focalizan en sólo unos pocos elementos es una pregunta que no podemos responder. Probablemente, la razón reside en limitaciones cognitivas (ej: la famosa regla de limitación de la memoria a corto plazo a $7 \pm 2$ elementos (Anderson, 2000), actualmente matizada por diversos estudios y/o problemas relacionados con el número y tipo de preguntas realizadas por los analistas.

\section{3 ¿̇nfluye la formación académica en la efectividad del proceso de educción? (RQ3)}

No es posible llegar a conclusiones sólidas respecto a efecto de la formación académica en la efectividad del proceso de educción de los requisitos, debido fundamentalmente a la falta de diversidad en las titulaciones académicas de los sujetos experimentales que han participado de los estudios empíricos. Solo hemos podido explorar el efecto de la titulación académica en dos experimentos ( Q-2007 y Q2012).

Nuestros resultados ponen de manifiesto un efecto positivo significativo en Q-2007, y por el contrario, un efecto negativo no significativo para Q-2012. Nos fiamos más de los resultados obtenidos en Q-2007, por dos motivos: 1) el grupo experimental está más balanceado (3 frente a 4) y 2) los sujetos son más uniformes en lo que respecta a sus años de experiencia. En Q-2012, el grupo está más desbalanceado ( 3 frente 18) y existe mucha más diversidad de experiencias. Es probable que exista algún tipo de interacción de la experiencia por titulación. Es decir, los sujetos con mayores experiencias tienden a hacerlo mejor, pero al poseer mayor edad, podría ocurrir que justamente sus titulaciones sean distintas a la informática.

Aunque esta suposición no podemos probarla, creemos que la titulación académica tiene un efecto positivo en la efectividad de los analistas. Este resultado es consistente con el trabajo de Niknafs (2014), donde la formación académica es un factor que influye positiva y significativamente en la efectividad de educción de los sujetos, esto es, el grupo compuesto por sujetos con formación en ciencias de la computación son más efectivos. Por el contrario, en el área de inspección de requisitos, (Albayrak \& Carver, 2014; Carver et al., 2008) los sujetos no informáticos son más efectivos en la inspección de requisitos.

\subsection{Variables Moderadoras}

El experimento base E-2012 A y su replicación E-2012 B han permitido comprobar estadísticamente los efectos de algunas de las variables moderadoras, como pueden ser el entrevistado y la formación. Los efectos de estas variables pueden comprobarse también utilizando algunos otros de los estudios que hemos realizado; por ejemplo, el efecto del entrevistado puede estudiarse en E-2013 y E-2015.

Además de las variables mencionadas, creemos que el tiempo que los sujetos han empleado en el curso de Ingeniería de Requisitos antes de participar en los estudios empíricos (lo que hemos denominado warming up) puede jercer también un efecto moderador.

En las secciones siguientes resumiremos nuestros hallazgos correspondientes al efecto entrevistado (Sección 7.4.1), a la formación (Sección 7.4.2) y al warming up (Sección 7.4.3). Lamentablemente no podremos comparar con estudios previos de la literatura debido a que, por lo que sabemos, dichas variables moderadoras no han sido explícitamente estudiadas empíricamente.

\subsubsection{Efecto del Entrevistado}

Es ampliamente reconocido que el cliente/usuario juega un papel muy importante durante el proceso de requisitos (Pacheco \& Garcia, 2012; Razali \& Anwar, 2011), sin embargo, en ninguno de los estudios 
incluidos en el estado de la cuestión hace referencia explícita al cliente/usuario como generador de información, esto es, en su papel de entrevistado.

Nuestros datos experimentales (véase la sección 6.1.1.2.1 sobre el ajuste de los datos) indican que, al menos en lo que respecta a la educción temprana de requisitos, la diferencia entre entrevistar a uno $u$ otro entrevistado (en nuestro caso: OD, JW y AG) implica un \% de efectividad entre un $18 \%$ y un $23 \%$ en promedio. Esto equivale a efectos moderados altos según nuestra propia escala de valoración de los tamaños de efecto para las Bs obtenidas en los modelos de regresión.

Los datos indicados provienen del procedimiento de ajuste realizado, pero si observamos los datos crudos (presentados en la Tabla 7.7) la situación no cambia sustancialmente. Los datos presentados en la Tabla 7.7 reflejan las comparaciones directas que se pueden hacer entre OD y JW. La Tabla 7.7 presenta por cada experimento, el tamaño muestral y la efectividad media obtenida por cada entrevistado, tanto en el dominio conocido PC1 como en el desconocido PD1. El efecto del entrevistado (\%), por cada dominio (PC y PD) corresponde a la diferencia de medias entre ambos entrevistados (JWOD).

Tabla 7.7 - Efecto Entrevistado diferenciado por experimento y por dominio del problema

\begin{tabular}{|c|c|c|c|c|c|c|c|c|c|c|}
\hline \multirow{3}{*}{$\begin{array}{l}\text { Experimen } \\
\text { to }\end{array}$} & \multicolumn{4}{|c|}{ OD } & \multicolumn{4}{|c|}{ JW } & \multirow{2}{*}{\multicolumn{2}{|c|}{$\begin{array}{c}\text { \% Efecto } \\
\text { Entrevistado } \\
\text { (JW-OD) }\end{array}$}} \\
\hline & \multicolumn{2}{|r|}{ PC1 } & \multicolumn{2}{|r|}{ PD1 } & \multicolumn{2}{|r|}{ PC1 } & \multicolumn{2}{|r|}{ PD1 } & & \\
\hline & $\mathrm{N}$ & Media (\%) & $\mathrm{N}$ & Media (\%) & $\mathrm{N}$ & Media (\%) & $\mathrm{N}$ & Media (\%) & PC & PD \\
\hline E-2012 & 7 & 28.04 & 7 & 24.93 & 7 & 47.88 & 7 & 50.98 & 19.84 & 26.05 \\
\hline E-2013 & 3 & 16.67 & 5 & 28.63 & 4 & 46.30 & 3 & 44.44 & 29.63 & 15.82 \\
\hline E-2015 & 5 & 26.67 & 3 & 43.79 & 3 & 48.77 & 2 & 45.10 & 22.10 & 1.31 \\
\hline
\end{tabular}

Debemos señalar que en nuestro experimento existe una confusión entrevistado -idioma, por lo que dicha diferencia puede explicarse en parte por el hecho de que la entrevista haya sido realizada en lengua nativa o extranjera. En cualquier caso, la diferencia de efectividad observada (entorno al 20\%) indica que aspectos aparentemente accidentales del proceso de educción (como puede ser el idioma o la propia persona a la que se entrevista) pueden jugar un papel tan importante, o más, que los aspectos aparentemente esenciales (por ejemplo, el conocimiento del analista).

\subsubsection{Efecto de la Formación}

El efecto de la formación hace referencia al hecho de si los sujetos han recibido formación específica o no en requisitos, antes de participar en el estudio empírico. En nuestros estudios (ver sección 6.1.1.2) hemos obtenido que el efecto de la formación es de un $12 \%$ (un efecto moderado de acuerdo a la escala que nosotros mismos hemos definido).

El estudio donde mejor se observa el efecto de la formación es E-2012. En E-2012 A, el experimento se realizó antes de que los sujetos recibieran formación en requisitos (es decir, antes del inicio del curso académico). La replicación del experimento realizada (E-2012B) al final del curso de requisitos arrojó un efecto de la formación (calculada mediante el modelo mixto, véase sección 6.2.1.1) de un 20\%, independientemente del entrevistado y dominio (conocido o desconocido) tratados.

Este valor, comparado con el obtenido mediante el procedimiento de ajuste, es ligeramente mayor. Esto podría explicarse, en parte, por el hecho de que el dominio del problema PC2, es probablemente, demasiado sencillo en comparación con el dominio PC1, lo que provoca a su vez que los promedios sean más altos. En cualquier caso, parece lógico concluir que la formación en requisitos aumenta considerablemente la efectividad de los analistas, al menos para la población de conveniencia utilizada (estudiantes de máster, con poca experiencia profesional). 
Una posible objeción al efecto del aprendizaje (más de índole metodológico y de crítica científica que por verdadero convencimiento, ya que pocos dudarán de los efectos beneficiosos de la formación) sería el riesgo de que el profesor del curso sesgase el proceso formativo (no necesariamente de forma consciente) de modo que los alumnos tuvieran un desempeño mayor durante la replicación, pero no necesariamente en otro proceso de educción (por ejemplo, un experimento ejecutado por investigadores independientes, o una entrevista real). Es innegable que dicho sesgo es plausible. No obstante, el carácter de medidas repetidas de las dos replicaciones experimentales permite calcular la mejora de los sujetos no sólo entre antes y después de la formación en requisitos, sino también entre sesiones de educción (es decir.: variable Sesión, que aparece explícitamente en la tabla 6.17 del capítulo 6, sección 6.2.1.1). Entre sesiones no se produce ningún proceso formativo y, por lo tanto, cualquier diferencia debe trazarse a la mayor efectividad que consigue el analista por mera realización de entrevistas (o lo que es lo mismo, por el entrenamiento recibido en el trabajo). La mejora en la efectividad de los analistas entre sesiones supera el $9 \%$ en promedio, lo cual es un valor muy elevado, comparable al propio efecto del conocimiento (que es también aproximadamente del 9\%). Esto implica que al menos el training ( $y$ es más que posible que la formación también) ejercen un efecto muy beneficioso, y casi inmediato, en la efectividad de los analistas.

\subsubsection{Efecto del Warming up}

El efecto de warming up consiste en una formación breve en actividades relacionadas con requisitos. La diferencia con la variable moderadora formación indicada anteriormente reside en que esta última es esencialmente una variable binaria (con los valores antes y después). El warming up, por el contrario, hace referencia a la duración de la formación breve, que en nuestro caso oscila de 0 a 6 semanas.

Utilizando el procedimiento de ajustes descrito en la sección 6.1.1.2.1, hemos obtenido los siguientes efectos asociados al warming up: $1 \%$ para una semana, $7 \%$ para dos y $10 \%$ para 6 semanas. Al igual que las variables moderadoras anteriores, el efecto warming up puede estimarse a partir de los datos crudos (presentados en los gráficos de dispersión de la Figura 7.15). Los gráficos de la Figura 7.15 presentan por cada dominio del problema, el warming up por semanas, frente a la efectividad de la consolidación, diferenciado por entrevistado.

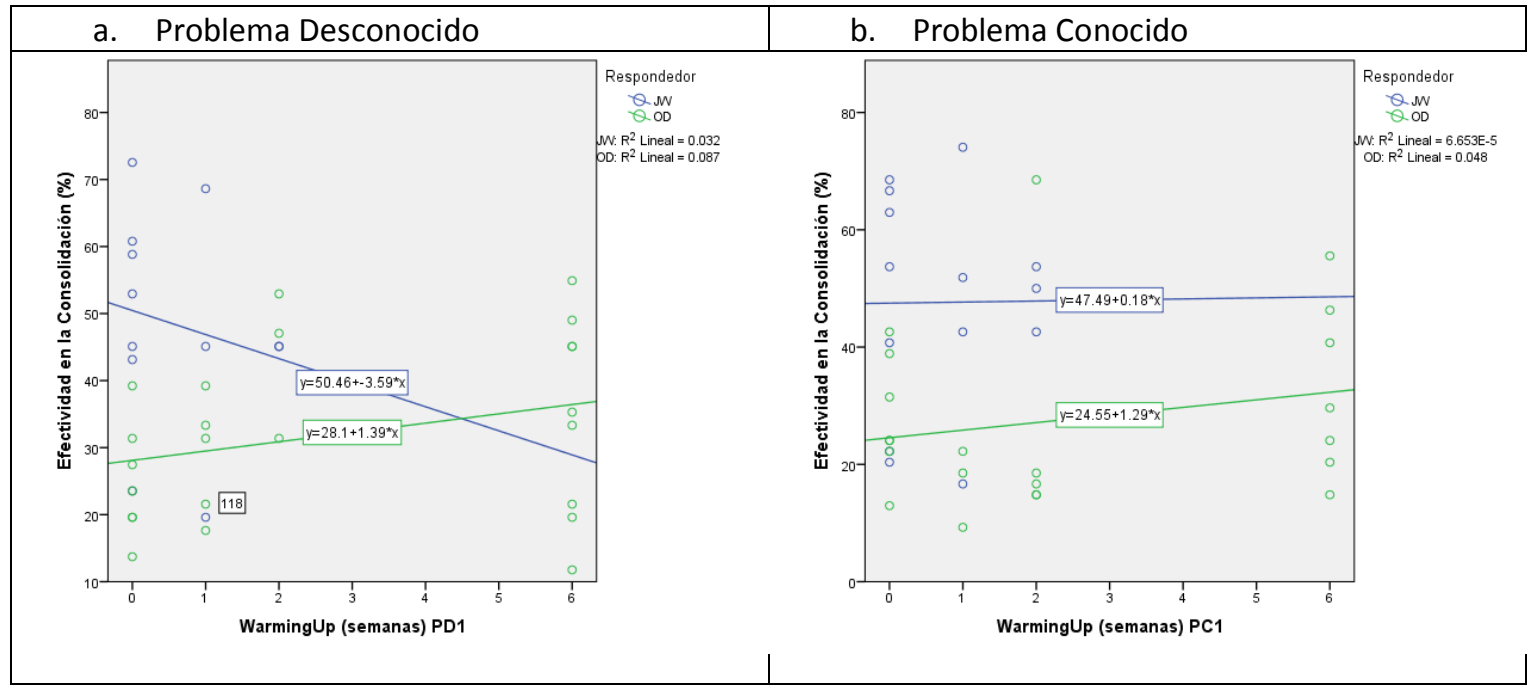

Figura 7.15 - Efecto warming up diferenciado por dominio del problema

Los efectos de warming up tanto para PD1 como PC1, diferenciados por entrevistado, pueden ser obtenidos calculando la recta de regresión. Dichos efectos se resumen en la Tabla 7.8. 
Tabla 7.8 - Efecto warming up diferenciado por dominio del problema y entrevistado

\begin{tabular}{|l|r|r|r|r|}
\hline \multirow{2}{*}{ WARMING UP } & \multicolumn{2}{|c|}{ PC1 } & \multicolumn{2}{|c|}{ PD1 } \\
\cline { 2 - 5 } & JW & OD & JW & OD \\
\hline 1 semana & $0.18 \%$ & $1.29 \%$ & $-3.59 \%$ & $1.39 \%$ \\
2 semanas & $0.36 \%$ & $2.58 \%$ & $-7.18 \%$ & $2.78 \%$ \\
6 semanas & - & $7.74 \%$ & - & $8.34 \%$ \\
\hline
\end{tabular}

Como se puede observar, los resultados son muy similares a los obtenidos con el procedimiento de ajuste. Los resultados de la figura anterior muestran un posible efecto en la efectividad de los analistas, con la posible excepción de JW para el problema desconocido. En este caso, en nuestra opinión, no es que el efecto warming up no exista, sino que el reducido número de puntos de datos que disponemos afecta dramáticamente al cálculo del efecto del warming up. A modo ilustrativo, la Figura 7.16 muestra el cálculo del warming up para el problema desconocido eliminando los 3 sujetos menos efectivos para el entrevistado JW. Sólo eliminando estos tres casos el efecto warming up es claramente visible, evidenciando los efectos perniciosos de las pequeñas muestras.

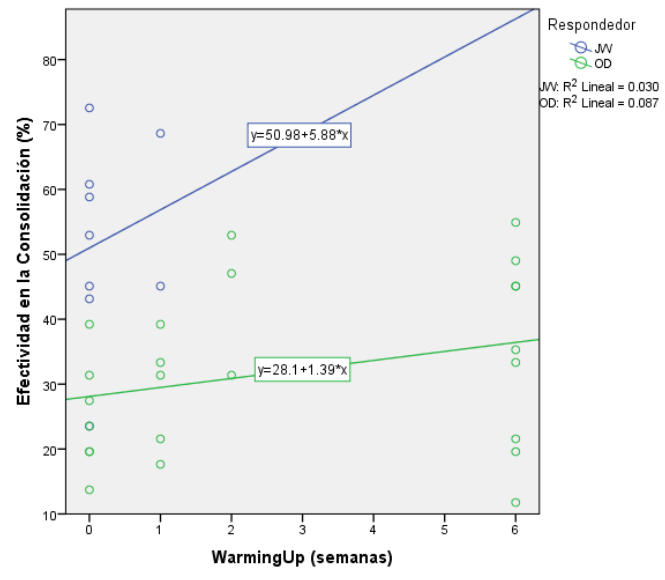

Figura 7.16 - Ejemplo efecto warming up positivo - PD1

\subsection{Medición utilizando variables subjetivas y objetivas}

Como hemos indicado a lo largo de la investigación, tanto la Experiencia como el Conocimiento fueron operacionalizados mediante una métrica objetiva (años de experiencia) y otra subjetiva (una escala de Likert que refleja la percepción del sujeto sobre su experiencia o conocimiento).

En esta sección, con la finalidad de mostrar que el tipo de métrica utilizada para medir los efectos de una variable puede influir en los resultados, compararemos los resultados obtenidos tanto para el constructo EXPERIENCIA (sección 7.6.1) como para el constructo CONOCIMIENTO DEL DOMINIO (sección 7.6.2).

\subsubsection{Experiencia vs Habilidad}

La Tabla 7.9 presenta por cada dominio del problema, el efecto y significación de la EXPERIENCIA obtenido mediante el meta-análisis de los datos individuales y agregados. Dada la diferencia en fiabilidad de los análisis realizados, la presencia de un sesgo en los resultados se observan mejor en el meta-análisis de datos individuales. En el meta-análisis de los datos agregados, las diferencias entre las métricas son menos observables, por el hecho de que las diferencias existentes entre el tamaño muestral de los experimentos, hace que los efectos tiendan hacia la dirección de aquellos experimentos de mayor tamaño. Por tanto, discutiremos los resultados empleando los resultados obtenidos mediante el metaanálisis de los datos individuales. 
Como se puede apreciar en la Tabla 7.9, al comparar los resultados, en todos los casos, las correlaciones estimadas mediante habilidades tienden a obtener valores muchos más bajos que las correlaciones calculadas mediante experiencia en años. Este hecho pone de manifiesto que las variables medidas objetivamente tienden a obtener valores, aunque muy levemente, superiores que las variables medidas subjetivamente.

En nuestro caso, este hecho se observa claramente en el PC1. Por ejemplo, en la Tabla 7.9 para el PC1, la experiencia en entrevistas ejerce una influencia positiva moderada $(r=.34)$ en la efectividad, mientras que la habilidad en entrevistas un efecto muy bajo, nulo a efectos prácticos ( $r=0.06)$. En la misma línea, la experiencia en requisitos ejerce un efecto positivo bajo $(r=.22)$, mientras que la habilidad en requisitos un efecto nulo ( $r=.07)$.

Para el dominio PD1 también se observa un sesgo entre la efectividad y la habilidad, aunque en menor grado, dado que dichas variables ejercen un efecto nulo en la efectividad (como hemos comprobado en la sección de síntesis).

Tabla 7.9 - Relación de la efectividad del analista con la experiencia y la habilidad en entrevistas y requisitos

\begin{tabular}{|c|c|c|c|c|c|c|c|c|c|}
\hline \multirow{2}{*}{$\begin{array}{c}\text { DOMINIO } \\
\text { DEL } \\
\text { PROBLEMA }\end{array}$} & \multirow[t]{2}{*}{$\begin{array}{l}\text { META- } \\
\text { ANÁLISIS }\end{array}$} & \multicolumn{2}{|c|}{$\begin{array}{c}\text { EXPERIENCIA } \\
\text { EN } \\
\text { ENTREVISTAS }\end{array}$} & \multicolumn{2}{|c|}{$\begin{array}{c}\text { HABILIDAD } \\
\text { EN } \\
\text { ENTREVISTAS }\end{array}$} & \multicolumn{2}{|c|}{$\begin{array}{l}\text { EXPERIENCIA } \\
\text { EN REQUISITOS }\end{array}$} & \multicolumn{2}{|c|}{$\begin{array}{c}\text { HABILIDAD } \\
\text { EN } \\
\text { REQUISITOS }\end{array}$} \\
\hline & & $r$ & Sig. & $r$ & Sig. & $r$ & Sig. & $\mathbf{R}$ & Sig. \\
\hline \multirow{2}{*}{ PD1 } & $\begin{array}{l}\text { Datos } \\
\text { Individuales }\end{array}$ & .08 & .500 & -.03 & .789 & .05 & .707 & -.03 & .783 \\
\hline & $\begin{array}{l}\text { Datos } \\
\text { Agregados }\end{array}$ & .09 & .461 & .03 & .813 & .09 & .689 & .05 & .751 \\
\hline \multirow{2}{*}{ PC1 } & $\begin{array}{l}\text { Datos } \\
\text { Individuales }\end{array}$ & .34 & .080 & .06 & .693 & .22 & .270 & .07 & .761 \\
\hline & $\begin{array}{l}\text { Datos } \\
\text { Agregados }\end{array}$ & .16 & .484 & .11 & .623 & .12 & .583 & .15 & .508 \\
\hline
\end{tabular}

La relevancia de los datos empíricos presentados en la tabla anterior reside en que ambas variables (experiencia y habilidad) representan distintas operacionalizaciones del mismo constructo (la EXPERIENCIA ya sea en requisitos o en entrevistas), pero su análisis arroja resultados distintos. Según nuestros datos, un estudio empírico que utilizase la variable Experiencia concluiría que existe una clara relación con la efectividad, mientras que otro que utilizase la Habilidad concluiría que dicha relación es inversa, baja o, en el peor de los casos, que no existe; esto es: el resultado de una investigación acerca de la influencia de la EXPERIENCIA en la efectividad del analista dependería de la operacionalización (Experiencia o Habilidad) que se utilizase. En nuestra opinión, el motivo por el cual la variable Habilidad no consigue predecir la efectividad reside en que las personas valoran sus habilidades en general por encima de lo que su experiencia sugiere.

Por ejemplo, la Figura 7.17 presenta un gráfico de box, donde el eje de abscisas representa la habilidad en requisitos (menor a mayor habilidad) y el eje de ordenas los años de experiencia. Como se puede apreciar en el gráfico, los sujetos que reportan tener habilidades medias (3) en requisitos, tienen muy pocos años de experiencia entre 0 y 2 años, o sujetos que mencionan tener más habilidades (4) en realidad poseen entre uno y dos años de experiencia. Se observa claramente, como los sujetos tienden a sobrevalorar sus experiencias. 


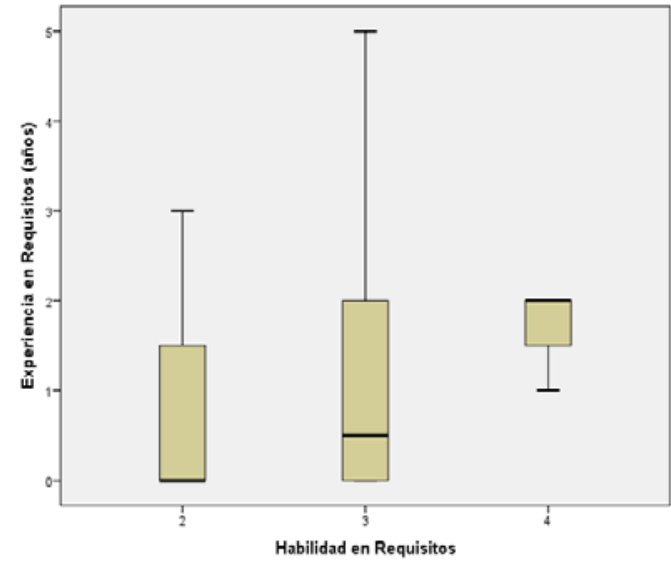

Figura 7.17 - Ejemplo sobrevaloración de la experiencia en requisitos

En resumen, parece claro que el modo de medición de las variables (objetiva o subjetiva) ejerce una marcada influencia en los resultados de los estudios empíricos. Nuestros resultados, en lo que respecta al constructo EXPERIENCIA, apuntan hacia un sesgo (bias) negativo de las métricas subjetivas frente a las objetivas, tanto en el dominio del problema conocido como en el desconocido. Por tanto, las variables medidas subjetivamente tienden a estar expuestas a sesgos que pueden provocar resultados incorrectos o con menor precisión.

\subsubsection{Conocimiento vs Familiaridad}

Antes de presentar los resultados, conviene indicar que la familiaridad la hemos analizado diferenciado por dominio del problema, debido que a que en E-2012 la familiaridad, al no ser un factor, no es posible analizarla mediante un modelo de medidas repetidas o modelo mixto.

Nuestros resultados para el dominio desconocido PD1, muestran un efecto negativo bajo $(r=-0.15)$ de la familiaridad en la efectividad, mientras que para el dominio conocido PC1 un efecto nulo ( $r=0.05)$, en ambos casos no significativos, tal y como se puede apreciar en la Tabla 7.10.

Tabla 7.10 - Efecto de la familiaridad diferenciado por dominio del problema

\begin{tabular}{|c|l|c|r|}
\hline \multirow{2}{*}{ DominIO } & \multirow{2}{*}{ MetA-ANÁLISIS } & \multicolumn{2}{|c|}{ FAMILIARIDAD } \\
\cline { 3 - 4 } & & $\mathbf{d}$ & \multicolumn{1}{|c|}{ Sig. } \\
\hline \multirow{2}{*}{ PD1 } & Datos Individuales & -.15 & .524 \\
\cline { 2 - 4 } & Datos Agregados & -.14 & .648 \\
\hline \multirow{2}{*}{ PC1 } & Datos Individuales & .058 & .876 \\
\cline { 2 - 4 } & Datos Agregados & 0.08 & .834 \\
\hline
\end{tabular}

Por el contrario, el conocimiento (variable objetiva) tiende a ejercer un efecto moderado positivo $(r=0.31)$ estadísticamente significativo, tal y como se puede apreciar en la Tabla 7.11.

Tabla 7.11 - Efecto del conocimiento (meta-análisis)

\begin{tabular}{|l|l|l|l|}
\hline \multicolumn{2}{|c|}{ MetA-ANÁLISIS } & \multicolumn{2}{c|}{ CONOCIMIENTO } \\
\cline { 2 - 4 } & d & Sig. \\
\hline \multirow{2}{*}{ Datos Individuales } & within & .60 & .044 \\
\cline { 2 - 4 } & between & -.29 & .354 \\
\hline \multirow{2}{*}{ Datos Agregados } & .31 & .029 \\
\hline
\end{tabular}

Nótese que al igual que el constructo Experiencia, observamos que los efectos de la familiaridad (variable subjetiva) están sesgados negativamente. Es decir, en todos los casos los valores de las d's correspondientes son menores que la d's del conocimiento. Creemos que esto ocurre por el hecho de 
que los sujetos sobre valoran su familiaridad acerca del dominio, es decir, manifiestan conocer más el dominio del problema de lo que realmente conocen.

En conclusión, con los ejemplos y análisis anteriores hemos intentado demostrar que las variables cuyos valores se pueden establecer de manera objetiva (en nuestro caso, la experiencia y el conocimiento del dominio) generan resultados más precisos que los subjetivos (la habilidad y la familiaridad). Aunque nuestros resultados no son conclusivos, creemos que los estudios que utilizan predominantemente variables medidas subjetivamente, como las encuestas de opinión o la adquisición de opinión de expertos, deben tomar las precauciones oportunas para evitar sesgos que puede dar lugar a resultados incorrectos.

\subsection{Observaciones del tipo metodológico}

En la sección anterior, hemos discutido el impacto que tiene sobre los resultados la utilización de variables objetivas o subjetivas para medición de constructos. No obstante, el tipo de variable no es la única circunstancia que puede alterar los resultados. La experiencia que hemos adquirido en esta investigación indica que el tipo de diseño experimental y tamaño muestral utilizado ejerce también una influencia considerable.

\subsubsection{Diseño experimental}

Una de las diferencias fundamentales de nuestros experimentos reside en el diseño experimental utilizado. Nótese que en E-2012 hemos empleado un diseño de medidas repetidas (within-subjects) y en los experimentos siguientes (E-2013, E-2014 y E-2015) un diseño between-subjects.

En E-2012 con 14 sujetos, gracias al diseño within-subjects, hemos conseguido 54 unidades experimentales, lo que permitió aumentar el poder estadístico y en consecuencia obtener resultados estadísticamente significativos. Empleando tres experimentos between-subjects (E-2013, E-2014 y E2015) con 15, 16 y 13 sujetos experimentales respectivamente, hemos conseguido en total 44 sujetos equivalente a 44 unidades experimentales. Sin embargo los resultados obtenidos no alcanzaron la significación estadística, probablemente en parte debido al bajo poder estadístico de los mismos.

Es importante tener en cuenta que las conclusiones de una investigación dependen en gran medida de la buena elección del diseño experimental. Por tanto, bajo nuestra experiencia, para experimentos con tamaños muestrales reducidos conviene escoger diseños que permitan incrementar el poder estadístico. En nuestra opinión, si bien el modelo de medidas repetidas introduce ciertas amenazas a la validez en los resultados, permite obtener resultados más fiables que los experimentos betweensubjects, empleando un menor tamaño muestral y alcanzando un mayor poder estadístico.

\subsubsection{Tamaño muestral}

En pequeñas muestras (nótese que una pequeña muestra puede ser tan alta como 150 sujetos (Hoyle, 1999), aunque 50 sujetos es una cifra probablemente más ajustada (Graham \& Schafer, 1999; Richy, Ethgen, Bruyere, Deceulaer, \& Reginster, 2004)), es muy frecuente observar efectos en cualquier dirección simplemente por error (Richy et al., 2004). Esto es justamente lo que nos ha ocurrido en la serie de experimentos sobre la experiencia.

En nuestro caso, al comparar los efectos obtenidos en los estudios individuales, no se observa un efecto claro de la variable bajo estudio en la efectividad. Por ejemplo, el efecto de la experiencia en requisitos para el problema desconocido (ver Anexo F), en algunos casos es positivo, en otros negativo e incluso nulo. Esta variabilidad puede deberse a las pequeñas muestras, ya que un punto de dato singular puede cambiar radicalmente el efecto. Por tanto, separadamente los estudios individuales no llegan a identificar correctamente el resultado final conjunto. 
Lo anterior pone de manifiesto que es muy importante utilizar un tamaño muestral adecuado para la obtención de conocimiento empírico. Durante el diseño experimental es imperativo realizar un análisis de poder estadístico que nos informe de las posibilidades de detectar un determinado tamaño de efecto. Si disponemos de pocos sujetos, será necesario replicar el experimento el número suficiente de veces y sintetizar los resultados para alcanzar errores tipo II razonables, en lugar de extraer conclusiones a partir de los experimentos individuales por separado. Nótese que la síntesis debe ser formal, ya sea meta-análisis o ANOVA bloqueada, o cualquier procedimiento equivalente. Un vote counting clásico (esto es, contar cuantos experimentos han generado resultados en una u otra dirección) arrojaría resultados erróneos. Por ejemplo, para ambos dominios del problema (conocido y desconocido) el vote counting arroja que la experiencia no posee efecto alguno, lo cual como hemos observado en los meta-análisis individual y agregado es incorrecto, en el caso del dominio conocido.

\subsubsection{Dicotomización}

Una práctica habitual en el procesamiento de los datos es la categorización o dicotomización de variables de naturaleza continua. Por ejemplo, el rendimiento académico frente a un examen puede evaluarse como una escala cuantitativa del 0 al $10 \mathrm{y}$ posteriormente dicotomizarse, registrando únicamente si el sujeto ha aprobado o suspendido.

Sin embargo, uno de los aspectos más controvertidos de la categorización de variables es la elección de los puntos de cortes utilizados (MacCallum, Zhang, Preacher, \& Rucker, 2002). Escoger un punto de corte $u$ otro puede alterar sustancialmente los resultados. Por ejemplo, empleando los datos de nuestra investigación, evaluaremos la relación entre la experiencia en requisitos y la efectividad de los analistas usando distintos puntos de corte para los valores de la experiencia. Los datos que utilizamos son los de Q-2012 ya que es el estudio con más sujetos experimentales. La Figura 7.18 muestra los efectos de la experiencia en función de si el punto de corte escogido es de 2, 4 o 5 años. Para un punto de corte de 2 años (esto es, los sujetos con menos años de experiencia son considerados novatos, y con más de dos expertos), se observa un efecto negativo de la experiencia. Para 4 años el efecto tiende a ser neutro y finalmente, para 5 años el efecto tiende a ser positivo.

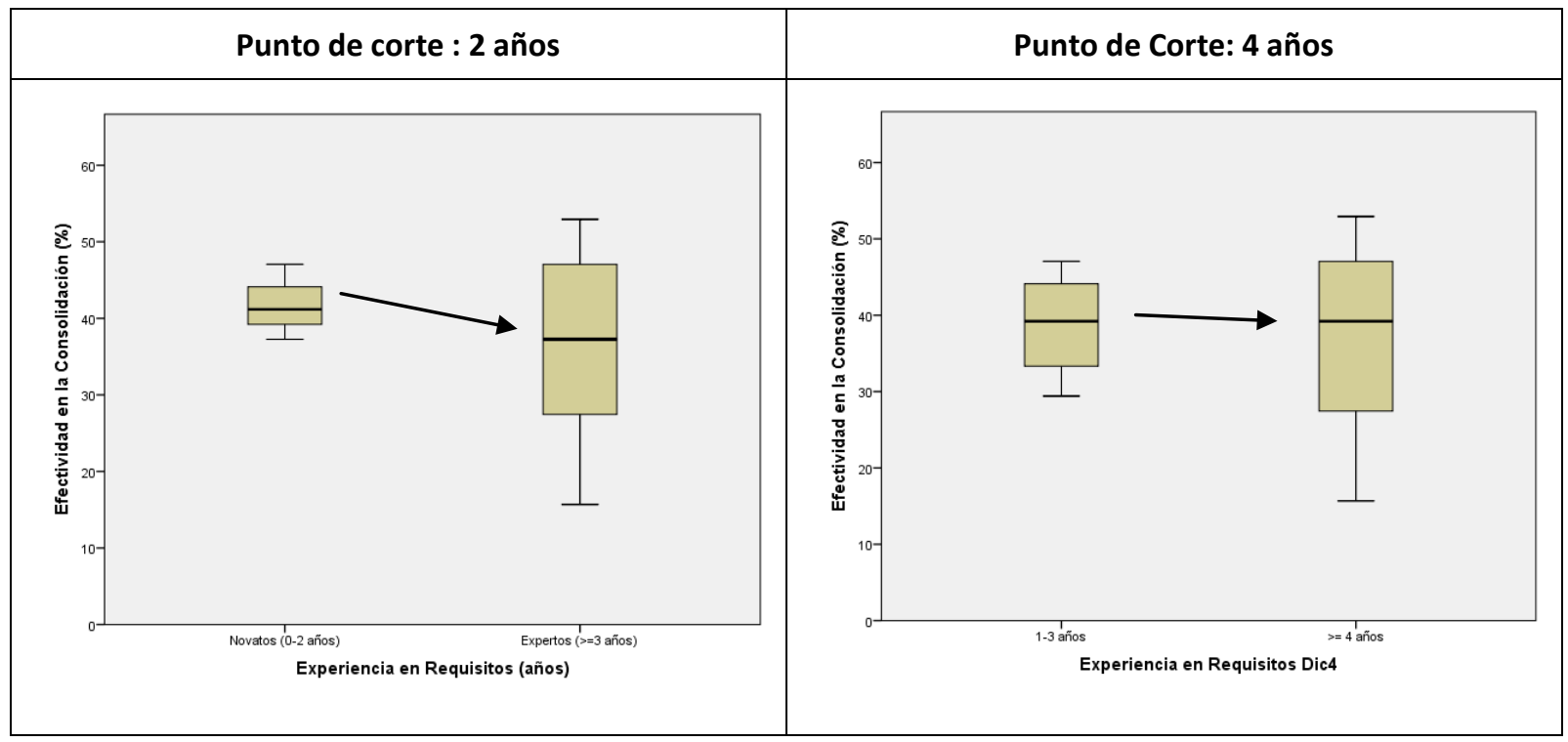




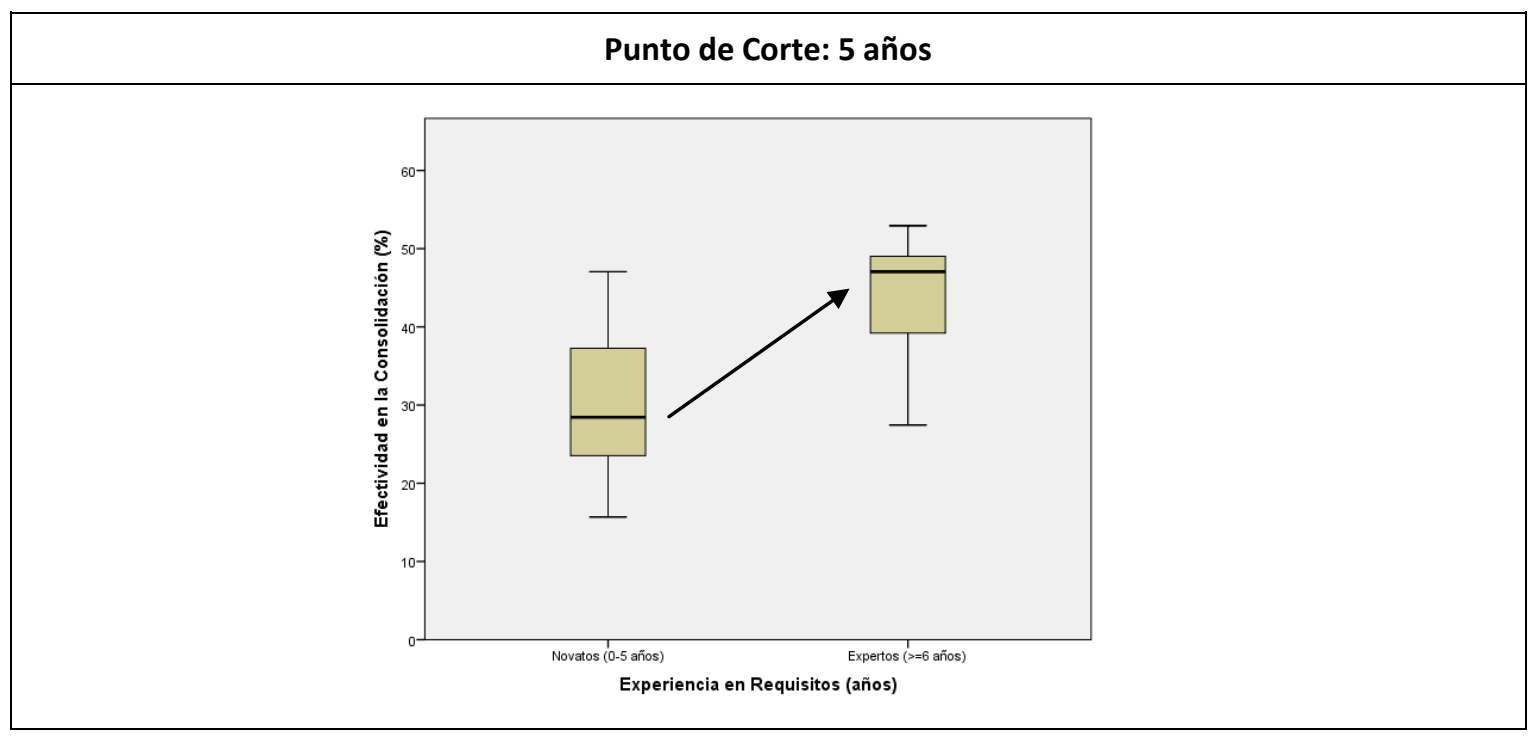

Figura 7.18 - Efectos de la experiencia en función del punto de corte escogido

La percepción visual se puede comprobar estadísticamente mediante la prueba de t-test, que compara si la diferencia de dos grupos es significativa. En la Tabla 7.12 se puede apreciar un efecto claramente negativo de la experiencia cuando el punto de corte está entre 2 años. Para 4 años el efecto sigue siendo negativo, pero más bajo y muy lejos de la significación. Para 5 años el efecto es claramente positivo. No se obtienen efectos significativos en ningún caso, aunque los p-valores son bajos para el 1 으 y 3 o puntos de corte.

Tabla 7.12 - Efecto de la Experiencia de requisitos en función de los puntos de corte

\begin{tabular}{|c|c|c|c|c|c|c|}
\hline EXPERIMENTO & $\begin{array}{c}\text { PUNTO DE } \\
\text { CORTE }\end{array}$ & $\mathbf{N}$ & $\begin{array}{c}\text { EFECTIVIDAD } \\
\text { MEDIA (\%) }\end{array}$ & $\mathbf{t}$ & $\begin{array}{l}\text { SIG. } \\
\text { T-TEST }\end{array}$ & $\begin{array}{l}\text { EFECTO } \\
\text { EXPREO }\end{array}$ \\
\hline \multirow{2}{*}{$\begin{array}{c}\text { Q-2012 } \\
\text { (2 años) }\end{array}$} & ExpReq $>=2$ & 19 & 36 & \multirow{2}{*}{-.923} & \multirow{2}{*}{.366} & \multirow{2}{*}{$(-)$} \\
\hline & ExpReq $<2$ & 2 & 44 & & & \\
\hline \multirow{2}{*}{$\begin{array}{c}\text { Q-2012 } \\
\text { (4 años) }\end{array}$} & ExpReq $>=4$ & 17 & 37 & \multirow{2}{*}{-.319} & \multirow{2}{*}{.753} & \multirow{2}{*}{$(-)$} \\
\hline & ExpReq $<4$ & 4 & 39 & & & \\
\hline \multirow{2}{*}{$\begin{array}{l}\text { Q-2012 } \\
\text { (5 años) }\end{array}$} & ExpReq $>=5$ & 14 & 39 & \multirow[b]{2}{*}{.992} & \multirow[b]{2}{*}{.334} & \multirow[b]{2}{*}{$(+)$} \\
\hline & ExpReq $<5$ & 7 & 34 & & & \\
\hline
\end{tabular}

En consecuencia, podemos afirmar que las conclusiones de una investigación están estrechamente vinculadas con las estrategias de análisis aplicadas y el procesamiento de los datos anterior a dicho análisis. En bien es cierto que la dicotomización puede ser un método útil que nos permite realizar comparaciones entre grupos y facilita la interpretación de los resultados. Sin embargo los resultados pueden ser menos fiables, dado que se pierde información de los datos originales. Es más, como hemos mostrado, la dicotomización puede afectar muy fuertemente a los cuasi-experimentos, porque dependiendo de los puntos de corte, éstos pueden provocar grandes diferencias. Es importante elegir y justificar bien los puntos de corte utilizados al dicotomizar, dado a que las conclusiones y tendencias podrían variar.

Es importante mencionar que el análisis original que se reporta en el artículo del INTEAMSE'12 (A. Aranda et al., 2012) utiliza la dicotomización en las variables independientes experiencia y familiaridad. Dichas variables dicotomizadas se han usado para generar los gráficos de box-plots y test estadísticos. Actualmente, consideramos que parte de los resultados reportados en ese artículo son discutibles. 


\section{CAPÍTULO 8}

\section{AMENAZAS A LA VALIDEZ}

El presente capítulo tiene como propósito presentar al lector un resumen de las principales amenazas a la validez de los resultados de la presente investigación. Algunos aspectos ya han sido discutidos y se han planteado las correspondientes estrategias de mitigación durante el mismo diseño de los experimentos. En este capítulo describiremos aquellas amenazas más generales que no han podido ser afrontadas durante el diseño. Wohlin et al. (2012) agrupan los diferentes tipos de amenazas en cuatro categorías. Amenazas a la validez de la conclusión estadística (Sección 8.1): se refieren a aspectos que pueden producir que las conclusiones obtenidas acerca de la relación entre la variable independiente y la variable respuesta no sean estadísticamente válidas; Amenazas a la validez interna (Sección 8.2): corresponden a aquellos aspectos que amenazan la relación causa-efecto entre las variables independientes y dependiente; Amenazas a la validez de constructo (Sección 8.3): se refieren a aspectos que pueden influir negativamente en la relación que hay entre la teoría y la observación; Amenazas a la validez externa (Sección 8.4): estas amenazas referencian aspectos que pueden limitar la generalización de los resultados del experimento a otros contextos.

Nótese que seguimos fundamentalmente Wohlin porque es frecuentemente usado en IS. Wohlin se basa en Cook y Campbell (1979), aunque una nueva versión, más moderna, de amenazas ha sido publicada en Shadish, Cook T., y Campbell D.T. (2001). Por tanto, donde Wohlin no sea suficiente (e.g.: amenazas a la validez externa), usaremos ésta última.

\subsection{Amenazas a la validez de conclusión estadística}

La validez de conclusión estadística define en qué medida las conclusiones obtenidas son estadísticamente válidas. Corresponde al grado de confianza que se puede tener, dado un nivel determinado de significación estadística, en la correcta inferencia sobre las hipótesis.

- Bajo Poder Estadístico: El poder o potencia estadística es la probabilidad de rechazar la hipótesis nula cuando la hipótesis alternativa es cierta. Cuando no se elige adecuadamente el 
nivel de significación estadística y, sobre todo, el tamaño muestral, se puede concluir de forma incorrecta que la relación entre la variable independiente y la dependiente no existe cuando en realidad si la hay. Es lo que se denomina un error tipo II.

- La principal amenaza a la validez de los resultados tiene relación directa con el tamaño muestral. El reducido tamaño muestral de los experimentos analizados por separado puede por sí solo provocar la falta de significación estadística en los resultados individuales. Para mitigar esta amenaza hemos replicado tanto los cuasi-experimentos como los experimentos.

- Para el estudio de la experiencia en dominio de problemas desconocidos, según nuestros cálculos son necesarios 84 sujetos experimentales. Hemos conseguido recolectar información de 84 sujetos. Los meta-análisis (tanto de medidas individuales como de agregadas) incorporan información de entre 69 y 84 sujetos. En consecuencia, creemos que para esta parte de nuestra investigación no debería ocurrir un error de Tipo II.

- Para el estudio de la experiencia en dominios de problemas conocidos, se necesita la misma cantidad de sujetos que en el caso anterior. En total hemos recolectado información de 32 sujetos, lo que es claramente insuficiente. Esto puede comprobarse observando los p-valores asociados a los distintos tipos de experiencias en el análisis mostrado en la sección 7.1.2.1.1 todos ellos son no significativos, aunque en varios casos están muy cercanos a la significación. En nuestra opinión, dichos p-valores bajos son resultados de un error tipo II y, actuando de forma proactiva, hemos reportado las variables dependientes correspondientes como influyentes a lo largo de la tesis.

- Para el estudio del conocimiento en el diseño within-subjects, según nuestros cálculos son necesarios 34 sujetos experimentales. En E-2012 A hemos conseguido un total de 28 unidades experimentales, cantidad insuficiente para poder alcanzar un poder estadístico. Para ello, hemos replicado el experimento internamente (E-2012 B) recolectado un total de 54 unidades experimentales. Nótese que, esta amenaza la hemos eliminado replicando internamente el experimento. Tras el análisis conjunto, el efecto del conocimiento resultó significativo. Ello implica que no pudo haberse cometido un error tipo II, mientras que en el análisis conjunto de los cuasiexperimentos la falta de significación estadística puede deberse a la falta de poder estadístico. Creemos que esta amenaza no opera, porque para efectos medios relevantes en estudios de ingeniería del software, tenemos muestra suficiente. Lo que podría estar ocurriendo es un error del tipo II o que exista un problema de heterocedasticidad en los datos, como se indica en la siguiente amenaza.

- Para el estudio del conocimiento en el diseño between-subject, se necesita 128 sujetos experimentales según nuestros cálculos. En nuestro caso, fue imposible conseguir esa cantidad de sujetos por experimento individual. Para paliar esta amenaza, hemos replicado 3 veces el experimento between (E-2013, E-2014 y E-2015) y los hemos analizado conjuntamente. Aún así, no hemos logrado alcanzar el tamaño muestral requerido (44 de 128). El efecto del conocimiento resulto no significativo, ello se debe claramente a la falta de significación estadística. Tras este hecho, decidimos analizar conjuntamente mediante meta-análisis de datos agregados, los experimentos within y between subjects. En total hemos recopilado 97 sujetos experimentales. Si bien, aún no hemos logrado el valor estimable, creemos que aunque se reportan efectos bajos y p-valores próximos a la significación al diferenciarlo por tipo de diseño (ver sección 
6.2.1.2), finalmente conjuntamente hemos observado un bajo efecto positivo y estadísticamente significativo. Por lo que el error tipo II no se aprecia.

- Tasa de Error Tipo I: Esta amenaza contiene dos partes. Por un lado, los investigadores pueden influir en los resultados buscando una respuesta específica mediante la realización arbitraria de diversos tests estadísticos; por otro lado, cuando se conducen múltiples análisis legítimos el nivel de significación actual debería ser ajustado para no inflar el error tipo I.

- Si bien a lo largo de la investigación hemos presentado resultados parciales por cada uno de los experimentos individuales empleando dos métricas distintas (una objetiva y otra subjetiva) por cada constructo, creemos que esta amenaza no opera, ya que nuestras conclusiones se basan en un único análisis (análisis conjunto con todos los datos recogidos a lo largo de la investigación) con una única métrica objetiva por cada constructo. La métrica subjetiva, si bien también la hemos analizado conjuntamente, no la hemos tenido en cuenta para derivar nuestras conclusiones, por el hecho de que creemos que introduce sesgo en resultados obtenidos.

- Por otro lado, los investigadores no buscan un resultado específico. No poseemos un criterio a priori respecto a que la experiencia o el conocimiento tenga o no un efecto. Como prueba, si la experiencia tuviese un efecto negativo sería un resultado quizás mucho más publicable. Sin embargo, nuestros resultados apuntan a un bajo efecto positivo, que está en concordancia con el conocimiento folk sobre la experiencia o el conocimiento en Ingeniería de Requisitos. Y es potencialmente menos publicable.

- Fiabilidad de la medición: Si la fiabilidad o exactitud de una métrica es muy baja, ello puede implicar errores o sesgos que afecta a la validez de los resultados.

- En esta investigación, tanto la experiencia como el conocimiento fueron medidos objetiva como subjetivamente. La comparación de las medidas objetivas (por ejemplo, la experiencia medidas en años) y subjetivas (por ejemplo, la experiencia medida como habilidad en una escala de Likert) ha puesto de manifiesto que las medidas subjetivas parecen estar sesgadas negativamente respecto a las medidas objetivas, por ese motivo hemos descartado las medidas subjetivas y hemos basado nuestras conclusiones en las las objetivas.

- Dado que las medidas son tomadas de distintos contextos (por ejemplo, entrevistas en grupo o individual), asumimos que existen ciertos efectos derivados del setting que podrían estar influyendo en la efectividad. Dichos efectos fueron eliminados mediante el procedimiento de ajuste de los datos. En la Figura 8.1 se puede apreciar que tras eliminar los efectos sumativos de las potenciales variables moderadoras, las efectividades promedios y dispersiones entre estudios son muy similares, lo que sugiere que la medición se ha llevado a cabo de forma fiable. 


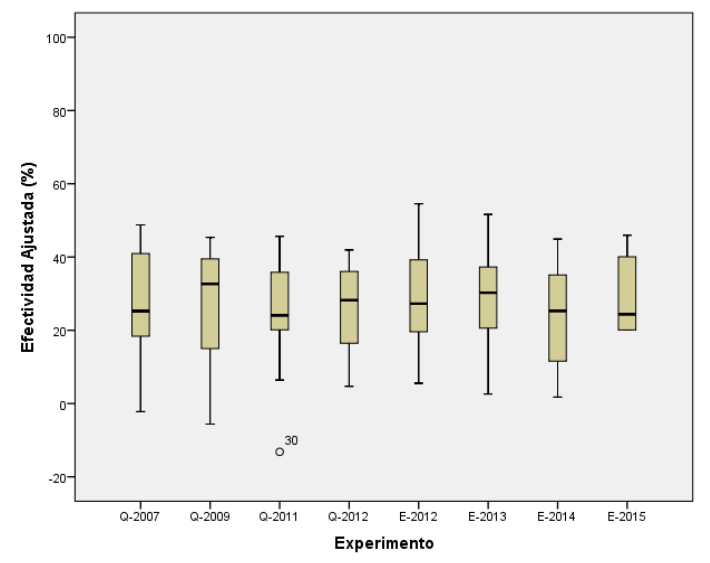

Figura 8.1 - Efectividad media de los sujetos a lo largo de la serie histórica (PD1)

- Fiabilidad de la administración de los tratamientos: Si el procedimiento experimental es aplicado de forma diferente a cada tratamiento, comparar los resultados de los tratamientos no arroja resultados fiables.

- En esta investigación, todos los sujetos que participaron en los distintos experimentos realizaron la misma tarea experimental: educción de requisitos mediante entrevista abierta y consolidación de la información educida en un reporte escrito. Los sentrevistados han intentado responder con naturalidad, y proporcionar toda la información relevante durante la educción. Sin embargo, hay cierto riesgo de que los entrevistados puedan proporcionar más o menos información debido al cansancio, a la realización de la sesión de educción en días diferentes, etc. Este hecho lo hemos intentado controlar mediante descansos entre sesiones y evitando que el entrevistado use más de un día para cada tratamiento. No podemos asegurar la fiabilidad de la administración de los tratamientos al $100 \%$, sin embargo los resultados son bastante homogéneos a lo largo del tiempo, tal y como puede comprobarse en la Figura 8.1.

- Irrelevancias aleatorias en la situación experimental: Elementos externos al experimento que pueden perturbar los resultados.

- En esta investigación, se hizo todo lo posible de que no existieran elementos externos al experimento (distintos entornos físicos, superposición de asignaturas, etc.) que pudieran influir durante las sesiones de educción o consolidación de la información. No podemos descartar que algún factor externo al experimento influya, pero creemos que hemos controlado adecuadamente todas las variables contextuales relevantes.

- Heterogeneidad de los sujetos: Si el grupo es muy heterogéneo, existe un riesgo debido a las diferencias individuales sea mayor que el del tratamiento.

- En la presente investigación, esta amenaza afecta sobre todo al estudio experimental y no al cuasi-experimental, ya que en el estudio cuasi-experimental es necesario que exista heterogeneidad entre los sujetos, sobre todo en términos de experiencia, para que la determinación del efecto de la experiencia sea fiable y además tenga una mayor validez externa.

En el estudio experimental cuando el grupo es muy heterogéneo puede no ser posible determinar si los efectos se deben al tratamiento o a las diferencias individuales de los sujetos, sobre todo con tamaños muestrales bajos. Esta amenaza en los experimentos fue mitigada de la siguiente manera: 
1. Los sujetos son (en el caso de los estudios experimentales) estudiantes de máster, lo que reduce la heterogeneidad entre los mismos ya que poseen background, experiencias, etc. muy similares.

2. En el experimento E-2012 A y su replicación interna E-2012 B, hemos aplicado un diseño de medidas repetidas, lo que hace que los efectos intra-sujetos desaparezcan, ya que cada sujeto es control de sí mismo.

3. En E-2013, E-2014 y E-2015 no aplicamos ninguna medida correctora de la heterogeneidad de los sujetos, ya que el diseño utilizado es between-subjects. Con la finalidad de usar distintos diseños en nuestra investigación. Aún así, creemos que la replicación y agregación mediante meta-análisis de los datos de los tres experimentos minimiza el problema de la heterogeneidad de los sujetos experimentales.

\subsection{Amenazas a la validez interna}

La validez interna hace referencia a la capacidad de obtener conclusiones acerca del efecto de la variable independiente sobre la dependiente. Un experimento tiene validez interna en la medida en que los controles establecidos permiten rechazar interpretaciones alternativas de los resultados (Campbell y Stanley, 1963). Es decir, la validez interna es el grado en que ciertamente la manipulación de la variable independiente es responsable de los cambios de la variable dependiente.

- Historia: Se refieren a los acontecimientos que pueden ocurrir durante el desarrollo del experimento que pueden afectar a la variable dependiente y confundir resultados.

- Tanto en los cuasi-experimentos como en los experimentos creemos que no opera la amenaza de historia. En los cuasi-experimentos, porque las sesiones de educción se realizan en un único momento. En los experimentos, aunque los tratamientos se aplican en momentos distintos, se tuvo en cuenta de que las sesiones estuvieran muy próximas entre sí, distribuidas de tal forma que se evitase el cansancio por parte de los entrevistados y la copia entre los sujetos experimentales.

- En los experimentos Q-2007 y Q-2009, durante el proceso de consolidación de la información, existe el riesgo que los sujetos se copien o proporcionen información sesgada, ya que las sesiones de educción se realizan en un día distinto al de la consolidación. Una manera de mitigar esta amenaza fue reduciendo el tiempo de consolidación de 7 días a una consolidación inmediata, es decir, realizar la consolidación en el mismo día de la ejecución de las sesiones de educción.

- Durante la ejecución de los estudios experimentales (cuasi-experimentos y experimentos) existe el riesgo de que los alumnos se pueden copiar. Para mitigar esta amenaza se ha informado a cada sujeto individualmente el horario y sitio donde realizaría la sesión de educción. Además, los alumnos no sabían si el problema era el mismo para todos o si les iba a proporcionar a todos la misma información.

- Maduración: Se refiere a que los sujetos del experimento reaccionen de forma distinta como consecuencia del transcurso del tiempo.

- Creemos que esta amenaza podría operar (aunque muy levemente) en el experimento $\mathrm{E}-2012 \mathrm{~B}$ (de medidas repetidas), ya que al ser una réplica interna de E-2012 A, los sujetos realizaron varias veces la misma tarea experimental aunque con problemas distintos, lo que puede ocasionar en los sujetos un efecto de formación derivado de la ejecución de la misma tarea (esto es, la realización de entrevistas o consolidación de la información). No obstante, al analizar 
conjuntamente E-2012 A y E-2012 B, hemos podido separar y estudiar el efecto de formación, evitando la amenaza de maduración.

- Esta amenaza podría operar también en los experimentadores (sujeto en el rol de entrevistado). El hecho de que el entrevistado tenga que repetir varias veces la misma tarea experimental, al estar las sesiones de educción muy próximas en el tiempo y ser varios los sujetos experimentales con lo que tiene que interactuar, provoca que el entrevistado experimente un efecto cansancio que haga que disminuya la su efectividad y en consecuencia influya en la efectividad de los sujetos experimentales. Este hecho se ha mitigado, incrementando el número de entrevistados y limitando el número de sesiones de educción a 5-7 por día.

- Administración de las pruebas: Se refiere a que si se ha administrado una prueba varias veces, el sujeto puede responder de forma distinta en momentos distintos, porque ya conoce cómo se conduce la prueba.

- En nuestra investigación, esta amenaza no opera ya que no hemos aplicado ninguna prueba que podría hacer que los sujetos actuaran de forma distinta. La tarea experimental consiste en una entrevista abierta y elaboración de un reporte sin formato.

- En la medida en que la entrevista abierta y la elaboración del reporte de consolidación pudieran considerase un tipo de prueba, sólo se ha producido una administración reiterada en E-2012. En este caso, dicha administración reiterada se ha controlado explícitamente (mediante las variables formación y orden).

- Instrumentación: Esta amenaza se refiere al proceso de medición de la variable dependiente. Está provocada por los cambios que pueden darse a lo largo del tiempo en los instrumentos, procedimiento de recogida o medida (por ejemplo, formularios de recolección de datos, documentos utilizados en el experimento, etc.)

- Esta amenaza creemos que no aplica a nuestra investigación por los siguientes motivos:

a. En el proceso de consolidación, los sujetos emplearon un formato libre para la consolidación de la información educida; por tanto no cuentan con ningún formulario que pudiera estar afectando al reporte de información sobre la comprensión del problema.

b. En lo que respecta a los cuestionarios post-experimentales, estos son bastante simples, ya que hacen referencia a aspectos muy concretos como pueden ser los años de experiencia que el sujeto puede tener o el conocimiento sobre dominio medidos objetiva y subjetivamente. Además, los cambios que han sufrido dichos formularios en el tiempo son relativamente reducidos.

- Regresión estadística: Esta amenaza está relacionada con la selección de sujetos. Ocurre cuando los sujetos son clasificados por grupos experimentales basados en experimentos o casos de estudios previos. Por ejemplo, los diez mejores o peores.

- Esta amenaza no opera en los cuasi-experimentos porque no existe una clasificación de los sujetos por grupos. Tampoco opera en los experimentos, porque la clasificación de los grupos no se realiza con base a experimentos o estudios previos.

- Selección: Esta amenaza está relacionada con la selección de los sujetos o formación de los grupos experimentales. Los grupos deben ser equivalentes. Si los grupos no se han formado 
aleatoriamente o son tan pequeños que no ha podido actuar correctamente el azar, no serán equivalentes.

- $\quad$ No podemos negar que esta amenaza pueda estar operando, concretamente en Q2012 donde los sujetos que participaron del cuasi-experimento han sido voluntarios. En los demás cuasi-experimentos y experimentos, ello no puede ocurrir, ya que los sujetos corresponden a una muestra formada por conveniencia.

- Los experimentos E-2013, E-2014 y E-2015 poseen muy pocos sujetos por grupo. No obstante, creemos que el análisis conjunto permite evitar los problemas asociados a los bajos tamaños muestrales individuales.

- Mortalidad: Se refiere a la pérdida o deserción de los participantes durante el experimento.

- Esta amenaza es difícil que ocurra ya que, en nuestra investigación sólo tenemos dos casos de 110 donde los sujetos no terminaron el proceso de consolidación por motivos particulares (lo que da lugar a los 108 sujetos totales en los que basamos nuestros análisis)

- Ambigüedad acerca de la dirección de la influencia causal: Esta amenaza consiste en la falta de certidumbre que se puede dar sobre cuál es la causa y cuál es el efecto, debido a la ambigüedad que puede haber respecto a la contigüidad temporal de las variables objeto de estudio.

- Esta amenaza no opera, ya que en nuestros estudios no se puede invertir la direccion causal. Por ejemplo, está claro que la experiencia o conocimiento del sujeto no puede venir provocado por la efectividad de los mismos, sino que al contrario la efectividad podría depender de la experiencia o conocimiento del sujeto. Bien es cierto que los cuasi-experimentos no pueden identificar relaciones causales, pero ello es independiente de la determinación de la relación causal entre dos variables.

- Interacción con la selección: Se da cuando existe un comportamiento distinto en diferentes grupos.

- En los cuasi-experimentos esta amenaza no opera porque tratamos un único grupo.

- En los experimentos, aunque contamos con dos grupos (grupos de comparación), creemos que esta amenaza no aplica, ya que los grupos se tratan de forma equivalentes, es decir, los sujetos reciben la misma formación, los mismos tratamientos, etc.

- Difusión e imitación de tratamientos: Este efecto ocurre cuando un grupo de control aprende acerca del tratamiento del grupo experimental o tratan de imitar el comportamiento del grupo experimental.

- Esta amenaza no opera por dos motivos: 1) En los cuasi-experimentos no existen un grupo de control y un grupo experimental; 2) En los experimentos no contamos con grupos de control propiamente dichos sino que con dos grupos de comparación. Por tanto, no es posible que los sujetos aprendan entre ellos ya que todos aplican la misma tarea experimental diferenciándose únicamente en el dominio del problema.

- Igualdad compensatoria: Si al grupo de control se le da una compensación por ser grupo de control, como por ejemplo enseñarles algo en compensación al tratamiento, eso puede afectar a los resultados esperados. 
- Esta amenaza no se aplica ya que todos los sujetos reciben la misma formación, aplican los mismos tratamientos y no se diferencian por grupos de control y experimental.

- Rivalidad compensatoria: Esta amenaza es opuesta a la amenaza anterior. El sujeto que recibe un tratamiento menos deseable está tentado a reducir o invertir el resultado esperable del experimento.

- Dado que todos los sujetos aplican los mismos tratamientos, no da lugar a este tipo de amenazas, al igual que el caso anterior.

\subsection{Amenazas a la validez de constructo}

La validez de constructo determina en qué grado las variables representan correctamente los constructos teóricos.

- Explicación pre-operacional inadecuada del constructo. Esto significa que el constructo no está definido con la suficiente claridad, antes de convertirse en métrica o tratamiento. Esto es, la teoría o la forma de medir no está clara.

- En los experimentos donde participan dos entrevistados (E-2012, E-2013), los entrevistados pueden proporcionar informaciones distintas, según la comprensión que éstos tengan de los dominios. Para evitar esta amenaza en primer lugar, los objetos experimentales utilizados en la presente investigación (PC1, PD2, PC2 y PD2) fueron definidos de forma explícita y exhaustiva, tal y como se indica en el Anexo B. En segundo lugar, los experimentadores se han reunido para discutir y llegar a un acuerdo acerca de qué información proporcionar a los sujetos experimentales, tanto acerca de los elementos del dominio del problema como de aspectos no relacionados directamente con los requisitos, en especial los aspectos relacionados con la gestión (plazo, tiempos, presupuestos, etc).

- El constructo de efecto (Efectividad) está completamente definido y justificado tal y como se ha indicado en la sección 4.2.1.2. Por tanto, creemos que esta amenaza no opera ya que contamos con una lista patrón de los dominios, y la efectividad se mide comparando los elementos contendos en la lista patrón junto con el reporte de sujetos.

- La imposibilidad de anticipar todas las preguntas que los entrevistadores (sujetos experimentales) pueden plantear podría considerarse durante las sesiones de educción, podría amenazar la validez de los resultados. En particular, hemos excluido los requisitos no funcionales de la lista patrón (o gold standard) que definen los elementos de los que se componen los dominios del problema (tanto conocido como desconocido) utilizados. Los entrevistadores que se focalicen en este tipo de requisitos podrían ver perjudicada su efectividad. Para paliar esta amenaza a la validez, los entrevistados (entrevistados) han proporcionado respuestas directas y han intentado derivar la conversación por otros medios. Sin embargo, este proceder puede no haber funcionado siempre.

- Sesgo debido al empleo de operacionalizaciones únicas: $\mathrm{Si}$ el número de variables independientes o participantes es muy bajo, el experimento podía no identificar correctamente los fenómenos subyacentes.

- En la investigación hemos intentado tener múltiples instancias de las variables independientes o factores. La experiencia y el conocimiento los hemos medio 
objetiva y subjetivamente; hemos empleado en total cuatro objetos experimentales: dos conocidos y dos desconocidos. En lo que respecta a los entrevistados, hemos utilizado hasta tres entrevistados y por otro lado hemos adquirido datos de 110 sujetos, con distintos años de experiencia y niveles de conocimiento (familiaridad) con los dominios del problema utilizados.

Nótese que uno de los entrevistados (investigador) ha participado en casi todas las replicaciones ejecutadas en la presente investigación y al igual que uno de los objetos experimentales (dominio de problema PD1). Este hecho fue necesario para alcanzar un poder estadístico deseable que asegure la fiabilidad de los resultados.

- Sesgo debido al empleo de un método de operacionalización único: Si solamente una métrica o método de medición es utilizado, aumenta el riesgo de que los resultados no sean fiables y por lo tanto el experimento sea engañoso.

- Medición del constructo Conocimiento sobre el Dominio del Problema. Al principio de la investigación, el conocimiento del dominio del problema hacía referencia a la familiaridad que poseen los analistas sobre el dominio del problema. La Familiaridad, ha sido medida utilizando una escala de Likert. A partir de E-2012, el Conocimiento también se ha operacionalizado como un factor de dos niveles (conocido y desconocido).

- Medición del constructo EXPERIENCIA. El constructo experiencia fue medido mediante el número de años y como la habilidad mediante una escala de Likert.

Creemos por tanto, que esta amenaza no opera ya que, el conocimiento como la experiencia, fueron medidos con más de una métrica.

- La efectividad de los sujetos la hemos medido únicamente como la cantidad de elementos que definen el dominio del problema. No obstante, esta amenaza creemos que no opera ya que dicha medición no se basa en un único elemento, sino que en los requisitos, conceptos y procesos los cuales son naturales del dominio del problema.

- Confusión entre constructo y niveles de constructo: En algunas relaciones no es relevante la presencia o ausencia de un constructo, sino el nivel del constructo ensayado. Por ejemplo, la presencia o ausencia del conocimiento previo en un leguaje de programación puede no explicar los resultados de en un experimento, pero si el hecho de que el sujeto tenga 1,3 y 5 años de experiencia con el lenguaje.

- Para el constructo EXPERIENCIA, creemos que esta amenaza no opera, ya que no hemos categorizado a los sujetos como con o sin experiencia, sino que hemos medido la experiencia mediante el número de años que posee el sujeto en una determinada actividad o su habilidad (percepción subjetiva de su experiencia) medida mediante una escala de Likert.

- Para el constructo Conocmiento, esta amenaza podría operar. No obstante, creemos que distinguir e implementar distintos niveles de conocimiento acerca del dominio del problema, representa una amenaza más importante. Esto es, no vemos de forma clara, como podría ser posible definir un dominio del problema "parcialmente conocido". Por este motivo hemos mantenido sólo dos niveles para el factor conocimiento. Una alternativa que hemos ensayado es oporacionalizar el constructo conocimiento mediante la métrica de familiaridad. No obstante, al final hemos descubierto que la familiaridad también es esencialmente dicotómica, lo que de nuevo no evita esta amenaza. 
- Interacción de diferentes tratamientos. Si el sujeto está involucrado en más de un tratamiento, estos pueden interactuar entre sí. Luego no es posible concluir si el efecto es debido al tratamiento $o$ a la combinación de tratamientos.

- Esta amenaza no se aplica a los cuasi-experimentos, ya que los sujetos realizan un solo tratamiento.

- Esta amenaza tampoco aplica a los experimentos donde los sujetos participan en un único estudio y realizan una única sesión de educción (E-2013, E-2014).

Sin embargo, existe la posibilidad de que en los experimentos E-2012 A y E-2012 B los sujetos por el hecho de realizar más de una entrevista mejoren o empeoren sus efectividades. Hemos podido evitar esta amenaza debido a que los efectos de momento y orden han podido ser idénticos mediante un análisis conjunto de $\mathrm{E}$ 2012 A y E-2012 B.

- Confusión de efectos. Durante la ejecución de los estudios empíricos (cuasiexperimentos y experimentos) hemos confundido a propósito ciertas variables para evitar estudiar su interacción. A continuación mencionamos qué variables se han confundido.

a. Confusión entrevistado e idioma. En los experimentos controlados (E2012 y E-2013) el entrevistado y el idioma son variables que se confunden. JW realizó sus entrevistas en español, mientras que AG y OD realizaron las entrevistas en inglés. Existe, por tanto, la posibilidad de que la menor efectividad de OD haya venido motivada no por su habilidad para transmitir información, sino por las limitaciones en la comunicación debidas al uso del idioma inglés. No obstante, creemos que ello no ocurre, ya que AG también realizó las entrevistas en inglés. El conocimiento del idioma inglés de $O D$ y $A G$, es al menos, similar.

b. Confusión tiempo de educción y tipo de entrevista. En los cuasiexperimentos Q-2011 y Q-2012, el incremento de efectividad de los sujetos se podría deber al aumento del tiempo de educción (a 60 minutos) o al tipo de entrevista (entrevista en grupo) donde todos los participantes tienen acceso exactamente a la misma información. En este caso, no podemos separar los efectos de ambas variables. No obstante, como siempre se han confundido enteramente, y ni el tipo de entrevista ni el tiempo de educción son variables relevantes en nuestra investigación, su confusión no supone un riesgo para nuestras conclusiones.

- Interacción de administración de pruebas y tratamientos. La prueba por sí misma, es decir, la aplicación del tratamiento, puede hacer que los sujetos sean más sensibles o receptivos al tratamiento. Por ejemplo, si la prueba supone medir el número de errores hechos en el código, los sujetos serán más cautelosos acerca de sus errores, lo que puede hacer que disminuyan.

- En esta investigación, esta amenaza no opera ya que el mecanismo de medición de la efectividad es desconocido para a los sujetos experimentales. Los sujetos sólo conocen que deben adquirir cuanta información sea posible acerca de los dominios del problema, pero no como se establecerá cuanta información han adquirido.

- Generalidad restringida entre constructos. El tratamiento puede afectar al constructo estudiado positivamente, pero indirectamente puede afectar otros constructos negativamente, lo que hace que sea difícil generalizar los resultados. 
- Confusión entre el conocimiento y experiencia. Esta amenaza la hemos mitigado, separando los efectos del conocimiento y la experiencia. Para ello, el efecto de la experiencia se ha estudiado separadamente en dominios conocidos y desconocidos para los sujetos experimentales. En lo que respecta al conocimiento, en E-2012 hemos realizado un experimento controlado con un diseño de medidas repetidas donde el efecto de la experiencia queda cancelado, ya que cada sujeto actúa como control de sí mismo. En E-2013, E-2014 y E-2015 el efecto de la experiencia debería cancelarse gracias a la aleatorización.

- Adivinación de la hipótesis. Si un participante puede adivinar la hipótesis del experimento, el puede alterar de modo que la hipótesis se vea favorecida o perjudicada.

- Creemos que esta amenaza no opera en la práctica, al menos en el caso de los cuasi-experimentos, debido al carácter correlacional de la hipótesis estadística. Si los sujetos pusieran más o menos empeño en un dominio del problema, ello equivaldría a la adición o substracción de una constante (nótese la simplificación), lo cual no tendría impacto alguno en la correlación estadística. En el caso de los experimentos, no podemos descartar la adivinación de hipótesis. Para evitar este riesgo, el cuestionario post-experimental se aplicó al final de cada experimento lo que evitaría que las preguntas indujeran a una sospecha sobre la investigación.

- Recelo de evaluación. Si la persona sabe que está siendo evaluada, puede cambiar su comportamiento según su norma.

- Creemos que esta amenaza no se aplica, ya que los estudios empíricos formaron parte de una práctica o evaluación final de la asignatura. La evaluación era, por tanto, parte integral de los estudios, favoreciendo además a que los sujetos se comportasen del modo más efectivo posible.

- Expectativas del experimentador. Si los resultados no son conforme a lo que el experimentador esperaba, éste podía (probablemente de forma involuntaria) sesgar el experimento hacia un resultado esperado.

- Las sesiones de educción podrían estar afectadas por el investigador, ya que uno de los investigadores (OD) actuó en un gran número de estudios, como entrevistado. Sin embargo, la serie histórica de experimentos muestra resultados tanto en una como en otra dirección para OD. Adicionalmente, en la investigación participaron otros dos entrevistados que no forman parte del quepo del proyecto. Al comparar las efectividades de los sujetos que realizaron las entrevistas con OD frente a aquellos que realizaron las entrevistas con JW o AG, las efectividades se parecen mucho, no hay un cambio de dirección o un cambio de efecto evidente entre entrevistados. Esto ayuda a limitar esta amenaza a la validez.

- Adicionalmente en el caso de los cuasi-experimentos es muy difícil que esta amenaza opere. Nótese que el experimentador, en el momento de ejecutar el estudio, desconoce la experiencia de los sujetos, lo que impide que proporcione más o menos información a los sujetos con más o menos experiencia.

Por otro lado, en los cuasi-experimentos donde la entrevista es en grupo, esta amenaza está explícitamente controlada, ya que el experimentador proporciona al mismo tiempo la misma información a todos los sujetos. 


\subsection{Amenazas a la validez externa}

La validez externa hace referencia a la posibilidad de generalización de los resultados de una investigación a otras poblaciones (validez poblacional), situaciones (validez ecológica) o momentos temporales (validez histórica). Es decir, hace referencia a la posibilidad de generalizar la relación causal observada en un determinado estudio más allá de las circunstancias bajo las que se ha obtenido dicha relación. Para que un experimento tenga validez externa, es fundamental que la muestra sea representativa de la población de referencia y que sea haya seleccionado aleatoriamente. Las amenazas a la validez externa son las siguientes:

- Interacción entre selección y tratamiento (amenaza poblacional). Una investigación carece de validez poblacional, cuando los resultados obtenidos en una muestra no pueden generalizarse a la población referida ni a otras poblaciones, debido a que la relación hallada entre las variables es específica de los participantes en el estudio. Es decir, el tratamiento provoca unos efectos determinados en un grupo de participantes por sus características concretas que no representan a las de la población.

- $\quad$ El hecho de que los sujetos experimentales no provengan de una muestra aleatoria sino de una muestra de conveniencia (esto es, los sujetos no han sido reclutados de una población mayor, sino que son los estudiantes matriculados en un curso determinado) representa una amenaza a la validez externa del experimento. Por tanto, la generalización de nuestros resultados a analistas profesionales debe ser hecha con debida cautela. No obstante, esta amenaza fue afrontada por el hecho de que los estudiantes estaban cursando un máster con orientación profesional y a su vez, la mayoría contaba con experiencia profesional en tareas afines a informática. Por lo tanto, los sujetos pueden ser considerados razonablemente representativos de la población de desarrolladores/analistas. Al menos, creemos que nuestros resultados pueden ser generalizables a desarrolladores junior novatos en técnicas de educción.

- Interacción del setting y el tratamiento (validez ecológica). Está provocada por la artificialidad de las situaciones experimentales, lo que podría llevar a que sea imposible generalizar los resultados a situaciones reales.

- El diseño experimental es completamente diferente a lo que los analistas realizan en el mundo profesional:

a. El cliente que participa en las entrevistas es simulado. Por tanto será, en cierta medida, distinto a un cliente real.

b. El/los sistemas software a desarrollar no son reales,

c. El tiempo empleado en las entrevistas es limitado;

d. El proceso de educción se realiza en una única sesión.

Las medidas adoptadas para mitigar estas amenzas son:

a. El sujeto en el rol de cliente ha estudiado cuidadosamente el/los dominios de problema, con el objetivo de responder con la mayor naturalidad y veracidad posible. Por otro lado, como los entrevistados desempeñan su rol varias veces en la secuencia de experimentos posee, la naturalidad de las entrevistas aumenta con el tiempo.

b. Los sistemas usados en los experimentos se basan en sistemas software reales. Se tuvo cierta cautela en que los problemas sean lo más parecido posibles en 
complejidad de forma que el tamaño de los problemas no sea otro factor influyente en la efectividad de los analistas.

c. Para aumentar la validez externa de nuestros experimentos, hemos utilizado a partir de E-2012 dos entrevistados y dos problemas diferentes. No obstante, para que nuestros resultados sean extrapolables a la generalidad de problemas y entrevistados es necesario realizar más experimentos.

d. Creemos que el tiempo de educción no fue un obstáculo para obtener información. L mayoría de los sujetos terminaron la sesión de educción antes del tiempo establecido. Además la mayor parte de la complejidad del sistema original ha sido eliminado para que sea fácil de entender por completo en un período de tiempo limitado.

- Interacción historia y tratamiento. Se refiere al efecto que surge cuando un experimento se lleva en un determinado momento o día, el cual afecta a los resultados, de modo que no pueden ser generalizados en otro período de tiempo.

- En esta investigación, las entrevistas no parecen depender del momento específico del tiempo cuando son realizadas. Entendemos, por tanto, que esta amenaza no opera.

- Interacción de la relación causal con las variaciones en el tratamiento. Un efecto encontrado con una variación del tratamiento podría no resultar con otra variación de aquel tratamiento, o cuando aquel tratamiento es combinado con otro tratamiento, o cuando solamente parte del tratamiento es usado.

- Creemos que esta amenaza no opera ya que el tratamiento es único para todos los experimentos y cuasi-experimentos, esto es, una conversación mediante entrevista abierta.

- Interacción de la relación causal con las variables dependientes. Un efecto encontrado con un tipo de variable dependiente puede no resultar si otra variable dependiente fue usada.

- Como variable dependiente hemos utilizado la medida efectividad del proceso de la consolidación, operacionalizada como el \% de elementos del dominio identificados por los sujetos experimentales. Variables dependientes como la efectividad son frecuentemente utilizadas en otros estudios empíricos de Ingeniería de Requisitos. No obstante, no podemos afirmar que nuestras conclusiones se puedan extrapolar a otra variable dependiente.

- Mediación dependiente del contexto. Un mediador explicativo de una relación causal en un contexto puede no mediar en otro contexto.

- En la presente investigación, hemos intentado bloquear todas las variables contextuales que creemos influyentes, pero no podemos descartar que alguna variable que hayamos pasado por alto esté ejerciendo algún efecto. Para paliar esta amenaza hemos planteado diversos análisis post-hoc en la sección de discusión (ej. el referido al liderazgo en la conversación). Dichos análisis post-hoc nos han permitido vislumbrar variables potencialmente influyentes. No obstante, no pretendemos afirmar que nuestra investigación haya identificado todas las variables relevantes. Muy al contrario, los $\mathrm{R}^{2}$ de los modelos de análisis de los datos individuales son muy bajos, lo que indica que muchas variables influyentes en el proceso de educción quedan por ser identificadas y estudiadas. 



\section{CAPÍTULO 9 CONCLUSIONES Y FUTURAS LÍNEAS DE INVESTIGACIÓN}

Este capítulo tiene por propósito presentar al lector las principales conclusiones obtenidas en la presente tesis doctoral (Sección 9.1) así como las futuras líneas que podrían dar continuidad a la investigación (Sección 9.2).

\subsection{Conclusiones}

\subsection{1 ¿Influye la experiencia del analista en la efectividad del proceso de educción de los requisitos? (RQ1)}

Los resultados de la familia de estudios empíricos que hemos realizado han permitido comprobar, con un nivel razonable de certidumbre, que la experiencia ejerce efectos diferenciales en la efectividad de los analistas, dependiendo del tipo de dominio del problema (conocido, desconocido) en el que se produce la educción:

- En dominios del problema desconocidos, la experiencia (entrevistas, requisitos, desarrollo o profesional) no ejerce efecto alguno, ya sea positivo o negativo, en la efectividad de los analistas.

- En dominios del problema conocidos, la experiencia en entrevistas y la experiencia en requisitos ejercen efectos positivos, de tamaño moderado-bajo en la efectividad de los analistas.

Es necesario realizar aquí tres precisiones importantes. La primera es respecto al efecto de la experiencia en dominios conocidos. Nuestra opinión es que los tamaños de efecto están sesgados a la baja. El dominio del problema PC1, que es donde basamos la mayor parte de nuestras conclusiones, nos 
parece excesivamente artificioso en retrospectiva. Por ejemplo, existe un proceso como "Confirmar envío de mensaje" que es claramente nimio y, en consecuencia, realmente difícil no solo de identificar por el analista sino también de expresar por el entrevistado. Otros procesos y conceptos de PC1 pueden clasificarse en esta categoría. Como estos conceptos y procesos tienden a no ser identificados, la efectividad de los analistas se reduce de modo artificial, lo que a su vez reduce el efecto del conocimiento del dominio.

Si dichos procesos y conceptos en PC1 no existieran, la efectividad de los analistas aumentaría y el efecto del conocimiento del dominio se incrementaría en consecuencia. Esto podría probarse analíticamente eliminando los procesos y conceptos controvertidos del patrón de medida, obteniendo nuevas métricas, y corriendo de nuevo los análisis. No obstante, lo creemos innecesario y al mismo tiempo contraproducente. Por una parte, el aumento de la efectividad de los analistas puede asegurarse ya que eliminar conceptos y procesos en PC1 equivale a sumar una constante a la efectividad de todos los analistas. Por otra parte, hemos adoptado el criterio Intention to Treat a lo largo de toda la tesis, lo que induce a no recalcular resultados bajo ningún criterio.

La segunda precisión hace referencia al concepto mismo de experiencia en requisitos (o entrevistas). En dominios conocidos hemos observado que la experiencia aumenta la efectividad de los analistas. Sin embargo, en dominios desconocidos, no existe tal efecto. ¿Significa esto que la experiencia en requisitos se reduce a conocimientos específicos del dominio del problema, sin relación alguna a la disciplina en sí misma?

Nuestros resultados indican que no es así. En el dominio de problema desconocido, se observa claramente que los analistas con más experiencia poseen una efectividad mínima superior a los analistas con menos experiencia. El mismo fenómeno se observa en el dominio del problema conocido. Nuestra interpretación de este resultado es que la disciplina de Requisitos en sí misma proporciona conocimientos que son empleados por los analistas durante el proceso de educción, independientemente de los conocimientos acerca del dominio del problema.

Esta interpretación es corroborada por el efecto de la formación en Requisitos, que ha resultado tremendamente influyente en la efectividad de los analistas. Si los conocimientos específicos de la disciplina de Requisitos no ejerciesen una influencia positiva, el efecto de la formación no podría entenderse.

Ya por último, la tercera precisión hace referencia al efecto diferencial de la experiencia en relación al tipo de elemento del dominio del problema. En el dominio desconocido, se observa que la experiencia posee una correlación de tipo medio/bajo con el número de procesos, identificados por los analistas. Sin embargo, esta correlación no es tan fuerte como para sobresalir cuando todos los tipos de elementos (procesos, conceptos y requisitos) se consideran conjuntamente. Por el contrario, en el dominio conocido, la mayor efectividad de los analistas con experiencia, es perceptible, en la identificación de conceptos. Parece posible afirmar, por lo tanto, que la experiencia siempre es beneficiosa para el analista, aunque sus efectos son más perceptibles en dominios conocidos que en dominios desconocidos.

\subsection{2 ¿̇nfluye el Conocimiento del dominio en la efectividad del proceso de educción? (RQ2)}

Los experimentos que hemos realizado señalan también que los analistas son más efectivos en dominios del problema conocidos que en dominios del problema desconocidos. El tamaño de efecto asociado al conocimiento del dominio es bajo.

Ahora bien; el efecto diferencial de la experiencia indicado anteriormente no deja de ser una interacción Experiencia $x$ Conocimiento, lo que obliga a matizar la conclusión anterior. 
Afortunadamente, la interacción Experiencia x Conocimiento es de carácter ordinal, lo que nos permite afirmar que la efectividad de los analistas en dominios conocidos es mayor o igual que en dominios desconocidos, pero nunca menor.

Lo anterior implica que el tamaño de efecto bajo que hemos identificado para el conocimiento puede tratarse de una estimación sesgada, siendo igualmente posible que no exista efecto de conocimiento, esto es, que el tamaño de efecto sea 0 . Podríamos intentar conseguir una estimación del efecto del conocimiento independientemente de la experiencia, pero tenemos pocos datos respecto a PC1 y creemos que dicha estimación sería muy inestable. Por ello, preferimos dejar este asunto pendiente para las líneas futuras de investigación.

No obstante, en nuestra opinión el efecto del conocimiento no es nulo, sino pequeño o, más probablemente, medio. Hay dos razones para ello. Por una parte, el experimento internamente replicado E-2012, el cual posee un poder estadístico bastante razonable al tratarse de un experimento within con 54 unidades experimentales, sugirió la existencia de un efecto del conocimiento independiente de la experiencia. Además, el experimento E-2012 fue realizado utilizando a estudiantes con relativamente poca experiencia como sujetos experimentales, lo que refuerza nuestra impresión de que los efectos detectados se deben al conocimiento del dominio, y no la experiencia de la que en buena medida carecían los sujetos.

En segundo lugar, el contacto con los dominios del problema puede ser de muy distintos tipos. En el caso de los problemas experimentales usados más frecuentemente (PC1 y PD1), y de las poblaciones estudiadas, creemos que lo más probable es que el contacto de los sujetos con PC1 sea somero, esto es, los sujetos conocen los conceptos del dominio, pero no han desarrollado una actividad profesional (educción, diseño, implementación, etc.) sustancial en el mismo. Aún así, hemos detectado efectos bajos del conocimiento del dominio. Si el contacto de los sujetos con PC1 hubiera sido sustancial, es posible que el tamaño de efecto se incrementase sustancialmente, quizás hasta alcanzar niveles medios.

\subsection{3 ¿̇nfluye la formación académica en la efectividad del proceso de educción? (RQ3)}

Nuestros resultados apuntan a un efecto positivo de la titulación académica en Informática, pero las evidencias que poseemos al respecto son muy débiles. No obstante, nos decantamos por esta conclusión, ya que ello estaría en completa concordancia con el efecto positivo de la formación, que si hemos podido comprobar con un grado razonable de certidumbre.

El efecto de la formación merece un comentario aparte. No deja de ser sospechoso que, en estudios realizados en un ámbito académico, la formación haya resultado tener un impacto tan importante en la efectividad de los analistas. Este particular ya ha sido discutido en la sección de Amenazas a la Validez, pero merece la pena retomarlo aquí.

Nuestro marco de referencia respecto a la titulación académica provenía de Carver et al. (2008), y ello derivó en una postura similar en lo que respecta a la formación, esto es, asumíamos que la formación podría ejercer efectos negativos. Por ello, para nosotros fuimos los primeros sorprendidos al observar un efecto positivo y alto de la formación, así como evidencias de un efecto positivo de la titulación académica. Al menos de forma consciente, no hemos hecho nada que haya permitido sesgar los resultados en esta dirección.

\subsubsection{Existencia de variables moderadoras}

Hemos confirmado la existencia de múltiples variables moderadoras que afectan al proceso de educción, como son el entrevistado o la formación. Bien es cierto que la influencia de dichas variables 
podía predecirse en base al sentido común, pero conviene no confiar ciegamente en esta fuente de conocimiento.

Además, por lo que nosotros sabemos, no existe constancia en la literatura empírica de la influencia de estas variables. A este respecto, podemos ser incluso más específicos: ningún estudio acerca de educción de requisitos con entrevistas (véase, por ejemplo, el anexo web de (Dieste \& Juristo, 2011)) especifica quién o quiénes actúan a modo de entrevistados. Esto no supone necesariamente una amenaza a la validez de dichos estudios, pero cabe la posibilidad de que no considerar los entrevistados pueda haber perjudicado la obtención de resultados estadísticamente significativos, ya que no se ha extraído la varianza del entrevistado del término error.

\subsubsection{Aspectos metodológicos}

Finalmente, hemos también podido establecer la importancia de ciertos aspectos metodológicos durante esta investigación: (1) ha resultado crucial contar con un diseño experimental y tamaño muestral adecuados para identificar con seguridad los efectos de las variables independientes y factores bajo estudio y (2) la dicotomización de variables continuas debe evitarse debido a que es sencillo que arrojen resultados espurios.

\subsection{Futuras Líneas de Investigación}

La familia de estudios empíricos realizados apunta claramente a efectos positivos de la experiencia (restringida a dominios del problema conocidos), conocimiento del dominio del problema y, probablemente, titulación académica en la efectividad de los analistas cuando realizan actividades de educción. Este resultado está ligado, adicionalmente, a las fases tempranas de la educción, usando como técnica de educción la entrevista abierta (o no estructurada).

La propia formulación de los resultados obtenidos sugiere claramente ciertas líneas de actuación. Una de ellas, aunque quizás no la más importante, consiste en replicar, a ser posible utilizando distintos protocolos, los estudios empíricos realizados. Decimos que no la más importante aún a sabiendas de que resulta pretencioso por nuestra parte. En efecto, la replicación siempre es necesaria para confirmar o refutar los resultados de estudios previos. Sin embargo, después de 8 estudios con resultados razonablemente coherentes y que pueden explicar, al menos en parte, los resultados del estado de la cuestión, en nuestra opinión la investigación debería dirigirse a terrenos no tan explorados. La única excepción sería realizar las replicaciones con sujetos y en entornos profesionales. Ello sí que constituiría una aportación de la mayor relevancia.

Por ejemplo, parece mucho más relevante investigar qué ocurre con la efectividad de los analistas en entrevistas posteriores a la primera. ¿Son más efectivos los analistas con conocimiento del dominio en proporción al número de entrevistas realizadas? ¿Permite la experiencia que los analistas mejoren su efectividad en dominios del problema desconocidos? Ambas preguntas son relevantes y ayudarían a entender mejor la actividad de educción.

A medida que progresa en la actividad de educción, el analista se aproxima a la actividad de análisis. En realidad, el análisis es inherente a la propia conceptualización del dominio del problema y, por lo tanto, ocurre durante la misma consolidación de la entrevista. Sin embargo, durante la actividad de análisis, el analista dispone de herramientas, como los modelos conceptuales, las cuales le pueden ayudar a mostrar omisiones e inconsistencias en la información educida. Una pregunta de investigación de la máxima relevancia podría ser el efecto que la utilización de modelos conceptuales ejerce sobre la efectividad del analista. Otro atractivo de esta línea es que existen una buena cantidad de trabajos realizados en el área de modelización conceptual, por lo que cualquier resultado obtenido podría contribuir a crear una teoría que englobase la educción y el análisis conjuntamente. 
Otra línea de investigación que creemos relevante es estudiar el efecto que la transmisión de información tiene en la efectividad del analista. En esta investigación, los entrevistados contestaron libremente a las preguntas de los analistas. Si bien este es el modo adecuado de proceder para aumentar el realismo de los estudios empíricos, oculta ciertos aspectos que podrían ser relevantes. Por ejemplo ¿Qué ocurriría si el entrevistado ejerciera un rol más pasivo? ¿O si explicitara siempre toda la información? ¿Contribuiría ello a cambiar la visibilidad de los elementos del problema, o el techo de cristal?

No obstante, uno de los resultados más consistentes que hemos obtenido en esta tesis es la incapacidad de las variables independientes utilizadas para explicar la mayor parte de la variabilidad observada. De ello se desprende que la mayor parte de la efectividad del analista viene dada por aspectos internos, psicológicos o personales. Identificar las habilidades débiles (soft skills) asociados a analistas con alta efectividad supondría no sólo comprender mejor que hace a un analista altamente efectivo, sino también permitiría mejorar su formación. $Y$ aunque no somos proclives a ello por aspectos fundamentalmente éticos, confesamos que indagar en los fundamentos psicológicos de la efectividad podría resultar igualmente esclarecedor. 



\section{REFERENCIAS}

Acuña, S. T., \& Juristo, N. (2004). Assigning people to roles in software projects. Software: Practice and Experience, 34(7), 675-696. doi:10.1002/spe.586

Acuña, S. T., Gómez, M. N., Hannay, J. E., Juristo, N., \& Pfahl, D. (2015). Are team personality and climate related to satisfaction and software quality? aggregating results from a twice replicated experiment. Information and Software Technology, 57, 141-156. doi:http://dx.doi.org/10.1016/i.infsof.2014.09.002

Acuña, S. T., Gómez, M., \& Juristo, N. (2009). How do personality, team processes and task characteristics relate to job satisfaction and software quality? Information and Software Technology, 51(3), 627-639. doi:10.1016/j.infsof.2008.08.006

Agarwal, R., \& Tanniru, M. R. (1990). Knowledge acquisition using structured interviewing: An empirical investigation. Journal of Management Information Systems, 7(1), 123-141.

Ahmed, F., Capretz, L. F., \& Campbell, P. (2012). Evaluating the demand for soft skills in software development. IT Professional, 14(1), 44-49. doi:10.1109/MITP.2012.7

Ahmed, F., Capretz, L. F., Bouktif, S., \& Campbell, P. (2013). Soft skills and software development: A reflection from the software industry. International Journal of Information Processing and Management (IJIPM), 4(3), 171-191. doi:10.4156/ijipm.vol4.issue3.17

Albayrak, Ã., \& Carver, J. (2014). Investigation of individual factors impacting the effectiveness of requirements inspections: A replicated experiment. Empirical Software Engineering, 19(1), 241266. doi:10.1007/s10664-012-9221-0

Al-Rawas, A., \& Easterbrook, S. M. (1996). Communication problems in requirements engineering: A field study. Brighton, UK: National Aeronautics and Space Administration.

Amrit, C., Daneva, M., \& Damian, D. (2014). Human factors in software development: On its underlying theories and the value of learning from related disciplines; A guest editorial introduction to the special issue. Information and Software Technology, 56, 1537-1542. doi:10.1016/j.infsof.2014.07.006

Anderson, J. (2000). Cognitive psychology and its implications (5th ed.). USA: Worth Publishers.

Anwar, F., Razali, R., \& Ahmad, K. (2011). Achieving effective communication during requirements elicitation - A conceptual framework. In J. Zain, W. Wan Mohd \& E. El-Qawasmeh (Eds.), Software engineering and computer systems (pp. 600-610) Springer Berlin Heidelberg. doi:10.1007/978-3-642-22203-0_51

Appan, R., \& Browne, G. J. (2012). The impact of analyst-induced misinformation on the requirements elicitation process. MIS Quarterly, 36(1), 85.

Aranda, A. M., Dieste, O., \& Juristo, N. (2013). Proposal of a quasi-experiment for studying the effect of experience on elicitation effectiveness. Proceedings of the REFSQ 2013 Workshops CreaRE, IWSPM, and RePriCo, the REFSQ 2013 Empirical Track (Empirical Live Experiment and Empirical Research Fair), the REFSQ 2013 Doctoral Symposium, and the REFSQ 2013 Poster Session, Essen, Germany. , 56 155-158. 
Aranda, A., Dieste, O., \& Juristo, N. (2012). In search of requirements analyst characteristics that influence requirements elicitation effectiveness: A quasi-experiment. In S. T. Acuña, M. Gómez \& K. Koroutchev (Eds.), 1st workshop on managing the influence of people and team factors in software engineering (pp. 20-29). Madrid.

Aranda, A., Dieste, O., \& Juristo, N. (2014). Evidence of the presence of bias in subjective metrics: Analysis within a family of experiments. Proceedings of the 18th International Conference on Evaluation and Assessment in Software Engineering (EASE 2014), London, UK. 24-27.

Atkins, C. (2013). An investigation of the impact of requirements engineering skills on project success

Aurum, A., \& Wohlin, C. (2005). Engineering and managing software requirements. Berlín: Springer.

Baron, R. M., \& Kenny, D. A. (1986). The moderator-mediator variable distinction in social psychological research: Conceptual, strategic, and statistical considerations. Journal of Personality and Social Psychology, 51(6), 1173-1182. doi:10.1037/0022-3514.51.6.1173

Belsley, D. A. (1991). Conditioning diagnostics: Collinearity and weak data in regression. New York: Wiley.

Brown, B. W. J. (1980). The crossover experiment for clinical trials. Biometrics, 36(1), 69-79.

Browne, G. J., \& Rogich, M. B. (2001). An empirical investigation of user requirements elicitation: Comparing the effectiveness of prompting techniques. Journal of Management Information Systems, 17(4), 223-249.

Burton, A. M., Shadbolt, N. R., Rugg, G., \& Hedgecock, A. P. (1988). Knowledge elicitation techniques in classification domains. In Y. Kodratoff (Ed.), ECAl-88 proceedings of the eighth europuean conferene on Al (London, UK ed., pp. 85-90) Pitman.

Camerer, C. F., \& Johnson, E. J. (1997). The process-performance paradox in expert judgment: How can experts know so much and predict so badly? In W. Goldstein, \& R. Hogarth (Eds.), Research on judgment and decision making: Currents, connections, and controversies (pp. 342-364) Cambridge University Press.

Capretz, L. F., \& Ahmed, F. (2010). Making sense of software development and personality types. IT Professional, 12(1), 6-13. doi:10.1109/MITP.2010.33

Carrizo, D., Dieste, O., \& Juristo, N. (2014). Systematizing requirements elicitation technique selection. Information and Software Technology, 564(6), doi:http://dx.doi.org/10.1016/j.infsof.2014.01.009

Carver, J. C. (2010). Towards reporting guidelines for experimental replications: A proposal. Proceedings of the 1st International Workshop on Replication in Empirical Software Engineering Research (RESER), Cape Town, South Africa. , 35(5) 42-44.

Carver, J. C., Nagappan, N., \& Page, A. (2008). The impact of educational background on the effectiveness of requirements inspections: An empirical study. IEEE Transactions on Software Engineering, 34(6), 800-812.

Chakraborty, S., Sarker, S., \& and Valacich, J. S.(2007). Understanding analyst effectiveness in requirements elicitation: A gestalt fit perspective. ECIS 2007 Proceedings, ,771-782.

Chakraborty, S., Sarker, S., \& Sarker, S. (2010). An exploration into the process of requirements elicitation: A grounded approach. Journal of the Association for Information Systems, 11(4), 1.

Chase, W. G., \& Simon, H. A. (1973). The mind's eye in chess. 
Chatzoglou, P. D. (1997). Factors affecting completion of the requirements capture stage of projects with different characteristics. Information and Software Technology.39(9), 627-640.

Chatzoglou, P. D., \& Macaulay, L. A. (1997). The importance of human factors in planning the requirements capture stage of a project. International Journal of Project Management, 15(1), 39-53. doi:http://dx.doi.org/10.1016/S0263-7863(96)00038-5

Chi, M. T., Feltovich, P. J., \& Glaser, R. (1981). Categorization and representation of physics problems by experts and novices. Cognitive Science, 5(2), 121-152.

Chmiel, R., \& Loui, M. C. (2004). Debugging: From novice to expert. ACM SIGCSE Bulletin, , 36(1) 17-21.

Christel, M. G., \& Kang, K. C. (1992). Issues in requirements elicitation. Pittsburgh, PA: Carnegie Mellon University, Software Engineering Institute

Cohen, J. (1988). Statistical power analysis for the behavioral sciences (Second ed.). Hillsdale, NJ: Lawrence Erlbaum Associates.

Colvin, G. (2008). Talent is overrated: What really separates world-class performers from EverybodyElse Penguin Publishing Group.

Condori-Fernandez, N., Daneva, M., Sikkel, K., Wieringa, R., Dieste, O., \& Pastor, O. (2009). A systematic mapping study on empirical evaluation of software requirements specifications techniques. Empirical Software Engineering and Measurement, 2009. ESEM 2009. 3rd International Symposium on, 502-505. doi:10.1109/ESEM.2009.5314232

Cook, T. D., \& Campbell, D. T. (1979). Quasi-experimentation: Design \& analysis issues for field settings. Boston: Houghton Mifflin.

Cooke, N. J. (1999). Knowledge elicitation. In F. Thomas Durso, \& R. S. Nickerson (Eds.), Knowledge elicitation (pp. 479-510). Chichester, England: John Wiley \& Sons Ltd.

Coughlan, J., Lycett, M., \& Macredie, R. D. (2003). Communication issues in requirements elicitation: A content analysis of stakeholder experiences. Information and Software Technology, 45(8), 525537.

Curtis, B. (1984). Fifteen years of psychology in software engineering: Individual differences and cognitive science. Orlando, Florida, USA: IEEE Press.

Curtis, B., Krasner, H., \& Iscoe, N. (1988). A field study of the software design process for large systems. Communications of the ACM, 31(11), 1268-1287.

Dattalo, P. (2007). Determining sample size : Balancing power, precision, and practicality. USA: Oxford University Press.

Davis, A. (1993). Software requirements: Objects, functions and states. Englewood Cliffs, N.J.: PrenticeHall.

De Groot, A. D. (1978). Thought and choice in chess Walter de Gruyter.

Dieste, O., \& Juristo, N. (2011). Systematic review and aggregation of empirical studies on elicitation techniques. IEEE Transactions on Software Engineering, 37(2), 283-304. doi:10.1109/TSE.2010.33

Ericsson, K. A. (2006). The influence of experience and deliberate practice on the development of superior expert performance. The Cambridge Handbook of Expertise and Expert Performance, , 683-703.

Ericsson, K. A. (2006b). An introduction to cambridge handbook of expertise and expert performance: Its development, organization, and content. In Ericsson, N. Charness, R. R. Hoffman \& P. J. 
Feltovich (Eds.), The cambridge handbook of expertise and expert performance (pp. 3-19) Cambridge University Press.

Ericsson, K. A., \& Simon, H. A. (1996). Protocol analysis: Verbal reports as data. Cambridge, MA, USA: MIT Press.

Ericsson, K. A., \& Smith, J. (1991). Prospects and limits of the empirical study of expertise: An introduction. Toward a General Theory of Expertise: Prospects and Limits, (344), 1-38.

Falkenberg, E. D., Hesse, W., Lindgreen, P., Nilsson, B. E., Oei, J. L. H., Rolland, C., . . Voss, K. (1996). FRISCO: A framework of information system concepts. Group FRISCO.

Faul, F., Erdfelder, E., Lang, A., \& Buchner, A. (2007). G* power 3: A flexible statistical power analysis program for the social, behavioral, and biomedical sciences. Behavior Research Methods, 39(2), 175-191.

Gómez, O. S., Juristo, N., \& Vegas, S. (2014). Understanding replication of experiments in software engineering: A classification. Information and Software Technology, 56(8), 1033-1048. doi:http://dx.doi.org/10.1016/j.infsof.2014.04.004

Graham, J. W., \& Schafer, J. L. (1999). On the performance of multiple imputation for multivariate data with small sample size. In R. H. Hoyle (Ed.), Statistical strategies for small sample research (pp. v-29) Sage Publications.

Green, S. B. (1991). How many subjects does it take to do A regression analysis. Multivariate Behavioral Research, 26(3), 499-510. doi:10.1207/s15327906mbr2603_7

Gunter, C. A., Gunter, E. L., Jackson, M., \& Zave, P. (2000). A reference model for requirements and specifications. Software, IEEE, 17(3), 37-43. doi:10.1109/52.896248

Gupta, S. K. (2011). Intention-to-treat concept: A review. Perspectives in Clinical Research, 2(3), 109-112. doi:10.4103/2229-3485.83221 [doi]

Hadar, I., Soffer, P., \& Kenzi, K. (2012). The role of domain knowledge in requirements elicitation via interviews: An exploratory study. Requirements Engineering, 19, 1-17. doi:10.1007/s00766-0120163-2

Hair, J. F., Hair, J. F., Black, W. C., Babin, B. J., \& Anderson, R. E. (2013). Multivariate data analysis. U.K: Pearson Education Limited.

Heiberger, R. M., \& Holland, B. (2013). Statistical analysis and data display: An intermediate course with examples in S-plus, $R$, and SAS (1st ed.). Verlag New York: Springer. doi:10.1007/978-1-47574284-8

Herrmann, A. (2013). Requirements engineering in practice: There is no requirements engineer position. In J. Doerr, \& A. Opdahl (Eds.), (pp. 347-361) Berlin Heidelberg: Springer. doi:10.1007/978-3642-37422-7_25

Hove, S. E., \& Anda, B. (2005). Experiences from conducting semi-structured interviews in empirical software engineering research. Software Metrics, 2005. 11th IEEE International Symposium, (10) 23.

Hoyle, R. H. (1999). Preface. In R. H. Hoyle (Ed.), Statistical strategies for small sample research (pp. v-vii) Sage Publications.

Jabar, M. A., Yeong, C. C., \& Sidi, F. (2012). Information systems development knowledge sharingorganizational justice, physical distance and social interdependence. Journal of Computer Science, 8(1), 31-40. doi:10.3844/jcssp.2012.31.40 
Jedlitschka, A., \& Pfahl, D. (2005). Reporting guidelines for controlled experiments in software engineering Fraunhofer IESE.

Jeffries, R., Turner, A. A., Polson, P. G., \& Atwood, M. E. (1981). The processes involved in designing software. Cognitive Skills and their Acquisition, 255, 283.

Juristo, N., \& Moreno, A. M. (2001). Basics of software engineering experimentation (1st ed.) Kluwer Academic Publishers.

Kitchenham, B. A., Pfleeger, S. L., Pickard, L. M., Jones, P. W., Hoaglin, D. C., El Emam, K., \& Rosenberg, J. (2002). Preliminary guidelines for empirical research in software engineering. IEEE Transactions on Software Engineering, 28(8), 721-734.

Kitchenham, B., \& Charters, S. (2007). Guidelines for performing systematic literature reviews in software engineering. version 2.3. ( No. EBSE-2007-01).Keele University.

Kotonya, G., \& Sommerville, I. (1998). Requirements engineering: A good practice guide. New York , NY, USA: Wiley.

Kristensson, P., Gustafsson, A., \& Archer, T. (2004). Harnessing the creative potential among users*. Journal of Product Innovation Management, 21(1), 4-14. doi:10.1111/j.0737-6782.2004.00050.x

Kuehl, R. O. (2000). Design of experiments: Statistical principles of research design and analysis Duxbury/Thomson Learning.

Loucopoulos, P., \& Karakostas, V. (1995). Systems requirements engineering. London: McGraw-Hill.

MacCallum, R., Zhang, S., Preacher, K., \& Rucker, D. (2002). On the practice of dichotomization of quantitative variables. , 7(1) 19-40.

MacDorman, K. F., Whalen, T. J., Ho, C., \& Patel, H. (2011). An improved usability measure based on novice and expert performance. International Journal of Human-Computer Interaction, 27(3), 280-302. doi:10.1080/10447318.2011.540472

Marakas, G. M., \& Elam, J. J. (1998). Semantic structuring in analyst and representation of facts in requirements analysis. Information Systems Research, 9(1), 37-63.

Marakas, G. M., \& Elam, J. J. (1998). Semantic structuring in analyst and representation of facts in requirements analysis. Information Systems Research, 9(1), 37-63. doi:10.1287/isre.9.1.37

Matturro, G. (2013). Soft skills in software engineering: A study of its demand by software companies in uruguay. Cooperative and Human Aspects of Software Engineering (CHASE), 2013 6th International Workshop on, 133-136. doi:10.1109/CHASE.2013.6614749

McAllister, C. A. (2006). Requirements determination of information systems: User and developer perceptions of factors contributing to misunderstandings: Capella University.

McKeithen, K. B., Reitman, J. S., Rueter, H. H., \& Hirtle, S. C. (1981). Knowledge organization and skill differences in computer programmers. Cognitive Psychology, 13(3), 307-325.

McLeod, L., \& MacDonell, S. G. (2011). Factors that affect software systems development project outcomes: A survey of research. ACM Comput. Surv, 43(4), http://dl.acm.org/citation.cfm?id=1978803-1-56.

Mehrotra, G. (2011). Role of domain ignorance in software development. (Unpublished University of Waterloo)

Meyers, L. S., Gamst, G., \& Guarino, A. J. (2012). Applied multivariate research: Design and interpretation SAGE Publications. 
Estudio empírico de la influencia de la experiencia y del conocimiento del dominio del analista en la efectividad del proceso de educción de requisitos

Miles, J., \& Shevlin, M. (2001). Applying regression and correlation: A guide for students and researchers SAGE Publications.

Mishra, J., \& Mohanty, A. (2011). Software engineering. India: Pearson Education.

Misic, M. M., \& Graf, D. K. (2004). Systems analyst activities and skills in the new millennium. Journal of Systems and Software, 71(1-2), 31-36. doi:10.1016/S0164-1212(02)00124-3

Moody, J. W., Blanton, J. E., \& Will, R. P. (1999). Capturing expertise from experts: The need to match knowledge elicitation techniques with expert system types. Journal of Computer Information Systems, 39(2), 89-95. doi:10.1080/08874417.1999.11647396

Niknafs, A. (2014). The impact of domain knowledge on the effectiveness of requirements engineering activities

Niknafs, A. (2014). The impact of domain knowledge on the effectiveness of requirements engineering activities. (Unpublished University of Waterloo)

Niknafs, A., \& Berry, D. M. (2012). The impact of domain knowledge on the effectiveness of requirements idea generation during requirements elicitation. Requirements Engineering Conference (RE), 2012 20th IEEE International, Chicago, IL. 181-190.

doi:10.1109/RE.2012.6345802

Niknafs, A., \& Berry, D. M. (2013). An industrial case study of the impact of domain ignorance on the effectiveness of requirements idea generation during requirements elicitation. Requirements Engineering Conference (RE), 2013 21st IEEE International, 279-283. doi:10.1109/RE.2013.6636730

O'brien, R. (2007). A caution regarding rules of thumb for variance inflation factors. Quality \& Quantity, 41(5), 673-690. doi:10.1007/s11135-006-9018-6

Osborn, A. F. (1963). Applied imagination: Principles and procedures of creative problem-solving (3rd Edition ed.). New York, NY: Charles Scribner's Sons.

Pacheco, C., \& Garcia, I. (2012). A systematic literature review of stakeholder identification methods in requirements elicitation. Journal of Systems and Software, 85(9), 2171-2181. doi:http://dx.doi.org/10.1016/j.jss.2012.04.075

Pirzadeh, L. (2010). Human factors in software development: A systematic literature review. (Unpublished Chalmers University of Technology)

Pitts, M. G., \& Browne, G. J. (2004). Stopping behavior of systems analysts during information requirements elicitation. Journal of Management Information Systems, 21(1), 203-226.

Razali, R., \& Anwar, F. (2011). Selecting the right stakeholders for requirements elicitation: A systematic approach. Journal of Theoretical and Applied Information Technology, 33(2), 250-257.

Richy, F., Ethgen, O., Bruyere, O., Deceulaer, F., \& Reginster, J. (2004). From sample size to effect-size: Small study effect investigation (SSEi). The Internet Journal of Epidemiology, 1(2)

Saiediana, H., \& Daleb, R. (2000). Requirements engineering: Making the connection between the software developer and customer. Information and Software Technology, 42(6), 419-428. doi:10.1016/S0950-5849(99)00101-9

Schenk, K. D., Vitalari, N. P., \& Davis, K. S. (1998). Differences between novice and expert systems analysts: What do we know and what do we do? Journal of Management Information Systems,15(1), 9-50. doi:10.1080/07421222.1998.11518195.

Senn, S. (2003). Cross-over trials in clinical research (2nd ed.) John Wiley \& Sons. 
Shadish, W., Cook T., \& Campbell D.T. (2001). Experimental and quasi-experimental designs for generalized causal inference: Houghton Mifflin Company.

Siegmund, J., Kästner, C., Liebig, J., Apel, S., \& Hanenberg, S. (2014). Measuring and modeling programming experience. Empirical Software Engineering, 19(5), 1299-1334. doi:10.1007/s10664-013-9286-4

Sommerville, I. (2009). Requirements engineering: A good practice guide Wiley India Pvt. Limited.

Sonnentag, S. (1998). Expertise in professional software design: A process study. Journal of Applied Psychology, 83(5), 703-715. doi:10.1037/0021-9010.83.5.703

Tuya, J., Ramos Román, I., \& Dolado Cosín, J. J. (2007). Técnicas cuantitativas para la gestión en la ingeniería del software: Netbiblo, S.L.

Urquhart, C. (2001). Analysts and clients in organisational contexts: A conversational perspective. The Journal of Strategic Information Systems, 10(3), 243-262. doi:http://dx.doi.org/10.1016/S09638687(01)00046-4

Vale, L., Albuquerque, A. B., \& Beserra, P. (2010). Relevant skills to requirement analysts according to the literature and the project managers perspective. 7th International Conference on the Quality of Information and Communications Technology, QUATIC 2010, Porto. 228-232. doi:10.1109/QUATIC.2010.40

Vale, L., Albuquerque, A. B., \& Beserra, P. V. (2011). The importance of professional quality of requirements analysts for success of software development projects: A study to identify the most relevant skills. 25th Brazilian Symposium on Software Engineering, SBES 2011, Sao Paulo. 253-262. doi:10.1109/SBES.2011.24

Valenti, S., Panti, M., \& Cucchiarelli, A. (1998). Overcoming communication obstacles in user-analyst interaction for functional requirements elicitation. SIGSOFT Software Engineering Notes, 23(1), 50-55.

Vitalari, N. P. (1992). Structuring the requirements analysis process for information systems: A proposition viewpoint. In C. William W., \& S. James A. (Eds.), Challenges and strategies for research in systems development (pp. 163-179). New York, NY, USA: John Wiley \& Sons, Inc.

Vitalari, N. P., \& Dickson, G. W. (1983). Problem solving for effective systems analysis: An experimental exploration. Communications of the ACM, 9(1), 948-956. doi:10.1145/182.358458.

Vitharana, P., Jain, H., \& Zahedi, F. M. (2012). A knowledge based component/service repository to enhance analysts' domain knowledge for requirements analysis. Information \& Management, 49(1), 24-35. doi:http://dx.doi.org/10.1016/j.im.2011.12.004

Wagner, W. P., Otto, J., \& Chung, Q. B. (2002). Knowledge acquisition for expert systems in accounting and financial problem domains. Knowledge-Based Systems, 15(8), 439-447. doi:10.1016/S09507051(02)00026-6

Walz, D. B., Elam, J. J., \& Curtis, B. (1993). Inside a software design team: Knowledge acquisition, sharing, and integration. Communications of the ACM, 36, 62-77. doi:10.1145/163430.163447

Wiegers, K. (2003). So you want to be a requirements analyst. Originally Published in Software Development, 11(7)

Wohlin, C., Runeson, P., Höst, M., Ohlsson, M. C., Regnell, B., \& Wesslén, A. (2012). Experimentation in software engineering (1st ed.). Berlin Heidelberg: Springer. doi:10.1007/978-3-642-29044-2

Wood, J., \& Silver, D. (1989). Joint application design: How to design quality systems in $40 \%$ less time. New York: Wiley. 
Estudio empírico de la influencia de la experiencia y del conocimiento del dominio del analista en la efectividad del proceso de educción de requisitos

Yadav, S. B., Bravoco, R. R., Chatfield, A. T., \& Rajkumar, T. M. (1988). Comparison of analysis techniques for information requirements determination. Communications of the ACM, 31(9), 1090-1097.

Young, R. R. (2002). Recommended requirements gathering practices. Crosstalk, April 2002, 9-12.

Zhang, H., \& Babar, M. A. (2010). On searching relevant studies in software engineering. Proceedings of the 14th International Conference on Evaluation and Assessment in Software Engineering, UK. 111120.

Zowghi, D., \& Coulin, C. (2005). Requirements elicitation: A survey of techniques, approaches, and tools. In A. Aurum, \& C. Wohlin (Eds.), Engineering and managing software requirements (pp. 19-46) Berlin Heidelberg: Springer. doi:10.1007/3-540-28244-0_2 
ANEXOS 



\section{ANEXO A}

\section{Cuestionarios}

El presente anexo contiene los cuestionarios post-experimentales utilizados en los distintos cuasiexperimentos y experimentos ejecutados a lo largo de la investigación. Nótese que los mismos fueron evolucionando en paralelo con los estudios experimentales. Los cuestionarios contienen preguntas que recogen información de los sujetos experimentales respecto a su formación, experiencia en distintas actividades relacionadas con requisitos, conocimientos previos, entre otras. Como dichos cuestionarios fueron aplicados al final de cada estudio experimental, también recogen información sobre los objetos experimentales utilizados: familiaridad con el dominio, dificultad, cantidad de sesiones, etc.

\section{A.1. Cuasi-Experimento Q-2007}

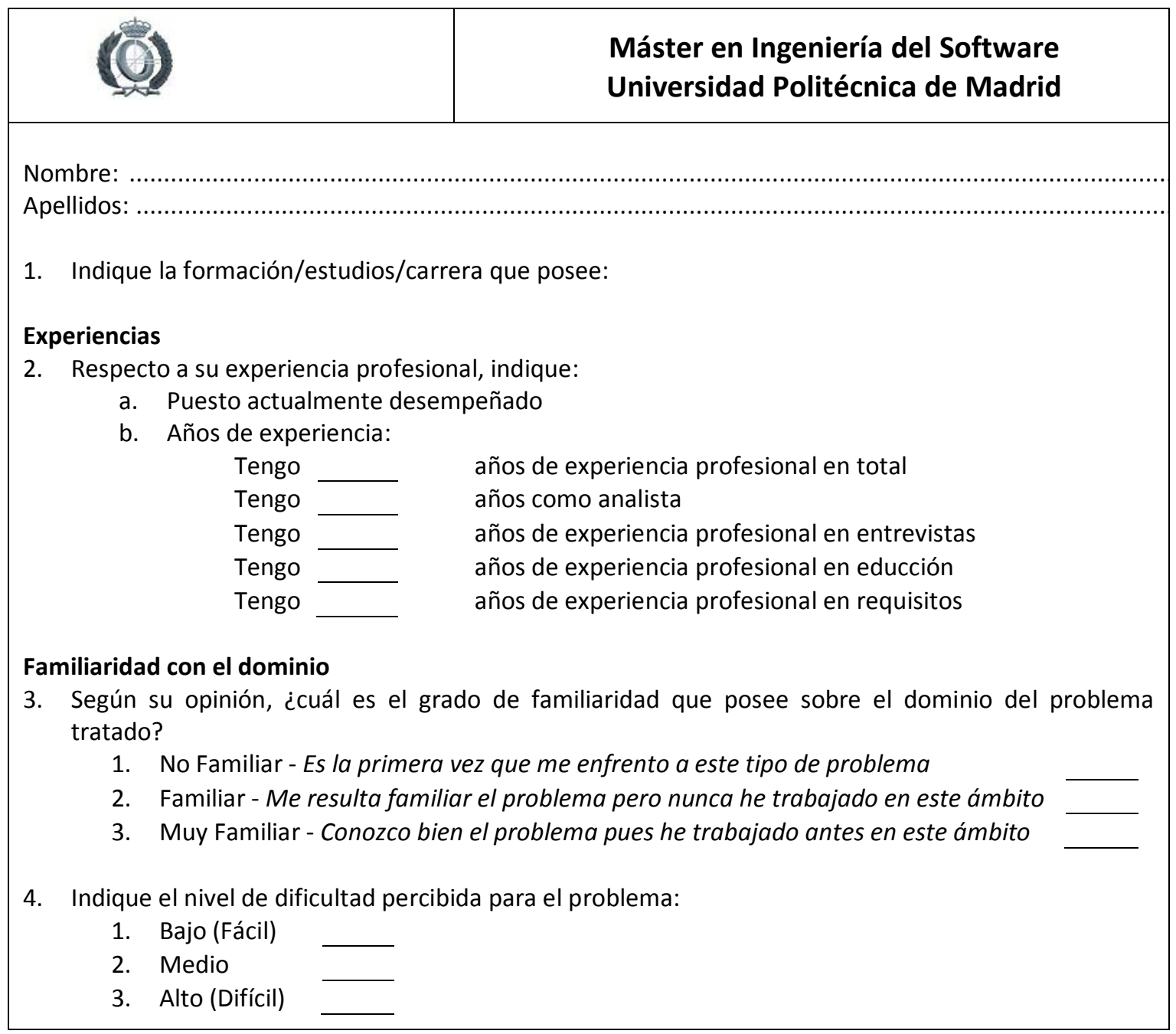




\section{A.2. Cuasi-Experimento Q-2009}

Name:

Last Name:

\section{Professional Experience}

1. How many years of interviewing experience did you have before the master? (If you do not know it exactly indicate the approximate number; decimals are allowed) $\left(^{*}\right)$

2. How many years of elicitation experience did you have before the master? (If you do not know it exactly indicate the approximate number; decimals are allowed) $\left({ }^{*}\right)$

3. How many years of requirements experience did you have before the master? (If you do not know it exactly indicate the approximate number; decimals are allowed) $\left({ }^{*}\right)$

4. How many years of software development experience did you have before the master? (If you do not know it exactly indicate the approximate number; decimals are allowed) $\left({ }^{*}\right)$

5. How many years of system professional experience did you have before the master? (If you do not know it exactly indicate the approximate number; decimals are allowed) $(*)$

6. According to your opinion, indicate your skills during the master in (from 1=very low to $5=$ very high): $(*)$

\begin{tabular}{|l|c|c|c|c|c|}
\hline & 1 & 2 & 3 & 4 & 5 \\
\hline Interviews & 0 & 0 & 0 & 0 & 0 \\
\hline Elicitation & 0 & 0 & 0 & 0 & 0 \\
\hline Requirements Specification & 0 & 0 & 0 & 0 & 0 \\
\hline Systems Development & 0 & & & 0 & 0 \\
\hline
\end{tabular}

Knowledge about the problem domain (Batteries Recycling Problem)

7. According to your opinion, what was your knowledge of the problem proposed in the exercise? $\left(^{*}\right)$

( ) You knew the problem because you have worked on it before

( ) It' was familiar to you, but you haven't worked on it before

( ) It' was the first time that I had this kind of problem

Thanks for your answer!! 


\section{A.3. Cuasi-Experimento Q-2011}

Name:

Last Name:

\section{English Language}

1. Your listening comprehension is:
( ) Advanced
( ) Intermediate
( ) Basic
( ) English is my native language

2. Your writing is:
( ) Advanced
( ) Intermediate
( ) Basic
( ) English is my native language

\section{Academic Education}

3. What is your bachelor degree?

4. How many years does your degree have?

5. Select the requirements engineering topics that you studies before enrolling the current master at UPM:

[ ] Elicitation techniques

[ ] Natural language analysis

[ ] Data modeling

[ ] Process modeling

[ ] Use cases / user stories

[ ] Requirements writing

[ ] Requirements tools

[ ] Reviews

[ ] Mock-ups / storyboards / prototyping

[ ] Change management

[ ] Formal specification

[ ] Model checking

[ ] Product lines

[ ] Others

If you have checked "others", please specify further: 


\section{Professional Experience}

6. Are you currently:
( ) Studying?
( ) Working?
( ) Studying and Working?
If you are working, indicate your job position:

7. Indicate your previous job positions (if any):

8. How many years of interviewing experience do you have? (If you do not know it exactly indicate the approximate number)

9. How many years of elicitation experience do you have? (If you do not know it exactly indicate the approximate number)

10. According to your opinion, indicate your skills (1=very low to $5=$ vary much) in:

\begin{tabular}{|l|c|c|c|c|c|}
\hline \multicolumn{1}{|c|}{ Skills } & $\mathbf{1}$ & $\mathbf{2}$ & $\mathbf{3}$ & $\mathbf{4}$ & $\mathbf{5}$ \\
\hline Interviews & ( ) & $($ ) & $($ ) & ( ) & ( ) \\
\hline Requirements Specification & $($ ) & $($ ) & $($ ) & ( ) & ( ) \\
\hline Conceptualization or Modeling & $($ ) & $($ ) & $($ ) & ( ) & ( ) \\
\hline
\end{tabular}

\section{Knowledge of the domain problem}

11. According to your opinion, what is your knowledge of the problem proposed in the final (written) test?

( ) You know the problem because you have worked on it before

( ) It's familiar to you, but you haven't worked on it before

( ) It's the first time I have this kind of problem

12. According to your opinion, what is the level of difficulty of the problem proposed in the final (written) test?
( ) High
( ) Medium
( ) Low

\section{Elicitation and conceptualization}

13. Do you think there has been enough time for the elicitation process during the final (written) test?
( ) Yes

( ) No

In case of a negative answer, explain why:

14. Do you think there has been enough time for the consolidation process during the final (written) test?
( ) Yes
( ) No

In case of a negative answer, explain why: 
15. Do you think there has been enough time to write the requirements specification during the final (written) test?
( ) Yes
( ) No

In case of a negative answer, explain why:

\section{A.4. Cuasi-Experimento Q-2012}

First Name:

Last Name:

\section{Academic Education}

1. What is your bachelor degree? (*)

2. Is English your native language?
( ) Yes
( ) No

\section{Professional Experience}

3. Indicate your previous and actual job positions and how long have you been working in these job positions:

4. How many years of interviewing experience do you have? (If you do not know exactly indicate an approximate number) $(*)$

5. How many years of elicitation experience do you have? (If you do not know exactly indicate an approximate number) $\left({ }^{*}\right)$

6. How many years of requirements experience do you have? (If you do not know exactly indicate an approximate number) $(*)$

7. How many years of system development experience do you have? (If you do not know exactly indicate an approximate number) $\left({ }^{*}\right)$

8. In your opinion, grade your skills below (from low to high): $\left({ }^{*}\right.$ )

\begin{tabular}{|l|c|c|c|c|c|}
\hline \multicolumn{1}{|c|}{ Skills } & $\mathbf{1}$ & $\mathbf{2}$ & $\mathbf{3}$ & $\mathbf{4}$ & $\mathbf{5}$ \\
\hline Interviews & ( ) & ( ) & ( ) & ( ) & ( ) \\
\hline Requirements Specification & ( ) & $($ ) & ( ) & ( ) & ( ) \\
\hline Systems Development & ( ) & $($ ) & $($ ) & ( ) & ( ) \\
\hline
\end{tabular}

\section{Knowledge about the problem domain}

9. According to your opinion, what was your knowledge of the problem proposed in the exercise? $\left({ }^{*}\right)$

( ) You knew the problem because you have worked on it before

( ) It' was familiar to you, but you haven't worked on it before

( ) It' was the first time that I had this kind of problem 
10. According to your opinion, what was the level of difficulty of the problem proposed in the exercises? $\left(^{*}\right)$
( ) Low
( ) Medium
( ) High

\section{Elicitation and consolidation}

11. Do you think there has been enough time for the elicitation process?
( ) Yes
( ) No
In case of a negative answer, explain why:

12. Do you think there has been enough time to write the interview report? $\left({ }^{*}\right)$
( ) Yes
( ) No

In case of a negative answer, explain why:

\section{@ Contact}

13. If we need some additional information for our investigation, may we contact with your help?

( ) Yes. Can you give us email?

( ) No

\section{Thanks for your answers!!}

Note: All data collected from you will be regarded as confidential.

\section{A.5. Experimentos: E-2012, E-2013, E-2014 y E-2015}

Dado que los cuestionarios utilizados en dichos experimentos son muy similares entre ellos. Se indicará, según corresponda, las preguntas que difieren entre experimentos. Si no se indica nada, significa que se consideraron en los tres experimentos.

Name:

Last Name:

\section{Academic Education}

1. What is your bachelor degree?

2. How many years does your degree have?

3. Select the requirements engineering topics that you studies before enrolling the current master at UPM: 
[ ] Elicitation techniques

[ ] Natural language analysis

[ ] Data modeling

[ ] Process modeling

[ ] Use cases / user stories

[ ] Requirements writing

[ ] Requirements tools

[ ] Reviews

[ ] Mock-ups / storyboards / prototyping

[ ] Change management

[ ] Formal specification

[ ] Model checking

[ ] Product lines

[ ] Others

If you have checked "others", please specify further:

4. Did you attend any course or seminar about Requirements Elicitation? (excluding the current EMSE Master)

( ) Never

() During my Bachelor

( ) In a specific seminar

5. Have you carried out assignments or practical exercises about Requirements Elicitation? (excluding the current EMSE Master)
( ) Never
() During my Bachelor
( ) In a specific seminar

\section{Professional Experience}

6. Are you currently:
( ) Studying?
( ) Working?
( ) Studying and Working?
If you are working, indicate your job position:

7. Indicate your previous job positions (if any):

8. Have you participated in a real project as analyst? How many times?

9. How many years of interviewing experience do you have? (If you do not know it exactly indicate the approximate number; decimals are allowed)

10. How many years of elicitation experience do you have? (If you do not know it exactly indicate the approximate number; decimals are allowed) 
11. How many requirements experience do you have? (If you do not know it exactly indicate the approximate number; decimals are allowed)

12. According to your opinion, indicate your skills ( $1=$ very low to $5=$ vary much) in:

\begin{tabular}{|l|c|c|c|c|c|}
\hline \multicolumn{1}{|c|}{ Skills } & $\mathbf{1}$ & $\mathbf{2}$ & $\mathbf{3}$ & $\mathbf{4}$ & $\mathbf{5}$ \\
\hline Interviews & $(\mathrm{)}$ & $(\mathrm{)}$ & $(\mathrm{)}$ & $(\mathrm{)}$ & $(\mathrm{)}$ \\
\hline Requirements Specification & $(\mathrm{)}$ & $(\mathrm{)}$ & $(\mathrm{)}$ & $(\mathrm{)}$ & $(\mathrm{)}$ \\
\hline System Development & $(\mathrm{)}$ & $(\mathrm{)}$ & $(\mathrm{)}$ & $(\mathrm{)}$ & $(\mathrm{)}$ \\
\hline
\end{tabular}

\section{Knowledge of the domain problem}

13. According to your opinion, what is your knowledge of the problem proposed in the final the exercises? ${ }^{47}$

\begin{tabular}{|l|c|c|c|}
\hline \multicolumn{1}{|c|}{ Problem Domain } & 1 & 2 & 3 \\
\hline P1. Messaging Problem & ( ) & ( ) & ( ) \\
\hline P2. Recycling Batteries Problem & ( ) & ( ) & ( ) \\
\hline P3. Stock Exchange Problem & ( ) & ( ) & ( ) \\
\hline P4. University Registration System & ( ) & ( ) & ( ) \\
\hline
\end{tabular}

1. You know the problem because you have worked on it before

2. It's familiar to you, but you haven't worked on it before

3. It's the first time I have this kind of problem

14. According to your opinion, what is the level of difficulty of the problem proposed in the exercises?. Respond according to the problem that you have made. (from $1=$ low and $3=$ high)

\begin{tabular}{|l|c|c|c|}
\hline \multicolumn{1}{|c|}{ Problem Domain } & 1 & 2 & 3 \\
\hline P1. Messaging Problem & ( ) & ( ) & ( ) \\
\hline P2. Recycling Batteries Problem & ( ) & ( ) & ( ) \\
\hline P3. Stock Exchange Problem & ( ) & ( ) & ( ) \\
\hline P4. University Registration System & ( ) & ( ) & ( ) \\
\hline
\end{tabular}

1. Low

2. Medium

3. High

\section{Need of further interviews ${ }^{48}$}

15. In the first simulated interview, do you think that you understood the problem domain and identified the main requirements? If you think there were differences among problems, please give a brief explanation:

16. Do you think that more interactions with the customers (that is more interview) are necessary to understand the different problems? How many?

47 Los cuatro dominios de problema fueron utilizados únicamente en E-2012, mientras que en E-2013 y E-2014 únicamente los dos primeros (P1 y P2)

${ }^{48}$ Preguntas formuladas en E-2012 


\section{First Interview}

17. Do you think that you got a good understanding of the problem domain (Text Messaging or Recycling Batteries) and the main requirements in the first interview session?

() Yes

() No

18. Was the time assigned to the first interview $\left(25^{\prime}\right)$ enough? i.e: you would have finished in a similar time in any case.

() Yes

() No

In case of a negative answer, explain why:

\section{Second Interview ${ }^{50}$}

19. Do you think tour understanding about problem domain (Text Messaging or Recycling Batteries) improve after the second interview?

( ) Yes

( ) No

20. Which aspects of the problem (Text Messaging or Recycling Batteries Problem) did you focus on in the second interview?

21. Do you think more interviews are necessary to understand the different problems? How many? ${ }^{51}$

\section{Elicitation and Conceptualization ${ }^{52}$}

22. Do you think that you got a good understanding of the problem domain (Text Messaging or Recycling Batteries) and the main requirements in the first interview session?
( ) Yes
( ) No

23. Was the time assigned to the first interview (25') enough?, i.e.: you would have finished in a similar time in any case.

( ) Yes

( ) No

In case of a negative answer, explain why:

24. Do you think there has been enough time to write the meeting minute?
( ) Yes
( ) No

${ }^{49}$ Preguntas formuladas a los sujetos que participaron en E-2013. Nótese que en este experimento fue cuando se añadió una segunda entrevista.

${ }^{50}$ Preguntas formuladas a los sujetos que participaron en E-2013. Nótese que este es el experimento donde se realizaron dos sesiones de educción por sujeto, con la finalidad de refinar o complementar la información adquirida en la primera.

${ }^{51}$ Pregunta formulada también en E-2013 y E-2014

52 Preguntas formuladas en E-2012, E-2013 y E-2014 


\section{Objetos Experimentales}

A continuación se presenta en detalle la descripción de los elementos (requisitos, conceptos y procesos) que conforman los dominios de problema utilizados en la investigación.

\section{B.1. Problema Conocido: Mensajería de Texto (PC1)}

Tabla 1 - Elementos que definen el dominio conocido PC1 - Mensajería de Texto

\begin{tabular}{|c|c|c|}
\hline TIPO & IDELEMENTO & DESCRIPCIÓN \\
\hline \multirow{15}{*}{ 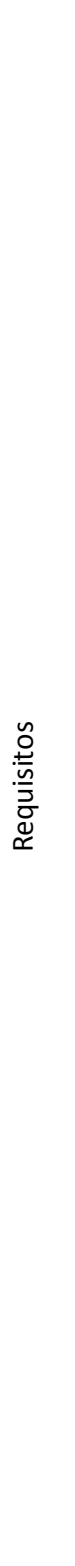 } & $\mathrm{R} 1$ & $\begin{array}{l}\text { Acceso al sistema: El PIU (Punto de Información Universitaria) permitirá a los alumnos } \\
\text { acceder mediante el uso de sus carnets universitarios. Para ello, deberán introducir el } \\
\text { carnet en un lector de tarjetas inteligentes e introducir su PIN. El sistema presentará los } \\
\text { datos básicos del alumno, extraídos de la tarjeta. Son datos del alumno: Nombres, } \\
\text { Apellidos, e-mail }\end{array}$ \\
\hline & $\mathrm{R} 2$ & El sistema permitirá al alumno cambiar su PIN o contraseña \\
\hline & R3 & $\begin{array}{l}\text { EI PIU permitirá al alumno matricularse en un conjunto de asignaturas cualesquiera (esto } \\
\text { es, añadir asignaturas), siempre que } \\
\text { a. Esté abierto el periodo de matrícula. } \\
\text { b. Las asignaturas pertenecen al programa de estudios (grado, postgrado) en el } \\
\text { c. El alumno no ha superado dichas asignaturas. } \\
\text { d. El número de asignaturas no supere un máximo de ECTS }\end{array}$ \\
\hline & R4 & $\begin{array}{l}\text { EI PIU no permitirá matrículas que no respeten los créditos obligatorios y optativos del } \\
\text { programa. }\end{array}$ \\
\hline & R5 & $\begin{array}{l}\text { El sistema presentará, en función a los créditos ECTS matriculados, la tasa de pago } \\
\text { correspondiente. }\end{array}$ \\
\hline & R6 & $\begin{array}{l}\text { Al finalizar el proceso de matriculación, el sistema imprimirá un justificante de pago. (o } \\
\text { justificante de matrícula). }\end{array}$ \\
\hline & R7 & $\begin{array}{l}\text { Pago de tasas: EI PIU permitirá realizar pago de tasas, mediante un sistema de banca } \\
\text { online o }\end{array}$ \\
\hline & R8 & $\begin{array}{l}\text { En el banco, mediante la impresión de una carta de pago con un código de barras } \\
\text { identificativo. En este caso, los documentos solicitados se imprimirán después de justificar } \\
\text { el alumno el pago }\end{array}$ \\
\hline & R9 & $\begin{array}{l}\text { Justificación Tasas: Cuando el alumno paga las tasas por banco, deberá volver al PIU y } \\
\text { escanear el documento certificado por el banco para justificar el pago. Al justificar el pago, } \\
\text { se imprimen los documentos solicitados y pendientes de impresión }\end{array}$ \\
\hline & R10 & $\begin{array}{l}\text { Renuncia de asignaturas: El sistema permitirá al alumno renunciar a asignaturas de su } \\
\text { matrícula libremente mientras esté abierto el periodo de renuncia. }\end{array}$ \\
\hline & R11 & $\begin{array}{l}\text { Devolución Tasas: el sistema devolverá al alumno las tasas correspondientes a las } \\
\text { asignaturas eliminadas. }\end{array}$ \\
\hline & R12 & $\begin{array}{l}\text { PIU realizará la devolución de tasas en el mismo medio de pago usado originalmente. } \\
\text { a. Mediante tarjeta; b. Mediante cheque nominativo, generado por el PIU. }\end{array}$ \\
\hline & R13 & $\begin{array}{l}\text { Visualización del expediente: El sistema permitirá a los alumnos visualizar las calificaciones } \\
\text { de un semestre determinado. }\end{array}$ \\
\hline & R14 & $\begin{array}{l}\text { Impresión del expediente: El sistema permitirá, opcionalmente, generar un certificado } \\
\text { oficial de notas, que saldrá por la impresora del PIU, sellado con el sello de la facultad y un } \\
\text { código de autenticación. }\end{array}$ \\
\hline & R15 & La impresión del expediente implica una tasa de 5 EUR (variable en el tiempo). \\
\hline
\end{tabular}




\begin{tabular}{|c|c|c|}
\hline TIPO & IDELEMENTO & DESCRIPCIÓN \\
\hline & R16 & $\begin{array}{l}\text { Los periodos de matrícula y renuncia, el número máximo de créditos a cursar por los } \\
\text { alumnos, el número de créditos optativos y el número de créditos obligatorios son fijados } \\
\text { por la facultad (Dichos datos provienen de otro sistema). Existen fechas y valores distintos } \\
\text { para cada programa. }\end{array}$ \\
\hline & R17 & $\begin{array}{l}\text { EI PIU permitirá a sus usuarios hacer un log-out. El log-out podrá ser: } \\
\begin{aligned}- & \text { Directamente. } \\
\text { - } & \text { Automáticamente mediante la extracción del carnet universitario del lector de } \\
& \text { tarjetas inteligentes. }\end{aligned}\end{array}$ \\
\hline \multirow{20}{*}{ 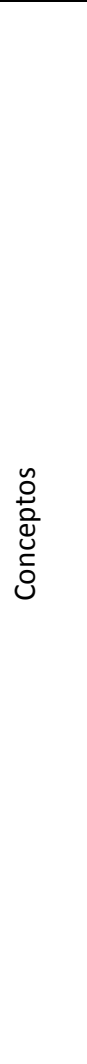 } & $\mathrm{C} 1$ & PIU (Punto de Información Universitaria) \\
\hline & $\mathrm{C} 2$ & Computadora con impresora \\
\hline & C3 & Lector de tarjetas inteligentes \\
\hline & C4 & Escáner \\
\hline & $\mathrm{C5}$ & Matrícula \\
\hline & C6 & Asignaturas \\
\hline & C7 & Asignaturas de carácter obligatorio \\
\hline & C8 & Asignaturas de carácter optativo (electivo) \\
\hline & C9 & Programa \\
\hline & C10 & Programa Grado \\
\hline & C11 & Programa Postgrado \\
\hline & C12 & Tasas Matrícula \\
\hline & C13 & Tasas Renuncia Asignatura \\
\hline & C14 & Tasas Expediente \\
\hline & C15 & Alumno \\
\hline & C16 & Documentos \\
\hline & C17 & Expediente Académico \\
\hline & C18 & Justificante Matrícula \\
\hline & C19 & Justificante asignaturas renunciadas \\
\hline & $\mathrm{C} 20$ & Plazo \\
\hline \multirow{17}{*}{ 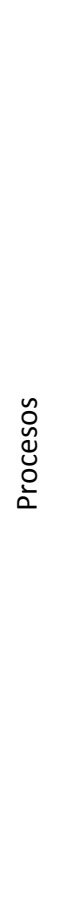 } & A1 & Introducir el carnet en el lector de tarjetas inteligentes \\
\hline & $\mathrm{A} 2$ & Introducir el PIN \\
\hline & A3 & Cambiar el PIN \\
\hline & A4 & Realizar Matrícula \\
\hline & A5 & Renunciar a asignaturas (Eliminar asignaturas de la matrícula) \\
\hline & A6 & Visualizar Expediente \\
\hline & A7 & Imprimir Expediente (Generar certificado oficial de notas) \\
\hline & A8 & Pagar tasas Expediente \\
\hline & A9 & Pagar tasas Matrícula \\
\hline & A10 & Pagar tasas online \\
\hline & A11 & Pagar tasas por Banco \\
\hline & A12 & Justificar Pago \\
\hline & A13 & Escanear carta de pago (banco) \\
\hline & A14 & Imprimir comprobante matrícula \\
\hline & A15 & Devolver valor de las tasas correspondientes. Por tarjeta \\
\hline & A16 & Generar cheque \\
\hline & A17 & Log-out del sistema \\
\hline
\end{tabular}




\section{PC1 - Modelo de conceptos}

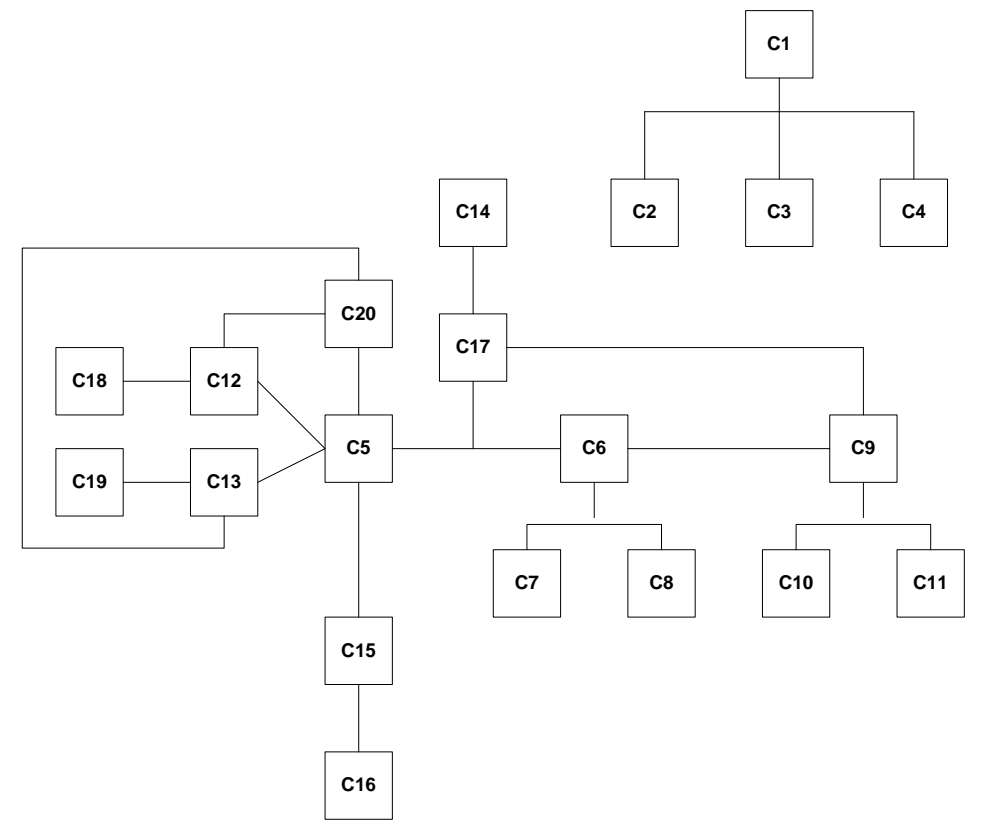

Figura 1 - Modelo de Conceptos del PC1

\section{PC1 - Diagrama de Actividades}

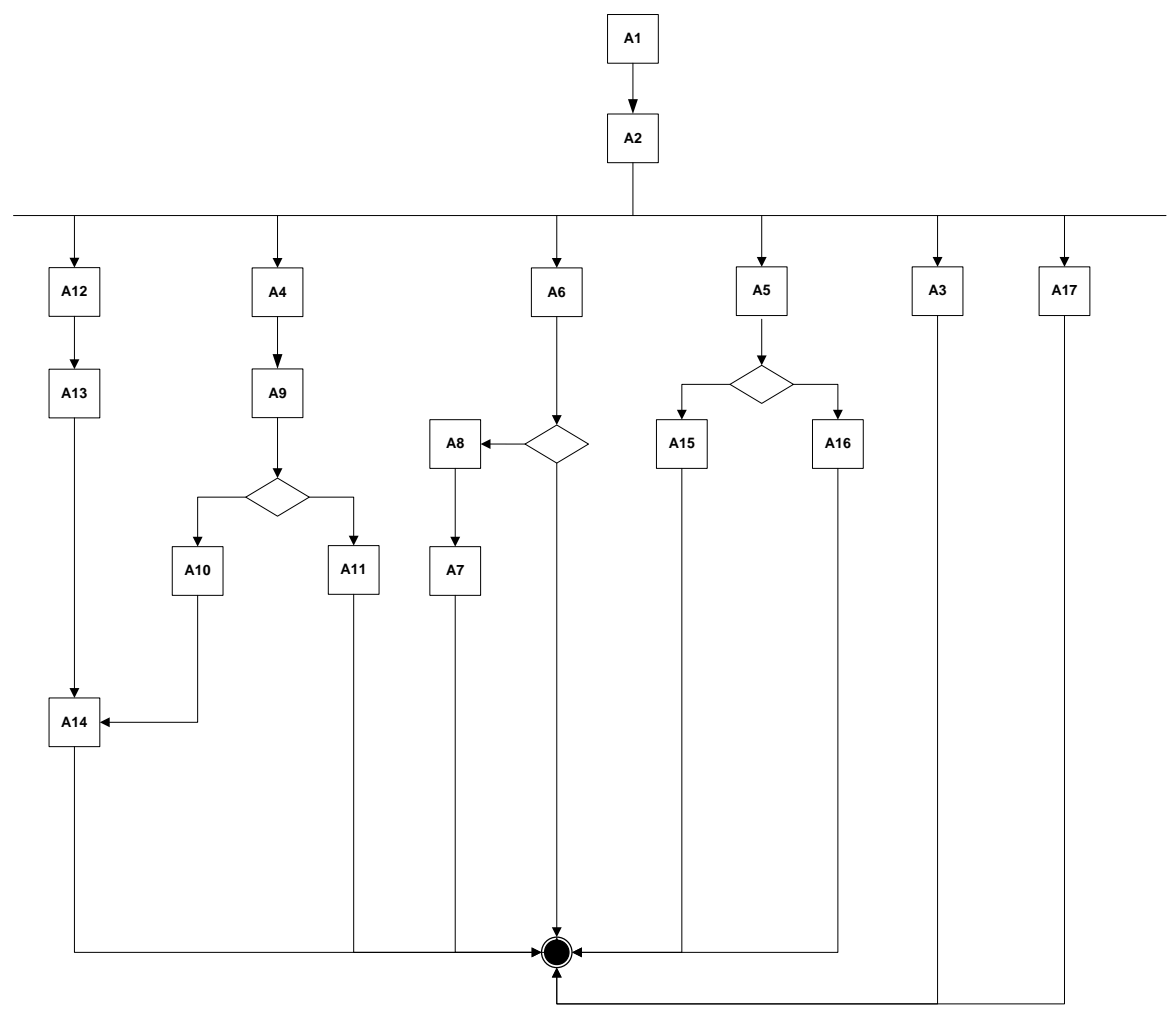

Figura 2 - Diagrama de actividades Problema PC1 


\section{B.2. Problema Desconocido: Reciclado de Pilas (PD1)}

Tabla 2 - Elementos que definen el dominio desconocido PD1 - Reciclado de Pilas

\begin{tabular}{|c|c|c|}
\hline TIPO & IDELEMENTO & DESCRIPCIÓN \\
\hline \multirow{15}{*}{ 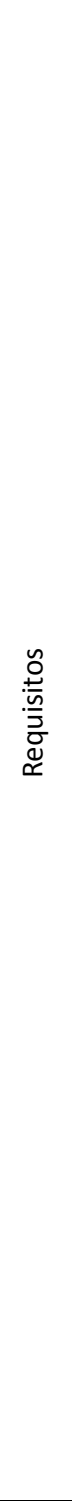 } & R1 & El sistema permitirá arrancar manualmente la máquina separadora. \\
\hline & R2 & $\begin{array}{l}\text { El sistema permitirá parar automáticamente la máquina separadora cuando } \\
\text { alcance una determinada cantidad de pilas en cualquiera de las } 3 \text { bandejas de } \\
\text { salida. }\end{array}$ \\
\hline & R3 & El sistema permitirá arrancar manualmente la máquina trituradora. \\
\hline & R4 & $\begin{array}{l}\text { El sistema permitirá parar automáticamente la máquina trituradora cuando } \\
\text { alcance una determinada cantidad de polvo de pila en la bandeja de salida. }\end{array}$ \\
\hline & R5 & El sistema permitirá arrancar manualmente la máquina prensadora. \\
\hline & R6 & $\begin{array}{l}\text { El sistema permitirá parar automáticamente la máquina prensadora cuando } \\
\text { alcance una determinada cantidad de polvo de pila en la bandeja de salida. }\end{array}$ \\
\hline & R7 & El sistema permitirá arrancar manualmente la máquina destiladora. \\
\hline & R8 & $\begin{array}{l}\text { El sistema permitirá parar automáticamente la máquina destiladora cuando } \\
\text { alcance una determinada cantidad de metal en cualquiera de los cajetines de } \\
\text { salida. }\end{array}$ \\
\hline & R9 & $\begin{array}{l}\text { El sistema parará la máquina destiladora cuando se haya sobrepasado el } \\
\text { tiempo de destilado. }\end{array}$ \\
\hline & R10 & $\begin{array}{l}\text { El sistema permitirá registrar a qué lote de reciclado pertenecen las cenizas } \\
\text { almacenadas en cada bidón de desecho. }\end{array}$ \\
\hline & R11 & $\begin{array}{l}\text { El sistema permitirá registrar los albaranes de entrega proporcionados por los } \\
\text { proveedores de pilas. }\end{array}$ \\
\hline & R12 & $\begin{array}{l}\text { El sistema permitirá registrar a qué lote de reciclado van destinadas las pilas } \\
\text { de cada albarán. }\end{array}$ \\
\hline & R13 & $\begin{array}{l}\text { El sistema permitirá registrar los albaranes de recogida proporcionados por } \\
\text { los proveedores de transporte de bidones. }\end{array}$ \\
\hline & R14 & $\begin{array}{l}\text { El sistema permitirá registrar los bidones que corresponden a cada albarán de } \\
\text { recogida. }\end{array}$ \\
\hline & R15 & $\begin{array}{l}\text { El sistema permitirá registrar la cantidad de metales obtenidos del proceso de } \\
\text { reciclado. }\end{array}$ \\
\hline \multirow{11}{*}{ 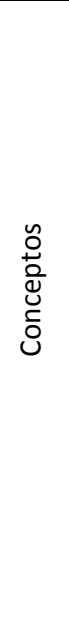 } & $\mathrm{C} 1$ & Metal \\
\hline & $\mathrm{C} 2$ & Manganeso \\
\hline & $\mathrm{C} 3$ & Mercurio \\
\hline & C4 & Niquel \\
\hline & C5 & Cadmio \\
\hline & C6 & Cobre \\
\hline & $\mathrm{C7}$ & Cinc \\
\hline & $\mathrm{C} 8$ & Pila \\
\hline & C9 & Pilas Normales \\
\hline & C10 & Pilas de Botón \\
\hline & C11 & Pilas de Botón con manganeso \\
\hline
\end{tabular}


Estudio empírico de la influencia de la experiencia y del conocimiento del dominio del analista en la efectividad del proceso de educción de requisitos

\begin{tabular}{|c|c|c|}
\hline TIPO & IDELEMENTO & DESCRIPCIÓN \\
\hline & $\mathrm{C} 12$ & Pilas de Botón sin manganeso \\
\hline \multirow{12}{*}{ 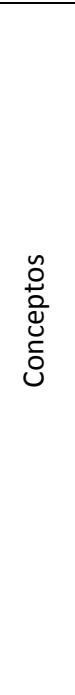 } & C13 & Proveedor \\
\hline & C14 & Albarán de entrega \\
\hline & C15 & Lote \\
\hline & C16 & Bidón \\
\hline & C17 & Cenizas \\
\hline & C18 & Albarán de Recogida \\
\hline & C19 & Máquina \\
\hline & $\mathrm{C} 20$ & Separadora \\
\hline & $\mathrm{C} 21$ & Trituradora \\
\hline & $\mathrm{C} 22$ & Destiladora \\
\hline & $\mathrm{C} 23$ & Incineradora \\
\hline & $\mathrm{C} 24$ & Prensadora \\
\hline \multirow{12}{*}{ 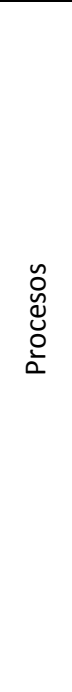 } & A1 & Apuntar albarán de entrega \\
\hline & $\mathrm{A} 2$ & Separar pilas \\
\hline & A3 & Prensar pilas botón s/mang \\
\hline & A4 & Triturar Pilas normales \\
\hline & A5 & Prensar pilas botón c/mang \\
\hline & A6 & Destilar con acero \\
\hline & A7 & Destilar sin acero \\
\hline & A8 & Decantar \\
\hline & A9 & Incinerar \\
\hline & A10 & Almacenar en bidones \\
\hline & A11 & Apuntar albarán de recogida \\
\hline & A12 & Enviar metales a almacén \\
\hline
\end{tabular}

\section{PD1 - Modelo de Conceptos}

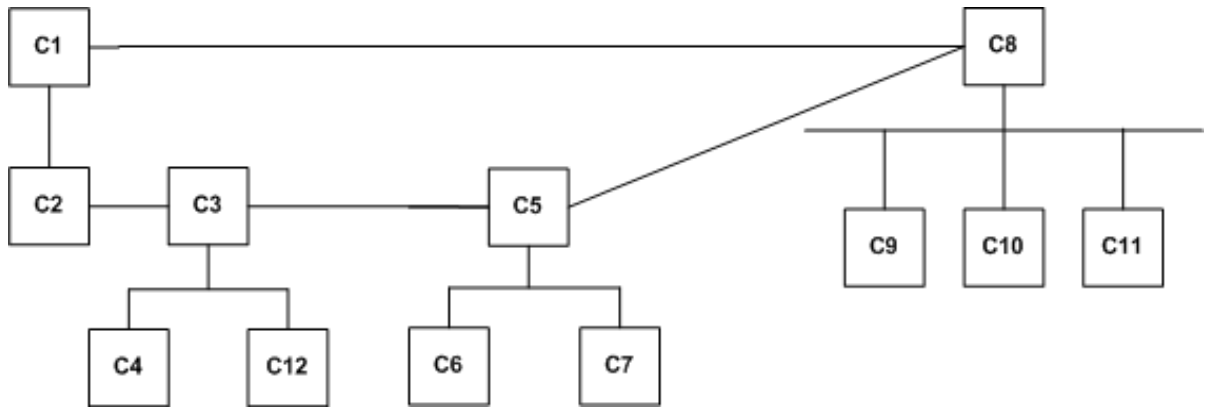

Figura 3 - Modelo de Conceptos del PD1 


\section{PD1 - Diagrama de Actividades}

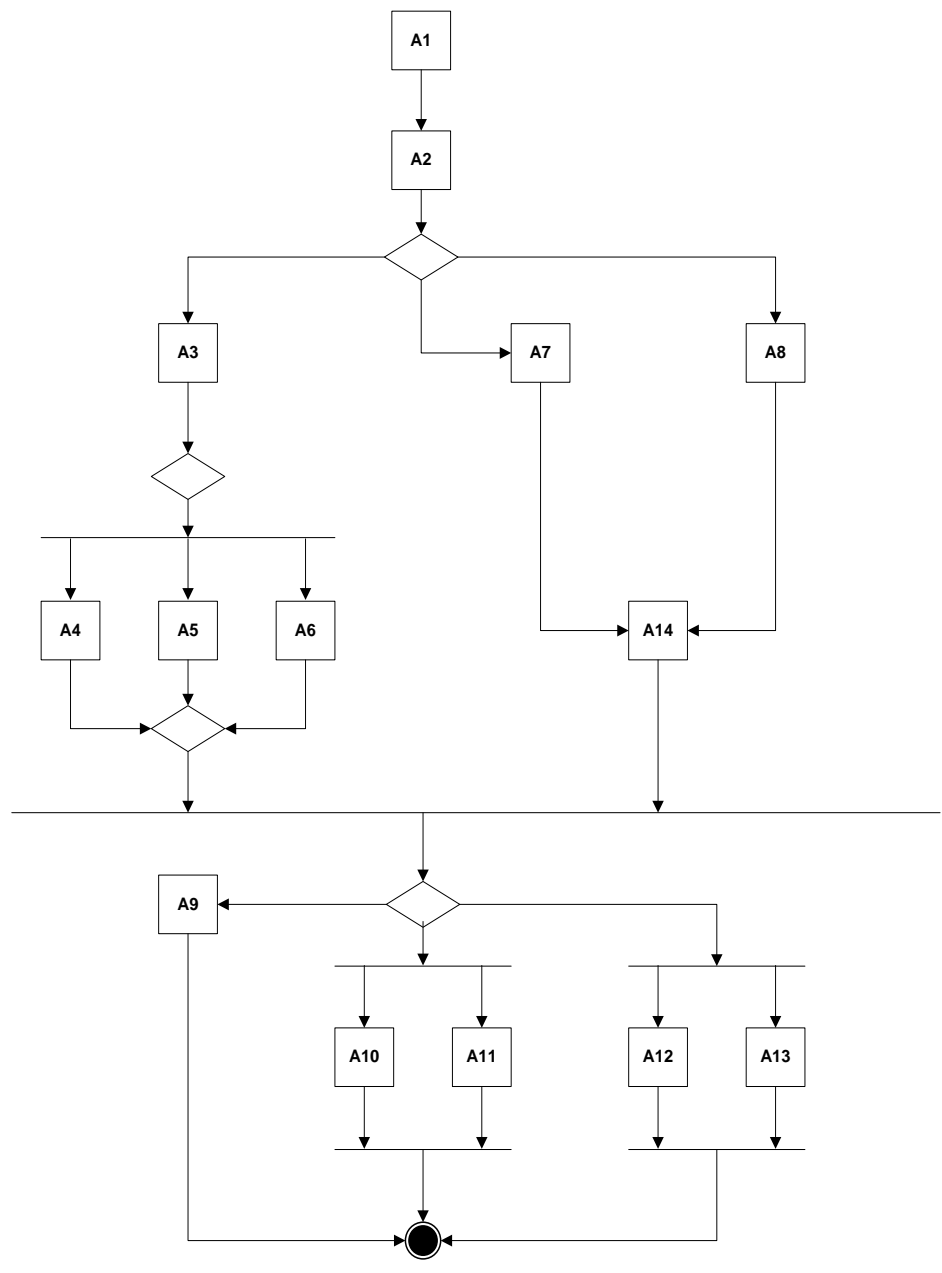

Figura 4 - Modelo de Conceptos del PD1

\section{B.3. Problema Conocido: Punto de Información Universitaria (PC2)}

Tabla 3 - Elementos que definen el dominio conocido PD1 - Punto de Información Universitaria

\begin{tabular}{|c|c|c|}
\hline TIPO & IDELEMENTO & DESCRIPCIÓN \\
\hline \multirow{3}{*}{ 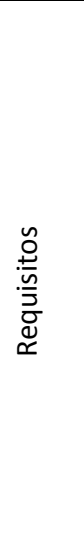 } & $\mathrm{R} 1$ & $\begin{array}{l}\text { Acceso al sistema: EI PIU (Punto de Información Universitaria) permitirá a los alumnos } \\
\text { acceder mediante el uso de sus carnets universitarios. Para ello, deberán introducir el } \\
\text { carnet en un lector de tarjetas inteligentes e introducir su PIN. El sistema presentará los } \\
\text { datos básicos del alumno, extraídos de la tarjeta. Son datos del alumno: Nombres, } \\
\text { Apellidos, e-mail. }\end{array}$ \\
\hline & R2 & $\begin{array}{l}\text { El PIU permitirá realizar las siguientes operaciones: } \\
\text { Cambio de PIN: El sistema permitirá al alumno cambiar su PIN o contraseña. }\end{array}$ \\
\hline & R3 & $\begin{array}{l}\text { Matrícula: El PIU permitirá al alumno matricularse en un conjunto de asignaturas } \\
\text { cualesquiera (esto es, añadir asignaturas), siempre que } \\
\text { a. Esté abierto el periodo de matrícula. } \\
\text { b. Las asignaturas pertenecen al programa de estudios (grado, postgrado) en el que } \\
\text { el alumno ha sido aceptado. } \\
\text { c. El alumno no ha superado dichas asignaturas. } \\
\text { d. El número de asignaturas no supere un máximo de ECTS. }\end{array}$ \\
\hline
\end{tabular}


Estudio empírico de la influencia de la experiencia y del conocimiento del dominio del analista en la efectividad del proceso de educción de requisitos

\begin{tabular}{|c|c|c|}
\hline TIPO & IDELEMENTO & DESCRIPCIÓN \\
\hline & R4 & $\begin{array}{l}\text { EI PIU no permitirá matrículas que no respeten los créditos obligatorios y optativos del } \\
\text { programa. }\end{array}$ \\
\hline & R4 & $\begin{array}{l}\text { El sistema presentará, en función a los créditos ECTS matriculados, la tasa de pago } \\
\text { correspondiente. }\end{array}$ \\
\hline & R6 & $\begin{array}{l}\text { Al finalizar el proceso de matriculación, el sistema imprimirá un justificante de pago. (o } \\
\text { justificante de matrícula). }\end{array}$ \\
\hline & R7 & $\begin{array}{l}\text { El PIU permitirá realizar pago de tasas, mediante un sistema de banca online o en el banco, } \\
\text { mediante la impresión de una carta de pago con un código de barras identificativo. En este } \\
\text { caso, los documentos solicitados se imprimirán después de justificar el alumno el pago. }\end{array}$ \\
\hline & R8 & $\begin{array}{l}\text { El PIU permitirá realizar pago de tasas en el banco, mediante la impresión de una carta de } \\
\text { pago con un código de barras identificativo. En este caso, los documentos solicitados se } \\
\text { imprimirán después de justificar el alumno el pago }\end{array}$ \\
\hline & R9 & $\begin{array}{l}\text { Justificación Tasas: Cuando el alumno paga las tasas por banco, deberá volver al PIU y } \\
\text { escanear el documento certificado por el banco para justificar el pago. Al justificar el pago, } \\
\text { se imprimen los documentos solicitados y pendientes de impresión }\end{array}$ \\
\hline & R10 & $\begin{array}{l}\text { Renuncia de asignaturas: El sistema permitirá al alumno renunciar a asignaturas de su } \\
\text { matrícula libremente mientras esté abierto el periodo de renuncia. }\end{array}$ \\
\hline & R11 & $\begin{array}{l}\text { Devolución Tasas: el sistema devolverá al alumno las tasas correspondientes a las } \\
\text { asignaturas eliminadas. }\end{array}$ \\
\hline & $\mathrm{R} 12$ & $\begin{array}{l}\text { PIU realizará la devolución de tasas en el mismo medio de pago usado originalmente. } \\
\text { a. Mediante tarjeta. } \\
\text { b. Mediante cheque nominativo, generado por el PIU. }\end{array}$ \\
\hline & R13 & $\begin{array}{l}\text { Visualización del expediente: El sistema permitirá a los alumnos visualizar las calificaciones } \\
\text { de un semestre determinado. }\end{array}$ \\
\hline & R14 & $\begin{array}{l}\text { Impresión del expediente: El sistema permitirá, opcionalmente, generar un certificado } \\
\text { oficial de notas, que saldrá por la impresora del PIU, sellado con el sello de la facultad y un } \\
\text { código de autenticación. }\end{array}$ \\
\hline & R15 & La impresión del expediente implica una tasa de 5 EUR (variable en el tiempo). \\
\hline & R16 & $\begin{array}{l}\text { Los periodos de matrícula y renuncia, el número máximo de créditos a cursar por los } \\
\text { alumnos, el número de créditos optativos y el número de créditos obligatorios son fijados } \\
\text { por la facultad (Dichos datos provienen de otro sistema). Existen fechas y valores distintos } \\
\text { para cada programa. }\end{array}$ \\
\hline & R17 & $\begin{array}{l}\text { El PIU permitirá a sus usuarios hacer un log-out. El log-out podrá ser: } \\
\begin{array}{l}\text { a. Directamente. } \\
\text { b. Automáticamente mediante la extracción del carnet universitario del lector de } \\
\text { tarjetas inteligentes. }\end{array}\end{array}$ \\
\hline \multirow{16}{*}{ 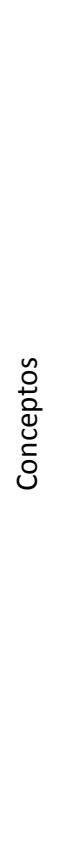 } & $\mathrm{C} 1$ & PIU (Punto de Información Universitaria) \\
\hline & $\mathrm{C} 2$ & Computadora con impresora \\
\hline & C3 & Lector de tarjetas inteligentes \\
\hline & $\mathrm{C} 4$ & Escáner \\
\hline & $\mathrm{C} 5$ & Matrícula \\
\hline & $\mathrm{C} 6$ & Asignaturas \\
\hline & $\mathrm{C7}$ & Asignaturas de carácter obligatorio \\
\hline & $\mathrm{C} 8$ & Asignaturas de carácter optativo (electivo) \\
\hline & C9 & Programa \\
\hline & $\mathrm{C} 10$ & Programa de Grado \\
\hline & C11 & Programa de PostGrado \\
\hline & $\mathrm{C} 12$ & Tasas Matrícula \\
\hline & C13 & Tasas renuncia Asignatura \\
\hline & C14 & Tasas Expediente \\
\hline & C15 & Alumno \\
\hline & C16 & Documento \\
\hline
\end{tabular}




\begin{tabular}{|c|c|c|}
\hline TIPO & IDELEMENTO & DESCRIPCIÓN \\
\hline & C17 & Expediente Académico \\
\hline & C18 & Justificante Matrícula \\
\hline & C19 & Justificante asignaturas renunciadas \\
\hline & $\mathrm{C} 20$ & Plazo \\
\hline \multirow{16}{*}{ 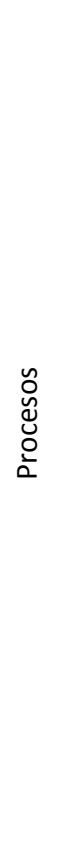 } & A1 & Introducir el carnet en el lector de tarjetas inteligentes \\
\hline & $\mathrm{A} 2$ & Introducir el PIN \\
\hline & A3 & Cambiar el PIN \\
\hline & A4 & Realizar Matrícula \\
\hline & A5 & Renunciar a asignaturas \\
\hline & A6 & Visualizar Expediente \\
\hline & A7 & Imprimir Expediente \\
\hline & A8 & Pagar tasas Expedientes \\
\hline & A9 & Pagar tasas Matrícula \\
\hline & A10 & Pagar tasas online \\
\hline & A11 & Pagar tasas por Banco \\
\hline & A12 & Justificar pago \\
\hline & A14 & Escanear carta de pago \\
\hline & A15 & Imprimir comprobante matrícula \\
\hline & A16 & Devolver valor de las tasas correspondientes \\
\hline & A17 & Log-out del sistema \\
\hline
\end{tabular}

\section{PC2 - Modelo de Conceptos}

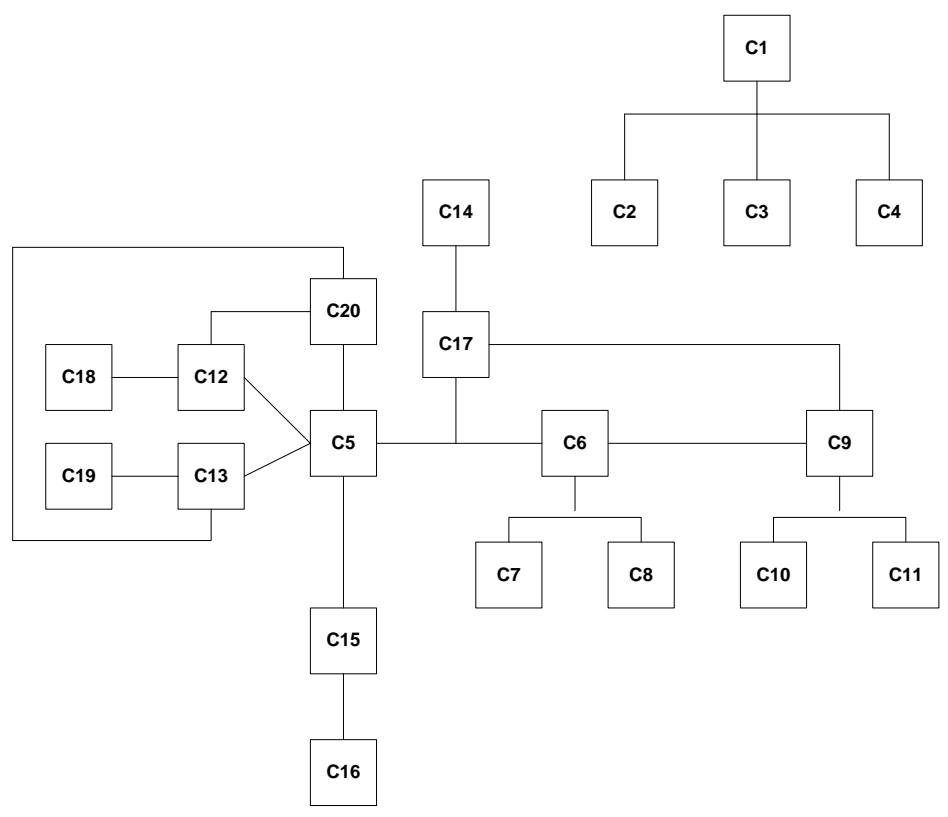

Figura 5 - Modelo de Conceptos del PC2 


\section{PC2 - Modelo de Actividades}

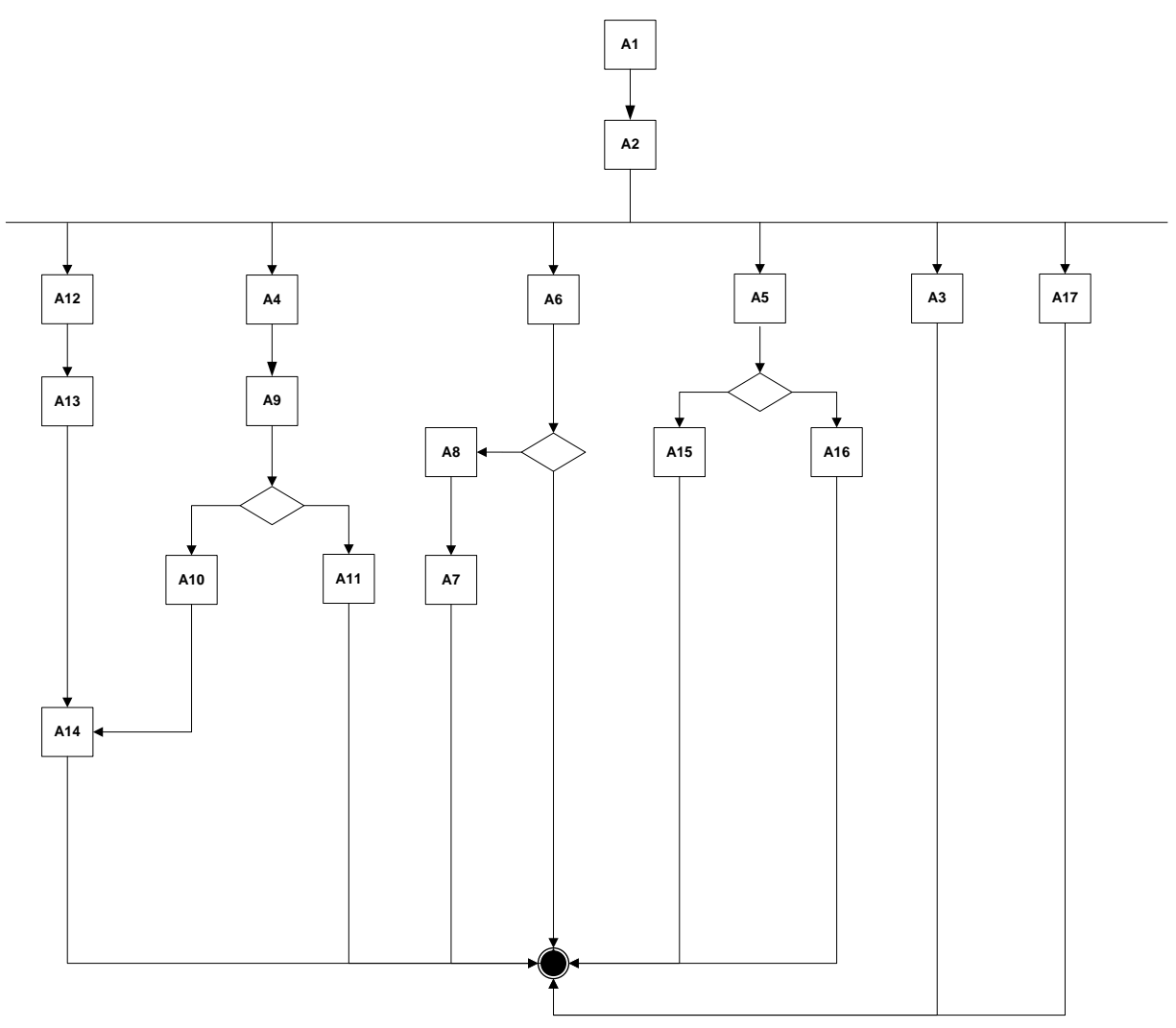

Figura 6 - Modelo de Actividades del PC2

\section{B.4. Problema Desconocido: Compra y venta de Acciones (PD2)}

Tabla 4 - Elementos que definen el dominio conocido PD2

\begin{tabular}{|c|c|c|}
\hline TIPO & IDELEMENTO & DESCRIPCIÓN \\
\hline \multirow{6}{*}{ 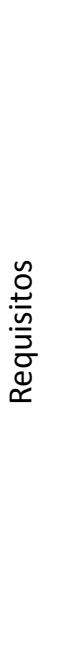 } & R1 & $\begin{array}{l}\text { El sistema permitirá al usuario conectarse al bróker mediante la introducción de } \\
\text { un ID y un password. }\end{array}$ \\
\hline & $\mathrm{R} 2$ & La creación del ID y el password se realiza en una página Web. \\
\hline & R3 & $\begin{array}{l}\text { Si el ID o el password son incorrectos, el sistema desplegará un mensaje indicando } \\
\text { tal situación. }\end{array}$ \\
\hline & R4 & $\begin{array}{l}\text { Una vez el sistema se haya conectado correctamente al servidor, quedará a la } \\
\text { espera de una acción del usuario o de la recepción de cotizaciones o resultados de } \\
\text { operaciones desde el broker }\end{array}$ \\
\hline & R5 & El sistema podrá funcionar tanto en primer plano como en segundo plano. \\
\hline & R6 & $\begin{array}{l}\text { El usuario podrá consultar, de forma jerárquica. Las acciones que posee. La } \\
\text { aplicación proporcionará el total de acciones, el coste total de compra, la } \\
\text { cotización actual, el total de comisiones y los beneficios o pérdidas en que se } \\
\text { incurriría en caso de venta. La aplicación proporcionará el total de acciones; el } \\
\text { coste total de compra; la cotización actual; el total de comisiones; los beneficios o } \\
\text { pérdidas en que se incurriría en caso de venta. }\end{array}$ \\
\hline
\end{tabular}




\begin{tabular}{|c|c|c|}
\hline TIPO & IDELEMENTO & DESCRIPCIÓN \\
\hline & R7 & $\begin{array}{l}\text { La aplicación permitirá al usuario consultar sus órdenes de compra individuales. } \\
\text { La aplicación proporcionará el total por orden de compra; el coste de la orden } \\
\text { compra; la cotización actual; el total de comisiones; los beneficios o pérdidas en } \\
\text { que se incurriría en caso de venta. }\end{array}$ \\
\hline & R8 & Las órdenes de compra podrán consultarse por fecha de compra. \\
\hline & R9 & $\begin{array}{l}\text { La aplicación permitirá al usuario consultar las acciones que ha vendido. La } \\
\text { aplicación proporcionará el total de acciones; el coste total de compra; precio total } \\
\text { de venta; el total de comisiones; los beneficios; las pérdidas. }\end{array}$ \\
\hline & R10 & $\begin{array}{l}\text { La aplicación permitirá al usuario consultar las órdenes de venta individuales. La } \\
\text { aplicación proporcionará el total por orden de venta; el coste de la orden venta; la } \\
\text { cotización actual; el total de comisiones; los beneficios o pérdidas }\end{array}$ \\
\hline & R11 & Las órdenes de venta podrán consultarse por fecha de venta. \\
\hline & R12 & La aplicación permitirá al usuario establecer niveles de stop-loss / take profit. \\
\hline & R13 & $\begin{array}{l}\text { El sistema permitirá al usuario vender acciones. Para ello el usuario especificará la } \\
\text { acción, el precio de venta (a mercado o a lo mejor) y la fecha de validez de la } \\
\text { orden de venta. }\end{array}$ \\
\hline & R14 & $\begin{array}{l}\text { El sistema permitirá al usuario comprar acciones. Para ello, el usuario especificará } \\
\text { la acción, el precio de compra (a mercado o a lo mejor) y la fecha de validez de la } \\
\text { orden de compra. }\end{array}$ \\
\hline & R15 & $\begin{array}{l}\text { Las órdenes de compraventa de acciones quedarán marcadas como pendientes en } \\
\text { la aplicación hasta que el bróker confirme su realización o denegación. }\end{array}$ \\
\hline & R16 & $\begin{array}{l}\text { El sistema recibe tres tipos de notificaciones desde el bróker: } \\
\text { Cotizaciones de acciones: Esta notificación incluye el ticker de una acción, el } \\
\text { timestamp y la cotización actual }\end{array}$ \\
\hline & R17 & $\begin{array}{l}\text { Confirmación/denegación de una orden de compra: Esta notificación incluye el } \\
\text { ticker de una acción, el timestamp el estado de la orden (confirmada o denegada), } \\
\text { la cantidad de acciones, el precio de compra y el total de la comisión }\end{array}$ \\
\hline & R18 & $\begin{array}{l}\text { Confirmación/denegación de una orden de venta: Esta notificación incluye el } \\
\text { ticker de una acción, el timestamp el estado de la orden (confirmada o denegada), } \\
\text { la cantidad de acciones, el precio de venta y el total de la comisión }\end{array}$ \\
\hline & R19 & Las operaciones siempre se realizan con las acciones más antiguas en cartera. \\
\hline & R20 & $\begin{array}{l}\text { Cuando la aplicación recibe cotizaciones de acciones, debe actualizar dichos } \\
\text { valores en la cartera de acciones }\end{array}$ \\
\hline & R21 & $\begin{array}{l}\text { Cuando la aplicación recibe una notificación de confirmación/denegación de } \\
\text { compra, debe actualizar la orden de compra correspondiente. }\end{array}$ \\
\hline & R22 & $\begin{array}{l}\text { Cuando la aplicación recibe una notificación de confirmación/denegación de } \\
\text { venta, debe actualizar la orden de venta correspondiente. }\end{array}$ \\
\hline & R23 & Las notificaciones de compraventa son notificadas al usuario por pantalla \\
\hline & $\mathrm{R} 24$ & $\begin{array}{l}\text { Asumir que existe un centro de notificaciones como en el ipad. En caso contrario, } \\
\text { la notificación permanece en pantalla hasta que se le da al OK. }\end{array}$ \\
\hline \multirow{10}{*}{ 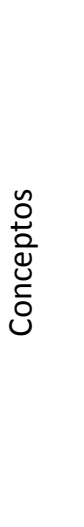 } & $\mathrm{C} 1$ & Usuario \\
\hline & $\mathrm{C} 2$ & Cartera de Acciones \\
\hline & $\mathrm{C} 3$ & Acciones \\
\hline & C4 & Cotizaciones \\
\hline & $\mathrm{C} 5$ & Órdenes \\
\hline & C6 & Órdenes de Compra \\
\hline & C7 & Órdenes de Venta \\
\hline & $\mathrm{C} 8$ & Notificaciones \\
\hline & C9 & Notificaciones de Aceptación \\
\hline & C10 & Notificaciones de Denegación \\
\hline
\end{tabular}


Estudio empírico de la influencia de la experiencia y del conocimiento del dominio del analista en la efectividad del proceso de educción de requisitos

\begin{tabular}{|c|c|c|}
\hline TIPO & IDELEMENTO & DESCRIPCIÓN \\
\hline & C11 & Notificación de Cotización de Acciones \\
\hline & C12 & Stoploss / takeprofit \\
\hline \multirow{15}{*}{ 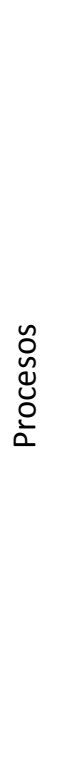 } & A1 & Conectarse al servidor \\
\hline & $\mathrm{A} 2$ & Esperar acción del usuario \\
\hline & A3 & Consultar cartera de acciones \\
\hline & A4 & Consultar acciones compradas \\
\hline & A5 & Consultar acciones vendidas \\
\hline & A6 & Establecer niveles de stop-loss / take profit \\
\hline & A7 & Comprar Acciones \\
\hline & A8 & Vender Acciones \\
\hline & A9 & Notificar cotizaciones de acciones (Actualizar) \\
\hline & A10 & Recibir notificación de si la orden de compra ha tenido éxito \\
\hline & A11 & Denegar orden de comprar \\
\hline & A12 & Recibir resultados de las operaciones del servidor \\
\hline & A13 & $\begin{array}{l}\text { Vender acciones (lo hace el sistema automáticamente en función de los valores } \\
\text { stop-loss y take-profit }\end{array}$ \\
\hline & A14 & Enviar orden \\
\hline & A15 & Notificar Usuario \\
\hline
\end{tabular}

PD2 - Modelo de Actividades

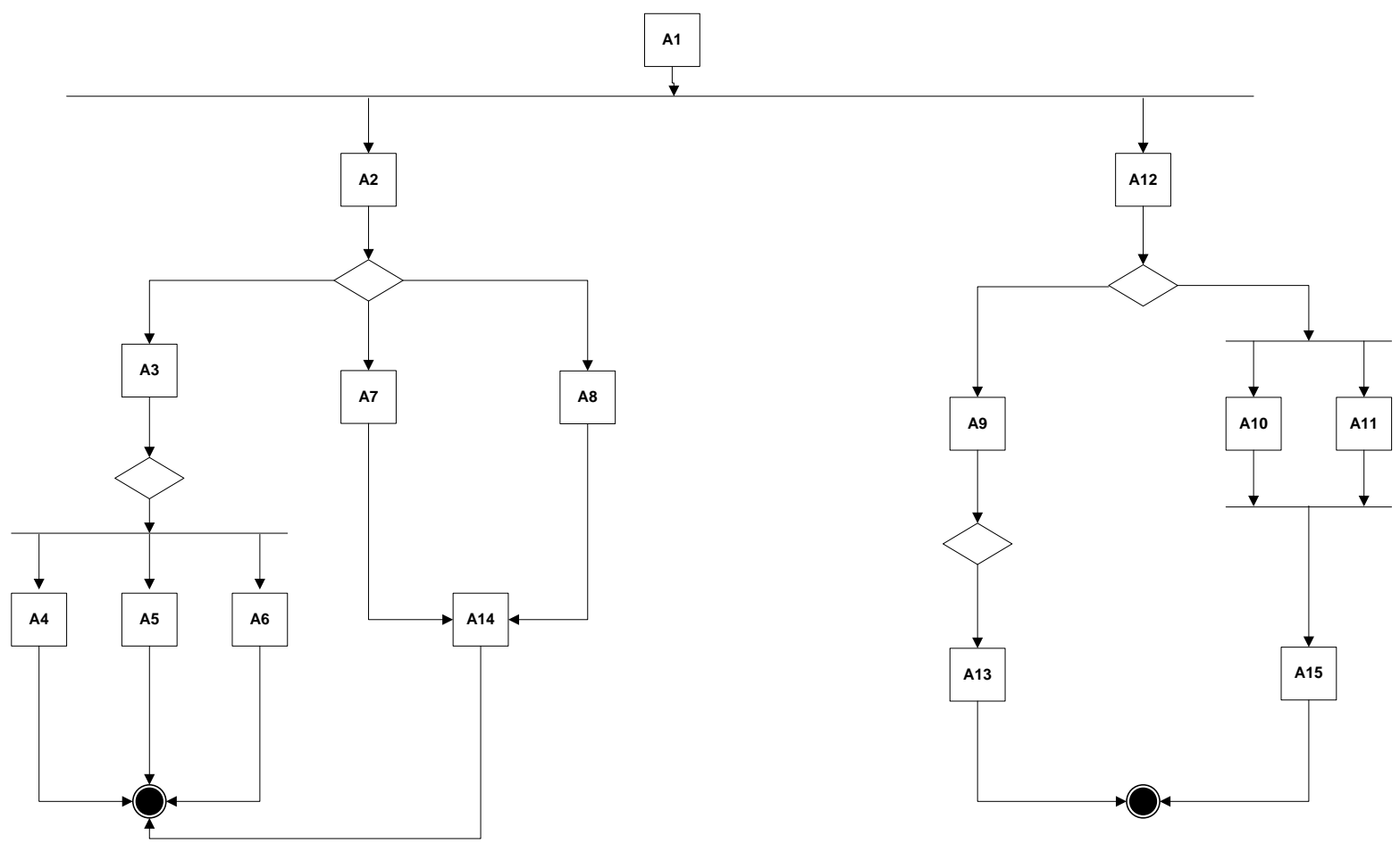

Figura 7 - Modelo de Conceptos del PD2 


\section{PD2 - Modelo de Conceptos}

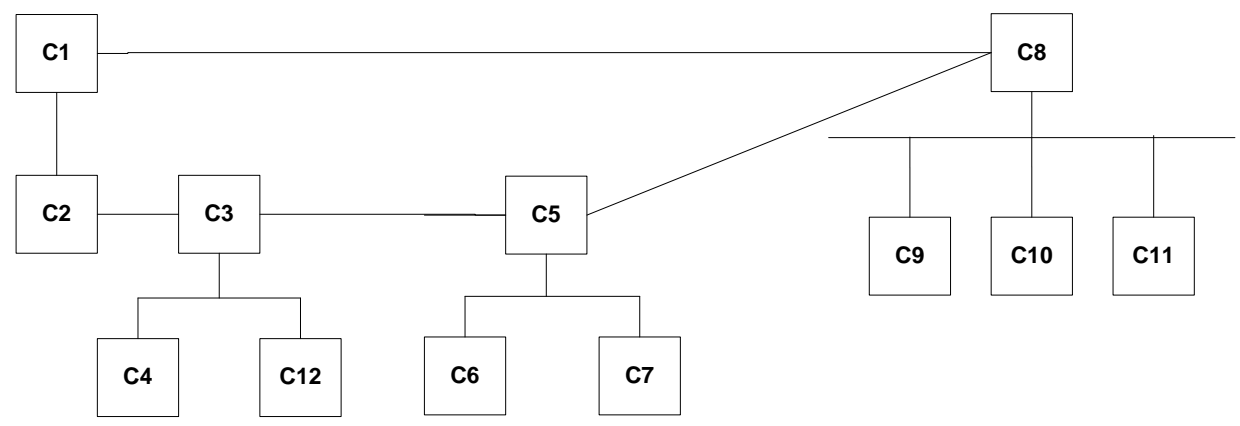

Figura 8 - Modelo de Conceptos del PD2 


\section{ANEXO C}

\section{Tabla Resúmenes}

El presente anexo presenta por cada dominio del problema utilizado en la investigación y por cada tipo de elemento (requisitos, conceptos y procesos) una tabla resumen, que muestra por cada experimento y sujeto los elementos consolidados (indicados con una $\mathrm{x}$ ), junto con la cantidad total de elementos adquiridos y su efectividad correspondiente. 


\section{C.1. Problema Desconocido: Reciclado de Pilas (PD1)}

Tabla 5 - Efectividad en función de los procesos que definen el dominio PD1

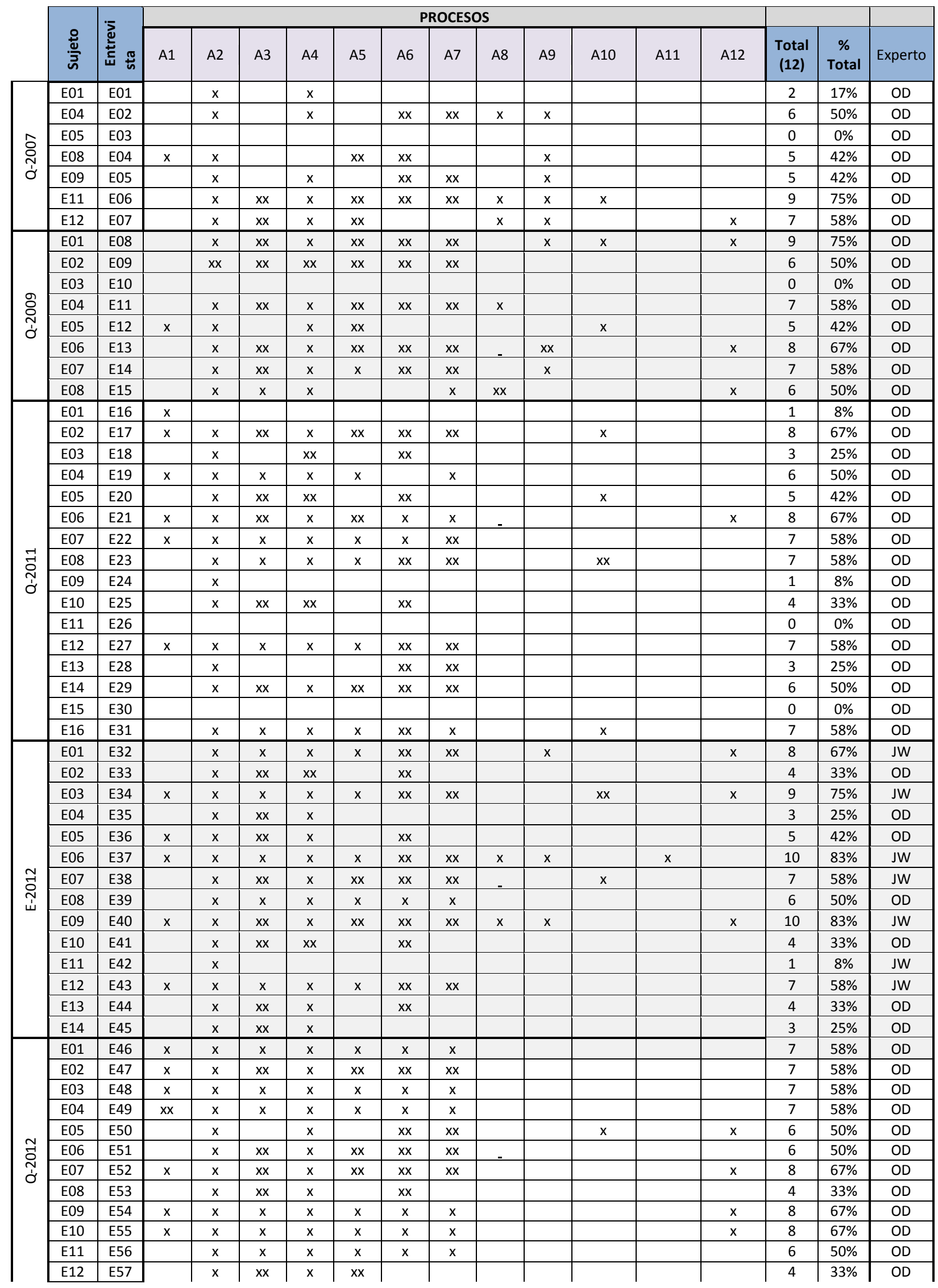


Estudio empírico de la influencia de la experiencia y del conocimiento del dominio del analista en la efectividad del proceso de educción de requisitos

\begin{tabular}{|c|c|c|c|c|c|c|c|c|c|c|c|c|c|c|c|c|c|}
\hline & \multirow[b]{2}{*}{ 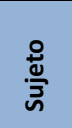 } & \multirow{2}{*}{ 选 } & \multicolumn{12}{|c|}{ PROCESOS } & \multirow[b]{2}{*}{$\begin{array}{l}\text { Total } \\
\text { (12) }\end{array}$} & \multirow[b]{2}{*}{$\begin{array}{c}\% \\
\text { Total }\end{array}$} & \multirow[b]{2}{*}{ Experto } \\
\hline & & & A1 & A2 & A3 & A4 & A5 & A6 & A7 & A8 & A9 & A10 & A11 & A12 & & & \\
\hline & E13 & E58 & & $\mathrm{x}$ & $x x$ & $x$ & & $x x$ & & & & & & & 4 & $33 \%$ & $O D$ \\
\hline & E14 & E59 & & $x$ & & $x$ & & $x x$ & & & & & & & 3 & $25 \%$ & OD \\
\hline & E15 & E60 & & $x$ & $x x$ & $x$ & $x x$ & $x x$ & $x x$ & & & & & & 6 & $50 \%$ & OD \\
\hline & E16 & E61 & & $x$ & & & & $x x$ & & & & & & & 2 & $17 \%$ & OD \\
\hline & E17 & E62 & & $x$ & $x x$ & $x$ & $x x$ & $x x$ & $x x$ & & & & & $x$ & 7 & $58 \%$ & OD \\
\hline & E18 & E63 & & $x$ & $x x$ & $x$ & & $x x$ & & & & & & $x$ & 5 & $42 \%$ & OD \\
\hline & E19 & E64 & & $x$ & $x x$ & $x$ & & $x x$ & & & & & & & 4 & $33 \%$ & OD \\
\hline & E20 & E65 & & $x$ & $x$ & $x$ & $x$ & $x$ & $x$ & & & & & $x$ & 7 & $58 \%$ & OD \\
\hline & E21 & E66 & & $x$ & $x$ & $x$ & $x$ & $x$ & $x$ & & & & & & 6 & $50 \%$ & OD \\
\hline \multirow{8}{*}{ 孞 } & E01 & E67 & & $\mathrm{x}$ & $\mathrm{x}$ & & & & & & & & & & 2 & $17 \%$ & $O D$ \\
\hline & E02 & E68 & $x$ & $x$ & $x$ & $x$ & $x$ & $x$ & $x$ & & & & & $\mathrm{x}$ & 8 & $67 \%$ & $\mathrm{JW}$ \\
\hline & E03 & E69 & & & & & & & & & & & & & 0 & $0 \%$ & $\mathrm{JW}$ \\
\hline & E04 & E70 & & $x$ & $x x$ & $x$ & $x x$ & $x x$ & $x x$ & & & & & & 6 & $50 \%$ & $O D$ \\
\hline & E05 & E71 & & $x$ & & $x$ & $x x$ & $x x$ & & & & & & & 4 & $33 \%$ & $O D$ \\
\hline & E06 & E72 & & $x$ & & $x$ & $x x$ & $x x$ & & & & & & & 4 & $33 \%$ & JW \\
\hline & E07 & E73 & & $x$ & & $x$ & $x$ & $x$ & & & & & & & 4 & $33 \%$ & $O D$ \\
\hline & E08 & E74 & & $x$ & $x$ & $x$ & $x$ & $x$ & $x$ & & & & & & 6 & $50 \%$ & $O D$ \\
\hline \multirow{9}{*}{ 壱 } & E01 & E75 & & $x$ & & $x$ & & $x x$ & & & & & & $\mathrm{x}$ & 4 & $33 \%$ & OD \\
\hline & E02 & E76 & & $x$ & $x$ & $x$ & $x$ & $\mathrm{x}$ & $x$ & & & & & & 6 & $50 \%$ & $O D$ \\
\hline & E03 & E77 & & $x$ & $x x$ & $x x$ & $x$ & $x x$ & $x x$ & & & & & & 6 & $50 \%$ & OD \\
\hline & E04 & E78 & & $x$ & $\mathrm{x}$ & $x$ & $x$ & $x$ & $x$ & & & & & & 6 & $50 \%$ & OD \\
\hline & E05 & E79 & & $\mathrm{x}$ & $x$ & $x$ & $x$ & $x$ & $x$ & & & & & & 6 & $50 \%$ & OD \\
\hline & E06 & $\mathrm{E} 80$ & & $x$ & $x x$ & $x$ & & & $x x$ & & & & & & 4 & $33 \%$ & OD \\
\hline & E07 & E81 & & $\mathrm{x}$ & $x$ & $x$ & $x$ & $x$ & $x$ & & & & & & 6 & $50 \%$ & OD \\
\hline & E08 & E82 & & $x$ & & $x x$ & & & $x x$ & & & & & & 3 & $25 \%$ & OD \\
\hline & E09 & E83 & & $x$ & $x$ & $\mathrm{x}$ & $x$ & $x$ & $x$ & & & & & & 6 & $50 \%$ & OD \\
\hline \multirow{5}{*}{ 号 } & E01 & E84 & & $x$ & & $x$ & & $\mathrm{x}$ & & & & & & & 3 & $25 \%$ & OD \\
\hline & E02 & E85 & $x$ & $x$ & $x x$ & $x$ & $x x$ & $x x$ & $x x$ & & & $x$ & & $x$ & 9 & $75 \%$ & OD \\
\hline & E03 & E86 & & $x$ & $\mathrm{x}$ & $x$ & $x x$ & $x$ & $x x$ & $x$ & & & & & 7 & $58 \%$ & OD \\
\hline & E04 & E87 & $x$ & $x$ & $x$ & $x$ & & $x$ & & & $x$ & & & & 6 & $50 \%$ & JW \\
\hline & E05 & E88 & $\mathrm{x}$ & $\mathrm{x}$ & $\mathrm{x}$ & $\mathrm{x}$ & & $\mathrm{x}$ & & $\mathrm{x}$ & $\mathrm{x}$ & & & $\mathrm{x}$ & 8 & $67 \%$ & JW \\
\hline
\end{tabular}


Tabla 6 - Efectividad en función de los requisitos que definen el dominio PD1

\begin{tabular}{|c|c|c|c|c|c|c|c|c|c|c|c|c|c|c|c|c|c|c|c|c|}
\hline & \multirow{2}{*}{ 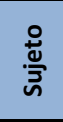 } & \multirow{2}{*}{ 总 } & \multicolumn{18}{|c|}{ REQUISITOS } \\
\hline & & & $\mathrm{R} 1$ & $\mathrm{R} 2$ & R3 & R4 & R5 & R6 & R7 & $\mathrm{R} 8$ & R9 & R10 & R11 & $\mathrm{R} 12$ & $\mathrm{R} 13$ & R14 & R15 & $\begin{array}{l}\mathbf{N}^{\circ} \text { Total } \\
\text { (15) }\end{array}$ & $\% \mathbf{N}^{\circ}$ Total & $\begin{array}{c}\text { Entrevis } \\
\text { tado }\end{array}$ \\
\hline \multirow{7}{*}{$\begin{array}{l}\hat{o} \\
\text { ơ } \\
\text { on }\end{array}$} & E01 & E01 & & & $x x$ & $x x$ & & & $x x$ & $x x$ & & & $\mathrm{x}$ & & & & $\mathrm{x}$ & 6 & $40 \%$ & OD \\
\hline & E04 & E02 & & & $x$ & $\mathrm{x}$ & & & $x$ & $x$ & & & & & & $x$ & $\mathrm{x}$ & 6 & $40 \%$ & OD \\
\hline & E05 & E03 & & & & & & & & & & & & & & & & 0 & $0 \%$ & $O D$ \\
\hline & E08 & E04 & & & & & & & & & & & & & & & $x$ & 1 & $7 \%$ & OD \\
\hline & E09 & E05 & & & & & & & & & & $x$ & & & & $x$ & $x$ & 3 & $20 \%$ & $O D$ \\
\hline & E11 & E06 & & $x$ & $x$ & $\mathrm{x}$ & & $\mathrm{x}$ & & $\mathrm{x}$ & & & $x$ & & & $x$ & & 7 & $47 \%$ & OD \\
\hline & E12 & E07 & & & & & & & & & & $x$ & & & & $x$ & $x$ & 3 & $20 \%$ & OD \\
\hline \multirow{8}{*}{$\begin{array}{l}\text { Oे } \\
\text { ơ } \\
\text { ơ }\end{array}$} & E01 & E08 & $x$ & $x$ & $x$ & $x$ & $x$ & $x$ & & & & & $x x$ & & & & $x x$ & 8 & $53 \%$ & OD \\
\hline & E02 & E09 & $x$ & $x x$ & $x$ & & $x$ & & & & & & & & & & & 4 & $27 \%$ & OD \\
\hline & E03 & E10 & $x x$ & & $x x$ & & $x x$ & & $x x$ & & & & & & & & $x x$ & 5 & $33 \%$ & OD \\
\hline & E04 & E11 & $x x$ & $x$ & $x x$ & $x$ & $x x$ & $x$ & $x x$ & $x$ & & & $x x$ & & & $x x$ & $x$ & 11 & $73 \%$ & OD \\
\hline & E05 & E12 & $x x$ & $x x$ & $x x$ & $x x$ & $x x$ & $x x$ & $x x$ & $x x$ & & $x$ & $x$ & & $x$ & $x$ & $x$ & 13 & $87 \%$ & OD \\
\hline & E06 & E13 & $x$ & & $x$ & & $x$ & & $x$ & & & & & $x$ & & & $x$ & 6 & $40 \%$ & $O D$ \\
\hline & E07 & E14 & $x x$ & $x x$ & $x x$ & $x x$ & $x x$ & $x x$ & $x x$ & $x x$ & & & & & & & & 8 & $53 \%$ & OD \\
\hline & E08 & E15 & $x x$ & $x$ & $\mathrm{xx}$ & $x$ & $\mathrm{xx}$ & $x$ & $x x$ & $x$ & & & $x$ & & $x$ & & $x$ & 11 & $73 \%$ & OD \\
\hline \multirow{9}{*}{ 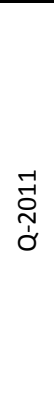 } & E01 & E16 & $x$ & $x$ & $x x$ & $\mathrm{xx}$ & $\mathrm{xx}$ & $x x$ & $x$ & $x$ & & $x x$ & $x$ & $x x$ & $x$ & & $x x$ & 13 & $87 \%$ & OD \\
\hline & E02 & E17 & $x$ & $x$ & $x$ & $x$ & $x$ & $x$ & $x$ & $x$ & & & & & & & & 8 & $53 \%$ & OD \\
\hline & E03 & E18 & $x$ & $x$ & $x$ & $x$ & & & $x$ & $x$ & & $x x$ & $x x$ & & & & $x$ & 9 & $60 \%$ & OD \\
\hline & E04 & E19 & $x$ & $x$ & $x$ & $x$ & $x$ & $x$ & $x$ & $x$ & & & $\mathrm{xx}$ & & $x x$ & & & 10 & $67 \%$ & OD \\
\hline & E05 & E20 & & $x x$ & & $x x$ & & $\mathrm{xx}$ & & $x x$ & & & $x x$ & & $x x$ & & $x x$ & 7 & $47 \%$ & $\mathrm{OD}$ \\
\hline & E06 & E21 & $x$ & $x$ & $x x$ & $x x$ & $x x$ & $x x$ & $x$ & $x$ & & & $x$ & & $x$ & & & 10 & $67 \%$ & $O D$ \\
\hline & E07 & E22 & $x$ & $x$ & $x x$ & $x x$ & $x x$ & $x x$ & $x$ & $x$ & & & $x$ & & $x$ & & & 10 & $67 \%$ & $O D$ \\
\hline & E08 & E23 & & & & & & & & & & & $x$ & & $x$ & & & 2 & $13 \%$ & OD \\
\hline & E09 & E24 & & & & & & & & & & & $x$ & $x x$ & $x x$ & $x x$ & & 4 & $27 \%$ & OD \\
\hline
\end{tabular}




\begin{tabular}{|c|c|c|c|c|c|c|c|c|c|c|c|c|c|c|c|c|c|c|c|c|}
\hline & \multirow{2}{*}{ 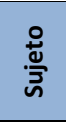 } & \multirow{2}{*}{ 总 } & \multicolumn{18}{|c|}{ REQUISITOS } \\
\hline & & & R1 & $\mathrm{R} 2$ & R3 & R4 & R5 & R6 & R7 & R8 & R9 & R10 & R11 & R12 & $\mathrm{R} 13$ & R14 & R15 & $\begin{array}{c}\mathbf{N}^{\circ} \text { Total } \\
\text { (15) }\end{array}$ & $\% \mathbf{N}^{\circ}$ Total & $\begin{array}{c}\text { Entrevis } \\
\text { tado }\end{array}$ \\
\hline & E10 & E25 & $x$ & $x$ & $x$ & $x$ & $x$ & $x$ & $x$ & $x$ & & & $x$ & & $x$ & & & 10 & $67 \%$ & OD \\
\hline & E11 & E26 & $x x$ & $x x$ & $x x$ & $x x$ & $\mathrm{xx}$ & $x x$ & $x x$ & $x x$ & & & $x$ & & $x$ & & & 10 & $67 \%$ & $O D$ \\
\hline & E12 & E27 & $x$ & & $\mathrm{x}$ & $\mathrm{x}$ & $\mathrm{x}$ & $\mathrm{x}$ & & $x$ & & & $\mathrm{x}$ & & $x$ & & & 8 & $53 \%$ & OD \\
\hline & E13 & E28 & & & & & & & & & & & $\mathrm{x}$ & $x$ & $\mathrm{xx}$ & $\mathrm{xx}$ & $x$ & 5 & $33 \%$ & OD \\
\hline & E14 & E29 & $x$ & $x$ & $x$ & $x$ & $x$ & $x$ & $x$ & $x$ & & & & & & & $x$ & 9 & $60 \%$ & OD \\
\hline & E15 & E30 & & & & & & & & & & & $x$ & & $\mathrm{x}$ & & & 2 & $13 \%$ & OD \\
\hline & E16 & E31 & $\mathrm{x}$ & $x$ & $x$ & $x$ & $x$ & $\mathrm{x}$ & $\mathrm{x}$ & $\mathrm{x}$ & & $x x$ & $\mathrm{x}$ & $x$ & $x$ & & $x$ & 13 & $87 \%$ & JW \\
\hline \multirow{14}{*}{ 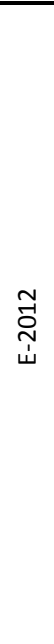 } & E01 & E32 & & & & & & & & & & & & & & & $x$ & 1 & $7 \%$ & $\mathrm{OD}$ \\
\hline & E02 & E33 & & & & & & & & & & & & & & & & 0 & $0 \%$ & JW \\
\hline & E03 & E34 & & . & & & & & & & & & $x$ & $x$ & & & $x$ & 3 & $20 \%$ & $\mathrm{OD}$ \\
\hline & E04 & E35 & & $x$ & & $x$ & & $\mathrm{x}$ & & & & & & & & & & 3 & $20 \%$ & OD \\
\hline & E05 & E36 & $x$ & $x$ & $x$ & $x$ & $x$ & $x$ & & & & & & & & & & 6 & $40 \%$ & $\mathrm{JW}$ \\
\hline & E06 & E37 & & & & & & & & & & & $x$ & $x$ & $x x$ & & $\mathrm{xx}$ & 4 & $27 \%$ & JW \\
\hline & E07 & E38 & $x$ & & & & & & & & & & & & & & & 1 & $7 \%$ & OD \\
\hline & E08 & E39 & & & & & & & & & & & & & & & & 0 & $0 \%$ & $\mathrm{JW}$ \\
\hline & E09 & $\mathrm{E} 40$ & $x$ & $x$ & & & & & & & & & $x$ & $x$ & & & $x$ & 5 & $33 \%$ & $O D$ \\
\hline & E10 & E41 & & $x x$ & & $x x$ & & $x x$ & & & & & & & & & & 3 & $20 \%$ & $\mathrm{JW}$ \\
\hline & E11 & E42 & & & & & & & & & & & $x$ & $x$ & & & $x$ & 3 & $20 \%$ & $\mathrm{JW}$ \\
\hline & E12 & E43 & $x$ & $x$ & $x$ & $x$ & $x$ & $x$ & $x$ & $x$ & & & $x$ & $x$ & & & $\mathrm{x}$ & 11 & $73 \%$ & OD \\
\hline & E13 & E44 & & $x$ & $x x$ & $x$ & $x x$ & $x$ & & $x$ & & & & & & & & 6 & $40 \%$ & OD \\
\hline & E14 & E45 & & & & & & & & & & & & & & & & 0 & $0 \%$ & OD \\
\hline \multirow{8}{*}{ 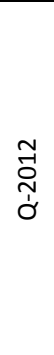 } & E01 & E46 & $x$ & $x x$ & & $x x$ & & & & & & & & & & & & 3 & $20 \%$ & $\mathrm{OD}$ \\
\hline & E02 & E47 & & & & & & & & & & & & $x x$ & & $x x$ & $x x$ & 3 & $20 \%$ & $\mathrm{OD}$ \\
\hline & E03 & E48 & & & & & & & & & & & & & & & $\mathrm{xx}$ & 1 & $7 \%$ & OD \\
\hline & E04 & E49 & $x x$ & $x x$ & $x x$ & $x x$ & $x x$ & $x x$ & & & & & $x x$ & $x$ & & & $\mathrm{xx}$ & 9 & $60 \%$ & OD \\
\hline & E05 & E50 & & & & & & & & & & & & & & & & 0 & $0 \%$ & OD \\
\hline & E06 & E51 & $x x$ & $x x$ & $x x$ & $x x$ & $x x$ & $x x$ & $x x$ & & & & & & & & & 7 & $47 \%$ & OD \\
\hline & E07 & E52 & $x x$ & $\mathrm{xx}$ & $x x$ & $x x$ & $x x$ & $x x$ & $\mathrm{xx}$ & & & & & & & & $x$ & 8 & $53 \%$ & OD \\
\hline & E08 & E53 & & & & & & & & & & & & & & & & 0 & $0 \%$ & OD \\
\hline
\end{tabular}




\begin{tabular}{|c|c|c|c|c|c|c|c|c|c|c|c|c|c|c|c|c|c|c|c|c|}
\hline & \multirow{2}{*}{ 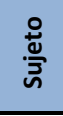 } & \multirow{2}{*}{ 总 } & \multicolumn{18}{|c|}{ REQUISITOS } \\
\hline & & & R1 & R2 & R3 & R4 & R5 & R6 & R7 & R8 & R9 & R10 & R11 & R12 & R13 & R14 & R15 & $\begin{array}{c}\mathrm{N}^{\circ} \text { Total } \\
\text { (15) }\end{array}$ & $\% \mathrm{~N}^{\circ}$ Total & $\begin{array}{c}\text { Entrevis } \\
\text { tado }\end{array}$ \\
\hline & E09 & E54 & & & & & & & & & & & & & & & & 0 & $0 \%$ & OD \\
\hline & E10 & E55 & & & & & & & & & & & & & & & & 0 & $0 \%$ & OD \\
\hline & E11 & E56 & & $x x$ & & $x x$ & & $x x$ & & & & & & & & & & 3 & $20 \%$ & OD \\
\hline & E12 & E57 & & $x x$ & & & & & & & & & & & & & & 1 & $7 \%$ & OD \\
\hline & E13 & E58 & & $x$ & & & & & & & & & & & & & & 1 & $7 \%$ & OD \\
\hline & E14 & E59 & & & & & & & & & & & & & & & & 0 & $0 \%$ & OD \\
\hline & E15 & E60 & & & & & & & & & & & & & & & & 0 & $0 \%$ & OD \\
\hline & E16 & E61 & & & & & & & & & $x$ & & & & & & & 1 & $7 \%$ & OD \\
\hline & E17 & E62 & & & & & & & & & & & & & & & & 0 & $0 \%$ & OD \\
\hline & E18 & E63 & & & & & & & & & & & & & & & & 0 & $0 \%$ & OD \\
\hline & E19 & E64 & $x x$ & $x x$ & $x x$ & $x x$ & $x x$ & $x x$ & $x x$ & & & & & & & & $x$ & 8 & $53 \%$ & OD \\
\hline & E20 & E65 & $x$ & $\mathrm{x}$ & & & & & & & & & & & & & & 2 & $13 \%$ & OD \\
\hline & E21 & E66 & & & & & & & & & & & & $x$ & & & $x$ & 2 & $13 \%$ & OD \\
\hline \multirow{8}{*}{$\underset{\text { ஸे }}{\stackrel{m}{\sim}}$} & E01 & E67 & $x x$ & $x x$ & & & & & & & & & & & & & & 2 & $13 \%$ & JW \\
\hline & E02 & E68 & $x$ & $x$ & $x$ & $x$ & $x$ & $x$ & $x$ & $x$ & & & $x$ & $x$ & & & $x$ & 11 & $73 \%$ & JW \\
\hline & E03 & E69 & & & & & & & & & & & $x x$ & $x$ & & & & 2 & $13 \%$ & OD \\
\hline & E04 & E70 & & & & & & & & & & & & & & & & 0 & $0 \%$ & OD \\
\hline & E05 & E71 & $x x$ & $x x$ & $x x$ & $x x$ & $x x$ & $x x$ & $x x$ & $x x$ & & & & & & & & 8 & $53 \%$ & JW \\
\hline & E06 & E72 & $x$ & $x$ & $x$ & $x$ & $x$ & $x$ & $x$ & $x$ & & & & & & & & 8 & $53 \%$ & $\mathrm{OD}$ \\
\hline & E07 & E73 & & & & & & & & & & & & & & & & 0 & $0 \%$ & $\mathrm{OD}$ \\
\hline & E08 & E74 & & & & & & & & & & & & & & & & 0 & $0 \%$ & OD \\
\hline \multirow{8}{*}{ 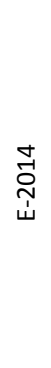 } & E01 & E75 & & & & & & & & & & & & & & & $x$ & 1 & $7 \%$ & OD \\
\hline & E02 & E76 & & & & & & & & & & & & & & & & 0 & $0 \%$ & OD \\
\hline & E03 & E77 & $x$ & & $x$ & & $x$ & & $x$ & & & & & & & & $x$ & 5 & $33 \%$ & OD \\
\hline & E04 & E78 & $x x$ & $x x$ & $x x$ & $x x$ & $x x$ & $x x$ & $x x$ & $x x$ & & & & & & & & 8 & $53 \%$ & OD \\
\hline & E05 & E79 & & & & & & & & & & & & & & & $x x$ & 1 & $7 \%$ & OD \\
\hline & E06 & E80 & & & & & & & & & & & & & & & & 0 & $0 \%$ & OD \\
\hline & E07 & E81 & & & & & & & & & & & & & & & & 0 & $0 \%$ & OD \\
\hline & E08 & E82 & & & & & & & & & & & & & & & $x$ & 1 & $7 \%$ & OD \\
\hline
\end{tabular}




\begin{tabular}{|c|c|c|c|c|c|c|c|c|c|c|c|c|c|c|c|c|c|c|c|c|}
\hline & \multirow{2}{*}{ 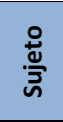 } & \multirow{2}{*}{ 离 } & \multicolumn{18}{|c|}{ REQUISITOS } \\
\hline & & & R1 & $\mathrm{R} 2$ & R3 & R4 & R5 & R6 & R7 & $\mathrm{R} 8$ & R9 & R10 & R11 & R12 & $\mathrm{R} 13$ & R14 & R15 & $\begin{array}{l}\mathbf{N}^{\circ} \text { Total } \\
\text { (15) }\end{array}$ & $\% \mathbf{N}^{\circ}$ Total & $\begin{array}{c}\text { Entrevis } \\
\text { tado }\end{array}$ \\
\hline & E09 & E83 & $x x$ & $x x$ & $x x$ & $x x$ & $x x$ & $x x$ & $x x$ & $x x$ & & & & & & & & 8 & $53 \%$ & $O D$ \\
\hline \multirow{5}{*}{ 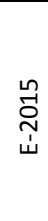 } & E01 & E84 & & $x$ & $x$ & $x$ & & & $x x$ & $x$ & & & $x x$ & & & & $x$ & 7 & $47 \%$ & $O D$ \\
\hline & E02 & E85 & & & & & & & & & & $x$ & & & & & $x$ & 2 & $13 \%$ & OD \\
\hline & E03 & E86 & $x$ & $x$ & $x$ & $x$ & $x$ & $x$ & $x$ & $x$ & & & & & & & & 8 & $53 \%$ & OD \\
\hline & E04 & E87 & & $x$ & & $x$ & & $x$ & & & & & $x$ & & & & $x$ & 5 & $33 \%$ & JW \\
\hline & E05 & E88 & & & & & & & & & & & & $x$ & & & $x$ & 2 & $13 \%$ & JW \\
\hline
\end{tabular}

Tabla 7 - Efectividad en función de los conceptos que definen el dominio PD1

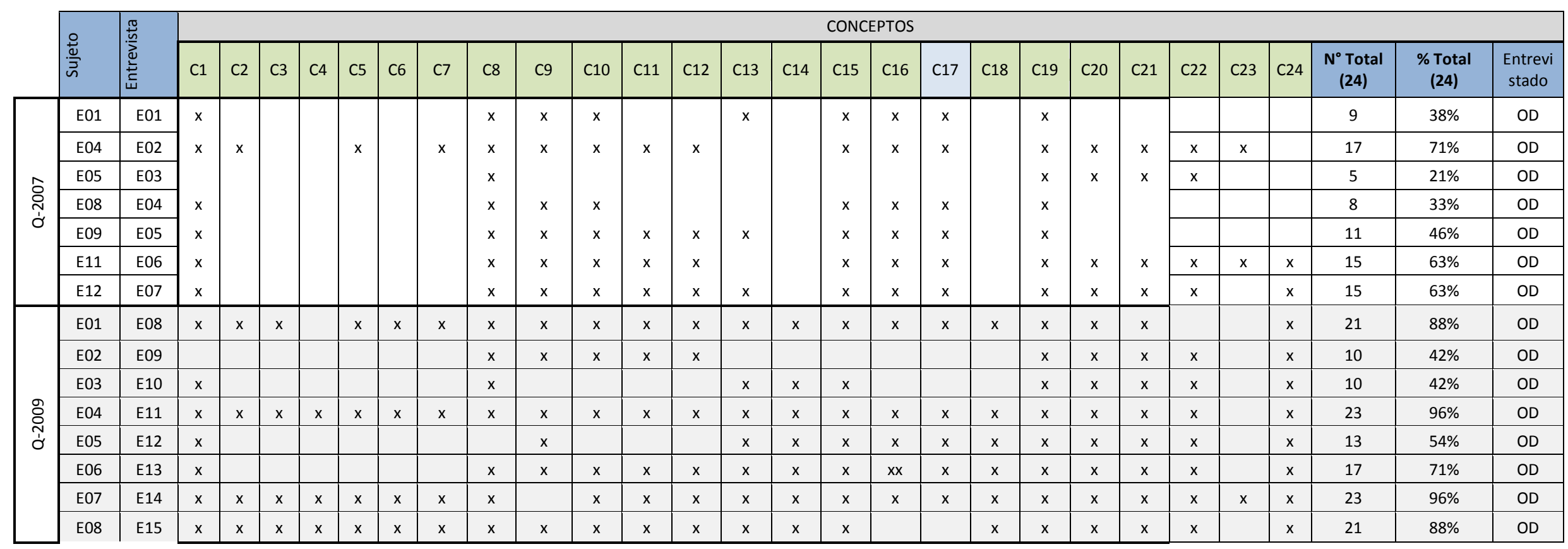




\begin{tabular}{|c|c|c|c|c|c|c|c|c|c|c|c|c|c|c|c|c|c|c|c|c|c|c|c|c|c|c|c|c|}
\hline \multirow[b]{2}{*}{ ڤั0 } & \multirow{2}{*}{ 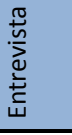 } & \multicolumn{27}{|c|}{ CONCEPTOS } \\
\hline & & C1 & $\mathrm{C} 2$ & C3 & C4 & C5 & C6 & C7 & $\mathrm{C} 8$ & C9 & C10 & C11 & $\mathrm{C} 12$ & C13 & C14 & C15 & C16 & C17 & C18 & C19 & C20 & C21 & C22 & C23 & C24 & $\begin{array}{l}\mathrm{N}^{\circ} \text { Total } \\
\text { (24) }\end{array}$ & $\begin{array}{l}\text { \% Total } \\
\text { (24) }\end{array}$ & $\begin{array}{c}\text { Entrevi } \\
\text { stado }\end{array}$ \\
\hline E01 & E16 & $x$ & & & & & & & & & & & & $x$ & $x x$ & $x$ & & & & $x$ & $x$ & $x x$ & $x$ & & $x x$ & 9 & $38 \%$ & OD \\
\hline E02 & E17 & & & & & & & & $x$ & $x$ & $x$ & $x$ & $x$ & $x$ & $x x$ & $x$ & & $x$ & & $x$ & $x$ & $x$ & $x$ & & $x$ & 14 & $58 \%$ & OD \\
\hline E03 & E18 & $x$ & & & & & & & $x$ & & & & & $x$ & $x x$ & $x$ & $x x$ & $x x$ & $x x$ & $x$ & $x$ & $x$ & $x$ & & & 12 & $50 \%$ & OD \\
\hline E04 & E19 & $x$ & & & & & & & $x$ & $x$ & $x$ & $x$ & $x$ & $x$ & $x x$ & & & & $x x$ & $x$ & $x$ & $x$ & $x$ & & $x$ & 14 & $58 \%$ & OD \\
\hline E05 & E20 & & & & & & & & $x$ & & & & & & $x x$ & $x x$ & & & & $x$ & $x$ & $x$ & $x$ & & $x$ & 8 & $33 \%$ & OD \\
\hline E06 & E21 & $x$ & & & & & & & $x$ & $x$ & $x$ & $x$ & $x$ & $x$ & $x$ & & & $x x$ & $x x$ & $x$ & $x$ & $x x$ & $x$ & & $x x$ & 15 & $63 \%$ & OD \\
\hline E07 & E22 & $x$ & & & & & & & $x$ & $x$ & $x$ & $x$ & $x$ & $x$ & $x$ & & & $x x$ & $x$ & $x$ & $x$ & $x x$ & $x$ & & $x x$ & 15 & $63 \%$ & OD \\
\hline E08 & E23 & & & & & & & & $x$ & $x$ & $x$ & $x$ & $x$ & $x$ & $x$ & & $x x$ & & $x$ & $x$ & $x$ & $x$ & $x$ & & $x$ & 14 & $58 \%$ & OD \\
\hline E09 & E24 & $x$ & & & & & & & $x$ & $x$ & $x$ & & & $x$ & $x$ & & & $x$ & & & $x$ & $\mathrm{xx}$ & & & $\mathrm{xx}$ & 10 & $42 \%$ & OD \\
\hline E10 & E25 & & & & & & & & $x$ & & & & & & $x$ & & & & $x$ & $x$ & $x$ & $x$ & $x$ & & $x$ & 8 & $33 \%$ & OD \\
\hline E11 & E26 & & & & & & & & $x$ & $x$ & $x$ & $x$ & $x$ & & $x$ & & & & $x$ & $x$ & $x$ & $x$ & $x$ & & $x$ & 12 & $50 \%$ & OD \\
\hline E12 & E27 & $x$ & & & & & & & $x$ & $x$ & $x$ & $x$ & $x$ & $x$ & & & & & & $x$ & $x$ & $x$ & $x$ & & $x$ & 12 & $50 \%$ & OD \\
\hline E13 & E28 & $x$ & & & & & & & $x$ & $x$ & $x$ & $x$ & $x$ & $x$ & $x x$ & $x$ & & $x$ & $x x$ & $x$ & $x$ & $x x$ & $x$ & & $x x$ & 16 & $67 \%$ & OD \\
\hline E14 & E29 & $x$ & & & & & & & $x$ & $x$ & $x$ & $x$ & $x$ & $x$ & $x x$ & $x$ & & & $x x$ & $x$ & $x$ & $x$ & $x$ & & $x$ & 15 & $63 \%$ & OD \\
\hline E15 & E30 & & & & & & & & $x$ & & & & & $x$ & & & & & & $x$ & & & & & & 3 & $13 \%$ & OD \\
\hline E16 & E31 & & & & & & & & $x$ & $x$ & $x$ & $x$ & $x$ & $x$ & $x x$ & & $x x$ & $x x$ & $x x$ & $x$ & $x$ & $x$ & $x$ & & $x$ & 15 & $63 \%$ & OD \\
\hline E01 & E32 & $x$ & $x$ & & & & & & $x$ & $x$ & $x$ & $x$ & $x$ & $x$ & & $x$ & & & & $x$ & $x$ & $x$ & $x$ & & $x$ & 14 & $58 \%$ & JW \\
\hline E02 & E33 & & & & & & & & $x$ & & & & & $x$ & & & & & & $x$ & & & & & & 3 & $13 \%$ & OD \\
\hline E03 & E34 & $x$ & $x$ & & & & & & $x$ & $x$ & $x$ & $x$ & $x$ & $x$ & $x$ & $x$ & & & & $x$ & $x$ & $x$ & $x$ & & $x$ & 15 & $63 \%$ & $\mathrm{JW}$ \\
\hline E04 & E35 & $x$ & & & & & & & $x$ & $x$ & $x$ & & & & & & & & & $x$ & $x$ & $x$ & & & $x$ & 8 & $33 \%$ & OD \\
\hline E05 & E36 & & & & & & & & $x$ & $x$ & $x$ & & & $x$ & & & & & & $x$ & $x$ & $x$ & $x$ & & $x$ & 9 & $38 \%$ & OD \\
\hline E06 & E37 & $x$ & $x$ & & & & & & $x$ & $x$ & $x$ & $x$ & $x$ & $x$ & $x$ & $x$ & & & $x x$ & $x$ & $x$ & $x$ & $x$ & & $x$ & 16 & $67 \%$ & $\mathrm{JW}$ \\
\hline E07 & E38 & $x$ & $x$ & & & & & & $x$ & $x$ & $x$ & $x$ & $x$ & $x$ & & & $x x$ & & & $x$ & $x$ & $x$ & $x$ & & $x$ & 14 & $58 \%$ & JW \\
\hline E08 & E39 & & & & & & & & $x$ & $x$ & $x$ & $x$ & $x$ & & & & & & & $x$ & & & & & 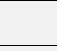 & 6 & $25 \%$ & OD \\
\hline E09 & $\mathrm{E} 40$ & $x$ & $x$ & & & & & & $x$ & $x$ & $x$ & $x$ & $x$ & $x$ & $x$ & $x$ & & & & $x$ & $x$ & $x$ & $x$ & $x$ & $x$ & 16 & $67 \%$ & $\mathrm{JW}$ \\
\hline E10 & E41 & & & & & & & & $x$ & & & & & $x$ & & & & & & $x$ & & & & & & 3 & $13 \%$ & $\mathrm{OD}$ \\
\hline E11 & $\mathrm{E} 42$ & $\mathrm{x}$ & $\mathrm{x}$ & & & & & & $x$ & & & & & $x$ & $x$ & $x$ & & & & $x$ & $x$ & & & & & 8 & $33 \%$ & $\mathrm{JW}$ \\
\hline E12 & E43 & $x$ & $x$ & $x$ & $x$ & $x$ & $x$ & & $x$ & $x$ & $x$ & $x$ & $x$ & $x$ & $x$ & & & & $x x$ & $\underline{x}$ & $x$ & $x$ & $x$ & & $x$ & 19 & $79 \%$ & $\mathrm{JW}$ \\
\hline E13 & E44 & & & & & & & & $x$ & & & & & & & & & & & $x$ & $x$ & $x$ & $x$ & & $x$ & 6 & $25 \%$ & $O D$ \\
\hline
\end{tabular}




\begin{tabular}{|c|c|c|c|c|c|c|c|c|c|c|c|c|c|c|c|c|c|c|c|c|c|c|c|c|c|c|c|c|c|}
\hline & \multirow[b]{2}{*}{ 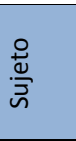 } & \multirow{2}{*}{ 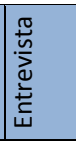 } & \multicolumn{27}{|c|}{ CONCEPTOS } \\
\hline & & & $\mathrm{C} 1$ & $\mathrm{C} 2$ & C3 & C4 & C5 & C6 & $\mathrm{C} 7$ & $\mathrm{C} 8$ & C9 & C10 & C11 & $\mathrm{C} 12$ & C13 & C14 & C15 & C16 & $\mathrm{C} 17$ & C18 & C19 & $\mathrm{C} 20$ & C21 & $\mathrm{C} 22$ & $\mathrm{C} 23$ & C24 & $\begin{array}{l}\mathrm{N}^{\circ} \text { Total } \\
\text { (24) }\end{array}$ & $\begin{array}{l}\text { \% Total } \\
\text { (24) }\end{array}$ & $\begin{array}{c}\text { Entrevi } \\
\text { stado }\end{array}$ \\
\hline & E14 & E45 & & & & & & & & $\mathrm{x}$ & $x$ & $\mathrm{x}$ & & & & & & & & & $\mathrm{x}$ & $\mathrm{x}$ & $x$ & & & $x$ & 7 & $29 \%$ & OD \\
\hline \multirow{21}{*}{$\begin{array}{l}\text { ָ̃ } \\
\text { ָั } \\
\text { ớ }\end{array}$} & E01 & $\mathrm{E} 46$ & & & & & & & & $x$ & $x$ & $x$ & $x$ & $x$ & $x$ & $\mathrm{x}$ & $\mathrm{x}$ & & & & $x$ & $x$ & $x$ & $x$ & & $\mathrm{x}$ & 13 & $54 \%$ & OD \\
\hline & E02 & E47 & $x x$ & & & & & & & $x$ & $x$ & $x$ & $x$ & $\mathrm{x}$ & & $x$ & $\mathrm{x}$ & $x$ & & & $x$ & $x$ & $x$ & $x$ & & $x$ & 14 & $58 \%$ & OD \\
\hline & E03 & E48 & $x x$ & & & & $x$ & $x$ & & $x$ & $x$ & $\mathrm{x}$ & $x$ & $\mathrm{x}$ & $x$ & $x$ & $\mathrm{x}$ & & & & $\mathrm{x}$ & & & & & & 12 & $50 \%$ & OD \\
\hline & E04 & $\mathrm{E} 49$ & $x$ & & & & & & & $x$ & $x$ & $x$ & $x$ & $x$ & & & $x$ & & & & $x$ & & & & & & 8 & $33 \%$ & $\mathrm{OD}$ \\
\hline & E05 & E50 & $\mathrm{x}$ & & & & & & & $x$ & $x$ & $\mathrm{x}$ & $\mathrm{x}$ & $\mathrm{x}$ & & $x$ & & $x$ & & & & & & & & & 8 & $33 \%$ & OD \\
\hline & E06 & E51 & $x$ & & & & & & & $x$ & $x x$ & $x x$ & $x x$ & $x x$ & $x$ & $x$ & & & & & $x$ & $x x$ & $x x$ & $x x$ & & $x x$ & 13 & $54 \%$ & OD \\
\hline & E07 & E52 & $\mathrm{x}$ & & & & $x$ & $x$ & $x$ & $x$ & $x$ & $x$ & $x$ & $x$ & & $x$ & & & & & $x$ & & & & & & 11 & $46 \%$ & OD \\
\hline & E08 & E53 & $x$ & & & & $x$ & & $x$ & $x$ & & & & & & $x$ & & $x$ & & & $x$ & $x x$ & $x x$ & $x x$ & & $x x$ & 11 & $46 \%$ & OD \\
\hline & E09 & E54 & $x$ & & & & $x$ & $x$ & & $x$ & $x$ & $x$ & $x$ & $x$ & & $x$ & $x$ & $x$ & & & $x$ & $x$ & $x$ & $x$ & & $x$ & 16 & $67 \%$ & OD \\
\hline & E10 & E55 & $x$ & & & & $x$ & $x$ & $\mathrm{x}$ & $x$ & $x$ & $x$ & $x$ & $\mathrm{x}$ & $x$ & $x$ & $x$ & $x$ & & & $x$ & $\mathrm{x}$ & $\mathrm{x}$ & $x$ & & $x$ & 18 & $75 \%$ & $\mathrm{OD}$ \\
\hline & E11 & E56 & $x$ & & & & & & & $x$ & $x$ & $\mathrm{x}$ & $x$ & $x$ & & & & & & & $x$ & $x$ & $x$ & $x$ & & $x$ & 11 & $46 \%$ & OD \\
\hline & E12 & E57 & $x$ & & & & & & & $x$ & $x$ & $x$ & $x$ & $\mathrm{x}$ & $x$ & & & $x$ & & & $x$ & & & & & & 9 & $38 \%$ & $O D$ \\
\hline & E13 & E58 & & & & & & & & $x$ & & & & & & $x$ & & & & & $\mathrm{x}$ & & & & & & 3 & $13 \%$ & OD \\
\hline & E14 & E59 & $x$ & & & & & & & $x$ & $x$ & $x$ & $x$ & $x$ & $x$ & $x$ & & & & & $x$ & & & & & & 9 & $38 \%$ & OD \\
\hline & E15 & E60 & $x$ & & & & & & & $x$ & $x$ & $x$ & $x$ & $\mathrm{x}$ & & & $x$ & & & & $x$ & & & & & & 8 & $33 \%$ & OD \\
\hline & E16 & E61 & $x$ & & & & & & & $x$ & & & & & & $x$ & $x$ & $x$ & & & $x$ & & & & & & 6 & $25 \%$ & $O D$ \\
\hline & E17 & E62 & & & & & & & & $x$ & $x$ & $x$ & $x$ & $x$ & & $x$ & & & & & $x$ & $x x$ & $x x$ & $x x$ & & $x x$ & 11 & $46 \%$ & OD \\
\hline & E18 & $\mathrm{E} 63$ & $x$ & & & & $x$ & & $x$ & $x$ & & & & & & $x$ & & & & & $x$ & $x$ & $x$ & $\mathrm{x}$ & & $x$ & 10 & $42 \%$ & OD \\
\hline & E19 & E64 & $x$ & & & & & & & $x$ & & & & & & & & & & & $x$ & $x$ & $x$ & $x$ & & $x$ & 7 & $29 \%$ & OD \\
\hline & E20 & E65 & $x$ & & & & $x$ & & & $x$ & $x$ & $x$ & $x$ & $\mathrm{x}$ & $x$ & $x$ & $x$ & & & & $\mathrm{x}$ & $x$ & $x$ & $\mathrm{x}$ & & $x$ & 15 & $63 \%$ & OD \\
\hline & E21 & E66 & $x$ & & & & & & & $x$ & & $x$ & $x$ & $\mathrm{x}$ & $x$ & $x$ & $x$ & & & & $\mathrm{x}$ & $x$ & $\mathrm{x}$ & $x$ & & $x$ & 13 & $54 \%$ & OD \\
\hline \multirow{7}{*}{$\underset{⿱ 亠 䒑}{\stackrel{m}{\sim}}$} & E01 & E67 & $x$ & & & & & & & $x$ & $x$ & & & & & & $x$ & & & & & $x$ & & & & & 5 & $21 \%$ & OD \\
\hline & E02 & E68 & $x$ & & & & & & & $x$ & $x$ & $x$ & $x$ & $\mathrm{x}$ & $x$ & $x$ & $\mathrm{x}$ & & $\mathrm{xx}$ & $x x$ & $x$ & $x$ & $x$ & $x$ & & $x$ & 16 & $67 \%$ & $\mathrm{JW}$ \\
\hline & E03 & E69 & & & & & & & & $x$ & $x$ & $x$ & & & $x$ & $x$ & $x$ & & & $x x$ & $x$ & & & & & & 8 & $33 \%$ & JW \\
\hline & E04 & E70 & & & & & & & & $x$ & $x$ & $x$ & $x$ & $x$ & & & & & & & $x$ & $x$ & $x$ & $x$ & & $x$ & 10 & $42 \%$ & OD \\
\hline & E05 & E71 & & & & & & & & $x$ & $\mathrm{x}$ & $x$ & & & & & & & & & $x$ & $x$ & $x$ & $x$ & & $x$ & 8 & $33 \%$ & OD \\
\hline & E06 & E72 & $x$ & & & & & & & $x$ & & & & & $\mathrm{x}$ & $x$ & $x$ & & & $x x$ & $x$ & $x$ & $x$ & $x$ & & $x$ & 11 & $46 \%$ & JW \\
\hline & E07 & E73 & $x x$ & & & & & & & $x$ & & & & & & & & & & $x x$ & $x$ & $x$ & $\mathrm{x}$ & $x$ & & & 7 & $29 \%$ & OD \\
\hline
\end{tabular}




\begin{tabular}{|c|c|c|c|c|c|c|c|c|c|c|c|c|c|c|c|c|c|c|c|c|c|c|c|c|c|c|c|c|c|}
\hline & \multirow{2}{*}{$\stackrel{\stackrel{8}{*}}{\stackrel{\leftrightarrow}{丂}}$} & \multirow{2}{*}{ 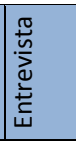 } & \multicolumn{27}{|c|}{ CONCEPTOS } \\
\hline & & & $\mathrm{C} 1$ & $\mathrm{C} 2$ & C3 & $\mathrm{C} 4$ & C5 & C6 & $\mathrm{C7}$ & $\mathrm{C} 8$ & C9 & $\mathrm{C} 10$ & C11 & $\mathrm{C} 12$ & $\mathrm{C} 13$ & C14 & $\mathrm{C} 15$ & C16 & $\mathrm{C} 17$ & $\mathrm{C} 18$ & $\mathrm{C} 19$ & $\mathrm{C} 20$ & $\mathrm{C} 21$ & $\mathrm{C} 22$ & $\mathrm{C} 23$ & C24 & $\begin{array}{l}\mathbf{N}^{\circ} \text { Total } \\
\text { (24) }\end{array}$ & $\begin{array}{l}\text { \% Total } \\
\text { (24) }\end{array}$ & $\begin{array}{l}\text { Entrevi } \\
\text { stado }\end{array}$ \\
\hline & E08 & E74 & $x$ & & & & & & & $x$ & $x$ & $x$ & $x$ & $x$ & & & & & & & $x$ & $x$ & $x$ & $x$ & & $x$ & 11 & $46 \%$ & OD \\
\hline \multirow{9}{*}{ 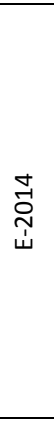 } & E01 & E75 & $x x$ & & & & & & & $x$ & & & & & & & & & & & $x$ & $x$ & $x$ & $x$ & & & 6 & $25 \%$ & OD \\
\hline & E02 & E76 & $x$ & $x$ & $x x$ & $x x$ & $x x$ & $x x$ & $x x$ & $x$ & $x$ & $x$ & $x$ & $x$ & & & & & & & $x$ & $x$ & $x$ & $x$ & & $x$ & 17 & $71 \%$ & OD \\
\hline & E03 & E77 & $x$ & $x$ & $x$ & $x$ & $x$ & $x$ & $x$ & $x$ & $x$ & $x$ & $x$ & $x$ & & & & & & & $x$ & $x$ & $x$ & $x$ & & $x$ & 17 & $71 \%$ & OD \\
\hline & E04 & E78 & $x x$ & & & & & & & $x$ & $x$ & $x$ & & & & & & & & & $x$ & $x$ & $x$ & $x$ & & $x$ & 9 & $38 \%$ & $O D$ \\
\hline & E05 & E79 & $\mathrm{xx}$ & & & & & & & $x$ & $x$ & $x$ & $x$ & $x$ & & & & & & & $x$ & $x x$ & $x x$ & $x x$ & & $x x$ & 11 & $46 \%$ & $O D$ \\
\hline & E06 & E80 & & & & & & & & $x$ & & & & & & & & & & & $x$ & & & & & & 2 & $8 \%$ & $O D$ \\
\hline & E07 & E81 & $x$ & & & & & & & $x$ & $x$ & $x$ & $x$ & $x$ & & & & & & & $x$ & $x$ & $x$ & $x$ & & $x$ & 11 & $46 \%$ & OD \\
\hline & E08 & E82 & $x x$ & & & & & & & $x$ & & & & & & & & & & & $x$ & $x x$ & $x x$ & $x x$ & & & 6 & $25 \%$ & OD \\
\hline & E09 & E83 & $x x$ & & & & & & & $x$ & $x$ & $x$ & $x$ & $\mathrm{x}$ & & & & & & & $x$ & $x$ & $x$ & $x$ & & $x$ & 11 & $46 \%$ & OD \\
\hline \multirow{5}{*}{ 㖞 } & E01 & E84 & $x$ & & & & & & & $x$ & & & & & & & & & & & $x$ & $x$ & $x$ & $x$ & & & 6 & $25 \%$ & OD \\
\hline & E02 & E85 & $x$ & & & & & & & $x$ & $x$ & $x$ & $x$ & $x$ & & & $x$ & $x$ & & & $x$ & $x$ & $x$ & $x$ & & $x x$ & 13 & $54 \%$ & OD \\
\hline & E03 & E86 & $x$ & $x$ & & & & & & $x$ & $x$ & $x x$ & $x x$ & $x x$ & & & & & & & $x$ & $x$ & $x$ & $x$ & & $x$ & 12 & $50 \%$ & OD \\
\hline & E04 & E87 & $x$ & & & & & & & $x$ & $x$ & $x$ & & & $x$ & $x$ & $x$ & & & & $x$ & $x$ & $x$ & $x$ & & $x$ & 12 & $50 \%$ & $\mathrm{JW}$ \\
\hline & E05 & E88 & $x$ & & & & & & & $x$ & $x$ & $x$ & & & $x$ & $x$ & $x$ & & & & $x$ & $x$ & $x$ & $x$ & $x x$ & $x$ & 13 & $54 \%$ & $\mathrm{JW}$ \\
\hline
\end{tabular}




\section{C.2. Problema Conocido: Mensajería de Texto (PC1)}

Tabla 8 - Efectividad en función de los procesos que definen el dominio PC1

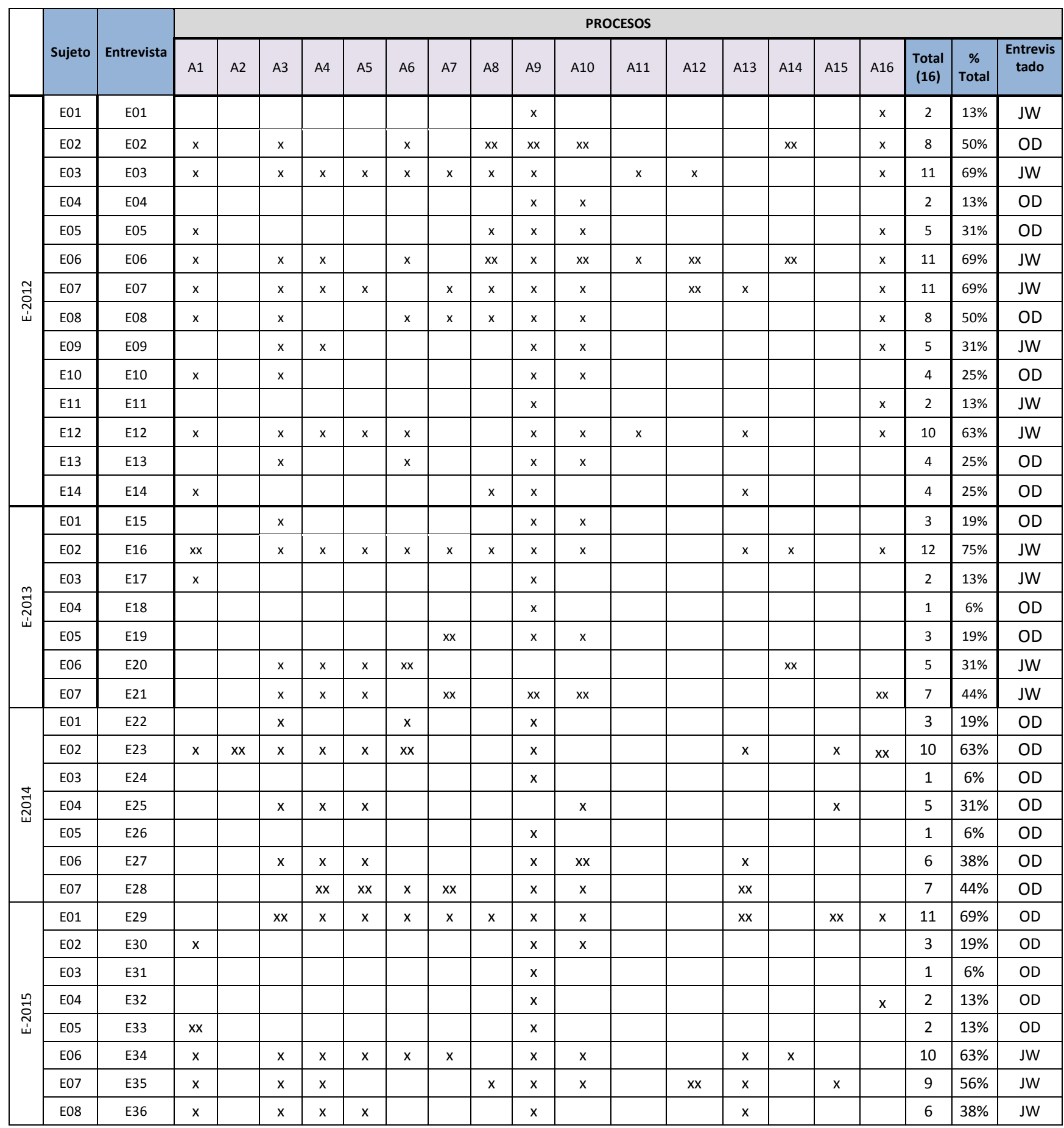


Tabla 9 - Efectividad en función de los requisitos que definen el dominio PC1

\begin{tabular}{|c|c|c|c|c|c|c|c|c|c|c|c|c|c|c|c|c|c|c|c|c|c|c|c|c|c|c|c|c|c|c|c|c|c|}
\hline & \multirow[b]{2}{*}{ 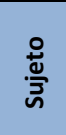 } & \multirow{2}{*}{ 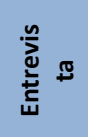 } & \multicolumn{31}{|c|}{ REQUISITOS } \\
\hline & & & R1 & R2 & R3 & R4 & R5 & R6 & R7 & R8 & R9 & R10 & R11 & R12 & R13 & R14 & R15 & R16 & R17 & R18 & R19 & R20 & R21 & R22 & R23 & R24 & R25 & R26 & R27 & R28 & $\begin{array}{c}\mathbf{N}^{\circ} \\
\text { Total }\end{array}$ & $\begin{array}{l}\% \mathbf{N}^{\circ} \\
\text { Total }\end{array}$ & $\begin{array}{c}\text { Entrevis } \\
\text { tado }\end{array}$ \\
\hline \multirow{14}{*}{ تָ } & E01 & E01 & & & & & & & & & & & & & & $x$ & & & $x$ & $x$ & & & & & & $x$ & & & & & 4 & $14 \%$ & JW \\
\hline & E02 & E02 & $\mathrm{x}$ & & & & & & $x x$ & & $x$ & $\mathrm{x}$ & & & $x x$ & & & & & $x$ & & & & & & & & & & & 6 & $21 \%$ & OD \\
\hline & E03 & E03 & $x$ & $x$ & & & & $x$ & $x$ & $x$ & $x$ & $x$ & $x$ & $x$ & $x$ & $x$ & & & $x$ & $x$ & & & & & & $x$ & & $x$ & & $x$ & 16 & $57 \%$ & JW \\
\hline & E04 & E04 & & & & & & & & $x x$ & & & & & $x x$ & & & & & & & & & & & & & & & & 2 & $7 \%$ & $O D$ \\
\hline & E05 & E05 & $x$ & & & & & $x$ & $x$ & $x$ & & & & & $x$ & & & & & & $x$ & & & & & & & & & & 6 & $21 \%$ & $O D$ \\
\hline & E06 & E06 & $x$ & $x$ & & & & & & $x$ & $x$ & $x$ & $x$ & & $x$ & $x$ & & $x$ & $x$ & $x$ & & & & & & $x$ & & $x$ & $x$ & & 14 & $50 \%$ & JW \\
\hline & E07 & E07 & $x$ & $x$ & & & & $x$ & $x$ & $x$ & $x$ & & $x$ & $x$ & $x$ & & & $x$ & $x$ & $x$ & $x$ & $x$ & & & & $x$ & & & $x$ & & 16 & $57 \%$ & $\mathrm{JW}$ \\
\hline & E08 & E08 & $\mathrm{x}$ & & & & & $\mathrm{x}$ & $x$ & $\mathrm{x}$ & $x$ & $x$ & & & $x$ & & & $x$ & & $x$ & & & & & & & & & & $x x$ & 10 & $36 \%$ & $O D$ \\
\hline & E09 & E09 & $x$ & & & & & & & $x$ & $x$ & & $x$ & $x x$ & $x$ & $x$ & & $x$ & & $x$ & & & & & & $x$ & & & & & 10 & $36 \%$ & JW \\
\hline & E10 & E10 & $x$ & $x$ & & & & & & & $x$ & & & & $x$ & & & & & & & & & & & & & & & & 4 & $14 \%$ & $O D$ \\
\hline & E11 & E11 & & & & & & & & $x$ & & & & & $x$ & & & & $x$ & $x$ & & & & & & $x$ & & & & & 5 & $18 \%$ & JW \\
\hline & E12 & E12 & $x$ & $x$ & & & & & & & $x$ & $x$ & $x$ & $x x$ & & $x$ & & & & $x$ & $x$ & $x$ & & & & & & & & $x$ & 11 & $39 \%$ & JW \\
\hline & E13 & E13 & & & & & & & & & $x$ & $x$ & & & $x$ & & & & & & $x$ & & & & & & & & & & 4 & $14 \%$ & OD \\
\hline & E14 & E14 & $x$ & & $x$ & & & & $x$ & & & & & & $x$ & & & & & $x$ & & & & & & & & & $x$ & & 6 & $21 \%$ & $\mathrm{OD}$ \\
\hline \multirow{7}{*}{$\underset{\sim}{\stackrel{m}{\sim}}$} & E01 & E15 & $x$ & & & & & & & $x$ & & & & & $x$ & $x$ & & & & & & & & & & & & & & & 4 & $14 \%$ & OD \\
\hline & E02 & E16 & $\mathrm{x}$ & $x$ & & $x$ & $x x$ & $x$ & $x$ & $x$ & $x$ & $x$ & & & $x$ & $x$ & $x$ & $x$ & $x$ & $x x$ & $x$ & & & $\mathrm{x}$ & $x$ & & & & & $\mathrm{x}$ & 19 & $68 \%$ & JW \\
\hline & E03 & E17 & & $\mathrm{x}$ & & & & & & & $x$ & & & & $x$ & & & & & & & & & & & & & & & & 3 & $11 \%$ & JW \\
\hline & E04 & E18 & & & & & & & & & & & & & $x$ & & & & & & & & & & & & & & & & 1 & $4 \%$ & $\mathrm{OD}$ \\
\hline & E05 & E19 & & $x$ & & & & $x$ & & & & & & & $x$ & & & & & & & & & & & & & & & & 3 & $11 \%$ & $O D$ \\
\hline & E06 & E20 & $x$ & & $x$ & & & & & $x x$ & $x$ & $x$ & & & $x$ & & & $x$ & & & & & & & & $x$ & & & $x$ & & 9 & $32 \%$ & JW \\
\hline & E07 & E21 & $x$ & & & & & $x$ & $x x$ & $x$ & $x$ & $x$ & $x$ & & $x x$ & $x$ & $x x$ & & $x$ & $x x$ & & & & & & & & & & $x$ & 13 & $46 \%$ & JW \\
\hline \multirow{6}{*}{ 总 } & E01 & E22 & & & & & & & & & $x$ & $x$ & & & $x$ & $x x$ & & & & & & & & & & & & & & & 4 & $14 \%$ & $O D$ \\
\hline & E02 & E23 & $x$ & $x$ & $x x$ & $x x$ & & & & $x$ & $x$ & $x$ & $x$ & $x$ & & & $x$ & & & & & & & & & & & & $x$ & & 11 & $39 \%$ & OD \\
\hline & E03 & E24 & & & & & & & & & & & & & $x x$ & $x$ & & & & & & & & & & & & & $x$ & & 3 & $11 \%$ & OD \\
\hline & E04 & E25 & $x$ & $x$ & & & & & & & $\mathrm{x}$ & & $x$ & $x$ & & & & & & & & & & & $x$ & & & & $\mathrm{x}$ & & 7 & $25 \%$ & $\mathrm{OD}$ \\
\hline & E05 & E26 & & & & & & & & $x$ & & & & & $x$ & & & & & & & & & & & & & & & & 2 & $7 \%$ & OD \\
\hline & E06 & E27 & & $x x$ & & & & $x$ & & & $x$ & & $x$ & $x$ & & $x$ & & & & & $x$ & & & & $x x$ & & & & & & 8 & $29 \%$ & OD \\
\hline
\end{tabular}




\begin{tabular}{|c|c|c|c|c|c|c|c|c|c|c|c|c|c|c|c|c|c|c|c|c|c|c|c|c|c|c|c|c|c|c|c|c|c|}
\hline & \multirow{2}{*}{ 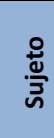 } & \multirow{2}{*}{ 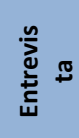 } & \multicolumn{31}{|c|}{ REQUISITOS } \\
\hline & & & R1 & R2 & R3 & R4 & R5 & R6 & R7 & R8 & R9 & R10 & R11 & R12 & R13 & R14 & R15 & R16 & R17 & R18 & R19 & R20 & R21 & R22 & R23 & R24 & R25 & R26 & R27 & R28 & $\begin{array}{l}\mathbf{N}^{\circ} \\
\text { Total }\end{array}$ & $\begin{array}{l}\% \mathbf{N}^{\circ} \\
\text { Total }\end{array}$ & $\begin{array}{c}\text { Entrevis } \\
\text { tado }\end{array}$ \\
\hline & E07 & E28 & $\mathrm{x}$ & $\mathrm{x}$ & $x x$ & & & & & $\mathrm{x}$ & & $x$ & & & & $x$ & $x$ & $\mathrm{x}$ & & & & & & & & & & & $x$ & $x$ & 10 & $36 \%$ & $O D$ \\
\hline \multirow{8}{*}{ 恣 } & E01 & E29 & $x$ & $\mathrm{x}$ & $x$ & & & $\mathrm{x}$ & $x$ & $x$ & $x$ & $\mathrm{x}$ & $\mathrm{x}$ & $\mathrm{x}$ & $\mathrm{x}$ & & $x$ & $x$ & & & $x$ & & & & & & $x x$ & & & $x x$ & 16 & $57 \%$ & $O D$ \\
\hline & E02 & E30 & $x$ & $x$ & & & & & & $x$ & & & & & & & & & & & & & & & & & $x$ & & & & 4 & $14 \%$ & OD \\
\hline & E03 & E31 & $x x$ & $\mathrm{x}$ & & & & & & $x$ & & & & & $x$ & & & & & & & & & & & & & & & & 4 & $14 \%$ & OD \\
\hline & E04 & E32 & & & & & & & & $x$ & & & & & $x$ & & & & & $x x$ & & & & & & & & & & & 3 & $11 \%$ & OD \\
\hline & E05 & E33 & $x x$ & & & & & & & $x$ & & & & & $x$ & & & & & & & & & & & & & & & & 3 & $11 \%$ & OD \\
\hline & E06 & E34 & $x$ & & & & & & & $x$ & $x$ & $x$ & $x$ & $x$ & $\mathrm{x}$ & & & & & & $x$ & & & & & & & & & & 8 & $29 \%$ & JW \\
\hline & E07 & E35 & $x$ & & $x$ & & & $x$ & $x$ & & $x$ & $x$ & $x$ & & $x$ & & & & & & $x$ & $x$ & $x x$ & & & & & & $x$ & & 12 & $43 \%$ & JW \\
\hline & E08 & E36 & $\mathrm{x}$ & $\mathrm{x}$ & & & & & & $x$ & $x$ & & $\mathrm{x}$ & $x$ & $\mathrm{x}$ & & $\mathrm{x}$ & & & & & & & & $x$ & & & & & & 9 & $32 \%$ & JW \\
\hline
\end{tabular}


Tabla 10 - Efectividad en función de los conceptos que definen el dominio PC1

\begin{tabular}{|c|c|c|c|c|c|c|c|c|c|c|c|c|c|c|c|}
\hline & \multirow[b]{2}{*}{ Sujeto } & \multirow[b]{2}{*}{ Entrevista } & \multicolumn{12}{|c|}{ CONCEPTOS } & \multirow[b]{2}{*}{$\begin{array}{c}\text { Entrevis } \\
\text { tado }\end{array}$} \\
\hline & & & $\mathrm{C} 1$ & $\mathrm{C} 2$ & C3 & C4 & C5 & C6 & $\mathrm{C7}$ & $\mathrm{C} 8$ & C9 & C10 & $\begin{array}{c}\mathbf{N}^{\circ} \\
\text { Total } \\
(10)\end{array}$ & $\begin{array}{c}\% \\
\text { Total }\end{array}$ & \\
\hline \multirow{13}{*}{ 공 } & E01 & E01 & $x$ & & $x$ & $x$ & $x x$ & & & & & $x$ & 5 & $50 \%$ & JW \\
\hline & E02 & E02 & $x$ & $x$ & $x$ & & $x$ & $x x$ & $x x$ & & & $x$ & 7 & $70 \%$ & OD \\
\hline & E03 & E03 & $x$ & $x$ & $x$ & $x$ & $x$ & $x$ & $x x$ & $x$ & $x$ & $x$ & 10 & $100 \%$ & JW \\
\hline & E04 & E04 & & & $x$ & $x$ & $x$ & & & & & & 3 & $30 \%$ & OD \\
\hline & E05 & E05 & $x$ & $x$ & $x$ & $x$ & $x$ & & & & & $x$ & 6 & $60 \%$ & OD \\
\hline & E06 & E06 & $x$ & $x$ & $x$ & $x$ & $x x$ & $x$ & $x x$ & $x$ & & $x$ & 9 & $90 \%$ & JW \\
\hline & E07 & E07 & $x$ & $x$ & $x$ & $\mathrm{x}$ & $x x$ & $x$ & $x$ & $x$ & & $x$ & 9 & $90 \%$ & JW \\
\hline & E08 & E08 & $x$ & $x$ & $x$ & $x$ & & & & & & $x$ & 5 & $50 \%$ & OD \\
\hline & E09 & E09 & $x$ & $x$ & $x$ & $x$ & & $x$ & & $x$ & & $\mathrm{x}$ & 7 & $70 \%$ & JW \\
\hline & E11 & E11 & $x$ & & $x$ & $x$ & $x$ & & & & & $x$ & 5 & $50 \%$ & JW \\
\hline & E12 & E12 & $x$ & $x$ & $x$ & $x$ & & $x$ & $x$ & $x$ & & $x$ & 8 & $80 \%$ & JW \\
\hline & E13 & E13 & $x$ & $x$ & $x$ & $x$ & $x$ & & & & & & 5 & $50 \%$ & OD \\
\hline & E14 & E14 & & & $x$ & $x$ & & & & & & & 2 & $20 \%$ & OD \\
\hline \multirow{7}{*}{ 孞 } & E01 & E15 & $x$ & $x$ & $x$ & & $x$ & $x$ & & & & & 5 & $50 \%$ & OD \\
\hline & E02 & E16 & $x$ & $x$ & $x$ & $x$ & & $x$ & $x$ & $x$ & $x$ & $x$ & 9 & $90 \%$ & $\mathrm{JW}$ \\
\hline & E03 & E17 & $x$ & $x x$ & $x$ & $x$ & & & & & & & 4 & $40 \%$ & JW \\
\hline & E04 & E18 & $x$ & & $x$ & $x$ & & & & & & & 3 & $30 \%$ & OD \\
\hline & E05 & E19 & $x$ & $x$ & $x$ & $x$ & & & & & & & 4 & $40 \%$ & OD \\
\hline & E06 & E20 & $x$ & $x$ & $x$ & $x$ & $x x$ & $x$ & $x$ & $x$ & $x$ & & 9 & $90 \%$ & JW \\
\hline & E07 & E21 & $x$ & $x$ & $x$ & $x$ & $x$ & $x$ & $x$ & $x$ & & & 8 & $80 \%$ & JW \\
\hline \multirow{5}{*}{ 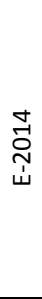 } & E01 & E22 & $x$ & $x$ & $x$ & $x$ & & $x$ & $x$ & & & & 6 & $60 \%$ & OD \\
\hline & E04 & E25 & $x$ & & $x$ & $x$ & $x x$ & & & & & & 4 & $40 \%$ & OD \\
\hline & E05 & E26 & $x$ & $x$ & $x$ & $x$ & & $x$ & & $x$ & $x$ & $x$ & 8 & $80 \%$ & OD \\
\hline & E06 & E27 & $x$ & $x$ & $x$ & $x$ & $x$ & $x$ & & $x$ & $x$ & & 8 & $80 \%$ & OD \\
\hline & E07 & E28 & $x$ & $x$ & $x$ & $x$ & $x$ & & $x$ & $x$ & $x x$ & & 8 & $80 \%$ & OD \\
\hline \multirow{8}{*}{ 资 } & E01 & E29 & $x$ & $x$ & $x$ & $x$ & $x x$ & $x x$ & $x x$ & $x$ & $x$ & $x$ & 10 & $100 \%$ & OD \\
\hline & E02 & E30 & $x$ & & $x$ & $x$ & & & & & & & 3 & $30 \%$ & OD \\
\hline & E03 & E31 & $x$ & & $x$ & $x$ & & & & & & & 3 & $30 \%$ & OD \\
\hline & E04 & E32 & $x$ & & $x$ & $x$ & & & & & & $x$ & 4 & $40 \%$ & OD \\
\hline & E05 & E33 & & & $x$ & $x x$ & $x$ & & & & & & 3 & $30 \%$ & OD \\
\hline & E06 & E34 & $x$ & $x$ & $x$ & $x$ & $x$ & $x$ & $x$ & $x$ & $x$ & & 9 & $90 \%$ & JW \\
\hline & E07 & E35 & $x$ & & $x$ & $x$ & $x$ & $x$ & $x$ & $x$ & & $x$ & 8 & $80 \%$ & JW \\
\hline & E08 & E36 & $x$ & $x$ & $x$ & $x$ & $x$ & $x$ & & $x$ & $x$ & & 8 & $80 \%$ & JW \\
\hline
\end{tabular}




\section{C.3. Problema Desconocido: Compra y Venta de acciones (PD2)}

Tabla 11 - Efectividad en función de los procesos que definen el dominio PD2

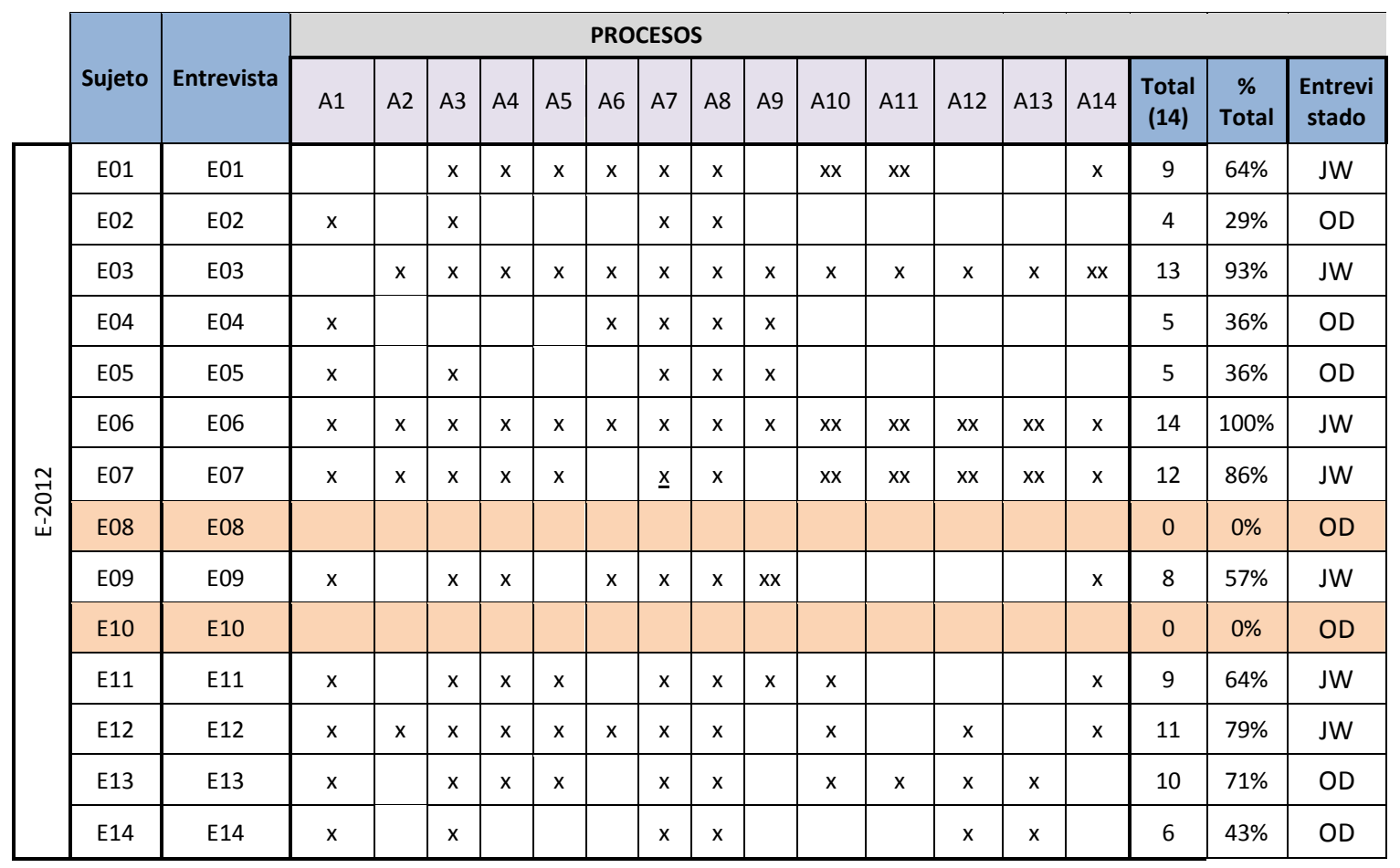

Tabla 12 - Efectividad en función de los conceptos que definen el dominio PD2

\begin{tabular}{|c|c|c|c|c|c|c|c|c|c|c|c|c|c|c|c|}
\hline & \multirow[b]{2}{*}{ Sujeto } & \multirow[b]{2}{*}{$\begin{array}{c}\text { Entrevist } \\
\text { a }\end{array}$} & \multicolumn{13}{|c|}{ CONCEPTOS } \\
\hline & & & C1 & $\mathrm{C} 2$ & C3 & C4 & C5 & C6 & C7 & C8 & C9 & C12 & $\begin{array}{l}\mathbf{N}^{\circ} \\
\text { Total } \\
\text { (12) }\end{array}$ & $\begin{array}{c}\% \\
\text { Total }\end{array}$ & $\begin{array}{c}\text { Entrevi } \\
\text { stado }\end{array}$ \\
\hline \multirow{14}{*}{ 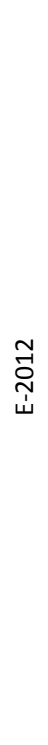 } & E01 & E01 & $\mathrm{x}$ & $x$ & $x$ & & & & & $x$ & & $\mathrm{x}$ & 6 & $50 \%$ & JW \\
\hline & E02 & E02 & $x$ & $x$ & $x$ & & & & & $x$ & & & 4 & $33 \%$ & OD \\
\hline & E03 & E03 & $x$ & $x$ & $x$ & $x$ & $x$ & $x$ & $x$ & $x$ & $\mathrm{x}$ & $\mathrm{x}$ & 12 & $100 \%$ & JW \\
\hline & E04 & E04 & $x$ & & $x$ & & & & & $x$ & & $x$ & 4 & $33 \%$ & OD \\
\hline & E05 & E05 & $x$ & $x$ & $x$ & $x$ & $x x$ & $x x$ & $x x$ & $x$ & $\mathrm{x}$ & $x$ & 10 & $83 \%$ & OD \\
\hline & E06 & E06 & $x$ & $x$ & $x$ & $x$ & $x$ & & $x$ & $x$ & $x x$ & $x$ & 11 & $92 \%$ & JW \\
\hline & E07 & E07 & $x$ & $x$ & $x$ & $x$ & & & & $\mathrm{x}$ & $x$ & $x$ & 8 & $67 \%$ & JW \\
\hline & E08 & E08 & & & & & & & & & & & 0 & $0 \%$ & OD \\
\hline & E09 & E09 & $x$ & $x$ & $x x$ & $x$ & $x$ & $x$ & $x$ & $x$ & $x$ & $\mathrm{x}$ & 10 & $83 \%$ & JW \\
\hline & E10 & E10 & & & & & & & & & & & 0 & $0 \%$ & OD \\
\hline & E11 & E11 & $x$ & $x$ & $x$ & $x$ & & & & $x$ & $x x$ & & 8 & $67 \%$ & JW \\
\hline & E12 & E12 & $x$ & $\mathrm{x}$ & $\mathrm{x}$ & $x x$ & & & & $\mathrm{x}$ & $\mathrm{x}$ & $x$ & 7 & $58 \%$ & JW \\
\hline & E13 & E13 & $\mathrm{x}$ & $x$ & $x$ & $x$ & $x$ & $x$ & $x$ & $x$ & $x$ & & 10 & $83 \%$ & OD \\
\hline & E14 & E14 & $\mathrm{x}$ & & $\mathrm{x}$ & & $\mathrm{x}$ & & & $x$ & $x x$ & $x$ & 7 & $58 \%$ & OD \\
\hline
\end{tabular}


Tabla 13 - Efectividad en función de los requisitos que definen el dominio PD2

\begin{tabular}{|c|c|c|c|c|c|c|c|c|c|c|c|c|c|c|c|c|c|c|c|c|c|c|c|c|c|c|c|c|c|}
\hline & & & \multicolumn{27}{|c|}{ REQUISITOS } \\
\hline & Sujeto & Entrevista & R1 & R2 & R3 & R4 & R5 & R6 & R7 & R8 & R9 & R10 & R11 & R12 & R13 & R14 & R15 & R16 & R1 & & R19 & R20 & R21 & R22 & R23 & R24 & $\begin{array}{l}\mathrm{N}^{\circ} \\
\text { Total } \\
\text { (24) }\end{array}$ & $\begin{array}{l}\% \mathbf{N}^{\circ} \\
\text { Total }\end{array}$ & $\begin{array}{l}\text { Entrev } \\
\text { istado }\end{array}$ \\
\hline \multirow{14}{*}{ 곤 } & E01 & E01 & $\mathrm{x}$ & & & & & $x x$ & & & $\mathrm{x}$ & & & $x$ & $x$ & $x$ & & & $x x$ & & & & & & & & 8 & $33 \%$ & JW \\
\hline & E02 & E02 & $\mathrm{x}$ & $x$ & & & & $x$ & & & $\mathrm{xx}$ & & & & $x$ & $x$ & & & & & & & & & & & 6 & $25 \%$ & OD \\
\hline & E03 & E03 & $\mathrm{x}$ & $x$ & $x x$ & $x$ & & $x$ & & & $\mathrm{x}$ & & & $x$ & $x$ & $x$ & & & $\mathrm{x}$ & & & & $x x$ & $x x$ & & $x$ & 14 & $58 \%$ & JW \\
\hline & E04 & E04 & & $x$ & & & & & & & & & & $x$ & $x$ & $x$ & & & & & & & & & & & 4 & $17 \%$ & OD \\
\hline & E05 & E05 & $\mathrm{x}$ & $x$ & & & & $x$ & & & & & & $x$ & $x$ & $x$ & & & $x x$ & & $x$ & & & & & & 9 & $38 \%$ & OD \\
\hline & E06 & E06 & $\mathrm{x}$ & & $x$ & $x$ & & $x x$ & $x$ & & $\mathrm{x}$ & & & $x$ & $x$ & $x$ & & $x$ & $\mathrm{x}$ & & & $\mathrm{x}$ & & $x$ & & & 14 & $58 \%$ & JW \\
\hline & E07 & E07 & $\mathrm{x}$ & $x$ & $x$ & $x$ & & $x x$ & $x$ & & $x \mathrm{x}$ & $x x$ & & $x$ & $x$ & $x$ & $x$ & & & & $x$ & & & & & & 13 & $54 \%$ & JW \\
\hline & E08 & E08 & & & & & & & & & & & & & & & & & & & & & & & & & 0 & $0 \%$ & $O D$ \\
\hline & E09 & E09 & $\mathrm{x}$ & & $x$ & & & $x$ & $x$ & & & & & $x$ & $x$ & $x$ & & & $\mathrm{x}$ & & & & $x x$ & $x x$ & & & 11 & $46 \%$ & JW \\
\hline & E10 & E10 & & & & & & & & & & & & & & & & & & & & & & & & & 0 & $0 \%$ & OD \\
\hline & E11 & E11 & $\mathrm{x}$ & & & & $\mathrm{x}$ & & & & $x x$ & & $x$ & & $x$ & $x$ & & $\mathrm{x}$ & & & & & & & $x$ & & 8 & $33 \%$ & JW \\
\hline & E12 & E12 & $\mathrm{x}$ & $x$ & & $x$ & & $x$ & & & $\mathrm{x}$ & & & $x$ & $x$ & $x$ & & & & & & $x x$ & $x x$ & $x x$ & $x$ & & 12 & $50 \%$ & JW \\
\hline & E13 & E13 & $\mathrm{x}$ & $x$ & & & & $x$ & $x$ & & $\mathrm{x}$ & & & & $x$ & $x$ & & & $\mathrm{x}$ & & & & & & & & 9 & $38 \%$ & OD \\
\hline & E14 & E14 & $\mathrm{x}$ & & & & & $x$ & & & & & & $x$ & $x$ & $x$ & & & $\mathrm{x}$ & & & & & & & & 7 & $29 \%$ & $O D$ \\
\hline
\end{tabular}




\section{C.4. Problema Conocido: Matrícula (PC2)}

Tabla 14 - Efectividad en función de los procesos que definen el dominio PC2

\begin{tabular}{|c|c|c|c|c|c|c|c|c|c|c|c|c|c|c|c|c|c|c|c|c|c|c|}
\hline & \multirow{2}{*}{ Sujeto } & \multirow{2}{*}{$\begin{array}{l}\text { Entre } \\
\text { vista }\end{array}$} & \multicolumn{17}{|c|}{ PROCESOS } & \multirow{2}{*}{$\begin{array}{c}\mathbf{N}^{\circ} \\
\text { Total } \\
(17)\end{array}$} & \multirow{2}{*}{$\begin{array}{l}\% \mathbf{N}^{\circ} \\
\text { Total }\end{array}$} & \multirow[t]{2}{*}{ Entrevistado } \\
\hline & & & A1 & $\mathrm{A} 2$ & A3 & A4 & A5 & A6 & A7 & A8 & A9 & A10 & A11 & A12 & A13 & A14 & A15 & A16 & A17 & & & \\
\hline \multirow{14}{*}{ 苂 } & E01 & E01 & $x$ & $x$ & & $x$ & $x$ & $x$ & $x$ & $x$ & $x$ & $x$ & $x$ & $x$ & & & $x$ & & & 12 & $71 \%$ & JW \\
\hline & E02 & E02 & $x$ & $x$ & & & $x x$ & $x$ & $x x$ & & & & & & & & & & & 5 & $29 \%$ & OD \\
\hline & E03 & E03 & $x$ & $x$ & $x$ & $x$ & $x$ & $x$ & $x$ & $x$ & $x$ & $x$ & $x$ & $x$ & & $x$ & $x$ & $x$ & & 15 & $88 \%$ & JW \\
\hline & E04 & E04 & $x$ & $x$ & & $x$ & $x$ & $x$ & $x$ & & & & & & & & & & & 6 & $35 \%$ & OD \\
\hline & E05 & E05 & $x$ & $x$ & $x$ & $x$ & & $x$ & $x x$ & & & $x$ & $x$ & $x$ & $x$ & $x$ & & & & 11 & $65 \%$ & $O D$ \\
\hline & E06 & E06 & $x$ & $x$ & $x$ & $x$ & $x$ & $x$ & $x$ & & $x$ & $x$ & $x$ & $x$ & $x x$ & $x$ & $x$ & $x$ & & 15 & $88 \%$ & JW \\
\hline & E07 & E07 & $x$ & $x$ & $x$ & $x$ & $x$ & $x$ & $x$ & $\underline{x}$ & $x$ & $x$ & $x$ & $x$ & $x$ & $x$ & $x$ & $x$ & $x$ & 17 & $100 \%$ & JW \\
\hline & E08 & E08 & & & & & & & & & & & & & & & & & & & & OD \\
\hline & E09 & E09 & $x$ & $x$ & $x$ & $x$ & $x$ & $x$ & $x$ & $x$ & $x$ & $x$ & $x$ & $x$ & $x x$ & $x$ & & $x$ & & 15 & $88 \%$ & JW \\
\hline & E10 & E10 & $x$ & $x$ & & $x$ & & $x$ & & & $x$ & & $x$ & $x$ & $x$ & $x$ & & & & 9 & $53 \%$ & OD \\
\hline & E11 & E11 & $x$ & $x$ & $x$ & $x$ & $x$ & $x$ & $x$ & $x$ & $x$ & $x$ & $x$ & $x$ & $x x$ & $x$ & $x$ & $x$ & & 16 & $94 \%$ & JW \\
\hline & E12 & E12 & $x$ & $x$ & $x$ & $x$ & $x$ & $x$ & $x$ & $x$ & $x$ & $x$ & $x$ & $x$ & $x$ & $x$ & $x$ & $x$ & & 16 & $94 \%$ & JW \\
\hline & E13 & E13 & $x$ & $x$ & $x$ & $x$ & $x$ & $x$ & $x$ & & $x x$ & $x$ & $x$ & $x$ & $x$ & $x$ & & & $x$ & 14 & $82 \%$ & OD \\
\hline & E14 & E14 & $x$ & $x$ & & $x$ & & $x$ & $x x$ & & & & & & & $x$ & & & & 6 & $35 \%$ & $O D$ \\
\hline
\end{tabular}

Tabla 15 - Efectividad en función de los conceptos que definen el dominio PC2

\begin{tabular}{|c|c|c|c|c|c|c|c|c|c|c|c|c|c|c|c|c|c|c|c|c|c|c|c|}
\hline & \multirow{2}{*}{ Sujeto } & \multirow{2}{*}{ Entrevista } & \multicolumn{18}{|c|}{ CONCEPTOS } & \multirow{2}{*}{$\begin{array}{l}\mathbf{N}^{\circ} \\
\text { Total } \\
\text { (20) }\end{array}$} & \multirow{2}{*}{$\begin{array}{c}\% \\
\text { Total }\end{array}$} & \multirow{2}{*}{$\begin{array}{c}\text { Entrevis } \\
\text { tados }\end{array}$} \\
\hline & & & $\mathrm{C} 1$ & $\mathrm{C} 2$ & C3 & $\mathrm{C} 4$ & C5 & C6 & $\mathrm{C} 7$ & $\mathrm{C} 8$ & C9 & C10 & C11 & C12 & C13 & C14 & C15 & C16 & C17 & $\mathrm{C} 20$ & & & \\
\hline \multirow{14}{*}{ 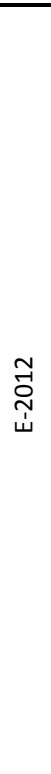 } & E01 & $x$ & $x$ & $x$ & $\mathrm{x}$ & $x x$ & $\mathrm{x}$ & $\mathrm{x}$ & $x x$ & $x x$ & $\mathrm{x}$ & $x$ & $x$ & $\mathrm{x}$ & & $x$ & $x$ & $x$ & $\mathrm{x}$ & $x$ & 18 & $90 \%$ & JW \\
\hline & E02 & $x$ & $x$ & & & & $x$ & $x$ & & & & & & & & & $x$ & $x x$ & $x$ & & 6 & $30 \%$ & OD \\
\hline & E03 & $x$ & $x$ & $x$ & $x$ & $x x$ & $x$ & $x$ & $x$ & $x$ & $x$ & & & $x$ & $x$ & $x$ & $x$ & $x$ & $x$ & $x$ & 18 & $90 \%$ & JW \\
\hline & E04 & $x$ & $x$ & & $x$ & & $x$ & & & & $x$ & & & & & & $x$ & $x x$ & $x$ & & 7 & $35 \%$ & OD \\
\hline & E05 & $x$ & $x$ & $x$ & $x$ & $x$ & $x$ & & & & $x$ & $x x$ & & & & $x$ & $x$ & $x x$ & $x$ & & 12 & $60 \%$ & OD \\
\hline & E06 & $x$ & $x$ & & $x$ & $x x$ & $x$ & $x$ & & & & & & $x$ & $x$ & & $x$ & $x x$ & $x$ & $x$ & 13 & $65 \%$ & JW \\
\hline & E07 & $x$ & $x$ & $x$ & $x$ & $x x$ & $x$ & $x$ & & & $\mathrm{x}$ & $x$ & & $x x$ & $x$ & $x$ & $x$ & $x x$ & $x$ & $x$ & 17 & $85 \%$ & JW \\
\hline & E08 & & & & & & & & & & & & & & & & & & & & & & OD \\
\hline & E09 & $x$ & $x$ & $x$ & $x$ & $x x$ & $x$ & $x$ & $x$ & $x$ & $x$ & & & $x$ & $x$ & $x$ & $x$ & $x$ & $x$ & $x$ & 18 & $90 \%$ & JW \\
\hline & E10 & $x$ & $x$ & $x$ & & $x$ & $x$ & $x$ & & & & & & $x x$ & & & $x$ & $x x$ & $x$ & & 10 & $50 \%$ & OD \\
\hline & E11 & $x$ & $x$ & $x$ & $x$ & $x x$ & $x$ & $x$ & $x$ & $x$ & & & & $x$ & $x$ & $x$ & $x$ & $x x$ & $x$ & $\underline{x}$ & 17 & $85 \%$ & JW \\
\hline & E12 & $x$ & $x$ & $x x$ & $x$ & $x$ & $x$ & $x$ & $x$ & $x$ & $x$ & $x$ & & $x x$ & $x$ & $x$ & $x$ & $x x$ & $x$ & $\underline{x}$ & 19 & $95 \%$ & JW \\
\hline & E13 & $x$ & $x$ & $x$ & $x$ & $x$ & $x$ & $x$ & & & $x$ & $x$ & & $x$ & & & $x$ & $x x$ & $x$ & & 13 & $65 \%$ & OD \\
\hline & E14 & $x$ & $\mathrm{x}$ & $\mathrm{x}$ & $x$ & & $\mathrm{x}$ & $\mathrm{x}$ & & & & & & & & & $x$ & $x x$ & $\mathrm{x}$ & & 9 & $45 \%$ & OD \\
\hline
\end{tabular}


Tabla 16 - Efectividad en función de los requisitos que definen el dominio PC2

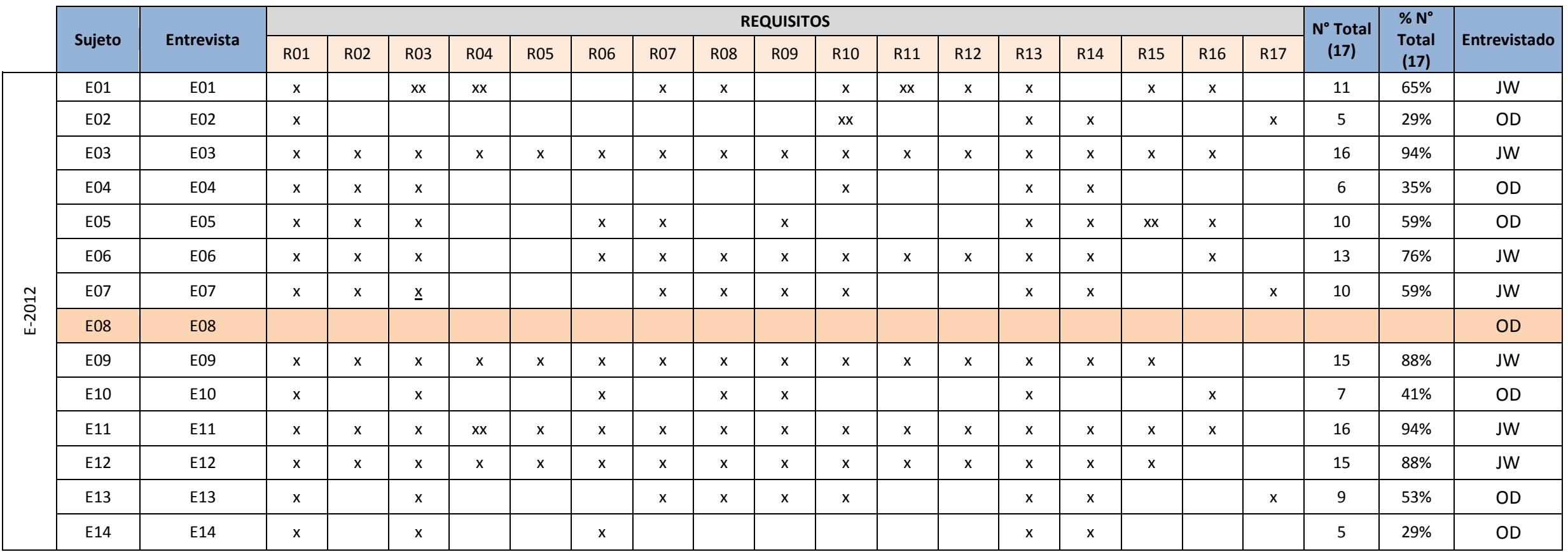




\section{ANEXO D}

\section{Conjunto de Datos (DataSet)}

El fichero de datos generados para esta investigación, está disponible en el formato del spss como un documento adjunto. 
ANEXO E

\section{Ajuste de Datos}

A continuación se detalla por cada dominio del problema utilizado en la investigación y por cada experimento, cómo se ha llevado a cabo el ajuste de los datos. Nótese que en la sección 6.1.1.del Capítulo 6, se describe el proceso seguido.

\section{E.1. Procedimiento de Ajuste de los Datos - Problema PD1}

El \% de ajuste para cada una de las variables moderadoras, se obtuvo mediante los valores presentados en la Tabla 17 se obtuvo Partiendo de las diferencias principales entre experimentos y efectividades promedios obtenidas.

Tabla 17 - Diferencia entre experimentos y efectividades promedio P2

Efectividad en la Consolidación (\%)

\begin{tabular}{|l|l|l|l|l|r|r|}
\hline \multirow{2}{*}{ Experimento } & \multicolumn{1}{|c|}{$\begin{array}{c}\text { Tipo } \\
\text { Entrevista }\end{array}$} & Formación & $\begin{array}{l}\text { WarmingUp } \\
\text { (Formación) }\end{array}$ & Entrevistado & $\mathbf{N}$ & Media \\
\hline Q-2007 & Individual & Final & & OD & 7 & 39.22 \\
\hline Q-2009 & Individual & Final & & AG & 8 & 61.76 \\
\hline Q-2011 & Grupal & Final & & OD & 16 & 48.41 \\
\hline Q-2012 & Grupal & Principio & Ninguno & OD & 21 & 37.07 \\
\hline E-2012 & Individual & Principio & Ninguno & OD & 7 & 24.93 \\
\cline { 5 - 8 } & & & & JW & 7 & 50.98 \\
\hline E-2013 & Individual & Principio & 1 semana & OD & 5 & 28.63 \\
\cline { 5 - 8 } & & & & JW & 3 & 44.44 \\
\hline E-2014 & Individual & Principio & 6 semanas & OD & 9 & 35.08 \\
\hline E-2015 & Individual & Principio & 2 semanas & OD & 3 & 43.79 \\
\cline { 5 - 8 } & & & & JW & 2 & 45.10 \\
\hline
\end{tabular}

- Efecto del Momento

EfectoMomentoOD = |Efectividad Q-2007 - Efectividad E-2012 $\mid$; N=7; N=7

EfectoMomentoOD $=|39-25|=|14|=14$

EfectoMomentoOD = | Efectividad Q-2012 - EfectividadQ-2011 $; \mathrm{N}=21 ; \mathrm{N}=16$

EfectoMomentoOD $=|37-48|=|-11|=11$

MediaPonderadaOD $=(14 * 14+11 * 37) / 51=11.82=12$

EfectoMomento $=12$

Los sujetos tienden promedio a ser $12 \%$ más efectivos después de que hayan recibido formación en actividades de requisitos.

\section{- Efecto del Entrevistado OD/JW}

EfectoEntrevistado $=|\mathrm{E}-2012 \mathrm{OD}-\mathrm{E} 2012 \mathrm{JW}| ; \mathrm{N}=7, \mathrm{~N}=7$

EfectoEntrevistado $=|25-51|=|-26|=26$

EfectoEntrevistado $=|\mathrm{E}-20130 \mathrm{D}-\mathrm{E} 2013 \mathrm{JW}| ; \mathrm{N}=5, \mathrm{~N}=3$ 

proceso de educción de requisitos

EfectoEntrevistado $=|29-44|=|-15|=15$

EfectoEntrevistado $=|\mathrm{E}-2015 \mathrm{OD}-\mathrm{E} 2015 \mathrm{JW}| ; \mathrm{N}=3, \mathrm{~N}=2$

EfectoEntrevistado $=|44-45|=|-1|=1$

MediaPonderada $=(26 * 14+15 * 8+1 * 5) / 27=18.11=18$

\section{EfectoEntrevistadoODJW $=18$}

La diferencia de efectividades entre JW y OD es de un $18 \%$. Alcanzando mayores efectividades los sujetos que entrevistaron a JW

\section{- Efecto del Entrevistado OD/AG}

EfectoEntrevistadoODAG $=|\mathrm{Q}-2009 A G-\mathrm{Q}-20070 D| \mathrm{N}=7 ; \mathrm{N}=8$

EfectoEntrevistadoODAG $=|62-39|=|23|=23$

EfectoEntrevistado ODAG $=23$

La diferencia de efectividades entre OD y AG es de un $23 \%$. Alcanzado mayores efectividades los sujetos que entrevistaron a $A G$.

\section{- Efecto del Tipo de Entrevista}

EfectoTipoEntrevista $=|\mathrm{Q}-2011-\mathrm{Q}-2007| \mathrm{N}=16 ; \mathrm{N}=7$

EfectoTipoEntrevista $=|48-39|=|9|=9$

EfectoTipoEntrevista $=|\mathrm{Q}-2012-\mathrm{E}-2012 \mathrm{OD}| \mathrm{N}=21 ; \mathrm{N}=7$

EfectoTipoEntrevista $=|37-25|=|12| \mid=12$

MediaPonderada $=(9 * 23+12 * 28) / 51=11$

\section{EfectoTipoEntrevista $=11$}

Los sujetos en entrevistas en grupo tienden a ser un $11 \%$ más efectivo. Conforme se espera, la efectividad aumenta (aunque muy levemente) en entrevistas en grupo.

\section{- Efecto del WarmingUp 1 semana}

EfectoWarmingUp1OD = E-20130D $-\mathrm{E}-20120 \mathrm{~N} ; \mathrm{N}=5, \mathrm{~N}=7$

EfectoWarmingUp1OD $=29-25=4$

EfectoWarmingUp1JW = E-2013JW- E-2012JW; N=3, N=7

EfectoWarmingUp1JW $=44-51=-7$

MediaPonderada $=(4 * 12+(-7) * 10) / 22=-1$

EfectoWarmingUp1 $=-1$

La efectividad promedio de los sujetos tiende a disminuir en un $1 \%$, prácticamente no se observa ningún tipo de mejora en las efectividades promedios.

\section{- Efecto del WarmingUp 6 semanas OD}

EfectoWarmingUp6 $=\mathrm{E}-20140 D-\mathrm{E}-20120 D$

EfectoWarmingUp6 $=35-25=10$

\section{EfectoWarmingUp6 $=10$}


La efectividad promedio de los sujetos tiende a aumentar en un $10 \%$, al cabo de 6 semanas de warming up.

\section{- Efecto del WarmingUp 2 semanas}

EfectoWarmingUp1OD $=\mathrm{E}-20150 D-\mathrm{E}-20120 D ; \mathrm{N}=3, \mathrm{~N}=7$

EfectoWarmingUp1OD $=44-25=19$

EfectoWarmingUp1JW = E-2015JW- E-2012JW; N=2, N=7

EfectoWarmingUp1JW $=45-51=-6$

MediaPonderada $=(19 * 10+(-6) * 9+) / 19=-7$

\section{EfectoWarmingUp2 = -7}

La efectividad promedio de los sujetos tiende a disminuir en un 7\%, al cabo de 2 semanas de Warming Up.

\section{E.2. Procedimiento de Ajuste de los Datos - Problema PC1}

El \% de ajuste para cada una de las variables moderadoras, se obtuvo mediante los valores presentados en la Tabla 18 se obtuvo Partiendo de las diferencias principales entre experimentos y efectividades promedios obtenidas.

Tabla 18 - Diferencia entre experimentos y efectividades promedio P1

Efectividad en la Consolidación (\%)

\begin{tabular}{|l|l|l|l|l|r|r|}
\hline \multirow{2}{*}{ Experimento } & \multirow{2}{*}{$\begin{array}{c}\text { Tipo } \\
\text { Entrevista }\end{array}$} & Formación & WarmingUp & Entrevistado & N & Media \\
\hline E-2012 & Individual & Principio & Ninguno & OD & 7 & 28.04 \\
\cline { 5 - 7 } & & & & JW & 7 & 47.88 \\
\hline E-2013 & Individual & Principio & \multirow{2}{*}{1 semana } & OD & 5 & 16.67 \\
\cline { 5 - 8 } & & & & JW & 3 & 46.30 \\
\hline E-2014 & Individual & Principio & 6 semanas & OD & 9 & 33.07 \\
\hline E-2015 & Individual & Principio & 2 semanas & OD & 5 & 26.67 \\
\cline { 5 - 8 } & & & & JW & 3 & 48.77 \\
\hline
\end{tabular}

- Efecto del Entrevistado OD/JW

EfectoEntrevistado $=|\mathrm{E}-2012 \mathrm{OD}-\mathrm{E} 2012 \mathrm{JW}| ; \mathrm{N}=7, \mathrm{~N}=7$

EfectoEntrevistado $=|48-28|=|-20|=20$

EfectoEntrevistado $=|\mathrm{E}-20130 \mathrm{D}-\mathrm{E} 2013 \mathrm{JW}| ; \mathrm{N}=3, \mathrm{~N}=4$

EfectoEntrevistado $=|17-46|=|-29|=29$

EfectoEntrevistado $=|\mathrm{E}-2015 \mathrm{OD}-\mathrm{E} 2015 \mathrm{JW}| ; \mathrm{N}=3, \mathrm{~N}=2$

EfectoEntrevistado $=|27-49|=|-22|=22$

MediaPonderada $=(20 * 14+29 * 7+22 * 8) / 29=22.73=23$

EfectoEntrevistadoODJW $=23$

La diferencia de efectividades entre JW y OD es de un $23 \%$. Alcanzando mayores efectividades los sujetos que entrevistaron a JW

\section{- Efecto del WarmingUp 1 semana}


EfectoWarmingUp1OD = E-20130D $-\mathrm{E}-20120 D ; \mathrm{N}=3, \mathrm{~N}=7$

EfectoWarmingUp1OD $=17-28=-11$

EfectoWarmingUp1JW = E-2013JW- E-2012JW; N=4, N=7

EfectoWarmingUp1JW $=46-48=-2$

MediaPonderada $=((-11) * 10+(-2) * 11) / 21=-6$

EfectoWarmingUp1 = - 6

La efectividad promedio de los sujetos tiende a disminuir en un $6 \%$ con una semana de warming up.

\section{- Efecto del WarmingUp 6 semanas OD}

EfectoWarmingUp6 $=\mathrm{E}-20140 D-\mathrm{E}-20120 \mathrm{D} ; \mathrm{N}=7, \mathrm{~N}=7$

EfectoWarmingUp6 $=33-28=5$

EfectoWarmingUp6 = 5

La efectividad promedio de los sujetos tiende a aumentar en un 5\%, al cabo de 6 semanas de warming up.

\section{- Efecto del WarmingUp 2 semanas}

EfectoWarmingUp1OD $=\mathrm{E}-20150 D-\mathrm{E}-20120 \mathrm{D} ; \mathrm{N}=5, \mathrm{~N}=7$

EfectoWarmingUp1OD $=27-28=-1$

EfectoWarmingUp1JW = E-2015JW- E-2012JW; N=3, N=7

EfectoWarmingUp1JW $=49-48=1$

MediaPonderada $=((-1) * 12+1 * 10+) / 22=-0.09=0$

EfectoWarmingUp2 = 0

La efectividad promedio de los sujetos se mantiene constante, no varía al cabo de 2 semanas de Warming Up. 


\section{ANEXO F}

\section{Efecto de la Experiencia}

A continuación se presenta por cada dominio del problema y estudio empírico (cuasi-experimentos y experimentos) la relación existente entre las distintas experiencias y la efectividad de los sujetos experimentales. Cada una de las tablas presenta por cada vertiente de la experiencia analizada: requisitos, educción, entrevistas, desarrollo y profesional, la cantidad total de sujetos analizados (tamaño muestral N), el coeficiente de correlación ( $r$ ), el valor de significación ( $p$-valor) y el efecto observado.

Como se ha indicado en el capítulo 4 de metodología y el capítulo 5 de resultados, para analizar el efecto de la experiencia en los experimentos $\left(E-201_{i}\right)$ se ha empleado el modelo de regresión con dos variables (la variable independiente correspondiente y la variable de bloque), con la finalidad de separar los efectos de la experiencia y el entrevistado. No obstante, la información proporcionada en las tablas hace referencia al índice de correlación $(r)$ y no a las betas $(\beta)$ coeficientes no estandarizados obtenidos en el modelo. Con la finalidad de presentar una información coherente y poder comparar los efectos, hemos aplicado una transformación ${ }^{53}$ partiendo del valor $\mathrm{t}$ asociado a cada experiencia obtenido de los modelos correspondientes y el tamaño muestral asociado. Nótese que el cálculo del df para un modelo de regresión, corresponde a $\mathrm{N}-\mathrm{k}$, donde $\mathrm{k}$ = número de predictores del modelo.

En lo que respecta a los efectos observados, hemos empleado los tamaños de efectos propuestos por Cohen:

\begin{tabular}{|c|c|c|c|c|}
\hline Efecto & FUeRTE & Moderado & BAJO & Ninguno \\
\hline Correlación $(r)$ & $\pm(0.5-1)$ & $\pm(0.3-0.5)$ & $\pm(0.1-0.3)$ & $\pm(0-0.09)$ \\
\hline
\end{tabular}

\section{F.1. PROBlema desconocido (PD1)}

Tabla 19 - Efecto de la experiencia en requisitos en los distintos experimentos - PD1

\begin{tabular}{|c|r|r|r|c|}
\hline \multirow{2}{*}{ EXPERIMENTO } & \multirow{2}{*}{$\mathbf{N}$} & \multicolumn{3}{|c|}{ Correlación } \\
\cline { 3 - 5 } & & \multicolumn{3}{|c|}{ Efectividad * [ExpReq] } \\
\cline { 3 - 5 } & 7 & -.348 & $\mathrm{No}(.444)$ & $(-)$ \\
\hline $\mathrm{Q}-2007$ & 7 & .640 & $\mathrm{No}(.122)$ & $(+)$ \\
\hline $\mathrm{Q}-2009$ & 16 & .004 & $\mathrm{No}(.988)$ & $(+)$ \\
\hline $\mathrm{Q}-2011$ & 21 & .338 & $\mathrm{No}(.134)$ & $(+)$ \\
\hline $\mathrm{Q}-2012$ & 13 & .734 & $\mathrm{No}(.050)$ & $(+)$ \\
\hline E-2012 & 7 & -.843 & $\mathrm{Si}(.025)$ & $(-)$ \\
\hline E-2013 & 8 & -.243 & $\mathrm{No}(.562)$ & $(-)$ \\
\hline E-2014 & 5 & 0.000 & $\mathrm{No}(1.00)$ & $(\mathrm{X})$ \\
\hline E-2015 & & & &
\end{tabular}

${ }^{53}$ http://www.uccs.edu/ /becker/ donde el $d f=N-2$ 
Estudio empírico de la influencia de la experiencia y del conocimiento del dominio del analista en la efectividad del proceso de educción de requisitos

Tabla 20 - Efecto de la experiencia en entrevistas en los distintos experimentos - PD1

\begin{tabular}{|c|c|c|c|c|}
\hline \multirow{3}{*}{ EXPERIMENTO } & \multirow{3}{*}{$\mathbf{N}$} & \multicolumn{3}{|c|}{ CORRELACIÓN } \\
\hline & & \multicolumn{3}{|c|}{ Efectividad * [ExpEntr] } \\
\hline & & $r$ & Sig. & Efecto \\
\hline Q-2007 & 7 & -.522 & $\mathrm{No}(.229)$ & $(-)$ \\
\hline Q-2009 & 7 & .537 & $\mathrm{No}(.214)$ & $(+)$ \\
\hline Q-2011 & 16 & .087 & No(.749) & $(+)$ \\
\hline Q-2012 & 21 & .441 & $\mathrm{Si}(.046)$ & $(+)$ \\
\hline $\mathrm{E}-2012$ & 13 & -.188 & $\mathrm{No}(.540)$ & $(-)$ \\
\hline $\mathrm{E}-2013$ & 7 & -.356 & No (.443) & $(-)$ \\
\hline E-2014 & 8 & -.126 & $\mathrm{No}(.767)$ & $(-)$ \\
\hline E-2015 & 5 & 0.00 & $\mathrm{No}(1.00)$ & (X) \\
\hline
\end{tabular}

Tabla 21 - Efecto de la experiencia en educción en los distintos experimentos - PD1

\begin{tabular}{|c|c|c|c|c|}
\hline \multirow{3}{*}{ EXPERIMENTO } & \multirow{3}{*}{$\mathbf{N}$} & \multicolumn{3}{|c|}{ CORRELACIÓN } \\
\hline & & \multicolumn{3}{|c|}{ Efectividad * [ExpEduc] } \\
\hline & & $r$ & Sig. & Efecto \\
\hline Q-2007 & 7 & -.384 & No(.396) & $(-)$ \\
\hline Q-2009 & 7 & .630 & $\mathrm{No}(.129)$ & $(+)$ \\
\hline Q-2011 & 0 & & & . \\
\hline $\mathrm{Q}-2012$ & 21 & .369 & No $(.100)$ & $(+)$ \\
\hline $\mathrm{E}-2012$ & 13 & .516 & $\mathrm{No}(.063)$ & $(+)$ \\
\hline E-2013 & 7 & 0.00 & No (1.00) & $(\mathrm{X})$ \\
\hline E-2014 & 8 & -.065 & No(.878) & $(\mathrm{X})$ \\
\hline E-2015 & 5 & -.554 & No (.369) & $(-)$ \\
\hline
\end{tabular}

Tabla 22 - Efecto de la experiencia en desarrollo en los distintos experimentos - PD1

\begin{tabular}{|c|r|r|r|c|}
\hline \multirow{2}{*}{ EXPERIMENTO } & \multirow{2}{*}{$\mathbf{N}$} & \multicolumn{3}{|c|}{ Correlación } \\
\cline { 3 - 5 } & & \multicolumn{3}{|c|}{ Efectividad * [ExpDes] } \\
\cline { 3 - 5 } & & $\mathrm{r}$ & \multicolumn{1}{|c|}{ Sig. } & Efecto \\
\hline Q-2007 & 0 & & &. \\
\hline $\mathrm{Q}-2009$ & 7 & .046 & $\mathrm{No}(.923)$ & $(\mathrm{X})$ \\
\hline $\mathrm{Q}-2011$ & 10 & -.301 & $\mathrm{No}(.399)$ & $(-)$ \\
\hline $\mathrm{Q}-2012$ & 21 & .322 & $\mathrm{No}(.155)$ & $(+)$ \\
\hline $\mathrm{E}-2012$ & 11 & .111 & $\mathrm{No}(.710)$ & $(+)$ \\
\hline $\mathrm{E}-2013$ & 7 & .300 & $\mathrm{No}(.521)$ & $(+)$ \\
\hline E-2014 & 8 & .128 & $\mathrm{No}(.762)$ & $(+)$ \\
\hline E-2015 & 5 & -.592 & $\mathrm{No}(.331)$ & $(-)$ \\
\hline
\end{tabular}

Tabla 23 - Efecto de la experiencia profesional en los distintos experimentos - PD1

\begin{tabular}{|c|r|r|r|c|}
\hline \multirow{2}{*}{ EXPERIMENTO } & \multirow{2}{*}{$\mathbf{N}$} & \multicolumn{3}{|c|}{ Correlación } \\
\cline { 3 - 5 } & & \multicolumn{3}{|c|}{ Efectividad * [ExpProf] } \\
\cline { 3 - 5 } & & $\mathrm{r}$ & \multicolumn{1}{c|}{ Sig. } & \multicolumn{1}{c|}{ Efecto } \\
\hline $\mathrm{Q}-2007$ & 7 & -.355 & $\mathrm{No}(-.435)$ & $(-)$ \\
\hline $\mathrm{Q}-2009$ & 7 & .457 & $\mathrm{No}(.303)$ & $(+)$ \\
\hline $\mathrm{Q}-2011$ & 10 & -.095 & $\mathrm{No}(.794)$ & $(-)$ \\
\hline $\mathrm{Q}-2012$ & 21 & $.485^{*}$ & $\mathrm{Si}(.026)$ & $(+)$ \\
\hline $\mathrm{E}-2012$ & 12 & -.295 & $\mathrm{No}(.312)$ & $(-)$ \\
\hline $\mathrm{E}-2013$ & 7 & .025 & $\mathrm{No}(.957)$ & $(\mathrm{X})$ \\
\hline $\mathrm{E}-2014$ & 8 & -.440 & $\mathrm{No}(.275)$ & $(-)$ \\
\hline $\mathrm{E}-2015$ & 5 & -.656 & $\mathrm{No}(.271)$ & $(-)$ \\
\hline
\end{tabular}




\section{F.2. PROBLEMA CONOCIDO (PC1)}

Tabla 24 - Efecto de la experiencia en requisitos en los distintos experimentos - PC1

\begin{tabular}{|c|c|r|c|c|}
\hline \multirow{2}{*}{ EXPERIMENTO } & \multirow{2}{*}{$\mathbf{N}$} & \multicolumn{3}{|c|}{ Correlación } \\
\cline { 3 - 5 } & & \multicolumn{3}{|c|}{ Efectividad * [ExpReq] } \\
\cline { 3 - 5 } & & $\mathrm{r}$ & \multicolumn{1}{|c|}{ Sig. } & Efecto \\
\hline E-2012 & 13 & .234 & $\mathrm{No}(.443)$ & $(-)$ \\
\hline $\mathrm{E}-2013$ & 6 & .083 & $\mathrm{No}(.879)$ & $(\mathrm{X})$ \\
\hline $\mathrm{E}-2014$ & 7 & -.049 & $\mathrm{No}(.916)$ & $(\mathrm{X})$ \\
\hline E-2015 & 6 & .007 & $\mathrm{No}(.989)$ & $\mathrm{X}$ \\
\hline
\end{tabular}

Tabla 25 - Efecto de la experiencia en entrevistas en los distintos experimentos - PC1

\begin{tabular}{|c|c|r|c|c|}
\hline \multirow{2}{*}{ EXPERIMENTO } & \multirow{2}{*}{$\mathbf{N}$} & \multicolumn{3}{|c|}{ Correlación } \\
\cline { 3 - 5 } & & \multicolumn{3}{|c|}{ Efectividad * [ExpEntr] } \\
\cline { 3 - 5 } & & $\mathrm{r}$ & \multicolumn{1}{c|}{ Sig. } & Efecto \\
\hline E-2012 & 13 & -.188 & No $(.540)$ & $(-)$ \\
\hline E-2013 & 6 & .558 & No $(.271)$ & $(+)$ \\
\hline E-2014 & 7 & .750 & No(.052) & $(+)$ \\
\hline E-2015 & 6 & -.249 & No(.643) & $(-)$ \\
\hline
\end{tabular}

Tabla 26 - Efecto de la experiencia en educción en los distintos experimentos - PC1

\begin{tabular}{|c|c|c|c|c|}
\hline \multirow{3}{*}{ EXPERIMENTO } & \multirow{3}{*}{$\mathbf{N}$} & \multicolumn{3}{|c|}{ CORRELACIÓN } \\
\hline & & \multicolumn{3}{|c|}{ Efectividad * [ExpEduc] } \\
\hline & & r & Sig. & Efecto \\
\hline $\mathrm{E}-2012$ & 13 & .322 & $\mathrm{No}(.286)$ & $(+)$ \\
\hline$E-2013$ & 6 & .712 & No (.135) & $(+)$ \\
\hline E-2014 & 7 & .740 & $\mathrm{No}(.057)$ & $(+)$ \\
\hline E-2015 & 6 & \multicolumn{3}{|c|}{ No es posible- valores constantes } \\
\hline
\end{tabular}

Tabla 27 - Efecto de la experiencia en desarrollo en los distintos experimentos - PC1

\begin{tabular}{|c|c|r|c|c|}
\hline \multirow{2}{*}{ EXPERIMENTO } & \multirow{2}{*}{$\mathbf{N}$} & \multicolumn{3}{|c|}{ CORRELACIÓN } \\
\cline { 3 - 5 } & & \multicolumn{3}{|c|}{ Efectividad * [ExpDes] } \\
\cline { 3 - 5 } & & $\mathrm{r}$ & \multicolumn{1}{|c|}{ Sig. } & Efecto \\
\hline E-2012 & 11 & -.103 & $\mathrm{No}(.765)$ & $(-)$ \\
\hline $\mathrm{E}-2013$ & 6 & .067 & $\mathrm{No}(.901)$ & $(\mathrm{X})$ \\
\hline $\mathrm{E}-2014$ & 7 & .209 & $\mathrm{No}(.653)$ & $(+)$ \\
\hline E-2015 & 6 & -.522 & $\mathrm{No}(.308)$ & $(-)$ \\
\hline
\end{tabular}

Tabla 28 - Efecto de la experiencia profesional en los distintos experimentos - PC1

\begin{tabular}{|c|c|r|r|r|}
\hline \multirow{2}{*}{ EXPERIMENTO } & \multirow{2}{*}{$\mathbf{N}$} & \multicolumn{3}{|c|}{ CORRELACIÓN } \\
\cline { 3 - 5 } & & \multicolumn{3}{|c|}{ Efectividad * [ExpProf] } \\
\cline { 3 - 5 } & & \multicolumn{1}{|c|}{ Sig. } & Efecto \\
\hline E-2012 & 12 & -.286 & $\mathrm{No}(.370)$ & $(-)$ \\
\hline E-2013 & 6 & -.876 & $\mathrm{Si}(.036)$ & $(-)$ \\
\hline E-2014 & 7 & .134 & $\mathrm{No}(.775)$ & $(+)$ \\
\hline E-2015 & 6 & -.355 & $\mathrm{No}(.503)$ & $(-)$ \\
\hline
\end{tabular}




\section{ANEXO G}

\section{Condiciones de Colinealidad}

Este anexo presenta los resultados parciales de los modelos correspondientes al efecto de las experiencias en la efectividad de los analistas en el dominio del problema desconocido (Sección G.1) y el dominio del problema conocido (Sección G.2) así como también los diagnósticos de colinealidad asociados a cada modelo. 


\section{G.1. PROBlema desConocido (PD1)}

\section{Modelo 1. Con 5 variables}

La Tabla 29 expone los resultados del análisis de colinealidad correspondiente al Modelo (1) con 5 variables independientes. En la Tabla 29 se observa una tendencia de que la Experiencia en educción y la Experiencia en entrevistas tiene problemas de colinealidad, ya los valores del factor de inflación de la Varianza superan los valores establecidos (FIV $>10$ y $T<1$ ), incluso si se aplica la condición más rigurosa, (FIV > 5 y $\mathrm{T}<2$ ), la experiencia en requisitos y la experiencia profesional también tienen problemas de colinealidad asociados.

Tabla 29 - Efectos de la Experiencia - Modelo 1

Coeficientes $^{\mathrm{a}}$

\begin{tabular}{|c|c|c|c|c|c|c|c|c|}
\hline \multirow{2}{*}{\multicolumn{2}{|c|}{ Modelo }} & \multicolumn{2}{|c|}{$\begin{array}{l}\text { Coeficientes no } \\
\text { estandarizados }\end{array}$} & \multirow{2}{*}{$\begin{array}{l}\text { Coeficientes } \\
\text { tipificados } \\
\text { Beta }\end{array}$} & \multirow[b]{2}{*}{$\mathrm{t}$} & \multirow[b]{2}{*}{ Sig. } & \multicolumn{2}{|c|}{$\begin{array}{l}\text { Estadísticos de } \\
\text { colinealidad }\end{array}$} \\
\hline & & B & Error típ. & & & & Tolerancia & FIV \\
\hline \multirow[t]{6}{*}{1} & (Constante) & 28.202 & 2.576 & & 10.949 & .000 & & \\
\hline & $\begin{array}{l}\text { Experiencia en } \\
\text { Entrevistas (años) }\end{array}$ & -.789 & 1.514 & -.242 & -.521 & .604 & .084 & 11.903 \\
\hline & $\begin{array}{l}\text { Experiencia en } \\
\text { Educción (años) }\end{array}$ & 1.511 & 1.618 & .454 & .934 & .355 & .077 & 13.033 \\
\hline & $\begin{array}{l}\text { Experiencia en } \\
\text { Requisitos (años) }\end{array}$ & .233 & .791 & .096 & .294 & .770 & .170 & 5.870 \\
\hline & $\begin{array}{l}\text { Experiencia en } \\
\text { Desarrollo (años) }\end{array}$ & .216 & .584 & .074 & .370 & .713 & .452 & 2.214 \\
\hline & $\begin{array}{l}\text { Experiencia Profesional } \\
\text { (años) }\end{array}$ & -.604 & .733 & -.286 & -.823 & .414 & .150 & 6.662 \\
\hline
\end{tabular}

a. Variable dependiente: Efectividad Ajustada (\%)

La Tabla 30 muestra los resultados del diagnóstico de colinealidad del modelo indicado en la Tabla 29. Nótese que en la dimensión 6 , el índice de condición (IC = 12.705) sugiere un moderado grado de colinealidad entre las variables. Al comparar la proporción de varianza de cada una de las variables independientes del modelo, se observa que la Experiencia en Educción y la Experiencia en Entrevistas, poseen una proporción de varianza elevada igual a 0.91 y 0.89 respectivamente, lo que confirma la alta correlación entre las mismas. Una de las soluciones para resolver el problema de colinealidad es eliminar del modelo, la variable que está más afectada por la colinealidad, en este caso sería la variable Experiencia en Educción.

Tabla 30 - Diagnóstico de Colinealidad - Modelo 1

Diagnósticos de colinealidad ${ }^{\mathrm{a}}$

\begin{tabular}{|c|c|c|c|c|c|c|c|c|c|}
\hline \multirow[b]{2}{*}{ Modelo } & \multirow[b]{2}{*}{ Dimensión } & \multirow[b]{2}{*}{$\begin{array}{c}\text { Autoval } \\
\text { ores }\end{array}$} & \multirow[b]{2}{*}{$\begin{array}{l}\text { Índice de } \\
\text { condición }\end{array}$} & \multicolumn{6}{|c|}{ Proporciones de la varianza } \\
\hline & & & & $\begin{array}{c}\text { (Constant } \\
\text { e) }\end{array}$ & $\begin{array}{l}\text { Experiencia } \\
\text { en } \\
\text { Entrevistas } \\
\text { (años) }\end{array}$ & $\begin{array}{c}\text { Experiencia } \\
\text { en } \\
\text { Educción } \\
\text { (años) }\end{array}$ & $\begin{array}{l}\text { Experiencia } \\
\text { en } \\
\text { Requisitos } \\
\text { (años) }\end{array}$ & $\begin{array}{l}\text { Experiencia } \\
\text { en } \\
\text { Desarrollo } \\
\text { (años) }\end{array}$ & $\begin{array}{l}\text { Experiencia } \\
\text { Profesional } \\
\text { (años) }\end{array}$ \\
\hline \multirow[t]{6}{*}{1} & 1 & 4.762 & 1.000 & .01 & .00 & .00 & .00 & .01 & .00 \\
\hline & 2 & .733 & 2.550 & .25 & .02 & .01 & .01 & .05 & .00 \\
\hline & 3 & .260 & 4.278 & .67 & .02 & .01 & .01 & .27 & .02 \\
\hline & 4 & .162 & 5.423 & .04 & .04 & .05 & .31 & .26 & .05 \\
\hline & 5 & .053 & 9.448 & .02 & .03 & .03 & .63 & .19 & .85 \\
\hline & 6 & .030 & 12.705 & .00 & .89 & .91 & .04 & .22 & .07 \\
\hline
\end{tabular}

a. Variable dependiente: Efectividad Ajustada (\%) 


\section{Modelo 2. Con 4 variables}

La Tabla 31 expone los resultados del diagnóstico de colinealidad correspondiente al Modelo (2) con 4 variables, el cual está compuesto por todas las variables del modelo (1) sin la experiencia en educción (eliminada por problema de colinealidad). Nótese que el índice de condición (IC = 7.166) está dentro de lo esperado (IC < 10, baja colinealidad). Según las propociones de varianza, las variables relacionadas serían Experiencia profesional y experiencia en requisitos. Desde el punto de vista de la colinealidad de las variables, el modelo 2 es perfectamente válido para estudiar los efectos de la experiencia en la efectividad de los sujetos.

Tabla 31 - Efectos de la Experiencia - Modelo 2

\begin{tabular}{|c|c|c|c|c|c|c|c|c|}
\hline & & & & jagnósticos $\mathrm{d}$ & colinealidad $^{a}$ & & & \\
\hline \multirow[b]{2}{*}{ Modelo } & \multirow[b]{2}{*}{ Dimensión } & \multirow[b]{2}{*}{$\begin{array}{c}\text { Autoval } \\
\text { ores }\end{array}$} & \multirow[b]{2}{*}{$\begin{array}{l}\text { Índice de } \\
\text { condición }\end{array}$} & \multicolumn{5}{|c|}{ Proporciones de la varianza } \\
\hline & & & & (Constante) & $\begin{array}{c}\text { Experiencia } \\
\text { en Entrevistas } \\
\text { (años) }\end{array}$ & $\begin{array}{c}\text { Experiencia } \\
\text { en Requisitos } \\
\text { (años) }\end{array}$ & $\begin{array}{l}\text { Experiencia } \\
\text { en Desarrollo } \\
\text { (años) }\end{array}$ & $\begin{array}{l}\text { Experiencia } \\
\text { Profesional } \\
\text { (años) }\end{array}$ \\
\hline \multirow[t]{5}{*}{1} & 1 & 3.871 & 1.000 & .02 & .01 & .01 & .01 & .01 \\
\hline & 2 & .674 & 2.396 & .24 & .10 & .03 & .06 & .00 \\
\hline & 3 & .250 & 3.938 & .63 & .11 & .00 & .47 & .01 \\
\hline & 4 & .130 & 5.447 & .01 & .77 & .37 & .29 & .09 \\
\hline & 5 & .075 & 7.166 & .09 & .01 & .59 & .17 & .90 \\
\hline
\end{tabular}

a. Variable dependiente: Efectividad Ajustada (\%)

\section{Modelo 3. Con 3 variables}

La Tabla 32 expone los resultados del diagnóstico de colinealidad correspondiente al Modelo (3) con 3 variables, el cual está compuesto por todas las variables del modelo (2) sin la experiencia profesional (ya que es la que más variabilidad posee, en comparación con las demás). Nótese que el índice de condición (IC = 4.920) está dentro de lo esperado (IC < 10, baja colinealidad).

Tabla 32 - Efectos de la Experiencia - Modelo 3

Diagnósticos de colinealidad ${ }^{\mathrm{a}}$

\begin{tabular}{|c|c|c|c|c|c|c|c|}
\hline \multirow[b]{2}{*}{ Modelo } & \multirow[b]{2}{*}{ Dimensión } & \multirow[b]{2}{*}{ Autovalores } & \multirow[b]{2}{*}{$\begin{array}{l}\text { Índice de } \\
\text { condición }\end{array}$} & \multicolumn{4}{|c|}{ Proporciones de la varianza } \\
\hline & & & & (Constante) & $\begin{array}{c}\text { Experiencia } \\
\text { en Entrevistas } \\
\text { (años) }\end{array}$ & $\begin{array}{l}\text { Experiencia } \\
\text { en Requisitos } \\
\text { (años) }\end{array}$ & $\begin{array}{c}\text { Experiencia } \\
\text { en Desarrollo } \\
\text { (años) }\end{array}$ \\
\hline \multirow[t]{4}{*}{1} & 1 & 2.960 & 1.000 & .03 & .02 & .02 & .03 \\
\hline & 2 & .673 & 2.097 & .26 & .11 & .05 & .07 \\
\hline & 3 & .245 & 3.476 & .67 & .08 & .01 & .73 \\
\hline & 4 & .122 & 4.920 & .03 & .79 & .92 & .17 \\
\hline
\end{tabular}

a. Variable dependiente: Efectividad Ajustada (\%)

\section{Modelo 4. Con 3 variables}

Si bien los modelos anteriores ya cumplen con las condiciones de colinealidad, la ejecución del modelo 3 y el modelo 4 es innecesaria. No obstante, como se indicó en el capítulo 6 de síntesis dichos modelos se ejecutaron con la finalidad aumentar el poder estadístico (cuanto menor es el número de variables independientes en el modelo, menor es el tamaño muestral deseable).

La Tabla 33 expone los resultados del diagnóstico de colinealidad correspondiente al Modelo (4) con 3 variables, el cual está compuesto por todas las variables del modelo (2) sin la experiencia desarrollo. Nótese que el índice de condición (IC = 5.726) está dentro de lo esperado (IC < 10, baja colinealidad). 
Tabla 33 - Efectos de la Experiencia - Modelo 3

Diagnósticos de colinealidad ${ }^{\mathrm{a}}$

\begin{tabular}{|c|c|c|c|c|c|c|c|}
\hline \multirow[b]{2}{*}{ Modelo } & \multirow[b]{2}{*}{ Dimensión } & \multirow[b]{2}{*}{ Autovalores } & \multirow[b]{2}{*}{$\begin{array}{l}\text { Índice de } \\
\text { condición }\end{array}$} & \multicolumn{4}{|c|}{ Proporciones de la varianza } \\
\hline & & & & (Constante) & $\begin{array}{c}\text { Experiencia } \\
\text { en Entrevistas } \\
\text { (años) }\end{array}$ & $\begin{array}{c}\text { Experiencia } \\
\text { en Requisitos } \\
\text { (años) }\end{array}$ & $\begin{array}{l}\text { Experiencia } \\
\text { Profesional } \\
\text { (años) }\end{array}$ \\
\hline \multirow[t]{4}{*}{1} & 1 & 3.176 & 1.000 & .03 & .02 & .02 & .01 \\
\hline & 2 & .560 & 2.381 & .54 & .08 & .04 & .00 \\
\hline & 3 & .167 & 4.357 & .05 & .88 & .41 & .05 \\
\hline & 4 & .097 & 5.726 & .38 & .02 & .53 & .93 \\
\hline
\end{tabular}

a. Variable dependiente: Efectividad Ajustada (\%)

\section{G.2. Problema CONOCido (PC1)}

\section{Modelo 1. Con 5 variables}

La Tabla 34 expone los resultados del análisis de colinealidad correspondiente al Modelo (1) con 5 variables independientes. En la Tabla 34 se observa una tendencia de que la Experiencia en educción podría poseer problemas de colinealidad, ya que presenta valores próximos a los límites establecidos al factor de inflación de la Varianza (FIV=3.596). Por el contrario, los estadísticos de colinealidad de las demás variables están dentro de los valores esperados (FIV $<5$ y $T>0.2$ ), lo que indica ausencia de colinealidad entre las mismas.

Tabla 34 - Efectos de la Experiencia - Modelo 1

\section{Coeficientes $^{\mathrm{a}}$}

\begin{tabular}{|c|c|c|c|c|c|c|c|}
\hline \multirow[b]{2}{*}{ Modelo } & \multicolumn{2}{|c|}{$\begin{array}{l}\text { Coeficientes no } \\
\text { estandarizados }\end{array}$} & \multirow{2}{*}{$\begin{array}{c}\begin{array}{c}\text { Coeficiente } \\
\text { s tipificados }\end{array} \\
\text { Beta }\end{array}$} & \multirow[b]{2}{*}{$\mathrm{t}$} & \multirow[b]{2}{*}{ Sig. } & \multicolumn{2}{|c|}{$\begin{array}{l}\text { Estadísticos de } \\
\text { colinealidad }\end{array}$} \\
\hline & B & Error típ. & & & & $\begin{array}{c}\text { Toleranci } \\
\text { a }\end{array}$ & FIV \\
\hline (Constante) & 28.144 & 5.927 & & 4.749 & .000 & & \\
\hline $\begin{array}{l}\text { Experiencia en } \\
\text { Entrevistas (años) }\end{array}$ & 1.551 & 3.763 & 132 & .412 & .684 & .321 & 3.119 \\
\hline $\begin{array}{l}\text { Experiencia en } \\
\text { Educción (años) }\end{array}$ & 5.905 & 5.907 & .343 & 1.000 & .328 & .278 & 3.596 \\
\hline $\begin{array}{l}\text { Experiencia en } \\
\text { Requisitos (años) }\end{array}$ & .771 & 3.296 & .066 & .234 & .817 & .415 & 2.407 \\
\hline $\begin{array}{l}\text { Experiencia en } \\
\text { Desarrollo (años) }\end{array}$ & -.243 & 2.084 & -.028 & -.117 & .908 & .578 & 1.730 \\
\hline $\begin{array}{l}\text { Experiencia } \\
\text { Profesional (años) }\end{array}$ & -2.095 & 1.458 & -.345 & -1.437 & .164 & .568 & 1.761 \\
\hline
\end{tabular}

La

Tabla 35 muestra los resultados del diagnóstico de colinealidad del modelo indicado en la Tabla 34. Nótese que el índice de condición (IC = 7.365) sugiere un bajo grado de colinealidad entre las variables. Al comparar la proporción de varianza de cada una de las variables independientes del modelo, se observa que la Experiencia en Educción y la Experiencia en Entrevistas, poseen una proporción de varianza elevada igual a 0.70 y 0.68 respectivamente, lo que confirma la alta correlación entre las mismas. Una de las soluciones para resolver el problema de colinealidad es eliminar del modelo, dicha variable que está más afectada por la colinealidad, en este caso sería la variable Experiencia en Educción. 
Tabla 35 - Diagnóstico de Colinealidad - Modelo 1

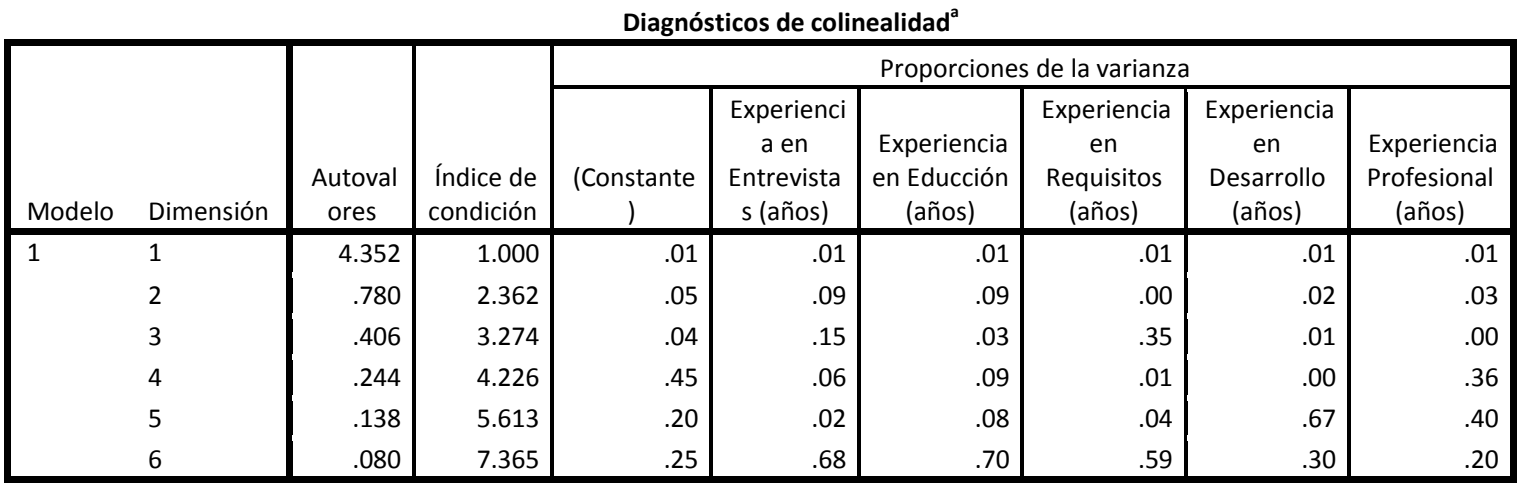

a. Variable dependiente: Efectividad Ajustada (\%)

\section{Modelo 2. Con 4 variables}

La Tabla 36 expone los resultados del análisis de colinealidad correspondiente al Modelo (2) con 4 variables independientes, corresponde a todas las variables del Modelo (1) menos la variable Experiencia en Educción. Como se puede apreciar Tabla 36 todas las variables del modelo (2) cumplen con las condiciones de no colinealidad (FIV $<10$ y $\mathrm{T}>0.1$ ) o más rigurosamente (FIV $<5$ y $\mathrm{T}>0.2$ ) lo que indica ausencia de colinealidad entre las mismas.

Tabla 36 - Efectos de la Experiencia - Modelo 2

\begin{tabular}{|c|c|c|c|c|c|c|c|}
\hline \multirow[b]{2}{*}{ Modelo } & \multicolumn{2}{|c|}{$\begin{array}{l}\text { Coeficientes no } \\
\text { estandarizados }\end{array}$} & \multirow{2}{*}{$\begin{array}{c}\begin{array}{c}\text { Coeficiente } \\
\text { s tipificados }\end{array} \\
\text { Beta }\end{array}$} & \multirow[b]{2}{*}{$\mathrm{t}$} & \multirow[b]{2}{*}{ Sig. } & \multicolumn{2}{|c|}{$\begin{array}{l}\text { Estadísticos de } \\
\text { colinealidad }\end{array}$} \\
\hline & B & Error típ. & & & & $\begin{array}{c}\text { Toleranci } \\
\text { a }\end{array}$ & FIV \\
\hline (Constante) & 29.247 & 5.823 & & 5.023 & .000 & & \\
\hline $\begin{array}{l}\text { Experiencia en } \\
\text { Entrevistas (años) }\end{array}$ & 4.429 & 2.424 & .376 & 1.827 & .080 & .773 & 1.294 \\
\hline $\begin{array}{l}\text { Experiencia en } \\
\text { Requisitos (años) }\end{array}$ & 2.868 & 2.542 & .244 & 1.128 & .270 & .698 & 1.432 \\
\hline $\begin{array}{l}\text { Experiencia en } \\
\text { Desarrollo (años) }\end{array}$ & -.619 & 2.050 & -.071 & -.302 & .765 & .597 & 1.674 \\
\hline $\begin{array}{l}\text { Experiencia } \\
\text { Profesional (años) }\end{array}$ & -2.556 & 1.383 & -.421 & -1.848 & .077 & .631 & 1.585 \\
\hline
\end{tabular}

La Tabla 37 muestra los resultados del diagnóstico de colinealidad del modelo indicado en la Tabla 36. Nótese que el índice de condición (IC = 5.483) está dentro de lo esperado (IC < 10, baja colinealidad). Desde el punto de vista de la colinealidad de las variables, el modelo 2 es perfectamente válido para estudiar los efectos de la experiencia en la efectividad de los sujetos.

Tabla 37 - Diagnóstico de Colinealidad - Modelo 2

Diagnósticos de colinealidad $^{\mathrm{a}}$

\begin{tabular}{|c|c|c|c|c|c|c|c|c|}
\hline \multirow[b]{2}{*}{ Modelo } & \multirow[b]{2}{*}{ Dimensión } & \multirow[b]{2}{*}{ Autovalores } & \multirow[b]{2}{*}{$\begin{array}{l}\text { Índice de } \\
\text { condición }\end{array}$} & \multicolumn{5}{|c|}{ Proporciones de la varianza } \\
\hline & & & & $\begin{array}{c}\text { (Constante } \\
\text { ) }\end{array}$ & $\begin{array}{c}\text { Experiencia } \\
\text { en } \\
\text { Entrevistas } \\
\text { (años) }\end{array}$ & $\begin{array}{c}\text { Experiencia } \\
\text { en Requisitos } \\
\text { (años) }\end{array}$ & $\begin{array}{c}\text { Experiencia } \\
\text { en Desarrollo } \\
\text { (años) }\end{array}$ & $\begin{array}{l}\text { Experiencia } \\
\text { Profesional } \\
\text { (años) }\end{array}$ \\
\hline 1 & 1 & 3.778 & 1.000 & .01 & .02 & .02 & .01 & .01 \\
\hline & 2 & .533 & 2.661 & .05 & .87 & .03 & .00 & .01 \\
\hline & 3 & .364 & 3.223 & .21 & .00 & .75 & .02 & .00 \\
\hline & 4 & .199 & 4.360 & .25 & .02 & .16 & .01 & .90 \\
\hline & 5 & .126 & 5.483 & .48 & .09 & .04 & .96 & .07 \\
\hline
\end{tabular}

a. Variable dependiente: Efectividad Ajustada (\%) 
ANEXO H

\section{Meta-análisis por tipo de elementos}

El presente anexo presenta el meta-análisis de datos agregados correspondiente al efecto de la experiencia en requisitos y entrevistas, diferenciado por tipo de elemento (requisitos, conceptos y procesos) que definen el dominio del problema conocido (Sección H.1 y H3) y el desconocido (sección H. 2 y H4).

\section{H.1. Meta-AnÁlisis de la Experiencia en ReQuisitos diferenciada pOR Tipo de} ELEMENTO PC1

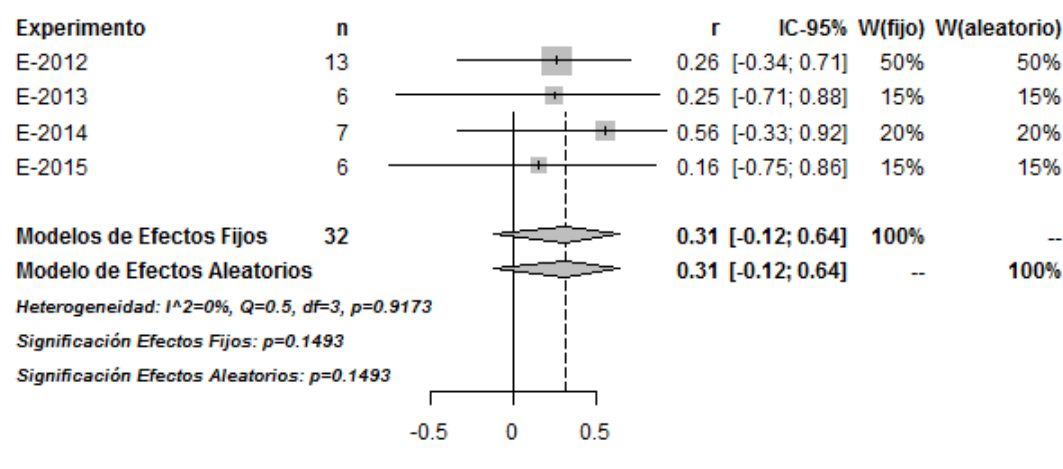

Efecto de la Experiencia en Requisitos - Conceptos

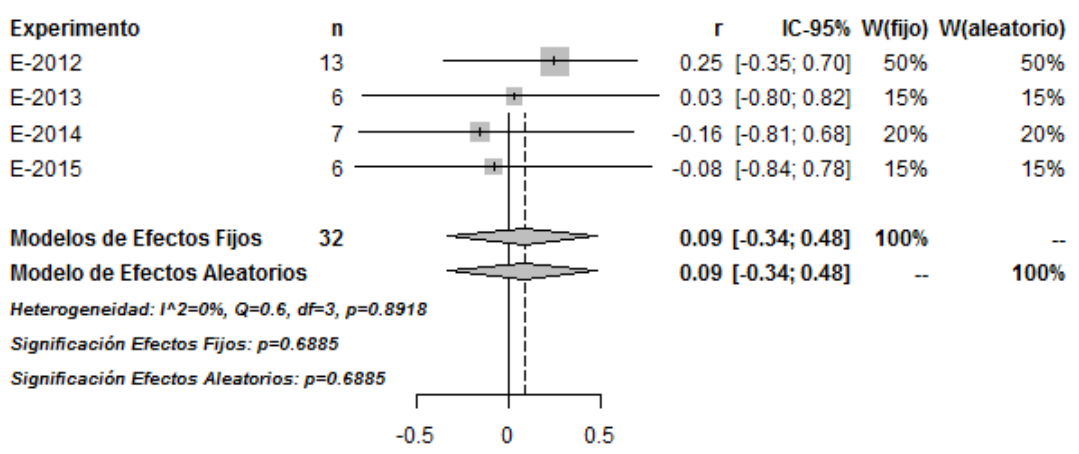

Efecto de la Experiencia en Requisitos - Procesos

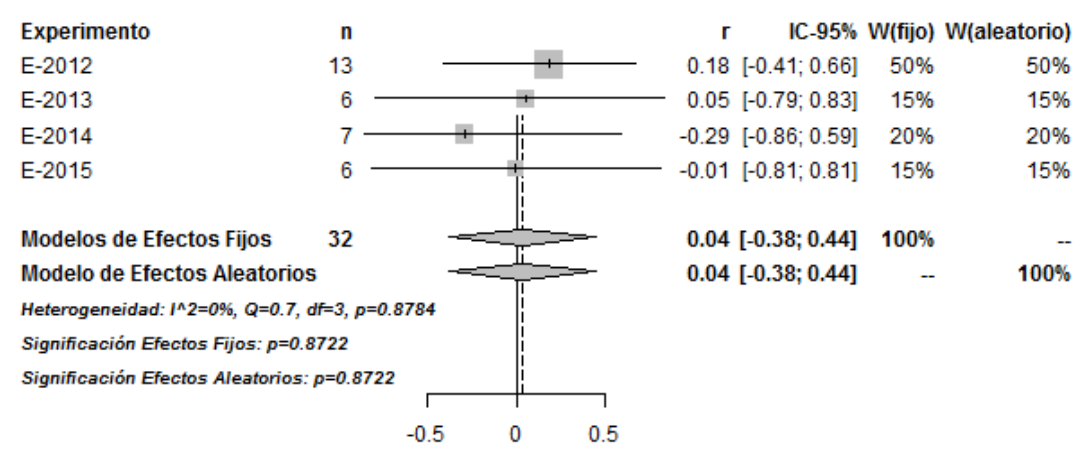

Efecto de la Experiencia en Requisitos - Requisitos 
Figura 9 - Meta-análisis de datos agregados - efecto de la experiencia en requisitos en función del tipo de elemento que define el dominio de problema conocido (PC1)

\section{H.2. Meta-ANÁlisis de la Experiencia en ReQuisitos diferenciada por Tipo de ELEMENTO PD1}
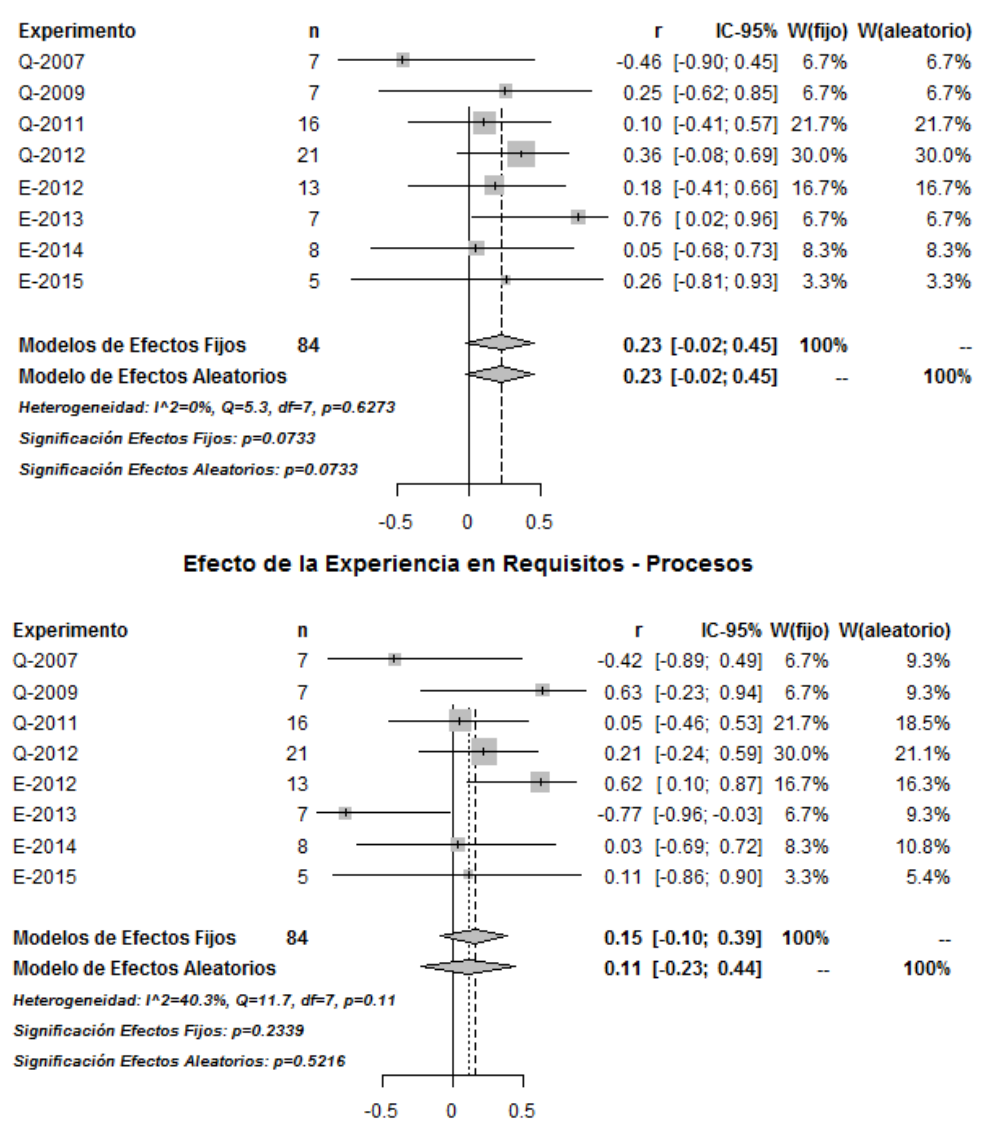

Efecto de la Experiencia en Requisitos - Conceptos

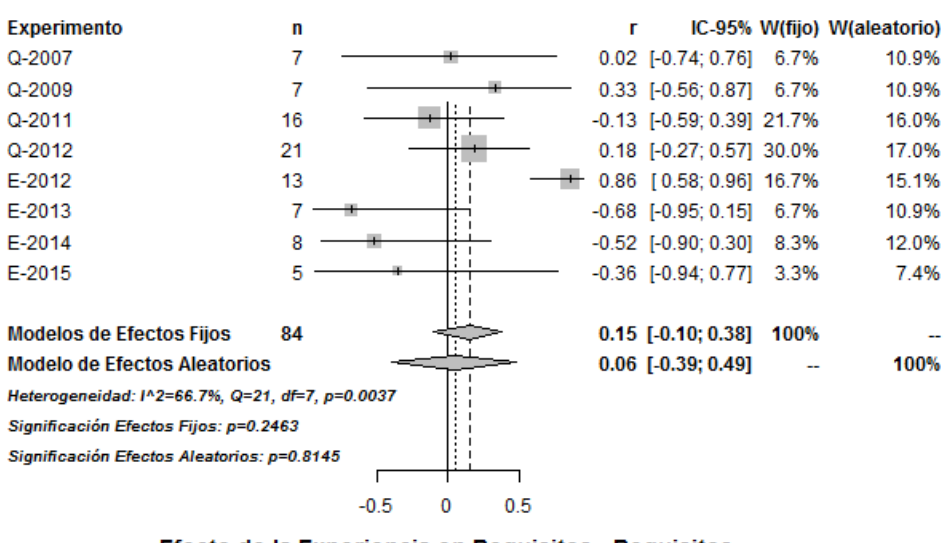

Efecto de la Experiencia en Requisitos - Requisitos

Figura 10 - Meta-análisis de datos agregados - efecto de la experiencia en requisitos en función del tipo de elemento que define el dominio de problema desconocido (PD1) 


\section{H.3. Meta-AnÁlisis de la Experiencia en Entrevistas diferenciada por Tipo de ELEMENTO PC1}

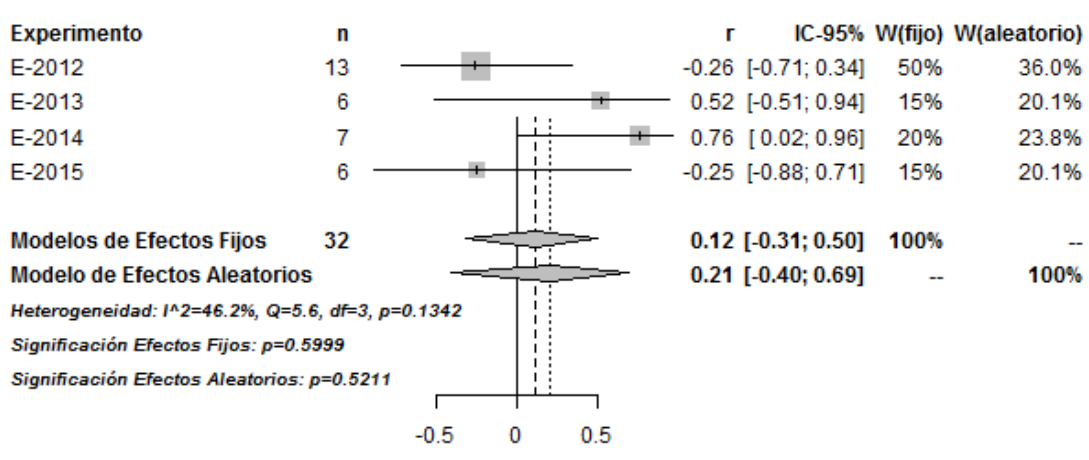

Efecto de la Experiencia en Entrevistas - Procesos

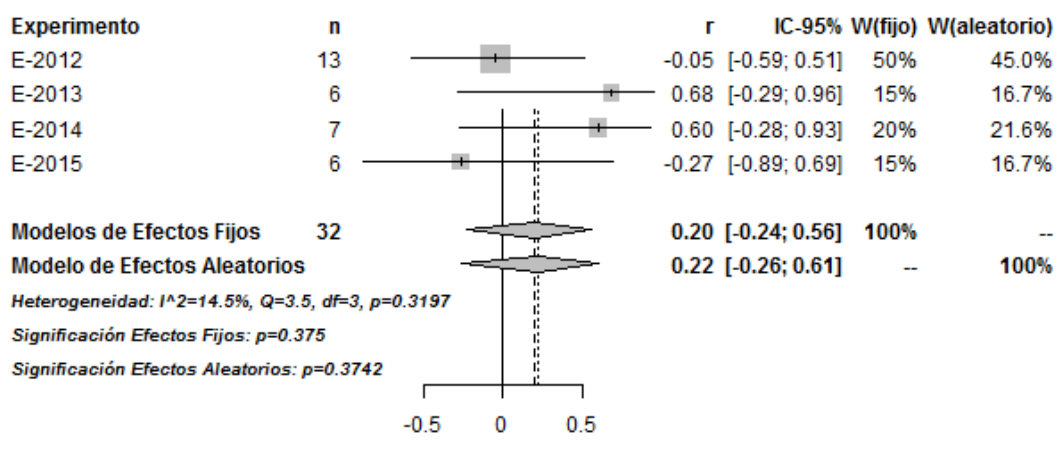

Efecto de la Experiencia en Entrevistas - Conceptos

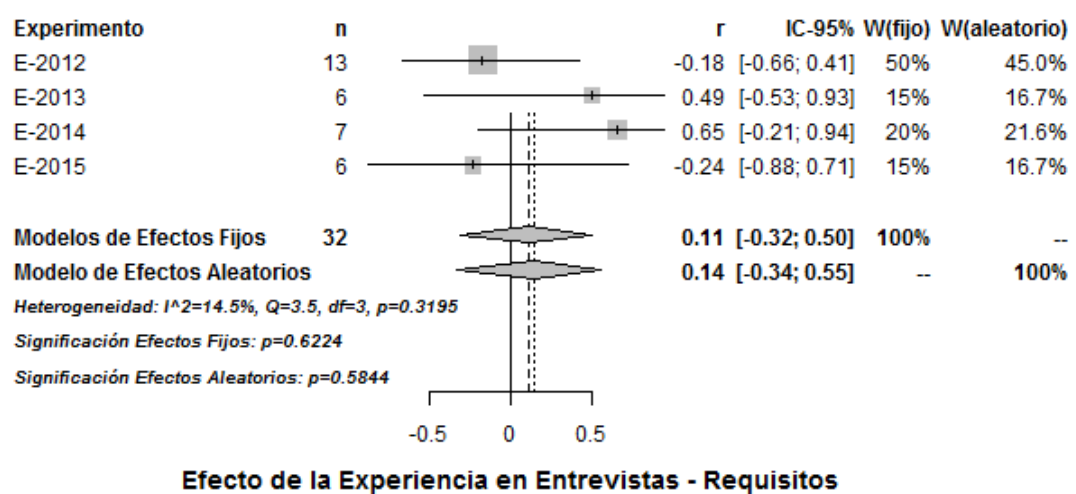

Figura 11 - Meta-análisis de datos agregados - efecto de la experiencia en entrevistas en función del tipo de elemento que define el dominio de problema conocido (PC1) 


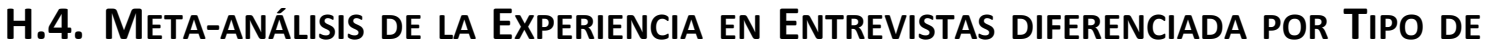 ELEMENTO PD1}

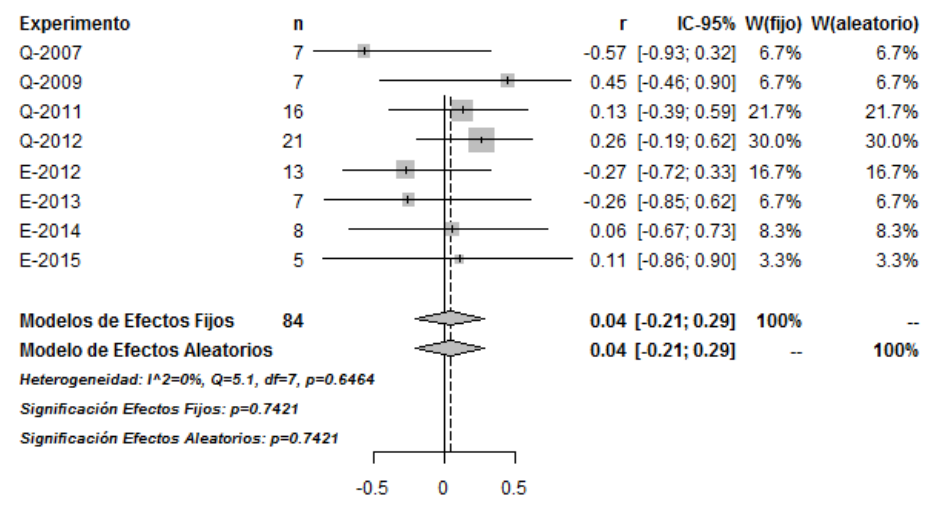

Efecto de la Experiencia en Entrevistas - Conceptos
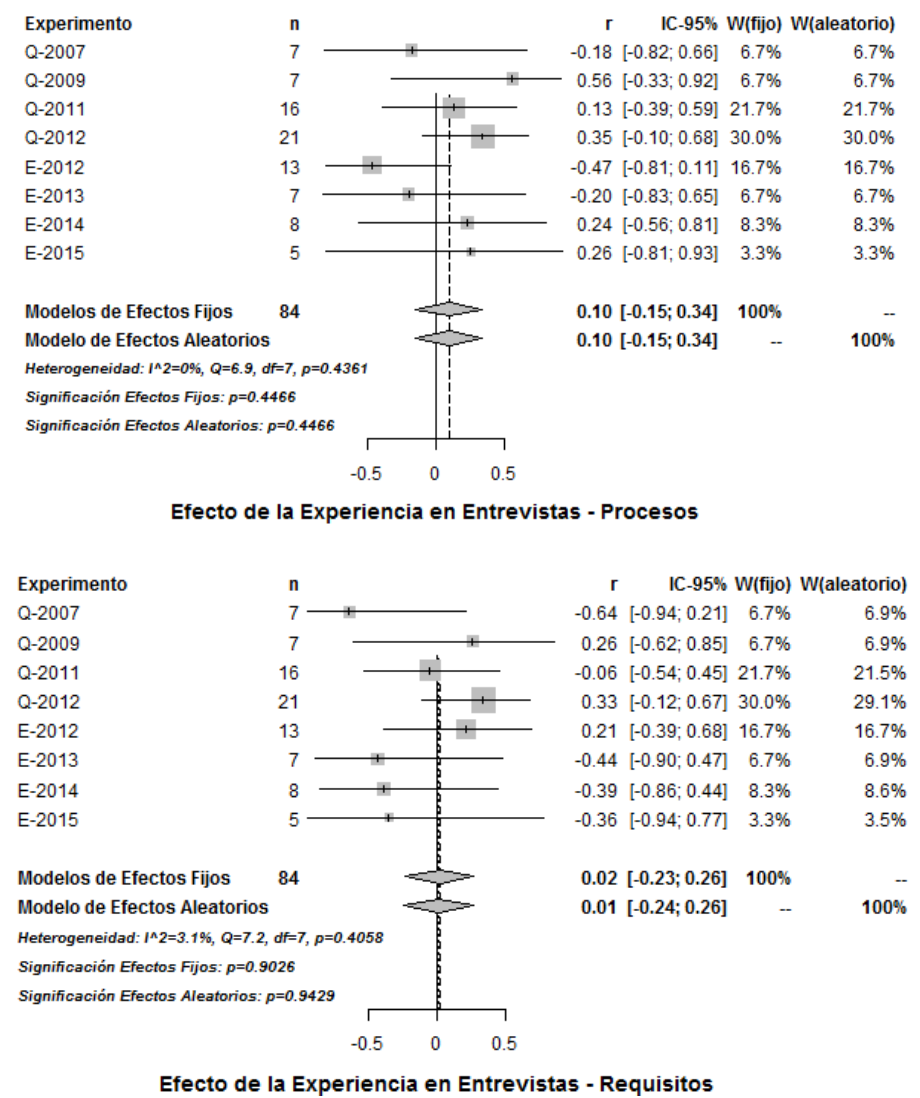

Figura 12 - Meta-análisis de datos agregados - efecto de la experiencia en entrevistas en función del tipo de elemento que define el dominio de problema desconocido (PD1) 


\section{Comparación de los efectos de entrevistas individuales vs. grupales}

En la serie de cuasi-experimentos realizados, seis de ellos (Q-2007, Q-2009 y E2012 en adelante) fueron llevados a cabo utilizando entrevista abierta en modo individual. Los dos restantes (Q-2011 y Q2012) fueron llevados a cabo mediante entrevistas abiertas en grupo, debido a restricciones contextuales. Nótese que Q-2011 y Q-2012 sólo utilizaron el dominio desconocido PD1.

Para poder realizar el análisis conjunto de los datos, debemos eliminar los efectos de las variables moderadoras, tal y como se ha explicado en la sección 6.1.1.2.1. Más concretamente, los efectos positivos de la entrevista en grupo (un aumento en efectividad del $11 \%$ en promedio) deben ser eliminados para no inflar artificialmente los coeficientes del meta-análisis de datos individuales (el metaanálisis de datos agregados no se ve afectado).

No obstante, la entrevista en grupo puede influir en los sujetos no sólo a nivel promedio, sino también a nivel individual. El riesgo más importante es que los sujetos con menor experiencia se beneficien de la información que surge en la conversación, generada por los sujetos con mayor experiencia. Esto es, la efectividad de los analistas con menor experiencia podría incrementarse más allá de lo que ellos mismos serían capaces de alcanzar en solitario gracias a la transferencia de información desde los analistas con mayor experiencia.

Este riesgo no es puramente teórico. En las entrevistas en grupo, pudimos observar que sólo un subconjunto de sujetos realizaba preguntas. Estos sujetos eran precisamente aquellos con mayor prestigio dentro del grupo, lo que a su vez va asociado al reconocimiento por parte del grupo de su experiencia, conocimiento, u cualquier otra cualidad positiva.

La transferencia de información de analistas expertos a analistas novatos puede explorarse a partir de los mismos datos que usamos en nuestra investigación. Si tal transferencia existiera, deberíamos observar rectas de regresión prácticamente horizontales en la entrevista en grupo (los analistas serían más o menos igualmente efectivos, independientemente de sus años de experiencia), mientras que la recta de regresión de las entrevistas individuales debería ser creciente (al no producirse transferencia, los analistas expertos serían más efectivos que los novatos).

No utilizamos modelos de regresión para realizar esta comparación, ya que al dividir el conjunto de datos en dos grupos de aproximadamente 40 sujetos, quedamos muy lejos del tamaño muestral necesario para ajustar un modelo de 4 variables (unos 84 sujetos para tamaños de efectos medios).

La Figura 13 muestra las rectas de regresión entre la experiencia en (a) entrevistas y (b) requisitos y la efectividad de los analistas, obtenidas en las entrevistas en grupo. Los coeficientes de correlación son pequeños-medios ( $r=0.27$ y $r=0.193$, respectivamente) y no significativos ( $p$-valor $=0.096$ y $p$-valor $=$ 
0.252, respectivamente). El p-valor asociado a la correlación con la experiencia en entrevistas es casi significativo.

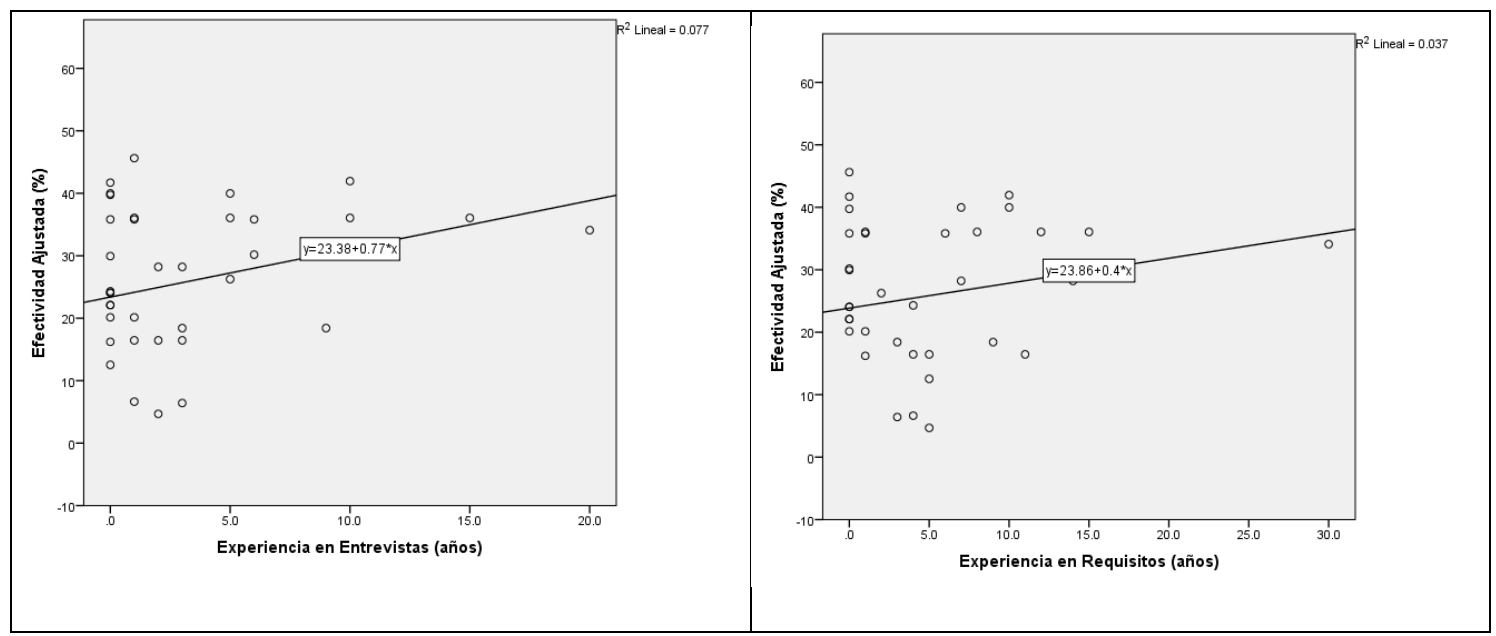

Figura 13 - Rectas de regresión para las entrevistas en grupo.

Las rectas de regresión son completamente contrarias a lo que sería esperable en el caso de que existiera transferencia de información entre analistas expertos y novatos en la entrevista en grupo. Las rectas de regresión de la Figura 13 muestran pendientes crecientes, lo que significa que los novatos se comportan peor que los expertos.

No obstante, siempre cabe la posibilidad de que exista transferencia, pero ésta no sea tan intensa como para aplanar completamente las rectas de regresión. En otras palabras; la Figura 13 muestra correlaciones positivas, pero estas serían aún mayores si el tipo de entrevista fuese individual.

Nuestros datos nos permiten comparar las rectas de regresión de las entrevistas en grupo con las entrevistas individuales. La Figura 14 muestra las rectas de regresión entre la experiencia en (a) entrevistas y (b) requisitos y la efectividad de los analistas, obtenidas en las entrevistas en individuales. Los coeficientes de correlación son pequeños-medios ( $r=-0.23$ y $r=0.031$, respectivamente) y no significativos ( $p$-valor $=0.114$ y $p$-valor $=0.835$, respectivamente) .

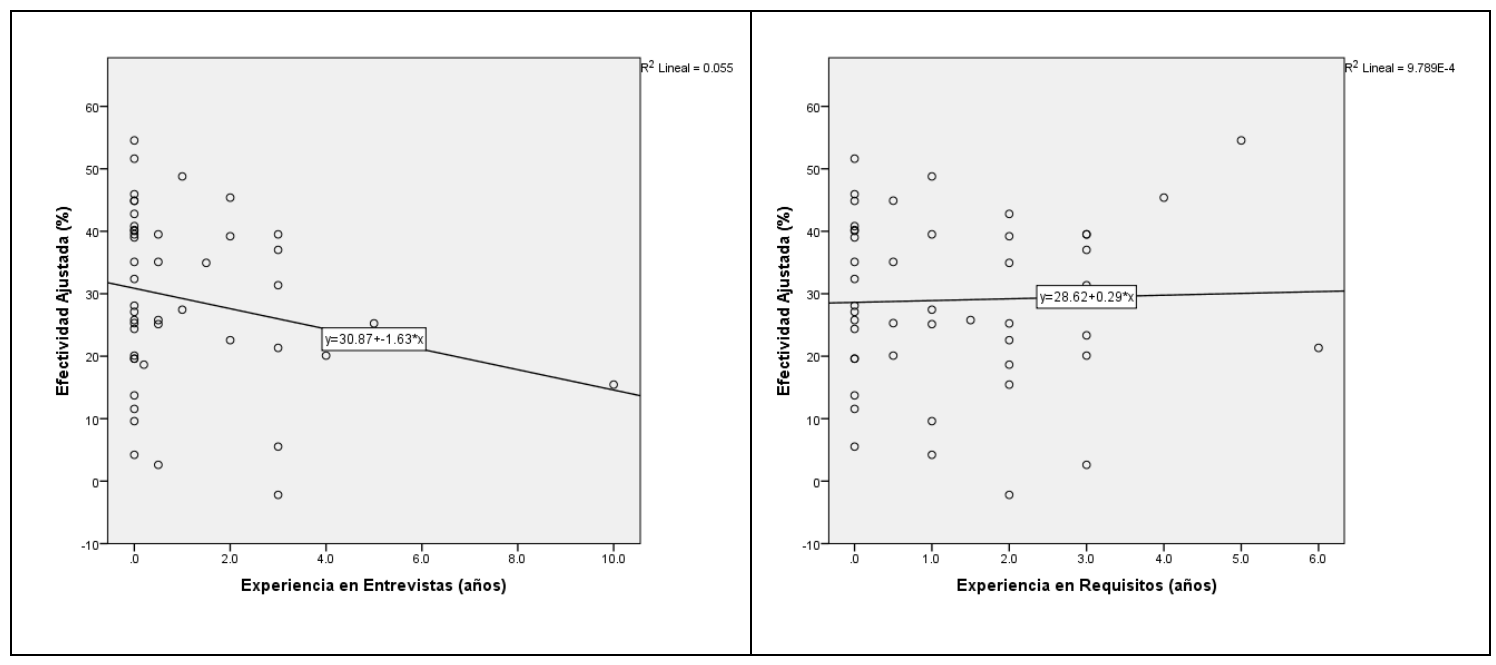

Figura 14 - Rectas de regresión para las entrevistas individuales.

En el caso de la experiencia en requisitos, podemos observar claramente que la correlación asociada es mayor en la entrevista en grupo que en la entrevista individual. Creemos que este es otro argumento en contra de la transferencia de información entre expertos y novatos. En el caso de la experiencia en entrevistas, la situación es más compleja. La experiencia en entrevistas es mayor en el caso de las 
entrevistas en grupo que en las entrevistas individuales (de nuevo, señalando la inexistencia de transferencia de información). Lo que es extraño es que la correlación en este último caso es negativa. En nuestra opinión, esto podría deberse a una mezcla de falta de motivación y sobrevaloración de la experiencia en entrevistas realizada por los propios sujetos experimentales.

En consecuencia, parece que los datos de las entrevistas individuales y las entrevistas en grupo pueden analizarse conjuntamente. 